Prepared for the New Jersey Toxics Reduction Workplan for NY-NJ Harbor Ambient Monitoring of Loading to Major Tributaries at Head-of-Tide Study I-C

\title{
Concentrations and Loads of Organic Compounds and Trace Elements in Tributaries to Newark and Raritan Bays, New Jersey
}

Scientific Investigations Report 2007-5059 



\section{Concentrations and Loads of Organic Compounds and Trace Elements in Tributaries to Newark and Raritan Bays, New Jersey}

By Timothy P. Wilson and Jennifer L. Bonin

Prepared for the New Jersey Toxics Reduction Workplan for NY-NJ Harbor

Ambient Monitoring of Loading to Major Tributaries at the Head-of-Tide Study I-C

Scientific Investigations Report 2007-5059 


\section{U.S. Department of the Interior DIRK KEMPTHORNE, Secretary}

\section{U.S. Geological Survey \\ Mark D. Myers, Director}

\section{U.S. Geological Survey, Reston, Virginia: 2007}

For product and ordering information:

World Wide Web: http://www.usgs.gov/pubprod

Telephone: 1-888-ASK-USGS

For more information on the USGS--the Federal source for science about the Earth, its natural and living resources, natural hazards, and the environment:

World Wide Web: http://www.usgs.gov

Telephone: 1-888-ASK-USGS

Any use of trade, product, or firm names is for descriptive purposes only and does not imply endorsement by the U.S. Government.

Although this report is in the public domain, permission must be secured from the individual copyright owners to reproduce any copyrighted materials contained within this report.

Suggested citation:

Wilson, T.P. and Bonin, J.L., 2007, Concentrations and Loads of Organic Compounds and Trace Elements in Tributaries to Newark and Raritan Bays, New Jersey: U.S. Geological Survey Scientific Investigations Report 2007-5059, 176 p. 


\section{Contents}

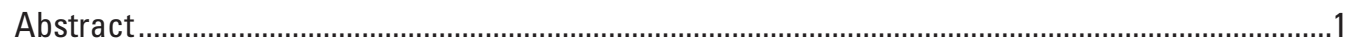

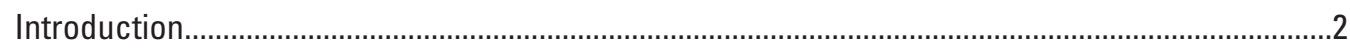

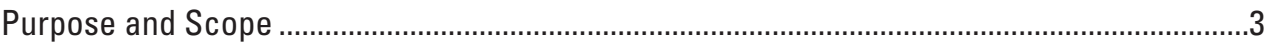

Geochemical Cycling in Estuaries ..........................................................................................

Description of Sample Collection, Sample Analysis, and Methods for Calculating

Concentrations..........................................................................................................

Concentrations of Organic Compounds and Trace Elements.......................................................12

Polychlorinated Biphenyls ..............................................................................................12

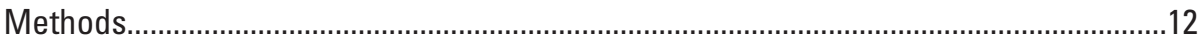

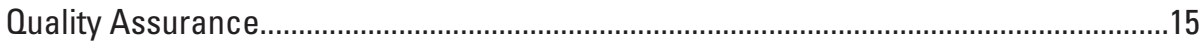

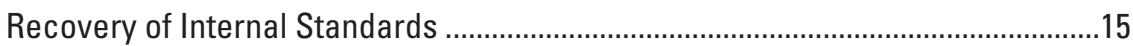

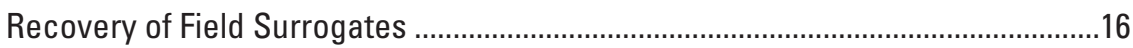

Contamination of Blanks and Data Censoring .........................................................16

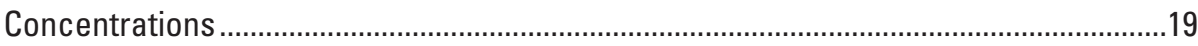

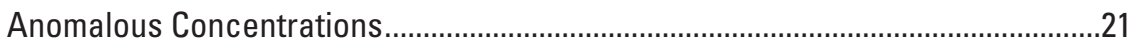

Relation of Whole-Water Concentrations to Water-Quality Criteria........................22

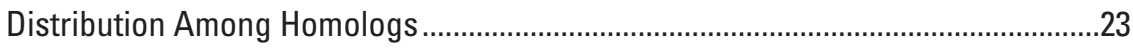

Concentrations During Stormflow and Low Flow..................................................23

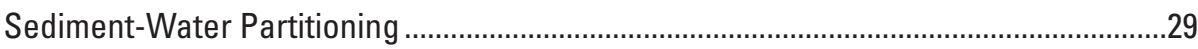

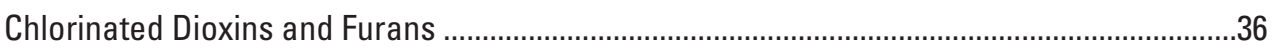

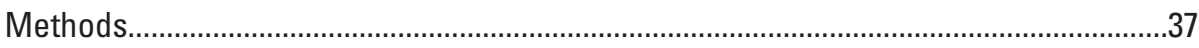

Quality Assurance ..........................................................................................................

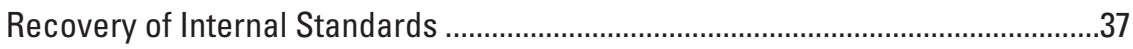

Contamination of Blanks and Data Censoring .......................................................37

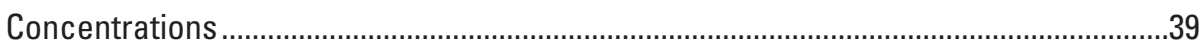

Anomalous Concentrations...................................................................................4

Relation of Whole-Water Concentrations to Water-Quality Criteria........................44

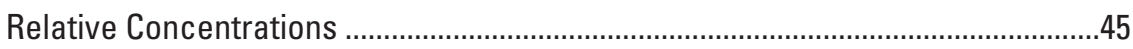

Concentrations During Stormflow and Low Flow...................................................47

Sources of Dioxins and Furans................................................................................

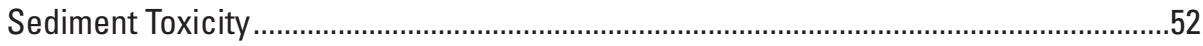

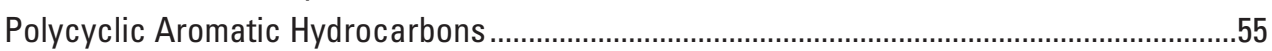

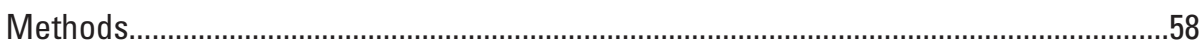

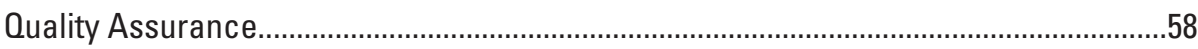

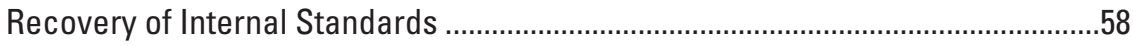

Contamination of Blanks and Data Censoring .....................................................60

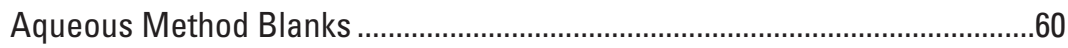

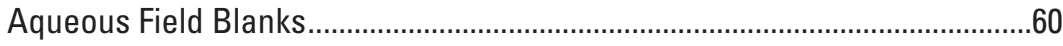

Filter Method Blanks ........................................................................................60

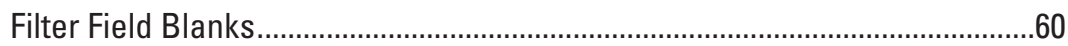

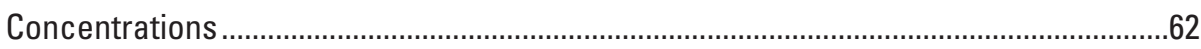

Anomolous Concentrations................................................................................

Relation of Whole-Water Concentrations to Water-Quality Criteria.........................76 
Sources for the Polycyclic Aromatic Hydrocarbon Compounds .......................................78

Sediment-Water Partitioning ................................................................................... 82

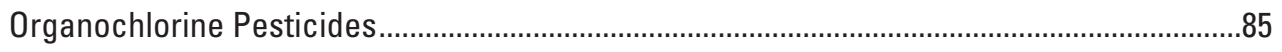

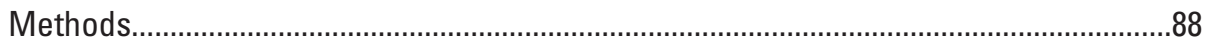

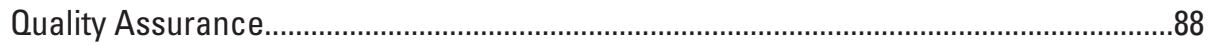

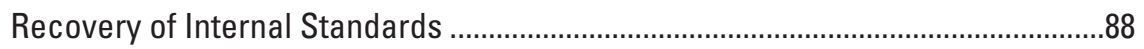

Contamination of Blanks and Data Censoring .......................................................88

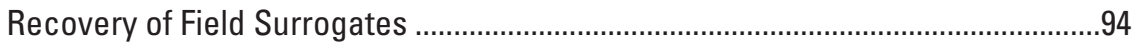

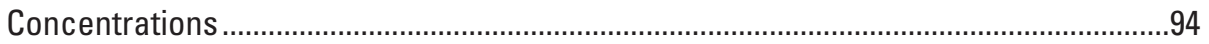

Relation of Whole-Water Concentrations to Surface-Water-Quality Criteria ......108

Concentrations During Stormflow and Low Flow.................................................108

Pesticide Degradation, Relative Concentrations of Metabolites, and

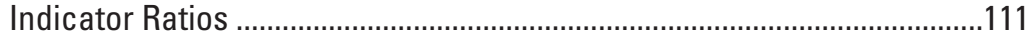

Sediment-Water Partitioning ...................................................................................115

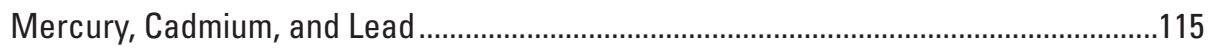

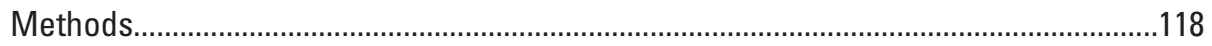

Quality Assurance .................................................................................................118

Contamination of Blanks and Data Censoring ………..............................................118

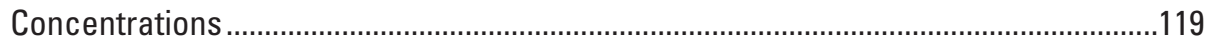

Relation of Whole-Water Concentrations to Surface-Water-Quality Criteria......121

Sediment-Water Partitioning ...................................................................................123

Predicted Concentrations in the Sediment and Water Phases ....................................128

Tributary Loads of Sediment, Carbon, and Chemicals ..............................................................130

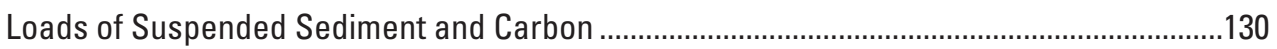

Methods Used to Calculate Sediment and Carbon Loads ............................................130

Concentrations and Loads of Particulates During Sampled Events ..............................131

Annual Loads of Sediment Estimated From Historical Data ...........................................137

Annual Loads of Dissolved and Particulate Carbon Estimated From Historical Data ...............................................................................................142

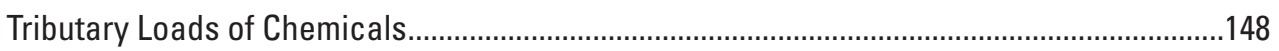

Methods Used to Estimate Chemical Loads................................................................148

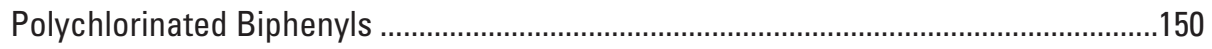

Dioxins, Furans, and Dioxin-Like Polychlorinated Biphenyls .........................................153

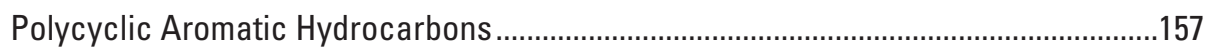

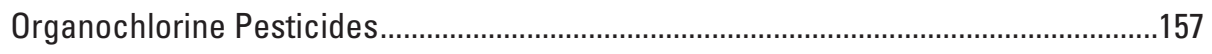

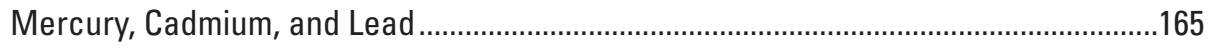

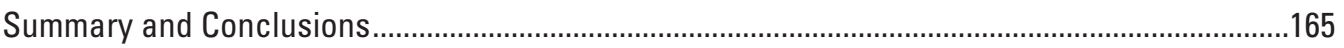

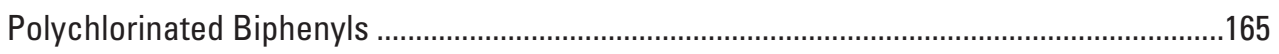

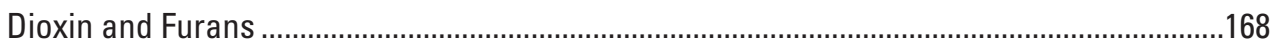

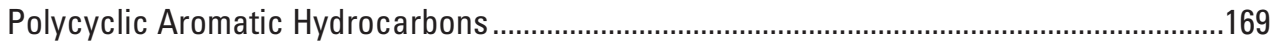

Organochlorine Pesticides.............................................................................................

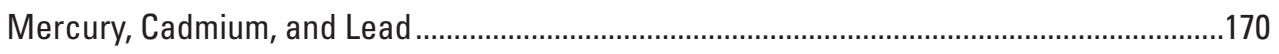

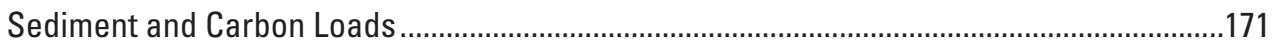

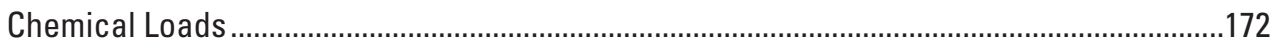

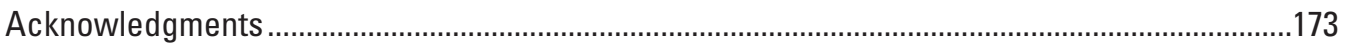

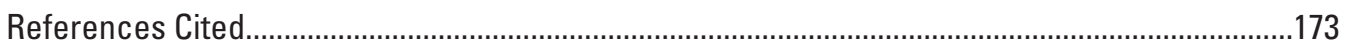




\section{Figures}

1. Schematic diagram of sources, sinks, and the geochemical processes that operate in estuaries. Arrows show directions of mass transfer of chemicals and sediment

2. Map showing location of study area and surface-water sampling sites in New Jersey.

3. Schematic diagram of a Trace Organic Platform Sampler (TOPS)

4. Structure and numbering system for chlorine substitution in polychlorinated biphenyls

5-14. Graphs showing -

5. Concentration of suspended-sediment and discharge in the Passaic River at Little Falls, N.J., December 2000

6. Average homolog distribution (by weight) of polychlorinated biphenyls (PCBs) in sediment from selected rivers in New Jersey

7. Ratio of concentration of polychlorinated biphenyl (PCB) congeners in sediment in storm samples to the concentration in low-flow samples from the Passaic River, New Jersey.

8. Ratio of concentration of dissolved polychlorinated biphenyl (PCB) congeners in storm samples to the concentration in low-flow samples from the Passaic River, New Jersey.

9. Ratio of concentration of polychlorinated biphenyl (PCB) congeners in sediment in storm samples to the concentration in low-flow samples from Elizabeth River, New Jersey

10. Ratio of concentration of dissolved polychlorinated biphenyl (PCB) congeners in storm samples to the concentration in low-flow samples from Elizabeth River, New Jersey

11. Relation between concentrations of total polychlorinated biphenyls in storm sediment and in water samples collected from selected rivers in New Jersey

12. Relation between logrithmic concentration of total polychlorinated biphenyls in sediment samples and in water samples from selected rivers in New Jersey

13. Relation between logrithmic concentrations of total polychlorinated biphenyls (carbon-normalized) in sediment and in water samples from selected rivers in New Jersey.

14. Relation between chlorination level and logarithm of ratio of average concentration of polychlorinated biphenyls in sediment (carbon-normalized) to average dissolved concentration in samples from selected rivers in New Jersey, and the logarithm of octanol-water partitioning coefficient

15. Molecular structure of (A) 2,3,7,8-tetrachloro-p-doxin (2,3,7,8-TCDD) and (B)

2,3,7,8-tetrachloro-p-difuran (2,3,7,8-TCDF)

16-27. Graphs showing-

16. Concentrations of individual dioxin and difuran compounds in average sediment from selected rivers in New Jersey

17. Average percent contribution of all 2,3,7,8-substituted dioxins and firans in sediment samples frm selected rivers in New Jersey

18. Average percent contribution of selected 2,3,7,8-substituted dioxin/furans in sediment samples from selected rivers in New Jersey. 
19. Percent contribution of individual dioxins and difurans congeners in samples from the Raritan River, New Jersey.

20. Percent contribution of individual dioxin and difuran congeners in sediment samples from the Passaic River, New Jersey...

21. Percent contribution of individual dioxin and difuran congeners in sediment samples from the Rahway River, New Jersey.

22. Percent contribution of individual dioxin and difuran congeners in sediment samples from the Elizabeth River, New Jersey.

23. Percent contribution of individual dioxin and difuran congeners in sediment samples from the Hackensack River, New Jersey

24. Congener profiles of dioxin and difuran congeners in average river sediments from selected rivers in New Jersey, and in diesel engine emission

25. Congener profiles of dioxin and difuran congeners in average river sediments from selected rivers in New Jersey, and in diesel engine emission with the octa-chlorinated compounds removed.

26. Percent contribution of all 2,3,7,8-substituted dioxin and difuran congeners to the toxic equivalencies (TEO) calculated for average sediment from selected rivers in New Jersey...

27. Percent contribution of selected 2,3,7,8-substituted dioxin and furan congeners to the toxic equivalencies (TEO) calculated for average sediment from selected rivers in New Jersey

28. Structures of selected polycyclic aromatic hydrocarbons.

29-37. Graphs showing-

29. Average concentrations of polycyclic aromatic hydrocarbons in suspended-sediment samples collected from selected rivers in New Jersey.......74

30. Percent contribution of polycyclic aromatic hydrocarbons in average suspended sediment collected from selected rivers in New Jersey

31. Average mole percent contribution of polycyclic aromatic hydrocarbons in suspended sediment collected from selected rivers in New Jersey.

32. Average concentrations of dissolved polycyclic aromatic hydrocarbons in samples collected from selected rivers in New Jersey...

33. Ratio of fluoranthene to fluoranthene plus pyrene, and anthracene to anthracene plus phenanthrene in suspended-sediment samples collected from selected rivers in New Jersey

34. Ratio of fluoranthene plus pyrene, and benzo(a)anthacene to benzo(a)anthracene plus chrysene in suspended-sediment samples collected from selected rivers in New Jersey

35. Ratio of fluroanthene to fluoranthene plus pyrene, and indenopyrene to indenopyrene plus benzo(ghi)perylene in suspended-sediment samples collected from selected rivers in New Jersey.

36. Alkylated naphthalenes in average suspended sediment in samples collected from selected rivers in New Jersey.

37. Measured and calculated distribution coefficients for polycyclic aromatic hydrocarbons in samples collected from selected rivers in New Jersey

38. Structures of selected organochlorine pesticides. .87

39-43. Graphs showing-

39. Percent contribution of selected organochlorine pesticide (OC) groups to 
the total average concentrations of organochlorine pesticides in suspended-

sediment samples collected from selected rivers in New Jersey.

40. Percent contribution of selected organochlorine pesticide groups to the total dissolved organochlorine pesticide concentrations in water samples collected from selected rivers in New Jersey......

41. Percent contribution of selected organochlorine pesticides in average suspended-sediment composition of samples from selected rivers in New Jersey.

42. Percent contribution of selected organochlorine pesticides in average dissolved composition of samples from selected rivers in New Jersey

43. Sediment-carbon water ratios for pesticide compounds in a low-flow sample collected from the Elizabeth River, Hillside, NJ, April 25, 2001

44. The biologic cycle of mercury and methyl-mercury in the environment.....

45-56. Graphs showing-

45. Relation between concentration of dissolved mercury and $(A)$ concentration of particulate-bound mercury and (B) concentration of particulate-carbonbound mercury in samples collected from selected rivers in New Jersey.

46. Relation between concentration of dissolved lead and (A) concentration of particulate-bound lead and (B) concentration of particulate-carbon-bound lead in grab samples collected from selected rivers in New Jersey.....

47. Relation between concentration of dissolved cadmium and $(A)$ concentration of particulate-bound cadmium and (B) concentration of particulate-carbon bound-cadmium in grab samples collected from selected rivers in New Jersey.

48. Discharge and the concentration of suspended sediment in samples collected from the Raritan River at Bound Brook, NJ, March 17 to 23, 2002

49. Discharge and the concentration of particulate organic carbon (POC)

in samples collected from the Raritan River at Bound Brook, NJ, March 17 to 23, 2002

50. Discharge and the concentration of suspended sediment in samples collected from the Elizabeth River at Hillside, NJ, May 21 to 24, 2001

51. Discharge and the concentration of particulate organic carbon (POC) in samples collected from the Elizabeth River at Hillside, NJ, May 21 to 24, 2001....133

52. Concentrations of suspended sediment and instantaneous discharge in the Raritan River, March 18 to 25, 2002.

53. Distribution of concentrations of suspended sediment in samples from the Raritan River at Queens Bridge, Bound Brook, NJ

54. Relation between mean daily discharge $(0)$ and daily sediment load for the Raritan River at Bound Brook, NJ

55. Discharge, specific conductance, and concentrations of dissolved organic carbon in the Raritan River at Bound Brook, NJ, March 18 to 23, 2001.

56. Relation between mean daily discharge and daily load of dissolved organic carbon in the Raritan River at Bound Brook, NJ 


\section{Tables}

1. Description of the surface-water sampling stations on the Raritan, Passaic, Hackensack, Rahway, and Elizabeth Rivers, New Jersey................................................6

3. Methods used to analyze water and sediment samples ................................................

4. Constituents measured in sediment and water samples collected from the Raritan, Passaic, Hackensack, Rahway, and Elizabeth Rivers, New Jersey..................................

5. Polychlorinated biphenyl congeners measured in this study ........................................13

6. Summary of normalized estimated detection limits for nondetected polychlorinated biphenyls in samples from selected rivers in New Jersey.............................................15

7. Average percent recoveries of internal standards in blanks and samples from selected rivers in New Jersey

8. Samples having low recoveries of labeled polychlorinated biphenyl internal standards

9. Summary of recoveries of labeled polychlorinated biphenyl field surrogates from blanks and samples from selected rivers in New Jersey.

10. Summary of polychlorinated biphenyl homolog masses measured and estimated detection limits in method and field blanks.

11. Frequency of the polychlorinated biphenyl congeners in sediment and water samples collected from selected rivers in New Jersey that were affected by blank elimination.

12. Summary of total polychlorinated biphenyl concentrations in sediment and water in samples from selected rivers in New Jersey

13. Average homolog distribution of polychlorinated biphenyls (PCBs) in sediment and water in samples from selected rivers in New Jersey

13. Average homolog distribution of polychlorinated biphenyls (PCBs) in sediment and water in samples from selected rivers in New Jersey...

14. Ratio of the average concentration of polychlorinated biphenyl (PCB) homologs in storm samples to that in low-flow samples collected from selected rivers in New Jersey.

15. Average logarithmic sediment-water ratios for polychlorinated biphenyl homolog groups in samples collected during low flow on selected rivers in New Jersey............33

16. The chlorinated dibenzo-p-dioxin (CDD) and dibenzo-p-difuran (CDF) compounds measured in samples collected from the Raritan, Passaic, Rahway, Elizabeth, and Hackensack Rivers, New Jersey

17. Summary of masses of dioxins and furans and the estimated detection limits in method and field blanks

18. Summary of estimated detection limits for nondetected dioxins and difurans in sediment samples collected from selected rivers in New Jersey

19. Concentrations of dioxins and furans in suspended sediment from selected rivers in New Jersey.

20. Average concentrations of dioxins and furans in suspended sediment from selected rivers in New Jersey

21. Toxic equivalency factors for $2,3,7,8$-substituted dioxins and furans.

22. Average toxic equivalencies (TEOs) for suspended sediment in selected rivers in New Jersey.

23. Average toxic equivalencies (TEOs) for the dioxin-like co-planar polychlorinated biphenyl compounds in sediment and water from selected rivers in New Jersey. 
24. Properties of the polycyclic aromatic hydrocarbons (PAHs) measured in this study ....59

25. Average masses of polycyclic aromatic hydrocarbons (PAH) in method blanks, field blanks, and samples.

26. Summary of detection limits for dissolved and particulate-bound polycyclic aromatic hydrocarbons (PAH) in samples from selected rivers in New Jersey..............63

27. Concentrations of polycyclic aromatic hydrocarbons (PAHs) measured in suspended sediment samples collected from selected rivers in New Jersey

28. Concentrations of dissolved polycyclic aromatic hydrocarbons measured in samples collected from selected rivers in New Jersey..

29. Whole-water concentrations and surface-water-quality criteria for polycyclic aromatic hydrocarbons in selected rivers in New Jersey

30. Average concentrations of dissolved polycyclic aromatic hydrocarbons (PAH) in samples collected from selected rivers in New Jersey..

31. Average concentrations of polycyclic aromatic hydrocarbons (PAH) in suspended sediment samples collected from selected rivers in New Jersey.

32. Average concentrations of polycyclic aromatic hydrocarbons in suspended sediment normalized to particulate carbon in samples collected from selected rivers in New Jersey

33. Average mole percentage of polycyclic aromatic hydrocarbons in suspended sediment samples collected from selected rivers in New Jersey.....

34. Identifiers and predicted sediment-water partitioning values for compounds used in figure 37

35. Organochlorine pesticides and their physical properties ................................................86

36. Native pesticide compounds and referenced internal standards ....................................89

37. Internal standard recoveries for selected pesticides in sediment samples collected from selected rivers in New Jersey

38. Summary of masses and estimated detection limits for pesticides in exchange-resin field blanks.

39. Summary of masses and estimated detection limits for pesticides in filter blanks ........92

40. Summary of results for Fraction I and II compounds in resin and filter method blanks

41. Recoveries of field surrogates from XAD samples...

42. Concentrations of suspended sediment-bound organochlorine pesticides in samples collected from selected rivers in New Jersey...

43. Concentrations of dissolved organochlorine pesticides in samples collected from selected rivers in New Jersey.

44. Concentrations of whole-water organochlorine pesticides in samples collected from selected rivers in New Jersey.....

44. Concentrations of whole-water organochlorine pesticides in samples collected from selected rivers in New Jersey...

45. Average concentrations of dissolved organochlorine pesticides in samples collected from selected rivers in New Jersey.

46. Average concentrations of organochlorine pesticides in suspended sediment in samples collected from selected rivers in New Jersey..

47. Average concentrations, normalized to carbon, of organochlorine pesticides in suspended sediment from samples collected in selected rivers in New Jersey

48. Ratio of the average concentration of organochlorine pesticides in storm samples to that in low-flow samples collected from selected rivers in New Jersey 
49. Ratios of concentrations of selected organochlorine pesticide metabolites, and 2,3,7,8-tetrachloro-p-dioxin, in the average composition of sediment from selected rivers in New Jersey.

50. Sediment-water partitioning ratios for organochlorine pesticides in selected low-discharge samples collected from selected rivers in New Jersey.

51. Concentrations of mercury, cadmium, and lead measured in the grab samples collected from selected rivers in New Jersey.

52. Concentrations of total mercury, cadmium, and lead in composite samples collected from selected rivers in New Jersey.

53. Average concentrations of mercury, cadmium, and lead in grab and composite samples collected from selected rivers in New Jersey.

54. Concentrations of particulate-bound mercury, cadmium, and lead in grab samples normalized to particulate carbon in samples collected from selected rivers in New Jersey.

55. Ratio of average concentrations of trace elements in composite samples to concentrations in grab samples collected from selected rivers in New Jersey.

56. Average apparent sediment-water distribution coefficients.

57. Average concentrations of mercury, lead, and cadmium predicted for water and sediment in selected rivers in New Jersey.

58. Concentrations of methyl-mercury in samples collected from selected rivers in New Jersey and apparent partitioning coefficients

59. Summary of average concentrations of suspended sediment, particulate organic carbon, and dissolved organic carbon in sampled events on selected rivers in New Jersey.

60. Ranges in discharge for storm events during an average year for selected rivers in New Jersey.

61. Estimated loads of suspended sediment and dissolved and particulate carbon in samples collected during storms from selected rivers in New Jersey.

62. Estimated daily loads of suspended sediment, dissolved, and particulate carbon during low flow in selected rivers in New Jersey.

63. Summary of water-quality data available for selected rivers in New Jersey... 139

64. Calculated regression lines used for predicting load of suspended sediment from discharge in selected rivers in New Jersey.....

65. Total annual discharge for water years 1988, 1994, and 1998-2002 and the average annual discharge for water years 1975 to 2000 in selected rivers in New Jersey.........141

66. Estimated annual sediment loads predicted for selected water years for selected rivers in New Jersey.

67. Sediment loads measured during sampled events and loads predicted using rating-curve method for selected rivers in New Jersey.

67. Sediment loads measured during sampled events and loads predicted using rating-curve method for selected rivers in New Jersey.

68. Calculated regression lines for predicting load of particulate organic carbon and dissolved organic carbon from discharge in selected rivers in New Jersey...

69. Estimated loads of particulate organic carbon in selected rivers in New Jersey .........146

70. Estimated loads of dissolved organic carbon in selected rivers in New Jersey............146

71. Estimated average annual loads of total organic carbon in selected rivers in New Jersey.

72. Average ratio of concentrations of particulate and dissolved organic carbon to suspended sediment in loads calculated for selected rivers in New Jersey water years 1988-2001 
73. Suspended sediment, particulate organic carbon, and dissolved organic carbon loads normalized to discharge for selected rivers in New Jersey.

74. Contribution to total concentration from estimated detection levels for dissolved polychlorinated biphenyls in a sample collected from the Hackensack River, New Jersey, on June 23, 2000

75. Estimated loads of polychlorinated biphenyls in samples collected during storms and low-flow conditions in selected rivers in New Jersey..

76. Estimated loads of sediment-bound and dissolved phase polychlorinated biphenyls (PCBs) for water years 1988 through 2002, and for the average annual discharge in selected rivers in New Jersey.

77. Contribution of sediment-bound polychlorinated biphenyl (PCB) homologs to the total polychlorinated biphenyl load for the average annual discharge in selected rivers in New Jersey

78. Estimated loads of polychlorinated dioxins and difurans in samples collected during storms and low-flow conditions in selected rivers in New Jersey.....

79. Estimated loads of sediment-bound dioxin, difurans, and co-planar polychlorinated biphenyls for water years 1988 through 2002, and for the average annual discharge in selected rivers in New Jersey

80. Loads of dioxin, furans, and dioxin-like polychlorinated biphenyls estimated for the average annual discharge in selected rivers in New Jersey

81. Concentrations of dissolved dioxin and difuran compounds in a sample collected from the Passaic River, N.J.

82. Estimated loads of polycyclic aromatic hydrocarbons in samples collected during storms and low-flow conditions in selected rivers in New Jersey.

83. Estimated loads of sediment-bound and dissolved total polycyclic aromatic hydrocarbons (PAH) for water years 1988 through 2002, and for the average annual discharge in selected rivers in New Jersey

84. Estimated loads of individual polycyclic aromatic hydrocarbon (PAH) compounds and contribution to total load by sediment-bound compounds for the average annual discharge in selected rivers in New Jersey

85. Estimated loads of organochlorine pesticides in samples collected during storms and low-flow conditions in selected rivers in New Jersey...

86. Estimated loads of sediment-bound and dissolved total organochlorine pesticides (OCP) for water years 1988 through 2002, and for the average annual discharge in selected rivers in New Jersey.

87. Estimated loads of dissolved and sediment-bound organochlorine pesticides and contribution to total load by sediment-bound compounds for the average annual discharge in selected rivers in New Jersey.

88. Estimated loads of trace elements in samples collected during storms and low-flow conditions in selected rivers in New Jersey.

89. Estimated loads of sediment-bound and dissolved total mercury, lead, and cadmium for water years 1988 through 2002, and for the average annual discharge in selected rivers in New Jersey.....

90. Estimated loads of sediment-bound mercury $(\mathrm{Hg})$, cadmium $(\mathrm{Cd})$, and lead $(\mathrm{Pb})$ for the average annual discharge in selected rivers in New Jersey, calculated using grab sample and predicted concentrations.

91. Contribution of sediment-bound trace elements to the total load of trace metals for the average annual discharge in selected rivers in New Jersey. 


\section{Conversion Factors, Datum, and Water-Quality Abbreviations}

\begin{tabular}{|c|c|c|}
\hline Multiply & By & To obtain \\
\hline \multicolumn{3}{|c|}{ Length } \\
\hline centimeter $(\mathrm{cm})$ & 0.3937 & inch (in.) \\
\hline millimeter $(\mathrm{mm})$ & 0.03937 & inch (in.) \\
\hline meter $(\mathrm{m})$ & 3.281 & foot $(\mathrm{ft})$ \\
\hline kilometer $(\mathrm{km})$ & 0.6214 & mile (mi) \\
\hline \multicolumn{3}{|c|}{ Area } \\
\hline square meter $\left(\mathrm{m}^{2}\right)$ & 0.0002471 & acre \\
\hline square kilometer $\left(\mathrm{km}^{2}\right)$ & 0.3861 & square mile $\left(\mathrm{mi}^{2}\right)$ \\
\hline \multicolumn{3}{|c|}{ Volume } \\
\hline liter (L) & 0.2642 & gallon (gal) \\
\hline milliliter $(\mathrm{mL})$ & 0.0002642 & gallon (gal) \\
\hline \multicolumn{3}{|c|}{ Flow rate } \\
\hline cubic meter per second $\left(\mathrm{m}^{3} / \mathrm{s}\right)$ & 35.31 & cubic foot per second $\left(\mathrm{ft}^{3} / \mathrm{s}\right)$ \\
\hline liter per second $(\mathrm{L} / \mathrm{s})$ & 15.85 & gallon per minute $(\mathrm{gal} / \mathrm{min})$ \\
\hline \multicolumn{3}{|c|}{ Mass } \\
\hline gram $(\mathrm{g})$ & 0.03527 & ounce, avoirdupois (oz) \\
\hline
\end{tabular}

Vertical coordinate information is referenced to the National Geodetic Vertical Datum of 1929 (NAVD 29)

Horizontal coordinate information is referenced to the North American Datum of 1983 (NAD 83)

\section{Water-quality abbreviations:}

\begin{tabular}{ll}
\hline PCB & Polychlorinated biphenyl \\
TOPS & Trace organic platform sampler \\
PAH & Polycyclic aromatic hydrocarbons \\
CDD & Chlorinated dibenzo-p-dioxins \\
CDF & Chlorinated dibenzo-p-furans \\
TEQ & Toxic Equivalency \\
SS & Suspended sediment \\
POC & Particulate organic carbon \\
DOC & Dissolved organic carbon \\
Kg & kilogram \\
mg & milligram \\
$\mu \mathrm{g}$ & microgram \\
ng & nanogram \\
pg & picogram \\
g/mol & grams per mole \\
mg/kg & milligrams per kilogram \\
ng/g & nonograms per year \\
\hline
\end{tabular}

\begin{tabular}{ll}
\hline $\mathrm{g} / \mathrm{yr}$ & grams per year \\
$\mathrm{kg} / \mathrm{yr}$ & kilogram per year \\
$\mathrm{L} / \mathrm{kg}$ & liters per kilogram \\
$\mathrm{pg} / \mathrm{L}$ & picograms per liter \\
$\mathrm{ng} / \mathrm{L}$ & nanograms per liter \\
$\mathrm{MGD}$ & million gallons per day \\
$\mathrm{Mgal}$ & millions of gallons \\
$\mathrm{EDL}$ & Estimated detection limit \\
$\mathrm{IS}$ & Internal standard \\
$\mathrm{FS}$ & Field surrogate \\
$\mathrm{SRM}$ & Standard reference material \\
${ }^{13} \mathrm{C}$ & Carbon isotope 13 \\
$\mathrm{GFF}$ & Glass fiber filter \\
$\mathrm{XAD}$ & Chemical exchange resin \\
$\mathrm{Hg}$ & mercury \\
$\mathrm{Cd}$ & cadmium \\
$\mathrm{Pb}$ & lead \\
\hline
\end{tabular}




\title{
Concentrations and Loads of Organic Compounds and Trace Elements in Tributaries to Newark and Raritan Bays, New Jersey
}

\author{
By Timothy P. Wilson and Jennifer L. Bonin
}

\section{Abstract}

A study was undertaken to determine the concentrations and loads of sediment and chemicals delivered to Newark and Raritan Bays by five major tributaries: the Raritan, Passaic, Rahway, Elizabeth, and Hackensack Rivers. This study was initiated by the State of New Jersey as Study I-C of the New Jersey Toxics Reduction Workplan for the New York-New Jersey Harbor, working under the NY-NJ Harbor Estuary Program (HEP) Contaminant Assessment and Reduction Program (CARP). The CARP is a comprehensive effort to evaluate the levels and sources of toxic contaminants to the tributaries and estuarine areas of the NY-NJ Harbor, including Newark and Raritan Bays. The Raritan and Passaic Rivers are large rivers (mean daily discharges of 1,189 and 1,132 cubic feet per second $\left(\mathrm{ft}^{3} / \mathrm{s}\right)$, respectively), that drain large, mixed rural/urban basins. The Elizabeth and Rahway Rivers are small rivers (mean daily discharges of 25.9 and $49.1 \mathrm{ft}^{3} / \mathrm{s}$, respectively) that drain small, highly urbanized and industrialized basins. The Hackensack River drains a small, mixed rural/urban basin, and its flow is highly controlled by an upstream reservoir (mean daily discharge of $90.4 \mathrm{ft}^{3} / \mathrm{s}$ ). These rivers flow into urbanized estuaries and ultimately, to the Atlantic Ocean.

Each of these tributaries were sampled during two to four storm events, and twice each during low-flow discharge conditions. Samples were collected using automated equipment installed at stations adjacent to U.S. Geological Survey streamflow-gaging stations near the heads-of-tide of these rivers. Large-volume (greater than 50 liters of water and a target of 1 gram of sediment), flow-weighted composite samples were collected for chemical analysis using filtration to collect suspended particulates and exchange resin (XAD-2) to sequester dissolved contaminants. Composite whole-water samples were collected for dissolved polycyclic aromatic hydrocarbons (PAH) and for trace element analysis. Additional discrete grab samples were collected throughout each event for trace-element analysis, and multiple samples were collected for suspended sediment (SS), particulate carbon (POC), and dissolved organic carbon (DOC) analysis. The suspended sediment and exchange resin were analyzed for 114 polychlorinated biphenyls (PCBs, by US EPA method 1668A, modi- fied), seven 2,3,7,8-substituted chlorinated dibenzo-p-dioxins (CDD) and 10 dibenzo-p-difurans (CDF) (by US EPA method 1613), $24 \mathrm{PAHs}$ (by low-resolution isotope dilution/massspectral methods), 27 organo-chlorine pesticides (OCPs) (by high resolution isotope dilution/mass-spectral methods), and the trace elements mercury $(\mathrm{Hg})$, methyl-mercury $(\mathrm{MeHg})$, lead $(\mathrm{Pb})$, and cadmium $(\mathrm{Cd})$. Isotope dilution methods using gas chromatography and high-and low-resolution mass spectral (GC/MS) detection were used to accurately identify and quantify organic compounds in the sediment and water phases. Trace elements were measured using inductively coupled plasma-mass spectrometry and cold-vapor atomic fluorescence spectrometry methods.

The loads of sediment, carbon, and chemicals were calculated for each storm and low-flow event sampled. Because only a few storm events were sampled, yearly loads of sediment were calculated from rating curves developed using historical SS and POC data. The average annual loads of sediment and carbon were calculated for the period 19752000 , along with the loads for the selected water years being modeled as part of the New York New Jersey Harbor Estuary Program CARP. Comparison of loads calculated using the rating curve method to loads measured during the sampled storm events indicated that the rating curve method likely underpredicts annual loads.

Average annual loads of suspended sediment in the tributaries were estimated to be 395,000 kilograms per year $(\mathrm{kg} / \mathrm{yr})$ in the Hackensack River, 417,000 kg/yr in the Elizabeth River, $882,000 \mathrm{~kg} / \mathrm{yr}$ in the Rahway River, $22,700,000 \mathrm{~kg} / \mathrm{yr}$ in the Passaic River, and 93,100,000 kg/yr in the Raritan River. Average annual loads of POC were estimated to range from $14,400 \mathrm{~kg}$ in the Elizabeth River to 866,000 kg in the Raritan River. DOC ranged from $89,000 \mathrm{~kg} / \mathrm{yr}$ in the Elizabeth River to $4,260,000 \mathrm{~kg} / \mathrm{yr}$ in the Passaic River. These sediment loads and the average chemical concentrations measured in this study were used to estimate the loads of organic compounds and trace elements for the average year and for selected water years.

The highest average concentrations of sediment-bound total PCBs were found in the Elizabeth River $(2,460 \mathrm{ng} / \mathrm{g})$ and the lowest in the Raritan River (44 ng/g). The highest average concentrations of dissolved total PCBs were also found in the 
Elizabeth River $(5,050 \mathrm{pg} / \mathrm{L})$, while the lowest were found in the Hackensack River $(740 \mathrm{pg} / \mathrm{L})$. Average annual loads of total PCBs (sum of all congeners measured) in the tributaries were estimated to be $74 \mathrm{~g} / \mathrm{yr}$ in the Hackensack River, $440 \mathrm{~g} / \mathrm{yr}$ in the Rahway River, $1,150 \mathrm{~g} / \mathrm{yr}$ in the Elizabeth River, $5,000 \mathrm{~g} / \mathrm{yr}$ in the Raritan River, and 7,200 g/yr in the Passaic River. From 47 to 90 percent of the total load was estimated to be associated with the particulate phase. The New Jersey State Surface Water Quality Criteria (NJSWQC) for Human Health was exceeded by the average concentration in all the rivers and the aquatic chronic criteria was exceeded by the average concentration in the Elizabeth and individual samples in the Passaic and Rahway Rivers.

The highest average concentrations of sediment-bound total CDD plus CDFs were found in the Elizabeth River $(28.9 \mathrm{ng} / \mathrm{g})$ and the lowest in the Hackensack River $(5.6 \mathrm{ng} / \mathrm{g})$. The CDD and CDF congeners were detected in the suspended sediment from all the tributaries, although the most toxic congener (2,3,7,8-TCDD) was detected only occasionally in the Passaic, Elizabeth, and Raritan Rivers and at very low concentrations. The dominant CDD and CDF compounds in all the rivers were the octachloro-dioxin and octachlorodifuran congeners. The average annual total loads of 2,3,7,8substituted dioxins plus furans were estimated to be $2.2 \mathrm{~g} / \mathrm{yr}$ in the Hackensack River, $10 \mathrm{~g} / \mathrm{yr}$ in the Rahway River, $12 \mathrm{~g} /$ $\mathrm{yr}$ in the Elizabeth River, $260 \mathrm{~g} / \mathrm{yr}$ in the Passaic River, and $1,070 \mathrm{~g} / \mathrm{yr}$ in the Raritan River. The higest average toxicity concentrations represented by toxic equivalencies (TEQs), of dioxins, furans, and dioxin-like PCBs was measured in the Elizabeth River (201 pg/g), and the lowest in the Raritan River $(20 \mathrm{pg} / \mathrm{g})$. Average annual total toxicity loads from CDD, CDF, and co-planar PCBs (as TEQ) were estimated to be 11 milligrams per year (mg/yr) in the Hackensack River, $56 \mathrm{mg} / \mathrm{yr}$ in the Rahway River, $84 \mathrm{mg} / \mathrm{yr}$ in the Elizabeth River, $870 \mathrm{mg} / \mathrm{yr}$ in the Passaic River, and 1,800 mg/yr in the Raritan River. The contribution to the total TEQ load contributed by dioxin-like PCBs ranged from 18 to 33 percent.

Average concentrations of sediment-bound and dissolved total PAH compounds were generally largest in the Elizabeth River and the lowest in the Hackensack and Raritan Rivers. Average annual loads of total PAHs (sum of all sediment-bound and dissolved PAH compounds measured) were estimated to be $15 \mathrm{~kg} / \mathrm{yr}$ in the Hackensack River, 69 $\mathrm{kg} / \mathrm{yr}$ in the Rahway River, $280 \mathrm{~kg} / \mathrm{yr}$ in the Elizabeth River, $1,000 \mathrm{~kg} / \mathrm{yr}$ in the Passaic River, and 1,400 kg in the Raritan River. Sediment-bound PAHs dominated (71 percent) the total PAH load in the Raritan River while dissolved PAH compounds dominated (80 percent) the PAH load in the Elizabeth River. Dissolved PAH compounds comprise about 60 percent of the load in the Passaic, Rahway, and Hackensack Rivers. Sediment-bound PAHs and dissolved PAHs were dominated by the high molecular-weight (greater than $202 \mathrm{~g}$ per mole) compounds. Because of the small 1 to 2 Liter sample volumes used for analysis, and blank contamination, low concentrations of dissolved PAH could not be measured, resulting in some uncertainty and underestimation in the dissolved loads.
Whole-water concentrations of several of the PAH compounds were found to exceed the NJSWQC in all of the rivers studied.

Average concentrations of sediment-bound total OCP compounds were generally highest in the Elizabeth River $(1,170 \mathrm{ng} / \mathrm{g})$ and the lowest were in the Raritan River (60 ng/g), while the highest dissolved concentrations were found in the Rahway River (9.5 ng/L) and the lowest were in the Raritan River $(2.3 \mathrm{ng} / \mathrm{L})$. Average annual loads of total OCPs (sum of all OCP compounds measured) were estimated to be $420 \mathrm{~g} / \mathrm{yr}$ in the Hackensack River, $670 \mathrm{~g} / \mathrm{yr}$ in the Elizabeth River, 1,100 g/yr in the Rahway River, 6,300 g/yr in the Passaic River, and 6,600 g/yr in the Raritan River. Between 40 and 74 percent of these compounds were associated with the particulate phase. The dominant compounds in suspended sediment were the DDT series (DDT, DDD, and DDE) and chlordane series. The dominant compounds in the dissolved phase were the chloradane series in the Rahway, Elizabeth and Hackensack Rivers, and the BHC series in the Passaic and Raritan Rivers. The NJSWQC for 4,4'-DDD, DDE, and DDT were exceeded in all the samples from the Rahway and Elizabeth Rivers, and occasionally in other river samples.

Average concentrations of total (whole-water) mercury and lead were highest in the Rahway River, while the average whole-water $\mathrm{Cd}$ concentration was highest in the Elizabeth River. Average annual loads of $\mathrm{Hg}$ were found to fall in the order: Hackensack River (.070 kg/yr) $<$ Rahway River $(1.3)<$ Elizabeth River (2.2)<Passaic River (8.0)<Raritan River (13). The average annual loads of $\mathrm{Pb}$ were found fall in the order: Hackensack River $(20 \mathrm{~kg} / \mathrm{yr})<$ Rahway River $(450)<$ Elizabeth River $(1,800)<$ Passaic River $(2,100)<$ Raritan River $(3,400)$. Average annual loads of $\mathrm{Cd}$ were found to fall in the order: Hackensack River $(0.26 \mathrm{~kg} / \mathrm{yr})<$ Rahway River $(4.5)<$ Elizabeth River (17)<Raritan River (54)<Passaic River (88). A varying proportion of the metal loads were associated with the sediment phase. Generally, 76 to 98 percent of the $\mathrm{Hg}$ and $\mathrm{Pb}$ load was found to be associated with sediment, while between 34 and 79 percent was associated with sediment.

\section{Introduction}

The Raritan, Passaic, Hackensack, Rahway, and Elizabeth Rivers are the main New Jersey tributaries to the New York-New Jersey (NY-NJ) Harbor estuary system. Urbanization and industrialization within the tributary watersheds and the estuaries have contributed a variety of contaminants to the water column and to the sediment deposited in the estuaries. This contamination poses a substantial health threat to the harbor ecosystem and makes it difficult to safely dispose of and manage harbor sediments when they are dredged (NY-NJ Harbor Estuary Program Comprehensive Conservation and Management Plan, 1996).

Restoring this estuary and reducing the amount of contaminated sediment that must be dredged from the navigation channels and ship berths are important concerns of Federal 
and State government agencies in the New Jersey/New York area. Toward these goals, the States of New Jersey and New York are working under the U.S. Environmental Protection Agency (USEPA) NY-NJ Harbor Estuary Plan (HEP), and together with other stakeholders have initiated the Contaminant Assessment and Reduction Program (CARP; see www. carpweb.org for more information). The CARP is a comprehensive program to evaluate the effects of toxic contamination on the condition of the NY-NJ Harbor estuary system and its tributaries. The New Jersey Toxics Reduction Workplan for the NY-NJ Harbor (NJTRWP) has been implemented by the New Jersey Department of Environmental Protection (NJDEP) as the New Jersey component of CARP. To help prioritize remediation efforts, the U.S.Gelogical Survey participated in a cooperative program to characterize the types and concentrations of contaminants and sediments contributed from the tributary basins.

Concurrent with this work were studies that characterized conditions within the tidal reaches of the New Jersey tributaries and estuarine areas (NJTRWP Studies I-D and I-E), and discharges from publicly owned treatment works (POTWs), combined sewer overflows (CSO), and stormwater outfalls (SWO) in the harbor (NJTRWP Study I-G). The New York State Department of Environment and Conservation (NYSDEC) conducted a similar program within the harbor, focusing on the Hudson River and its tributaries (Litten, 2003). The combined objective of the various NJTRWP studies is to determine the relative importance of loadings of toxic chemicals and sediments throughout the harbor from sources (1) above the HOT of major tributaries (this study), and (2) within the tidal watershed areas of the major tributaries, including the Newark Bay complex.

\section{Purpose and Scope}

This report presents the results of Study I-C of the NJTRWP including the methods, concentrations, and estimates of loads of sediment, carbon, organic compounds, and trace elements from above the HOT in the Raritan, Passaic, Rahway, Elizabeth, and Hackensack Rivers. Loads are presented for seven hydrologic events, for selected years, and for the 25-year average discharge conditions. Preliminary interpretations regarding sources and behaviors of the toxic chemicals of concern and relations between contaminant concentrations and the hydrologic attributes of these tributaries are presented. Because novel analytical methods were developed for this work, various analytical parameters are presentated in detail. Samples discussed in this study were collected from June 2000 to June 2003. The report by Bonin and Wilson (2006) presents additional information about the methods and data described in this report.

\section{Geochemical Cycling in Estuaries}

The data generated in the NJTRWP and CARP Program are being used in part to understand and model the geochemical cycling of sediment and contaminants within the NY-NJ Harbor estuary system. Geochemical cycling refers to the transport and reactions that affect water, sediment, and chemicals as they move from source(s) to sink(s) through various environments. Sources of sediment and chemicals to an estuary (fig. 1) include the tributaries, the ocean through tidal movement, point sources such as sewer or industrial outfalls, the erosion and resuspension of buried sediment and its associated pore water, diffusion through pore water, atmospheric deposition, overland surface flow, and the influx from ground

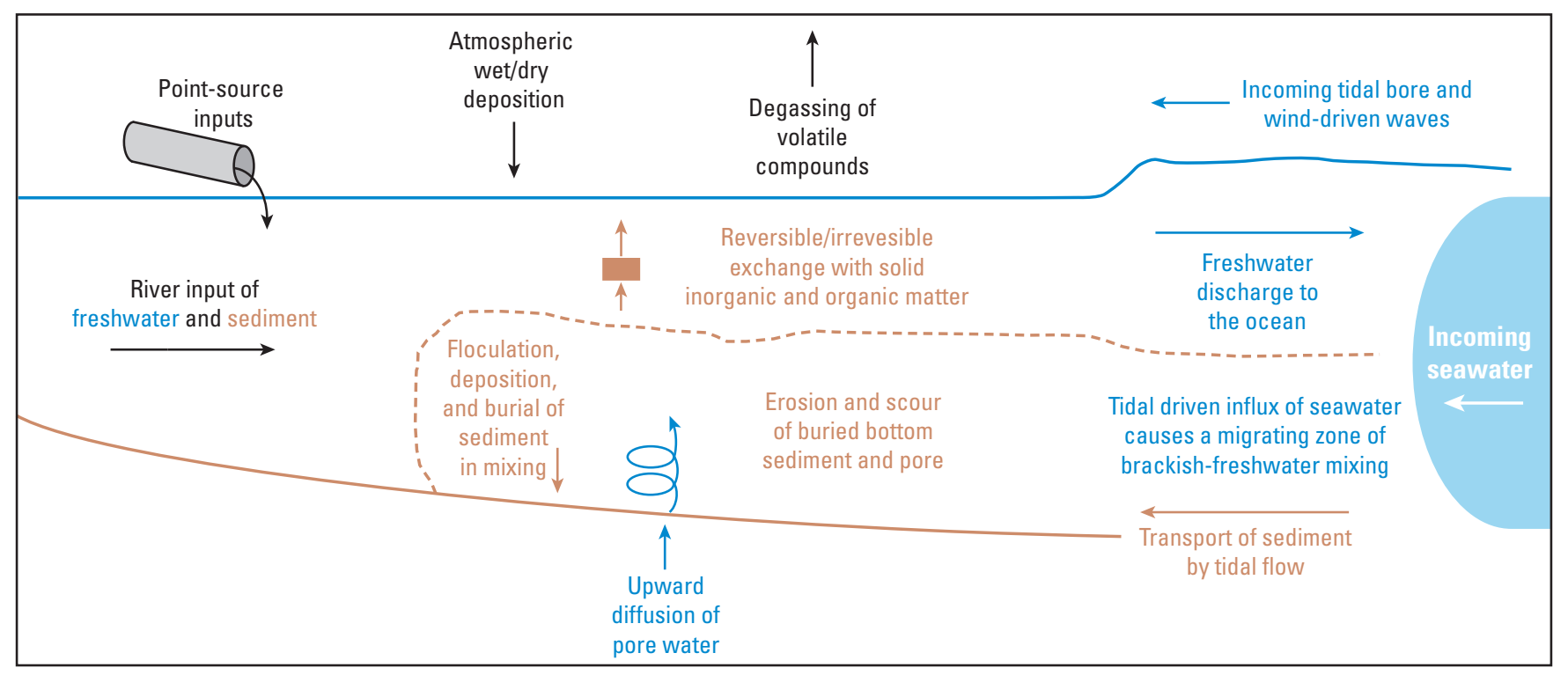

Figure 1. Schematic diagram of sources, sinks, and the geochemical processes that operate in estuaries. Arrows show directions of mass transfer of chemicals and sediment. 
water. In urbanized areas, many known and unknown sources exist, such as wastes released from operating or abandoned factories and runoff from roads. Once introduced, the sediment and chemicals move throughout the estuary where they are affected by many processes until they are lost or stored in various sinks. Outputs or sinks for chemicals in estuaries include transport to the open ocean, degassing from water to the atmosphere, the incorporation of chemicals into water droplets and sea-salt blown into the atmosphere from wave tops, the uptake of chemicals by plants and organisms, and sorption onto sediment and subsequent burial in the streambed or the ocean.

Two processes that greatly affect sediments and chemicals in freshwater and estuarine river systems are the flocculation and deposition of freshwater-derived sediments and carbon and the partitioning of chemicals between the water and sediments. As fresh river water encounters seawater, the changing salinity affects the electrostatic interactions between suspended particles, causing them to form larger flocks that quickly settle. Most organic chemicals will partition into organic matter and deposit with the flocks. The sorption of chemicals onto particulates that flocculate and deposit within the mixing zone in an estuary represents a short-term sink for many anthropogenic contaminants.

To predict how chemicals cycle in an estuarine environment, the sources and magnitudes of input, the nature of the sinks, and the physical, geochemical, and biogeochemical processes within each component or reservoir of the estuary must first be described. A numerical model can then be constructed to explain these geochemical observations, thereby allowing quantification and prediction of the movement and storage of chemicals through the environment (Albarede, 1995). As part of the CARP, a comprehensive mass-balance model of the geochemical cycling of sediments and chemicals (Hydroqual, 2000) through the NJ-NY Harbor system is being constructed. In this model, the estuary is dissected into multiple, boxlike, grid cells. The model includes all the substantial inputs and outputs to each grid cell, along with basic functions that describe the partitioning of chemicals among the sediment, water, and gas phases and the other physical-chemical processes that operate within each cell. Mass-balance models are based on the principle of conservation of mass, which states that the mass of a chemical entering a cell must equal the mass leaving the cell minus any mass stored within the cell, and the assumption that geochemical reactions reach instantaneous, reversible equilibrium. The geochemical model of the NJ-NY Harbor system is being developed in conjunction with hydrodynamic, bioaccumulation, and toxicity models that together describe the physical transport of sediment and fate of contaminants. Together, the models will be used to predict the importance of each contaminant source and the time required before dredged sediments will meet Federal regulatory standards for safe ocean disposal if the largest contaminant sources are removed (New Jersey Department of Environmental Protection, 2001).

The study described in this report was conducted to estimate the mass of sediment and selected chemicals that enter the New Jersey estuaries and bays from the five major tributaries (fig.2, table 1). In this study, co-existing water and suspended sediment from the Raritan, Passaic, Rahway, Elizabeth, and Hackensack Rivers were collected during stormflow and low-discharge conditions, and were analyzed for selected organic and inorganic chemicals-of-concern (table 1). Sampling was conducted at the head-of-tide (HOT) of these rivers, which refers to the farthest point upstream in a coastal river affected by daily diurnal tidal cycles. The data were used to estimate the loads of sediment and chemicals originating from the freshwater watersheds, to demonstrate the in situ partitioning of chemicals between the water and sediment phases in the freshwater portions of the estuary, and as input for the CARP geochemical model being developed for the harbor-estuary system.

\section{Description of Sample Collection, Sample Analysis, and Methods for Calculating Concentrations}

A complete description of the sampling and analytical methods is presented by Bonin and Wilson (2006). Organic contaminants (polychlorinated biphenyls (PCBs), dioxin/ furans, polycyclic aromatic hydrocarbons (PAHs), organochlorine pesticides (OCPs), trace elements) were measured in flow-weighted, composite samples collected using a Trace Organic Platform Sampler (TOPS) (fig. 3). TOPS are largevolume samplers that collect suspended sediment using filters and dissolved contaminants using exchange resin. Dissolved PAHs and whole-water trace elements were measured in flowweighted composite grab samples collected using automatic grab composite samplers. Trace elements also were measured in discrete grab samples collected near the time of peak discharge of each event. These various samples were collected using automated sampling equipment that calculated river discharge and controlled the various samplers. With the exception of dissolved dioxins/furans (which were not measured in this study) and dissolved PAHs, organic compounds were measured in suspended sediment collected on pre-baked glassfiber canister and flat filters (1.0 and 0.7 micron nominal pore size, respectively), and dissolved organic compounds were collected by passing the filtered water through exchange resin (XAD-2). Typically, 1 to $3 \mathrm{~g}$ of suspended particulate matter was collected for analysis, and $50 \mathrm{~L}$ of water were processed to obtain dissolved-phase concentrations.

The organic compounds were extracted from the sediment and exchange resin and were subsequently analyzed using the methods listed in tables 3 and 4 . For organic compounds, sample extracts were analyzed using either high- or low-resolution gas chromatography/mass spectrometry. Trace elements were analyzed using inductively coupled plasmamass spectrometry or cold-vapor flouresence methods. 


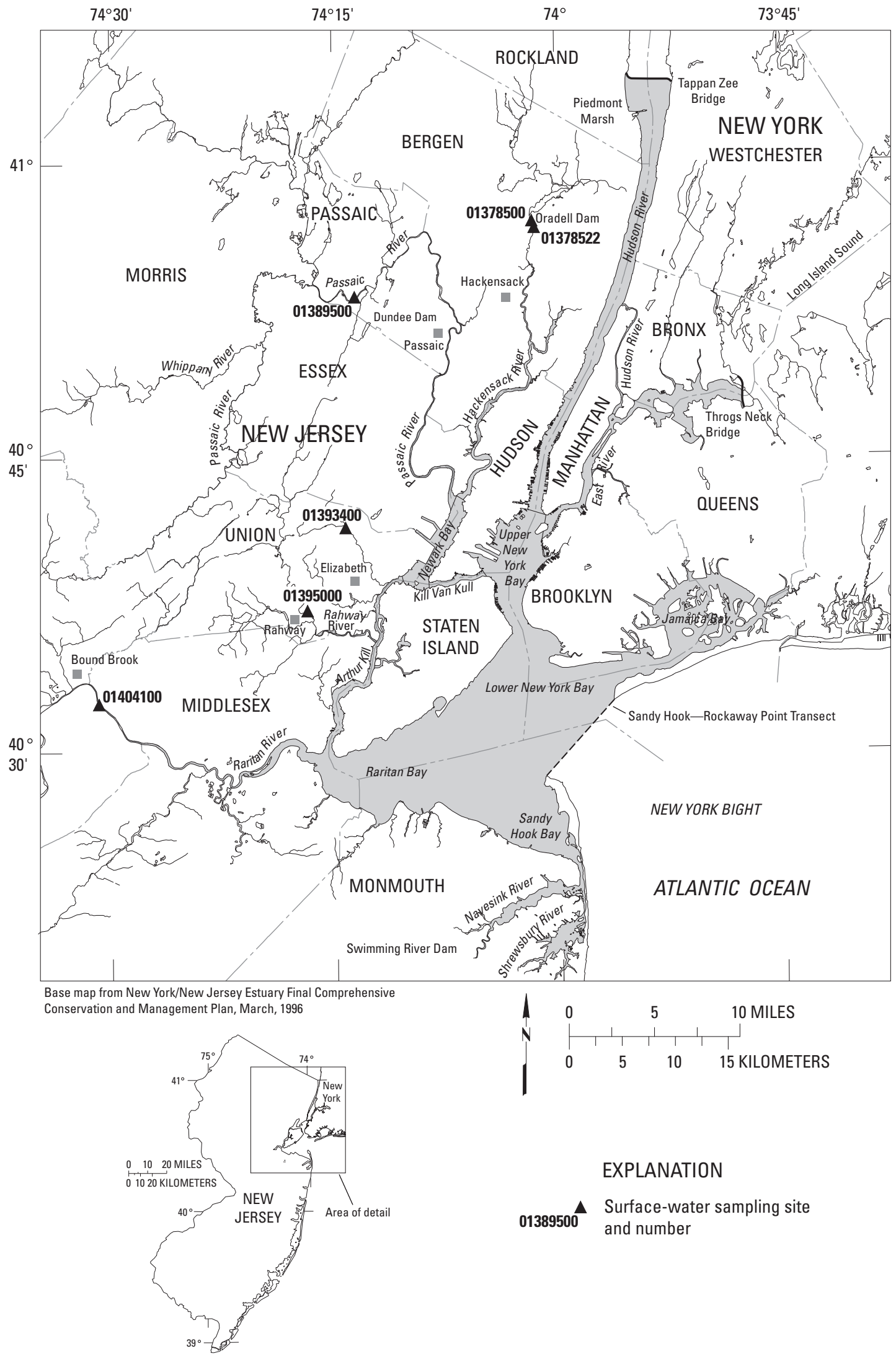

Figure 2. Location of study area and surface-water sampling sites in New Jersey. 


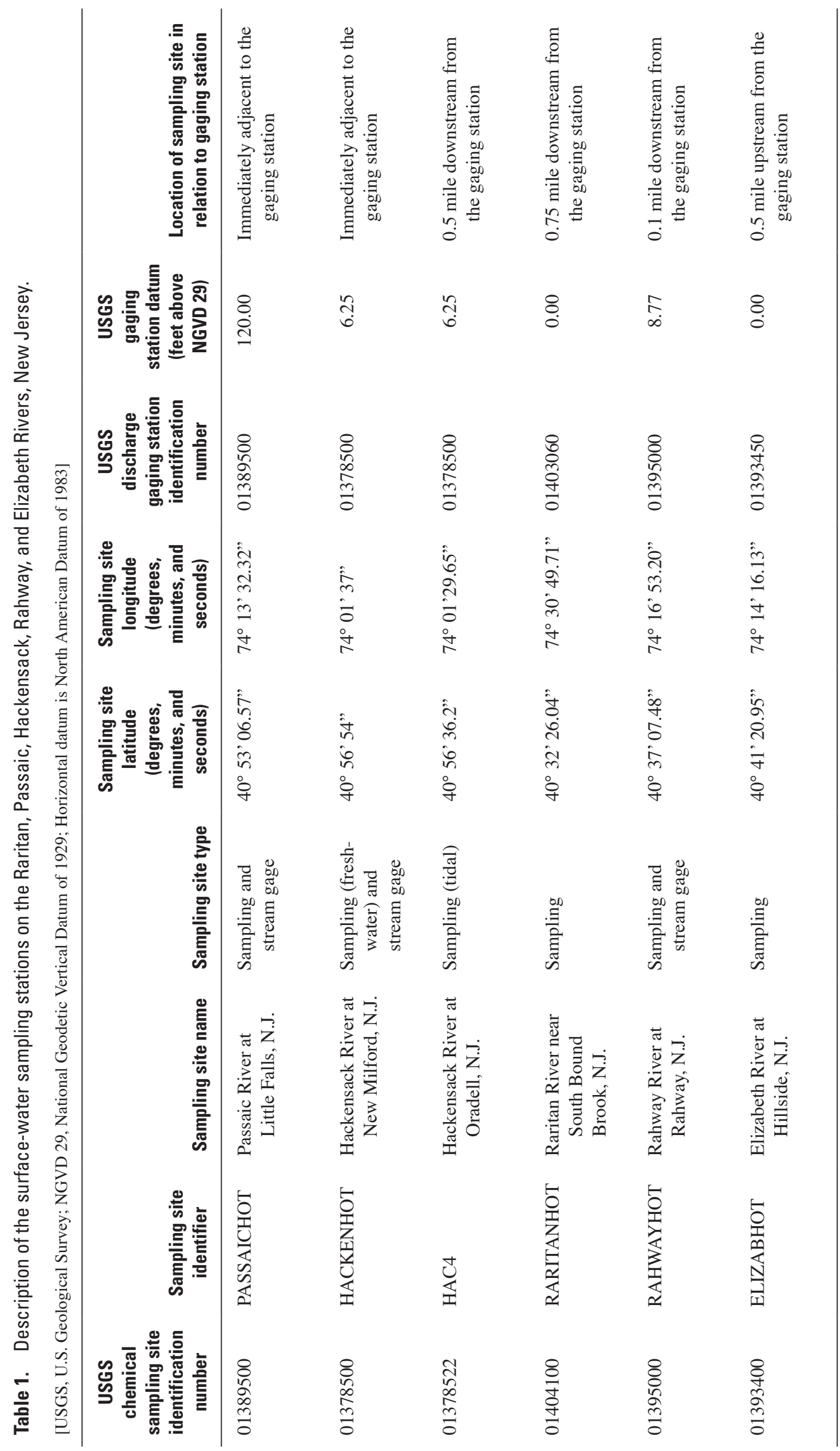




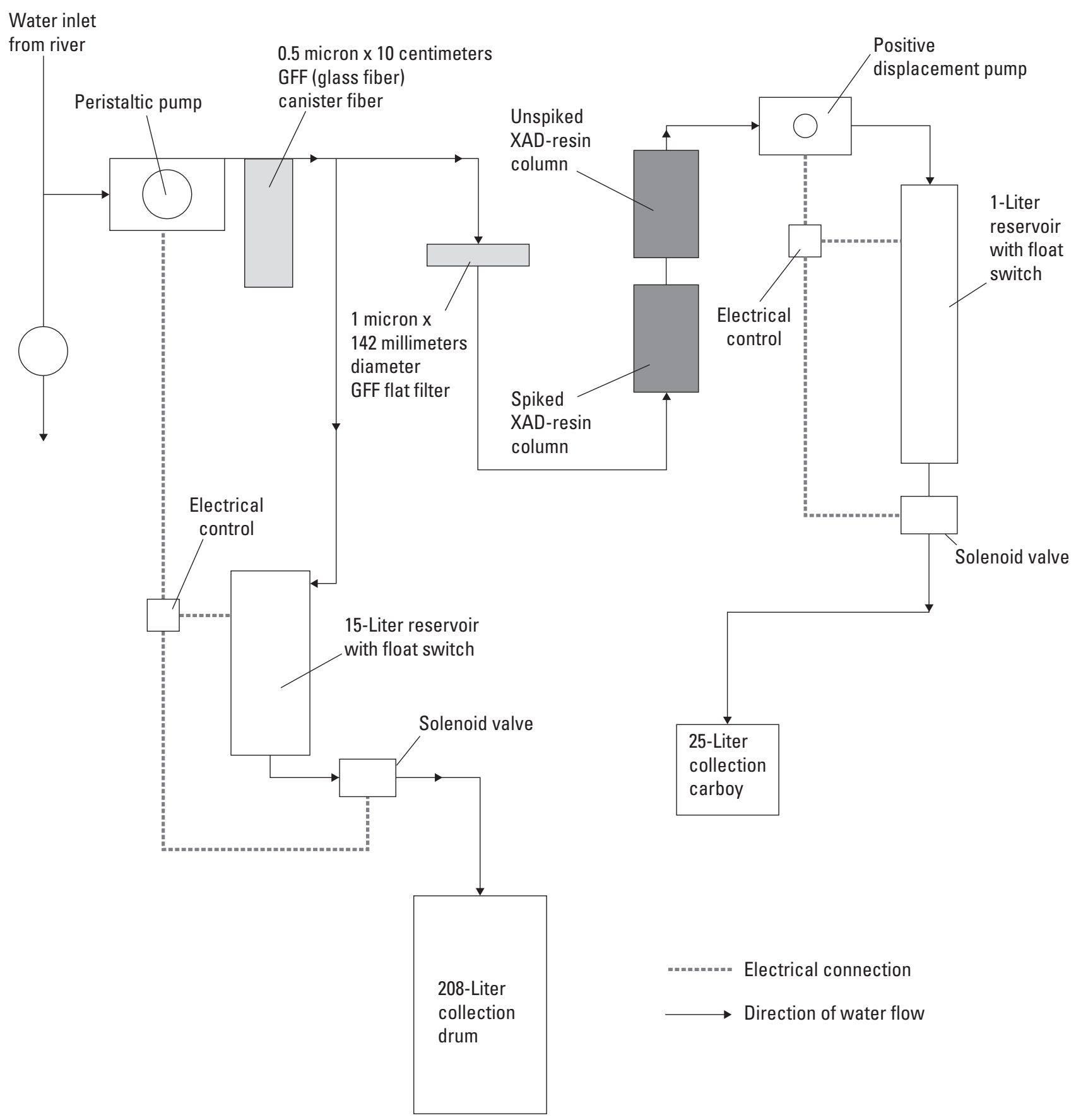

Figure 3. Schematic diagram of a Trace Organic Platform Sampler (TOPS). From Bonin and Wilson (2006). 
Table 3. Methods used to analyze water and sediment samples.

[PCB, Polychlorinated biphenyls; PAHs, Polycyclic aromatic hydrocarbons; GC/MS, gas chromatography/mass spectrometry; HR, High-resolution; LR, low-resolution; ICP-MS, Inductively coupled plasma-mass spectrometry; CV-AFS, Cold-vapor atomic fluorescence spectrometry; IR, Infrared; USEPA, U.S. Environmental Protection Agency; CEPA-ARB, California Environmental Protection Agency Air Resources Board; STL KNOX, STL laboratory, Knoxville, Tenn.; USGS, U.S. Geological Survey. Table adapted from Bonin and Wilson, 2006]

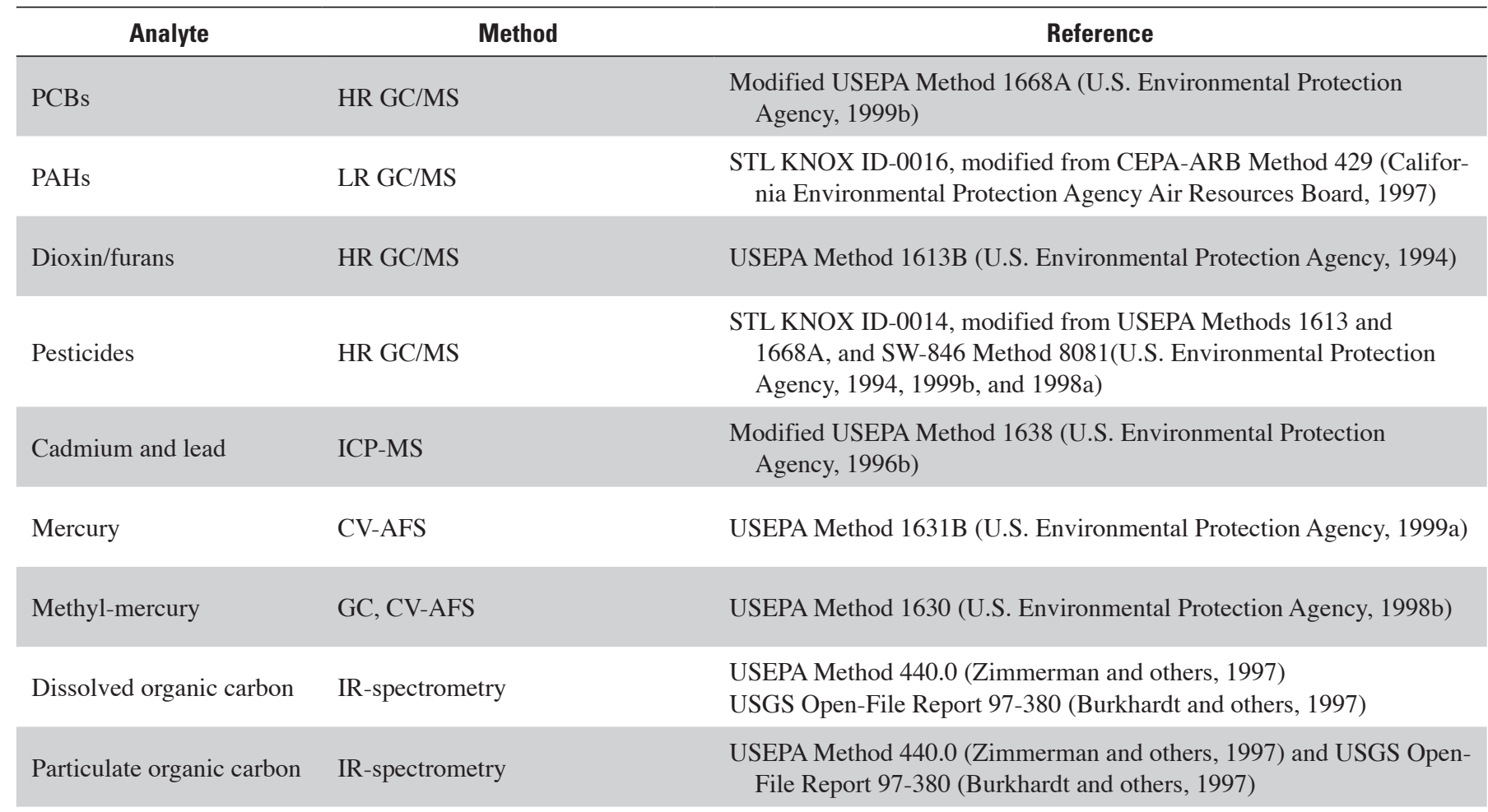

Suspended Sediment

Filtration and gravimetric analysis

USGS Open-File Report 98-384 (Sholar and Shreve, 1998)

Ancillary data collected included concentrations of suspended sediment (SS), particulate organic carbon (POC), dissolved organic carbon (DOC), and specific conductance of the river water being sampled. These components were measured in multiple discrete grab samples collected using automatic samplers. Field data collected included volume of water filtered and volume passed through the XAD resin, continuous records of stage and discharge of the rivers, and the amount and timing of precipitation. These ancillary field data are tabulated in Bonin and Wilson (2006).

The results as reported by the analytical laboratories and the field data collected during sampling are presented by Bonin and Wilson (2006). The raw data also are available through the CARP database. Results for the organic compounds were delivered from the laboratory as masses of analytes recovered from the sediment phase (extracted from the combined canister and flat filters) and masses of analytes recovered from the exchange resin for the dissolved phase. Results for the composite and discrete grab samples analyzed for trace elements, dissolved PAHs, SS, POC, and DOC were reported as concentrations per liter of water.
To convert masses to concentrations, the (1) volume of raw river water passed through the canister and flat filters, (2) the volume of filtered water passed through the exchange resin, and (3) the SS, DOC, and POC concentrations associated with the sampled water are needed. The information required to convert masses of constituents into concentrations, with units of volume (liter) of water or unit mass of SS (typically grams), is included in the field data (Bonin and Wilson, 2006).

The mass of SS and POC collected on the canister and flat filter required a correction to account for incomplete filtering (breakthrough) of the canister filter. Preliminary tests showed that the canister filters, on average, had a trapping efficiency of 90 percent. The addition of a flat filter (fig. 3) increased the trapping efficiency even further and prevented sediment from entering the XAD canister. The mass of sediment trapped on the filters is further reduced where the filter outfall is split; 90 percent of the flow went to waste and 10 percent was directed through flat filters and the XAD columns. Because it was not possible to confirm the mass of sediment collected on the flat filter, the assumption was made that the 
Table 4. Constituents measured in sediment and water samples collected from the Raritan, Passaic, Hackensack, Rahway, and Elizabeth Rivers, New Jersey.

[CAS, Chemical Abstract Service; IUPAC, International Union of Physical and Analytical Chemistry; PCB, Polychlorinated biphenyl; n/a, not applicable]

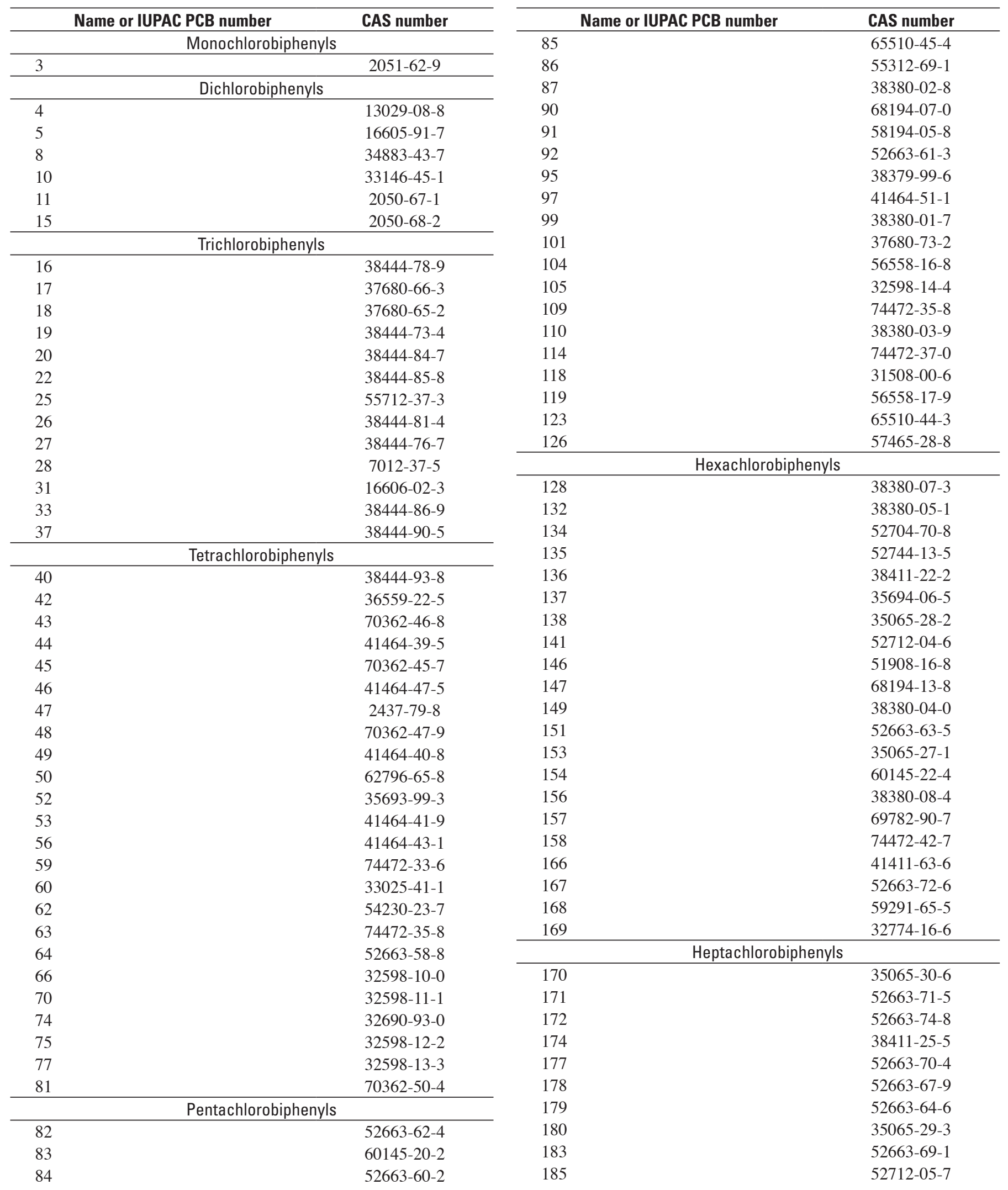


Table 4. Constituents measured in sediment and water samples collected from the Raritan, Passaic, Hackensack, Rahway, and Elizabeth Rivers, New Jersey.-Continued

[CAS, Chemical Abstract Service; IUPAC, International Union of Physical and Analytical Chemistry; PCB, Polychlorinated biphenyl; n/a, not applicable]

\begin{tabular}{|c|c|}
\hline Name or IUPAC PCB number & CAS number \\
\hline 187 & $52663-68-0$ \\
\hline 189 & $39635-31-9$ \\
\hline 190 & 41411-64-7 \\
\hline 191 & $74472-50-7$ \\
\hline \multicolumn{2}{|c|}{ Octachlorobiphenyls } \\
\hline 194 & $35694-08-7$ \\
\hline 195 & $52663-78-2$ \\
\hline 196 & $42740-50-1$ \\
\hline 198 & 68194-17-2 \\
\hline 199 & $52663-75-9$ \\
\hline 200 & $52663-73-7$ \\
\hline 201 & $40186-71-8$ \\
\hline 203 & $52663-76-0$ \\
\hline 205 & $74472-53-0$ \\
\hline \multicolumn{2}{|c|}{ Nonachlorobiphenyls } \\
\hline 206 & $40186-72-9$ \\
\hline 207 & $52663-79-3$ \\
\hline 208 & $52663-77-1$ \\
\hline \multicolumn{2}{|c|}{ Decachlorobiphenyls } \\
\hline 209 & 2051-24-3 \\
\hline \multicolumn{2}{|c|}{ Dioxins } \\
\hline $2,3,7,8$-Trichlorodioxin & $1746-01-6$ \\
\hline $1,2,3,7,8$-Pentachlorodioxin & $40321-76-4$ \\
\hline 1,2,3,7,8,9-Hexachlorodioxin & $19408-74-3$ \\
\hline $1,2,3,4,7,8$-Hexachlorodioxin & $39227-28-6$ \\
\hline $1,2,3,6,7,8$-Hexachlorodioxin & $57653-85-7$ \\
\hline $1,2,3,4,6,7,8-$ Heptachlorodioxin & $35822-46-9$ \\
\hline Octachlorodioxin & $3268-87-9$ \\
\hline \multicolumn{2}{|c|}{ Furans } \\
\hline 2,3,7,8-Trichlorodifuran & $51207-31-9$ \\
\hline 1,2,3,7,8-Pentachlorodifuran & $57117-41-6$ \\
\hline 2,3,4,7,8-Pentachlorodifuran & $57117-31-4$ \\
\hline $1,2,3,4,7,8$-Hexachlorodifuran & $70648-26-9$ \\
\hline 2,3,4,6,7,8-Hexachlorodifuran & $60851-34-5$ \\
\hline $1,2,3,7,8,9-$ Hexachlorodifuran & 72918-21-9 \\
\hline $1,2,3,6,7,8$-Hexachlorodifuran & 57117-44-9 \\
\hline 1,2,3,4,7,8,9-Heptachlorodifuran & $55673-89-7$ \\
\hline $1,2,3,4,6,7,8$-Heptachlorodifuran & $67562-39-4$ \\
\hline Octachlorodifuran & $39001-02-0$ \\
\hline
\end{tabular}

\begin{tabular}{|c|c|}
\hline Name or IUPAC PCB number & CAS number \\
\hline Benzo(a)pyrene & $50-32-8$ \\
\hline Benzo(b)fluoranthene & $205-99-2$ \\
\hline Benzo(e)pyrene & $192-97-2$ \\
\hline Benzo(ghi)perylene & $191-24-2$ \\
\hline Benzo(k)fluoranthene & $207-08-9$ \\
\hline Biphenyl & $92-52-4$ \\
\hline Chrysene & $218-01-9$ \\
\hline Dibenz(a,h)anthracene & $53-70-3$ \\
\hline Fluoranthene & $206-44-0$ \\
\hline Fluorene & $86-73-7$ \\
\hline Indeno(1,2,3-cd)pyrene & $193-39-5$ \\
\hline Naphthalene & $91-20-3$ \\
\hline C2 Alkylnaphthalenes & $\mathrm{n} / \mathrm{a}$ \\
\hline C3 Alkylnaphthalenes & $\mathrm{n} / \mathrm{a}$ \\
\hline \multicolumn{2}{|c|}{ Pesticides } \\
\hline 2,4'-DDD & $53-19-0$ \\
\hline 2,4'-DDE & $3424-82-6$ \\
\hline 2,4'-DDT & $789-02-6$ \\
\hline 4,4'-DDD & $72-54-8$ \\
\hline 4,4'-DDE & $72-55-9$ \\
\hline 4,4'-DDT & $50-29-3$ \\
\hline Aldrin & $309-00-2$ \\
\hline alpha-BHC & $319-84-6$ \\
\hline beta-BHC & $319-85-7$ \\
\hline gamma-BHC (Lindane) & $58-89-9$ \\
\hline alpha-Chlordane & $5103-71-9$ \\
\hline gamma-Chlordane & $5103-74-2$ \\
\hline oxy-Chlordane & 27304-13-8 \\
\hline alpha-Endosulfan & $959-98-8$ \\
\hline beta-Endosulfan & $33213-65-9$ \\
\hline cis-Nonachlor & $5103-73-1$ \\
\hline trans-Nonachlor & $39765-80-5$ \\
\hline Dieldrin & $60-57-1$ \\
\hline Endosulfan sulfate & $1031-07-8$ \\
\hline Endrin & $72-20-8$ \\
\hline Endrin aldehyde & $7421-93-4$ \\
\hline Endrin ketone & 53494-70-5 \\
\hline Heptachlor & $76-44-8$ \\
\hline Heptachlor epoxide & $1024-57-3$ \\
\hline Hexachlorobenzene & $118-74-1$ \\
\hline Methoxychlor & $72-43-5$ \\
\hline Mirex & $2385-85-5$ \\
\hline \multicolumn{2}{|c|}{ Trace Elements } \\
\hline Cadmium & $7440-43-9$ \\
\hline Lead & $7439-92-1$ \\
\hline Mercury & $7439-97-6$ \\
\hline Methyl-mercury & $\mathrm{n} / \mathrm{a}$ \\
\hline \multicolumn{2}{|c|}{ Other } \\
\hline Carbon, organic & $\mathrm{n} / \mathrm{a}$ \\
\hline Suspended sediment & $\mathrm{n} / \mathrm{a}$ \\
\hline
\end{tabular}

Polycyclic Aromatic Hydrocarbons

Perylene 198-55-0

Phenanthrene 85-01-8

Pyrene $\quad 129-00-0$

1-Methylnaphthalene $\quad 90-12-0$

1-Methylphenanthrene 832-69-9

2,3,5-Trimethylnaphthalene 2245-38-7

2,6-Dimethylnaphthalene 581-42-0

2-Methylnaphthalene 91-57-6

Acenaphthene 83-32-9

Acenaphthylene 208-96-8

Anthracene 120-12-7

Benzo(a)anthracene 56-55-3 
entire mass of sediment not captured on the canister filter was sent to waste. As a result, the mass of sediment (or organic carbon) calculated to have been trapped on the TOPS filters was reduced by 10 percent. Therefore, the sediment mass is considered a conservative estimate of the amount of sediment captured on the filters. Although flat filters captured most of any sediment that broke through, it is possible some particles entered the columns. A correction could not be applied to the dissolved concentrations to account for any particulate-bound contaminants that may have become entrapped in the columns, so the dissolved concentrations may be be over-estimations.

The dissolved concentrations of constituents recovered in the XAD-resin columns were calculated using the equation

$$
C_{d}=M_{x a d} / V_{x a d}
$$

where

$$
\begin{aligned}
C_{d}= & \text { dissolved concentration, in mass per liter } \\
& \text { of water; } \\
M_{x a d}= & \text { mass of constituent recovered from the } \\
& \text { XAD-resin sample, in nanograms or } \\
& \text { picograms; }
\end{aligned}
$$

and

$$
V_{\text {xad }}=\text { volume of water processed through the }
$$$$
\text { XAD column, in liters. }
$$

The concentration of organic compounds in the suspended sediment was calculated using the equation

$$
C_{p}=M_{f} /\left(V_{f} * S S * f * 1,000\right)
$$

where

$$
\begin{aligned}
& C_{p} \quad=\text { concentration in suspended sediment, in } \\
& \text { mass per gram of sediment; } \\
& M_{f} \quad=\text { mass of constituent recovered in the filter } \\
& \text { sample, in picograms or nanograms; } \\
& V_{f} \quad=\text { volume of water processed through the } \\
& \text { canister filter, in liters; } \\
& \text { SS = mean suspended sediment concentration, } \\
& \text { in milligram of sediment per liter; }
\end{aligned}
$$

and

$$
f \quad=\text { filter efficiency, } 0.9 \text {. }
$$

POC normalized concentrations in units per gram of organic carbon were calculated using the equation

$$
C_{p c}=M_{f} /\left(V_{f}^{*} P O C * f * 1,000\right)
$$

where

$$
\begin{aligned}
C_{p c}= & \begin{array}{l}
\text { concentration of constituent normalized to } \\
\text { mass of particulate organic carbon, in mass } \\
\text { per gram of organic carbon; }
\end{array} \\
M_{f}= & \begin{array}{l}
\text { mass of constituent recovered on filter, in } \\
\text { picograms or nanograms; }
\end{array} \\
V_{f}= & \text { volume of water passed through filter, in } \\
& \text { liters; }
\end{aligned}
$$

and

$$
f \quad=\text { filter efficiency, } 0.9 \text {, }
$$

$$
\begin{aligned}
P O C= & \text { mean particulate organic carbon } \\
& \text { concentration, in milligrams of carbon per } \\
& \text { liter. }
\end{aligned}
$$

Analytical results for trace elements and PAHs in composite samples are reported in concentration units of mass per unit volume of water and require no further reduction.

Concentrations of trace elements in the particulate phase were determined as the difference between the total and dissolved trace-element concentrations using the equation

$$
p M=(t M-d M) * 1,000 / S S
$$

where

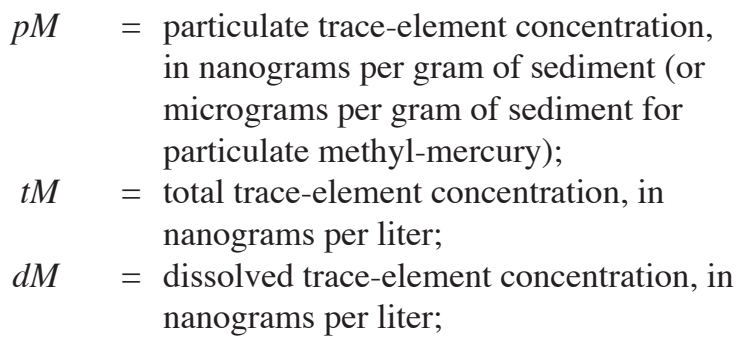

and

$$
\begin{aligned}
S S= & \text { concentration of suspended sediment, in } \\
& \text { milligrams per liter. }
\end{aligned}
$$

Particulate trace-element concentrations can be normalized to POC using the fraction of organic carbon, which is calculated using either equation

$$
F O C=P O C / S S
$$

Or to the mass of carbon directly

$$
p M^{\prime}=(t M-d M) / P O C
$$

where

$$
\begin{aligned}
\text { Foc }= & \text { fraction of organic carbon in particulate } \\
& \text { material (unitless) } \\
p M^{\prime}= & \text { particulate trace-element concentrations, in } \\
& \text { micrograms per gram of carbon; } \\
P O C= & \text { particulate organic carbon concentration, in } \\
& \text { milligrams of carbon per liter; }
\end{aligned}
$$

and

$$
\begin{aligned}
S S= & \text { concentration of suspended sediment, in } \\
& \text { milligrams per liter. }
\end{aligned}
$$

For some components such as methyl-Hg, the results were converted from nanograms per gram to micrograms per gram by dividing by 1,000 .

Total or whole-water concentrations were derived from dissolved and particulate analysis using the equation 


$$
C_{\text {total }}=C_{d}+\left(C_{p} * S S / 1000\right)
$$

where

$$
\begin{aligned}
C_{\text {total }}= & \text { whole-water total concentration, in mass } \\
& \text { per liter of water; } \\
C_{d}= & \text { dissolved concentration, in mass per liter } \\
& \text { of water; } \\
C_{p}= & \text { concentration in sediment, in mass per } \\
& \text { gram of sediment; }
\end{aligned}
$$

and

SS = suspended sediment concentration, in milligrams per liter.

\section{Concentrations of Organic Compounds and Trace Elements}

Samples of river water and suspended sediment were analyzed for PCBs, chlorinated dioxins and furans, PAHs, OCPs and the trace elements mercury $(\mathrm{Hg})$, cadmium $(\mathrm{Cd})$, and lead $(\mathrm{Pb})$. These concentrations were used to calculate loads for sampled hydrologic events and to estimate annual loads from the tributary basins.

\section{Polychlorinated Biphenyls}

The concentrations of 114 PCBs congeners, of which 15 were co-elutioning congeners, were measured in water and co-existing suspended sediment from the Raritan, Passaic, Rahway, Elizabeth, and Hackensack Rivers, the major tributaries to Newark and Raritan Bays. Large-volume, flow-weighted composite samples were collected during low-flow and storm conditions These data were used to make interpretations and to calculate riverine loads of PCBs to Newark and Raritan Bays from the watersheds above the HOT.

PCBs are a class of organic compounds having a structure consisting of a biphenyl $\left(\mathrm{C}_{12} \mathrm{H}_{10-\mathrm{n}} \mathrm{Cl}_{\mathrm{n}}\right)$ in which the two 6carbon benzene rings have their hydrogen replaced by a varying number of chlorine atoms (fig. 4). Ten different levels of chlorination exist, termed homolog groups, mono (1) through deca (10), resulting in 209 distinct congeners. However, not all 209 congeners have been synthesized for industrial use. The different compound names, the level of chlorination, and the corresponding identification number of the congeners measured in this work are listed in table 5.

PCBs, which have low electrical conductivity and high resistance to heat and thermal degradation, were used as transformer oils and in other electrical insulation applications, as well as in paints and dyes, as flame retardants in plastics, and as fire-resistant adhesive. The oils were developed in specific Aroclors, which are mixtures of individual PCB congeners. Aroclors are identified by their average chlorine content; for example, PCB aroclor 1248 contains an average of 48 percent chlorine and contains 70 congeners ranging from PCB congener \#3 to PCB \#180 (Erickson, 1997). Residual PCB oil or residuals from the burning of products that contain PCBs are the principal sources of PCBs to the environment. The individual PCB congeners are, for the most part, stable in the environment and resist degradation, but they can be affected by vaporization into the gas phase, by sorption to solids, by dissolution into water, and to a limited degree, by photodegradation, microbial degradation, and other reactions. Generally, PCBs degrade very slowly through dechlorination, whereby higher chlorinated compounds lose chlorine and assume a lower chlorination level. PCBs enter biota through ingestion of water or carbon matter and readily bio-accumulate in fatty portions of organisms. PCBs have cycled throughout the global environment and have been found in fish, birds, and mammals in nearly all environments (Hansen, 1999; Erickson, 1997).

Several of the PCB congeners have been found to be toxic and dangerous to organisms, acting as endocrine disruptors (Erickson, 1997). Generally, attention has focused on the congeners having their two biphenyl rings aligned in the same plane. Twelve coplanar congeners exist: 77, 81, 105, 114, 118, 123, 126, 156, 157, 167, 169, and 189. The coplanar PCBs exhibit toxic behaviors similar to the dioxin/furans and have been assigned toxic equivalent factors on the dioxin/furan scale. In the non-planar or orthogonal PCB compounds, the biphenyl rings lay perpendicular to one another because at least one chlorine atom is in the 2, 2', 6, or 6' position (fig. 4), which hinders the biphenyl rings from rotating into the same plane.

\section{Methods}

The sediment-bound and dissolved compounds (collected on XAD resin) were analyzed using a modification of USEPA Method 1668-A (U.S. Environmental Protection Agency, 1999b), which is an internal standard method utilizing high-resolution gas chromatography/mass spectrometer. Of the 114 PCB congeners selected by the program for measurement (table 5), 73 congeners did not co-elute with other congeners, 15 congeners co-eluted with congeners in the New Jersey list, and 26 co-eluted with congeners outside of the New Jersey program list (see list of co-elutions in Bonin and Wilson, 2006). In the database of reported congeners, values for coeluted congeners were reported with the lowest numbered

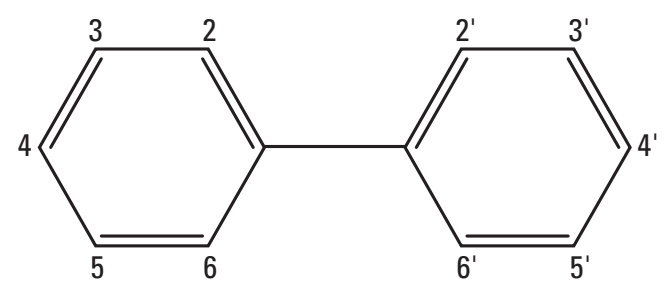

Figure 4. Structure and numbering system for chlorine substitution in polychlorinated biphenyls. 
Table 5. Polychlorinated biphenyl congeners measured in this study.

[CAS, Chemical Abstract Service number]

\begin{tabular}{ccc}
\hline Congener Number & $\begin{array}{c}\text { Substitutions and } \\
\text { homolog group }\end{array}$ & CAS \# \\
\hline \multicolumn{3}{c}{ Monodichlorobiphenyl } \\
\hline 3 & 4 & $2051-62-9$ \\
\hline 4 & Dichlorobyphenyl \\
5 & $2,2^{\prime}$ & $13029-08-8$ \\
8 & 2,3 & $16605-91-7$ \\
10 & $2,4^{\prime}$ & $34883-43-7$ \\
11 & 2,6 & $33146-45-1$ \\
15 & $3,3^{\prime}$ & $2050-67-1$ \\
\hline
\end{tabular}

\begin{tabular}{ccc}
\hline Congener Number & $\begin{array}{c}\text { Substitutions and } \\
\text { homolog group }\end{array}$ & CAS \# \\
\hline 53 & $2,2^{\prime}, 5^{\prime}, 6^{\prime}$ & $41464-41-9$ \\
55 & $2,3^{\prime}, 3^{\prime}, 4^{\prime}$ & $74338-24-2$ \\
56 & $2,3,3^{\prime}, 4^{\prime}$ & $41464-43-1$ \\
59 & $2,3,3^{\prime}, 6$ & $74472-33-6$ \\
60 & $2,3,4,4^{\prime}$ & $33025-41-1$ \\
62 & $2,3,4^{\prime}, 6$ & $54230-22-7$ \\
63 & $2,3,4^{\prime}, 5$ & $74472-34-7$ \\
64 & $2,3,4^{\prime}, 6$ & $52663-58-8$ \\
66 & $2,3^{\prime}, 4^{\prime}, 4^{\prime}$ & $32598-10-0$ \\
70 & $2,3^{\prime}, 4^{\prime}, 5$ & $32598-11-1$ \\
74 & $2,4,4^{\prime}, 5$ & $32690-93-0$ \\
75 & $2,4,4^{\prime}, 6$ & $32598-12-2$ \\
77 & $3,3^{\prime}, 4^{\prime}, 4^{\prime}$ & $32598-13-3$ \\
81 & $3,4,4^{\prime}, 5$ & $70362-50-4$ \\
\hline
\end{tabular}

\begin{tabular}{ccc}
\multicolumn{3}{c}{ Trichlorobiphenyl } \\
\hline 16 & $2,2^{\prime}, 3$ & $38444-78-9$ \\
17 & $2,2^{\prime}, 4$ & $37680-66-3$ \\
18 & $2,2^{\prime}, 5$ & $37680-65-2$ \\
19 & $2,2^{\prime}, 6$ & $38444-73-4$ \\
20 & $2,3,3^{\prime}$, & $38444-84-7$ \\
22 & $2,3,4^{\prime}$ & $38444-85-8$ \\
25 & $2,3^{\prime}, 4$ & $55712-37-3$ \\
26 & $2,3^{\prime}, 5$ & $38444-81-4$ \\
27 & $2,3^{\prime}, 6$ & $38444-76-7$ \\
28 & $2,4,4^{\prime}$ & $7012-37-5$ \\
29 & $2,4,5$ & $15862-07-4$ \\
31 & $2,4^{\prime}, 5$ & $16606-02-3$ \\
33 & $2^{\prime}, 3^{\prime}, 4$ & $38444-86-9$ \\
37 & $3,4,4^{\prime}$ & $38444-90-5$
\end{tabular}

\begin{tabular}{|c|c|c|}
\hline \multicolumn{3}{|c|}{ Pentachlorobiphenyl } \\
\hline 82 & $2,2^{\prime}, 3,3^{\prime}, 4$ & $52663-62-4$ \\
\hline 83 & $2,2^{\prime}, 3,3^{\prime}, 5$ & $60145-20-2$ \\
\hline 84 & $2,2^{\prime}, 3,3^{\prime}, 6$ & $52663-60-2$ \\
\hline 85 & $2,2^{\prime}, 3,4,4^{\prime}$ & $65510-45-4$ \\
\hline 86 & $2,2^{\prime}, 3,4,5$ & $55312-69-1$ \\
\hline 87 & $2,2^{\prime}, 3,4,5^{\prime}$ & $38380-02-8$ \\
\hline 90 & $2,2^{\prime}, 3,4^{\prime}, 5$ & $68194-07-0$ \\
\hline 91 & $2,2^{\prime}, 3,4^{\prime}, 6$ & $58194-05-8$ \\
\hline 92 & $2,2^{\prime}, 3,5,5^{\prime}$ & $52663-61-3$ \\
\hline 95 & $2,2^{\prime}, 3,5^{\prime}, 6$ & 38379-99-6 \\
\hline 97 & $2,2^{\prime}, 3^{\prime}, 4,5$ & $41464-51-1$ \\
\hline 99 & $2,2^{\prime}, 4,4^{\prime}, 5$ & $38380-01-7$ \\
\hline 101 & $2,2^{\prime}, 4,5,5^{\prime}$ & $37680-73-2$ \\
\hline 104 & $2,2^{\prime}, 4,6,6^{\prime}$ & $56558-16-8$ \\
\hline 105 & $2,3,3^{\prime}, 4,4^{\prime}$ & $32598-14-4$ \\
\hline 109 & $2,3,3^{\prime}, 4,6$ & $74472-35-8$ \\
\hline 110 & $2,3,3^{\prime}, 4^{\prime}, 6$ & $38380-03-9$ \\
\hline 114 & $2,3,4,4^{\prime}, 5$ & $74472-37-0$ \\
\hline 118 & $2,3^{\prime}, 4,4^{\prime}, 5$ & $31508-00-6$ \\
\hline 119 & $2,3^{\prime}, 4,4^{\prime}, 6$ & $56558-17-9$ \\
\hline 120 & $2,3^{\prime}, 4,5,5^{\prime}$ & 68194-12-7 \\
\hline
\end{tabular}


Table 5. Polychlorinated biphenyl congeners measured in this study.-Continued

[CAS, Chemical Abstract Service number]

\begin{tabular}{|c|c|c|c|c|c|}
\hline Congener Number & $\begin{array}{l}\text { Substitutions and } \\
\text { homolog group }\end{array}$ & CAS \# & Congener Number & $\begin{array}{l}\text { Substitutions and } \\
\text { homolog group }\end{array}$ & CAS \# \\
\hline 123 & $2^{\prime}, 3,4,4^{\prime}, 5$ & $65510-44-3$ & 185 & $2,2^{\prime}, 3,4,5,5^{\prime}, 6$ & $52712-05-7$ \\
\hline 124 & $2^{\prime}, 3,4,5,5^{\prime}$ & $70424-70-3$ & 187 & $2,2^{\prime}, 3,4^{\prime}, 5,5^{\prime}, 6$ & $52663-68-0$ \\
\hline 126 & $3,3^{\prime}, 4,4^{\prime}, 5$ & $57465-28-8$ & 189 & $2,3,3^{\prime}, 4,4^{\prime}, 5,5^{\prime}$ & $39635-31-9$ \\
\hline \multicolumn{3}{|c|}{ Hexachlorobiphenyl } & 190 & $2,3,3^{\prime}, 4,4^{\prime}, 5,6$ & 41411-64-7 \\
\hline 128 & $2,2^{\prime}, 3,3^{\prime}, 4,4^{\prime}$ & $38380-07-3$ & 191 & $2,3,3^{\prime}, 4,4^{\prime}, 5^{\prime}, 6$ & $74472-50-7$ \\
\hline 132 & $2,2^{\prime}, 3,3^{\prime}, 4,6^{\prime}$ & $38380-05-1$ & \multicolumn{3}{|c|}{ Octachlorobiphenyl } \\
\hline 134 & $2,2^{\prime}, 3,3^{\prime}, 5,6$ & $52704-70-8$ & 194 & $2,2^{\prime}, 3,3^{\prime}, 4,4^{\prime}, 5,5^{\prime}$ & $35694-08-7$ \\
\hline 135 & $2,2^{\prime}, 3,3^{\prime}, 5,6^{\prime}$ & $52744-13-5$ & 195 & $2,2^{\prime}, 3,3^{\prime}, 4,4^{\prime}, 5,6$ & $52663-78-2$ \\
\hline 136 & $2,2^{\prime}, 3,3^{\prime}, 6,6^{\prime}$ & $38411-22-2$ & 196 & $2,2^{\prime}, 3,3^{\prime}, 4,4^{\prime}, 5,6^{\prime}$ & $42740-50-1$ \\
\hline 137 & $2,2^{\prime}, 3,4,4^{\prime}, 5$ & $35694-06-5$ & 198 & $2,2^{\prime}, 3,3^{\prime}, 4,5,5^{\prime}, 6$ & 68194-17-2 \\
\hline 138 & $2,2^{\prime}, 3,4,4^{\prime}, 5^{\prime}$ & $35065-28-2$ & BZ-201 & $2,2^{\prime}, 3,3^{\prime}, 4,5,5^{\prime}, 6^{\prime}$ & $52663-75-9$ \\
\hline 141 & $2,2^{\prime}, 3,4,5,5^{\prime}$ & $52712-04-6$ & BZ-199 & $2,2^{\prime}, 3,3^{\prime}, 4,5,6,6^{\prime}$ & $52663-73-7$ \\
\hline 142 & $2,2^{\prime}, 3,4,5,6$ & 41411-61-4 & BZ-200 & $2,2^{\prime}, 3,3^{\prime}, 4,5^{\prime}, 6,6^{\prime}$ & $40186-71-8$ \\
\hline 146 & $2,2^{\prime}, 3,4^{\prime}, 5,5^{\prime}$ & $51908-16-8$ & 203 & $2,2^{\prime}, 3,4,4^{\prime}, 5,5^{\prime}, 6$ & $52663-76-0$ \\
\hline 147 & $2,2^{\prime}, 3,4^{\prime}, 5,6$ & $68194-13-8$ & 205 & $2,3,3^{\prime}, 4,4^{\prime}, 5,5^{\prime}, 6$ & $74472-53-0$ \\
\hline 149 & $2,2^{\prime}, 3,4^{\prime}, 5^{\prime}, 6$ & $38380-04-0$ & \multicolumn{3}{|c|}{ Nonachlorobiphenyl } \\
\hline 151 & $2,2^{\prime}, 3,5,5^{\prime}, 6$ & $52663-63-5$ & 206 & $2,2^{\prime}, 3,3^{\prime}, 4,4^{\prime}, 5,5^{\prime}, 6$ & 40186-72-9 \\
\hline 153 & $2,2^{\prime}, 4,4^{\prime}, 5,5^{\prime}$ & $35065-27-1$ & 207 & $2,2^{\prime}, 3,3^{\prime}, 4,4^{\prime}, 5,6,6^{\prime}$ & $52663-79-3$ \\
\hline 154 & $2,2^{\prime}, 4,4^{\prime}, 5,6^{\prime}$ & $60145-22-4$ & 208 & $2,2^{\prime}, 3,3^{\prime}, 4,5,5^{\prime}, 6,6^{\prime}$ & $52663-77-1$ \\
\hline 156 & $2,3,3^{\prime}, 4,4^{\prime}, 5$ & $38380-08-4$ & \multicolumn{3}{|c|}{ Decachlorobiphenyl } \\
\hline 157 & $2,3,3^{\prime}, 4,4^{\prime}, 5^{\prime}$ & 69782-90-7 & 209 & $2,2^{\prime}, 3,3^{\prime}, 4,4^{\prime}, 5,5^{\prime}, 6,6^{\prime}$ & 2051-24-3 \\
\hline 158 & $2,3,3^{\prime}, 4,4^{\prime}, 6$ & $74472-42-7$ & & & \\
\hline 166 & $2,3,4,4^{\prime}, 5,6$ & $41411-63-6$ & & & \\
\hline 167 & $2,3^{\prime}, 4,4^{\prime}, 5,55^{\prime}$ & $52663-72-6$ & & & \\
\hline 168 & $2,3^{\prime}, 4,4^{\prime}, 5^{\prime}, 6$ & $59291-65-5$ & & & \\
\hline 169 & $3,3^{\prime}, 4,4^{\prime}, 5,5$ & $32774-16-6$ & & & \\
\hline \multicolumn{3}{|c|}{ Heptachlorobiphenyl } & & & \\
\hline 170 & $2,2^{\prime}, 3,3^{\prime}, 4,4^{\prime}, 5$ & $35065-30-6$ & & & \\
\hline 171 & $2,2^{\prime}, 3,3^{\prime}, 4,4^{\prime}, 6$ & $52663-71-5$ & & & \\
\hline 172 & $2,2^{\prime}, 3,3^{\prime}, 4,5,5^{\prime}$ & $52663-74-8$ & & & \\
\hline 174 & $2,2^{\prime}, 3,3^{\prime}, 4,5,6^{\prime}$ & $38411-25-5$ & & & \\
\hline 177 & $2,2^{\prime}, 3,3^{\prime}, 4^{\prime}, 5,6$ & $52663-70-4$ & & & \\
\hline 178 & $2,2^{\prime}, 3,3^{\prime}, 5,5^{\prime}, 6$ & $52663-67-9$ & & & \\
\hline 179 & $2,2^{\prime}, 3,3^{\prime}, 5,6,6^{\prime}$ & $52663-64-6$ & & & \\
\hline 180 & $2,2^{\prime}, 3,4,4^{\prime}, 5,5^{\prime}$ & $35065-29-3$ & & & \\
\hline 183 & $2,2^{\prime}, 3,4,4^{\prime}, 5^{\prime}, 6$ & $52663-69-1$ & & & \\
\hline
\end{tabular}


congener in the co-elution (Bonin and Wilson, 2006). The distribution of the reported concentrations between the possible co-elutions cannot be unequivocally determined.

The total dissolved, total particulate, and total carbonnormalized sediment PCB concentrations in each sample were calculated by summing the concentrations of all non-coeluting PCB congeners, thus avoiding summing the co-eluting conger values more than once. Total concentrations and averages were calculated by replacing all non-detected congener values by one-half the reported (concentration normalized) detection limit. Arithmetic averages were calculated because the few samples collected in this study precluded determining if the data distribution was log-normal. The isotope-dilution methods used in this study provide EDLs that are unique for each congener and each sample but will generally fall in defined ranges for samples having similar matrices.

In this work, EDLs for each congener were determined from the average noise for the elution window of the corresponding homolog group, no peak-smoothing routines were applied for the base-line noise (D. Thal, oral comm., 2004). These summary values were calculated using EDLs for congeners that were not detected (U flagged values) in each homolog group. Average EDLs for detected and nondetected congeners in samples ranged from roughly $0.5 \mathrm{pg} / \mathrm{g}$ up to 1.5 $\mathrm{pg} / \mathrm{g}$ for a 1 -g sediment sample (reported values normalized to $1 \mathrm{~g}$ of sediment). Average EDLs for nondetected dissolved concentrations were normalized to a sample volume of 50
$\mathrm{L}$ and ranged from $3.5 \mathrm{pg} / \mathrm{L}$ up to $15 \mathrm{pg} / \mathrm{L}$ (table 6). Actual detection limits for individual congeners may vary from these values because of sample size, mass of sediment, and physical-chemical conditions in the sample.

\section{Quality Assurance}

The method performance, data quality, and accuracy were evaluated using a variety of data and by measuring standard reference materials (SRMs). Performance criteria for the methods used also included evaluation of the recoveries of internal standards (IS) and field surrogates (FS). The potential for contamination of the filter and resin, which affects data quality, was evaluated using a series of blanks. The accuracy of the PCB analytical work has been estimated to be $+/-10$ percent (Bonin and Wilson, 2006), with a relative precision, determined from multiple analyses of certified SRMs, of +/12 percent.

\section{Recovery of Internal Standards}

Nineteen carbon-13 $\left({ }^{13} \mathrm{C}\right)$ labeled IS were added to each sample to provide reference concentrations for quantification of native compounds present in the samples and to evaluate recovery at different steps during sample preparation. USEPA method 1668A sets acceptable recoveries of IS used as quantification references as 20 to 180 percent (U.S. Environmental

Table 6. Summary of normalized estimated detection limits for nondetected polychlorinated biphenyls in samples from selected rivers in New Jersey.

[pg/g, picogram per gram of sediment; pg/L, picogram per liter]

\begin{tabular}{|c|c|c|c|c|c|c|c|c|c|}
\hline \multicolumn{5}{|c|}{ Sediment $^{2}$} & \multicolumn{5}{|c|}{ Dissolved $^{3}$} \\
\hline mono+di & 18 & 83 & 2,700 & 740 & mono+di & 16 & 1.9 & 22 & 15 \\
\hline Tri & 5 & 52 & 2,900 & 860 & Tri & 3 & 6.1 & 22 & 14 \\
\hline Penta & 21 & 160 & 5,100 & 740 & Penta & 19 & .36 & 22 & 11 \\
\hline Hexa & 17 & 78 & 2,500 & 960 & Неха & 17 & .34 & 28 & 9.4 \\
\hline Septa & 5 & 150 & 1,900 & 1,300 & Septa & 18 & .30 & 22 & 7.9 \\
\hline
\end{tabular}

${ }^{1}$ This column displays the number of samples that had at least one nondetected concentration in the indicated homolog group. A total of 21 samples were collected.

${ }^{2}$ Sediment estimated detection levels are adjusted to a sample mass of 1 gram. Actual sample volumes ranged from 0.5 to 5 grams.

${ }^{3}$ Dissolved estimated detection levels are adjusted to a sample volume of 50 liters. Actual sample volumes ranged from 25 liters to over 50 liters. 
Protection Agency, 1999b). The average IS recoveries for nearly all samples collected in this work fell well within this acceptable range of recovery (table 7).

However, the sediment samples from the Hackensack River (Oct. 19, 2001), the Passaic River (Mar. 14, 2001), the Elizabeth River (May 22, 2001), and the Rahway River (Apr. 28, 2002) and dissolved samples from the Hackensack River (Mar. 13, 2001) and the Raritan River (Apr. 13, 2001) had recoveries for a number of IS below the lower acceptable limits (table 8). Although not substantially below the lower acceptable limit, the low recoveries may have biased the concentrations in these samples. The cause for the low recovery of IS in these samples is not known but may have been related to the large mass of POC that ultimately was captured on the filters for these sediment samples.

\section{Recovery of Field Surrogates}

The XAD columns were spiked with ${ }^{13} \mathrm{C}$-labeled PCB FS (80 ng each of PCB \#31L, 95L, and 153L) added to the inlet end of the first of the two XAD columns used for sampling (Bonin and Wilson, 2006). Average recoveries of these FS (table 9) ranged from 84 to 97 percent; the minimum value was 70 percent. No correction was applied to the concentrations of the native PCBs to correct for loss indicated by the FS. The minimum recoveries for field blanks were lower (61 to 66 percent) than were obtained for the environmental samples; the cause for the lower recoveries is unknown. The differences in recoveries for the three labeled FS reflect the differences in solubility and vapor pressure of these compounds. The lowest chlorinated FS, PCB \#31L (a trichlorobiphenyl), has a vapor pressure about 100 times greater and an aqueous solubility 17 times greater than the heavier PCB \#153L (a hexachlorobiphenyl). The lesser-chlorinated congener is, therefore, more likely to have either volatilized from the column or dissolved into the sampled water than is the heavier congener, which is reflected in the lower average recovery of PCB \#31L.

\section{Contamination of Blanks and Data Censoring}

In order to reduce the chance of reporting false-positive concentrations caused by PCBs associated with the sampling media, the data were culled using the "maximum blank- elimination" procedure chosen by the New Jersey Department of

Table 7. Average percent recoveries of internal standards in blanks and samples from selected rivers in New Jersey.

[n, number of samples or blanks analyzed; XAD, exchange resin]

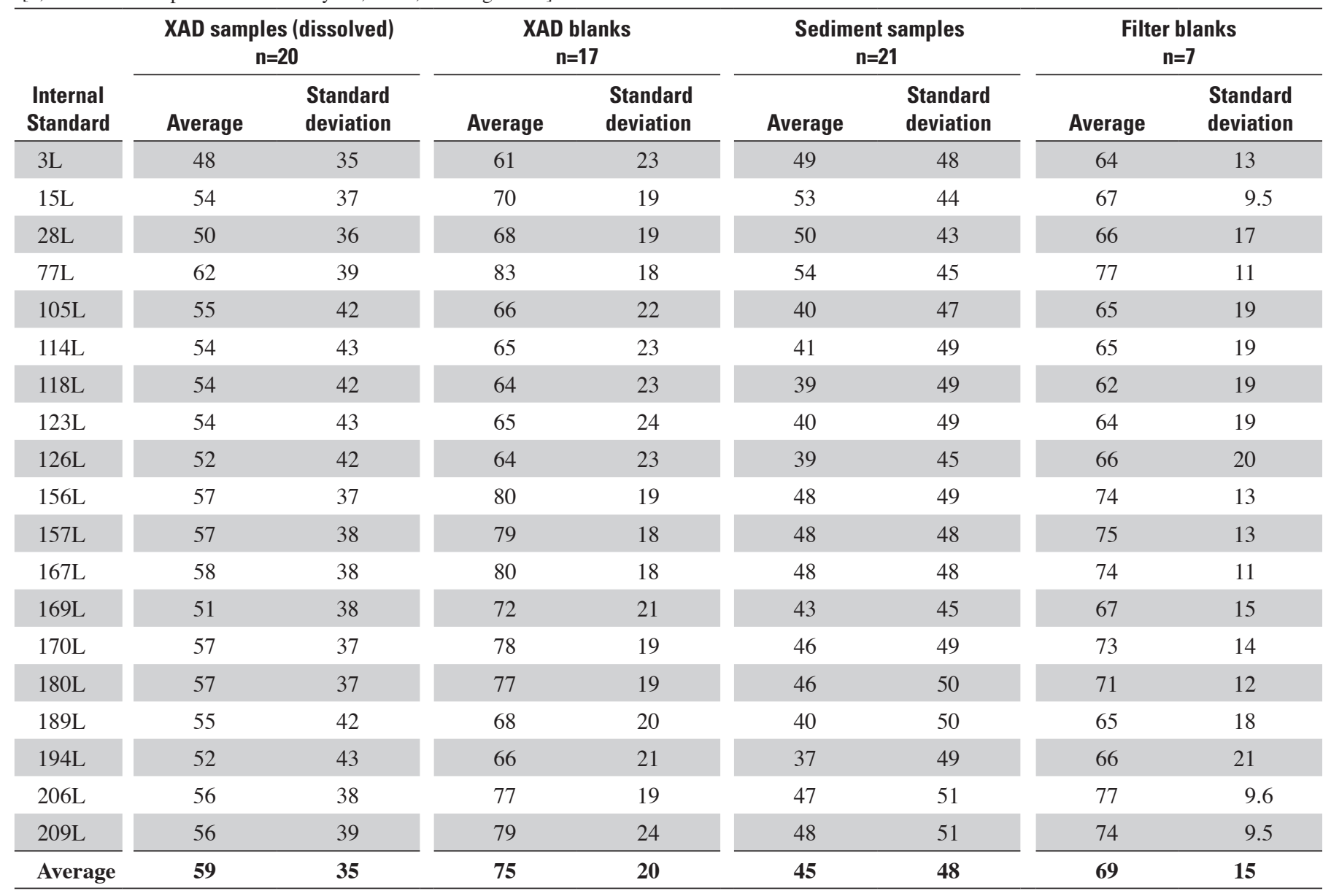


Table 8. Samples having low recoveries of labeled polychlorinated biphenyl internal standards.

[ mg/L, milligrams per liter]

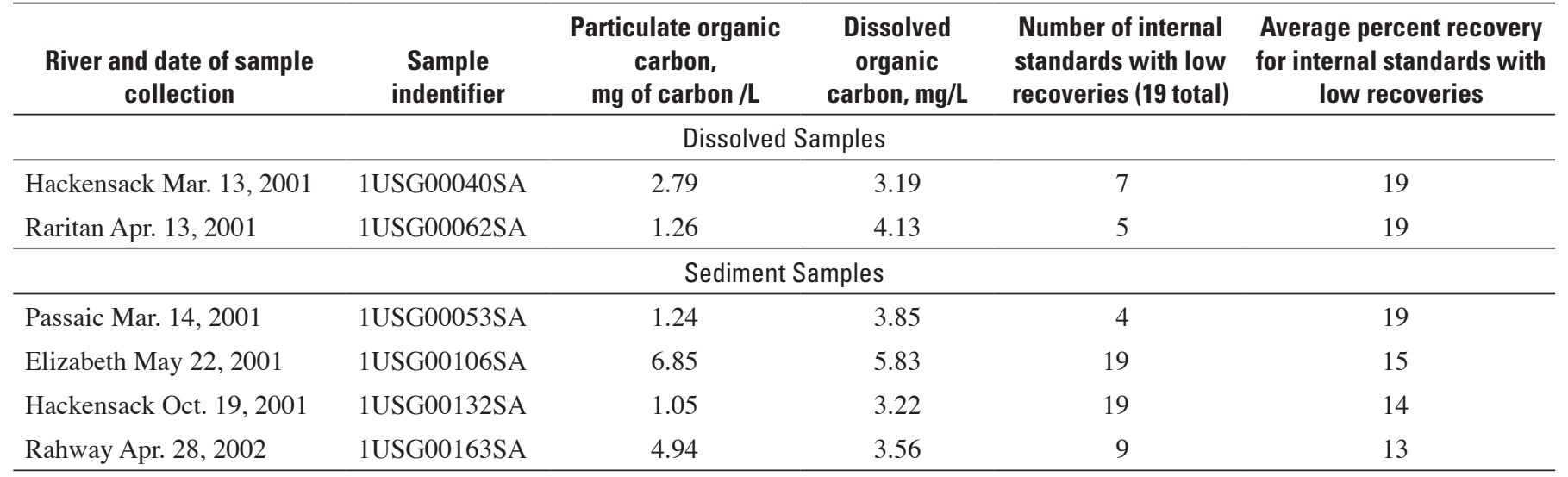

Table 9. Summary of recoveries of labeled polychlorinated biphenyl field surrogates from blanks and samples from selected rivers in New Jersey.

\begin{tabular}{|c|c|c|c|c|c|c|c|c|}
\hline \multirow[b]{2}{*}{$\begin{array}{l}\text { Labeled Standard } \\
\text { congener number }\end{array}$} & \multicolumn{4}{|c|}{ Recovery from Samples } & \multicolumn{4}{|c|}{ Recovery from Blanks } \\
\hline & $\begin{array}{c}\text { Minimum } \\
\text { recovery } \\
\text { (percent) }\end{array}$ & $\begin{array}{c}\text { Maximum } \\
\text { Recovery } \\
\text { (percent) }\end{array}$ & $\begin{array}{l}\text { Average } \\
\text { recovery } \\
\text { (percent) }\end{array}$ & $\begin{array}{l}\text { Standard } \\
\text { deviation } \\
\text { (percent) }\end{array}$ & $\begin{array}{l}\text { Minimum } \\
\text { Recovery } \\
\text { (percent) }\end{array}$ & $\begin{array}{c}\text { Maximum } \\
\text { recovery } \\
\text { (percent) }\end{array}$ & $\begin{array}{l}\text { Average } \\
\text { recovery } \\
\text { (percent) }\end{array}$ & $\begin{array}{l}\text { Standard } \\
\text { deviation } \\
\text { (percent) }\end{array}$ \\
\hline $31 \mathrm{~L}$ & 78 & 90 & 84 & 5.5 & 66 & 141 & 88 & 19 \\
\hline $95 \mathrm{~L}$ & 70 & 135 & 97 & 19 & 61 & 160 & 102 & 26 \\
\hline $153 \mathrm{~L}$ & 78 & 102 & 91 & 7.7 & 62 & 103 & 91 & 12 \\
\hline
\end{tabular}

Environmental Protection. Blank elimination removes from the data set any concentration that did not exceed a selected multiple of its maximum corresponding concentration in the blanks that were prepared with each sample. This procedure provides a liberal margin of confidence, ensuring that the reported concentrations in the environmental samples are real rather than artifacts of the sampling media. Positive bias of trace organics caused by the sampling media is of special concern when using exchange-resin and filters with large-volume samples. The XAD resin has a high affinity for gaseous PCBs from the atmosphere or dust; the filters can become contaminated during their preparatory baking and cleaning.

Field blanks, equipment blanks, and laboratory blanks were prepared throughout this work. Field blanks consisted of two XAD columns and one pair of GFF canister and flat filters opened to the atmosphere in the vicinity of the sampling equipment, during the time when the columns or filters were being installed and removed from the sampling equipment. Equipment blanks were prepared by pumping $50 \mathrm{~L}$ of deionized water through one pair of XAD columns that were installed on the clean sampling equipment. The field and equipment blanks were handled, shipped, and processed identically to the field samples. The laboratory blanks consisted of the chemical reagents and solvents that were processed and analyzed identically to the field samples.

Blank elimination of the PCB data consisted of removing reported masses of individual congeners that were less than three times the largest of their corresponding masses in the associated field, equipment, and method blanks. A summary of the homolog composition and EDLs for the various blanks that were prepared is presented in table 10. This information shows the approximate lower limits of actual measurements for the method. For those congeners that were affected by blank elimination process, the frequency each PCB congener was detected in the river samples is summarized in table 11. Congeners in the dissolved phase (collected on XAD resin) that were repeatedly removed by blank elimination included PCBs congeners \#3, 8, 11, 15, 20, and 37. For the sediment phase (filter samples), only PCB \#8 was repeatedly affected. 
Table 10. Summary of polychlorinated biphenyl homolog masses measured and estimated detection limits in method and field blanks.

[pg, picograms; EDL, estimated method detection limit; --, not detected; n, number of samples]

\begin{tabular}{|c|c|c|c|c|c|c|c|c|}
\hline $\begin{array}{c}\text { Homolog } \\
\text { group }\end{array}$ & \multicolumn{2}{|c|}{$\begin{array}{l}\text { Method blanks- } \\
\text { sediment } \\
n=10\end{array}$} & \multicolumn{2}{|c|}{$\begin{array}{l}\text { EDL for method blanks- } \\
\text { sediment } \\
n=10\end{array}$} & \multicolumn{2}{|c|}{$\begin{array}{l}\text { Method blanks- } \\
\text { dissolved } \\
n=12\end{array}$} & \multicolumn{2}{|c|}{$\begin{array}{l}\text { EDL for method blanks- } \\
\text { dissolved } \\
n=12\end{array}$} \\
\hline Mono+di & 203 & 96 & 545 & 247 & 181 & 99.3 & 339 & 149 \\
\hline Tetra & 100 & 40 & 178 & 30.2 & 61.0 & 28.2 & 128 & 21.4 \\
\hline Penta & 300 & 217 & 365 & 116 & 83.5 & 38.0 & 174 & 54.8 \\
\hline Hexa & 140 & 96 & 301 & 98.7 & 60.7 & 28.0 & 163 & 52.8 \\
\hline Nona & 68.7 & 23 & 189 & 18.1 & -- & -- & 137 & 12.7 \\
\hline Deca & 149 & 72 & 155 & 109 & 48.5 & 0.7 & 141 & 135 \\
\hline
\end{tabular}

\begin{tabular}{|c|c|c|c|c|c|c|c|c|}
\hline $\begin{array}{l}\text { Homolog } \\
\text { group }\end{array}$ & \multicolumn{2}{|c|}{$\begin{array}{c}\text { Field blanks- } \\
\text { sediment } \\
n=7\end{array}$} & \multicolumn{2}{|c|}{$\begin{array}{l}\text { EDL for field blanks- } \\
\text { sediment } \\
n=7\end{array}$} & \multicolumn{2}{|c|}{$\begin{array}{c}\text { Field blanks- } \\
\text { dissolved } \\
n=8\end{array}$} & \multicolumn{2}{|c|}{$\begin{array}{c}\text { EDL for field blanks- } \\
\text { dissolved } \\
n=8\end{array}$} \\
\hline Mono+di & 500 & 262 & 532 & 218 & 515 & 315 & 270 & 119 \\
\hline Tri & 398 & 211 & 319 & 179 & 313 & 222 & 183 & 105 \\
\hline Tetra & 175 & 50 & 218 & 37 & 157 & 106 & 114 & 19 \\
\hline Penta & 162 & 53 & 370 & 117 & 199 & 42 & 200 & 63 \\
\hline Octa & 0 & 0 & 518 & 125 & 45 & 0 & 233 & 57 \\
\hline Nona & 0 & 0 & 299 & 27 & 0 & 0 & 145 & 13 \\
\hline Deca & 0 & 0 & 222 & 0 & 120 & 0 & 112 & 0 \\
\hline
\end{tabular}


Table 11. Frequency of the polychlorinated biphenyl congeners in sediment and water samples collected from selected rivers in New Jersey that were affected by blank elimination.

$[--$, congener not affected in any sample; $n$, number of samples]

\begin{tabular}{|c|c|c|c|c|c|c|c|c|}
\hline Congener & $\begin{array}{c}\text { Frequency } \\
\text { detected in } \\
\text { XAD } \\
\text { (dissolved) } \\
\text { sample ( } n=19 \text { ) }\end{array}$ & $\begin{array}{c}\text { Frequency } \\
\text { detected in } \\
\text { filter collected } \\
\text { sediment sample } \\
\text { (n=19) }\end{array}$ & Congener & $\begin{array}{c}\text { Frequency } \\
\text { detected in } \\
\text { XAD } \\
\text { (dissolved) } \\
\text { sample ( } n=19 \text { ) }\end{array}$ & $\begin{array}{c}\text { Frequency } \\
\text { detected in } \\
\text { filter collected } \\
\text { sediment sample } \\
\quad(n=19)\end{array}$ & Congener & $\begin{array}{c}\text { Frequency } \\
\text { detected in } \\
\text { XAD } \\
\text { (dissolved) } \\
\text { sample (n=19) }\end{array}$ & $\begin{array}{c}\text { Frequency } \\
\text { detected in } \\
\text { filter collected } \\
\text { sediment sample } \\
\quad(n=19)\end{array}$ \\
\hline 3 & 14 & 2 & 45 & 4 & 1 & 110 & 2 & -- \\
\hline 4 & 5 & 4 & 47 & 8 & 3 & 118 & 5 & -- \\
\hline 8 & 11 & 10 & 49 & 1 & -- & 128 & 1 & -- \\
\hline 10 & 1 & -- & 53 & 1 & -- & 132 & 1 & -- \\
\hline 11 & 12 & 3 & 56 & 3 & - & 138 & 3 & -- \\
\hline 15 & 11 & 4 & 60 & 2 & -- & 147 & 4 & -- \\
\hline 20 & 9 & 3 & 81 & 2 & -- & 158 & 1 & -- \\
\hline 22 & 6 & 3 & 83 & 2 & -- & 168 & 1 & -- \\
\hline 25 & 2 & 2 & 84 & 1 & -- & 169 & 1 & -- \\
\hline 26 & 2 & 2 & 85 & 2 & -- & 170 & 1 & -- \\
\hline 28 & 6 & 2 & 86 & 2 & -- & 180 & 2 & -- \\
\hline 31 & 6 & 3 & 90 & 2 & -- & 187 & 2 & -- \\
\hline 37 & 10 & 1 & 91 & 1 & -- & 189 & -- & 1 \\
\hline 40 & 1 & -- & 92 & 1 & -- & 194 & 5 & 1 \\
\hline 42 & 1 & -- & 95 & 2 & -- & 209 & 2 & -- \\
\hline
\end{tabular}

\section{Concentrations}

Concentrations of total PCB ranged from 10 to 5,400 $\mathrm{ng} / \mathrm{g}$ for particulates and 473 to $7,840 \mathrm{pg} / \mathrm{L}$ for dissolved PCBs (table 12). Generally, the lowest total concentrations were measured in the Raritan and Hackensack Rivers, and the highest total concentrations were measured in the Elizabeth River. The average concentrations of PCBs in the SS phase generally were ranked in the order of increasing concentration of: Raritan $<$ Hackensack $<$ Passaic $<$ Rahway $<$ Elizabeth. With the exception of the Hackensack and Raritan Rivers, the same general ranking holds when the sediment-carbon bound concentrations are considered. The ranking for dissolved PCBs is Hackenasck $<$ Raritan $<$ Rahway $<$ Passaic $<$ Elizabeth River. With only a few exceptions, the concentrations measured during storms and low-flow discharges were nearly equal or within one order of magnitude. The samples having anomalous or suspect concentrations are discussed below.
For the dissolved samples, the nondetected concentrations (replaced by one-half the EDL) generally contributed less than 10 percent of the total PCB concentration of the samples, with the exception of the Hackensack River samples collected on Oct. 19, 2001 (43 percent), Mar. 13, 2001 ( 20 percent), and June 28, 2000 (17 percent), the Raritan River samples collected on Apr. 13, 2001 (57 percent), and Oct. 4, 2001 (21 percent), and the Rahway River sample collected on Apr. 24, 2001 (25 percent). For the sediment samples, the nondetected values (replaced by one-half the EDL) accounted for less than 1 percent of the total PCB, with the exception of the sample from the Hackensack River collected on Oct. 19, 2001 (7 percent). The use of EDLs in calculating average values (for total or homolog totals) sets an upper limit on the average concentration but does not unequivocally demonstrate the presences of these compounds.

Two congeners, PCBs \#11 and \#126, deserve specific discussion. PCB \#11 was found by Litten and others (2002) to 
Table 12. Summary of total polychlorinated biphenyl concentrations in sediment and water in samples from selected rivers in New Jersey.

[PCB, polychlorinated biphenyl; mg/L, milligrams per liter; $\mathrm{pg} / \mathrm{L}$, picograms per liter; ng/g, nanograms per gram sediment; ng/gC, nanograms per gram of carbon; ng/L, nanograms per liter; $\mathrm{ft}^{3} / \mathrm{s}$, cubic feet per second; averages calculated by replacing non-detected values with one-half the reported detection limit; shaded values exceed the New Jersey fresh surface-water-quality standards; New Jersey fresh surface-water-quality criteria are $14 \mathrm{ng} / \mathrm{L}$ for aquatic fauna and $0.064 \mathrm{ng} / \mathrm{L}$ for humans; --, not applicable]

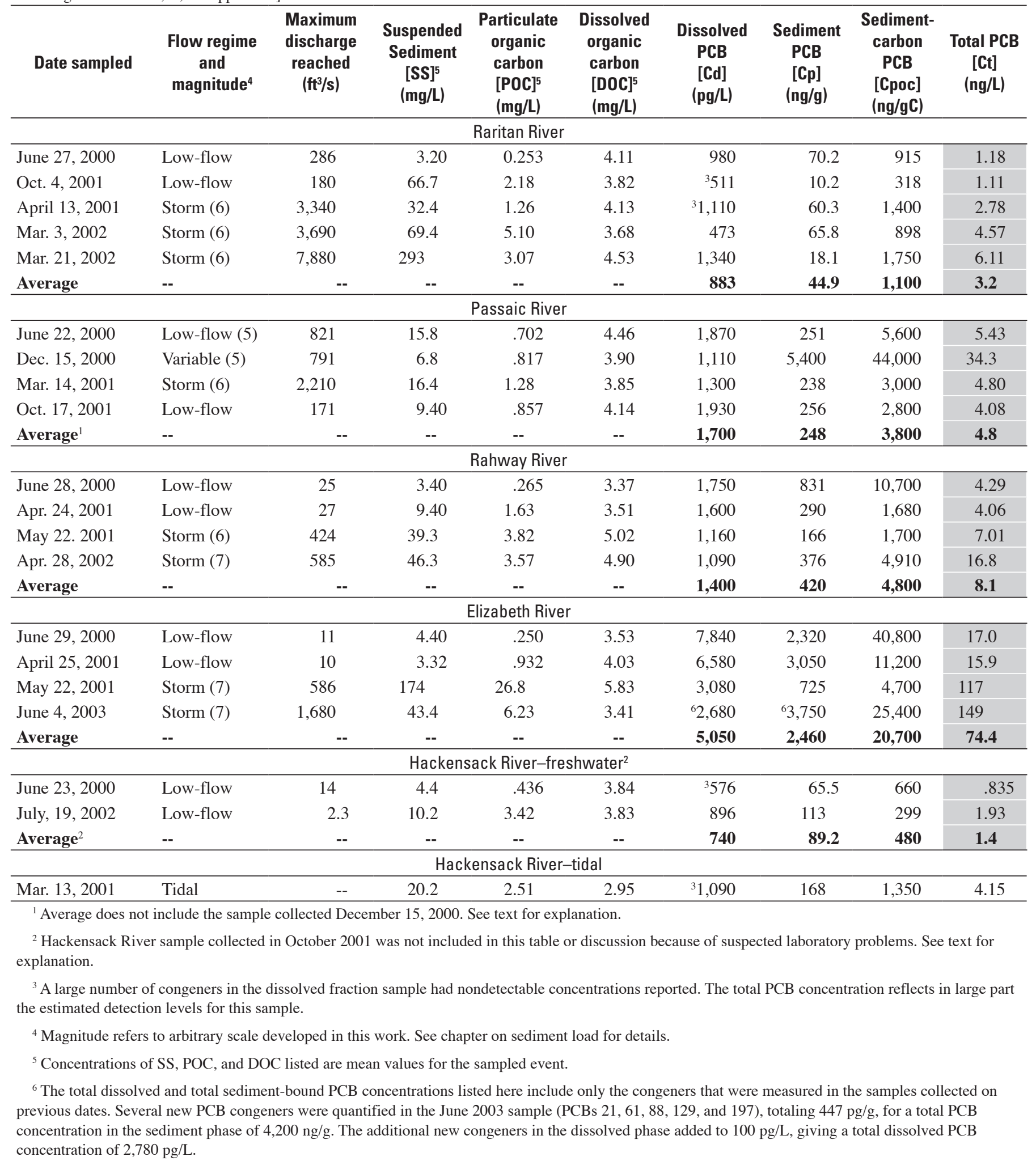


be derived from pigments used in manufacturing and printing. PCB \#11 was measured in most all sediment samples collected at the following average concentrations: Raritan River, 109 pg/g; Passaic River, 1,280 pg/g; Rahway River, 438 pg/g; Elizabeth River, 2,760 pg/g; and Hackensack River, 482 pg/g. Of particular note is the high concentration in the sample from the Passaic River collected on Dec. 15, 2000, which had a reported PCB \#11 concentration of $41,000 \mathrm{pg} / \mathrm{g}$. Dissolved PCB \#11 was measured in only a few samples at the following levels: Raritan River (1 sample), 43 pg/L; Rahway (1 sample), 17 pg/L; Elizabeth River (average), 69 pg/L; and Hackensack River (1 sample), 29 pg/L. PCB \#11 was not detected in any of the dissolved samples from the Passaic River.

PCB \#126 is of concern because it has the highest dioxinlike toxicity, as measured by its toxic equivalency factor $(0.1$, VanLeeuwen, 1997). PCB \#126 was measured in most of the sediment samples collected, at the following average concentrations (excluding non-detected values): Raritan River, (detected in 1 sample only) $31 \mathrm{pg} / \mathrm{g}$; Passaic River, $56 \mathrm{pg} / \mathrm{g}$; Rahway River, 119 pg/g; Elizabeth River, 605 pg/g; and the Hackensack River, 37 pg/g. Dissolved PCB \#126 was found only in one sample from the Rahway River, at a concentration of $0.52 \mathrm{pg} / \mathrm{L}$.

\section{Anomalous Concentrations}

The concentrations measured in a few samples differed greatly from the other samples collected within a river. While it is not possible to determine whether these samples were statistical outliers, the field data, stream conditions, and other analytical information provide some insight into these spurious values. The anomalous data for each river and their disposition include the following:

- Raritan River-Extremely high concentrations of SS were measured in the low-flow sample collected from the Raritan River on Oct. 4, 2001. Typically, four samples were collected for SS analysis for low-flow events (Bonin and Wilson, 2006). The four SS samples associated with this sample had concentrations that ranged from 15 to $184 \mathrm{mg} / \mathrm{L}$ and a mean concentration of SS of $67 \mathrm{mg} / \mathrm{L}$, a value that is more typical of wetweather events. The other low-flow sample collected from the Raritan River (June 2000) had a mean SS concentration of $3.2 \mathrm{mg} / \mathrm{L}$, which is typical of SS concentrations in low-flow discharge in New Jersey (less than $10 \mathrm{mg} / \mathrm{L}$ ). The use of a high SS concentration resulted in a large mass of sediment calculated to be on the filters, which in turn resulted in a very low total PCB (10 ng/g) concentration for the October sample. This value is approximately one-half to one-seventh of the total PCB concentrations in the other Raritan River sediment samples (18 ng/g to $70 \mathrm{ng} / \mathrm{g}$ ). The cause for the anomalously high SS concentrations could not be determined and may be the result of random sand particles having being caught in the grab samples or the result of lab error. An erroneous SS concentration can have a substantial effect on the resulting contaminant concentration. For example, if the SS concentration in the river was $9 \mathrm{mg} / \mathrm{L}$ rather than $67 \mathrm{mg} / \mathrm{L}$, the total PCB concentration in the Oct. 4, 2001, sample would match the PCB content in the other low-flow sample (June 27, 2000) collected on this river (table 12). Although the particulate concentration for this sample is considered to be anomalous, the sample was used in calculating the average concentrations for the Raritan River.

The samples collected from the Raritan River on Apr. 13, 2001, and again on Oct. 4, 2001, had a large number of dissolved congeners reported as nondetected. The total dissolved PCB concentrations reflect the EDLs that were reported for these samples.

- Passaic River - The Passaic River sample collected on Dec. 15, 2000, is considered anomalous and was not used. Sampling on this date was initiated several hours late, after the river discharge had peaked (fig. 5), during which time the discharge was constant at approximately four times the low-flow discharge. It is possible the river was being affected by water-supply diversion upstream from the sampling point. Concentrations of SS in the river dropped substantially after the sampling was initiated and remained steady throughout the sampled period at concentrations typical of low-flow conditions $(<10 \mathrm{mg} / \mathrm{L})$, well below the peak concentrations measured for this river during this and subsequent storm events. The total PCB concentration for the sediment $(5,400 \mathrm{ng} / \mathrm{g})$ is much greater than any other samples collected from this river. It is likely that finegrained-sized materials (containing a high content of carbon) remained in suspension and had been captured. Further work is required to verify this hypothesis. The data from this sampling event were not used to calculate average concentrations of $\mathrm{PCBs}, \mathrm{CDD} / \mathrm{CDF}$, PAHs, pesticides, or metals in the Passaic River.

The sample collected from the Passaic River on Mar. 14, 2001, had low recoveries of IS for the sediment phase.

- Rahway River-The sediment sample collected from the Rahway River on Apr. 28, 2002, had low recoveries for nine IS and a high recovery for one IS (\#32L). These recoveries may have affected the reported concentrations of several penta-homolog congeners. Nevertheless, the sample results were used.

- Elizabeth River - The Elizabeth River sample collected on May 22, 2001 (wet-weather), had a low concentrations of particulate PCBs compared with the other samples collected from this river. The low concentrations may result from the wet-weather discharge for this date. The high SS concentration of this sample 


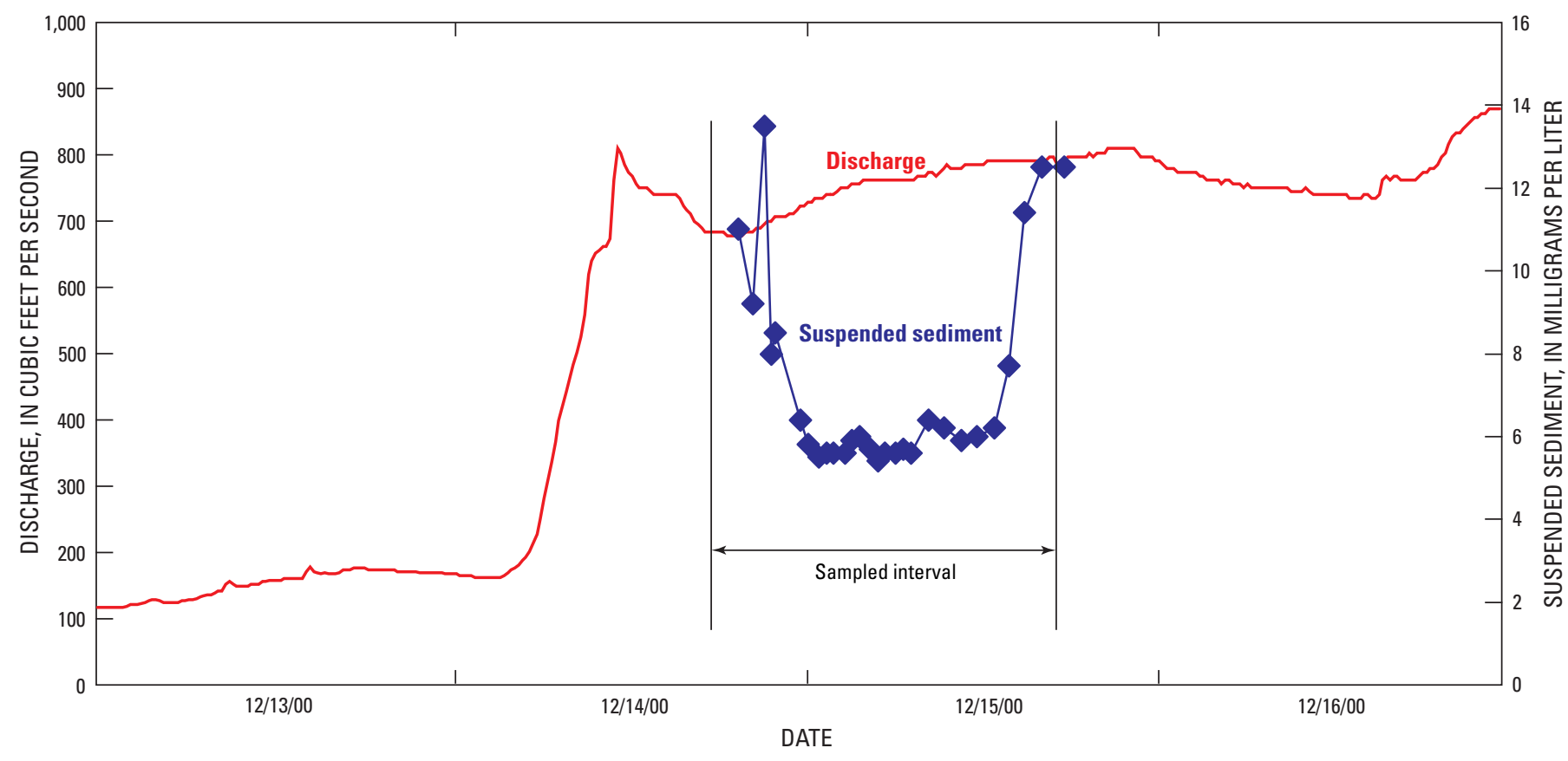

Figure 5. Concentration of suspended-sediment and discharge in the Passaic River at Little Falls, N.J., December 2000.

$(174 \mathrm{mg} / \mathrm{L})$ may indicate that sand was captured in the sample, thereby "diluting" the sediment-bound PCB concentration. Alternatively, the recoveries of all PCB IS were acceptable but low (11 to 17 percent), unlike any other sample collected in this work. These low recoveries are suspect and could have been the result of laboratory error or chemical interferences that affected recovery. However, because evidence was not found for laboratory error, the dissolved and particulate PCBs were included in calculating average concentrations for the Elizabeth River.

- Hackensack River-The Hackensack River sample collected on Oct. 19, 2001, was reported to have been mishandled in the laboratory. The PCB composition of this sample differs from the other low-flow samples collected on this river and are suspect. As a result, the Oct. 19, 2001, sample was removed from the data set and the river was resampled in July 2002. It is also important to note that the sample collected in the tidal area of the Hackensack River (downstream of the lower Oradell dam) in March 2001 is a mixture of freshwater from the Oradell Reservoir and water affected by tidal action. The data for the sample collected in March 2001 were not used in calculating average freshwater concentrations or loads for this river. A large number of the congeners in the dissolved fraction of this sample had nondetectable concentrations, resulting in a total dissolved $\mathrm{PCB}$ concentration highly biased by the EDL. A similar problem exists for the dissolved fraction of the low-flow sample collected in June 2000.

\section{Relation of Whole-Water Concentrations to Water-Quality Criteria}

Regulatory levels for chemicals including total PCBs (sum of all congeners) in surface water are promulgated in "whole-water" concentrations, in units of mass per volume.

Whole-water concentrations are the sum of the dissolved and sediment-bound concentrations and, therefore, will vary with the amount of suspended matter in the sample:

$$
C_{\text {total }}=C_{d}+\left(C_{p} * S S / 1000\right)
$$

where

$$
\begin{aligned}
C_{\text {total }}= & \text { whole-water total concentration, in mass } \\
& \text { per liter of water } \\
C_{d}= & \text { dissolved concentration, in mass per liter } \\
& \text { of water } \\
C_{p}= & \begin{array}{l}
\text { Sediment concentration, in mass per gram } \\
\text { of sediment; }
\end{array}
\end{aligned}
$$

and

$$
\begin{aligned}
S S= & \text { suspended sediment concentration, in mass } \\
& \text { per liter of water. }
\end{aligned}
$$

The New Jersey regulatory chronic level for total PCBs in fresh-surface water (FW2) is set at $14 \mathrm{ng} / \mathrm{L}$ for aquatic life and $0.064 \mathrm{ng} / \mathrm{L}$ for human exposure; in saline estuarine and coastal water, the criteria have been set at $30 \mathrm{ng} / \mathrm{L}$ for aquatic 
life and $0.064 \mathrm{ng} / \mathrm{L}$ for human exposure. The different criteria have been set on the basis of exposure, the chronic aquaticlife protection is the limit as a 4-day average concentration, and the human-health limit is the carcinogenic effect-based human health 70-day average exposure based on a risk level of one-in-one-million. The whole-water concentrations in the rivers sampled in this study are presented in table 12 . Concentrations ranged from $0.835 \mathrm{ng} / \mathrm{L}$ in the Hackensack River up to $149 \mathrm{ng} / \mathrm{L}$ in the Elizabeth River. All of samples from the Elizabeth River exceeded the freshwater chronic aquatic criteria of $14 \mathrm{ng} / \mathrm{L}$. Clearly, all the measured and averaged PCB concentrations in these waters exceeded the water-quality standards for human exposure, and individual samples from the Passaic, Rahway, and Elizabeth Rivers exceeded the aquatic-life criteria standard.

Whole-water concentrations of chemicals, especially organic compounds such as PCBs and dioxin/furans, will be very strongly affected by the amount of sediment captured in a sample. As is discussed later in this report, chemicals such as PCBs are strongly partitioned into the sediment phase. For example, the average in situ sediment/water ratios for PCBs measured in this study are typically on the order of 1 to $3 \times 10^{5}$ $\mathrm{L} / \mathrm{kg}$. If the suspended sediment has a total PCB concentration of $200 \mathrm{ng} / \mathrm{g}$ and is in water having a total PCB concentration of $1 \mathrm{ng} / \mathrm{L}$ (sediment $/$ water $=2 \times 10^{5} \mathrm{~L} / \mathrm{kg}$ ), then each milligram of sediment contributes $200 \mathrm{pg}$ of PCB, approximately onefifth the mass of PCB in a liter of this river water. Under these conditions, the freshwater water-quality criteria $(14 \mathrm{ng} / \mathrm{L})$ is exceeded whenever the SS in the surface water exceeds $65 \mathrm{mg} / \mathrm{L}$. The SS concentrations that will cause the water to exceed the freshwater chronic aquatic-life criteria, calculated using the average sediment and water PCB concentrations from table 12, are $294 \mathrm{mg} / \mathrm{L}$ for the Raritan River, $50 \mathrm{mg} / \mathrm{L}$ for the Passaic River, $30 \mathrm{mg} / \mathrm{L}$ for the Rahway River, $3.7 \mathrm{mg} / \mathrm{L}$ for the Elizabeth River, and $149 \mathrm{mg} / \mathrm{L}$ for the Hackensack River. Inspection of the historic USGS SS concentrations and the SS concentrations measured in this work shows these concentrations of SS often occur on these rivers (except the Hackensack River), and for the Elizabeth River, are often exceeded even during "low-flow" discharges. This example shows also the parameters of a water body (such as the SS concentration) must be defined when comparing measured concentrations to regulatory whole-water criteria.

\section{Distribution Among Homologs}

The distribution of the PCB congeners among the 10 homolog groups serves to help distinguish the chemistry of the different rivers and is a means to compare the sediment compositions with potential sources. The percentage each homolog group contributes to the average total PCB content of the sediment and water was calculated (table 13) and provides homolog "fingerprints" of the sediment in the various rivers (fig. 6). These fingerprints may reflect the original source(s) to each river basin but are complicated by the degradation that is likely to occur when sediment is buried in the streambeds. The distribution in the dissolved phase is complicated by degradation, sediment partitioning, and the relative ease at which the different homologs can dissolve into water.

The average homolog distribution is very similar in the sediment from the Raritan, Rahway, and Hackensack Rivers, being dominated by the tetra-, penta-, and hexa-chlorinated homolog groups. The average homolog distribution in the Passaic River is similar to the distribution in the other rivers but has slightly more (approximately 5 to 10 percent) of the tetrahomolog and slightly less (3 to 12 percent) of the penta- and hexa-homologs. In four of the rivers, over 30 percent of the total sediment-bound PCBs (by weight) are from the pentagroup, followed by the hexa- and tetra-chlorinated homologs. The average homolog distribution in the Elizabeth River sediment is different; nearly 30 percent of the total PCBs (by weight) are from the hexa-homolog group, followed by the hepta-, and the penta-homologs. In the Elizabeth River, the penta-homolog represents only 17 percent of the total PCB mass. In all rivers, the octa-homolog groups represent 2 to 6 percent of the total PCBs. The mono+di-, nona-, and decachlorinated homologs each make up less than 1 percent of the total.

The average homolog distribution in the sediment is compared to the homolog distribution of four Aroclors (1242, 1254,1248 , and 1260) in table 13 on both a weight and molar basis. Aroclor 1242 was the mixture released into the upper Hudson River (Erickson, 1997). The average sediment composition in the Elizabeth River is most similar to Aroclor 1260 in the percentage of hexa- through deca-chlorinated homologs, although the sediment is enriched in some homologs, especially the penta-chlorinated homolog. Close inspection of this table shows the average sediment compositions did not match any of these three Aroclors exactly. This indicates the river sediment has likely been impacted by a mixture of Aroclor sources as well as the degradation of heavier congeners or volatilization of the lighter congeners. Multivariate analysis or other methods might resolve the mixes that best match the composition of these sediments.

The homolog distribution for dissolved trace congeners in the Passaic River differed slightly from the other rivers, in that the hepta-, octa-, nona-, and deca-homologs each represented less than 1 percent of the total PCBs; in the other rivers, these homologs represented between 3 and 10 percent of the total PCBs. Using only detected values, the dissolved PCBs were found to be dominated by the tri- and tetra-homolog groups in all rivers except the Elizabeth, where the mono+di- and trihomologs each represented over 30 percent of the total PCBs.

\section{Concentrations During Stormflow and Low Flow}

The composition, as measured by the absolute and relative concentration, of the sediment and water transported in a river may change as discharge changes from low-level (base flow) to storm levels. Each upstream tributary and point/nonpoint source that discharges to the river may deliver sediment and water having a unique composition that, when mixed with 


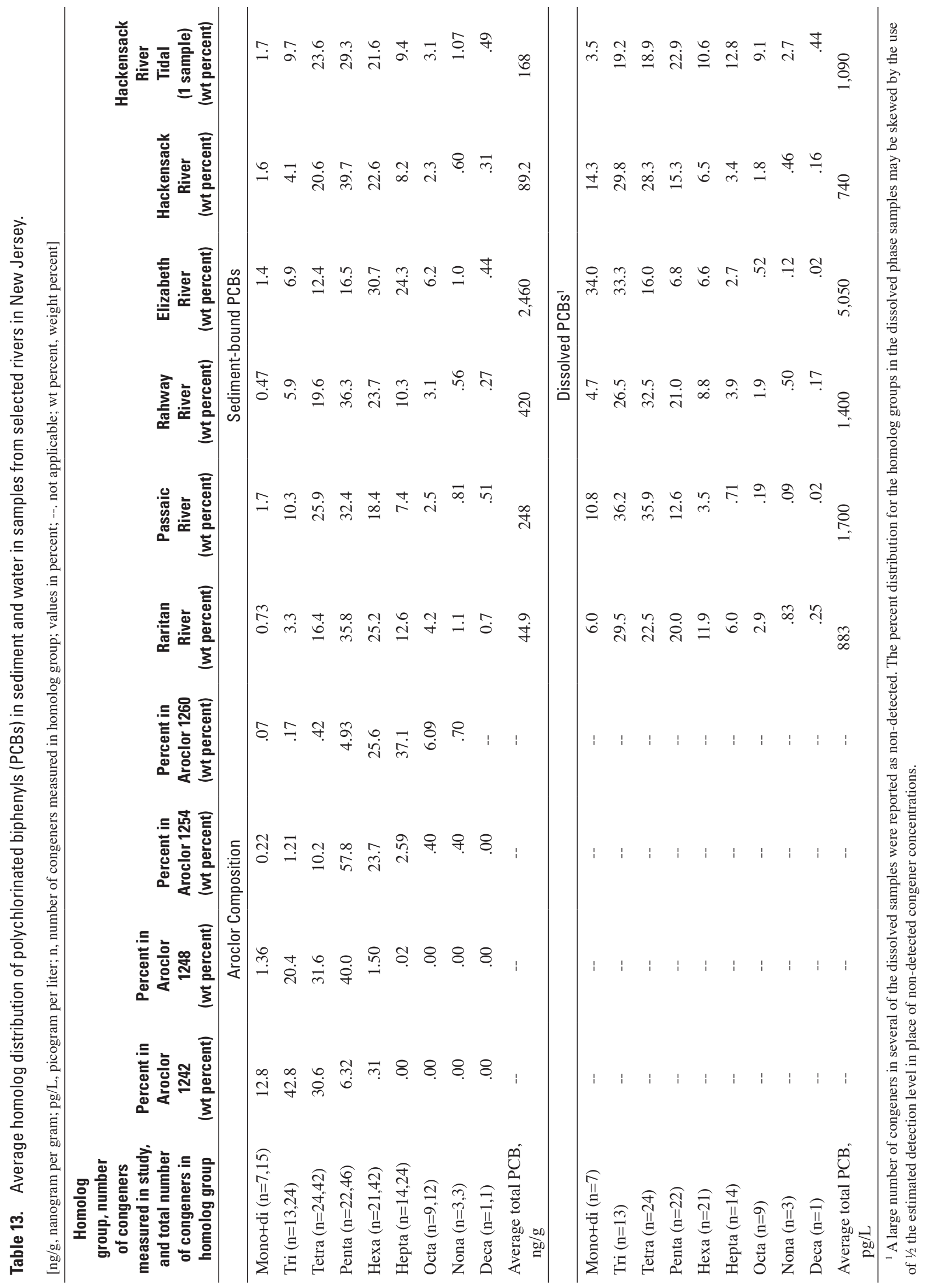




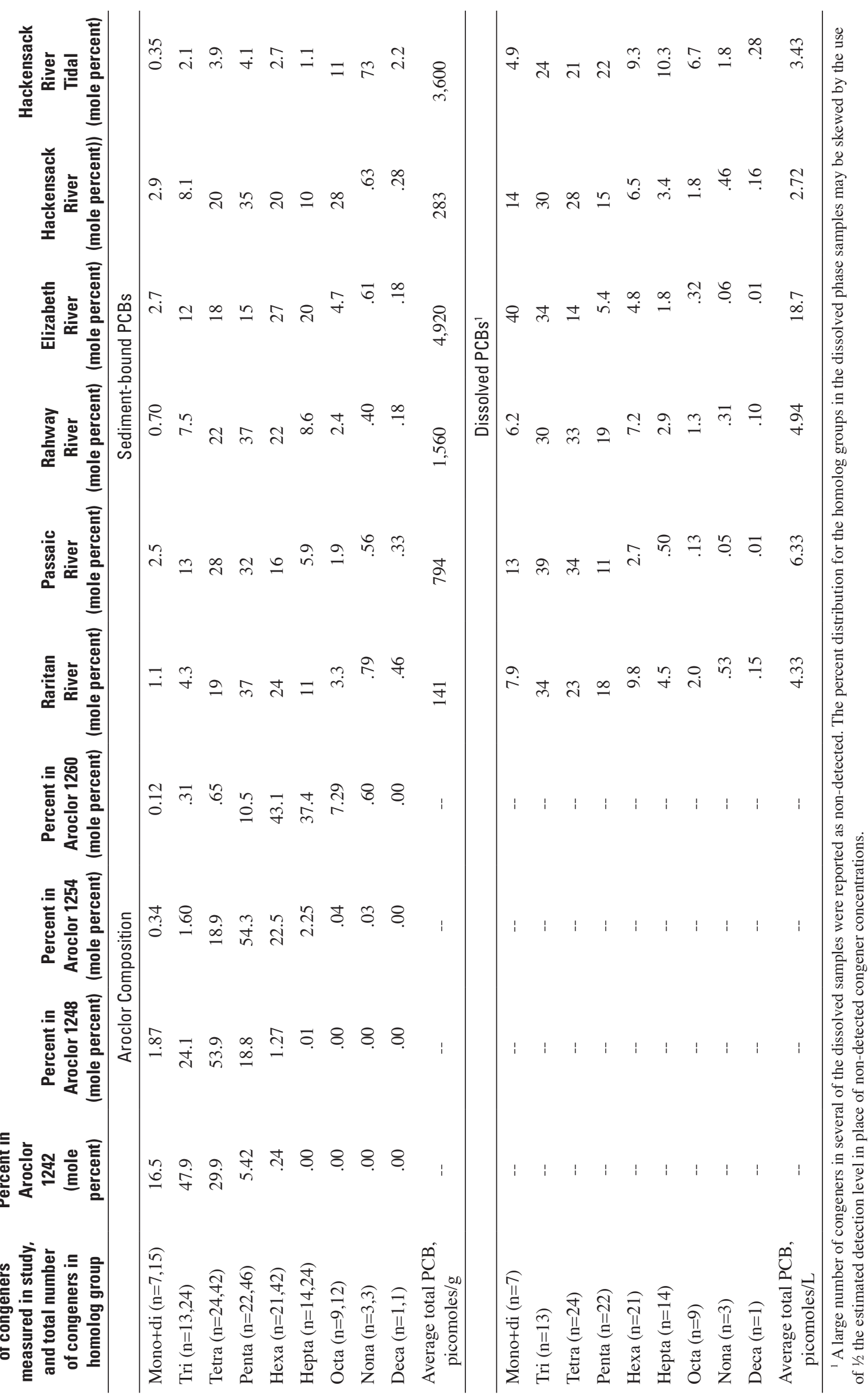




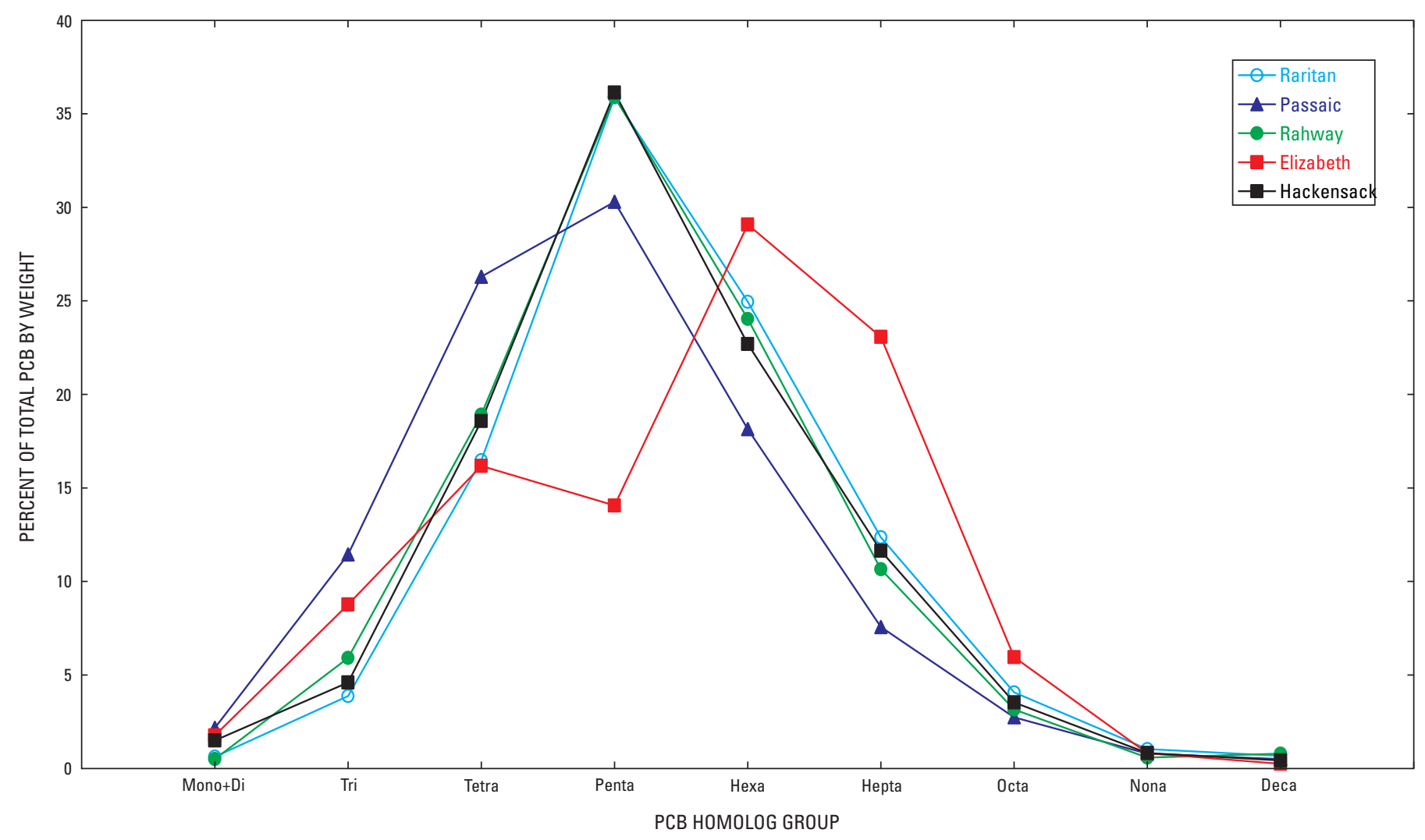

Figure 6. Average homolog distribution (by weight) of polychlorinated biphenyls (PCBs) in sediment from selected rivers in New Jersey.

the main branch of the river, causes the river composition to vary as a function of discharge. Thus, as discharge rises during a storm, water and sediment enter the river from point and nonpoint sources that normally would not contribute to the river during dry-weather flow. The sediment transported during low flow will be the finest grain-size material winnowed from the bottom sediment of the river. This material has a large surface area to weight ratio and may contain a high contaminant concentration per mass of sediment. During storms, not only will new sediment and water be introduced to the river, but also material may be eroded from the stream banks and bed; this material will generally include larger grain-sized material. Larger grained-sized materials will have small surface area to weight ratios and, because it is likely less favorable to sequester organic contaminants; commonly have lower contaminant concentration (lower mass per unit mass of sediment). In other words, it is possible that storm-transported materials may be cleaner than the fine-grained materials (per unit mass) transported under dry conditions. Material eroded from deep within the stream bed may also contain chemicals formed by the degradation of other chemicals and historical contamination. Depending on composition and volumes, storm inputs may cause the river composition to vary greatly.

Composite samples (produced by mixing multiple same-volume aliquots of river water collected over the course of a storm) are collected in order to "average out" the time dependent variations caused by the different storm-water sources. Large changes in the composition of composite samples collected during low flow and stormflow indicate a substantial input of storm-related discharge and/or sediment. In the Rahway River, for example, substantially different dissolved total PCBs concentrations were observed between low flow (having a high total PCB concentrations in the water) and storm discharge (where lower dissolved concentrations were found) (table 12). The change in total PCB concentrations during storms in sediment concentrations from the Elizabeth River is less clear, as both high and extremely low concentrations were measured (table 12). Alternatively, little variation in total concentration suggests that steady, well-mixed source(s) of sediment and water occur. The sediment and water in the Passaic River show this type of response (table 12). 
It is instructive, therefore, to compare the composition of the rivers during low-flow and stormflow discharges. The changes in concentrations of SS, carbon, and ion load (specific conductance) observed during storm events are discussed elsewhere in this report. To demonstrate the changes in the PCB composition, the ratio of the concentrations in storm samples to the concentrations in low-flow samples was calculated using the relative concentration of the individual congeners or averages for homolog groups. Ratios of the absolute concentration of total PCBs were also calculated to demonstrate if the dilution by "clean water" (precipitation) or sediment or the enrichment by runoff or discharges that contain high PCB content occurred. A similar comparison made using relative concentrations (weight percent) was made to determine if different sources were evident during storm and lower flow conditions.

The ratios of average relative concentrations in storm and low-flow discharge samples for the different PCB homo$\log$ groups are summarized in table 14. The ratio for the absolute concentration of total PCBs is also presented to illustrate if the storm water contained more or less total PCBs than the low flow. The storm/low-flow ratio for the individual homolog groups should equal (or nearly equal) 1 if the stormflow and low-flow chemical makeup were similar (independent of total concentration). A relative concentration ratio for a homolog group that differs substantially from 1 indicates the sediment or water that entered the stream during the storm is chemically different (for the specific homolog group) from the sediment transported during low flow. Considering the uncertainty associated with the concentrations, stormflow ratios within $+/-0.2$ are considered to be equal. The ratio for total PCBs calculated using absolute concentrations will indicate if the storm water contained more (ratios $>1$ ) or less (ratios $<1$ ) total PCBs than in low flow. Unfortunately, the small number of samples collected precludes the use of statistical significance testing and also limits the confidence that can be placed on hypotheses to explain the processes responsible for the observed differences in PCB makeup. Also, because these ratios are generated using average concentrations for homolog groups, enrichments or depletions of any specific PCB congener may be masked

The changes that occur in the PCB composition of each river during selected storm events can be summarized as follows:

- Raritan River-The ratio of mean storm to the mean low-flow total PCB concentration in the Raritan is 1.3 , indicating that the sediment transported during a storm contained about 30 percent more total PCBs than during low flow, which is greater than the estimated error associated with the chemical analyses (Bonin and Wilson, 2006). The ratios of the relative concentrations of the homolog groups, with the exception of the mono+di- and tri-chlorination group, are near $1(+/-$ 0.2 ), indicating the sediment transported during storms and low flow had nearly identical homolog composition. The mono+di- and tri-chlorinated congeners clearly were greatly enriched during the storms. An increase in only a low-chlorinated homolog group(s) may indicate that, during the storm, sediment transported was enriched in congeners formed by degredation of higher chlorinated PCBs (Brown and others, 1987). The ratio for the dissolved total PCB concentration is 1.3 , indicating the storm water had a PCB content 30 percent greater than the low-discharge water, similar to the enrichment in the sediment. The sources of water to the river during precipitation events clearly contained more PCBs than did the sources during lowflow conditions. The ratios of relative concentrations show that storm water contained higher percentages of the mono+di- and tri-homologs and lower percentages of the penta-, hepta-, and octa- congeners.

- Passaic River-The concentration ratio for total-PCBs in the sediment in the Passaic River is 0.9 , indicating the sediment transported during storms had about the same total PCB concentrations as sediment carried during low flow. The ratios of tri- and tetra-homologs are near 1.3, while the ratios for the other homologs are 0.7 to 0.9 . The ratio for the concentrations of dissolved total PCB (0.7) indicates the river water contained less total PCBs compared with low flow, indicating the effects of dilution. The diluting water differed in its composition from low flow, having a lower proportion of the penta- thru hepta-chlorinated homologs.

- Rahway River-The concentration ratio for the total PCBs in sediment in the Rahway River is 0.5 , indicating sediment transported during storms had about one-half the total PCB content of sediment carried during low flow. The sediment transported during storms contained about the same abundance of all homologs except the mono+di-congeners. The ratio for dissolved total PCBs (0.8) indicates storm waters also contained less total PCBs compared with low-flow; the relative concentration ratios show the storm water was enriched in the mono+di and the penta- to heptahomologs and was depleted in the tetra-homologs.

- Elizabeth River - The Elizabeth River shows changes in absolute concentrations between stormflow and low flow. The concentration ratio for total PCBs in the sediment of the Elizabeth River is 0.8 indicating sediment transported during storms contained 80 percent of the total PCBs in low-flow sediment. Mono+di-, tri-, and tetra-chlorinated homologs were lower in the storm water sediment and the penta-, hexa-, nona-, and deca-chlorinated homologs were enriched.

The ratio for the dissolved total PCB is 0.4 , showing that, like the sediment, the storm discharge also contained a substantially lower absolute concentration of total PCBs. All homologs except the octa-chlorinated congeners were depleted in the storm water. 


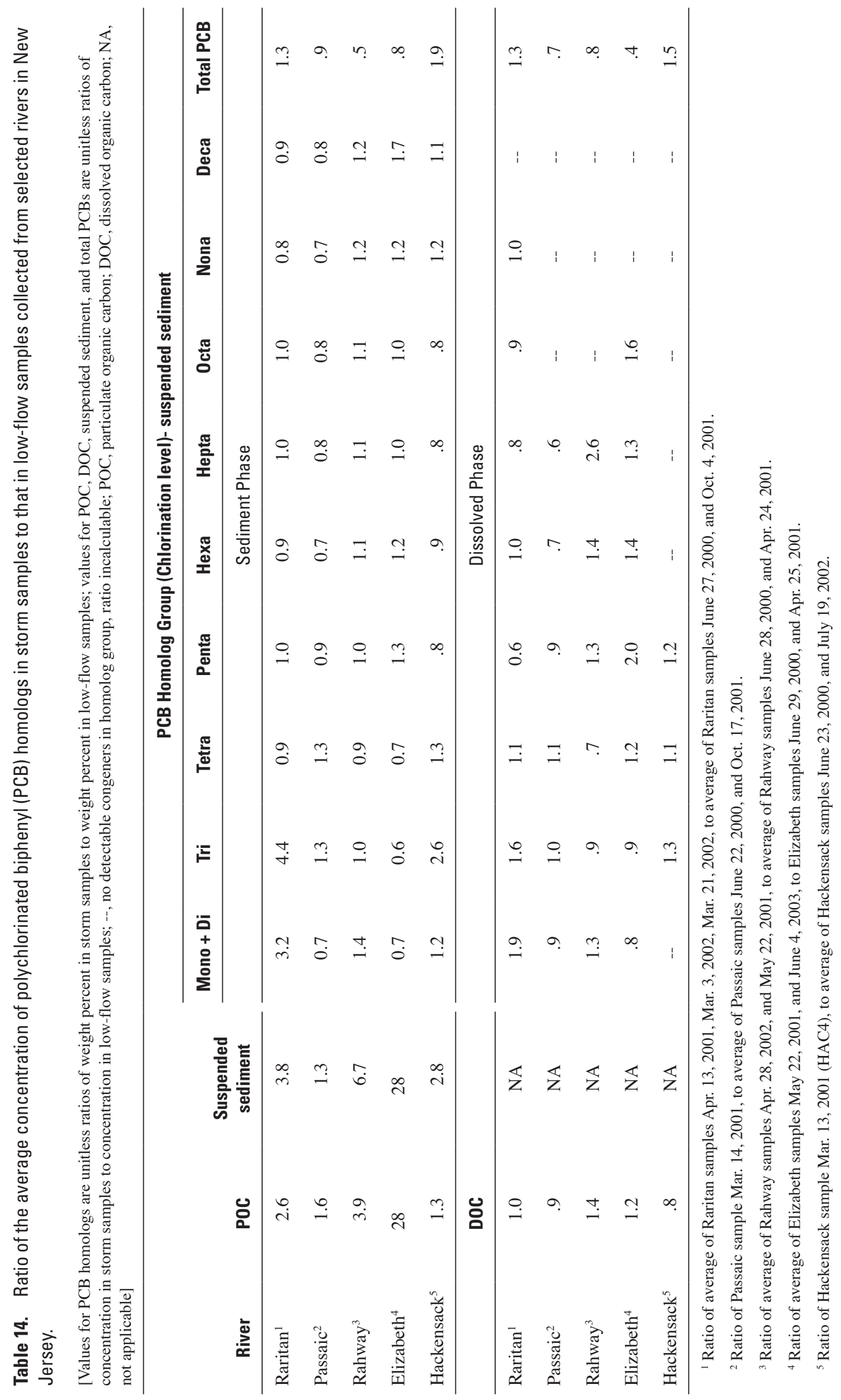


- Hackensack River - The Hackensack River was not sampled at the HOT during a storm. However, the chemistry of water/sediment discharged from the Oradell Reservoir could be compared with the composition from downstream of the lower Oradell dam (site HAC4), collected from an area affected by tidal action. The concentration ratio for total PCBs in the sediment is 1.9 , indicating sediment below the lower dam contained about twice the total PCBs compared with the sediment leaving the reservoir. The relative concentration ratios indicate sediment collected from the tidally affected area had a higher abundance of mono+di- through the tetra-homologs - all other homologs were about equal in the storm and low-flow sediment. The ratio for the dissolved total PCBs (1.5) indicates downstream water contained about 50 percent more dissolved total PCBs than did the water leaving the reservoir. The homolog ratio of the water downstream of the lower Oradell dam was roughly equal in the tri-, tetra-, and penta-homologs.

The variation in the composition of the Passaic and Elizabeth Rivers sediment and water during storms is especially interesting. Plots of the relative stormflow/low-flow ratios of the individual PCB congener (in weight percentage) were prepared using a low-flow sample and stormflow sample, rather than average concentrations, to demonstrate these changes (figs. 7 to 10).

In the Passaic River sediment, the total PCB concentration decreased only slightly, from $256 \mathrm{ng} / \mathrm{g}$ in the Oct. 17 , 2001, low-flow sample to $238 \mathrm{ng} / \mathrm{g}$ in the Mar. 14, 2001, storm sample. This change (7 percent) may be insignificant, because it is within the estimated precision of the analytical work. The plot shows the storm sediment contained slightly less pentathrough octa-chlorinated isomers and was enriched in the mono+di-, tri-, and tetra-chlorinated homologs. Five distinct congeners are highly enriched in the storm sample - the significance of these isolated enrichments is unclear. The dissolved total PCB concentration in the storm sample (fig. 8) was lower than that in the low-flow sample, as shown in the plot, was the result of lower penta-, hexa-, and hepta- -chlorinated congeners in the storm sample.

The Elizabeth River showed a different response to a storm; the total PCB concentration in the sediment (fig. 9) decreased 75 percent from $3,050 \mathrm{ng} / \mathrm{g}$ in low-flow sediment (April 25, 2001, sample) to $725 \mathrm{ng} / \mathrm{g}$ in storm sediment (May 22,2001 , sample). The sediment that was transported during the storm contained much higher abundance of only a few congeners, mainly from the penta- and hexa-chlorinated homologs. The remaining congeners remained at levels similar to those measured in sediment collected during low flow.

The absolute concentration of total PCBs in the dissolved phase (fig. 10) also decreased (53 percent) from 6,580 pg/L (April 25, 2001, sample) to 3,080 pg/L (May 22, 2001, sample) during the storm. The congener ratios plot in a distinct pattern that increases from the tetra- up to the nona-homologs, where enrichements of near two to three times are observed.
The pattern produced by the Elizabeth River data is unique among the rivers studied here, because the congener distribution of the dissolved phase changed greatly during the storm, although the absolute concentration of total PCBs decreased. Clearly, whatever the source of the water and sediment is during the storms, it had a great affect on the relative composition of this river.

\section{Sediment-Water Partitioning}

Hydrophobic organic contaminants such as PCBs will partition between coexisting water, sediment, carbon, and the gas phases in aqueous environments. Given sufficient time, contaminants will move between these phases until a thermodynamic and/or kinetic equilibrium is reached between uptake and release from each phase. To a large extent, phase partitioning is the dominant control on the fate and transport of chemical contaminants in the environment. Because of its importance, considerable effort has been placed on understanding the apparent water-sediment partitioning of organic chemicals. This partitioning is affected by temperature and other chemical-physical factors, for example, by the fact that as sediment repeatedly erodes, transports, and deposits in various environments in a river, it moves through different environments and conditions. As a result, river sediment and water are constantly attempting to reequilibrate with their environment. Although likely to be a kinetically controlled process, partitioning is commonly assumed to be an "instantanous equilibrium" process in fate and transport models of natural systems.

Semi-empirical models of equilibrium partitioning commonly involve two or more phases. In a two-phase model, the sorbate (PCBs or other organic compounds) is considered to be either in the particulate or dissolved phase. Other phases exist, for example, the non-filterable colloid fraction phase. In the work conducted here, colloidal particulates were not separated from the water and (along with the gas phase) are considered to contribute to the dissolved chemicals sequestered on the XAD columns. As described by Butcher and others (1998) and Schwarzenbach and others (1993), two-phase chemical partitioning can be described by:

$$
K d_{a}=C_{p, a} /\left(S S * C_{d, a}\right)
$$

where

and

$$
\begin{aligned}
K d_{a}= & \text { the apparent partition coefficient; } \\
p= & \text { particulate matter; } \\
d= & \text { dissolved phase; } \\
a= & \text { the apparent measure of concentration } \\
& \text { within the phase (based on filtration); } \\
C= & \text { concentration of the chemical "a" in the } \\
& \text { indicated phase in mass per liter or mass } \\
& \text { per kilogram; }
\end{aligned}
$$

SS $=$ the concentration of suspended solids in the sample, which includes inorganic and organic (abiotic and biotic) matter. 


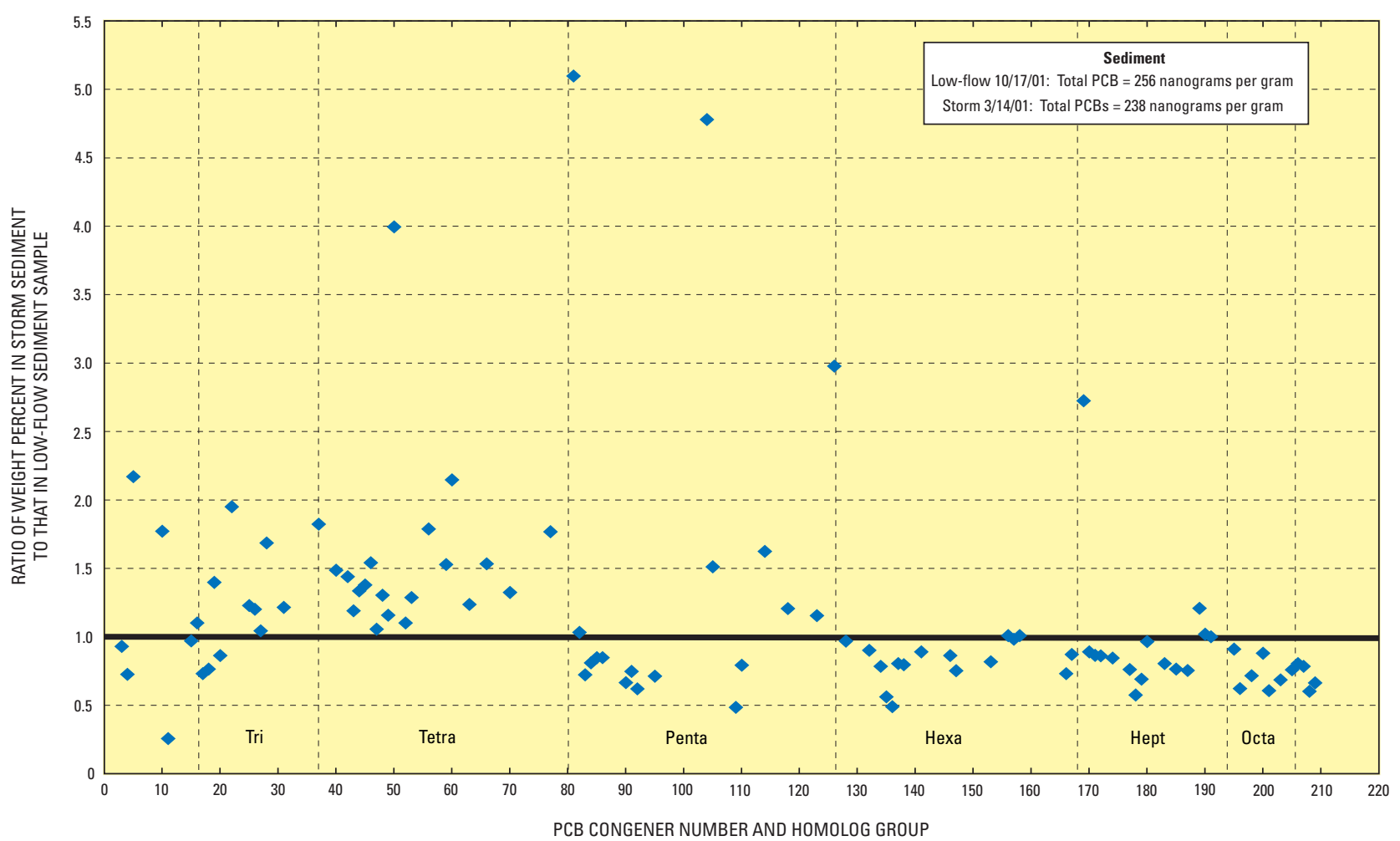

Figure 7. Ratio of concentration of polychlorinated biphenyl (PCB) congeners in sediment in storm samples to the concentration in low-flow samples from the Passaic River, New Jersey.

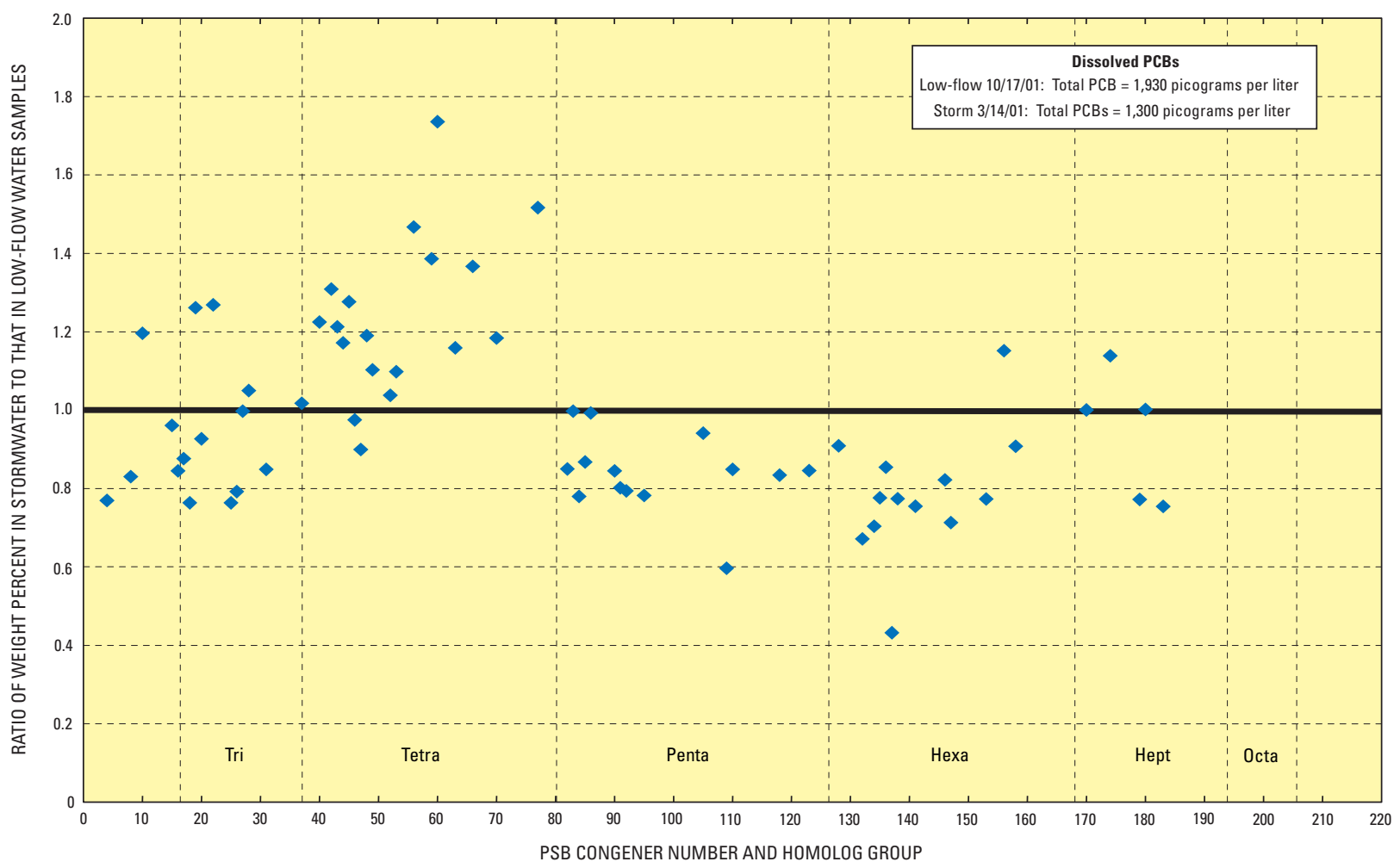

Figure 8. Ratio of concentration of dissolved polychlorinated biphenyl (PCB) congeners in storm samples to the concentration in lowflow samples from the Passaic River, New Jersey. 


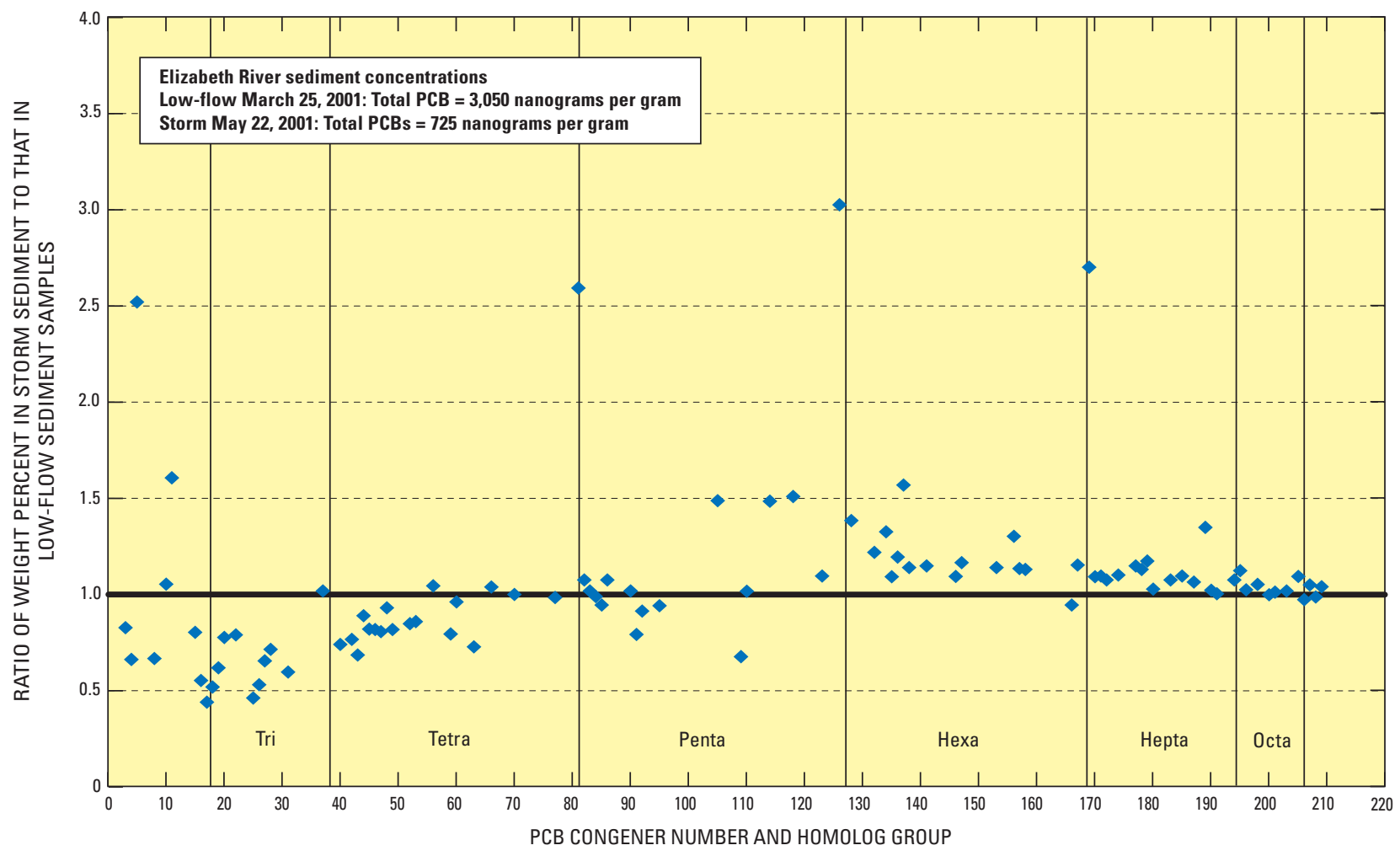

Figure 9. Ratio of concentration of polychlorinated biphenyl (PCB) congeners in sediment in storm samples to the concentration in low-flow samples from Elizabeth River, New Jersey.

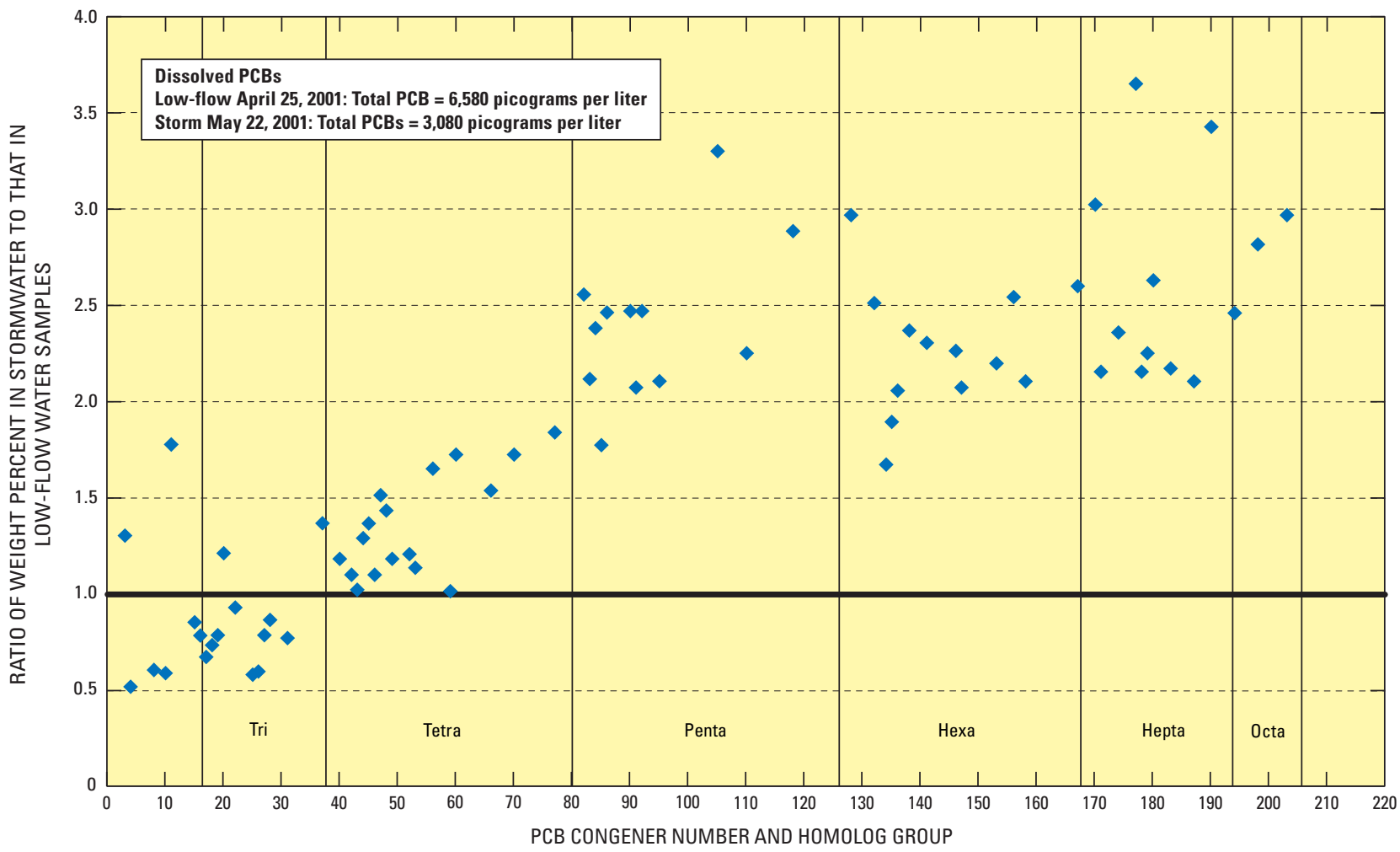

Figure 10. Ratio of concentration of dissolved polychlorinated biphenyl (PCB) congeners in storm samples to the concentration in lowflow samples from Elizabeth River, New Jersey. 
This equation reduces to:

$$
K d_{a}=C_{p, a} / C_{d, a}
$$

where

$$
\begin{aligned}
& C_{p, a}= \text { sediment normalized concentration of the } \\
& \text { chemical of interest }
\end{aligned}
$$

Sorption of hydrophobic organics such as PCBs occurs preferentially to organic matter associated with particles. For this reason, the partitioning is often described by

$$
K_{o c}=C_{p o c} / C_{d, a}
$$

where

$$
\begin{aligned}
K_{o c}= & \text { organic carbon normalized distribution } \\
& \text { coefficient; and } \\
C_{p o c}= & \text { particulate concentration of chemical } \\
& \text { normalized to either the mass of carbon } \\
& \text { or the percent fraction of carbon in the } \\
& \text { particulates. }
\end{aligned}
$$

A related constant that is commonly presented is Kom, the partitioning coefficient between water and solid organic matter (rather than organic carbon). $\mathrm{K}_{\mathrm{om}}$ and $\mathrm{K}_{\mathrm{oc}}$ are related. The mass of organic carbon in a suspended-sediment sample is calculated using the measured POC concentration and volume of water filtered. The fraction of organic carbon $\left(f_{o c}\right)$ in the particulate phase is calculated as:

$$
f_{o c}=P O C / S S
$$

For many natural materials that contain cellulose, lignin, fulvic acids from soils, humin, and humic acids derived from sediment and soils (Schwarzenbach and others, 1993), the fraction of organic matter $\left(\mathrm{f}_{\mathrm{om}}\right)$ relates to the foc by

$$
f_{\text {om }}=2 * f_{o c}
$$

This relation reflects the fact that organic matter is composed of about one-half organic carbon (Schwarzenbach and others, 1993). As a result, the relation between $\mathrm{Kd}, \mathrm{K}_{\mathrm{oc}}$, and $\mathrm{K}_{\mathrm{om}}$ is:

$$
\begin{gathered}
K_{o c}=K d / f_{o c} \\
K_{o m}=K d / f_{o m}=K d / 2 f_{o c}
\end{gathered}
$$

showing that Kom will be one-half the equivalent $\mathrm{K}_{\mathrm{oc}}$.

Partitioning is modeled using linear and non-linear regression analysis of the chemical concentrations in water and co-existing particulates. The calculated regression lines, called isotherms, allow the prediction of one phase concentra- tion from the measurement or estimation of the concentration in the second phase. The slope of the regression line represents the average sediment-water concentration ratio and is equivalent to $\mathrm{Kd}$ or $\mathrm{K}_{\mathrm{oc}}$. To accurately measure in situ partitioning, coexisting samples of the dissolved and particulate different phases must be collected with as little disturbance as possible to the chemical content of the sediment or water. As a result, most partitioning is studied by static experiments conducted in the laboratory where conditions can be controlled. The large volume sampling methods and the low-level analysis methods employed in this study allowed for evaluating the in situ partitioning, especially for samples collected during lowflow discharge. During low flow, the river discharge remains relatively constant, and thus so does the grain size of the sediment, the temperature, agitation, and volatilization. For these reasons, the partitioning of PCBs is best evaluated using only the low-flow sample data.

Partitioning constants for total PCBs were determined as the slopes of the best-fit regression lines to fit to nontransformed or logarithmic transformed data (fig. 11 to 13). Partitioning coefficients for the individual homolog groups were calculated as the logarithm of the average sedimentwater concentration ratio, or the average sediment carbonwater concentration ratio for each river (table 15) (note that the Elizabeth River sample from June, 2003 was not used in calculating the lines for all data in these figures). For some congeners where a large number of values were nondetected, the concentrations represent EDLs, which may bias the sediment-water ratios presented here.

A fairly strong correlation was found between the nontransformed total PCB concentrations (dissolved and sediment) in the low-flow samples $\left(\mathrm{r}^{2}=0.90\right)$, resulting in a $\mathrm{Kd}$ of $396,461 \mathrm{~L} / \mathrm{Kg}$ (fig. 11). Surprisingly, the correlation for the log-transformed concentrations was not as strong $\left(\mathrm{r}^{2}=0.69\right)$ and resulted in a $\log \mathrm{Kd}$ of $1.68 \mathrm{~L} / \mathrm{Kg}$ (fig. 12). The relation generated when the carbon-normalized sediment concentrations were used is similar to the relation obtained for the sediment-normalized values $\left(r^{2}=0.74\right)$ and resulted in a $\log$ Koc of $1.67 \mathrm{~L} / \mathrm{Kg}$ of carbon (fig. 13).

Each PCB homolog group will have unique partitioning properties, which are reflected in the variations in average sediment-water ratios (table 15) that were measured and in the different octanol-water partitioning coefficients that exist for each homolog. Octanol-water partitioning coefficients are experimentally derived values that describe the equilibrium partitioning between water and an organic solvent (octanol), which serves as a surrogate for natural organic matter. MacKay and others (2000) summarized the literature for experimentally derived octanol-water partitioning coefficients $\left(\mathrm{K}_{\mathrm{ow}}\right)$. A range of Kow values have been reported in the literature because of differences in experimental methodologies, analytical methods, temperature, and other experimental factors. Schwarzenbach and others (1993) described several empirical relations that relate ocatanol-water coefficients to measured Kom values. For example, a relation that Karickhoff 
(1981) developed for sorption of chlorinated hydrocarbons and chlorophenols in natural soils is:

$$
\log K_{o m}=0.88 * \log K_{o w}-0.27
$$

where

$$
\begin{aligned}
K_{o w}= & \text { octanol-water partition coefficient, in units } \\
& \text { of }(\mathrm{mol} / \mathrm{Kg} \text { octanol }) /(\mathrm{mol} / \mathrm{L} \text { water })
\end{aligned}
$$

and

$$
\begin{aligned}
K_{\text {om }}= & \text { organic matter distribution coefficient, in } \\
& \text { units of (mol/ } \mathrm{kg} \text { organic matter) / (mol/L } \\
& \text { water). }
\end{aligned}
$$

This relation illustrates that $\mathrm{K}_{\mathrm{om}}$ (and therefore $\mathrm{K}_{\mathrm{oc}}$ ) values are predicted to be less than their corresponding $\mathrm{K}_{\mathrm{ow}}$, which is likely because of the complex nature of natural organic matter compared with octanol.

The average sediment carbon-water concentration ratios for the different homolog groups in samples collected during low flow from the various rivers studied (table 15) can be compared with the range of reported $\mathrm{K}_{\mathrm{ow}}$ values, and the average $\mathrm{K}_{\text {ow }}$ 's reported by Mackay and others, 2000) (fig. 14). Average sediment carbon-water concentration ratios range from 5.05 for the mono+di- congeners up to 6.95 for the decahomolog congeners. These ratios follow the general pattern observed in $\mathrm{K}_{\text {ow }}$ 's, and show the higher chlorinated congener levels are more strongly favored to partition into organic carbon, or sorb onto solid matter, and thus have higher $\mathrm{Kd}$ or Koc constants.

In general, average concentration ratios for the monothrough penta-homolog groups in the sample data fall within the range of reported $\mathrm{K}_{\text {ow }}$ 's except perhaps for the mono+diand tetra- homologs which have minimum measured values less than their minimum respective $\mathrm{K}_{\mathrm{ow}}$ 's. The similarity in measured $\mathrm{K}_{\mathrm{oc}}$ and reported Kows suggests that (1) $\mathrm{K}_{\mathrm{ow}}$ can be used as surrogates for the PCB partitioning coefficients in these fresh waters, and (2) the sediment water partitioning is nearly that predicted by equilibrium partitioning. For the penta-chlorinated through deca-chlorinated congeners, however, the average measured ratios are less than the average $\mathrm{K}_{\text {ow }}$ values reported for these groups by Mackay and others (2000). For these compounds, using average $\mathrm{K}_{\text {ow }}$ 's as a surrogate for $\mathrm{K}_{\mathrm{oc}}$ would over-predict the sediment or under-predict the dissolved concentration.

One other consideration when using these in situ coefficients is the influence of the uncertainy in the analytical measurements. As discussed by Bonin and Wilson (2006), the analytic uncertainty is 10 to 12 percent of the reported concentration. For the partitioning relation shown in figure 12, this uncertainty results in an uncertainty in a predicted concentration (sediment or water) of $+/-17$ percent. An uncertainty of

\begin{tabular}{|c|c|c|c|c|c|c|c|c|c|c|}
\hline \multirow[b]{2}{*}{ River } & \multicolumn{9}{|c|}{ Homolog Group } & \multirow[b]{2}{*}{ Total } \\
\hline & Mono+Di & Tri & Tetra & Penta & Hexa & Hepta & Octa & Nona & Deca & \\
\hline \multicolumn{11}{|c|}{ Log (L/kg of sediment) } \\
\hline Passaic & 4.42 & 4.58 & 4.99 & 5.60 & 5.93 & 6.36 & 7.17 & -- & -- & 5.18 \\
\hline Rahway & 4.59 & 4.97 & 5.42 & 5.84 & 6.15 & 6.43 & 6.95 & 7.25 & -- & 5.65 \\
\hline Elizabeth & 4.49 & 5.22 & 5.77 & 6.07 & 6.40 & 6.71 & 7.03 & 7.80 & 7.72 & 5.76 \\
\hline Average & 4.28 & 4.43 & 5.14 & 5.59 & 5.87 & 6.14 & 6.54 & 7.07 & 6.49 & 5.28 \\
\hline \multicolumn{11}{|c|}{ Log (L/Kg of Carbon) } \\
\hline Raritan & 4.99 & 4.61 & 5.73 & 6.08 & 6.17 & 6.14 & 5.98 & 5.99 & 6.30 & 5.83 \\
\hline Passaic & 5.35 & 5.79 & 6.19 & 6.63 & 6.90 & 7.22 & 7.31 & 7.12 & 7.62 & 6.26 \\
\hline Rahway & 5.36 & 5.47 & 5.86 & 6.25 & 6.57 & 6.58 & 6.35 & 6.25 & 6.35 & 6.09 \\
\hline \multicolumn{11}{|c|}{ Log of octanol-water partition coefficients } \\
\hline Maximum Kow & 5.30 & 5.90 & 6.50 & 6.50 & 7.30 & 7.00 & 7.40 & 8.16 & 8.26 & -- \\
\hline Average Kow & 4.78 & 5.70 & 5.95 & 6.31 & 7.03 & 6.85 & 7.25 & 7.63 & 8.26 & -- \\
\hline Minimum Kow & 4.30 & 5.50 & 5.60 & 6.20 & 6.70 & 6.70 & 7.10 & 7.20 & 8.26 & -- \\
\hline
\end{tabular}
this magnitude can effect on the predictions made using an equilibrium-partitioning model approach.

Table 15. Average logarithmic sediment-water ratios for polychlorinated biphenyl homolog groups in samples collected during low flow on selected rivers in New Jersey.

[L/kg, liter per kilogram; octanol-water ratios from Mackay and others, 2000; --, not available] 


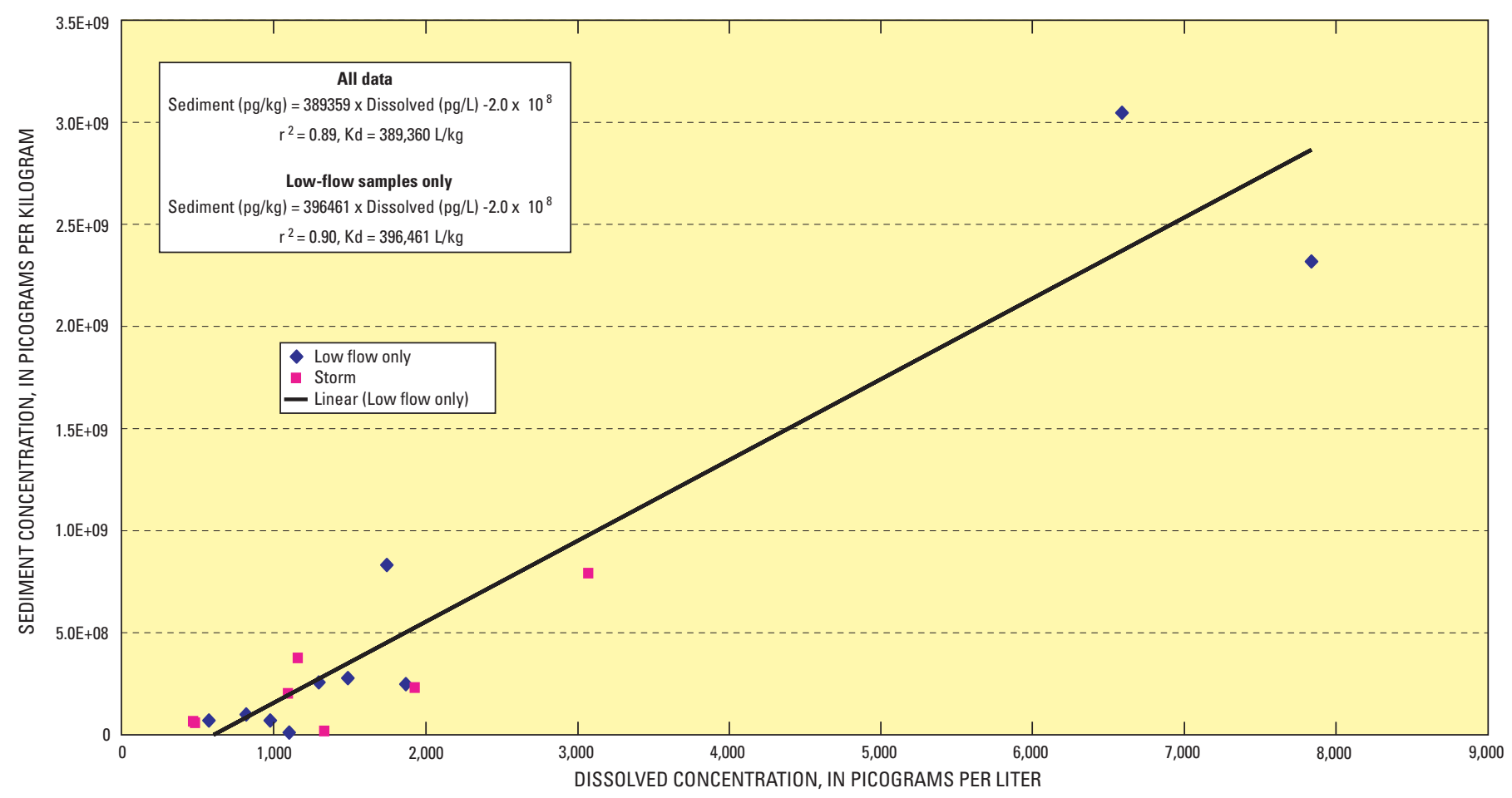

Figure 11. Relation between concentrations of total polychlorinated biphenyls in storm sediment and in water samples collected from selected rivers in New Jersey. (pg, picograms; L, liter; kg, kilogram)

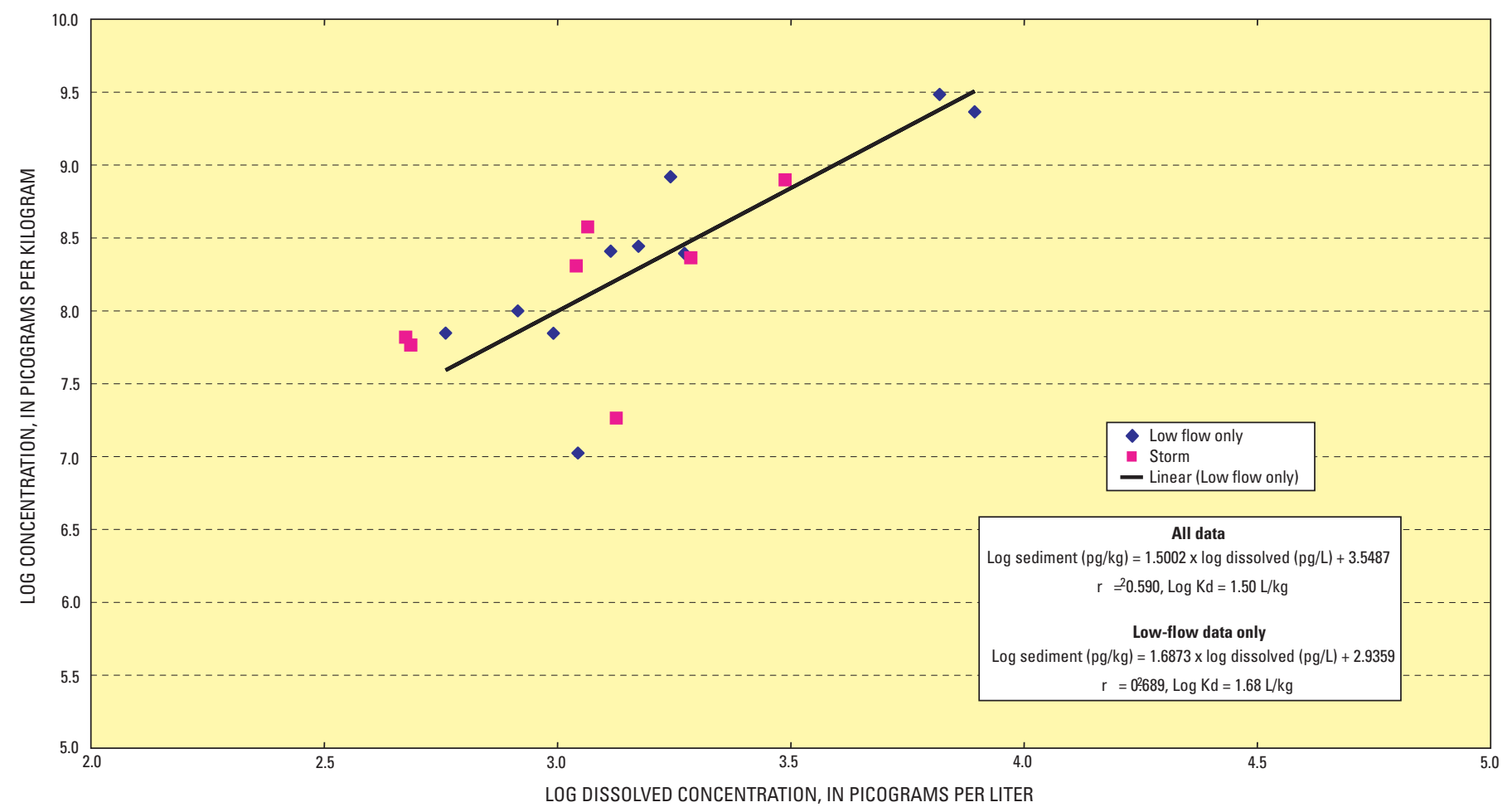

Figure 12. Relation between logrithmic concentration of total polychlorinated biphenyls in sediment samples and in water samples from selected rivers in New Jersey. (pg, picograms; L, liter; kg, kilogram) 


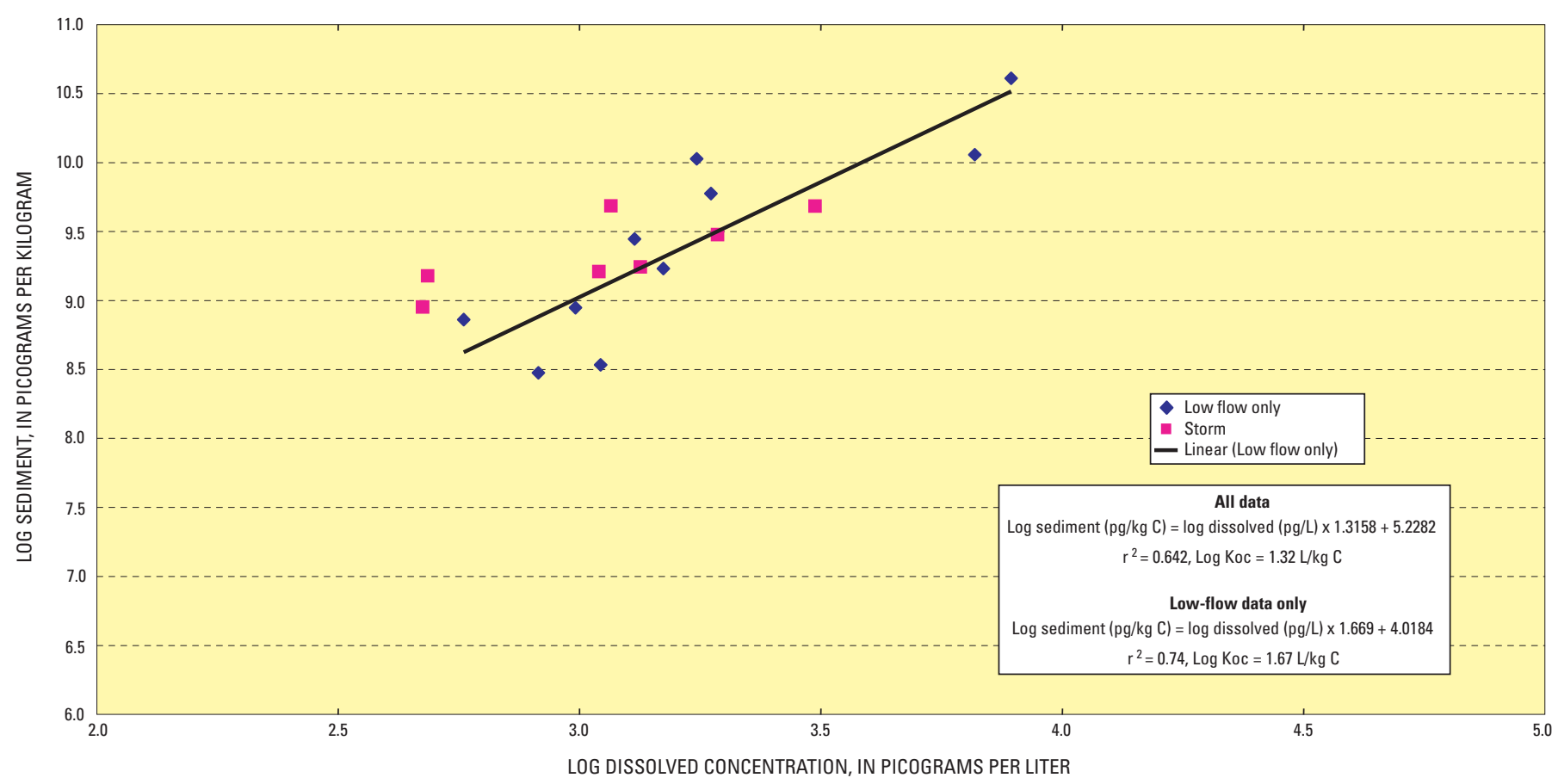

Figure 13. Relation between logrithmic concentrations of total polychlorinated biphenyls (carbon-normalized) in sediment and in water samples from selected rivers in New Jersey. (pg, picograms; L, liter; kg, kilogram)

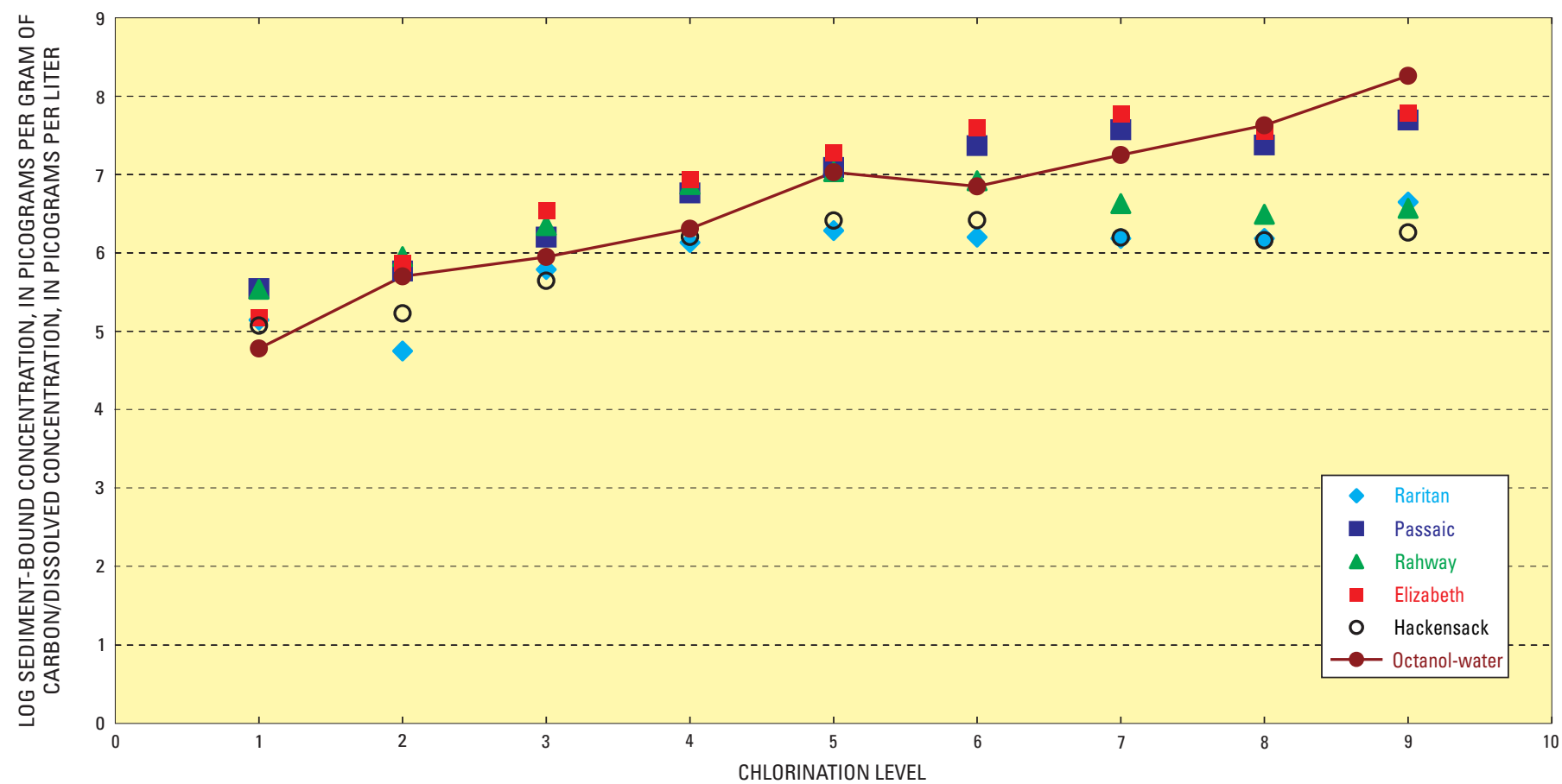

Figure 14. Relation between chlorination level and logarithm of ratio of average concentration of polychlorinated biphenyls in sediment (carbon-normalized) to average dissolved concentration in samples from selected rivers in New Jersey, and the logarithm of octanol-water partitioning coefficient. 


\section{Chlorinated Dioxins and Furans}

The concentrations of 7 chlorinated dibenzo-p-dioxins (CDD) and 10 dibenzo-p-furans (CDF) were measured in suspended sediment from the Raritan, Passaic, Rahway, Elizabeth, and Hackensack Rivers, the major tributaries to the Newark and Raritan Bays. Sediment was obtained from flowweighted composite samples collected during low-flow and storm discharge. These data are used to make interpretations, estimate toxicity, and to calculate riverine loads of chlorinated dioxins and furans to Newark and Raritan Bays from the watersheds above the HOT.

The chlorinated dioxin and furan compounds make up a class of 210 congeners having structures based on two aromatic rings connected by either one oxygen (for furans) or two oxygen atoms (for dioxins) (fig. 15). A varying number of chlorine atoms can attach to the rings, forming eight homolog groups or levels of chlorination. Congeners are numbered to indicate the positions of the chlorine atoms on the two-ring structures. A sub-group of the 7 dioxins and 10 furans have the chlorine atoms occupying the 2, 3, 7, and 8 position on the rings, such as 2,3,7,8-tetrachlorodioxin (2,3,7,8-TCDD) and 2,3,7,8-tetrachlorodifuran (2,3,7,8-TCDF) (fig. 15, table 16). These dioxin/furans are highly toxic to organisms and derive their toxicity from their 2,3,7,8-substituted, lateral or planar arrangements of the two rings that are of the appropriate size to bond to Ah-receptor sites on biologic cells (Barkovskii and Adriaens, 1996). Once bonded, the CDD or CDF molecule

Table 16. The chlorinated dibenzo-p-dioxin (CDD) and dibenzop-difuran (CDF) compounds measured in samples collected from the Raritan, Passaic, Rahway, Elizabeth, and Hackensack Rivers, New Jersey.

[CAS, Chemical Abstract Service]

\begin{tabular}{ll}
\hline CAS number & \multicolumn{1}{c}{ Compound } \\
\hline $1746-01-6$ & $2,3,7,8-$ Tetra-CDD \\
\hline $40321-76-4$ & $1,2,3,7,8-$ Penta-CDD \\
\hline $19408-74-3$ & $1,2,3,7,8,9-$ Hexa-CDD \\
\hline $39227-28-6$ & $1,2,3,4,7,8-H e x a-C D D$ \\
\hline $57653-85-7$ & $1,2,3,6,7,8-H e x a-C D D$ \\
\hline $35822-46-9$ & $1,2,3,4,6,7,8-H e p t a-C D D$ \\
\hline $3268-87-9$ & Octa-CDD \\
\hline $51207-31-9$ & $2,3,7,8-$ Tetra-CDF \\
\hline $57117-41-6$ & $1,2,3,7,8-$ Penta-CDF \\
\hline $57117-31-4$ & $2,3,4,7,8-$ Penta-CDF \\
\hline $70648-26-9$ & $1,2,3,4,7,8-H e x a-C D F$ \\
\hline $57117-44-9$ & $1,2,3,6,7,8-H e x a-C D F$ \\
\hline $60851-34-5$ & $2,3,4,6,7,8-H e x a-C D F$ \\
\hline $72918-21-9$ & $1,2,3,7,8,9-H e x a-C D F$ \\
\hline $67562-39-4$ & $1,2,3,4,6,7,8-H e p t a-C D F$ \\
\hline $55673-89-7$ & $1,2,3,4,7,8,9-H e p t a-C D F$ \\
\hline $39001-02-0$ & Octa-CDF \\
\hline
\end{tabular}

A<smiles>Clc1cc2c(cc1Cl)Cc1cc(Cl)c(Cl)cc1C2</smiles>

B<smiles>Clc1cc2c(cc1Cl)-c1cc(Cl)c(Cl)cc1-2</smiles>

2,3,7,8-TCDF

Figure 15. Molecular structure of (A) 2,3,7,8-tetrachloro-p-doxin (2,3,7,8-TCDD) and (B) 2,3,7,8-tetrachloro-p-difuran (2,3,7,8-TCDF).

interferes with normal cell activity. The other $\mathrm{CDD} / \mathrm{CDF}$ compounds exhibit lesser toxicity because of their different chlorine configurations.

Dioxins and furans are present in nearly all environments and are formed in three general ways: by the burning of organic matter at high temperatures in the presence of chlorine and oxygen, during industrial processes based on chlorine chemistry, and through biochemical transformations of precursors such as chlorophenols and natural organic matter and using peroxidases and hydrogen peroxide as catalysts (Hagenmaier and others, 1994). Burning of organic wastes in an oxygen-rich atmosphere tends to produce dioxins, whereas burning in oxygen-poorer conditions tends to produce furans. Pyrogenic sources include waste incineration and the burning of coal, diesel, and gasoline fuel. Industrial processes include the production of paper and chlorophenol-based insecticides, pesticides, and herbicides, including the synthesis of sodium 2,4,5-trichlorophenate (Umbreit and others, 1986). For example, 2,3,7,8-TCDD and other compounds were produced as impurities in the phenoxy-herbicide defoliant 2,4-D, which was produced in Newark, N.J., from 1940 to 1972 (Umbreit and others, 1986; Bopp and others, 1991).

Recent work has shown that 2,3,7,8-dioxins can be dechlorinated by bacteria naturally present in Passaic River sediment and, presumably, in other river sediments as well (Barkovskii and Adriaens, 1996; Albrecht and others, 1999). River sediments have high organic matter turnover, are predominantly anaerobic, and are very reduced, all suggesting that reductive dechlorination is a probable transformation mechanism operating in these environments and affecting CDDs (Albrecht and others, 1999) and, potentially, CDFs. Two pathways of dechlorination have been suggested, a mixed peri-lateral for non-2,3,7,8-substituted congeners and a peri-dechlorination pathway for the $2,3,7,8$-substituted octa- 
through penta-CDD isomers, which ultimately can enrich 2,3,7,8-TCDD. However, the 2,3,7,8-TCDD isomer was shown to further dechlorinate to tri-CDD, di-, and ultimately the mono-CDD congener (Barkovskii and Adriaens, 1996). Apparently, the peri-lateral dechlorination occurred through sub-populations of anaerobic non-spore-forming sediment microorganisms. Reductive dechlorination of PCDD congeners also can occur by metal-polyphenolic compounds or vitamins (Albrecht and others, 1999).

\section{Methods}

Only the sediment phase was analyzed for dioxins and furans in this program. Analysis was performed using USEPA method 1613B, an isotope dilution method that utilizes high-resolution gas chromatography high-resolution mass spectrometry (HRGC/HRMS) analysis methods. Dioxins and furans were resolved on a DB-5 gas-chromatography column, and if 2,3,7,8-TCDD or 2,3,7,8-TCDF were detected in a sample, a confirmation analysis was made using a DB-225 chromatograph column.

Analytic results reported by the laboratory were in units of mass (picograms) per sample. These values were reduced to concentration (picograms per gram of sediment) using the mass of sediment calculated to have been captured on the filters. In calculating the average concentrations, the nondetected concentrations were replaced by one-half the detection-limit values.

\section{Quality Assurance}

Data quality and assurance steps taken in this study for the analysis of dioxins and furans are detailed by Bonin and Wilson (2006). Data quality was assessed using repeated analyses of SRM. Data assurance was evaluated by reviewing the IS recovery and potential contamination from sampling media as determined from field and laboratory blanks.

\section{Recovery of Internal Standards}

The analysis method is based on the assumption that the IS and native compounds in a sample are affected equally during sample processing and analysis. Anomalous recoveries of IS may suggest that chemical interferences by the sample matrix existed or that poor analytical work was performed.

The generally accepted range for acceptable IS recoveries for USEPA Method 1613B is 20 to 150 percent of the original spiked amount (U.S. Environmental Protection Agency, 1994). Low recoveries of IS indicate loss during sample preparation; high recoveries may indicate error in the composition of the IS. Only two samples had low recoveries of IS:

1. The sample from the Passaic River, collected on Mar. 14, 2001 , had low recoveries (< 20 percent) for $1,2,3,6,7,8$ HxCDD; 2,3,7,8-TCDF; and 2,3,4,6,7,8-HxCDF.
2. The sample from the Elizabeth River, collected on May 22, 2001, had low recoveries for all IS with the exception of 2,3,7,8-TCDD. Recoveries for the CDD/ CDF IS ranged from 10 to 15 percent.

The low recoveries for the suite of IS (all except 2,3,7,8-TCDD) in the Elizabeth River sample is troublesome. Although the cause is presently unknown, low IS recoveries of dioxin/furnas, as well as PCBs, PAHs, and pesticides, may be related to the very high concentration of POC in these samples. Low recovery of an IS increases the uncertainty in the calculated concentration and suggests that native compound was lost along with the added standard compound. In spite of the low recoveries, the data for these samples were included when calculating average concentrations.

\section{Contamination of Blanks and Data Censoring}

Contamination of filters and sampling equipment and analytical equipment can introduce bias in the measured concentrations. Filters used in the sampling were obtained pre-baked by the manufacturer and, thus, were likely to contain trace amounts of CDD/CDFs from the oven used for preparation. Also, $\mathrm{CDD}$ and $\mathrm{CDF}$ are very difficult to remove from laboratory glassware, resulting in low-level contamination in many commercial analytical laboratories. In this work, a blank-elimination procedure was instituted to remove data that may have been biased by sampling media or laboratory contamination. This procedure compares the measured mass of each analyte in a sample with its mass in the field and method blanks produced for each sample. A field blank and a method blank were prepared for each event sampled. Field blanks were prepared by exposing a pre-baked, unused GFF canister and flat filter to the environment during the time filters were being installed in the sampling equipment. Method blanks were prepared in the laboratory and consisted of a mixture of solid $\mathrm{NaSO}_{4}$ and sand that were extracted identically to the samples.

Average concentrations of congeners measured in the field and method blanks, along with EDLs for compounds not detected in the blanks, are listed in table 17. The compounds commonly detected in the field blanks included OCDD, OCDF, along with lesser amounts of 1,2,3,4,6,7,8-HpCDD and 1,2,3,4,6,7,8-HpCDF. Typical masses in the blanks ranged from 5 to $400 \mathrm{pg}$ /sample for these compounds. For compounds not detected in the field blanks, the EDLs ranged from 3 to 15 $\mathrm{pg} / \mathrm{sample}$. Method blanks contained mainly OCDD; OCDF; 1,2,3,4,6,7,8-HpCDD; and 1,2,3,4,7,8,9-HpCDF at values up to $66 \mathrm{pg} / \mathrm{sample}$. The EDLs for the non-detected compounds were approximately 4 to $16 \mathrm{pg} / \mathrm{sample}$. Most of the PCDD and PCDFs were measured at approximately the same concentration in the field and method blanks, although OCDD was occasionally measured in the field blanks at higher masses than in the method blanks. As discussed elsewhere, OCDD and other chlorinated dixion/furans may have entered the glass-fiber filters in the baking processes. These compounds would not have been introduced in the method blanks. 


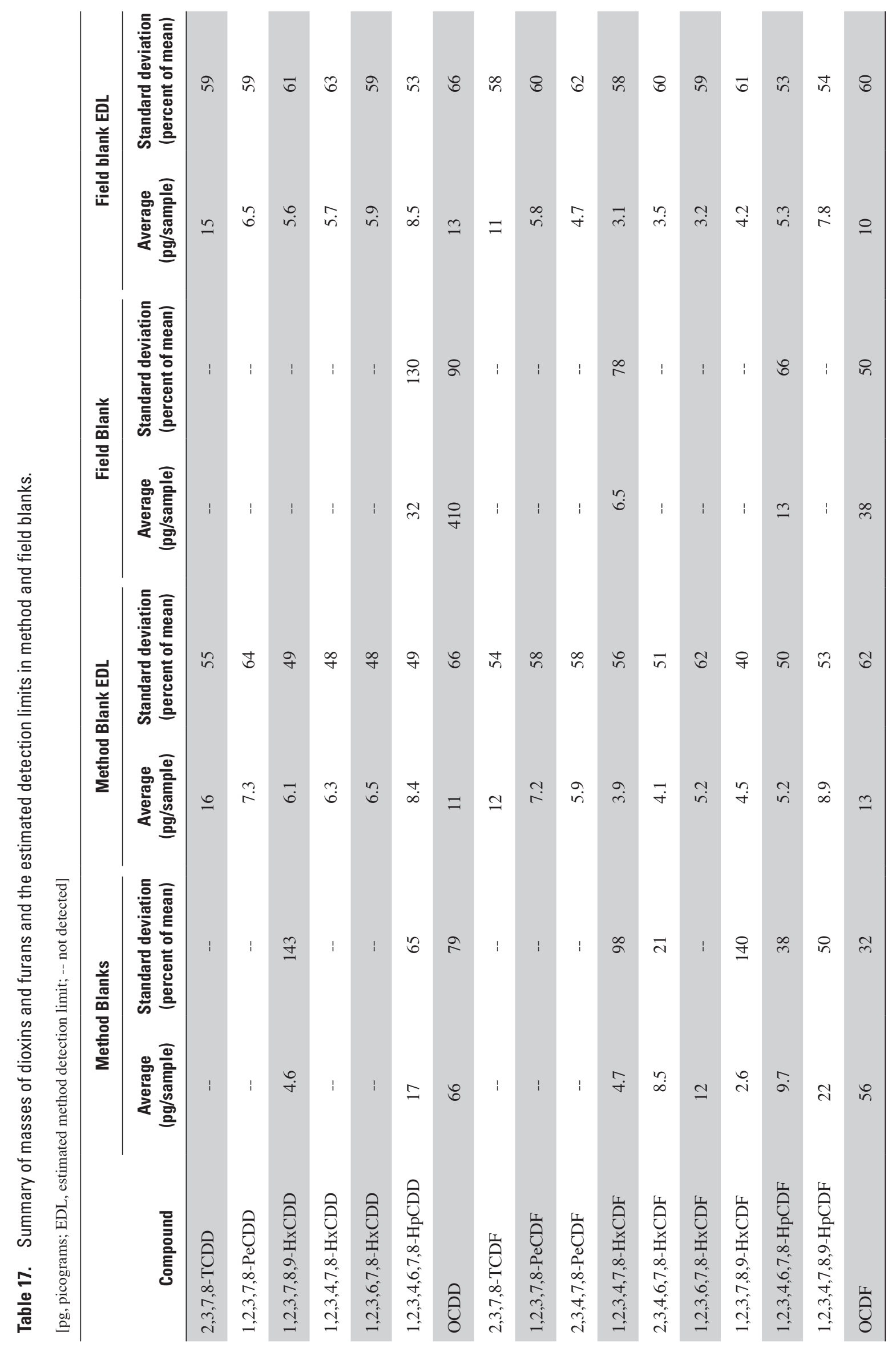


Concentrations in the sediment samples were eliminated from the data set if the measured mass of a congener was less than or equal to five times the larger of the mass measured in the field or method blanks. Only two samples were affected by blank elimination: the Raritan River sample collected on Oct. 4, 2001, where 1,2,3,4,7,8-HxCDF was eliminated, and the Passaic River sample collected on Oct. 17, 2001, where OCDF was removed from the data set.

\section{Concentrations}

A summary of the EDLs is presented in table 18, blankcorrected concentrations are listed in table 19, and average concentrations are presented in table 20. Congener specific EDLs for non-detected congeners in samples average from 4 to $16 \mathrm{pg} / \mathrm{g}$ (table 18 ), very similar to the range reported for method blanks (table 17).

Average sample concentrations calculated for several of the dioxin/furan compounds were based on a single measured concentration and/or entirely on EDLs. Compounds for which a high percentage of non-detectable concentrations were reported include 2,3,7,8-TCDD (16/21 samples) and 1,2,3,7,8,9-HxCDF (19/21 samples). Other compounds with substantial percentages of non-detectable concentrations include 1,2,3,4,7,8,9-HpCDF (in the Raritan River samples

Table 18. Summary of estimated detection limits for nondetected dioxins and difurans in sediment samples collected from selected rivers in New Jersey.

[pg/g, picogram per gram; --, not applicable]

\begin{tabular}{|c|c|c|c|c|}
\hline \multirow[b]{2}{*}{ Congener } & \multirow[b]{2}{*}{$\begin{array}{c}\text { Maxi- } \\
\text { mum } \\
\text { Count }^{1}\end{array}$} & \multicolumn{3}{|c|}{ Extimated detection limit } \\
\hline & & $\begin{array}{c}\text { Minimum } \\
(\mathrm{pg} / \mathrm{g})\end{array}$ & $\begin{array}{c}\text { Maxi- } \\
\text { mum } \\
(\mathrm{pg} / \mathrm{g})\end{array}$ & $\begin{array}{c}\text { Average } \\
(\mathrm{pg} / \mathrm{g})\end{array}$ \\
\hline 2,3,7,8-TCDD & 16 & 0.87 & 17 & 6.6 \\
\hline 1,2,3,7,8-PeCDD & 9 & .38 & 29 & 7.7 \\
\hline 1,2,3,7,8,9-HxCDD & 1 & 11 & 11 & 11 \\
\hline 1,2,3,4,7,8-HxCDD & 1 & 12 & 12 & 12 \\
\hline 1,2,3,6,7,8-HxCDD & 0 & -- & -- & -- \\
\hline 1,2,3,4,6,7,8-HpCDD & 0 & -- & -- & -- \\
\hline OCDD & 0 & -- & -- & -- \\
\hline $2,3,7,8-\mathrm{TCDF}$ & 2 & 9.8 & 15 & 12 \\
\hline $1,2,3,7,8-\mathrm{PeCDF}$ & 10 & .52 & 10 & 4.4 \\
\hline $2,3,4,7,8-\mathrm{PeCDF}$ & 2 & 8.2 & 8.7 & 8.5 \\
\hline $1,2,3,4,7,8-\mathrm{HxCDF}$ & 1 & 7.4 & 7.4 & 7.4 \\
\hline $2,3,4,6,7,8-\mathrm{HxCDF}$ & 2 & 3.2 & 6.9 & 5.0 \\
\hline $1,2,3,6,7,8-\mathrm{HxCDF}$ & 1 & 6.9 & 6.9 & 6.9 \\
\hline $1,2,3,7,8,9-\mathrm{HxCDF}$ & 19 & .22 & 17.9 & 3.9 \\
\hline $1,2,3,4,6,7,8-\mathrm{HpCDF}$ & 0 & -- & -- & -- \\
\hline $1,2,3,4,7,8,9-\mathrm{HpCDF}$ & 7 & 1.1 & 20 & 8.0 \\
\hline OCDF & 0 & -- & -- & -- \\
\hline
\end{tabular}

\footnotetext{
${ }^{1}$ Maximum count of congeners that had non-detected concentrations, out of a total possible of 21 samples collected.
}

only), 1,2,3,7,8-PeCDF (10/21 samples), and 1,2,3,7,8-PeCDD (9/21 samples). The use of EDLs in calculating average concentration sets an upper limit on the average concentration but does not unequivocally demonstrate the presence of these compounds. The effects of replacing non-detectable concentrations with EDLs are especially of concern when comparing different chemistries graphically and when calculating toxic equivalencies. Also, as mentioned earlier, a number of samples had low recoveries of IS reported. These data were included in the evaluations made in this report, although their use introduces uncertainty in the calculated average concentrations and other interpretations that were made.

With the exception of three congeners, all other CDD and CDF compounds were routinely detected in the suspended sediment from these rivers. However, care must be taken when evaluating differences and averages for the congeners 2,3,7,8TCDD; 1,2,3,7,8-PeCDF; and 1,2,3,7,8,9-HxCDF; which, as previously noted, had a large number of non-detected values. Average values calculated for these compounds may be biased and in large part represent only their EDLs, or, in some instances, a single measured concentration combined with several EDL values.

Average concentrations for the compounds commonly present (table 20, fig. 16) and for total CDD and CDF, demonstrate the similarities and differences among the concentrations of the various compounds within the different rivers. In all the rivers, the average total CDDs exceed the average total CDFs by a factor of 10 to 70 . The high total CDD values result from very high concentrations of the OCDD congener in the individual samples, ranging from $1,500 \mathrm{pg} / \mathrm{g}$ up to $48,000 \mathrm{pg} / \mathrm{g}$; the concentrations of OCDF ranged from $27 \mathrm{pg} / \mathrm{g}$ to $2,900 \mathrm{pg} / \mathrm{g}$ (table 19 ). Other compounds having notably high average concentrations are 1,2,3,4,6,7,8-HpCDD (240 to $2,200 \mathrm{pg} / \mathrm{g}$ ) and $1,2,3,4,6,7,8-\mathrm{HpCDF}$ (39 to $700 \mathrm{pg} / \mathrm{g}$ ), the hexa-furans $1,2,3,4,7,8-\mathrm{HxCDF}(6.9$ to $85 \mathrm{pg} / \mathrm{g}) ; 1,2,3,6,7,8$ $\mathrm{HxCDF}$ (6.1 to $120 \mathrm{pg} / \mathrm{g}$ ); and 2,3,7,8-TCDF (7.7 to $51 \mathrm{pg} / \mathrm{g}$ ). $2,3,7,8$-TCDD was detected in only four samples: the samples collected from the Passaic River on June 22, 2000, and Dec. 15, 2000, the sample collected from the Raritan River on Mar. 21, 2002, and the Elizabeth River, June, 2003 sample. In all other samples, 2,3,7,8-TCDD was below its detection limit, which ranged from 15 to $26 \mathrm{pg} / \mathrm{sample}$ (corresponding to 15 to $26 \mathrm{pg} / \mathrm{g}$ for a $1-\mathrm{g}$ sample). It is also noteworthy that the congener $1,2,3,7,8,9-\mathrm{HxCDF}$ was measured in only one sample (from the Passaic River). Apparently, this congener is not normally present in the tributary sediment or is affected by degradation processes.

The highest average concentrations of total CDD (26,400 $\mathrm{pg} / \mathrm{g})$, total CDF $(2,500 \mathrm{pg} / \mathrm{g})$, total CDF $(2,500 \mathrm{pg} / \mathrm{g})$ and, thus, total CDD+CDF $(28,900 \mathrm{pg} / \mathrm{g})$ were from the Elizabeth River (table 20). The Elizabeth River average total CDD and total CDD+CDF concentrations were about twice those found in the Passaic, Raritan, and Rahway Rivers where total CDD was 10,800 to $11,300 \mathrm{pg} / \mathrm{g}$ and total CDD+CDF was 11,500 to $11,700 \mathrm{pg} / \mathrm{g}$. The average concentration of total CDF in the Elizabeth River was about 3 times that in the Rahway River 


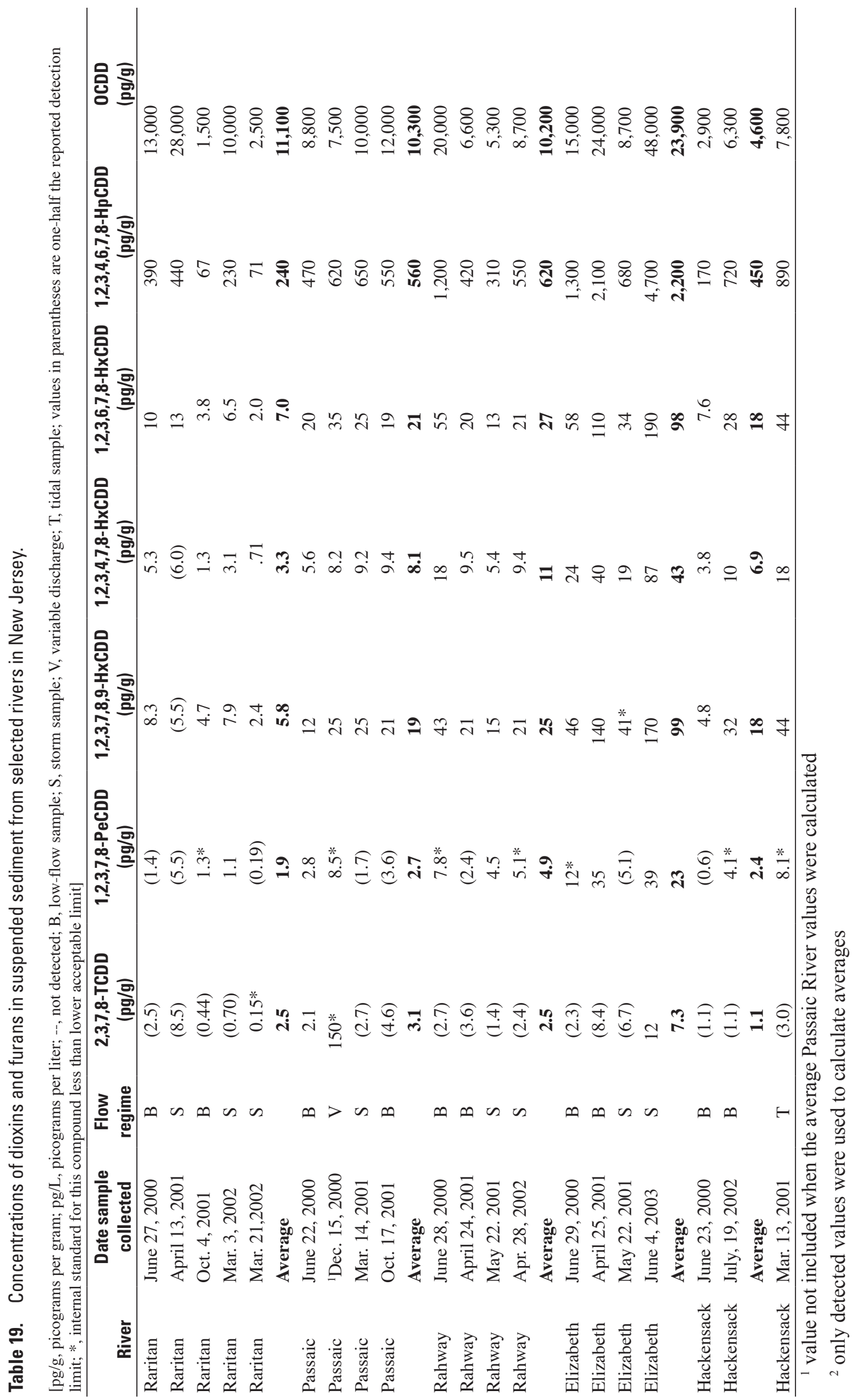




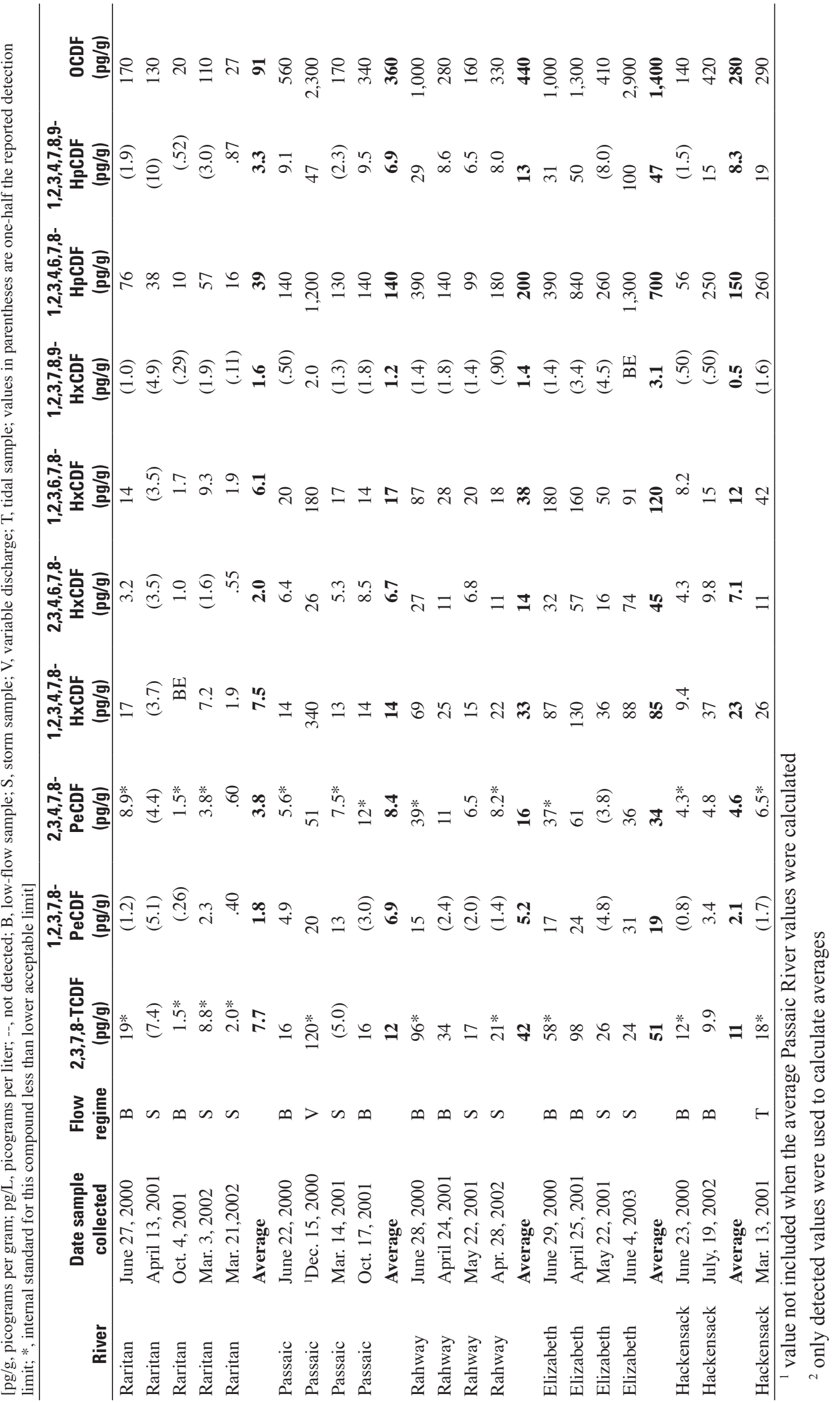




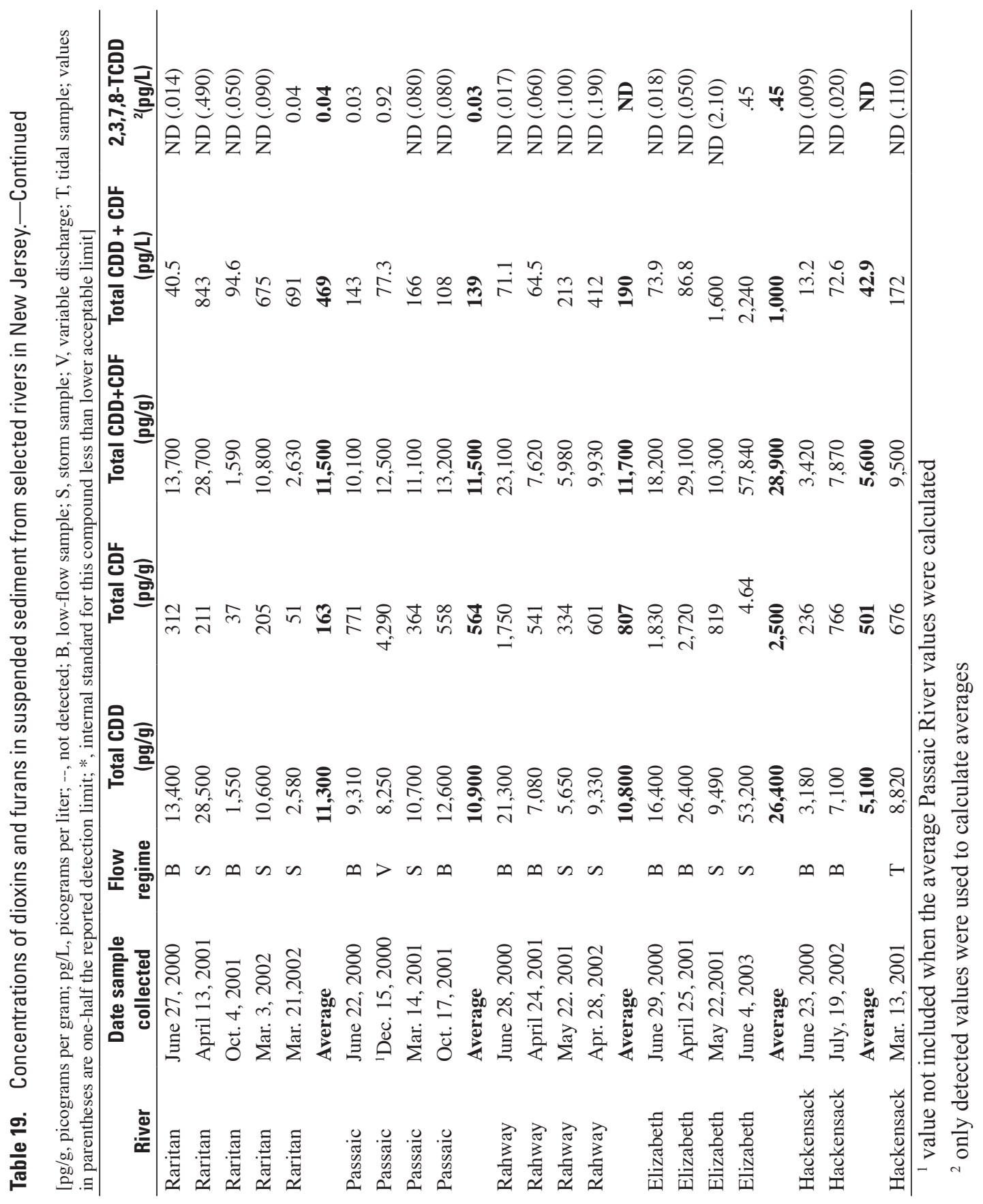




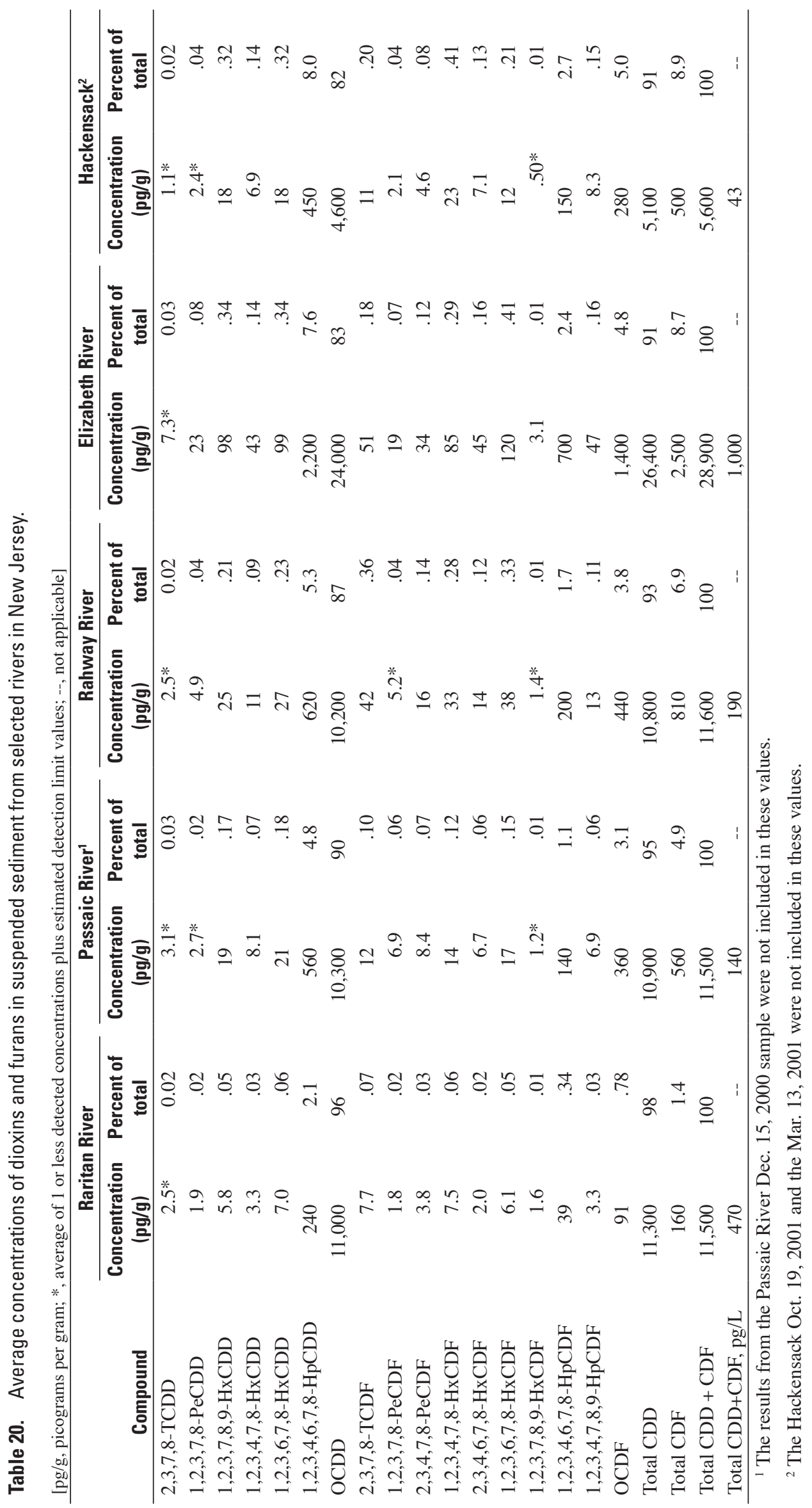




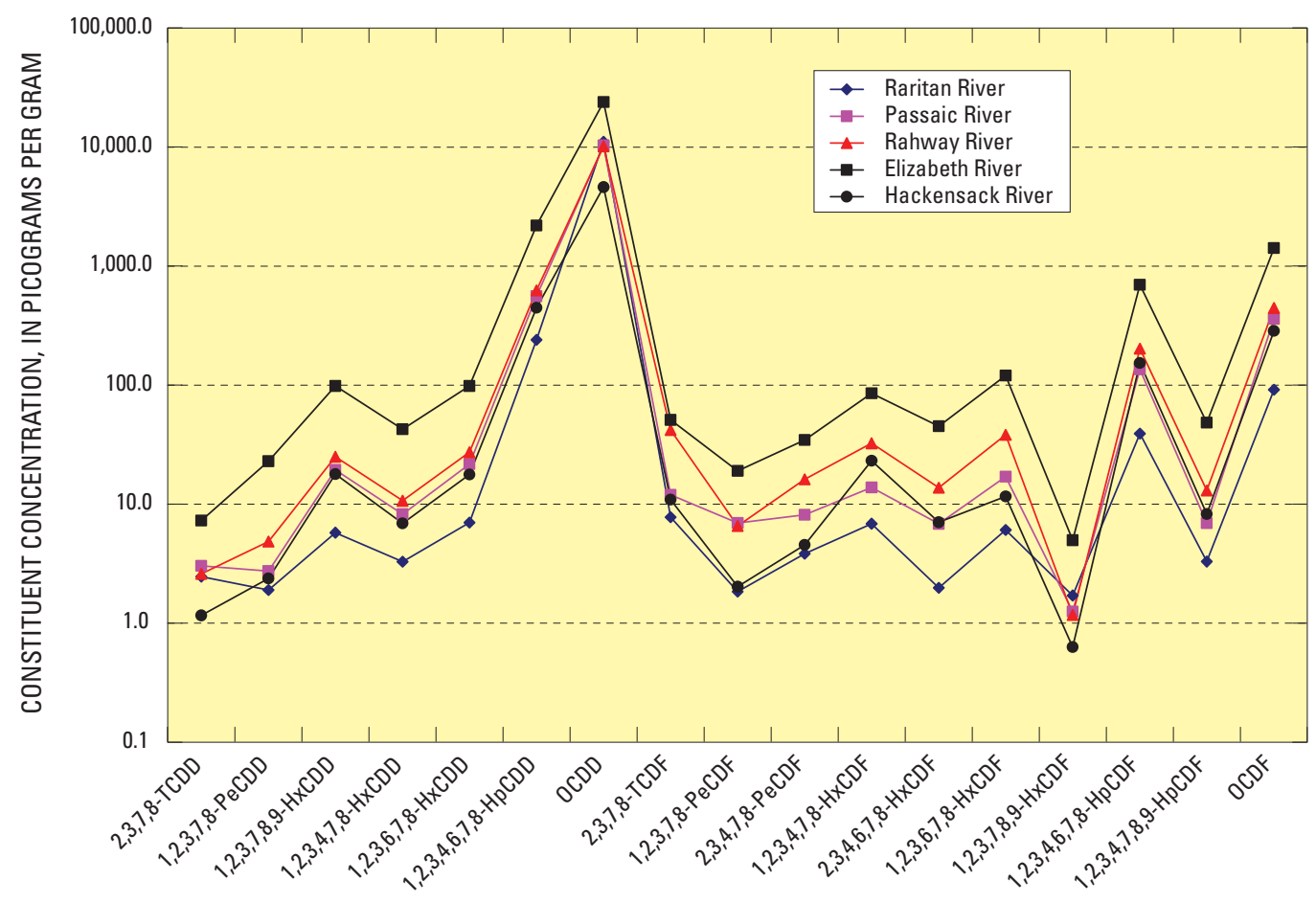

Figure 16. Concentrations of individual dioxin and difuran compounds in average sediment from selected rivers in New Jersey.

$(807 \mathrm{pg} / \mathrm{g})$, five times that in the Passaic and Hackensack Rivers (507 to $564 \mathrm{pg} / \mathrm{g}$ ) and 16 times that in the Raritan River $(163 \mathrm{pg} / \mathrm{g})$. The lowest average total concentration were in the Hackensack River $(5,100$ pg/g CDD, 501 pg/g CDF, and 5,600 $\mathrm{pg} / \mathrm{g} \mathrm{CDD}+\mathrm{CDF})$.

\section{Anomalous Concentrations}

Several samples were removed from the data set before calculating averages. The Passaic River sample collected Dec. 15,2000 was removed from the data set. As discussed previously, this sample is not considered to be representative of the river during a storm event. In addition to having anomalously elevated concentrations of total PCBs and dioxin/furans, the congener patterns (PCB and CDD/CDF) for this sample differed greatly from all other samples collected in the freshwater tributaries. On this basis, this sample was removed from the data set before calculating the average concentrations. The Hackensack River sample from Oct. 19, 2001, was removed because it was reported by the laboratory to have been contaminated by glassware. This sample was removed from the data set and is not being considered in this study. The Hackensack River sample collected Mar. 2001 from the tidal portion of the river was not included when calculating average concentrations for this river.

\section{Relation of Whole-Water Concentrations to Water-Quality Criteria}

Whole-water concentrations of dioxin/furans were calculated from the sediment data by multiplying the measured values by the geometric mean SS concentration. The resulting whole-water concentrations for total PCDD + PCDF and for the 2,3,7,8-TCDD congener are listed for each sampled event in table 19. Presently, a surface-water-quality standard ( $5 \mathrm{x}$ $10^{-9} \mu \mathrm{g} / \mathrm{L}, 0.005 \mathrm{pg} / \mathrm{L}$ ) has been set only for $2,3,7,8-\mathrm{TCDD}$ in fresh surface water and saline estuarine and coastal waters. This level is the carcinogenic effect based human-health criteria as a 70-year average concentration with no exceedance and is based on a risk level of one-in-one-million.

Only a few of the sampled events found the 2,3,7,8TCDD congener concentration to be above the EDL and the water-quality standard: the Raritan River (Mar. 21, 2002), the Passaic River (June 22, 2000, and Dec. 15, 2000), and the Elizabeth River (June 4, 2003). In all other samples, the concentration for this compound is reported as non-detectable.

Similar to PCBs, dioxins and furans strongly partition into the sediment phase in the environment. Therefore, wholewater concentrations are largely a function of the amount of suspended sediment in the river at the time of sample collection. For example, consider a sediment having a 2,3,7,8TCDD concentration of $7 \mathrm{pg} / \mathrm{g}$, slightly greater than the 


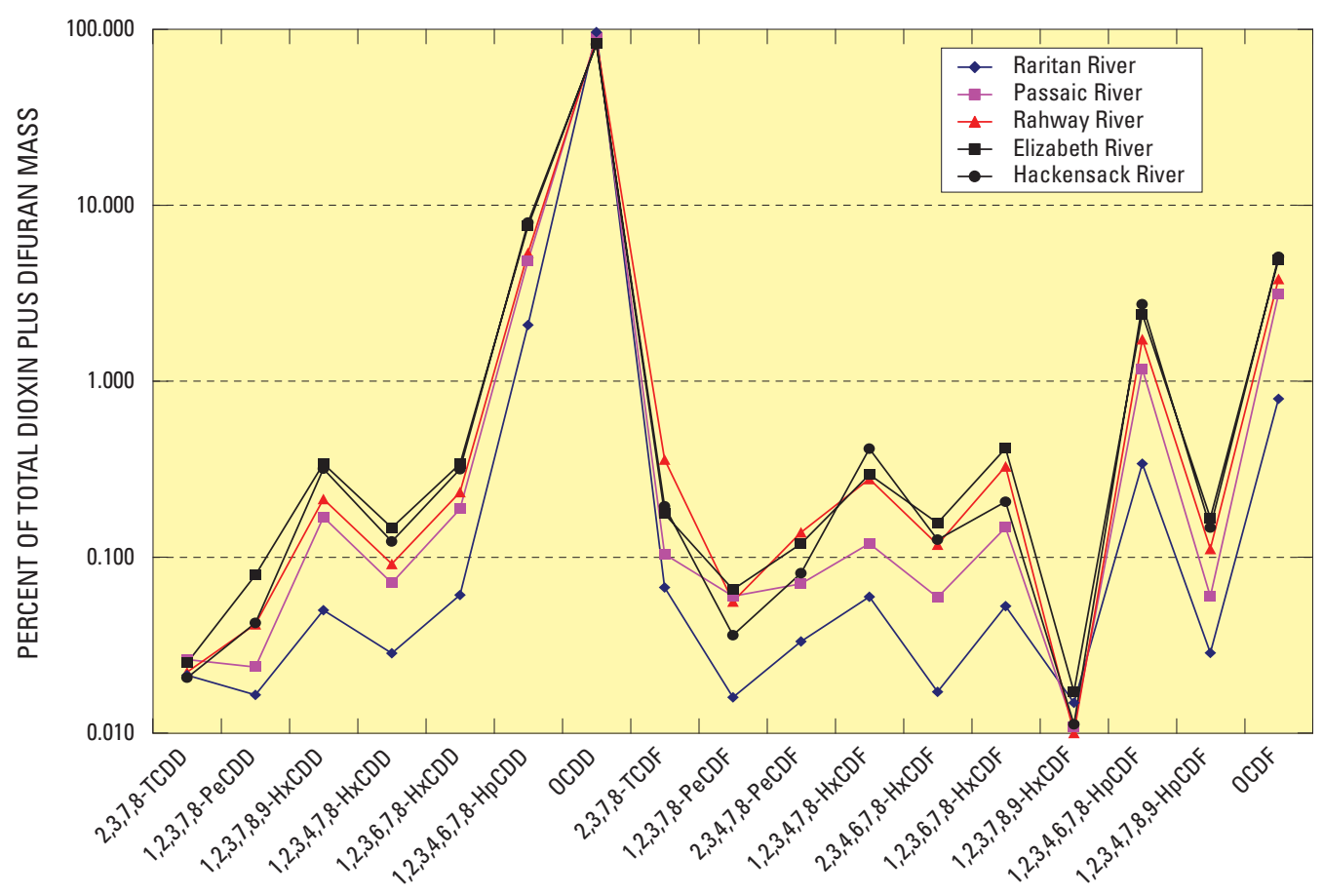

Figure 17. Average percent contribution of all 2,3,7,8-substituted dioxins and firans in sediment samples frm selected rivers in New Jersey.

average EDL for 2,3,7,8-TCDD $(6.6 \mathrm{pg} / \mathrm{g}$, the average value of non-detected concentrations, table 18). The surface-water quality standard would be exceeded whenever the SS content of river water exceeded $2 \mathrm{mg} / \mathrm{L}$ or more of SS (having a 2,3,7,8-TCDD concentration of $7 \mathrm{pg} / \mathrm{g}$ ). Concentrations of SS in excess of $2 \mathrm{mg} / \mathrm{L}$ are commonly measured in all the rivers sampled in this study even during low-flow conditions.

\section{Relative Concentrations}

The contribution of each CDD and CDF compound to the total CDD+CDF concentration in the samples, termed the relative or percent concentration, helps illustrate the differences among the various rivers and provides insight into possible sources for these compounds to the environment. Relative concentrations were calculated by dividing the average concentration of each congener by the sum of the average concentrations of CDD and CDF congeners. Care must be taken when evaluating profiles for congeners having multiple nondetected values, such as 2,3,7,8-TCDD, because the relative concentrations may represent the EDL. Generally, relative concentrations of less than 0.1 are likely to represent the detection limit rather than a measured concentration.

Two observations are made regarding the relative composition of dioxin/furans in these rivers. First, the dioxins were the dominant suite of compounds; the percentage of total
CDDs in the sediment ranged from 91 to 98 percent, and the percentage of total CDFs ranged from over 1 to near 9 percent (table 20). Secondly, CDFs in the Elizabeth and Hackensack Rivers made up a higher percentage (approximately 9 percent) of the total CDD+CDFs than in the other rivers. This may indicate a similar dioxin/furan source(s) exist in these basins. It is also interesting to note that the relative distribution of the CDD and CDF congeners in the Elizabeth and Hackensack Rivers was similar to one another (fig. 17).

The percent contribution of the individual CDD and CDF congeners to the average concentration of sediment in each river is shown in figure 17. Although the percentage each congener contributes to the weight of total CDD+CDFs may differ between rivers, the relative congener profiles were very similar in all the rivers especially for the Elizabeth and Hackensack Rivers; the lowest percentages of trace and minor components were generally in the Raritan River. OCDD was the dominant species accounting for 82 to 96 percent of the total CDD + CDF. Small (percentage) changes in the OCDD concentration caused large shifts in the percent contribution of the trace congeners. However, the similarity in contribution of each congener among the different rivers resulted in the similar patterns observed on these plots (similar changes between adjacent congeners).

Because of the overwhelming dominance of OCDD, a more unique characterization of the sediment may be found 
in the contribution of the minor congeners, those accounting for 1 to 10 percent of the total. The trace congeners, accounting for $<1$ percent of the total, may also be a useful characterization, but the contributions of these congeners can be greatly affected by analytical error and by the averaging of EDLs. Also, small differences in absolute concentration of trace components can represent a large difference in their percent contribution and will plot with a large displacement between points on a log-scale diagram. Likewise, large differences in the absolute concentrations of major components will represent a small difference in percentage but will not be represented on the log-scale plot. It is the similarity in patterns ("fingerprints") formed by the compounds (resulting from the difference in percentage between adjoining compounds) that may provide the best insight into the sediment composition.

Inspection of the average concentrations (table 20) and the concentration profiles (fig. 17) shows that the contributions of the minor and trace CDDs and CDFs were remarkably similar among the rivers. For the congeners 2,3,7,8-TCDD and $1,2,3,7,8,9-\mathrm{HxCDF}$, the similarity is the result of similar EDLs because these congeners were almost entirely not detected in the samples. The dioxin 1,2,3,4,6,7,8-HpCDD and, with the exception of the Raritan River, the furans 1,2,3,4,6,7,8HpCDF and OCDF, and (occasionally) 1,2,3,4,7,8-HxCDF were minor contributors to the total $\mathrm{CDD}+\mathrm{CDF}$ in all rivers. All the other congeners were trace contributors, accounting for 0.1 to 1 percent of the total.
Because of the dominance of the OCDD and OCDF congeners, and the fact that for several of the congeners only a few measurable values were available, a subset of the data were selected to provide a more useful "fingerprint" or congener profile for the rivers. This subset was selected on the basis of the work of Fernandez and others (2004), who showed that eight of these congeners were responsible for the majority of dixons/furans in livers of tomcod collected from the Hudson River and from Newark Bay. Atlantic tomcod, Microgadus tomcod, is a bottom-dwelling fish species in Atlantic coast estuaries. Tomcod spawn near the salt-water freshwater interface in estuaries, and although they may roam, they probably do not move into coastal waters (Fernandez and other, 2004). For the fish data collected by Fernandez and others (2004), eight congeners were responsible for 87 percent of the average $\mathrm{CDD} / \mathrm{CDF}$ toxicity as measured in the whole-fish fillets. These eight congeners were also dominant in the tissue of fish, crabs, and lobsters collected from Newark Bay and the New York Bight by Rappe and others (1991). The subset of congeners, therefore, represents the most important of the CDD and CDFs in the environment, in that these are the major congeners that accumulate in the organs of higher trophic-level aquatic organisms living in the estuary. The relative concentrations of this subset of congeners in the average sediment were recalculated and are presented in figure 18.

Although still similar among the rivers, the congener profiles generated using this subset show more displacement

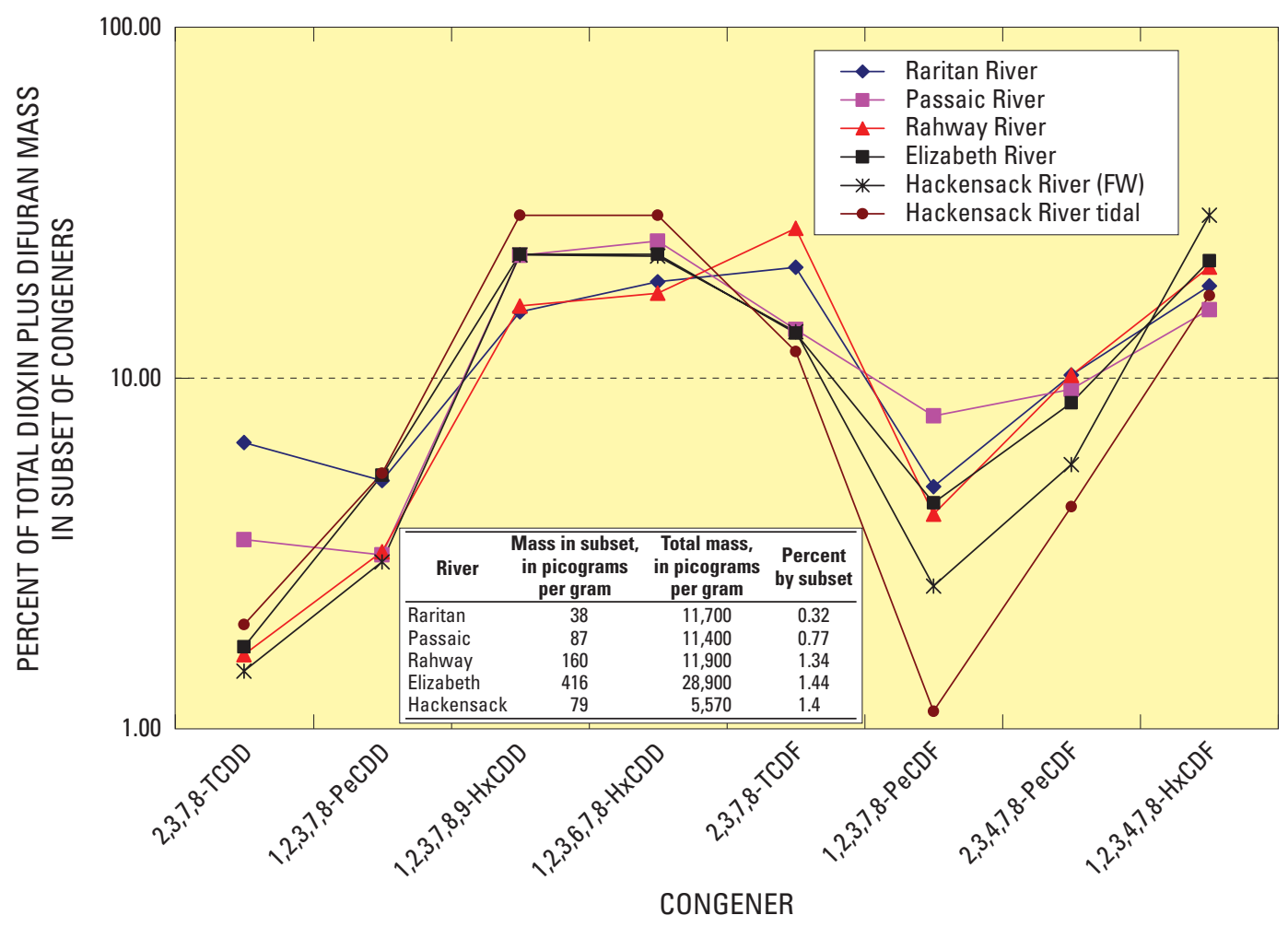

Figure 18. Average percent contribution of selected 2,3,7,8-substituted dioxin/furans in sediment samples from selected rivers in New Jersey. [These congeners were selected based on their contribution to the total dioxin/furan load in fish reported by Fernandez, 2004.] 
between rivers than did the profiles constructed using the entire CDD/CDF data set (fig. 17). For example, in the Passaic River, the $1,2,3,7,8$-PeCDF congener made up roughly 8 percent by weight of the subset; in the other rivers, its contribution ranged between 1.5 and 5 percent. Compounds such as 2,3,7,8-TCDF, 1,2,3,7,8-HxCDD and perhaps 1,2,3,4,7,8$\mathrm{HxCD}$ also show differences on this figure. The 2,3,7,8TCDD congener in the Passaic and Raritan Rivers contributed between 5 and 8 percent of the total mass of this subset, which is much greater than the approximately 2 percent contribution in the other rivers. It must be recalled, however, that the contribution of this congener in the rivers is mainly the result of the detection level reached in the analytical methods. As described below, the 2,3,7,8-TCDD and 1,2,3,7,8-PeCDD congeners are the most toxic of the CDD/CDFs and are followed by the 2,3,4,7,8-PeCDF congener. When recast using this subset, this latter congener represented between 5 and 11 percent of the mass.

\section{Concentrations During Stormflow and Low Flow}

Relative congener profiles were developed for each sample in order to discern if differences existed in the composition of sediment transported under low-flow and storm discharge (figs. 19 to 23). The following observations are made regarding the composition of sediment transported during storms:
- Raritan River - The low-flow sample collected Oct. 4, 2001, had higher percentages of the trace dioxin congeners than were present in the other samples collected from the Raritan River (fig. 19). This is because of the low concentration (and percent contribution) of OCDD in this sample compared with that of the OCDD in the other samples. The percent contribution of OCDD and the trace congeners in the other low-discharge sample (collected June 22, 2000) were very similar to the contribution in the storm samples except for the sample from Apr. 13, 2001. The storm sample collected on Apr. 13, 2001, also had a different trace-congener profile from the other samples; the percentage of penta-CDD, hexa-CDD, penta-CDF, and hexa-CDF compounds were much lower than the percentages in other samples collected from this river. The absolute concentrations of the congeners, with the exception of OCDD, were also lower in this sample, with many being reported as non-detected. Close inspection shows that the detection limits, however, were higher for this sample than in any other sample. OCDD in this sample was at the highest concentration of any of the samples collected in this river, which, together with the low concentrations of the other congeners, explains the different relative concentration profile for this sample.

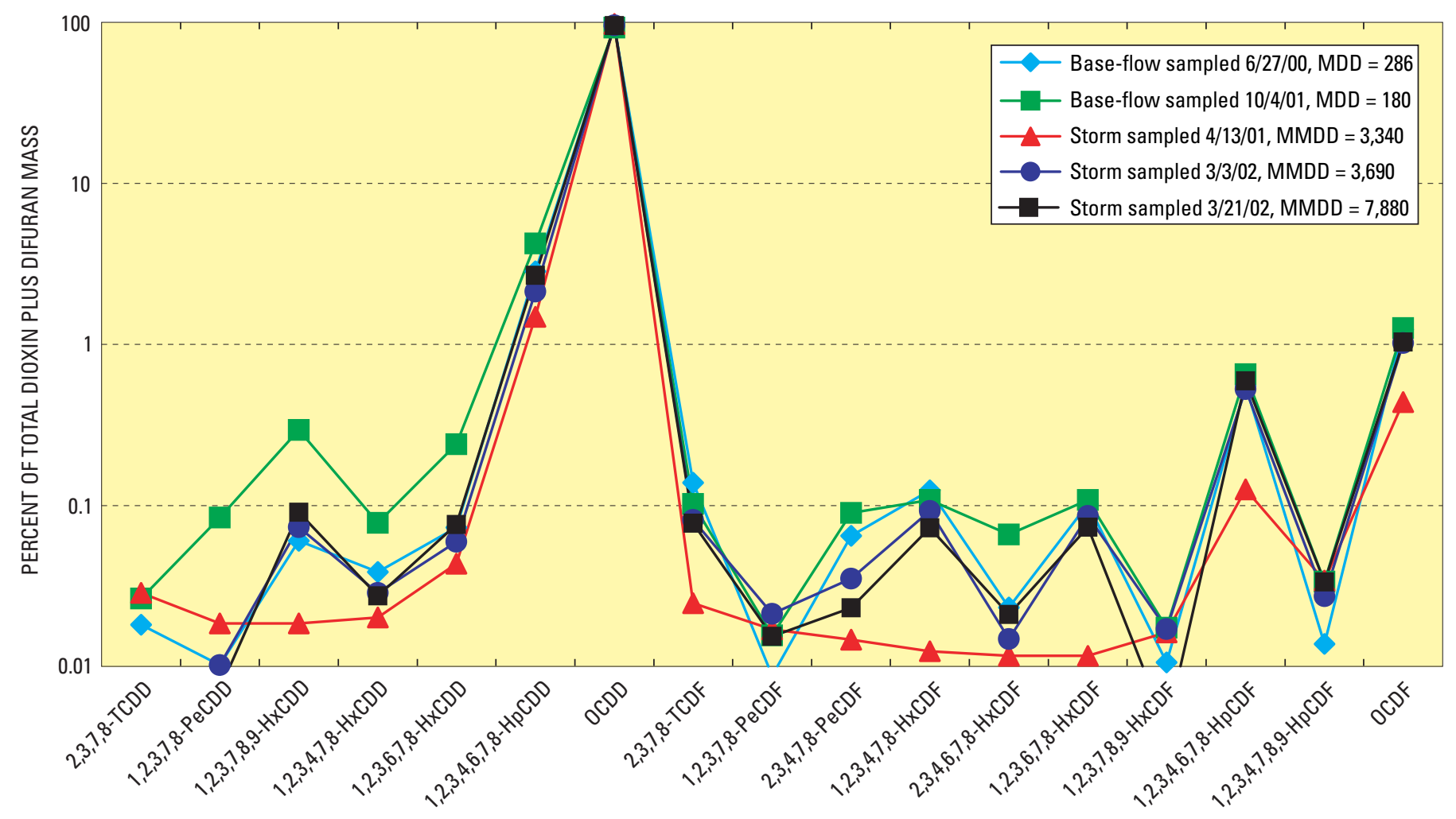

Figure 19. Percent contribution of individual dioxins and difurans congeners in samples from the Raritan River, New Jersey. [MDD, mean daily discharge, in cubic feet per second; MMDD, maximum mean daily discharge reached during event] 
- Passaic River-All samples, except the one collected on Dec. 15,2000 , had a very similar composition (fig. 20). The Dec. 15, 2000, sample is clearly different, having much higher percentages of 2,3,7,8-TCDD (approximately 1 percent), 2,3,7,8-TCDF and the penta-CDF and hexa-CDF compounds. This observation is consistent with the unique PCB composition of this sample, described earlier. The cause for the higher relative concentrations of the dioxins and PCBs is unknown at present and may be an artifact of timing of the collection of this sample (favoring capture of finegrained materials) or of lab contamination.

- Rahway and Elizabeth Rivers-The composition of sediment was similar among these rivers, and within each river, the composition was similar among low-flow and storm discharge samples (figs. 21 and 22). The concentrations of CDDs and CDFs in the Elizabeth River were much higher than present in the other rivers, especially for OCDD in the June 4, 2003, sample from the Elizabeth River, which had OCDD concentrations two to three times greater than in any other sample.

- Hackensack River-The congener profile of the sediment collected from the Oradell Reservoir outfall had a very similar profile to that of the sediment collected downstream of the lower dam (sample HAC4) (fig. 23).

\section{Sources of Dioxins and Furans}

The relative-concentration congener profiles may provide insight into the source(s) of the dioxins and furans and also serve as a baseline for evaluating changes in the sediment chemistry of the river as it moves into the estuary. The dioxin/ furan chemistry of the sediment is the result of emissions, atmospheric deposition, and other sources present in the local river basins and throughout the region as well. Comparing the congener profiles to the profiles for the various sources may provide insight to the source(s) and pathways that affect $\mathrm{CDD} / \mathrm{F}$ in the environment and in river sediments (Naf and others, 1992; Fiedler and others, 1995; Wenning and others, 1992; and Wenning and others, 1993). The similarity between the congener profiles for each basin (figs. 16 and 17) suggests common, region-wide source(s) dominate over localized processes. Cleverly and others (1997) constructed dioxin/furan profiles for many different emission sources using the USEPA Dioxin Database (U.S. Environmental Protection Agency, 2001). Profiles were presented for sources including municipal, medical, and hazardous-waste incinerators; cement kilns burning hazardous wastes; oil-fired industrial burners; coal- or wood-fired burners; automobile engines burning unleaded fuel; truck engines burning diesel fuel; secondary aluminum smelters; and sewage sludge incinerators. Profiles were also presented for liquid effluent from bleached chlorine paper pulp mills and trace dioxin/furan content of laboratory grade

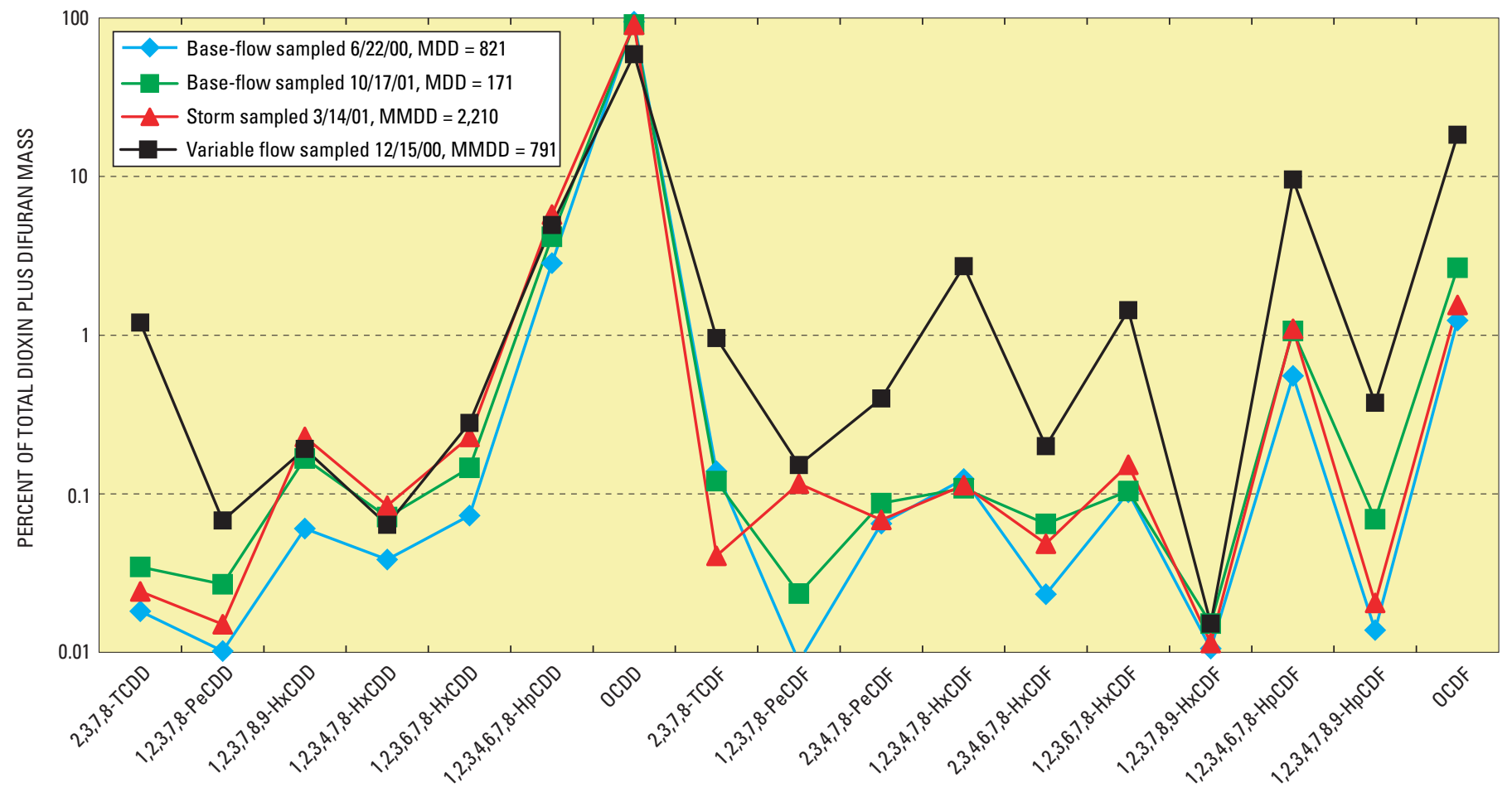

Figure 20. Percent contribution of individual dioxin and difuran congeners in sediment samples from the Passaic River, New Jersey. [MDD, mean daily discharge, in cubic feet per second; MMDD, maximum mean daily discharge reached during event] 


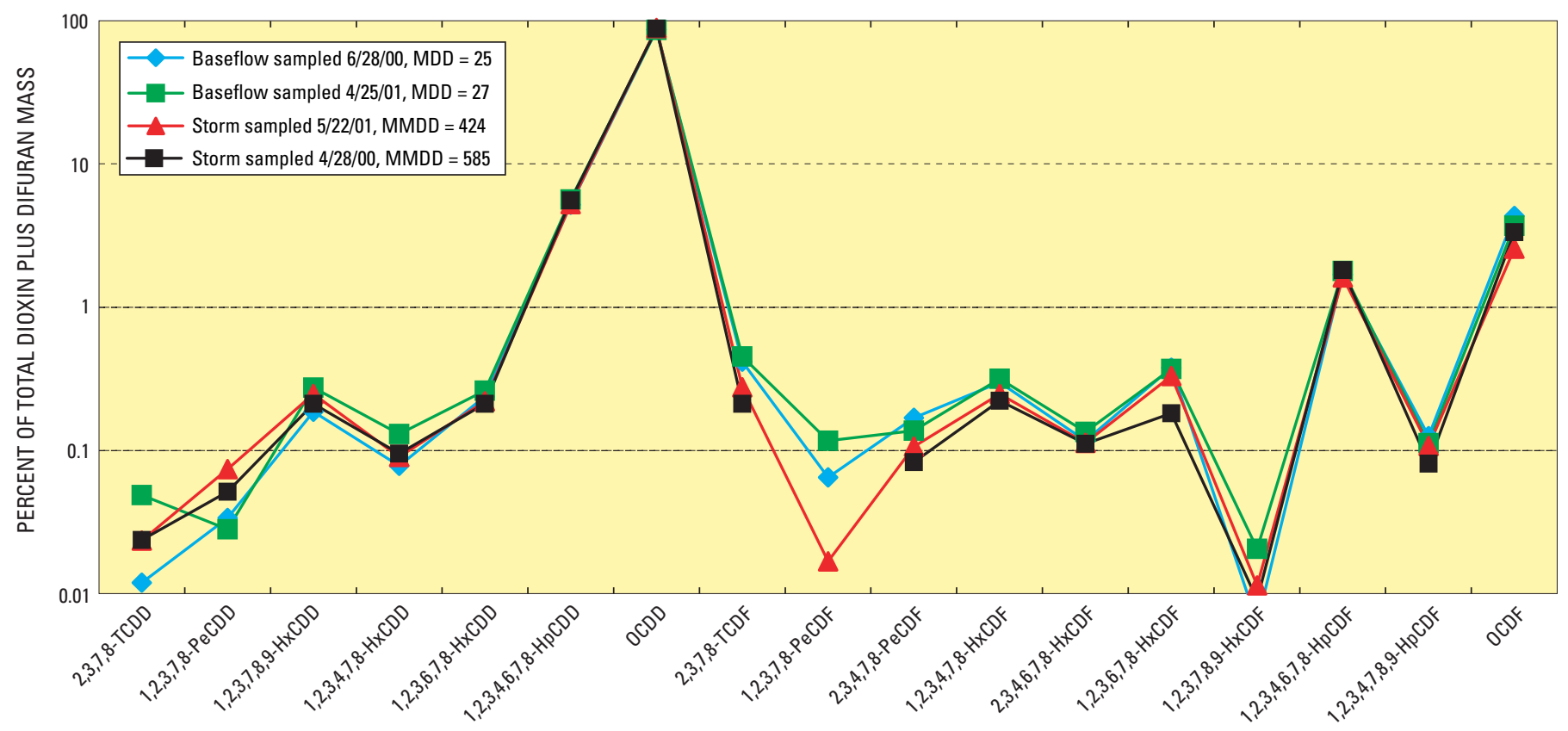

Figure 21. Percent contribution of individual dioxin and difuran congeners in sediment samples from the Rahway River, New Jersey. [MDD, mean daily discharge, in cubic feet per second; MMDD, maximum mean daily discharge reached during event]

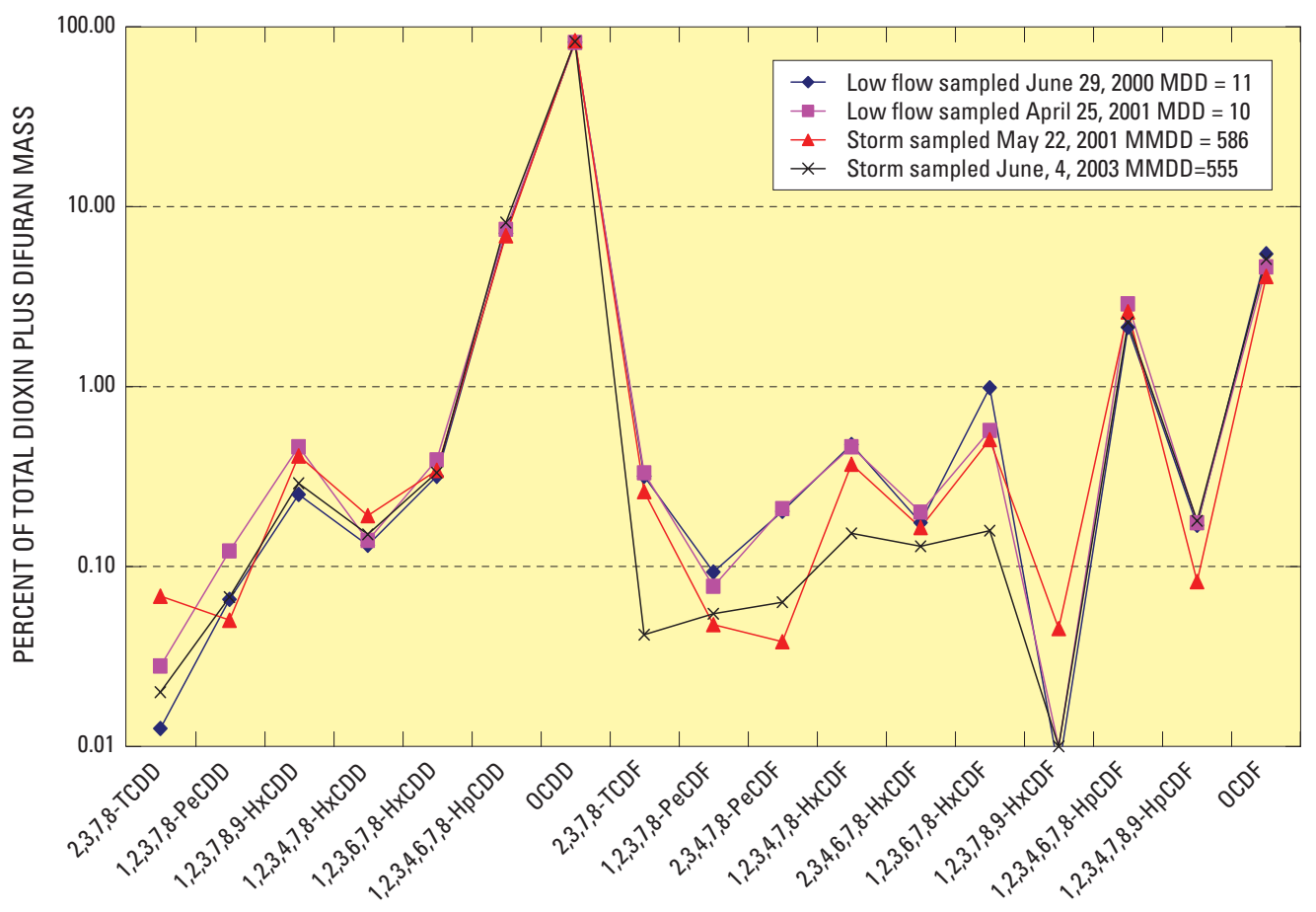

Figure 22. Percent contribution of individual dioxin and difuran congeners in sediment samples from the Elizabeth River, New Jersey. [MDD, mean daily discharge, in cubic feet per second; MMDD, maximum mean daily discharge reached during event] 


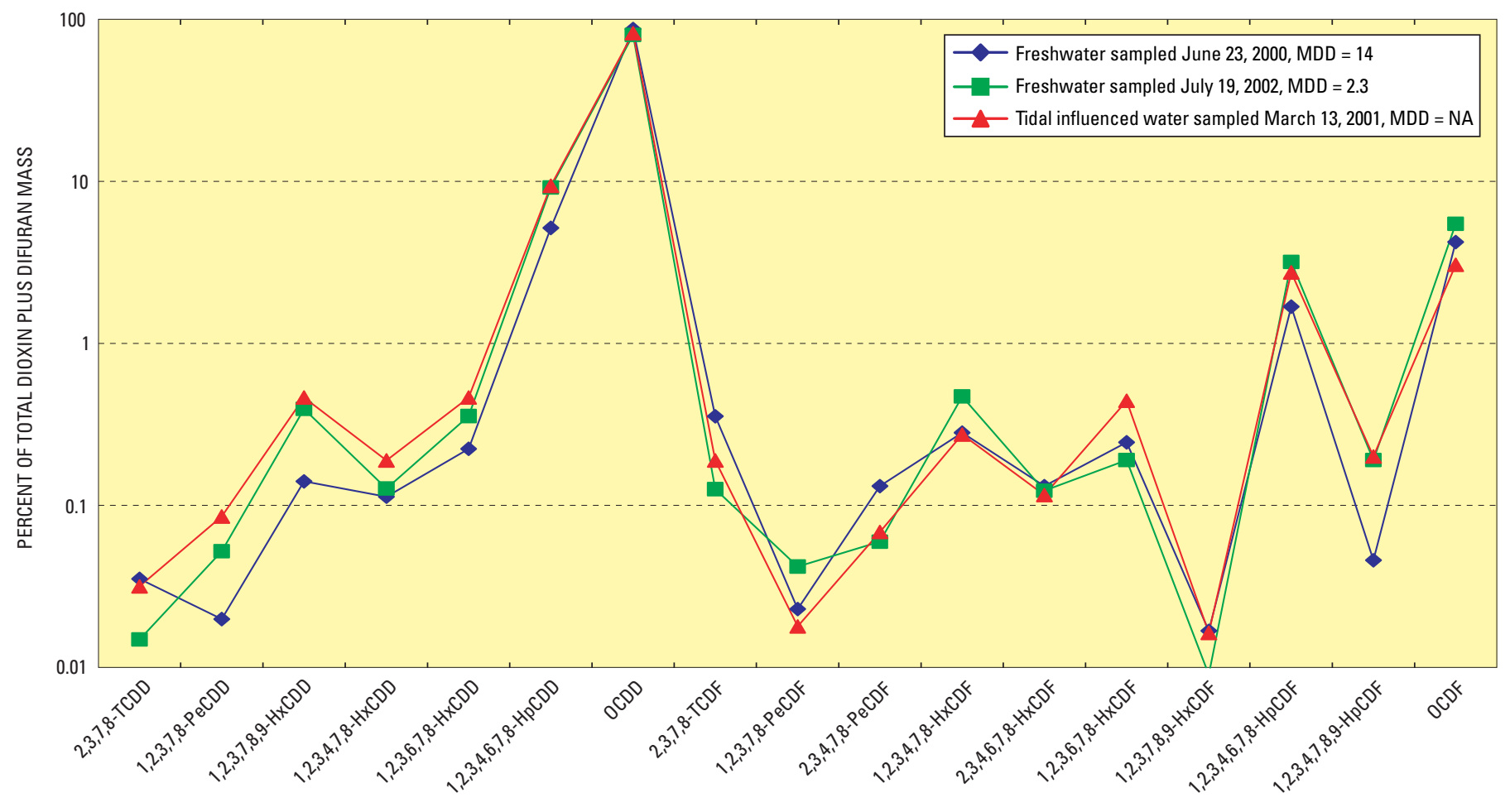

Figure 23. Percent contribution of individual dioxin and difuran congeners in sediment samples from the Hackensack River, New Jersey. [MDD, mean daily discharge, in cubic feet per second; NA, not applicable]

pentachlorophenol and in the various esters and salts of the defoliant 2,4-D and 2,4-T.

The concentration profiles for the river sediments were compared graphically with the profiles presented by Cleverly and others (1997) to determine if a single, dominant source profile was evident. The river sediment profiles do not match any single source profile exactly for all compounds, suggesting that multiple sources of CDD/CDF exist in the New Jersey area. However, the emission produced by diesel-fuel powered heavy truck engines (sampled as gas in Baltimore Harbor tunnel) (fig. 24) has a similar profile to the sediment profiles for many of the congeners, except that the emission pattern is displaced upwards from the sediment pattern. This offset can be explained by the greater percentage of OCDD in the river sediment than in the diesel emission (fig. 25).

Upon close inspection, other subtle differences were found; for example, a slightly higher percentage of 2,3,7,8TCDD; 1,2,3,5,6,7,8-HxCDD; 2,3,4,6,7,8-HxCDF; and $1,2,3,7,8,9-\mathrm{HxCDF}$ existed in the diesel-engine emission profile (fig. 25). Higher concentrations of hexa- and penta-CDD isomers were found in the emissions of waste incineration (Thomas and Sprio, 1996), a source that may have affected sediment in these river basins as well. The general similarity in profile shapes indicates that diesel-engine emissions may be a major contributor to the dioxins and furans in these rivers, while the differences in patterns indicate other sources must also contribute, and/or that the CDD/CDF have been degraded (Naf and others, 1992; Fiedler and others, 1995; Wenning and others, 1992; Wenning and others, 1993). It has been noted by several researchers that $\mathrm{CDD} / \mathrm{CDF}$ congener concentrations can be affected by dechlorination reactions involving natural bacteria (Albrecht and others, 1999; Barkovskii and Adriaens, 1996). 


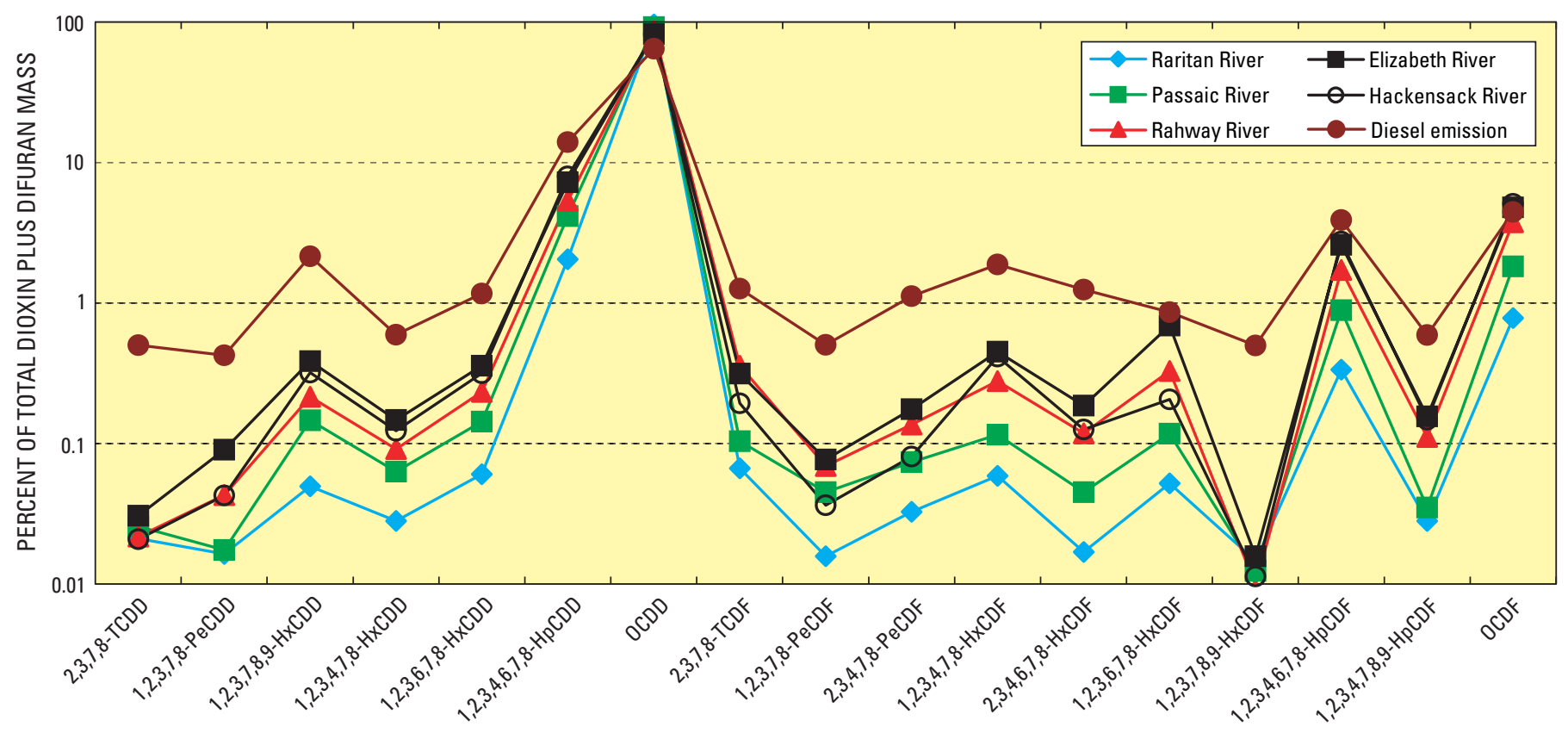

Figure 24. Congener profiles of dioxin and difuran congeners in average river sediments from selected rivers in New Jersey, and in diesel engine emission.

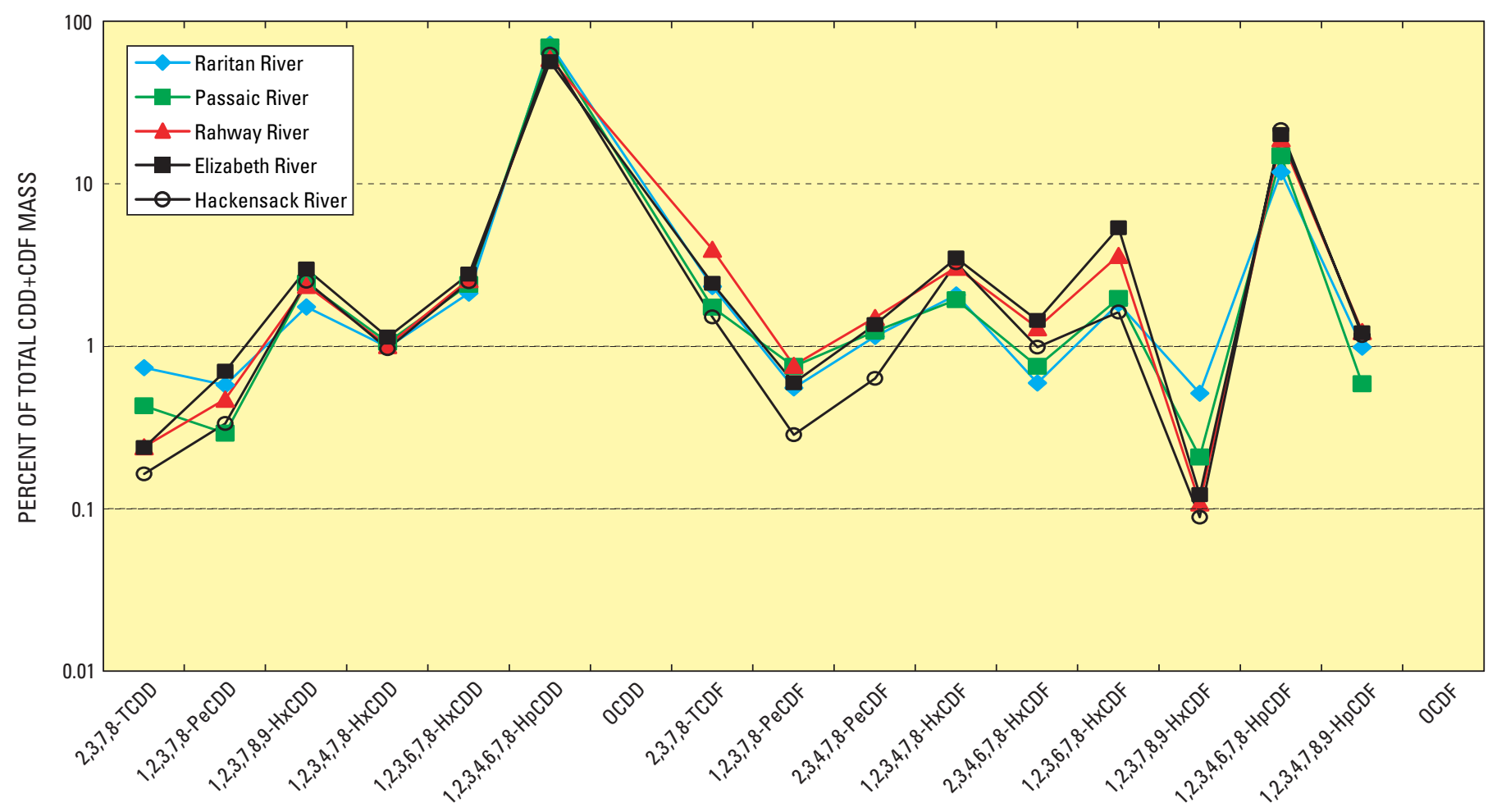

Figure 25. Congener profiles of dioxin and difuran congeners in average river sediments from selected rivers in New Jersey, and in diesel engine emission with the octa-chlorinated compounds removed. 


\section{Sediment Toxicity}

The toxicity of the sediment caused by the presence of dioxins, furans, and dioxin-like PCBs (Safe, 1990) can be estimated using the toxic equivalencies (TEQ) calculated for each sample. TEQs are calculated by multiplying the concentrations of the individual CDD and CDFs by a compound-specific toxic equivalency factor (TEF). The individual compound TEQs are then summed to obtain an overall TEQ for the sample:

$$
T E Q=\Sigma\left(T E F_{n} * C_{n}\right)
$$

where

$$
\begin{aligned}
T E Q= & \text { toxic equivalencies, in units of pictogram } \\
& \text { per gram as 2,3,7,8-TCDD; } \\
T E F_{n}= & \text { toxic equivalency factor for compound } \mathrm{n} ; \\
C_{n} \quad= & \begin{array}{l}
\text { concentration of compound } \mathrm{n}, \text { in picogram } \\
\text { per gram. }
\end{array}
\end{aligned}
$$

and

The TEFs used in this work (table 21) are from the World Health Organization (VanLeeuwen, 1997). The TEQ procedure is based on assigning a TEF of 1 for the 2,3,7,8-TCDD compound, and a value less than unity for other CDD and CDFs (and dioxin-like co-planar PCBs) (VanLeeuwen, 1997). TEF values are assigned on the basis of the relative toxicity of the compound, as determined from studies that have determined

\begin{tabular}{|c|c|}
\hline Compound & $\begin{array}{c}\text { Toxic equivalency } \\
\text { factor }^{1}\end{array}$ \\
\hline 2,3,7,8-Tetra-CDD & 1 \\
\hline 1,2,3,7,8-Penta-CDD & 1 \\
\hline 1,2,3,7,8,9-Неха-CDD & .1 \\
\hline 1,2,3,4,7,8-Hexa-CDD & .1 \\
\hline 1,2,3,6,7,8-Неха-CDD & .1 \\
\hline 1,2,3,4,6,7,8-Hepta-CDD & .01 \\
\hline Octa-CDD & .0001 \\
\hline 2,3,7,8-Tetra-CDF & .1 \\
\hline $1,2,3,7,8$-Penta-CDF & .05 \\
\hline 2,3,4,7,8-Penta-CDF & .5 \\
\hline 1,2,3,4,7,8-Hexa-CDF & .1 \\
\hline 1,2,3,6,7,8-Hexa-CDF & .1 \\
\hline 2,3,4,6,7,8-Hexa-CDF & .1 \\
\hline 1,2,3,7,8,9-Hexa-CDF & .1 \\
\hline 1,2,3,4,6,7,8-Hepta-CDF & .01 \\
\hline 1,2,3,4,7,8,9-Hepta-CDF & .01 \\
\hline Octa-CDF & .0001 \\
\hline
\end{tabular}
the toxic effects to aquatic and benthic organisms caused by exposure to different concentrations of the CDD and CDFs. For example, it has been found that $10,000 \mathrm{pg}$ of OCDD will

Table 21. Toxic equivalency factors for 2,3,7,8-substituted dioxins and furans. produce the toxic effects equivalent to $1 \mathrm{pg}$ of 2,3,7,8-TCDD; therefore, the TEF for OCDD is $1 / 10,000$ or 0.0001 .

The average composition for each river, determined from low-flow and storm samples (table 20), was multiplied by the respective TEF value (table 21) to obtain an average TEQ for each river (table 22). The Passaic River sample from Dec. 2000, and the Hackensack River sample (tidal) collected on Mar. 2001, were not included when average TEQs were calculated. For the purpose of calculating average concentrations, all nondetected concentrations were replaced by one-half the respective sediment-mass normalized detection limit. Because the compounds most commonly not detected are also the compounds with the highest TEF factors (2,3,7,8-TCDD and $1,2,3,7,8$-PeCDD), substantial amounts of the calculated sediment toxicity may be the result of analytical detection levels. This occurs in spite of the fact that the analytical procedures used in this work, and the large masses of sediment collected, provided the lowest possible achievable detection levels.

The average total TEQs (total toxicity from CDD + CDF compounds) ranged from $14 \mathrm{pg} / \mathrm{g}$ in the Raritan River up to $135 \mathrm{pg} / \mathrm{g}$ in the Elizabeth River (table 22), demonstrating that dioxin/furan toxicity existed in the sediment from all rivers studied. For reference, Ehrlich and others (1994) reported total TEQs for bottom-sediment samples from the upper Passaic River (collected from the pond above Dundee Dam) ranged from 2.3 to $156 \mathrm{pg} / \mathrm{g}$, which are similar to the values calculated in this study. They also reported TEQs for bottom sediment from the lower estuary of the Passaic River up to $5,458 \mathrm{pg} / \mathrm{g}$.

The contribution to the total TEQ by each of the individual dioxin and furan compounds differed among the rivers and can be shown by calculating the relative percentage of the total TEQ contributed by each CDD or CDF compound (table 22). TEQ congener profiles can be plotted to demonstrate the differences that existed among the rivers (fig. 26). These profiles are similar to the concentration-based congener profiles presented earlier but may be more unique to each river because the dominance of OCDD is removed (fig. 17).

The dioxin and furan compounds contributed roughly equally to the toxicity of these sediments; the dioxin congeners contributed from 48 percent of the TEQ in the Rahway River to a maximum of 68 percent in the Raritan River. The individual congeners can be classified as being major contributors to the toxicity if they contribute 10 or more percent of the total, minor contributors if they represent between 5 and 10 percent, and trace if they represent less than 5 percent of the total TEQ. Using this scheme, the following compounds were major contributors to the sediment toxicity in each river:

1. Raritan River: 2,3,7,8-TCDD; 1,2,3,7,8-PCDD; 2,3,4,7,8PCDF; and 1,2,3,4,6,7,8-HpCDD.

2. Passaic River: 1,2,3,4,6,7,8-HpCDD; 2,3,4,7,8-PeCDF; and 2,3,7,8-TCDD, 1,2,3,7,8-PeCDD.

3. Rahway River: 2,3,4,7,8-PeCDF; 1,2,3,4,6,7,8-HpCDD; and 1,2,3,7,8-PCDD, 2,3,7,8-TCDF. 


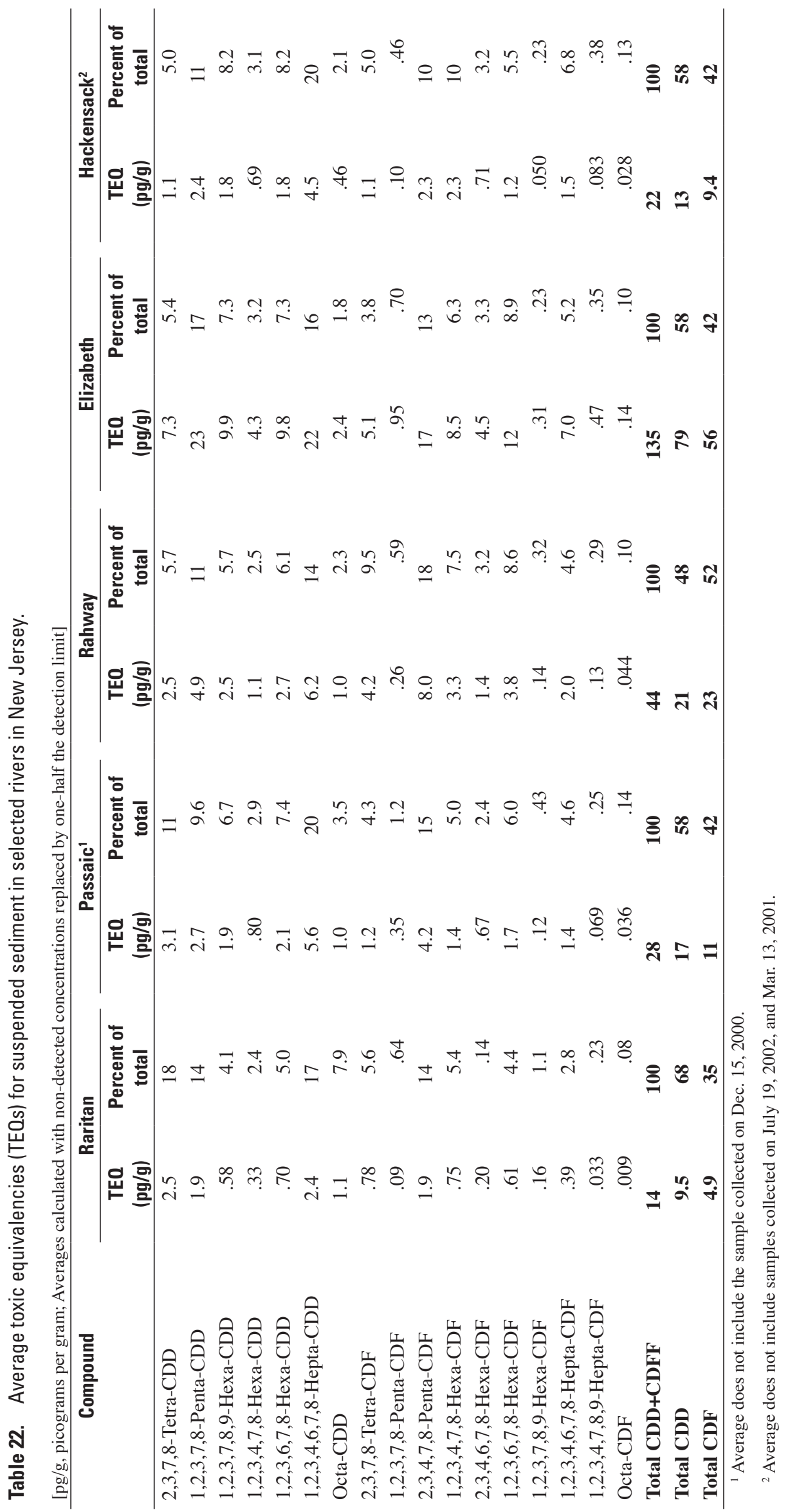




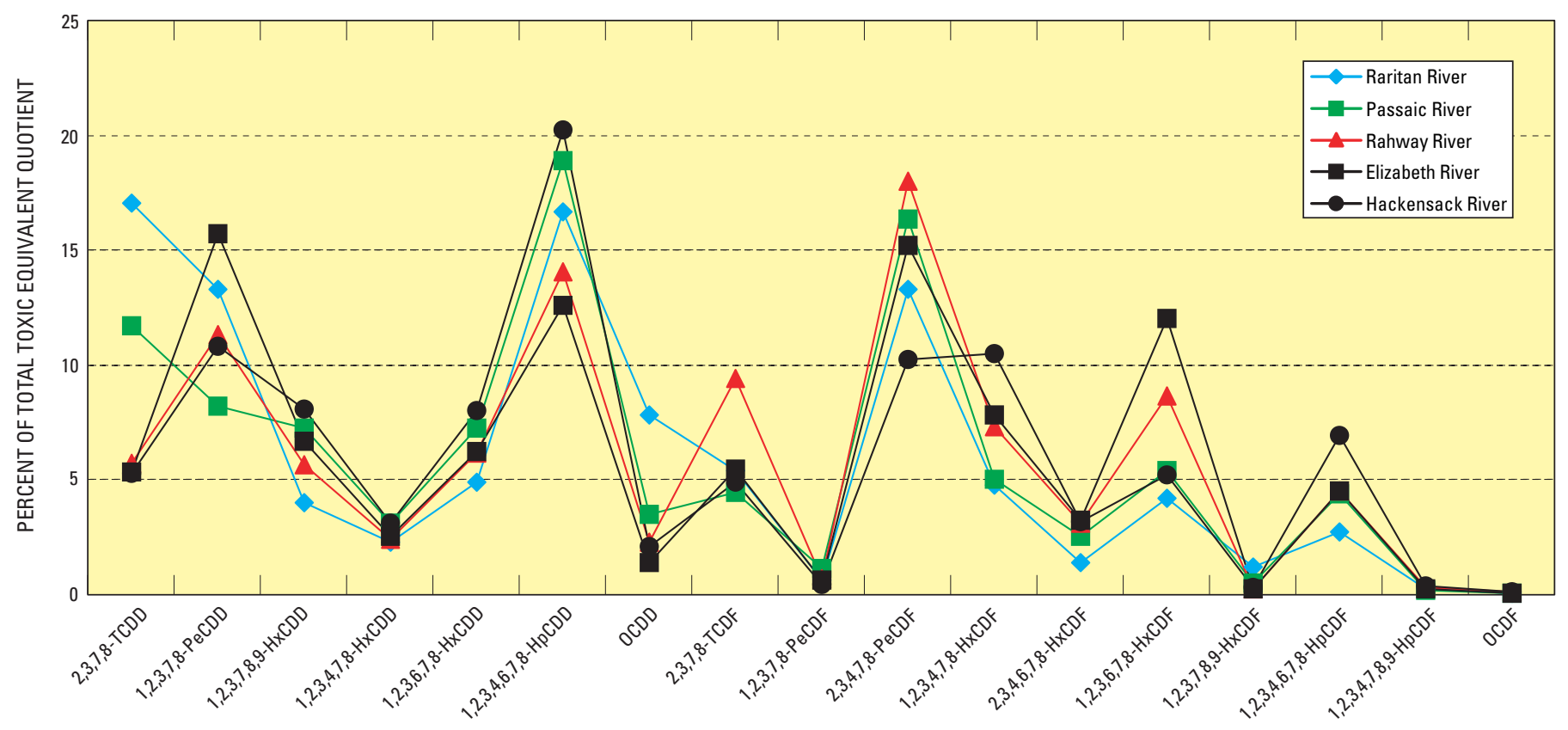

Figure 26. Percent contribution of all 2,3,7,8-substituted dioxin and difuran congeners to the toxic equivalencies (TE0) calculated for average sediment from selected rivers in New Jersey.

4. Elizabeth River; 1,2,3,7,8-PeCDD; 2,3,4,7,8-PeCDF; $1,2,3,4,6,7,8-\mathrm{HpCDD}$.

5. Hackensack River: 1,2,3,4,6,7,8,-HpCDD; $1,2,3,7,8-$ PeCDD; 2,3,4,7,8-PeCDF; and 1,2,3,4,7,8-HxCDF.

Again, it is important to note that several of the major contributors to sediment toxicity, such as 2,3,7,8-TCDD and $1,2,3,7,8-\mathrm{PeCDD}$, were not detected in the samples, and their contribution to sediment toxicity was the result of using onehalf the EDLs as surrogate concentrations in the calculations.

As described previously, a subset of eight congeners were the major contributors to the toxic body-burden of Tomcod collected from Newark Bay and the Hudson River estuary reported by Fernandez and others (2004). Using this subset, a congener profile "fingerprint" was developed (fig. 27) that removed the dominance of the OCDD and OCDF congeners, the compounds that contributed over 90 percent of the total 2,3,7,8-substituted mass in the tributary sediment. The dominance of these two compounds is removed when the relative TEQ values are considered, because of the very small TEF constants for the octa-chlorinated compounds (table 21). The eight congeners selected from the fish data contributed a majority of the toxicity of the sediment (61 to 71 percent of the total TEQ) (fig. 27). Again, the contribution of two of the congeners $(2,3,7,8$-TCDD and 1,2,3,7,8-PeCDD) are the result of replacing their nondetected values with $1 / 2$ the EDL. The selection of a subset of congeners increased the apparent contribution of these congeners to the toxicity profile of the sediment. However, one additional congener contributed substantially (14 to 20 percent) to the sediment toxicity $(1,2,3,4,6,7,8-\mathrm{HpCDD})$ but was not a major contributor to the fish toxicity. 1,2,3,4,6,7,8-HpCDD contributed, on average, 0.3 percent of the total TEQ and 7.8 percent of the total CDD+CDF mass in the fish collected by Fernandez and others (2004). Apparently, this hepta-chlorinated congener is not readily accumulated by these fish. The large TEQ this congener contributed to the total TEQ of the freshwater sediment (fig. 27) indicates it should be considered in the subset used to represent and study the $\mathrm{CDD} / \mathrm{CDF}$ profile of the river and estuary sediment.

An important observation regarding the dioxin/furan toxicity values is that the high percentage of $2,3,7,8$-TCDD in the Passaic and Raritan Rivers (10-15 percent) results from only one sample from each river. During other sampling events, this congener was not present. 1,2,3,7,8-penta-CDD; 1,2,3,4,6,7,8-Hepta-CDD; and 2,3,4,7,8-Penta-CDF are present in each river in all samples and represent the principle source of toxicity in these rivers. Further sampling would be needed to verify the presence of 2,3,7,8-TCDD in the Passaic and Raritan Rivers.

Toxicity also comes from the presence of dioxin-like PCBs. As discussed earlier, TEF values have been generated for the 13 co-planar PCBs and can be used to generate a TEQ for the PCB compounds (Safe, 1990) (table 23). Average TEQs from co-planar PCBs ranged from $5.3 \mathrm{pg} / \mathrm{g}$ in the Hackensack River up to $66 \mathrm{pg} / \mathrm{g}$ in the Elizabeth River. When combined with the dioxin/furan TEQs, total average TEQ values 


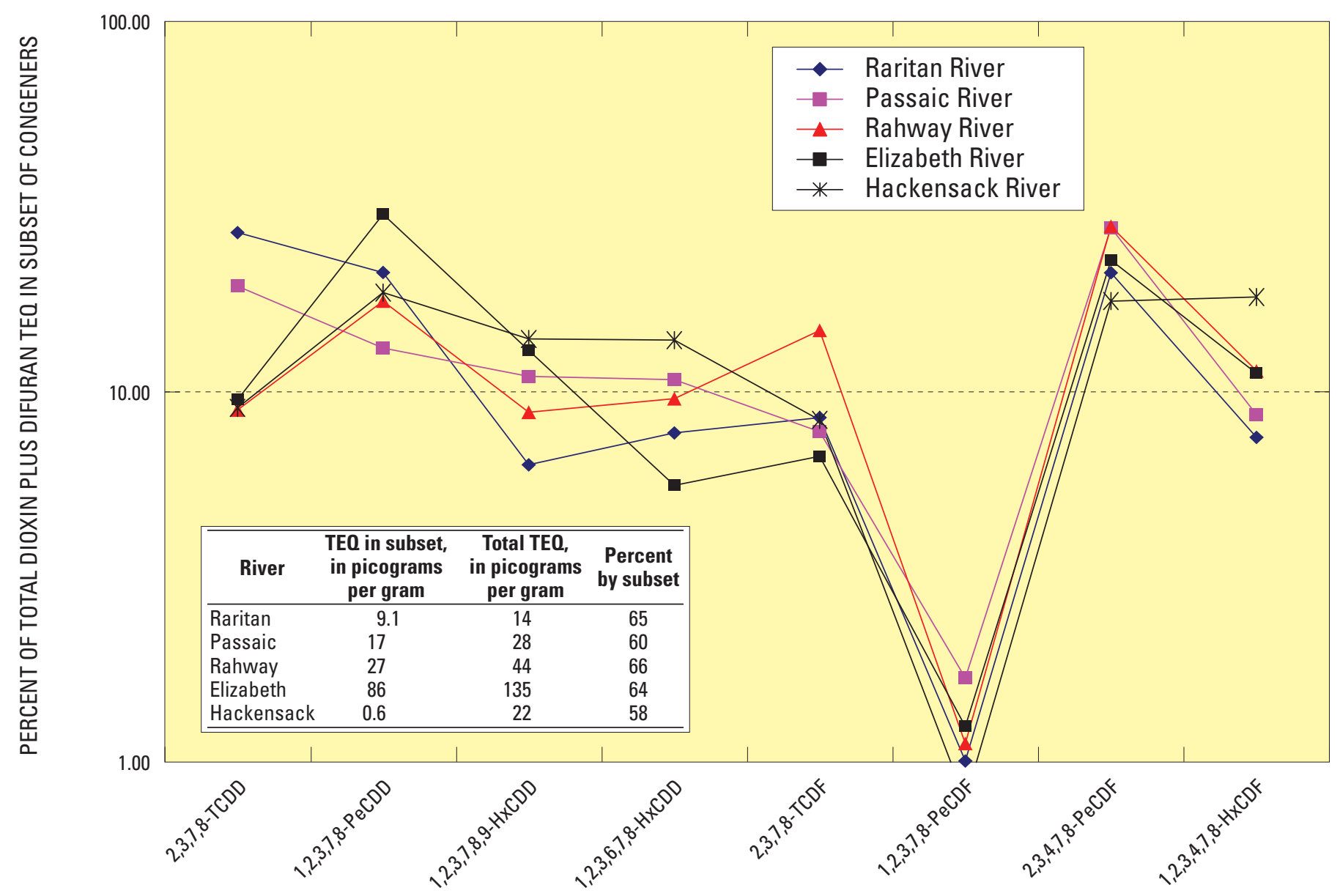

Figure 27. Percent contribution of selected 2,3,7,8-substituted dioxin and furan congeners to the toxic equivalencies (TE0) calculated for average sediment from selected rivers in New Jersey.

ranged from $20 \mathrm{pg} / \mathrm{g}$ in the Raritan River up to $201 \mathrm{pg} / \mathrm{g}$ in the Elizabeth River. The percentage of the total TEQ due to coplanar PCBs ranged from 20 percent in the Hackensack River up to 33 percent in the Elizabeth River (table 23). Similar to the dioxin/difurans, the toxicity calculated here for several of the PCBs, for example, \#81, \#126, and \#169, is the result of using one-half the EDL values for non-detected congeners.

\section{Polycyclic Aromatic Hydrocarbons}

The concentrations of 24 PAHs, including the 16 classified by the USEPA as priority pollutants, were measured in water and suspended sediment from the Raritan, Passaic, Rahway, Elizabeth, and Hackensack Rivers, the major tributaries to the Newark and Raritan Bays. Concentrations were measured in large-volume, flow-weighted composite samples of sediment and composite grab samples of water collected during low-flow and storm discharges. These data are used to make interpretations and to calculate riverine loads of PAH compounds to Newark and Raritan Bays from the watersheds above the HOT.

The PAH compounds consist of multiple $(2,3,4,5,6$, or more) aromatic rings fused together by shared carbon atoms (fig. 28). Naphthalene, the simplest of the joined aromatic structures, consists of two joined aromatic rings and forms the primary structure for the heavier PAHs. The larger PAHs have linear and block-like structures formed by the fusion of multiple rings. Several PAHs have isomers, for example, benzo(a)anthracene and chrysene, that contain four aromatic rings in different structural arrangements. Other important isomers include anthracene and phenanthracene (three rings), flouranthene and pyrene (four rings), benzo(b)flouranthene and benzo(a)pyrene (five rings), and indeno(1,2,3-cd)pyrene and benzo(ghi)perylene, which have six rings. Isomers are distinguished by the addition of letters such as (a), (b), (j), (k) or (ghi) that identify the different structures. PAHs such as naphthalene and phenanthrene may also be amended with alkyl-groups, typically one to three methyl, ethyl, or propyl 


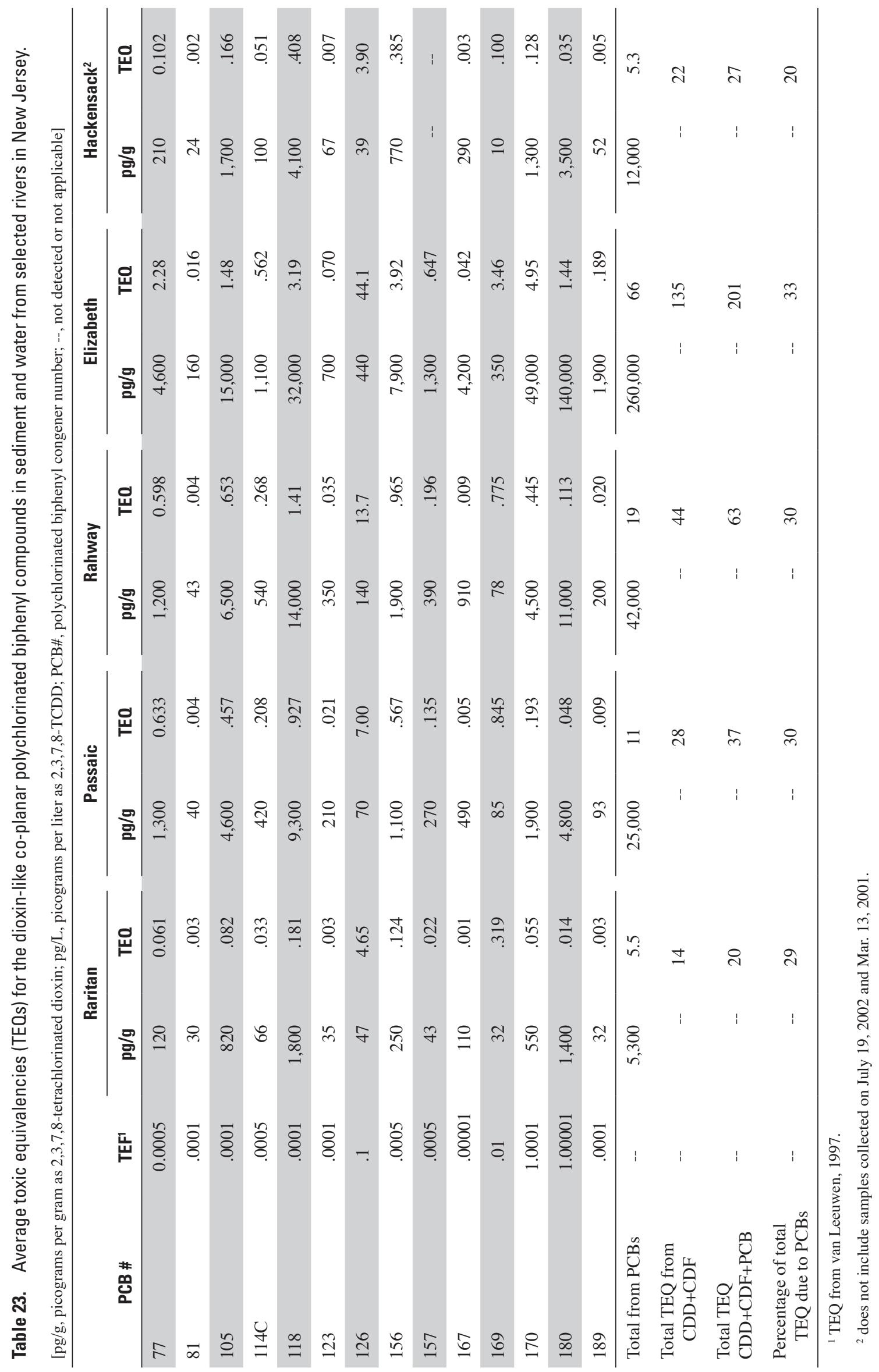




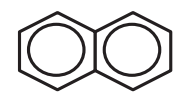

Naphthalene

MW 128.16 CAS 91-20-3

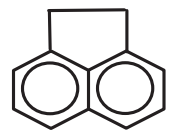

Acenaphthene MW 154.2 CAS 83-32-9

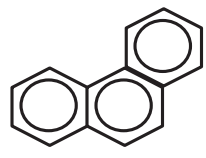

Phenanthrene MW 178.23 CAS 85-01-8

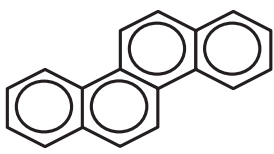

Chrysene

MW 228.2 CAS 218-01-9

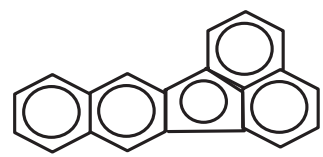

Benzo[k]fluoranthene MW 252 CAS 70-08-9

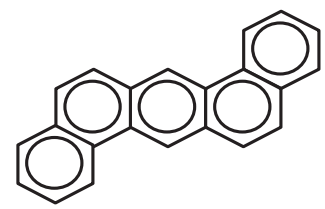

Bibenz[a,h]anthracene MW 278.32 CAS 53-70-1

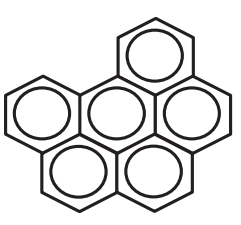

Benzo[g,h,i]perylene MW 276 CAS 191-24-2

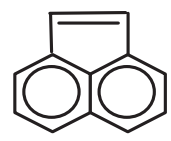

Acenaphthylene MW 152.2 CAS 208-96-8

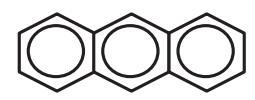

Anthracene MW 178.23 CAS 120-12-7

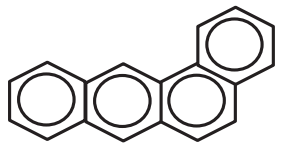

Benzo[a]anthracene MW 228 CAS 56-55-3
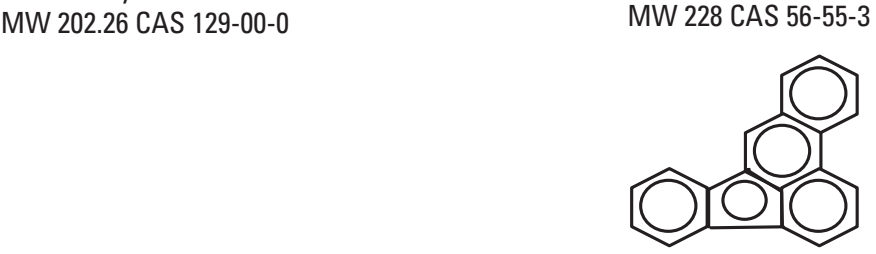

Benzo[b]fluoranthene MW 252 CAS 205-99-2

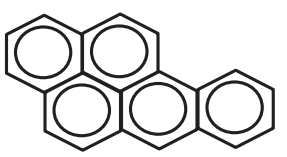

Benzo[a]pyrene MW 252.3 CAS 50-32-8

\section{More Stable Isomer}

Less Stable Isomer

Figure 28. Structures of selected polycyclic aromatic hydrocarbons. 
groups. The number of these additions and their positions are indicated by integers amended to the parent compound name.

The aromaticity of the benzene ring structure results in a high degree of stability and toxicity in the environment (Morrison and Boyd, 1987). The different shapes of the isomers, however, can lead to different degrees of stability in the environment. PAH compounds have mutagenic and carcinogenic properties related to their ability to disrupt DNA. There is some indication the methylated-forms may be more toxic than the parent compound (Morrision and Boyd, 1987). The most toxic of the PAHs, benzo(a)pyrene, can react directly with guanine present on the DNA and RNA in human cells. Other PAH molecules can also interact with DNA but form an epoxide intermediate that reacts with the nucleic acid DNA in the same manner as benzo(a)pyrene. The attachment of a large PAH hydrocarbon to guanine prevents it from fitting into the DNA molecule and keeps it from bonding to a cystine in the opposite DNA strand in a cell during division. This damage may lead to mutations and eventually carcinogenesis (Morrision and Boyd, 1987).

PAHs are residual compounds in the heavy fraction of raw hydrocarbons and coal, in refined petroleum products (gasoline, kerosene, diesel fuel, and heating oil), and in heavier petroleum distillates such as asphalt, coal tar, and creosote. PAHs may dissolve directly from sources such as newly paved asphalt, from oils and greases that collect on parking lots and roads, or from oily wastes derived from industrial activity. PAHs can form during incomplete combustion of coal, wood, or hydrocarbon fuels and whenever organic wastes are burned, where they condense from the gaseous emissions and attach themselves directly to soot particles washed out by precipitation. Also, the lower molecular weight PAHs are sufficiently volatile and soluble that they can dissolve from gases directly into precipitation.

The 24 distinct PAH compounds that were measured in this study included the 16 USEPA listed Priority Pollutants along with 8 methylated napthalenes and a methylated-phenanthrene compound (table 24). Additionally, the total C2 and C3 alklynaphthalenes, which are the sum of all alkylated naphthalenes having two or three substitution groups, respectively, were measured. The 24 PAHs can be separated into two groups on the basis of molecular weight; low-molecular weight PAHs (Lmw PAHs) having molecular weights of less than $202 \mathrm{~g} / \mathrm{mole}$, and high-molecular weight PAHs (Hmw PAHs) having molecular weights greater than $202 \mathrm{~g} / \mathrm{mole}$. The physical-chemical properties of these PAH compounds vary systematically with the increase in structure complexity and molecular weight (table 24). Examples include the decrease in solubility, the increase in hydrophobicity (as measured by the octanol-water partitioning coeffcient), and the decrease in vapor pressure (a measure of the ease at which a compound transfers to the gas phase) with increasing molecular weight. Much of the distribution, transport, and fate of the PAHs through the environment can be explained in light of these properties.

\section{Methods}

Unlike the other dissolved organic species measured in this study, the dissolved PAHs could only be measured in composite whole-water grab samples. The XAD-2 resin could not be used to sample the dissolved PAH phase because it is known to produce substantial quantities of naphthalene compounds as it ages (D. Thal, STL Laboratories, oral commun., 2000). These autochronously produced compounds would swamp many of the dissolved native compounds of interest present in the river water. The composite grab samples were produced by collecting aliquots $(100 \mathrm{~mL})$ of unfiltered river water concurrently with the collection of river water processed for suspended-sediment analysis. Typically, $4 \mathrm{~L}$ of sample were collected during each event, from which 1 or $2 \mathrm{~L}$ were ultimately extracted for dissolved PAHs. PAHs in the sediment phase were measured on the composite sediment collected by filtering river water through a glass fiber canister and flat filters. The sediment was extracted and analyzed for PAHs along with PCBs, pesticides, and dioxin/furans.

Laboratory analysis was done following a modification of the California-Air Resources Method CARB-410 (California Environmental Protection Agency Air Resources Board, 1997), which is an isotope-dilution method using low-resolution GC/MS for analysis (Bonin and Wilson, 2006). The method was adjusted to increase sensitivity after the May 2001 samples had been analyzed. This was done by adjustments to the GC/MS and by doubling the volume of dissolved sample extracted (to 2L). These modifications lowered the reported detection levels and concurrently the concentrations flagged as non-detectable.

\section{Quality Assurance}

Data quality and assurance were evaluated using the IS recoveries and the concentrations measured in the various field and method blanks that were prepared.

\section{Recovery of Internal Standards}

Recoveries of IS were considered acceptable if between 20 and 150 percent. Two sediment samples had low recoveries of almost all IS, the sample collected from the Elizabeth River on May 22, 2001, and the sample from the Hackensack River collected on Oct. 19, 2001. As mentioned, the Elizabeth River sample from May 2001 also had low recoveries of the IS for PCB and dioxin, which were attributed to the high particulate carbon content of this sample. Several of the naphthalene compounds in the sediment from the Passaic River (Mar. 14, 2001), the Rahway River (Apr. 24, 2001), and the Hackensack River tidal (Mar. 13, 2001) also were affected by low recoveries of IS.

Low recoveries of IS may have resulted in biased concentrations in these samples. The sediment data were not censored because of low recovery of IS, and all samples were used 


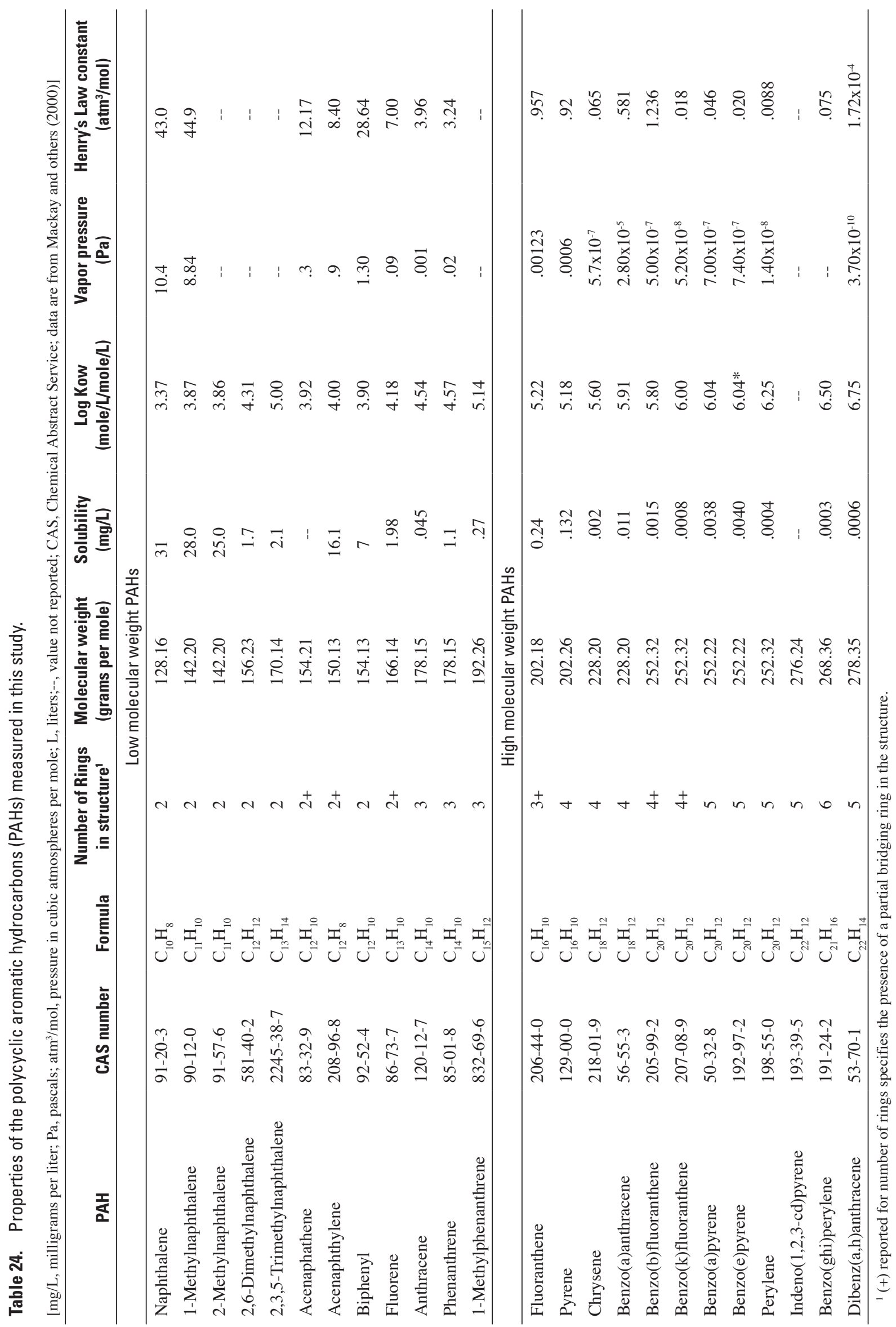


to calculate average concentrations. None of the dissolved samples had IS with unacceptable recoveries.

\section{Contamination of Blanks and Data Censoring}

PAHs derived from fossil-fuel combustion are ubiquitous in urban areas. Additionally, analytical laboratories that handle sediments containing high levels of PAHs commonly have problems with the contamination of glassware, solvents, and the laboratory air. Samples are easily contaminated by PAH compounds that exist in the field and laboratory, so special care was given to consider the effects of sample-contamination bias in the concentrations.

The possible bias in field samples caused by field or laboratory contamination was considered in this work by using the "maximum blank-elimination" procedure as directed by the New Jersey Department of Environmental Protection. PAHs in samples having concentrations that were within a factor of five times the highest concentration in the associated field or laboratory blanks were removed from the data set. As discussed below, blank elimination greatly affected the dissolved PAH data set produced in this study.

Field and laboratory method blanks were produced for the sediment and aqueous samples collected in this work. Field blanks for sediment samples were prepared by exposing an unused filter to the atmosphere during the time when filters were being installed in the sampling apparatus. The field blank for aqueous samples consisted of a bottle of laboratory water left opened in the bottom of the sampling chamber for the duration of the composite sample collection. Because of cost, only one filter and one dissolved blank could be analyzed per sampling event, which commonly involved sampling at two or three sites. Generally, about 50 percent of the samples did not have a field blank collected at the same location as the sample. Therefore, it is possible that PAH data were eliminated because of a blank prepared at a location far from the actual sampled location. Laboratory method blanks were prepared using sand and sodium sulfate for solid materials or laboratory water for dissolved samples.

Average concentrations of the field and laboratory method blanks for the aqueous and sediment samples are presented in table 25. Measurable concentrations of most or all PAHs were found in the field and method blanks. For description purposes, concentrations were classified as being "high" if they were greater than $10 \mathrm{ng} / \mathrm{L}$ (for dissolved) or 10 $\mathrm{ng} / \mathrm{sample}$ for sediment. The $10 \mathrm{ng}$ level is roughly the median concentration of the PAHs detected in the blanks that were prepared.

\section{Aqueous Method Blanks}

Of the 26 compounds measured in the aqueous samples, 7 compounds were present one or less times in the aqueous method blanks: 2,3,5-trimethylnapthalene, anthracene, benzo(b)fluoranthene and benzo(k)fluoranthene, benzo(a)pyrene and benzo(e)pyrene, and perylene. Of the remaining 19 compounds present in three or more method blanks, 4 compounds were consistently present at high (greater than $10 \mathrm{ng} / \mathrm{L}$ average) concentrations: naphthalene, 2-methylnapthalene, 2,6-dimethylnaphthalene, and the total of the C2-alkylnapthalenes. All other compounds were detected at concentrations less than $10 \mathrm{ng} / \mathrm{L}$.

\section{Aqueous Field Blanks}

PAHs that were consistently detected at high (greater than $10 \mathrm{ng} / \mathrm{L}$ average) concentration in the aqueous field blanks included naphthalene, 1-methylnaphthalene, 2-methylnapthalene, and the total of the C2-alkylnapthalenes. All other compounds were detected at less than $10 \mathrm{ng} / \mathrm{L}$. Compounds that were not present, or were present in only a few of the field blanks, included 2,3,5-trimethylnapthalene, benzo(a) and benzo(e)pyrene, anthracene, and perylene.

\section{Filter Method Blanks}

Compounds at high concentrations (greater than $10 \mathrm{ng}$ / sample average) in the filter method blanks included naphthalene, biphenyl, 2-methylnapthalene, 1-methylphenanthrene, pyrene, dibenzo(a,h)anthracene, indeno(1,2,3-cd)pyrene, benzo(ghi)perlyene, and the $\mathrm{C} 2$ - and $\mathrm{C} 3$-alkylnapthalenes.

\section{Filter Field Blanks}

Eighteen PAHs were present at high concentrations (greater than $10 \mathrm{ng} / \mathrm{sample}$ average) in all the filter field blanks. Only the compounds 2,3,5-trimethylnapthalene, fluorene,1-methylphenanthrene, chrysene, and benz(a)anthracene did not consistently exceed the $10 \mathrm{ng} / \mathrm{sample}$ average level in the filter field blank. All remaining PAHs in the field blanks had masses generally exceeding their values in the method blanks.

The aqueous method blanks contained a very similar suite of PAH compounds at about one-half the masses measured in the field blanks, indicating that laboratory contamination accounted for roughly one-half of the blank contamination. Several compounds (naphthalene, 1-methylphenanthrene, acenaphthene, acenaphthylene, and pyrene) were detected in the filter field blanks at concentrations four to five times greater than in the filter method blanks. Contamination of the sediment samples was apparently associated with the preparation of the filters, because the filter field blanks contained the same suite of PAHs as did the filter method blanks, but at much greater masses. The filters may have become contaminated during baking or during handling in the field. However, the vast majority of the PAHs in the sediment samples were detected at masses greatly exceeding those in the filter field or method blanks, so few of the compounds were ultimately eliminated from the sample data set. The naphthalenes were the compounds most affected by contamination of the filter blanks.

Because of the much lower concentrations in the river water and the small volumes ( 1 to $2 \mathrm{~L}$ ) of water extracted, a large number of aqueous sample data (10 to 100 percent, 


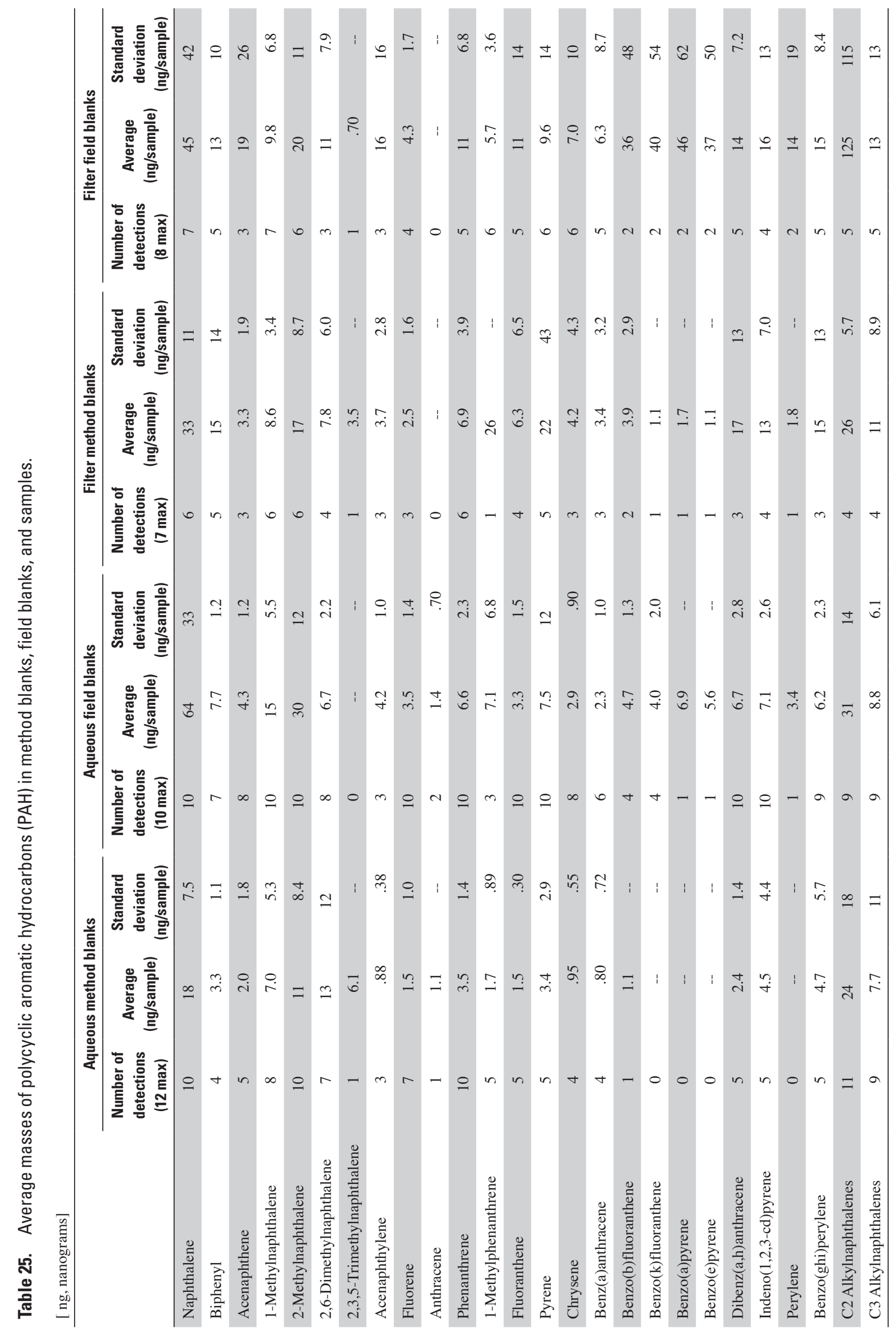


depending upon compound) were censored from the data set because of contamination of blanks. The following compounds were censored from over half of the dissolved samples: naphthalene, biphenyl, phenantrene, acenaphthene, 1- and 2methylnapthalene, 2,6-dimethylnapthalene, and flourene, and in a lesser number of samples, dibenzo(a,h)anthracene and the C2- and C3-alkylnapthalenes.

\section{Concentrations}

The concentrations of the PAH compounds measured in the suspended sediment and river water, and the reported detection limits, are listed in tables 26 through 29. Average values for each compound are presented in tables 30 and 31, and average sediment concentrations normalized to organic carbon are listed in table 32. Average concentrations were calculated using the blank-eliminated data set with the nondetected values replaced by one-half the reported EDL. For consistency with the PCB and dioxin data sets, the average values for the Passaic River were calculated without the Dec. 15, 2000, sample, and the average for the Hackensack River does not include the samples collected Mar. 14, 2001 (tidal). Average detection limits were calculated for samples collected prior to June 2001 (excluding the June 2000 samples, which had detection levels arbitrarily set at $25 \mathrm{ng}$ ), and for samples collected after June 2001. This separation was because of the improved analytical methods mentioned earlier.

Average detection limits for dissolved compounds present in the samples typically ranged from 1 to $9 \mathrm{ng} / \mathrm{L}$ for the earlier samples (pre-June 2001) and 0.15 to $0.6 \mathrm{ng} / \mathrm{L}$ for the later group of samples (post June 2001). Higher detection levels were achieved for the C2- and C3-alkylnaphthalenes (table 26). The typical range of detection levels for the nondetected dissolved compounds ranged from 1.5 to $8.9 \mathrm{ng} / \mathrm{L}$ for the earlier sample set. Very few of the later group of dissolved samples had nondetected compounds. Detection levels were $0.4 \mathrm{ng} / \mathrm{L}$ for the three compounds that were not detected in the post-June 2001 samples (2,3,5-trimethylnaphthalene, perylene, and dibenz(a,h)anthracene). These data demonstrate that the modifications made to the dissolved PAH analyses after the analysis of the May 2001 sample provided sufficiently low detection levels that allowed nearly all compounds to be detected in the water samples.

Average detection levels for detected compounds in the sediment samples ranged from 1.5 to $10 \mathrm{ng} / \mathrm{g}$ for the earlier samples (with the exception of the C2- and C3-alkylnaphthalenes that had detection levels of $59 \mathrm{ng} / \mathrm{g}$ ), and 0.4 to $4 \mathrm{ng} / \mathrm{g}$ for the later group of samples. Very few nondetected values were produced for the PAH compounds in the sediment phase. The detection levels for those few compounds that were not detected in this phase were nearly identical to the levels for detected concentrations.

Average concentrations (table 30) for several of the dissolved PAH compounds (naphthalene, 1- and 2-methylnaphthalene, 2,3,5-trimethylnaphthalene, biphenyl, and the C2- and C3- alkylnaphthalenes) were based on either a single measured value (generally samples after May 2001) and/or entirely on the EDL. The use of EDLs in calculating average values sets an upper limit on the average concentration (and, therefore, loads) but does not unequivocally demonstrate the presence of these compounds in the sample.

The PAHs were present in measurable concentrations in all sediment samples, although their concentrations varied over a large range within and among the different rivers (table 27). The concentrations of total sediment-bound PAHs (the sum of the concentrations of the individual PAHs) ranged from $230 \mathrm{ng} / \mathrm{g}$ in the Raritan River (Oct. 2001) up to $340,000 \mathrm{ng} / \mathrm{g}$ in the Elizabeth River (June 4, 2003). Average concentrations of the individual PAHs (calculated with the Passaic Dec. 15, 2000 sample removed to be consistent with the calculations of PCB and dioxin averages) were highest in the Elizabeth River. The elevated concentrations in the Elizabeth River were from the low-flow sample collected during April 2001, and the storm event in June 2003. The average concentration of total PAHs in the sediment were 11,200 ng/g in the Raritan ,14,700 $\mathrm{ng} / \mathrm{g}$ in the Hackensack, 17,600 ng/g in the Passaic, 28,000 $\mathrm{ng} / \mathrm{g}$ in the Rahway, and 129,000 ng/g in the Elizabeth Rivers (table 31).

Plotting the average concentrations for the individual compounds (fig. 29) shows the highest absolute concentrations in the sediment were associated with the Hmw PAHs (Hmw PAH > $202 \mathrm{~g} / \mathrm{mole}$ ), and for the most part, the highest individual concentrations were in the Elizabeth River. The absolute and relative average concentrations (fig. 30) for the $\mathrm{Hmw} \mathrm{PAH}$ in the sediment tend to decrease with increasing molecular weight from flouranthene to dibenzo(a,h)anthracene. In the Elizabeth River, the average concentrations of Hmw PAHs decreased from a high of nearly $19,000 \mathrm{ng} / \mathrm{g}$ for fluoranthene down to $1,200 \mathrm{ng} / \mathrm{g}$ for dibenz(a,h)anthracene (not considereing total C2 and C 3 compound values) Concentrations of the Hmw PAHs in the Passaic and Rahway Rivers decreased from roughly 2,700 ng/g fluoranthene to less than $270 \mathrm{ng} / \mathrm{g}$ for dibenz(a,h)anthracene; the concentrations in the Raritan River decreased from roughly $1,300 \mathrm{ng} / \mathrm{g}$ to roughly $140 \mathrm{ng} / \mathrm{g}$ for dibenz(a,h)anthracene (table 31).

With the exception of phenanthrene in the Rahway, Elizabeth, and Passaic Rivers, 1-methylphenanthrene in the Elizabeth and Hackensack Rivers, 2,6-dimethylnaphthalene in the Rahway River, anthracene in the Elizabeth River, and naphthalene in the Raritan River, the concentrations of all Lmw PAH ( Lmw PAHs < 202 g/mole) were less than 1,000 $\mathrm{ng} / \mathrm{g}$ in all rivers. Concentrations of the individual Lmw PAHs were relatively steady and did not appear to vary as a function of molecular weight at least until phenanthrene is reached (fig. 29). In general, the highest concentrations of the Lmw PAHs in the sediment were in the Elizabeth River, where three compounds dominated (phenanthrene, 1-trimethylnaphthalene, and anthracene) (fig. 29). Phenanthrene was also the dominant Lwm PAH in the Passaic and Rahway Rivers. When the relative concentrations were plotted as a function of molecular weight, the dominance of phenanthrene was apparent in all rivers (fig. 30). In the Raritan River average sediment com- 


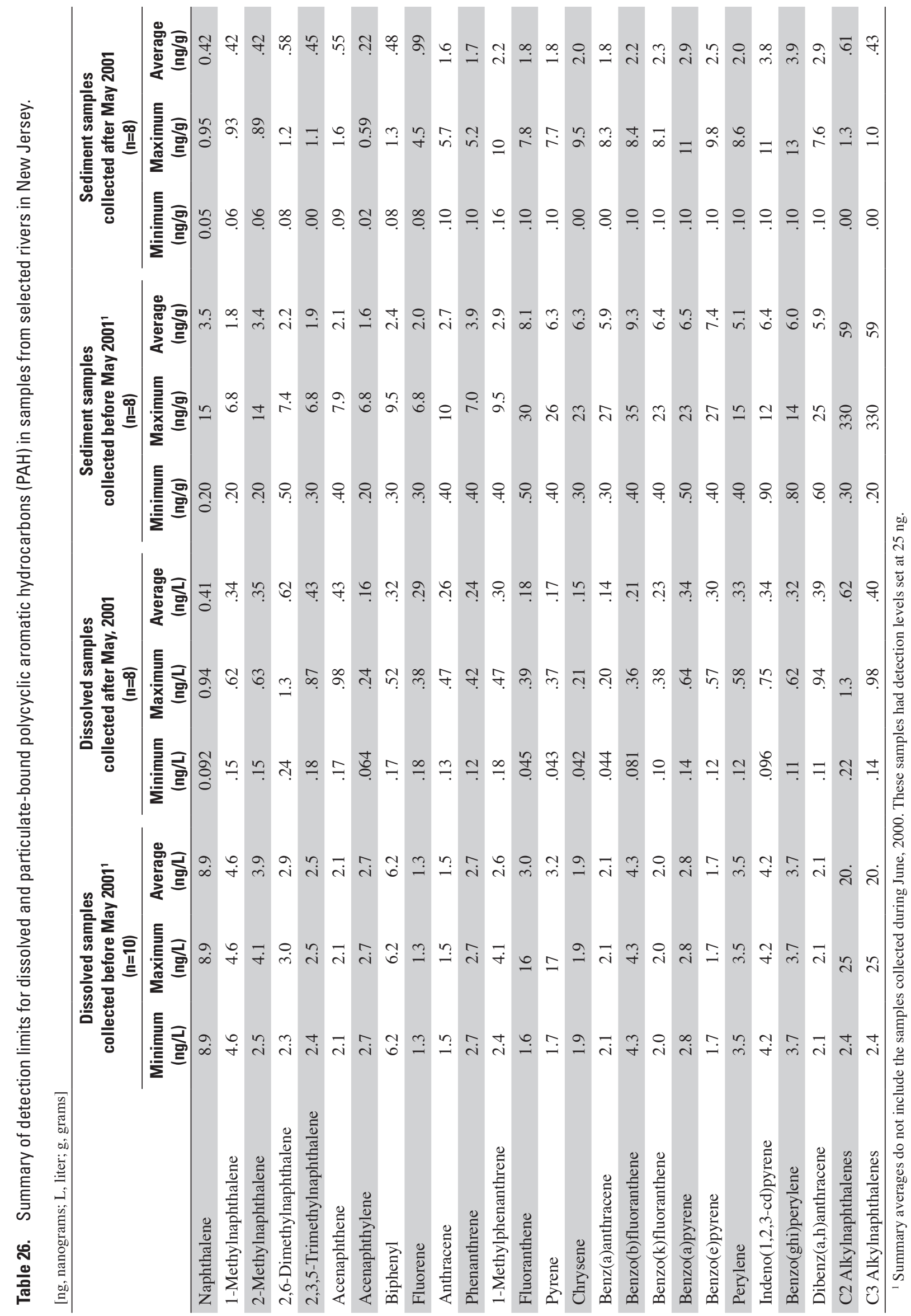




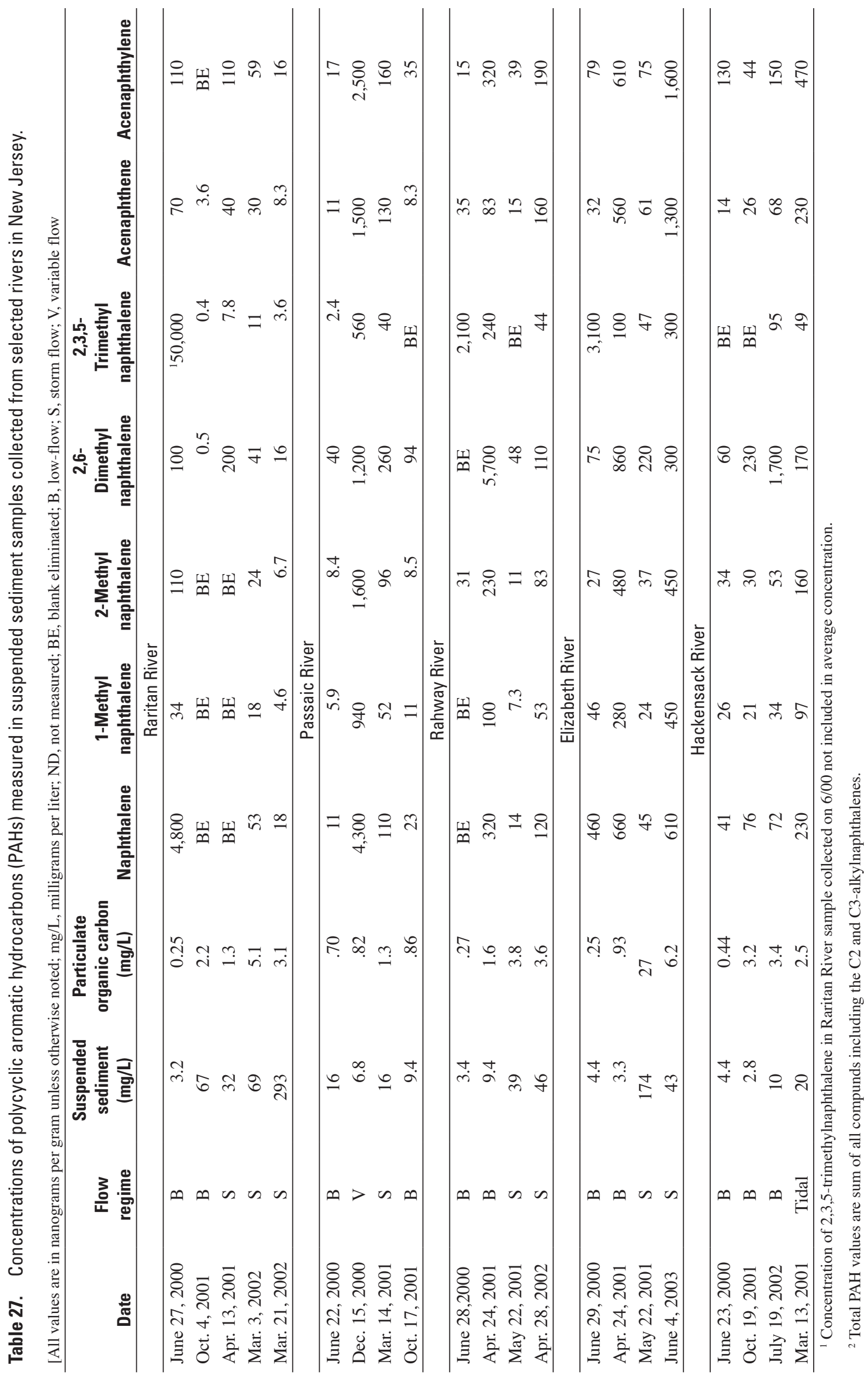




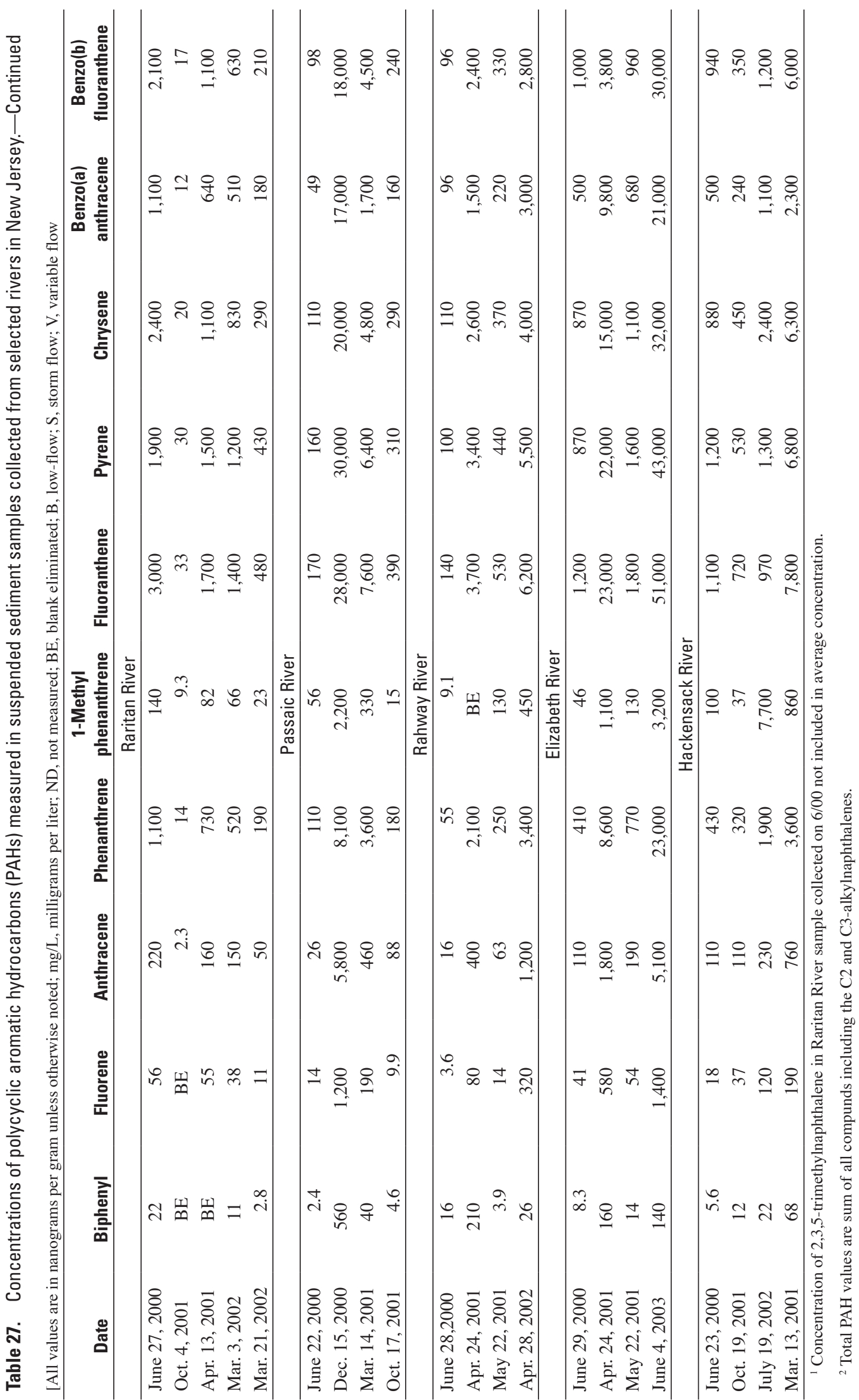




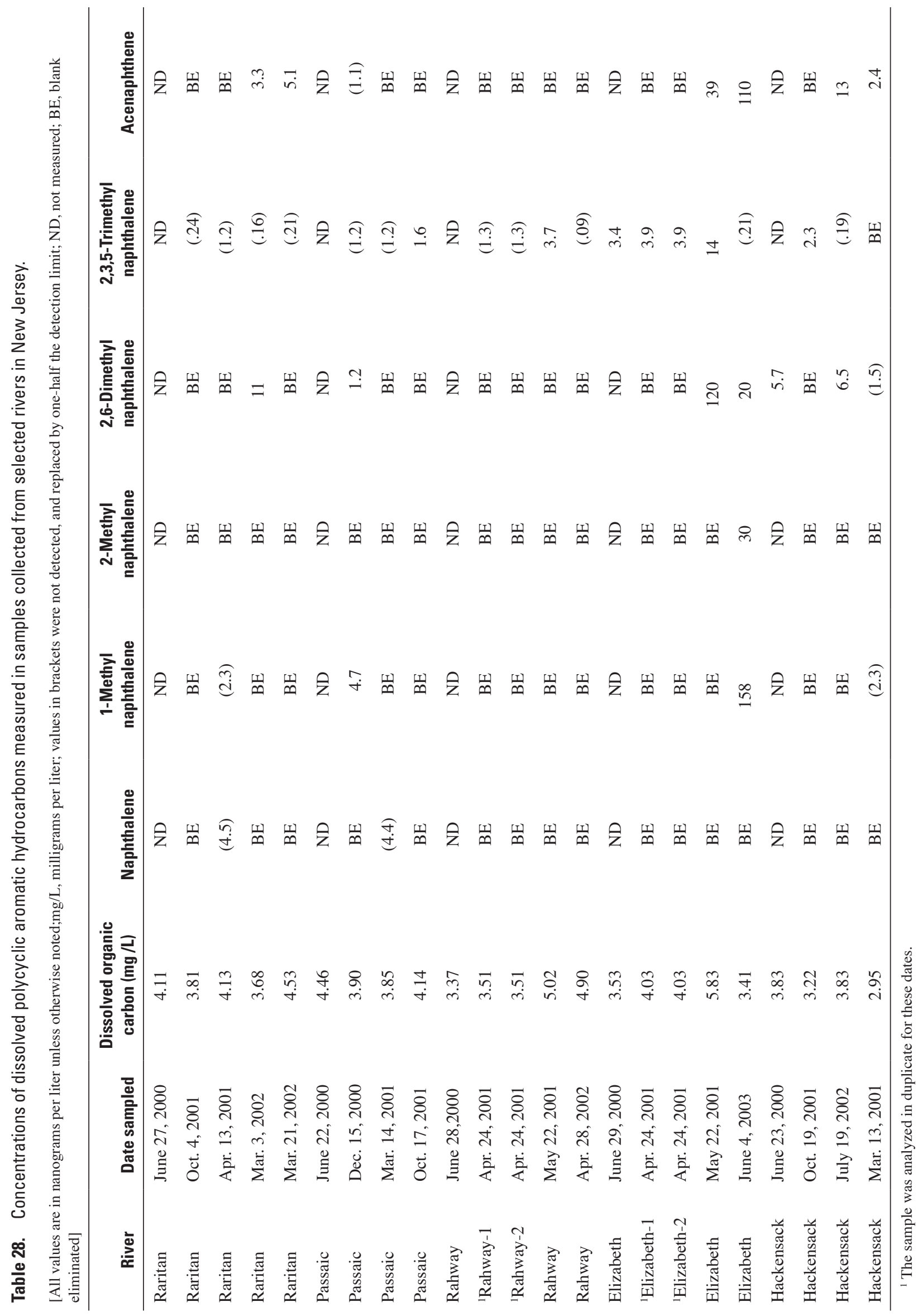




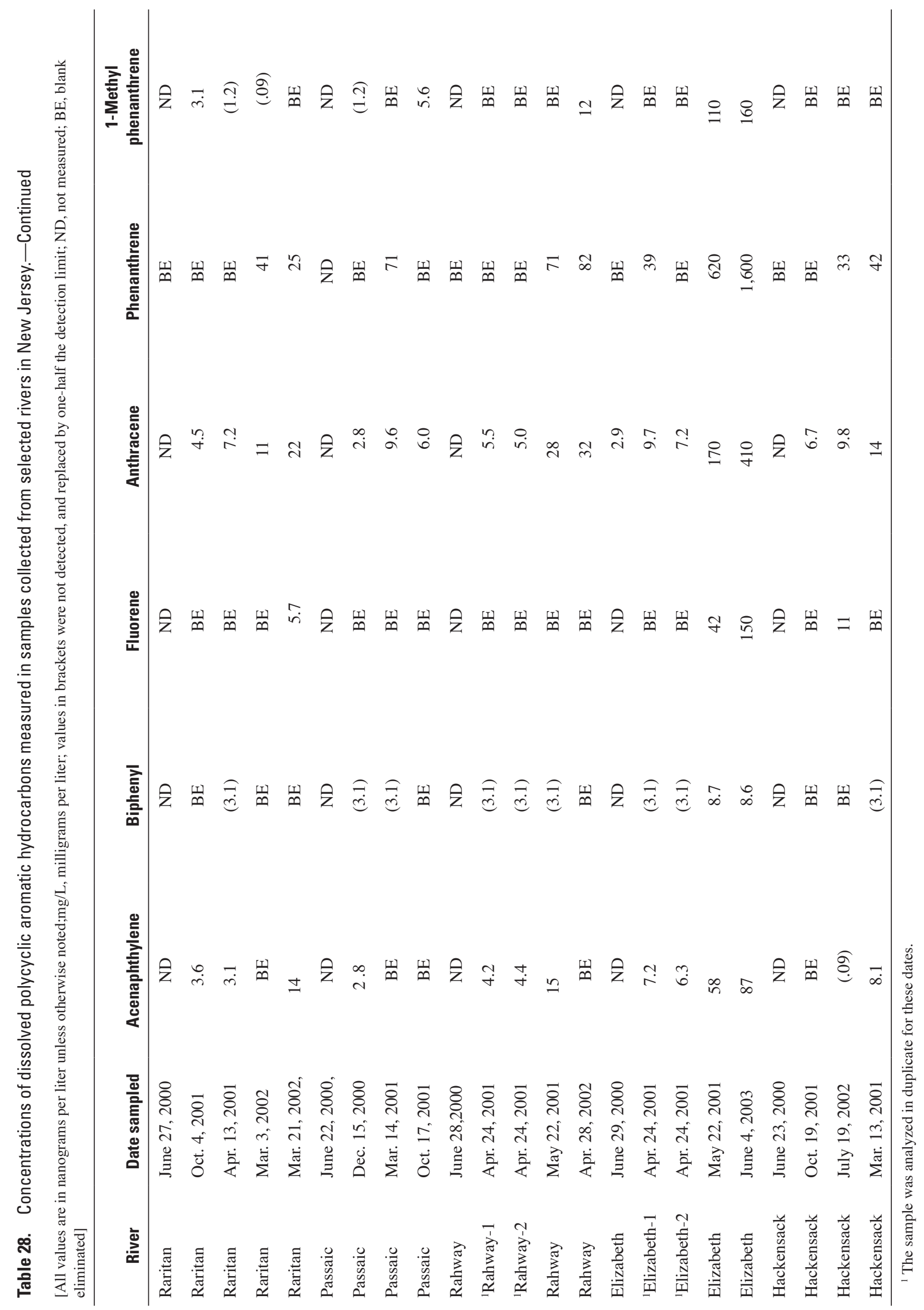




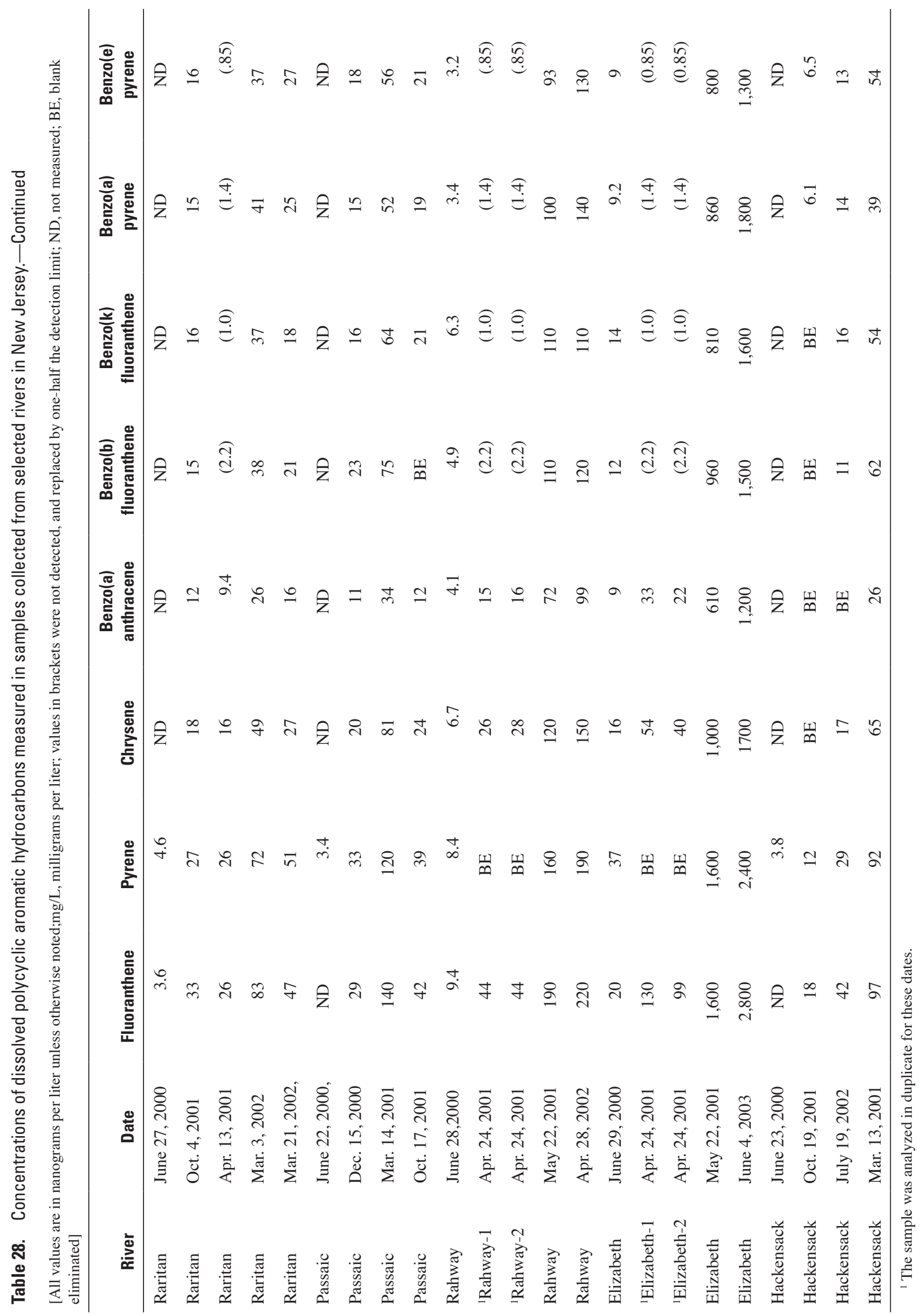




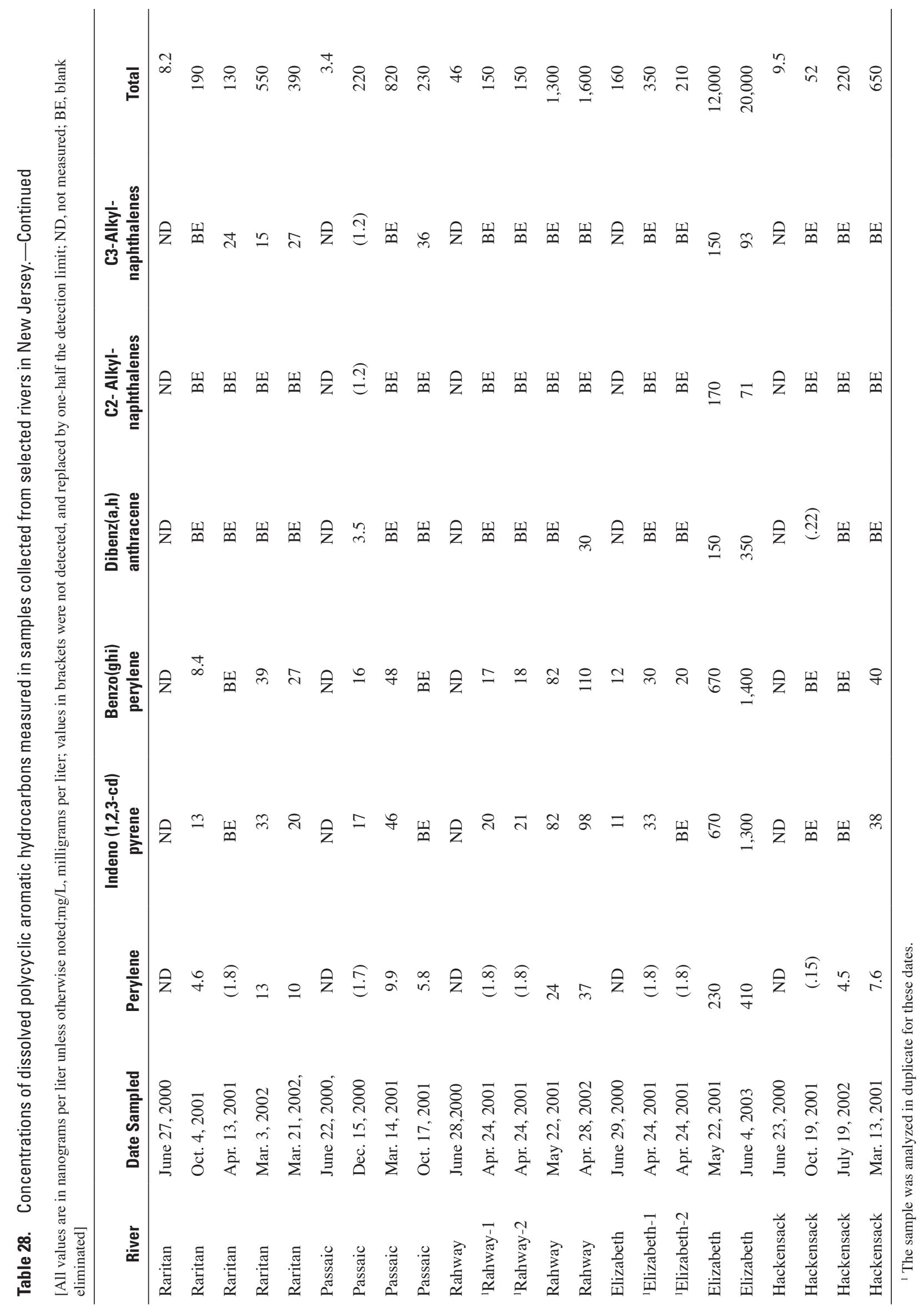




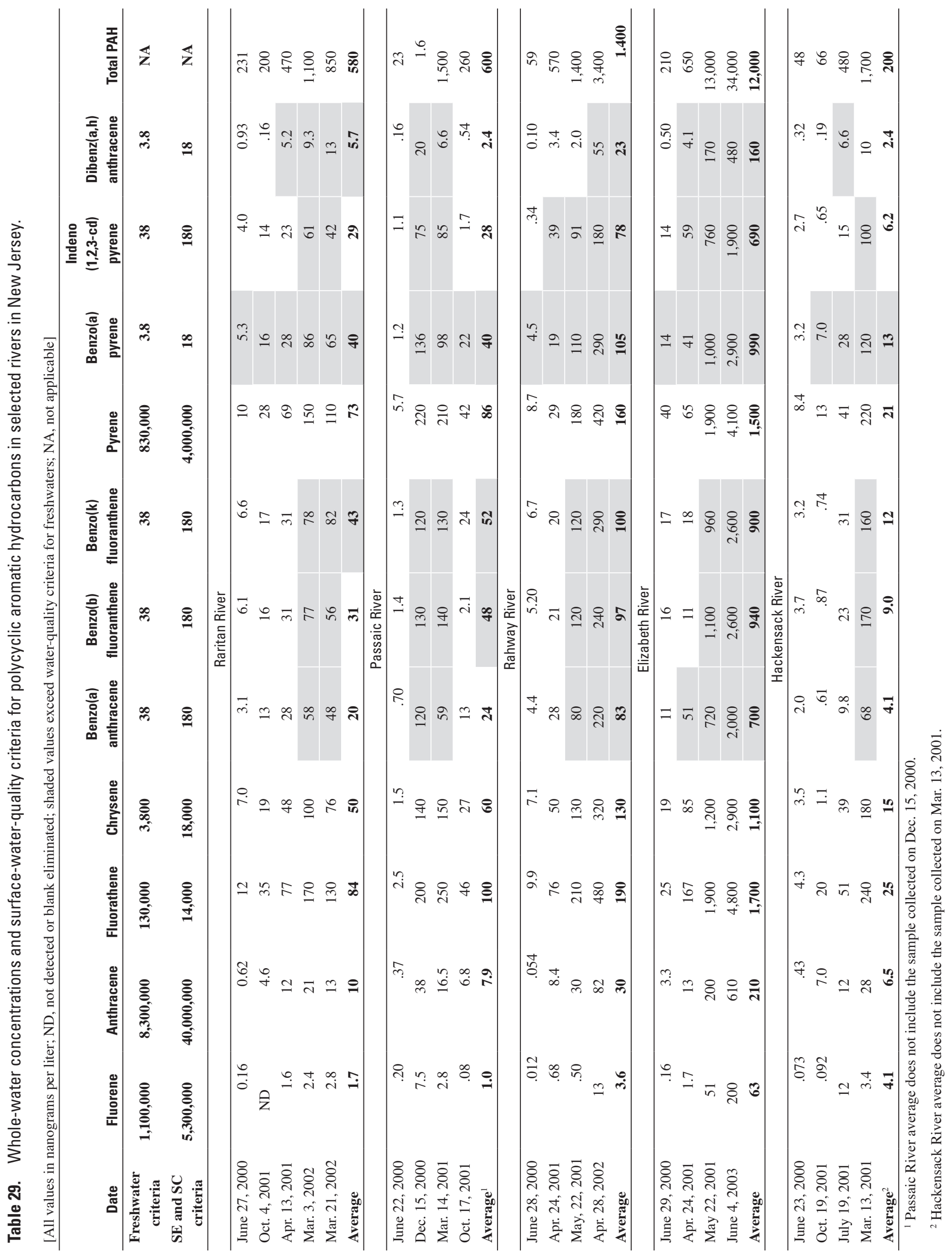


Table 30. Average concentrations of dissolved polycyclic aromatic hydrocarbons (PAH) in samples collected from selected rivers in New Jersey.

[ng/L, nanograms per liter; --, all available values were removed by blank elimination; *, value calculated from 1 or less measured concentration and/or estimated detection levels]

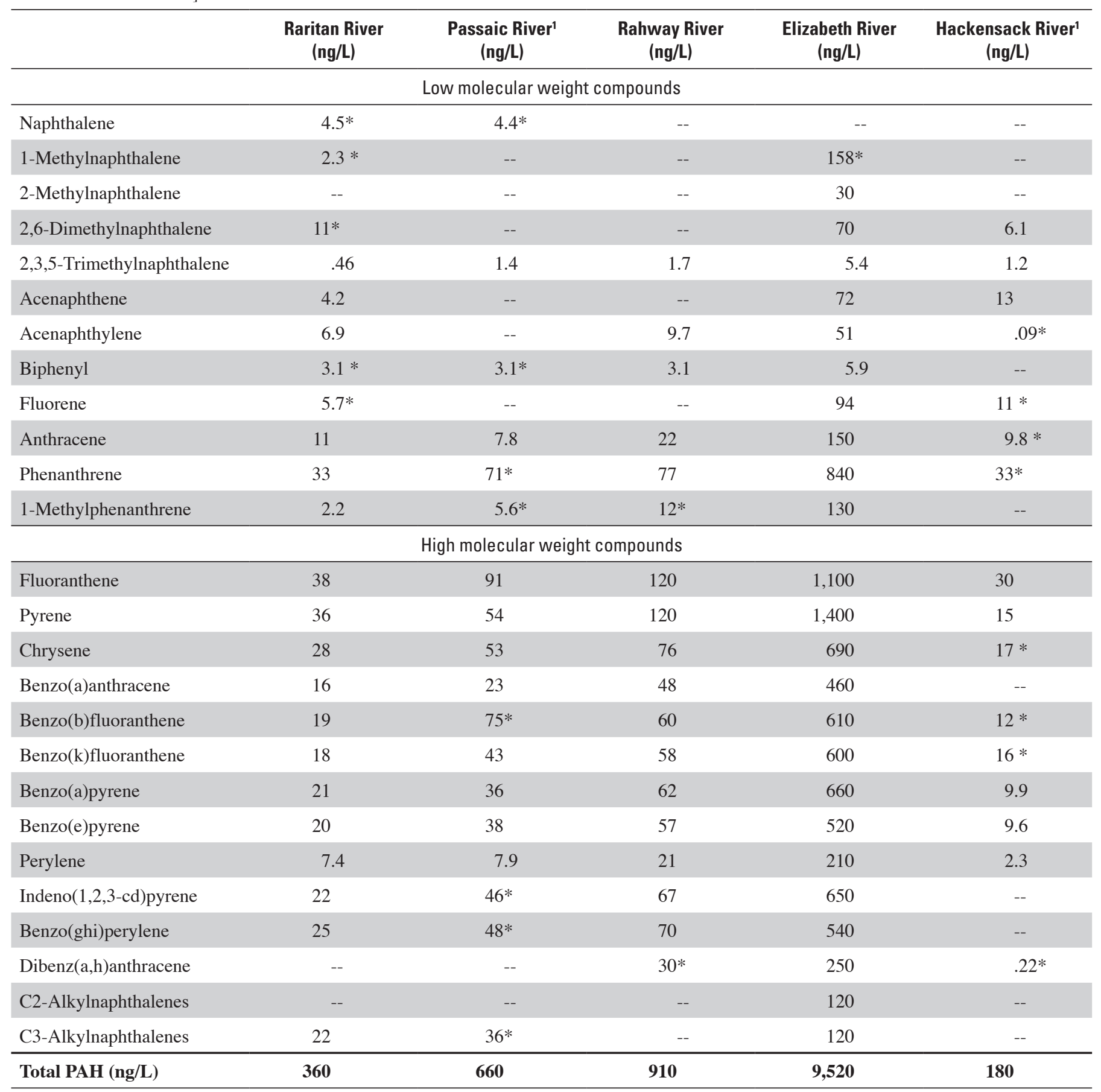

${ }^{1}$ The samples from the Passaic River, Dec. 15, 2000 and the Hackensack River, Mar. 14, 2001 (tidal), were not included when calculating the average concentrations. 
Table 31. Average concentrations of polycyclic aromatic hydrocarbons (PAH) in suspended sediment samples collected from selected rivers in New Jersey.

$[\mathrm{ng} / \mathrm{g}$, nanograms per gram]

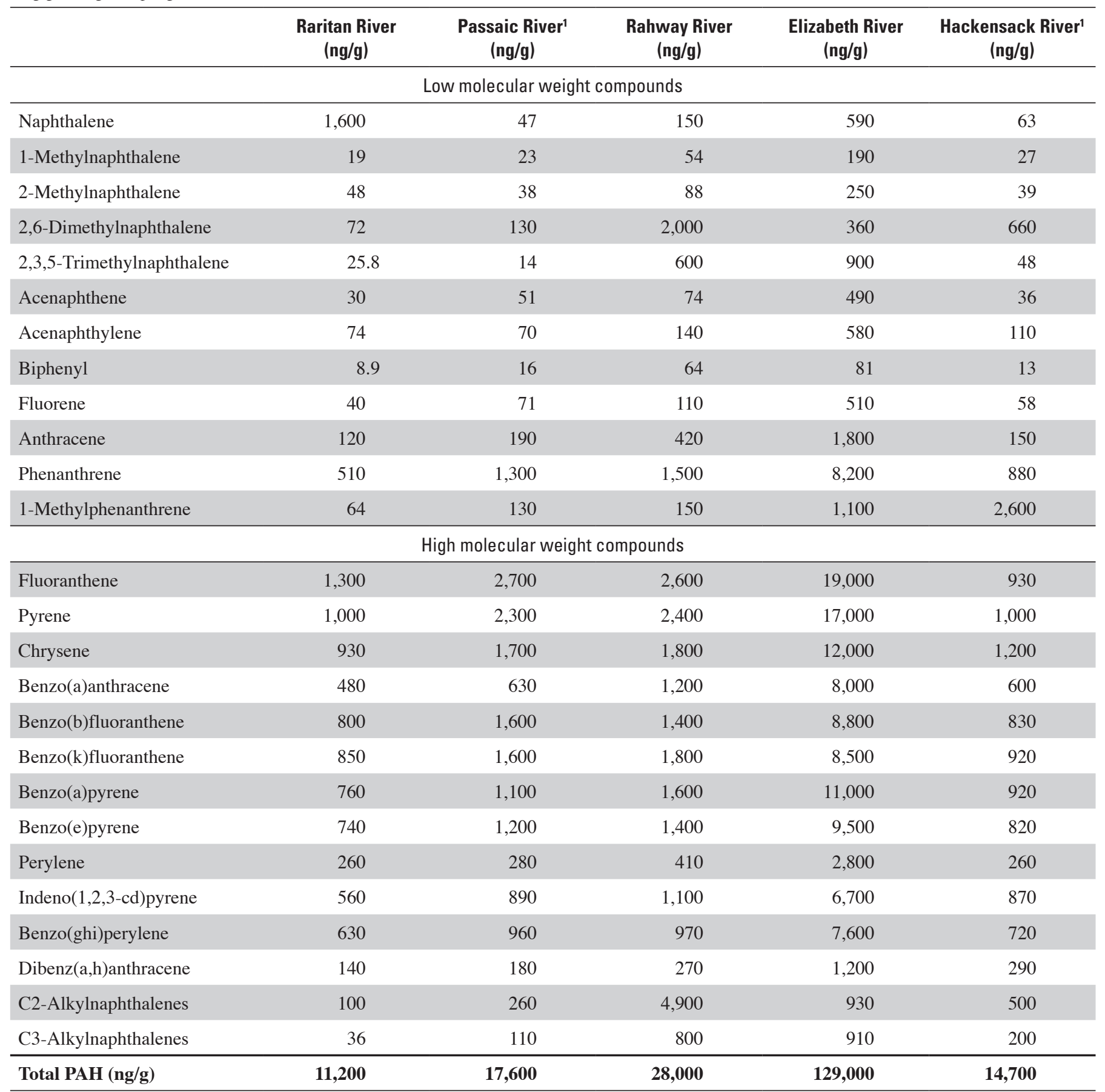

${ }^{1}$ The samples from the Passaic River, Dec. 15, 2000; and the Hackensack River, Mar. 14, 2001 (tidal), were not included when calculating the average concentrations.

${ }^{2}$ Average value for 2,3,5-trimethylnaphthalene does not include sample from June 2000. 
Table 32. Average concentrations of polycyclic aromatic hydrocarbons in suspended sediment normalized to particulate carbon in samples collected from selected rivers in New Jersey.

[ng/gC, nanograms per gram of carbon]

\begin{tabular}{|c|c|c|c|c|c|}
\hline & $\begin{array}{c}\text { Raritan River } \\
\quad(\mathbf{n g} / \mathbf{g C})\end{array}$ & $\begin{array}{l}\text { Passaic River } \\
\text { (ng/gC) }\end{array}$ & $\begin{array}{c}\text { Rahway River } \\
\text { (ng/gC) }\end{array}$ & $\begin{array}{l}\text { Elizabeth River } \\
\text { (ng/gC) }\end{array}$ & $\begin{array}{c}\text { Hackensack River } \\
\text { (ng/gC) }\end{array}$ \\
\hline Naphthalene & 22,000 & 630 & 1,200 & 3,700 & 280 \\
\hline 1-Methylnaphthalene & 370 & 310 & 450 & 1,200 & 140 \\
\hline 2-Methylnaphthalene & 820 & 510 & 720 & 1,500 & 190 \\
\hline 2,6-Dimethylnaphthalene & 1,700 & 1,800 & 12,000 & 1,900 & 2,100 \\
\hline 2,3,5-Trimethylnaphthalene & ${ }^{2} 180$ & 190 & 9,700 & 14,000 & 140 \\
\hline Acenaphthene & 640 & 690 & 810 & 3,000 & 140 \\
\hline Acenaphthylene & 1,600 & 940 & 1,200 & 3,600 & 630 \\
\hline Biphenyl & 180 & 210 & 450 & 440 & 51 \\
\hline Fluorene & 900 & 960 & 1,200 & 3,100 & 210 \\
\hline Anthracene & 2,800 & 2,500 & 4,700 & 11,000 & 700 \\
\hline Phenanthrene & 11,000 & 17,000 & 15,000 & 51,000 & 3,600 \\
\hline 1-Methylphenanthrene & 1,500 & 1,900 & 2,500 & 6,900 & 8,000 \\
\hline Fluoranthene & 30,000 & 35,000 & 27,000 & 120,000 & 5,300 \\
\hline Pyrene & 24,000 & 30,000 & 24,000 & 100,000 & 5,600 \\
\hline Chrysene & 20,000 & 23,000 & 18,000 & 74,000 & 5,700 \\
\hline Benzo(a)anthracene & 11,000 & 8,100 & 13,000 & 48,000 & 2,900 \\
\hline Benzo(b)fluoranthene & 17,000 & 21,000 & 14,000 & 60,000 & 4,600 \\
\hline Benzo(k)fluoranthene & 18,000 & 21,000 & 18,000 & 56,000 & 4,600 \\
\hline Benzo(a)pyrene & 16,000 & 15,000 & 16,000 & 69,000 & 4,600 \\
\hline Benzo(e)pyrene & 15,000 & 16,000 & 14,000 & 58,000 & 4,100 \\
\hline Perylene & 5,800 & 3,600 & 4,200 & 17,000 & 1,300 \\
\hline Indeno(1,2,3-cd)pyrene & 12,000 & 12,000 & 10,000 & 41,000 & 4,200 \\
\hline Benzo(ghi)perylene & 14,000 & 12,000 & 10,000 & 48,000 & 3,800 \\
\hline Dibenz(a,h)anthracene & 3,000 & 2,300 & 2,800 & 7,500 & 1,100 \\
\hline C2-Alkylnaphthalenes & 4,200 & 3,200 & 30,000 & 4,400 & 1,500 \\
\hline C3-Alkylnaphthalenes & 1,100 & 1,500 & 5,300 & 4,800 & 580 \\
\hline Total PAHs (ng/gC) & 342,000 & 230,000 & 260,000 & 810,000 & 66,000 \\
\hline
\end{tabular}

${ }^{1}$ The samples from the Passaic River, Dec. 15, 2000; and the Hackensack River, Mar. 14, 2001 (tidal), were not included when calculating the average.

${ }^{2}$ Average value for 2,3,5-trimethylnaphthalene does not include sample from June 2000. 


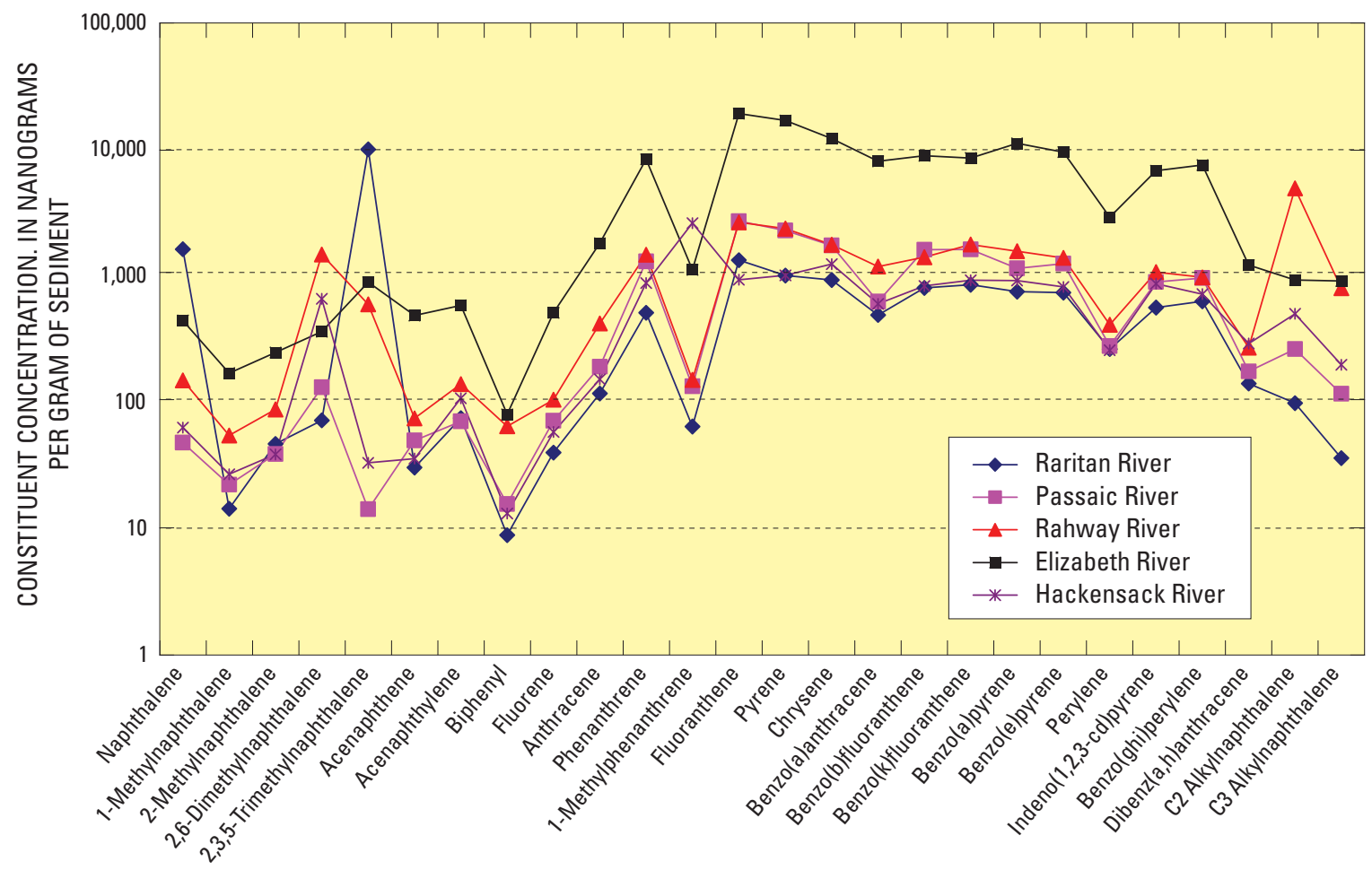

Figure 29. Average concentrations of polycyclic aromatic hydrocarbons in suspended-sediment samples collected from selected rivers in New Jersey. [Averages calculated without the Raritan River June 2000, nor Passaic River Dec. 2000 samples.]

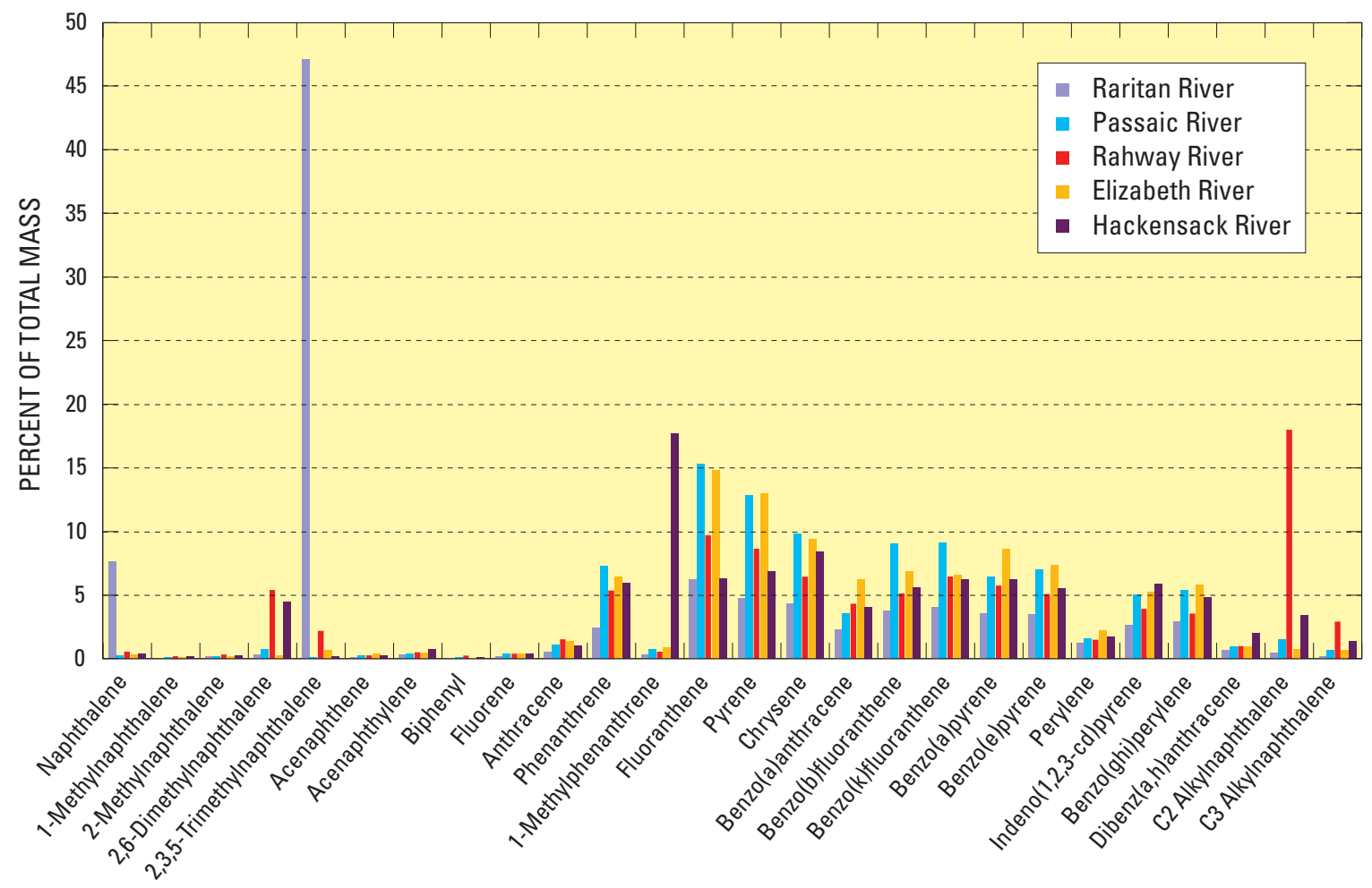

Figure 30. Percent contribution of polycyclic aromatic hydrocarbons in average suspended sediment collected from selected rivers in New Jersey. [Averages calculated without the Raritan River June 2000, nor Passaic River Dec. 2000 samples.] 
position, naphthalene was elevated and represented nearly 14 percent of the total PAH mass.

One PAH in the Raritan River sediment, 2,3,5-trimethylnapthalene, had an average concentration $(10,000 \mathrm{ng} / \mathrm{g})$ that exceeded the concentration of any other compound in any of the other rivers. The high 2,3,5-trimethylnaphthalene concentration was the result of the June 2000 sample, in which a concentration of $50,000 \mathrm{ng} / \mathrm{g}$ was measured and considered to be an outlier. Removing this value resulted in an average concentration of $5.8 \mathrm{ng} / \mathrm{g}$ for 2,3,5-trimethylnaphthalene, which was similar to the concentrations measured in the other rivers.

Because the suite of PAHs vary widely in molecular weight, the mass-based concentrations (nanograms per gram) were converted to molar concentrations (mole per gram) to demonstrate which of the compounds are present in greater abundance and not weight (table 33). The molar percentages of the individual PAH compounds in the average sediment compositions cluster into two groups - the Raritan River and the Passaic-Rahway-Elizabeth-Hackensack Rivers (fig. 31). Generally, the Passaic- Rahway, Elizabeth, and Hackensack
Rivers had much greater mole percentage of the Hmw species. Sediment from the Passaic River and the Raritan sample collected on June 2000 had a much higher percentage of naphthalene and 2,3,5-trimethylnapthalene than was present in the other rivers. In the sample collected from the Raritan River in June 2000, and the sediment from the Rahway, Elizabeth, and Hackensack Rivers, the most abundant PAHs were fluoranthene, pyrene, and chrysene.

The usefulness of the average dissolved PAH concentrations is limited because of the fact that many of the dissolved PAHs were either not detected or were removed by the blank-elimination procedures. The highest concentration of total dissolved PAHs $(20,000 \mathrm{ng} / \mathrm{L})$ was measured in the Elizabeth River (June 4, 2003); the lowest total PAH concentration $(3.4 \mathrm{ng} / \mathrm{L})$ was measured in the Passaic River (June 2000) (table 28). The average concentrations of total dissolved PAH values (table 30) followed the same trend exhibited by the total in the sediment (table 31): $180 \mathrm{ng} / \mathrm{L}$ for the Hackensack, $360 \mathrm{ng} / \mathrm{L}$ for the Raritan, $660 \mathrm{ng} / \mathrm{L}$ for the Passaic, $910 \mathrm{ng} / \mathrm{L}$ for the Rahway, and 9,520 ng/L for the Elizabeth.

Table 33. Average mole percentage of polycyclic aromatic hydrocarbons in suspended sediment samples collected from selected rivers in New Jersey.

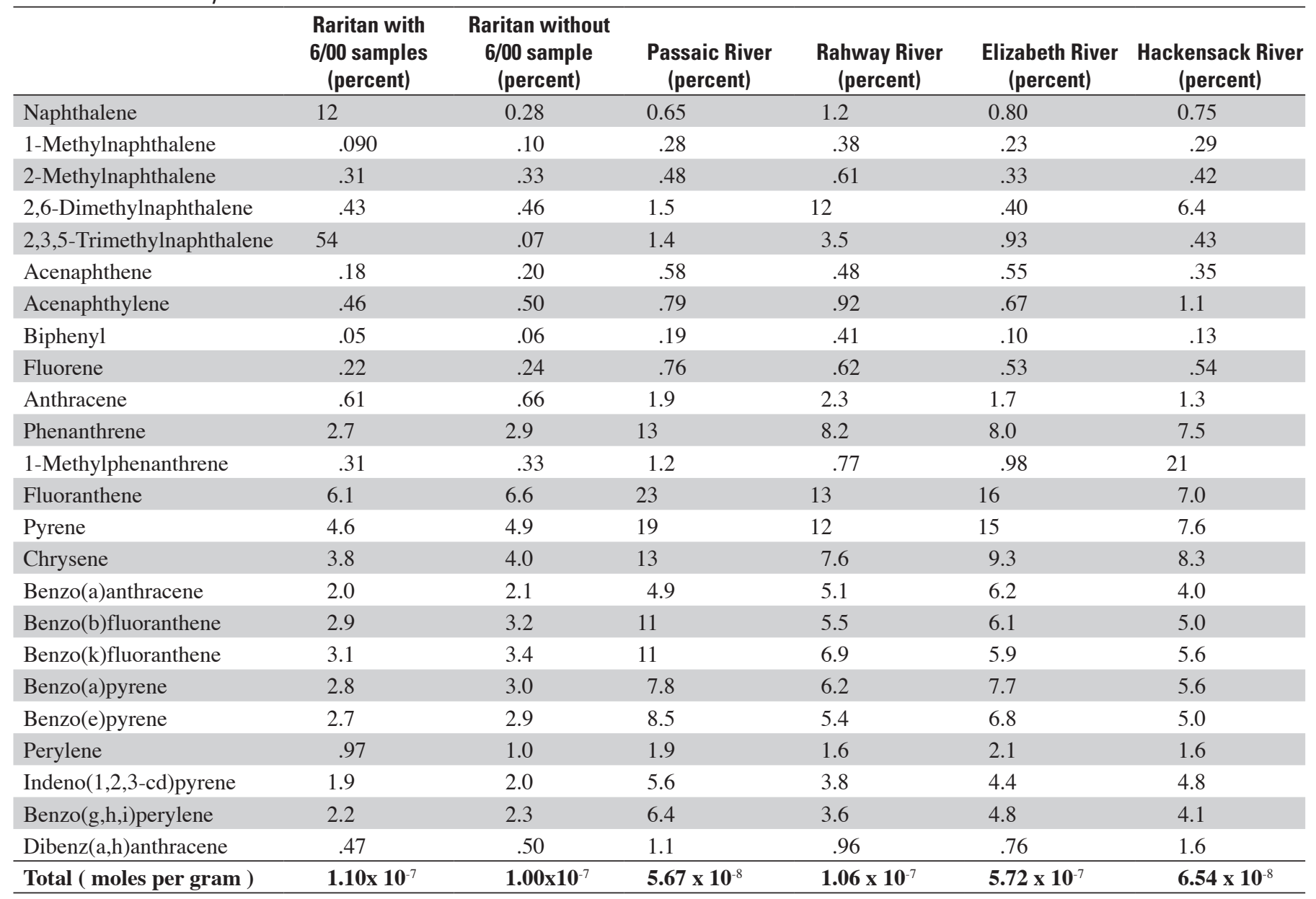




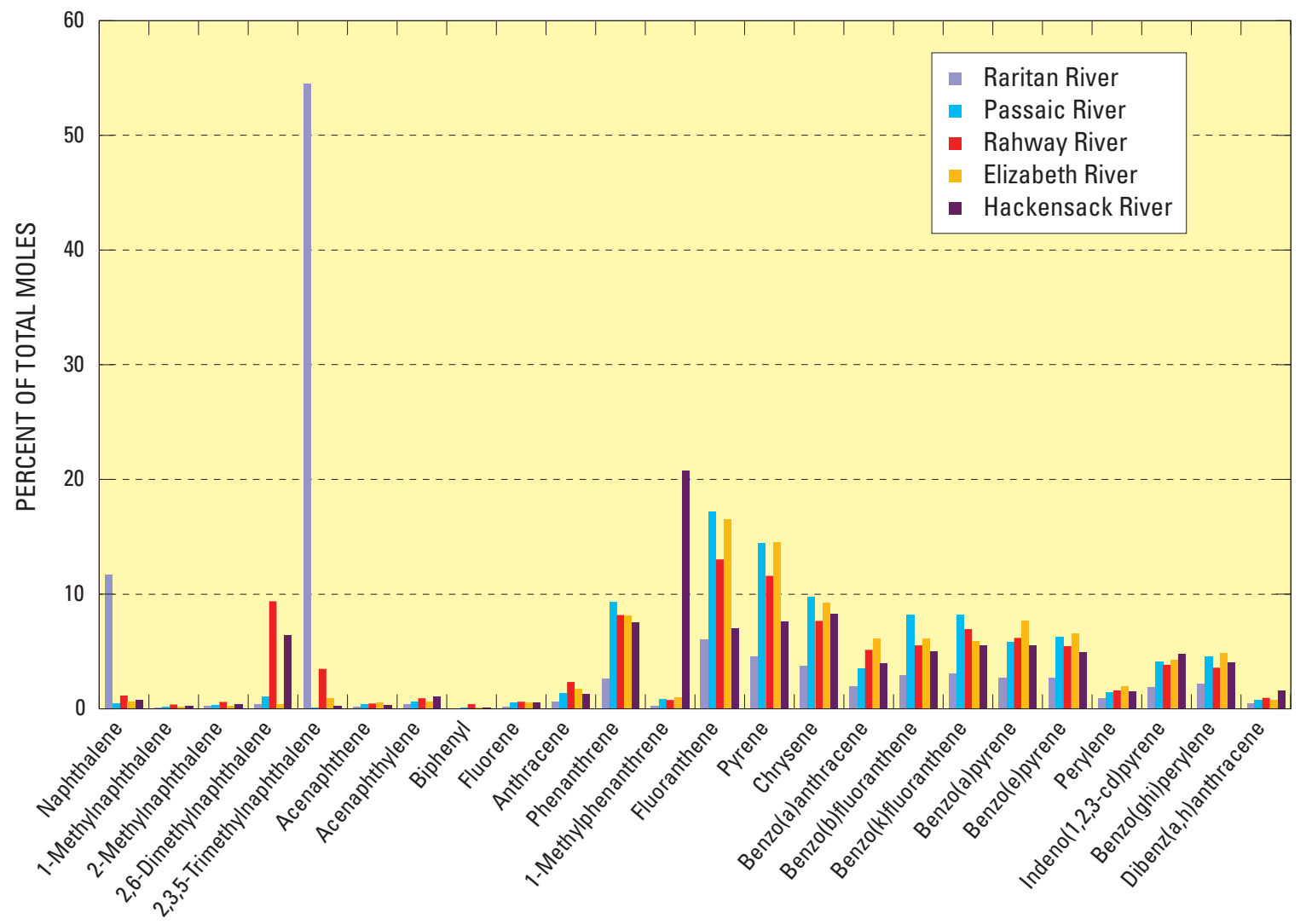

Figure 31. Average mole percent contribution of polycyclic aromatic hydrocarbons in suspended sediment collected from selected rivers in New Jersey. [Averages calculated without the Raritan River June 2000, nor Passaic River Dec. 2000 samples.]

The Hmw PAHs dominate in the dissolved phase (fig. 32), in spite of the higher solubility of the Lmw PAH compounds. The elevated concentrations of Hmw PAHs in the dissolved phase reflected higher concentration in the sediment phase and the higher volatility of the Lmw PAHs. The concentrations of dissolved Hmw PAHs in the Elizabeth River demonstrated the typical distribution of concentrations observed in the data sets. In contrast, the concentrations of the Lmw PAHs were highly variable between the rivers. The dissolved Lmw PAHs were dominated by phenanthracene, 1-methylphenanthrene, anthracene, and 2,6-dimethylnaphthalene; the Hmw PAHs were dominated by pyrene and fluoranthene.

The low dissolved concentrations and the preponderance of PAH contamination in the aqueous blanks resulted in only a few dissolved concentrations being available to calculate average concentrations. The available dissolved PAH concentrations and averages may not be representative of the conditions in the rivers because of the indication of field/laboratory contamination at levels sufficient to affect the sample concentrations. Therefore, the dissolved concentrations should be used with caution. Further work will be needed to develop large-volume sampling methods to accurately capture dissolved PAHs.

\section{Anomolous Concentrations}

The sample of suspended sediment collected from the Raritan River on June 27, 2000, had a reported concentration of 2,3,5-trimethylnaphthalene of 50,000 ng/L. Comparison with other measured concentrations show this level is extremely high, and therefore, this concentration is suspect and considered anomalous. The cause for this high concentration cannot be determined.

\section{Relation of Whole-Water Concentrations to Water-Quality Criteria}

Regulatory water-quality criteria for chemicals in surface water, expressed as "whole-water" concentrations in units of mass per volume of water, are the sum of the dissolved and sediment-bound concentrations calculated using:

$$
C_{T}=C_{s} *(S S / 1000)+C_{d}
$$

where

$$
\begin{aligned}
C_{T}= & \text { Total concentration, in mass per liter; } \\
C_{s}= & \text { Concentration of sediment-bound } \\
& \text { chemical, in mass per gram of sediment; }
\end{aligned}
$$




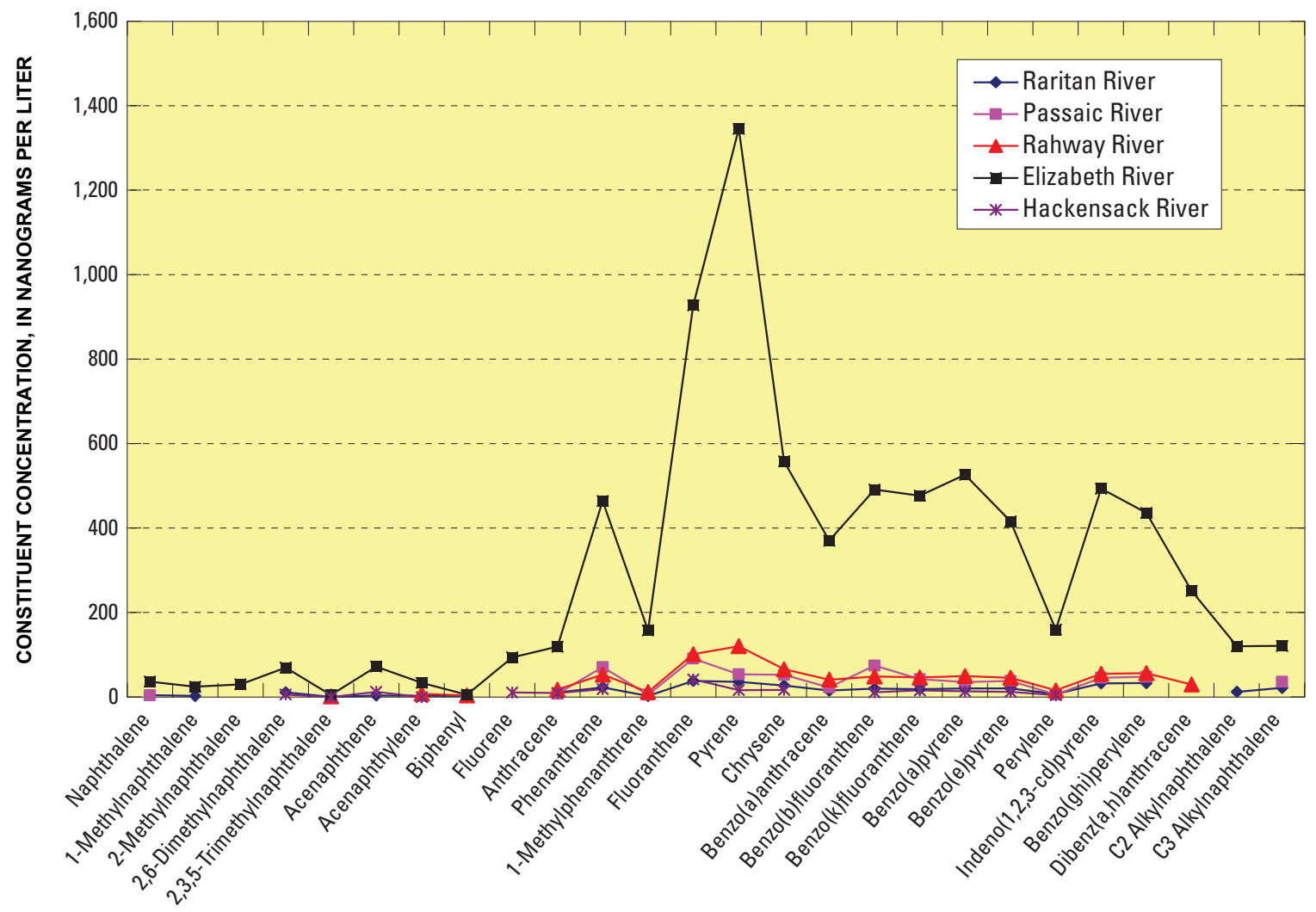

Figure 32. Average concentrations of dissolved polycyclic aromatic hydrocarbons in samples collected from selected rivers in New Jersey. [Averages calculated without the Raritan River June 2000, nor Passaic River Dec. 2000 samples.]

SS = Suspended-sediment concentration, in milligrams per liter;

and

$$
\begin{aligned}
& C_{d}= \text { Concentration of dissolved chemical, in } \\
& \text { mass per liter. }
\end{aligned}
$$

New Jersey regulatory water-quality criteria have been set for selected individual PAH compounds but not for total PAHs. Two criteria classes have been established, one for freshwater (FW2) such as the HOT samples, and another for saline estuarine or saline coastal waters (downstream of the HOT). Criteria classes include long-term (70-year) carcinogenic human-health exposure (based on a risk level of one-inone million), short-term noncarcinogenic exposure, chronic aquatic-life protections (4-day average exposure) and acute aquatic-life protection criteria for a 1-hour exposure. Criteria have not been set for all PAHs in all exposure categories.

The freshwater concentrations measured in this work were compared with the noncarcinogenic effect-based human-health criteria in table 29. Most of the samples collected exceeded the freshwater (FW2) water-quality criteria for benzo(a)anthracene, benzo(b)fluoranthene, benzo(k) fluoranthrene, benzo(a)pyrene, indeno(1,2,3-cd)pyrene, and dibenz(a,h)anthracene. The average concentrations for these compounds in each of the rivers also exceeded the FW2 water quality criteria. A lesser number of these samples exceeded the criteria for saline coastal/estuarine waters. None of the samples exceeded the water-quality criteria for fluorine, anthracene, fluoranthene, chrysene, or pyrene.

As discussed previously, a major control on the wholewater concentration of hydrophobic organic chemicals is the amount of sediment captured at the time of sampling. Total PAH concentrations are especially sensitive to the concentration of SS bound PAHs. Dissolved concentrations were very low and commonly were nondetected, in which case the total concentration is due entirely to the suspended-sediment phase. Also, when dissolved PAHs are found to be measurable, the sediment-bound PAH concentrations commonly can be 100 to 10,000 times greater (see for example, benzo(a)pyrene in the Elizabeth River sample). In these cases, a small change in the concentration of SS will result in a large change in the mass of chemicals associated with the sediment phase, thereby causing large changes in total concentration. Whole-water PAHs concentrations are unique in their sensitivity to changes in SS content, especially compared with the PCBs and dioxins. It is especially important, therefore, to define the conditions under which a sample was collected when total PAH concentrations are compared to water-quality standards. 


\section{Sources for the Polycyclic Aromatic Hydrocarbon Compounds}

PAHs are derived from three general sources: pyrogenic sources, which are the gases and particulates emitted during the burning of wood, coal, liquid hydrocarbon fuel, and the combustion of organic waste materials; petrogenic sources, which are raw and distilled petroleum products such as fuels, oils, tars, greases, and asphalt; and diagenetic sources, which are the natural products of the decay of organic matter such as muck and peat. Attempts have been made to use the relative abundances and ratios of selected "indicator" compounds to distinguish which of these general sources have contributed PAH to surface waters, lake and ocean sediments, and soils (Boehm and others, 1998; Yunker and others, 2002). This approach was employed to help elucidate the primary source(s) of PAH to the river sediments and water collected in this study.

Numerous pyrogenic and petrogenic PAH sources exist throughout the river basins studied here; the most ubiquitous being the combustion of hydrocarbons, such as the present-day burning of liquid gasoline, diesel fuel, and jet fuel for transportation and the burning of fuel oil for heating and electrical production. Also, the burning of wood and coal for residential heating and industrial power was historically common throughout the study area.

As described by Smicik and others (1996), PAHs are emitted in the gases of pyrogenic sources, where they condense from the gas phase and adhere to particulates. These particulates deposit onto the land or water surface in wet or dry precipitation and ultimately enter the rivers. Because the Hmw PAH will be more strongly attached to sediment, which helps protect these compounds from degradation, particles are likely to retain the Hmw-PAH signature of the pyrogenic source. The Lmw PAH compounds are more volatile and can transfer between the gas and the aqueous phases. As a result, the Lmw-PAH signature of the source(s) may not be fully retained in the sediment and water.

Adding to the pyrogenic PAHs are the petrogenic PAHs derived from unburnt hydrocarbons and coal-tar-based products. Petrogenic sources include crude or refined petroleum products (such as gasoline and heating oil) or impurities in oils, asphalt, tar, creosote used for wood preservation, or other heavy petroleum distillates such as asphalt and other bituminous road and building materials. Petrogenic PAHs are also common in leachate from landfill waste. PAHs are also present in coal, which was historically used throughout the region for residential and industrial uses. It is likely that unburnt coal particulates and dust have become incorporated into soils of the basins and ultimately will enter the rivers. Finally, diagenetic PAHs may be generated in the sediments stored behind small dams and wetlands that are common throughout the study area. These locations are favorable for degradation of natural organic matter and the formation of perylene, the 6-ringed PAH. Perylene is known to form in highly reducing sediments that receive substantial amounts of terrestrial organic matter (Boehm and others, 1998). Clearly, numerous pyrogenic, petrogenic, and diagenetic sources for PAHs exist in the New Jersey/New York area and likely have left a complex imprint on the PAH chemistry of the river sediment. It may be possible to identify the principal sources using the "fingerprint" of ratios of the PAHs in the tributary sediments.

The ratios of concentrations have been used to distinguish between petrogenic and pyrogenic sources (Hites and others, 1980; Laflamme and Hites, 1978; Simpson and others, 1996; Bumard and others, 1998; Yunker and others, 1996; Khalili and others, 1995). Generally, pyrogenic sources generate PAH assemblages in which the 4 and 5-ringed compounds dominate; petrogenic sources supply 2- and 3-ringed compounds along with alkylated naphthalene compounds (Boehm and others, 1998). As a result, sediment contaminated by pyrogenic sources typically has high percentages of the Hmw PAHs (>202 g/mole). Boehm and others (1998) showed the total pyrogenic PAH contribution can be estimated as the sum of the 3-, 4-, 5- and 6-ringed non-alkylated analytes (see figure 24 and table 21 for the identification of these compounds).

Building on the work of Boehm and others (1998), Bumard and others, (1998), Yunker and others (2002), selected ratios (using the less-stable PAH isomers in the numerator) of PAHs can be used to help identify sources. During combustion, the less-stable PAH isomer is favored to be produced over the more stable isomers of the same mass. The lessstable isomers are generally the linear compounds such as anthracene, benz(a)anthracene, and benz(a)pyrene, or for the 5-ringed compounds, fluoranthene and indeno(1,2,3-cd)pyrene (fig. 24). High abundances of these less-stable isomers is an indication of pyrogenic sources. Combustion also produces acenaphthene and acenapthylene that are apparently not common in petrogenic sources.

Yunker and others (2002) summarized four key concentration ratios that may be used for distinguishing between pyrogenic and petrogenic sources in environmental samples. These ratios include the 3-ringed PAH anthracene to anthracene + phenanthrene $(\mathrm{An} / \mathrm{An}+\mathrm{P})$, the 4-ringed $\mathrm{PAH}$ fluoranthene to fluoranthene + pyrene, $(\mathrm{Fl} / \mathrm{Fl}+\mathrm{Py})$ and benz(a)anthracene to benz(a)anthracene + chrysene, $(\mathrm{BaA} /$ $\mathrm{BaA}+\mathrm{Chy})$, and the 6-ringed PAH indeno(1,2,3-cd)pyrene to indeno(1,2,3-cd)pyrene + benzo(ghi)perylene (IP/IP+BghiP). The boundary values for the different ratios and the sources were identified as:

- Fl/Fl+Py ratios of $<0.4$ are characteristic of petroleum products, between 0.4 and 0.5 are characteristic of emissions from burning petroleum, and $>0.5$ are characteristic of the burning of grass, wood, or coal.

- An/An+P ratios of $\leq 0.1$ are characteristic of petroleum products, and $>0.1$ are characteristic of combustion of hydrocarbons.

- $\mathrm{BaA} / \mathrm{BaA}+$ Chy ratios of $<0.2$ are characteristic of petroleum products, $>0.35$ are characteristic of 
combustion emissions, and between 0.2 and 0.35 are characteristic of mixed petroleum-combustion sources.

- Ip/Ip+Bghi ratios $<0.2$ are characteristic of petroleum sources, between 0.20 and 0.50 are characteristic of liquid fossil-fuel combustion (vehicle and crude oil), and $>0.50$ are characteristic of grass, wood, and coal combustion.

The indicator ratios measured in the sediment and the boundaries for the ratios (Yunker and others, 2002) are plotted in figures 33 to 35 . The $\mathrm{Fl} / \mathrm{Fl}+\mathrm{Py}$ concentration ratios (fig. 33) for the sediments plot in the area suggesting a mixture of petroleum combustion sources for the PAHs; a few samples plot in the area indicating the combustion of grass/wood/ coal. The ratios of anthracene to phenathrene $(\mathrm{An} / \mathrm{An}+\mathrm{P})$ for the samples (fig. 33) plot well within the field indicating a combustion source, although a few samples from the Passaic River plot very near the boundary for petroleum (petrogenic) sources. The $\mathrm{BaA} / \mathrm{BaA}+\mathrm{Chy}$ ratios for the sediment plot within the combustion zone (fig. 34), although a number of samples have ratios that plot in the boundary for "mixed sources," indicating a combination of pyrogenic and petrogenic petroleum sources exist. The ratios of $\mathrm{Ip} / \mathrm{Ip}+\mathrm{BghiP}$ in the sediment (fig. 35) fall within the ranges for grass/wood/coal and fossil fuel combustion.

These indicator ratios indicate a mixture of combustion sources supplied PAHs to the river basins, which is also supported by the few ratios that could be calculated for the dissolved concentrations. A few of the dissolved samples from the Elizabeth River had ratios that may indicate petrogenic sources. The influence of combustion source is not surprising given the highly populated and industrialized nature of the study area, but it is interesting that the combustion of grass/ wood/coal is indicated for many of the samples. Because grass fires would be rare occurrences in this area, it is likely the PAH signature records the historic burning of coal and wood associated with heating and power production.

Although the concentration ratios for many of the PAHs indicate a mixed combustion source created the PAHs, there is an indication (for example, in the BaA ratios, fig. 34) that petrogenic source(s) may also have been important, because a number of samples have ratios indicating mixed sources. Further evidence for petrogenic sources comes from the concentrations of alkylated homologs of naphthalene (2-rings) and the alkylated-homologs of the PAHs phenanthrene (3-rings). Alkylated PAHs contain one or more alkane molecules (typically methyl, ethyl, or propyl) attached to the ring structure. Hydrocarbons (petrogenic sources) typically contain a high abundance of the Lmw (less than $202 \mathrm{~g} /$ mole) alkylated PAHs. For example, Sporsto and others (1983) reported that North Sea crude oil is dominated by the C1- and C2-alkylnaphthalenes, alkylphenanthrene, and alkylpyrene. They suggested these compounds serve as markers in sediment contaminated by a crude-oil source. Yunker and others (1993) demonstrated how the relative abundance of alky-substituted PAHs can be used to distinguish the presence of petrogenic sources. In

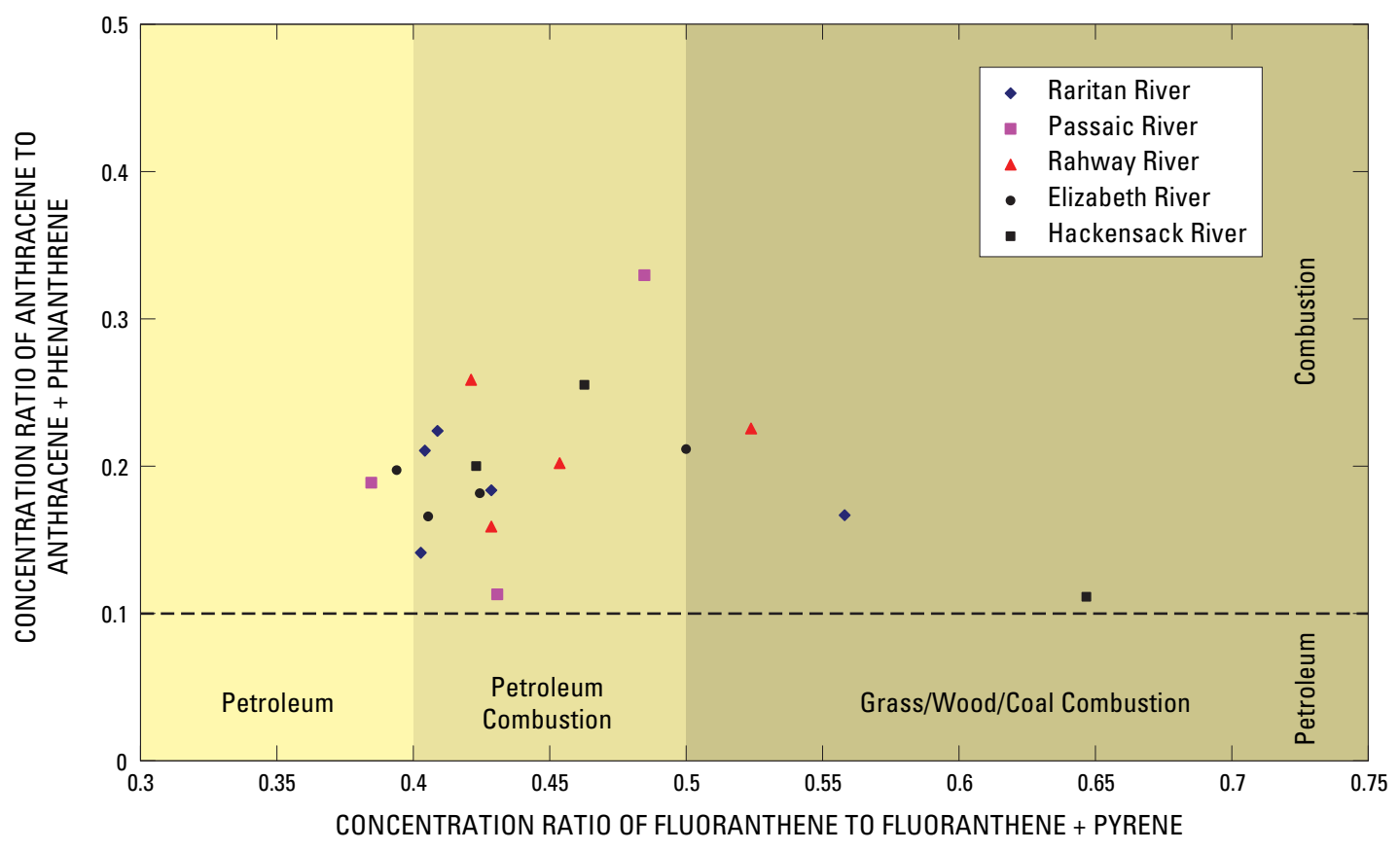

Figure 33. Ratio of fluoranthene to fluoranthene plus pyrene, and anthracene to anthracene plus phenanthrene in suspendedsediment samples collected from selected rivers in New Jersey. 


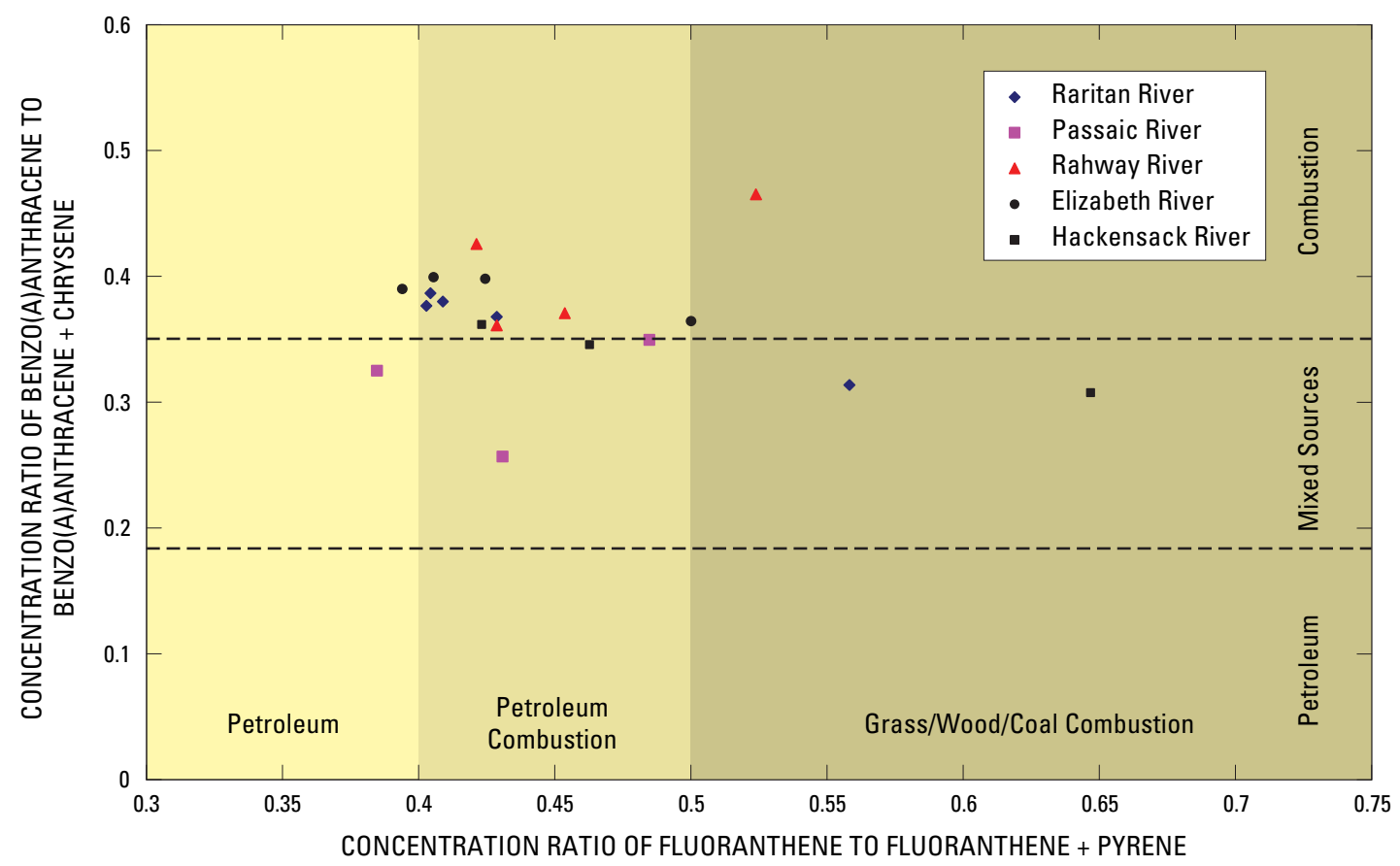

Figure 34. Ratio of fluoranthene plus pyrene, and benzo(a)anthacene to benzo(a)anthracene plus chrysene in suspended-sediment samples collected from selected rivers in New Jersey.

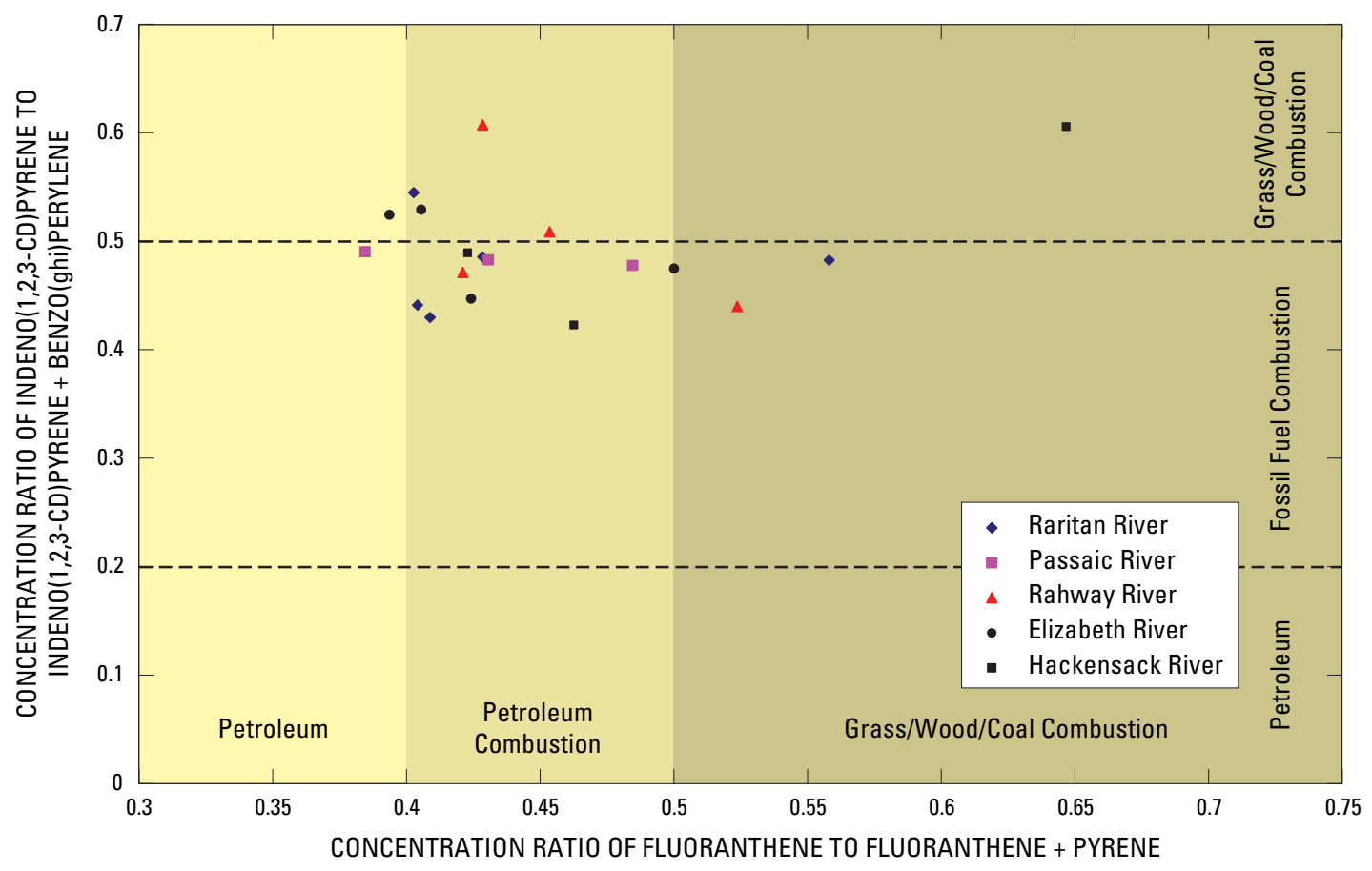

Figure 35. Ratio of fluroanthene to fluoranthene plus pyrene, and indenopyrene to indenopyrene plus benzo(ghi)perylene in suspended-sediment samples collected from selected rivers in New Jersey. 
sediment from the Mackenzie River, Yunker and others (1993) found that the trimethylated homolog dominated the naphthalene series, the mono-methyl homolog dominated the phenanthracene and anthracene groups, and the mono- or dimethylhomolog dominated the fluoranthene and pyrene groups. They interpreted these findings as indicating the sediment had been contaminated by a crude hydrocarbon source.

In this study, the alkylated naphthalenes measured were 1-methyl, 2-methyl, 2,6-dimethyl, and 2,3,5-trimethyl, and the total C2-alkylated and C3-alkylated naphthalenes. The C2- and C3-aklylated naphthalene values included all naphthalenes having either 2 or 3-alkane substitutions, respectively, which includes the individual naphthalene compounds reported in the analyses. For the alkylated phenanthrene group, only the compound 1-methylphenanthrene was measured.

Naphthalene and phenanthrene, along with their alkylated forms were detected in all the sediment samples collected from the New Jersey rivers. These compounds represent between 10 and 35 percent of the total PAHs concentration in the average suspended- sediment composition (table 31), and therefore, indicate petrogenic source(s) have supplied PAHs to these sediments. The relative concentrations were plotted (fig. 36); the Raritan River sample collected on June 22, 2000, was removed before calculating the average Raritan concen- tration. The June 27, 2000 sample from the Raritan River had a very high concentration of 2,3,5-trimethylnapthalene, the cause for which is unknown but may suggest a large, intermittent source existed for this compound in the river basin.

In general, the patterns produced by the relative compositions were similar for all the rivers (without the Raritan June 22, 2000, sample). Except in the Raritan River, the dominant naphthalene compounds in these rivers were usually the C2-alkylnaphthalenes, which can represent 23 to near 60 percent of the total naphthalenes in the sediment $(<5$ percent in the Raritan River sediment). The parent compound naphthalene made up only 2 to 14 percent of the total naphthalene; 2,6-dimethylnaphthalene represented 4 to 43 percent of the total. It is clear the alkylated compounds dominated this series of compounds, supporting that a hydrocarbon (petrogenic) source has impacted the sediment. The Elizabeth River composition differed from the other rivers, by having a much larger percentage of 2,3,5-trimethylnapthalene and smaller percentages of total $\mathrm{C} 2$-and $\mathrm{C} 3$-alkylated naphthalene compounds.

The alkylated phenanthrene homologs also indicate petrogenic sources exist for the PAHs in these rivers. While the phenanthrenes were dominated by the parent (non-alkylated) $\mathrm{C} 0$-phenanthrene, $\mathrm{C} 1$-methylphenanthrene was present at

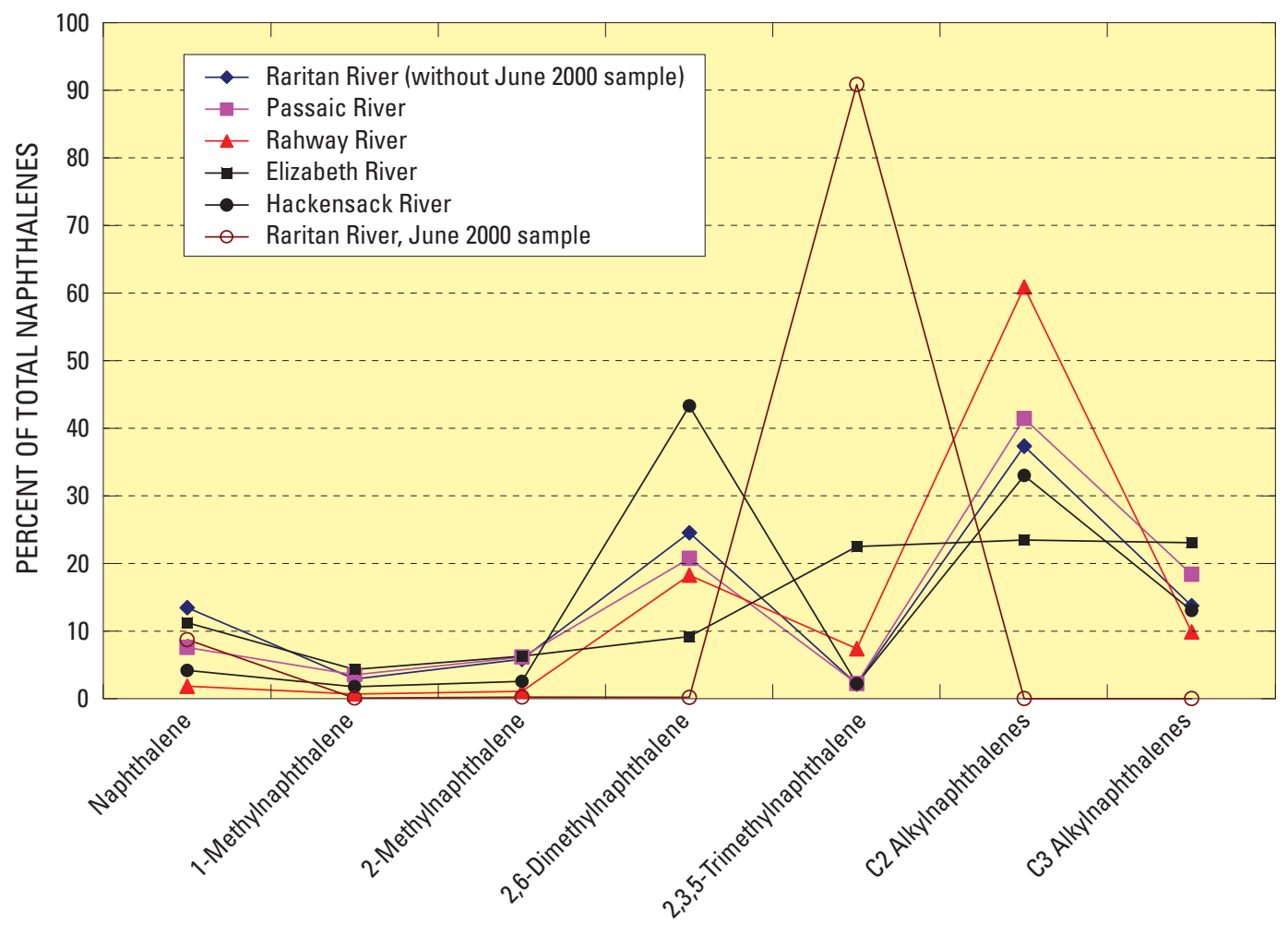

Figure 36. Alkylated naphthalenes in average suspended sediment in samples collected from selected rivers in New Jersey. 
substantial abundance, particulary in the Hackensack River. On average, it represented between 9 to 12 percent of the total phenanthrene except in the Hackensack River where it was 75 percent of the total. When calculated as $\mathrm{C} 0 / \mathrm{C} 0+\mathrm{C} 1$, the ratios ranged from 0.88 to 0.91 , except in the Hackensack River where the ratio was 0.25 . The low ratio in the Hackensack River implies that the waters in the Oradell Reservoir are generally protected from inputs of road-dust contaminants. Yunker and others (2002) reported that road dust and urban air had values ( 0.70 to 0.76$)$ near these levels, and all other pyrogenic and petrogenic sources had much lower ratios $(0.27$ to $0.53)$. The phenanthrene ratios in the river sediment, therefore, indicate road dust, which would contain a conglomeration of PAHs derived from combustion, soot emissions, and spilled hydrocarbons, is the source for the PAHs in the sediment.

Steinhauer and Boehm (1992) describe the calculation of a "fossil fuel pollution index" (FFPI), which uses the relative percent of the total of 2- and 3-ring $\mathrm{PAH}$, and polycyclic organosulfur compounds (dibenzothiophene and its alkyl homologues).

FFPI $=100 *\left[\Sigma\right.$ naphthalenes $\left(\mathrm{C}_{0}\right.$ to $\left.\mathrm{C}_{4}\right)+\Sigma$ dibenzothiphenes $\left(\mathrm{C}_{0}\right.$ to $\left.\mathrm{C}_{3}\right)+1 / 2 \Sigma$ phenanthrenes $\left(\mathrm{C}_{0}\right.$ to $\left.\mathrm{C}_{1}\right)+\Sigma$ phenanthrenes $\left(\mathrm{C}_{2}\right.$ to $\left.\left.\mathrm{C}_{4}\right)\right] / \Sigma \mathrm{PAH}$

where $\mathrm{C}_{0}$ represents the parent (non-alkylated) compound, $\mathrm{C}_{1}, \mathrm{C}_{2}, \mathrm{C}_{3}$, and $\mathrm{C}_{4}$ represent the mono- through tetra-alkylated compound concentration, and $\Sigma \mathrm{PAH}$ is the total PAH concentration in the sample. The FFPI index ranges from 100 for pure fossil fuel to 0 for pure combustion-derived PAH. The FFPI value therefore provides a means to quantify the contribution of each general source. FFPI values calculated for the average river sediment ranged from 34.7 for the Hackensack, 11.7 for the Passaic, 21.9 for the Raritan without the June 2000 sample, 10.4 for the Elizabeth, and 36.6 for the Rahway. A very high FFPI index (72.1) was obtained for the Raritan June 2000 sample, supporting the conclusion that this sample was affected by a substantial input of hydrocarbon. These FFPI values indicate (with the exception of the one Raritan sample) roughly 10 to 35 percent of the PAH were derived from petrogenic sources. However, the true FFPI index proportions are likely to be higher because the dibenzothiophenes (PAHs that containing a sulfur substitution) were not measured in this work.

Boehm and others (1998) discussed that perylene can be entirely assigned to the diagenetic production of PAHs. Perylene was present in all suspended-sediment samples collected in this work; the Elizabeth River had the highest average concentration $(2,800 \mathrm{ng} / \mathrm{g})$. The highest concentration $(7,500 \mathrm{ng} / \mathrm{g})$ was measured in a sample collected during December 2000 from the Passaic River. As discussed previously, this sample had anomalously high concentrations of PCBs and was thought to be fines that were transported after the peak storm discharge in the river had passed. The Passaic River drains the "Great Swamp" of northern New Jersey, an environment where compounds such as perylene are likely to form. Similarly, the Elizabeth and Rahway Rivers, which also had substantial concentrations of perylene in their sediment, flow through several small impoundments upstream of the sampling sites. These locations are favorable for anaerobic degradation of organic matter.

\section{Sediment-Water Partitioning}

The partitioning of the PAH between the sediment and water was investigated by calculating the respective concentration ratios. As mentioned previously, a limited number of "measureable" concentrations were reported for dissolved PAHs, because of the small sample size that was ultimately used for these compounds. This limits the number of compounds for which reliable in situ partitioning coefficients could be calculated. For the samples having co-existing dissolved and sediment concentrations, the available data allowed the organic-matter partitioning coefficient to be calculated:

$$
K_{o c}=C_{s} / C_{w}
$$

where

and

$$
\begin{aligned}
K_{o c}= & \text { organic matter distribution coefficient, in } \\
& \text { liters per kilogram of carbon; } \\
C_{s}= & \text { sediment concentration, in nanograms per } \\
& \text { kilogram of carbon; }
\end{aligned}
$$

$$
\begin{aligned}
& C_{w}= \text { dissolved concentration, in nanograms per } \\
& \text { liter. }
\end{aligned}
$$

A considerable amount of research has been performed investigating the partitioning of PAH compounds in soils and sediment (Mackay and others, 2000). Much of this work has used the distribution coefficient described in terms of organic matter content $\left(\mathrm{K}_{\mathrm{om}}\right)$ and related this coefficient to the octanolwater partitioning coefficient. For example, Means and others (1980) derived a logarithmic equation relating the distribution of 22 compounds that included pyrene, di-methylbenzanthracene, 3-methylchloranthrene, and dibenzanthracene to their $\mathrm{K}_{\text {ow }}$ values:

$$
\log K_{o m}=\log K_{o w} * 1.00-0.317
$$

where

$$
K_{o m}=\text { organic matter partitioning coefficient, in }
$$
liter per kilogram of organic matter;

and

$$
\begin{aligned}
K_{o w}= & \text { octanol-water partition coefficient, in } \\
& L_{\text {(octanol) }} / L_{(\text {water })}
\end{aligned}
$$

Schwarzenbach and others (1993) presented a similar equation relating $\mathrm{K}_{\mathrm{om}}$ to $\mathrm{K}_{\mathrm{ow}}$ for neutral organic aromatic compounds

$$
\log K_{o m}=\log K_{o w} * 1.01-0.7
$$


As discussed earlier, organic materials are typically made up of about one-half carbon, making $\mathrm{f}_{\text {om }}$ approximately equal to $2 * f_{\text {oc }}$, where $f_{\text {om }}$ (gram of organic matter/gram of sediment) and $f_{o c}$ (gram of organic carbon / gram of sediment) are the fraction of organic matter and fraction of organic carbon, respectively. The $f_{o c}$ value is related to the POC content of the water $(\mathrm{mgC} / \mathrm{L})$, the suspended-sediment concentration (mg sediment/Liter), and the volume filtered to obtain the sample (Liter):

$$
f_{o c}=P O C * L / S S * L=P O C / S S
$$

As a result, the $\mathrm{Kd}$ value related in terms of the organic matter content of the sample is given by:

$$
K_{o m}=K d / 2 * f_{o c}
$$

where

$$
\begin{aligned}
K_{o m}= & \text { organic matter distribution coefficient, in } \\
& \mathrm{kg}-1 \text { (organic matter) } / \mathrm{L}-1 \text { (water) } \\
f_{o c}= & \text { fraction of organic carbon }=\text { grams organic } \\
& \text { carbon } / \text { grams of sediment }
\end{aligned}
$$

The range and average $\mathrm{K}_{\mathrm{om}}$ 's measured in this work are shown on figure 37 by the solid lines and filled square symbols, respectively, for each compound having reportable dissolved concentrations. Only samples having measurable dissolved PAH compounds were used to construct these plots, nondetected concentrations replaced by one-half the EDL were not used. Also shown for each compound are the $\mathrm{K}_{\mathrm{om}}$ values (filled diamond symbols) for each compound predicted by the Means and others (1980) equation along with the average octanol-water partitioning coefficients (open circle) tabulated from literature values by Mackay and others (2000). These values are listed in table 34 .

Inspection of the data in figure 37 shows that the range of measured $\mathrm{K}_{\mathrm{om}}$ 's (calculated only for the compounds having measurable concentrations) spans two to three-orders of magnitude for each compound studied. The octanol-water coefficients and $\mathrm{K}_{\mathrm{om}}$ 's predicted from the octanol-water coefficients using the equations given above generally plot below the average measured $\mathrm{K}_{\mathrm{om}}$ value for the low-molecular weight compounds (fig. 37, compound number 1 through 12). The average $\mathrm{K}_{\text {om }}$ values for the Hmw PAHs plot near or slightly below the corresponding predicted $\mathrm{K}_{\mathrm{om}}$ values. Thus for the Lmw PAHs, the measured sediment concentrations are higher, or the

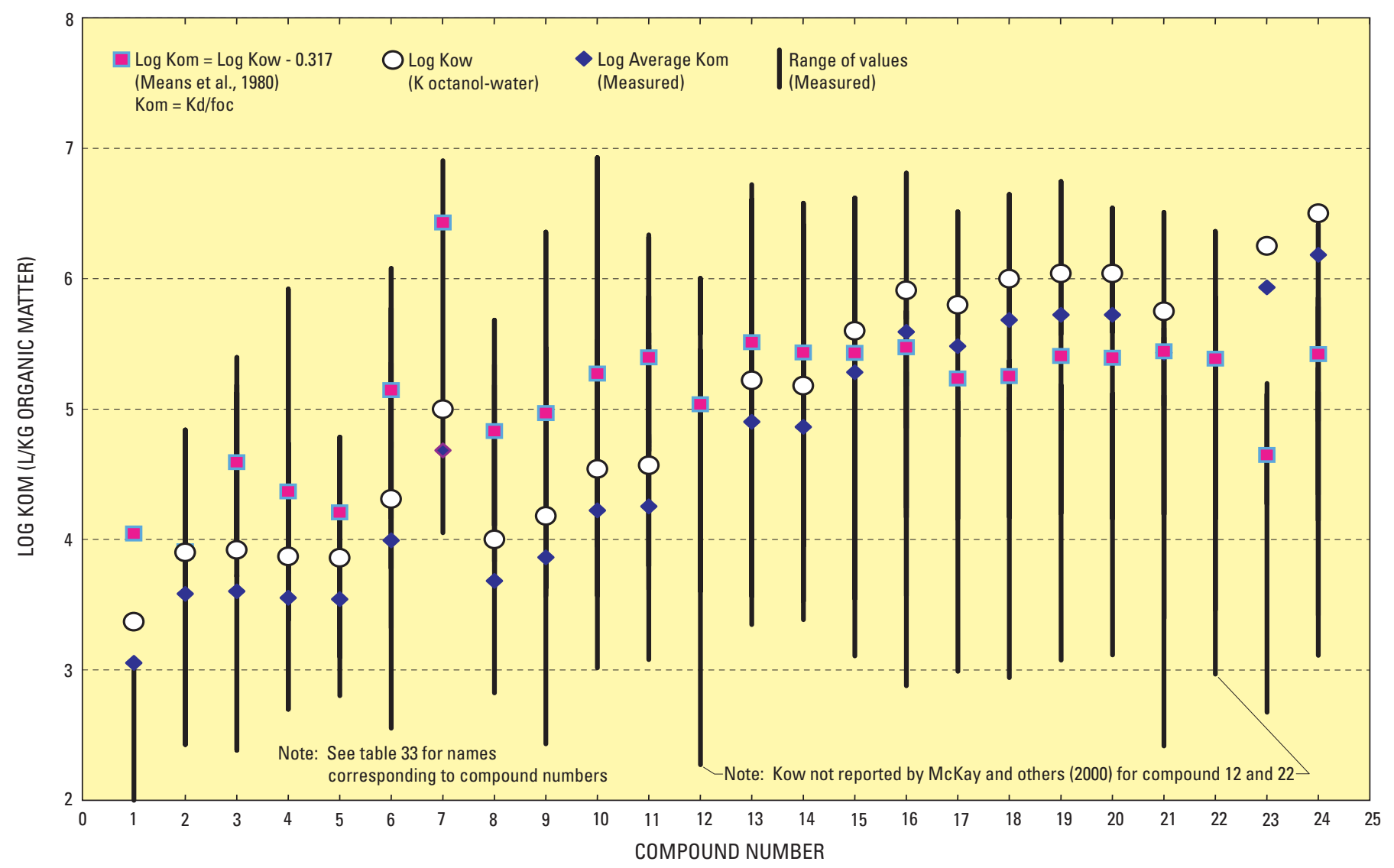

Figure 37. Measured and calculated distribution coefficients for polycyclic aromatic hydrocarbons in samples collected from selected rivers in New Jersey. 


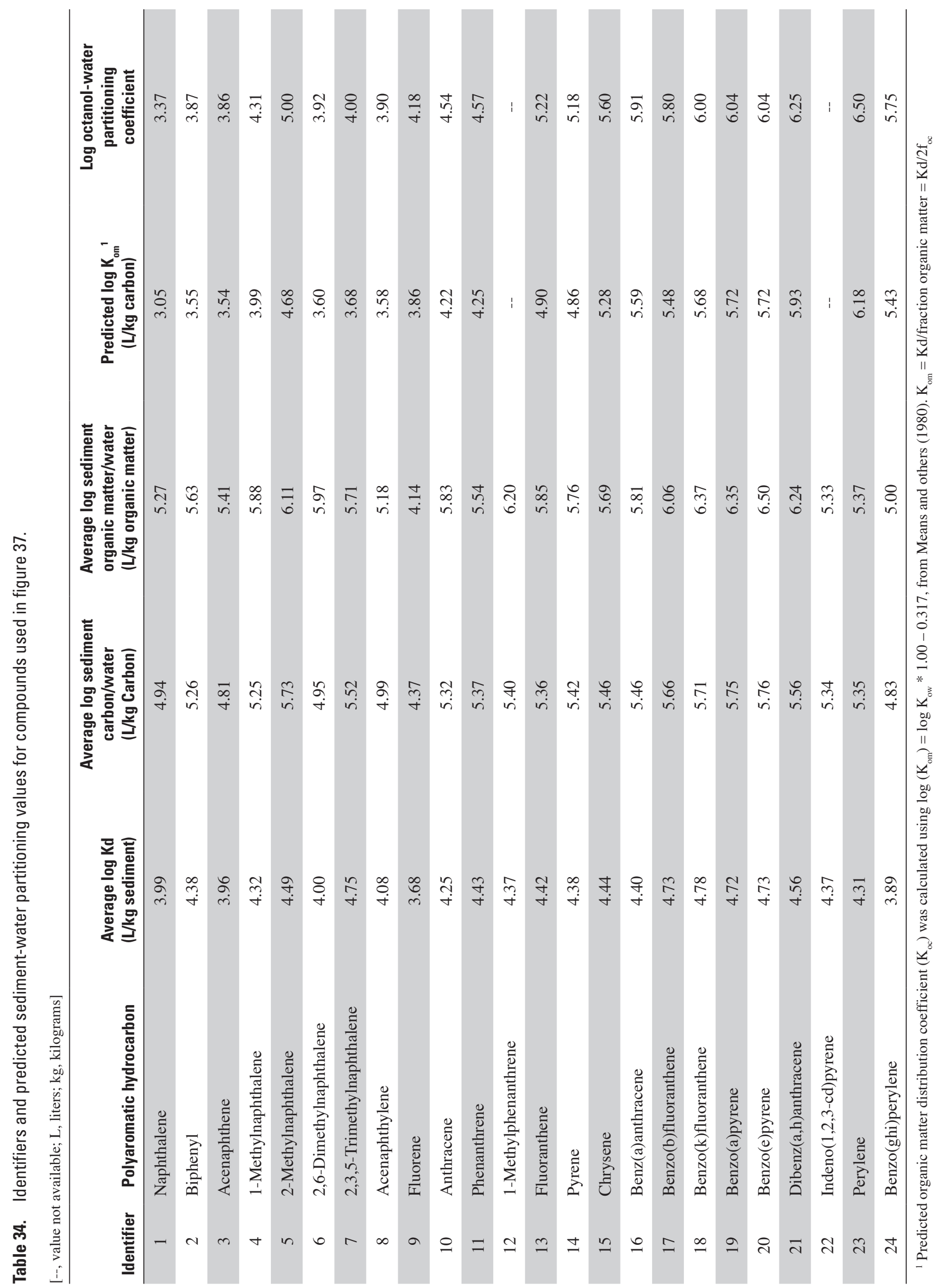


measured dissolved concentrations are lower, than would be expected on the basis of experimentally derived values $\left(\mathrm{K}_{\mathrm{ow}}\right)$. Predicted $\mathrm{K}_{\mathrm{om}}$ 's for the heavier molecular weight compounds would be much closer to the in situ values measured in these rivers. Perylene was the exception to this generalization; measured concentration ratios (fig. 37, compound 23) were much lower than the $\mathrm{K}_{\mathrm{om}}$ predicted from empirical relations.

The fact that the measured concentration ratios for the individual compounds spanned such a very large range may indicate that the PAHs in the suspended sediment of these rivers do not partition as expected, and thus the sediment and water may not be equilibrium. Predicting the sediment or water concentrations of the PAH compounds using $\mathrm{K}_{\mathrm{ow}}$ (or other empirical relations) may result in concentrations that differ considerably from actual values.

\section{Organochlorine Pesticides}

The concentrations of 27 organochlorine pesticides were measured in water and suspended sediment collected from the Raritan, Passaic, Rahway, Elizabeth, and Hackensack Rivers, the major tributaries to Newark and Raritan Bays. Of the organochlorine pesticides measured, the NY/NJ HEP plan has identified OCPs of concern: DDT and metabolites (DDE, DDD), chlordane and metabolites (alpha- and beta-chlordane, oxychlordane, cis- and trans-nonachlor), and dieldrin. Concentrations were measured in large-volume, flow-weighted composite samples collected during low-flow and storm discharge conditions. These data are used to make interpretations and to calculate riverine loads of OCPs to Newark and Raritan Bays from the watersheds above the HOT.

OCPs are a suite of anthropogenic chemicals designed to be toxic to cell functions of insects. With the exception of lindane, these compounds were banned from general use in the mid-1970s and 1980s, after which only limited use was allowed until the existing stocks were depleted. These pesticides were used throughout the New Jersey area for agricultural, residential, and commercial uses. A number of these pesticides, including DDT and hexachlorobenzene, were produced commercially in New Jersey and may have an industrial source in parts of the study area (Gillis and others, 1995; Bopp and others, 1991). However, the pesticides measured in this study most likely originated from use of commercial products in the river basins.

The OCPs that were studied (table 35) have structures consisting of aromatic rings amended with chlorine, oxygen, and sulfur (fig. 38). Hexachlorobenzene and the BHC compounds, for example, consist of an aromatic ring containing six attached chlorine atoms. The other OCPs have more complicated structures that, for many, resemble the structure of PCBs (for example, the DDT series). Several of the OCPs have metabolites, which are compounds formed from a parent compound through abiotic or biotic degradation reactions. An example are the metabolites of DDT (DDT (trichloro-bis(o-chlorophenyl)ethane)), DDE (dichloro-bis(p- chlorophenyl)ethane), and DDD (chloro-[dichloro(chloro phenylethyl]benzene), which are produced by degradation reactions. Isomers, which are compounds formed during the preparation of the parent compound but have distinctly different structural arrangements of atoms, also exist for several of the OCPs. Examples are the four BHC isomers, $\alpha-\mathrm{BHC}$, $\beta$-BHC, $\gamma$-BHC, and $\delta$-BHC. The parent compound $\gamma$-BHC (commonly known as lindane) contained varying proportions of each BHC isomer when it was produced.

Some of the other OCPs and their metabolites that were measured in this study include:

- DDT and its metabolites DDE and DDD, which are broad-spectrum chlorinated hydrocarbon insecticides. DDD was also formulated independently as an insecticide.

- Aldrin (hexacloro-hexahydro-dimethanonphthylene) and its epoxide metabolite dieldrin (hexacloro-epoxyoctahydro-dimethanonaphthalene), which are cyclodiene chlorinated hydrocarbon soil insecticides used extensively with corn production. Aldrin is rapidly metabolized to dieldrin by soil organisms.

- Endosulfan I and II (also known as $\alpha$-endosulfan and $\beta$-endosulfan, respectively), are two forms of a cyclodiene chlorinated hydrocarbon insecticide (hexachlorohexahydro-metano-benzodioxathiepin-oxide) that were made. Endosulfan sulfate (hexachloro-hexahydromethano-benzoioxathiepin-dioxide), the degradate of the endosulfans, was also measured.

- Heptachlor (heptachloro-tetrahydro-methano-Hindene) and its principal metabolite, heptachlor epoxide (heptachloro-hexahydro-methano- $2 \mathrm{H}$-indenooxirene), are polycyclic chlorinated hydrocarbon insecticides.

- Three isomers of BHC (also known as HCH or hexachlorocyclohexane) were measured: $\alpha-, \beta$-, and $\gamma$-BHC (commonly named lindane).

- Two isomers of chlordane (alpha-, beta,) exist, plus the oxygenated version oxychlordane. Chlordane's two forms are also called cis-nonachlor and trans-nonachlor, are typically considered separately from chlordane.

The OCPs exhibit a large range of physical-chemical properties including vapor pressure, solubility, and affinity for organic carbon (Mackay and others, 2000; Brooks, 1979) (table 35). Changes in compound structure (but not necessarily molecular composition) can result in profound changes in physical-chemical properties of the compounds, for example, vapor pressure or aqueous solubility. These differences help explain the relative concentrations observed in the sediment and aqueous phases. Like the other chlorinated hydrocarbon compounds measured in this study, the OCPs are generally (but not exclusively) hydrophobic and tend to associate with the particulates and POC. However, compounds such as BHC, 


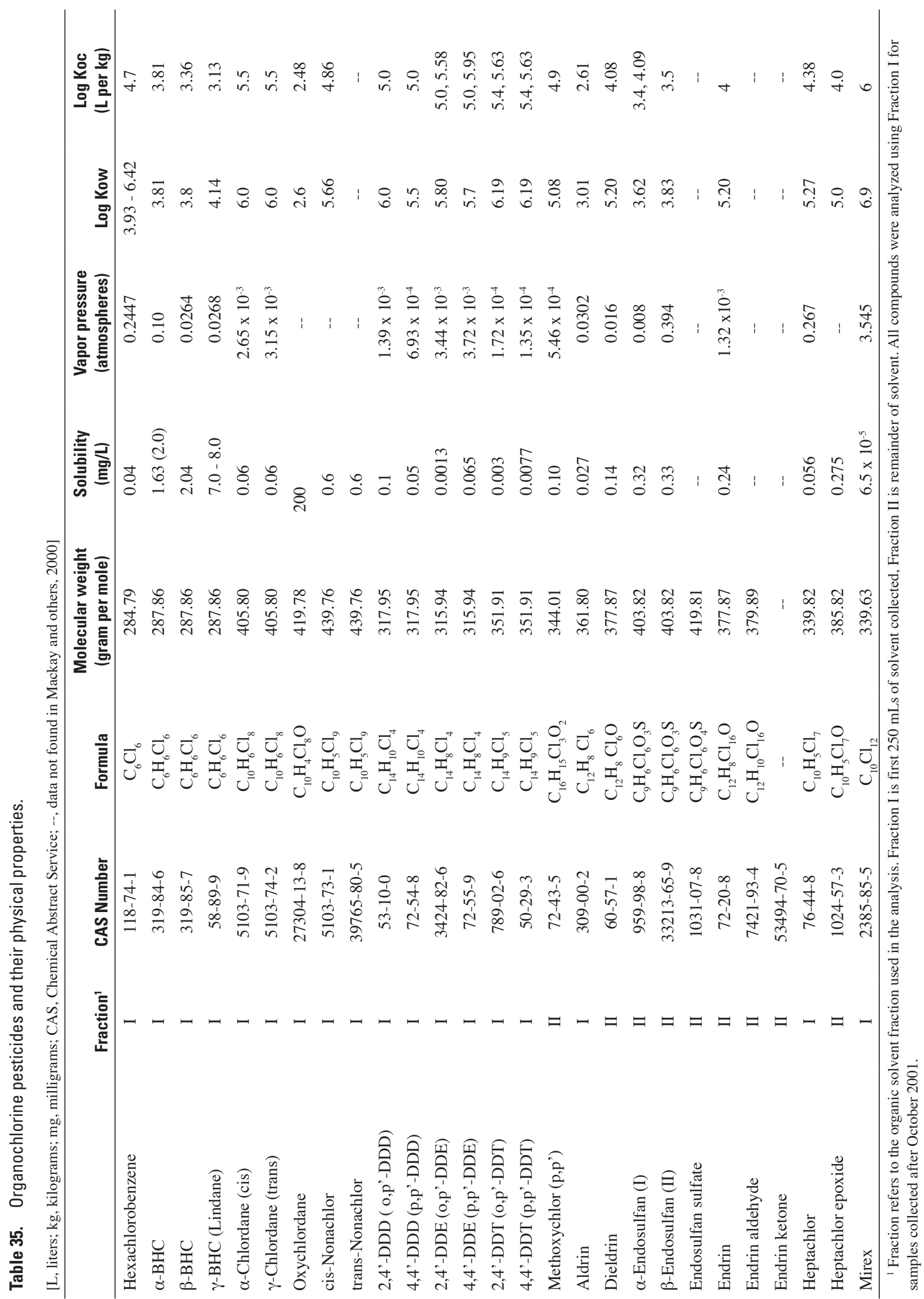



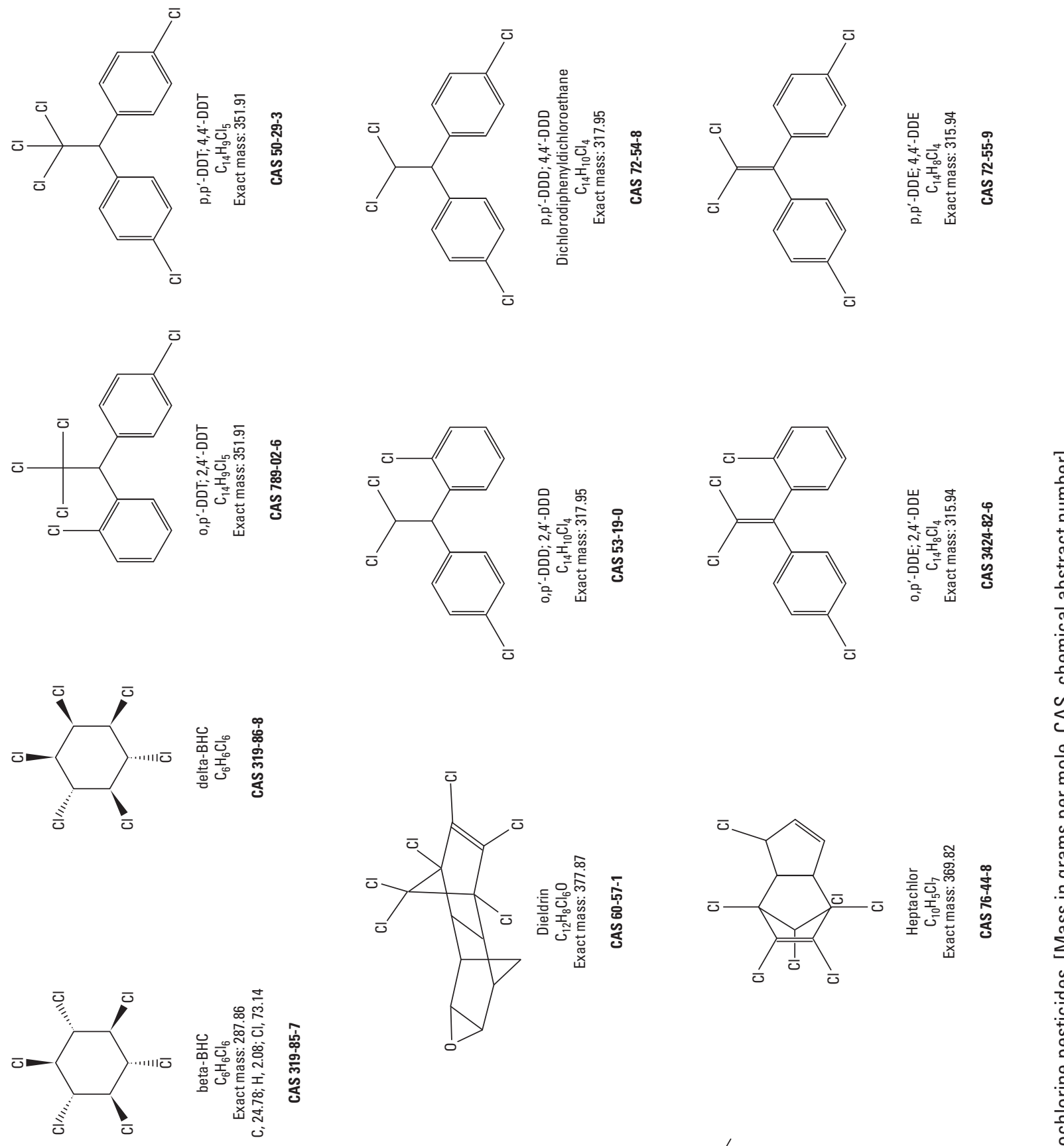
mirex, and to a lesser extent heptachlor, beta-endosulfan, and hexchlorobenzene, are sparingly soluble in water. As a result, these compounds are less persistent and are more mobile in the environment than the other OCPs and have dissolved forms that represent a substantial proportion of their total riverine load.

\section{Methods}

The sampling and analytical methods used are presented in detail in Bonin and Wilson (2006). The filters and XAD resin used to collect the samples were extracted and analyzed using a pseudo-isotope dilution method similar to the USEPA method for PCB analysis (1668A), using high resolution GC/ MS methods. It is important to note that this pesticide method is not a promulgated USEPA method. The chemists that developed the analysis felt that interferences may affect some of the OCPs, and therefore, recommended a two-fraction approach to the analysis. The filters and resin were extracted using a mixture of acetone and hexane and subjected to a Florisil/ sodium sulfate cleanup. Two portions of the extract were then collected. The first (approximately) $250 \mathrm{~mL}$ of the extract was collected as Fraction I, and the remainder collected as Fraction II. The only difference in the two fractions was the time in which the extract was in contact with the cleanup media, and therefore the polarity of the compounds eluted in the fractions. The two extracts were analyzed separately for the compounds listed in table 35. Nearly all the compounds were detected in Fraction I and usually only this extract was required to be analyzed (all samples after October 2001). However, if evidence of suppression or interference was found in Fraction I for endosulfan, endosulfan-sulfate, or the labeled endosulfan IS, Fraction II was then analyzed.

\section{Quality Assurance}

A number of quality control and assurance data were evaluated for the OCPs, including the IS recovery, and field and laboratory contamination of sampling media.

\section{Recovery of Internal Standards}

IS are ${ }^{13} \mathrm{C}$ or deuterated analogs of the native compounds added to each sample before extraction and are the reference used for calculating the mass of native compounds in the samples. The isotope dilution method is based on the premise that the labeled standards behave identically to the native compounds during sample preparation. Unlike the PCBs, dioxin/furans, and PAHs analyses, labeled OCP analogs were not available for every compound of interest. As a result, a number of pesticides had to be quantified by using closely related labeled analog compounds that may, or may not, act identically to the native OCPs during sample preparation. As a result, the analysis was not, by strict definition, an IS method but rather a surrogate standard method. The native compounds and the corresponding labeled analogs used to quantify con- centrations in this work are listed in table 36. A few of these IS were not yet available when the June and December 2000 samples were analyzed. Samples measured after October 2001 were analyzed with the larger suite of IS that included labeled endosulfan-II, aldrin, dieldrin, and endrin.

Because no promulgated IS method exists for pesticide analyses, the acceptable IS recoveries (20-150 percent recovery) for the pesticide compounds were adapted from USEPA PCB Method 1668-A (U.S. Environmental Protection Agency, 1999b). Low recoveries of a surrogate labeled standard (a standard that is not a direct analog of a native compound) may, or may not, indicate a problem or bias in referenced native compound(s) concentration(s). The lack of directly analogous labeled IS for each native compound of interest is a major weakness in the analytical methods used in this study.

Recoveries of less than 10 percent, including no recovery (indicated by NR on data tables) occurred for several of the IS in a number of sediment samples. Mainly affected were the labeled IS of endosulfan and $\alpha$-BHC. As a result, the concentrations of the native compounds referenced to these IS could not be reported, and the presence of these native compounds could not be verified. A total of 14 sediment samples had NR reported for the native endrin compounds, and 6 samples had NR reported for native dieldrin and heptachlor epoxide. Sediment samples affected by non-recoverable or low IS recoveries for three or more compounds (table 37) included Passaic River (June 2000, Mar. 2001, and Oct. 2001 samples), Hackensack (Mar. 2001 and Oct. 2001 samples), Rahway (April 2001 sample) and the Elizabeth River (the May 2001 sample).

None of the dissolved samples exhibited unacceptably low recovery of any of the IS, although low recoveries did occur for several of the field blanks and equipment blanks. One dissolved sample from the Hackensack River (July 2002) had unexplainably high recoveries of IS for ${ }^{13} \mathrm{C}_{6}-2,4^{\prime}$-DDT, ${ }^{13} \mathrm{C}_{12}-4,4$ '-DDT, ${ }^{13} \mathrm{C}_{6}$-heptachlor, and ${ }^{13} \mathrm{C}_{6}$-methoxychlor. As a result, concentrations of native compounds referenced to these standards may be biased.

Inspection of the IS recoveries for sediment samples indicates analytical problems affected only a few sediment analyses. Compounds most affected by the non-recovery of labeled IS included endosulfan I and II, $\gamma$-BHC, and methoxychlor, and to a lesser extent, compounds 4,4'-DDT and 4,4'DDE. The fact that poor recoveries affected only the sediment indicates that organic matter in the samples may have caused the low IS recoveries, and additional extract cleanup steps may be needed to ensure this method can be used for this suite of OCPs.

\section{Contamination of Blanks and Data Censoring}

Field blanks for the sediment and dissolved samples consisted of unused filters and XAD columns opened to the atmosphere at the time these sampling media were being installed in the field. Equipment blanks were produced by pumping 50 L of laboratory-grade water through a pair of XAD columns installed in a cleaned sampler immediately before it was 
Table 36. Native pesticide compounds and referenced internal standards.

[Native analytes are analytes that are present in the sample when it is collected; internal standards are added to the sample during the analytical procedure]

\begin{tabular}{|c|c|c|}
\hline $\begin{array}{l}\text { Labeled internal } \\
\text { standard }\end{array}$ & $\begin{array}{l}\text { Native analytes } \\
\text { referenced in samples } \\
\text { analyzed before } \\
\text { October } 2001\end{array}$ & $\begin{array}{l}\text { Native analytes } \\
\text { referenced in samples } \\
\text { analyzed after } \\
\text { October } 2001\end{array}$ \\
\hline${ }^{13} \mathrm{C}_{6}-$ Hexachlorobenzene & $\begin{array}{l}\text { Hexachlorobenzene } \\
\text { Heptachlor }\end{array}$ & Hexachlorobenzene \\
\hline${ }^{13} \mathrm{C}_{6} \beta-\mathrm{BHC}$ & $\begin{array}{l}\alpha-\mathrm{BHC} \\
\beta-\mathrm{BHC} \\
{ }^{13} \mathrm{C}_{6}-\alpha-\mathrm{BHC} \text { (field } \\
\quad \text { surrogate) } \\
\text { Aldrin }\end{array}$ & $\begin{array}{l}\alpha-\mathrm{BHC} \\
\beta-\mathrm{BHC} \\
{ }^{13} \mathrm{C}_{6}-\alpha-\mathrm{BHC} \text { (field } \\
\quad \text { surrogate) }\end{array}$ \\
\hline $\begin{array}{l}{ }^{13} \mathrm{C}_{6} \gamma \text {-BHC (Lindane) } \\
{ }^{13} \mathrm{C}_{6} \text { Oxychlordane } \\
{ }^{13} \mathrm{C}_{6} \text { trans-Nonachlor }\end{array}$ & $\begin{array}{l}\gamma \text {-BHC } \\
\delta \text {-BHC } \\
\text { cis-Chlordane } \\
\text { Not used } \\
\text { Not used }\end{array}$ & $\begin{array}{l}\gamma \text {-BHC } \\
\delta \text {-BHC } \\
\text { cis-Chlordane } \\
\text { Oxychlordane } \\
\text { trans-Chlordane }\end{array}$ \\
\hline 4,4'-DDD-d8 & $\begin{array}{l}4,4^{\prime} \text {-DDD } \\
2,4^{\prime} \text {-DDD } \\
\text { cis-nonachlor }\end{array}$ & $\begin{array}{l}\text { 4,4'-DDD } \\
\text { 2,4'-DDD } \\
\text { cis-nonachlor }\end{array}$ \\
\hline${ }^{13} \mathrm{C}_{6} 2,4$ '-DDE & $\begin{array}{l}2,4^{\prime}-\mathrm{DDE} \\
4,4^{\prime}-\mathrm{DDE}\end{array}$ & 2,4'-DDE \\
\hline${ }^{13} \mathrm{C}_{12} 4,4$ '-DDE & $\begin{array}{l}4,4^{\prime} \text {-DDE } \\
\text { Mirex }\end{array}$ & $\begin{array}{l}\text { 4,4'-DDE } \\
\text { Mirex }\end{array}$ \\
\hline${ }^{13} \mathrm{C}_{6} 2,4$ '-DDT & $\begin{array}{l}\text { 2,4'-DDT } \\
4,4^{\prime}-\mathrm{DDT}\end{array}$ & 2,4'-DDT \\
\hline${ }^{13} \mathrm{C}_{12} 4,4$ '-DDT & Not used & 4,4'-DDT \\
\hline $\begin{array}{l}{ }^{13} \mathrm{C}_{6} \text { Aldrin } \\
{ }^{13} \mathrm{C}_{6} \text { Dieldrin } \\
{ }^{13} \mathrm{C}_{6} \text { Endrin } \\
{ }^{13} \mathrm{C}_{6} \text { Heptachlor } \\
{ }^{13} \mathrm{C}_{6} \text { Heptachlor Epoxide }\end{array}$ & $\begin{array}{l}\text { Not used } \\
\text { Not used } \\
\text { Not used } \\
\text { Not used } \\
\text { Not used }\end{array}$ & $\begin{array}{l}\text { Aldrin } \\
\text { Dieldrin } \\
\text { Endrin } \\
\text { Heptachlor } \\
\text { Heptachlor Epoxide }\end{array}$ \\
\hline Endosulfan I-d4 & $\begin{array}{l}\text { Endosulfan-I } \\
\text { Endosulfan-II } \\
\text { Endrin } \\
\text { Endrin Aldehyde } \\
\text { Endrin Ketone }\end{array}$ & $\begin{array}{l}\text { Endosulfan-I } \\
\text { Endrin Aldehyde } \\
\text { Endrin Ketone }\end{array}$ \\
\hline Endosulfan II-d4 & Not used & Endosulfan-II \\
\hline${ }^{13} \mathrm{C}_{6}$ Methoxychlor & $\begin{array}{l}\text { Methoxychlor } \\
\text { Endosulfan-Sulfate } \\
\text { Heptachlor Epoxide B }\end{array}$ & $\begin{array}{l}\text { Methoxychlor } \\
\text { Endosulfan-Sulfate } \\
\text { Heptachlor Epoxide B }\end{array}$ \\
\hline
\end{tabular}

brought to the field. A summary of the results for the field, equipment, and laboratory method blanks is presented in tables 38, 39, and 40.

Method blanks were prepared in the laboratory with each batch of approximately 20 samples analyzed. Laboratory water was used for the dissolved samples (XAD resin), and clean quartz sand was used as media for the sediment samples (filters). The method blanks were extracted and analyzed identically to the field samples. Summaries of the average concentrations, minimum and maximum values, the number of detections in each fraction (I and II) for the data set consisting of XAD and filter method blanks, and the detection limits are presented in table 40. Hexachlorobenzene was present in nearly all method blanks at values up to $1.4 \mathrm{ng}$. 2,4'-DDT and 2,4'-DDD and methoxychlor were the compounds most commonly detected in the method blanks and were present at concentrations up to $0.49 \mathrm{ng}$. The ubiquitous presence of hexachlorobenzene in the method blanks at concentrations near the field and equipment blank levels indicates laboratory contamination may have affected measured concentrations and supports the importance of a comprehensive blank correction procedure to cull the measured concentrations.

The reported EDLs and the masses measured in the various blanks represented the lower limits for the reliable detection of dissolved pesticides by this method. Average levels for OCPs present in the XAD resin field and equipment blanks ranged from $0.04 \mathrm{ng}$ to $2.0 \mathrm{ng}$ (generally less than 0.5 ng) (table 38). Hexachlorobenzene was detected in all the resin blanks analyzed at values between 0.09 and $0.98 \mathrm{ng}$, indicating a laboratory contamination source for this compound. Heptachlor and methoxychlor were also present in most of the XAD resin blanks. Generally, the detected masses were below $1 \mathrm{ng}$, although in one blank methoxychlor was measured at $14 \mathrm{ng}$, the largest mass recorded for the prepared blanks. Detection limits for the compounds when not present in the XAD resin ranged from $0.01 \mathrm{ng}$ for aldrin, alpha-chlordane and transnanachlor, up to $9 \mathrm{ng}$ for endrin ketone, averaging between 0.05 and $2.0 \mathrm{ng}$. For 50-L sample volumes, these masses represent concentrations of 2 to $40 \mathrm{pg} / \mathrm{L}$.

With the exception of hexachlorobenzene, only a few of the pesticide compounds were consistently detected in the prepared filter blanks (table 39). Hexachlorobenzene was found at low (0.09 to $0.39 \mathrm{ng}$ ) but measurable concentrations in the prepared filter blanks, again indicating a laboratory contamination source. All other compounds were detected only occasionally and at masses that typically average less than $0.5 \mathrm{ng}$. For the compounds not detected in a field blank (filters), the average detection limits ranged from $0.02 \mathrm{ng}$ for hexachlorobenzene up to $0.88 \mathrm{ng}$ for cis-nonachlor, the compound for which the highest detection limit (3.7 ng) was recorded. These values approximate the lower limit of reliable results for pesticides in the sediment samples. 


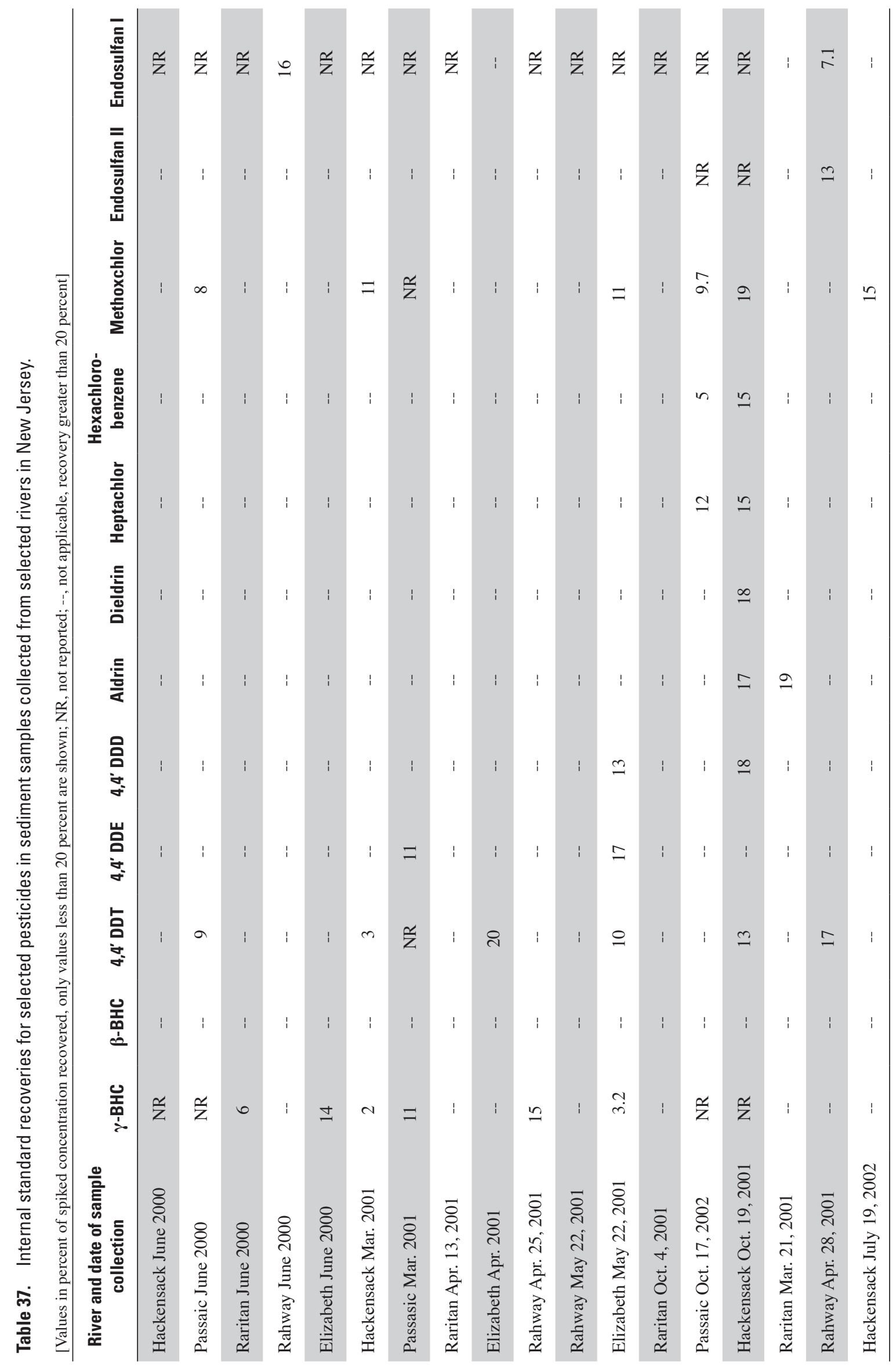


Table 38. Summary of masses and estimated detection limits for pesticides in exchange-resin field blanks.

[ng, nanograms; --, not applicable]

\begin{tabular}{|c|c|c|c|c|c|c|c|c|}
\hline & \multicolumn{4}{|c|}{$\begin{array}{l}\text { Dectection limits for compounds detected in } \\
\text { XAD resin field and equipment blanks }\end{array}$} & \multicolumn{4}{|c|}{$\begin{array}{l}\text { Detection limits for compounds } \\
\text { when not present in resin }\end{array}$} \\
\hline & $\begin{array}{l}\text { Minimum } \\
\text { (ng) }\end{array}$ & $\begin{array}{l}\text { Maximum } \\
\quad(\mathrm{ng})\end{array}$ & $\begin{array}{c}\text { Average } \\
\text { (ng) }\end{array}$ & $\begin{array}{c}\text { Count } \\
\text { (16 total) }\end{array}$ & $\begin{array}{c}\text { Minimum } \\
\text { (ng) }\end{array}$ & $\begin{array}{c}\text { Maximum } \\
\text { (ng) }\end{array}$ & $\begin{array}{c}\text { Average } \\
\text { (ng) }\end{array}$ & $\begin{array}{c}\text { Count } \\
\text { (16 total) }\end{array}$ \\
\hline Aldrin & 0.06 & 0.12 & 0.09 & 3 & 0.01 & 0.50 & 0.05 & 13 \\
\hline$\beta-\mathrm{BHC}$ & .00 & .00 & -- & 0 & .04 & 1.0 & .16 & 16 \\
\hline$\gamma$-BHC (Lindane) & .23 & .26 & .25 & 2 & .05 & 1.7 & .22 & 16 \\
\hline alpha-Chlordane & .00 & .00 & -- & 0 & .01 & 6.0 & 1.3 & 13 \\
\hline gamma-Chlordane & .11 & .34 & .25 & 4 & .06 & 2.4 & .33 & 16 \\
\hline 2,4'-DDE & .14 & .28 & .21 & 2 & .06 & 6.8 & .81 & 16 \\
\hline 2,4'-DDT & .05 & .07 & .06 & 2 & .06 & 3.5 & .47 & 16 \\
\hline 4,4'-DDD & .08 & .14 & .10 & 3 & .03 & .78 & .15 & 16 \\
\hline 4,4'-DDE & .49 & 2.2 & .99 & 4 & .05 & 1.2 & .18 & 16 \\
\hline 4,4'-DDT & .05 & 2.8 & 1.1 & 3 & .03 & .68 & .12 & 16 \\
\hline Hexachlorobenzene & .09 & .98 & .49 & 16 & .03 & 1.4 & .19 & 15 \\
\hline Mirex & .10 & .10 & .10 & 1 & .06 & 1.6 & .42 & 16 \\
\hline beta-Endosulfan & .00 & .00 & -- & 0 & .06 & 3.1 & 1.0 & 16 \\
\hline Endrin & .00 & .00 & -- & 0 & .03 & 2.2 & .25 & 15 \\
\hline Endrin aldehyde & .00 & .00 & -- & 0 & .06 & 6.5 & 1.5 & 16 \\
\hline Endrin ketone & .00 & .00 & -- & 0 & .06 & 9.0 & 2.0 & 16 \\
\hline Endosulfan sulfate & .20 & .20 & .20 & 1 & .06 & 6.2 & 1.9 & 16 \\
\hline Heptachlor & .08 & .98 & .33 & 14 & .03 & .09 & .05 & 12 \\
\hline Heptachlor epoxide & .04 & .04 & .04 & 1 & .05 & 2.3 & .31 & 16 \\
\hline Methoxychlor & .10 & 14 & 2.0 & 13 & .03 & .37 & .14 & 12 \\
\hline
\end{tabular}


Table 39. Summary of masses and estimated detection limits for pesticides in filter blanks.

[ ng, nanograms; --, not applicable]

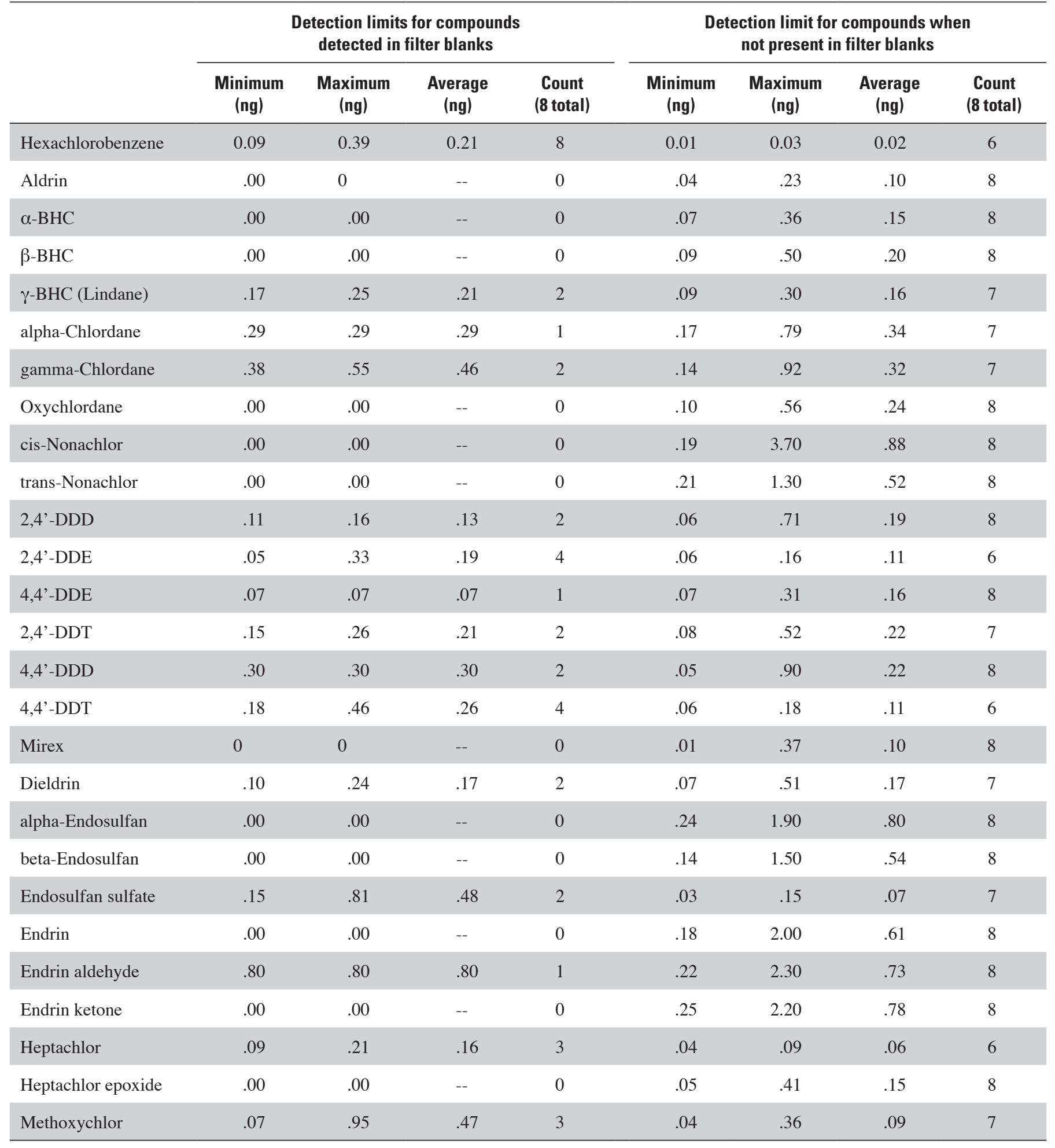


Table 40. Summary of results for Fraction I and II compounds in resin and filter method blanks.

[ng, nanograms; -- , not detected or not applicable]

\begin{tabular}{|c|c|c|c|c|c|c|c|c|}
\hline & \multicolumn{4}{|c|}{$\begin{array}{l}\text { Detection limits for compounds } \\
\text { detected in method blanks }\end{array}$} & \multicolumn{4}{|c|}{$\begin{array}{l}\text { Detection limits for compounds } \\
\text { not detected in method blanks }\end{array}$} \\
\hline & $\underset{\text { (ng) }}{\text { Minimum }}$ & $\begin{array}{l}\text { Maximum } \\
\text { (ng) }\end{array}$ & $\begin{array}{l}\text { Average } \\
\text { (ng) }\end{array}$ & $\begin{array}{l}\text { Count } \\
\text { (17) }\end{array}$ & $\begin{array}{l}\text { Minimum } \\
\text { (ng) }\end{array}$ & $\begin{array}{l}\text { Maximum } \\
\text { (ng) }\end{array}$ & $\begin{array}{l}\text { Average } \\
\text { (ng) }\end{array}$ & $\begin{array}{l}\text { Count } \\
\text { (17) }\end{array}$ \\
\hline \multicolumn{9}{|c|}{ Fraction I Compounds } \\
\hline Trans-Nonachlor & -- & -- & -- & 0 & 0.08 & 45 & 3.0 & 17 \\
\hline OxyChlordane & -- & -- & -- & 0 & .05 & 0.46 & .19 & 17 \\
\hline Mirex & 0.10 & 0.24 & 0.17 & 2 & .01 & .33 & .09 & 17 \\
\hline Hexachlorobenzene & .072 & 1.4 & .23 & 16 & .01 & .04 & .02 & 13 \\
\hline Heptachlor & .072 & .16 & .11 & 3 & .02 & .42 & .09 & 16 \\
\hline gamma-Chlordane & .12 & .12 & .12 & 1 & .06 & .79 & .29 & 16 \\
\hline$\gamma$-BHC (Lindane) & -- & -- & -- & 0 & .03 & .36 & .17 & 17 \\
\hline cis-Nonachlor & -- & -- & -- & 0 & .07 & 1.5 & .55 & 17 \\
\hline$\beta-\mathrm{BHC}$ & -- & -- & -- & 0 & .03 & .49 & .19 & 17 \\
\hline alpha-Chlordane & -- & -- & -- & 0 & .07 & .66 & .30 & 17 \\
\hline$\alpha-\mathrm{BHC}$ & -- & -- & -- & 0 & .03 & .26 & .13 & 17 \\
\hline Aldrin &.-- & -- & -- & 0 & .02 & .29 & .09 & 17 \\
\hline 4,4'-DDT & .076 & .12 & .10 & 3 & .03 & .49 & .17 & 17 \\
\hline 4,4'-DDE & .54 & .54 & .54 & 1 & .06 & .45 & .21 & 17 \\
\hline 4,4'-DDD & .079 & .15 & .12 & 2 & .02 & .50 & .15 & 17 \\
\hline 2,4'-DDT & .15 & .45 & .32 & 5 & .03 & 1.1 & .26 & 17 \\
\hline 2,4'-DDE & .11 & .20 & .16 & 3 & .04 & .38 & .15 & 17 \\
\hline 2,4'-DDD & .11 & .25 & .17 & 4 & .02 & .61 & .17 & 17 \\
\hline \multicolumn{9}{|c|}{ Fraction II Compounds } \\
\hline Dieldrin & .14 & .25 & .18 & 3 & .05 & .81 & .27 & 14 \\
\hline Endosulfan sulfate & -- & -- & -- & 0 & .03 & .75 & .21 & 16 \\
\hline Endrin & -- & -- & -- & 0 & .06 & 30 & 2.3 & 16 \\
\hline Endrin aldehyde & .33 & .80 & .57 & 2 & .12 & 23 & 2.3 & 16 \\
\hline Endrin ketone & -- & -- & -- & 1 & .13 & 24 & 2.4 & 16 \\
\hline Heptachlor epoxide & .08 & .08 & .08 & 1 & .03 & .93 & .19 & 15 \\
\hline Methoxychlor & .05 & .49 & .16 & 6 & .01 & .95 & .16 & 15 \\
\hline alpha-Endosulfan & .62 & .62 & .62 & 1 & .15 & 17 & 2.1 & 16 \\
\hline beta-Endosulfan & -- & -- & -- & 0 & .09 & 11 & 1.4 & 16 \\
\hline
\end{tabular}




\section{Recovery of Field Surrogates}

The field surrogate for pesticides in the dissolved phase consisted of ${ }^{13} \mathrm{C}$-labeled $\alpha$-BHC that was spiked (in the laboratory) onto the inlet end of one XAD column used during each sampling event. The field surrogate was included to help provide a measure of the efficiency of the sampling and extraction procedures. Specifically, the field surrogates were added as an attempt to determine if compounds were held by the resin when large volumes of river water were passed through the columns. The principal factor affecting the recovery of the field surrogate is the chemical nature of the sampled water, including the salinity and DOC. Other factors that affect the field-surrogate recovery are the length of time between the application of the spike solution and the extraction of the sample, the accuracy of the concentration of the spiking solution, the aggressiveness of the extraction procedure, and the accuracy and precision of the analytical methods. Acceptable recovery criteria were not set by the New Jersey program, and the recoveries are used only in a qualitative manner.

Unfortunately, because of the limited number of labeled pesticides available, only one pesticide field surrogate $\left({ }^{13} \mathrm{C}\right.$ $\alpha$-BHC) could be employed. The ${ }^{13} \mathrm{C}-\alpha$-BHC was spiked onto the columns along with the ${ }^{13} \mathrm{C}-\mathrm{PCBs} \# 31$, \#95, and \#153. Only the inlet of the first of each two column set was spiked. $\alpha$-BHC is a relatively low molecular weight compound $(290.8 \mathrm{~g} / \mathrm{mole})$ that is moderately soluble $(1.63 \mathrm{mg} / \mathrm{L})$, has a moderately high vapor pressure (0.10 atmospheres), and has a moderate $\mathrm{K}_{\mathrm{ow}}\left(\log \mathrm{K}_{\mathrm{ow}}=3.8\right)$ compared with other OCPs (table 35). These characteristics make the recovery of $\alpha$-BHC a liberal measure of the ability of the resin to retain chlorinated pesticide compounds.

The recoveries of the pesticide and PCB field surrogates are listed in table 41, along with the volume of water processed, DOC concentrations, and total mass of dissolved carbon that passed through the columns during sampling. Recoveries for the ${ }^{13} \mathrm{C}-\alpha$-BHC surrogate ranged from 58 to 101 percent, averaging 80.3 percent. The recoveries for $\mathrm{BHC}$ were lower than the recoveries for the three PCB surrogates, which had recoveries averaging between 84 and 97 percent. The recoveries indicate the resin sufficiently retained chlorinated organic compounds such as PCB, but may not be suitable for some of the more soluble OCPs such as oxychlordane and $\gamma$-BHC when large volumes of carbon-rich river water are passed through the columns.

The dissolved samples collected and processed in this work were low-salinity fresh-water with relatively constant concentrations of DOC between 3 and $5 \mathrm{mg} / \mathrm{L}$ (Bonin and Wilson, 2006). Therefore, little variation in field-surrogate recovery could be attributed to changes in the river-water chemistry. A clear relation was not apparent between the volume of water processed through the resin and the recovery of the pesticide surrogate, and there appears to be no relation between the recovery of $\alpha-\mathrm{BHC}$ and any of the PCB surrogates. Only a weakly inverse relation was observed between the average DOC passed through each column sample or the total mass of DOC and the pesticide-surrogate recovery. So in addition to the amount of dissolved carbon, the recovery of the pesticide surrogate was likely affected by factors including volatilization or to non-reversible migration of the field surrogate into the interior of the resin beads. Further work will be needed to verify these hypotheses, to better understand these field-surrogate recoveries, and to design better efficiency tests for OCP retention.

\section{Concentrations}

The concentrations of the individual pesticides measured in this work are presented in tables 42 to 44 , for the suspended sediment, dissolved phase, and whole-water, respectively, with average concentrations in each river presented in tables 45 to 48 . Average concentrations were calculated using the blank-eliminated data set with all nondetected values replaced with one-half of the reported detection limit. For several of the OCPs in the suspended sediment and dissolved phases (BHCs, endosulfan, endosulfan sulfate, endrin, endrin aldehyde, endrin ketone), the average values were calculated from a majority of non-detected or nonreported values. Thus, these average values for these compounds may represent the EDLs; averages represent an upper limit and do not unequivocally demonstrate the presence of the compound in a sample. Concentrations of total OCPs for selected series are also presented, which include the sum of the 2,4'- and 4,4'-isomers of DDD, DDE, and DDT, the total DDT series (sum of all DDD, DDE, and DDT isomers), the total BHC series (sum of $\alpha$-BHC, $\beta$ $\mathrm{BHC}$, and $\gamma$-BHC), the total chlordane series (sum of $\alpha-$ and $\gamma$-chlordane, and oxychlordane), and nonachlor series (cisand trans-nonachlor), the total endosulfan series (sum of $\alpha$ endosulfan (I), $\beta$-endosulfan (II), and endosulfan sulfate), and the endrin series (endrin, endrin aldehyde, and endrin ketone). To varying degress in each river, a small subset of the OCPs were the dominant compounds in the dissolved, suspended sediment, and POC-normalized fractions.

The average concentrations of total dissolved pesticides (sum of all compounds, table 45) were 2,300 pg/L in the Rari$\tan , 2,900 \mathrm{pg} / \mathrm{L}$ in the Passaic, 4,800 pg/L in the Hackensack, $7,600 \mathrm{pg} / \mathrm{L}$ in the Elizabeth, and $9,500 \mathrm{pg} / \mathrm{L}$ in the Rahway River. Dieldrin, $\alpha$-chlordane, and heptachlor epoxide were the dominant compounds in all rivers except the Raritan where dieldrine and $\gamma-\mathrm{BHC}$ were dominant, and in the Passaic, where $\gamma$-BHC was the dominant compound.

Average total pesticide concentrations in the suspendedsediment phase (table 46) were $60 \mathrm{ng} / \mathrm{g}$ in the Raritan, 140 $\mathrm{ng} / \mathrm{g}$ in the Passaic, $420 \mathrm{ng} / \mathrm{g}$ in the Hackensack (freshwater), $670 \mathrm{ng} / \mathrm{g}$ in the Rahway, and 1,170 ng/g in the Elizabeth River. In all rivers studied except the Raritan, high average concentrations were found for trans-nonaclor, the various DDT metabolites, alpha- and gamma-chlordan, and dieldrin. In the Raritan River, the highest average concentrations were found for 4,4-DDT and 4,4'-DDE.

Average concentrations of OCPs in suspended sediment normalized to particulate carbon (table 47 ), were $1,540 \mathrm{ng} / \mathrm{gC}$ 


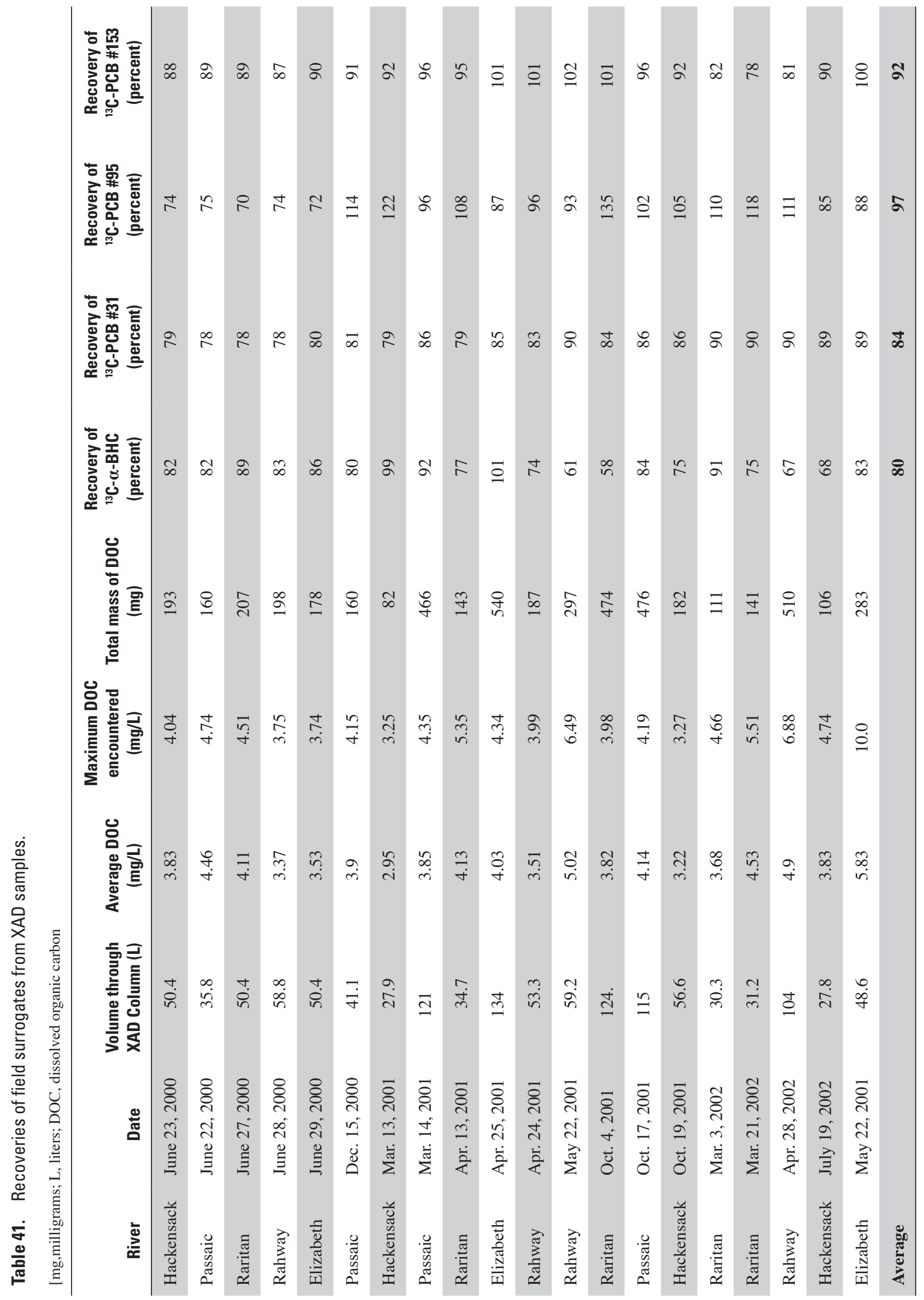




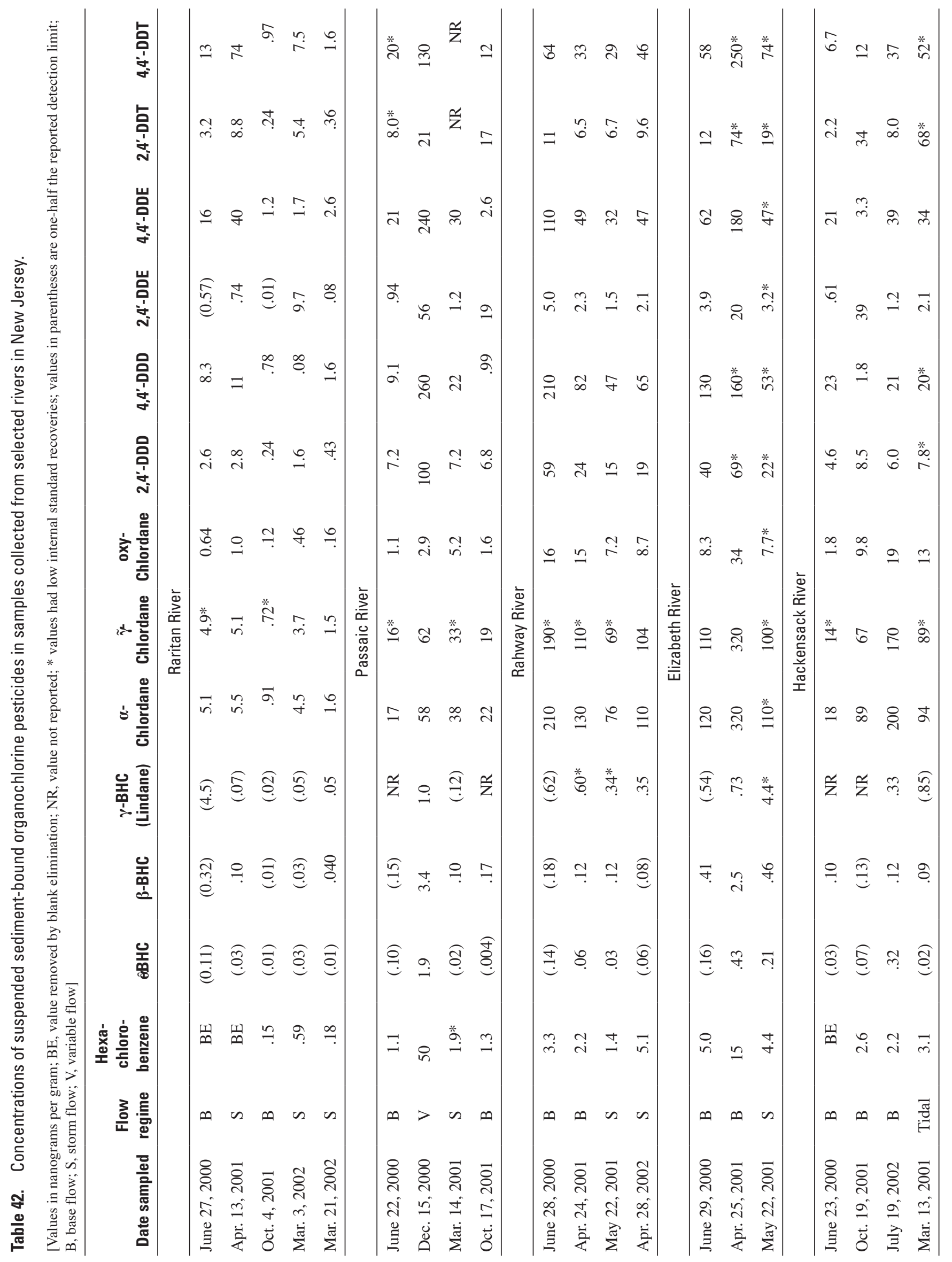




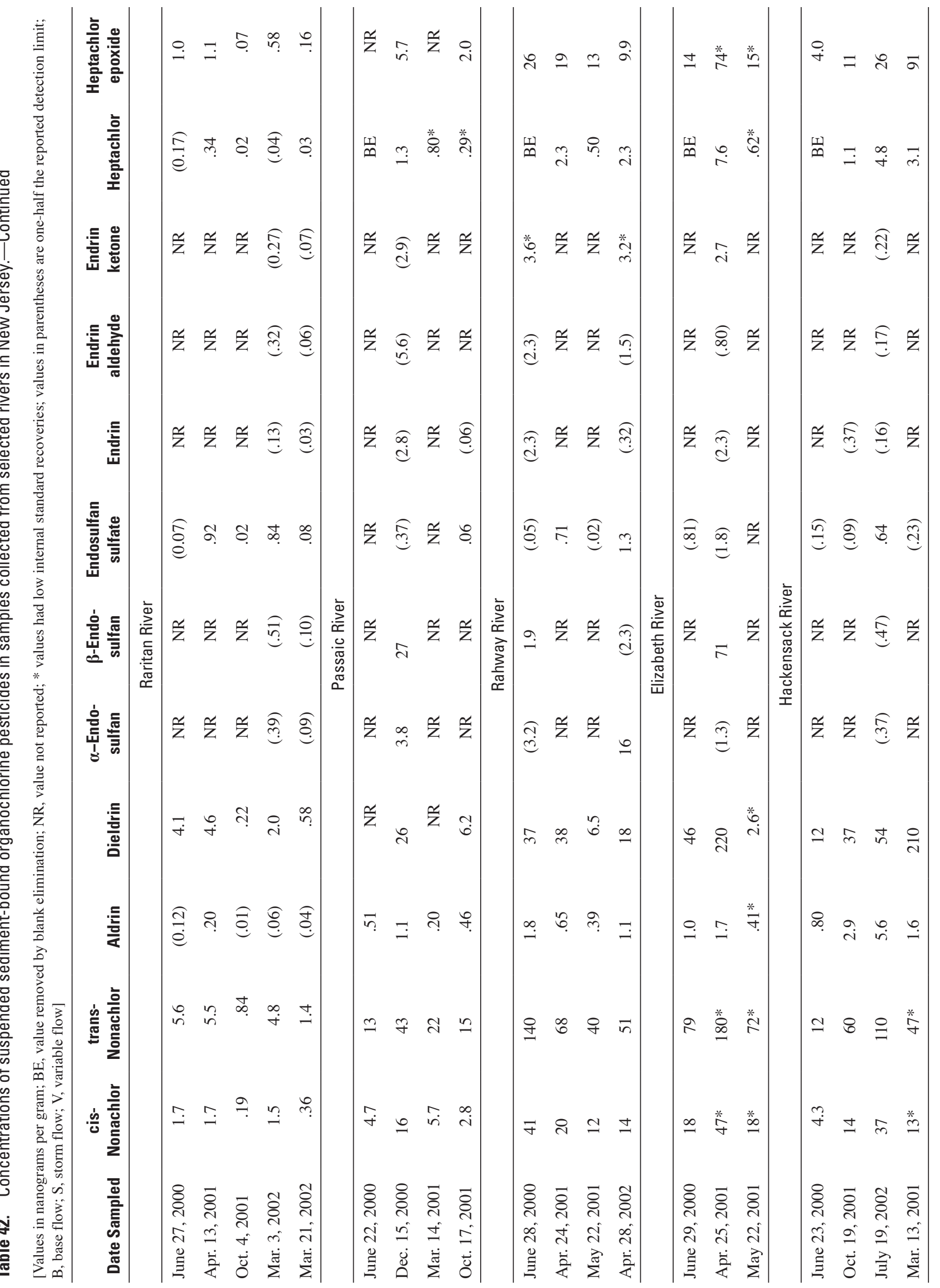




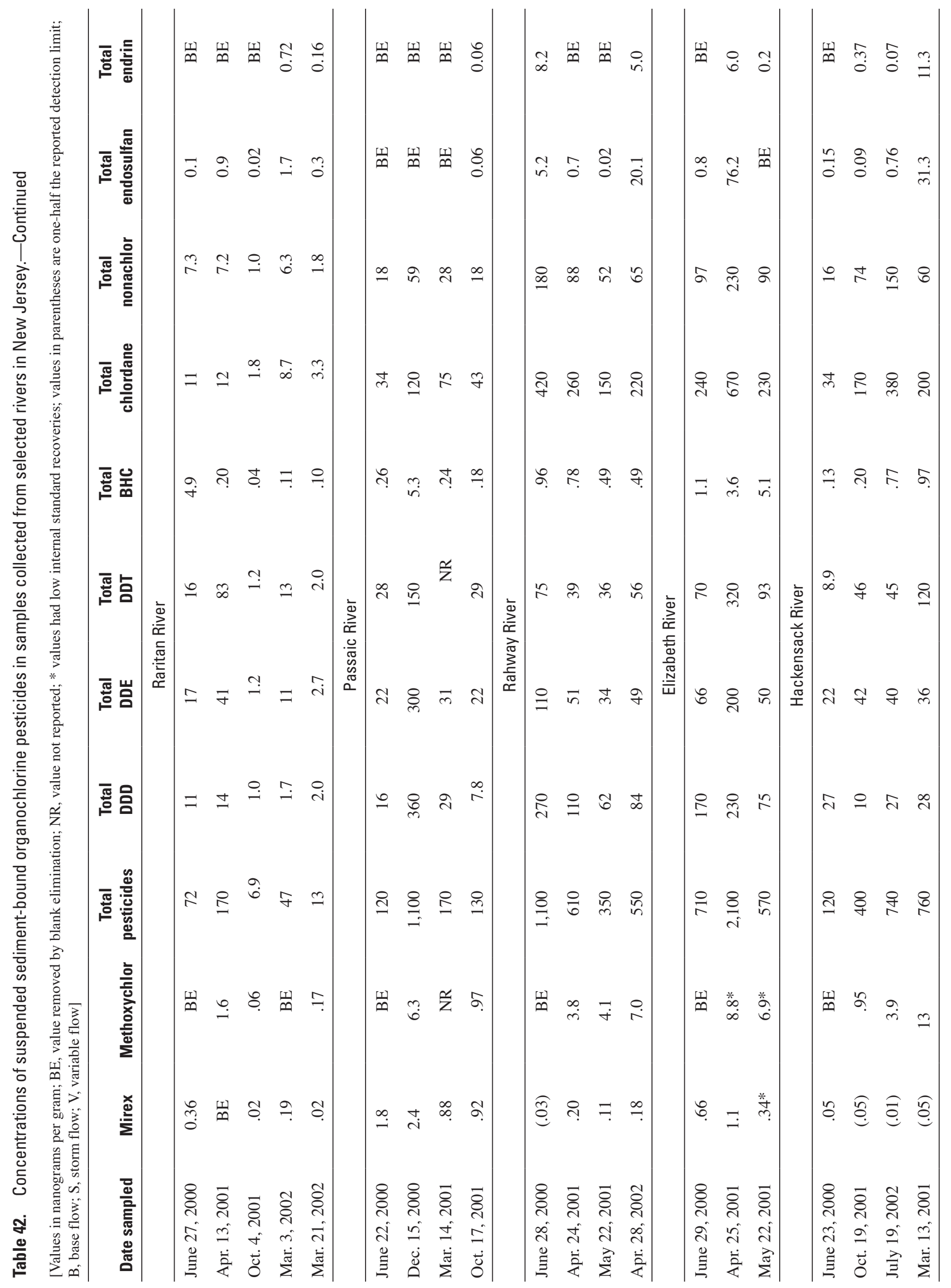




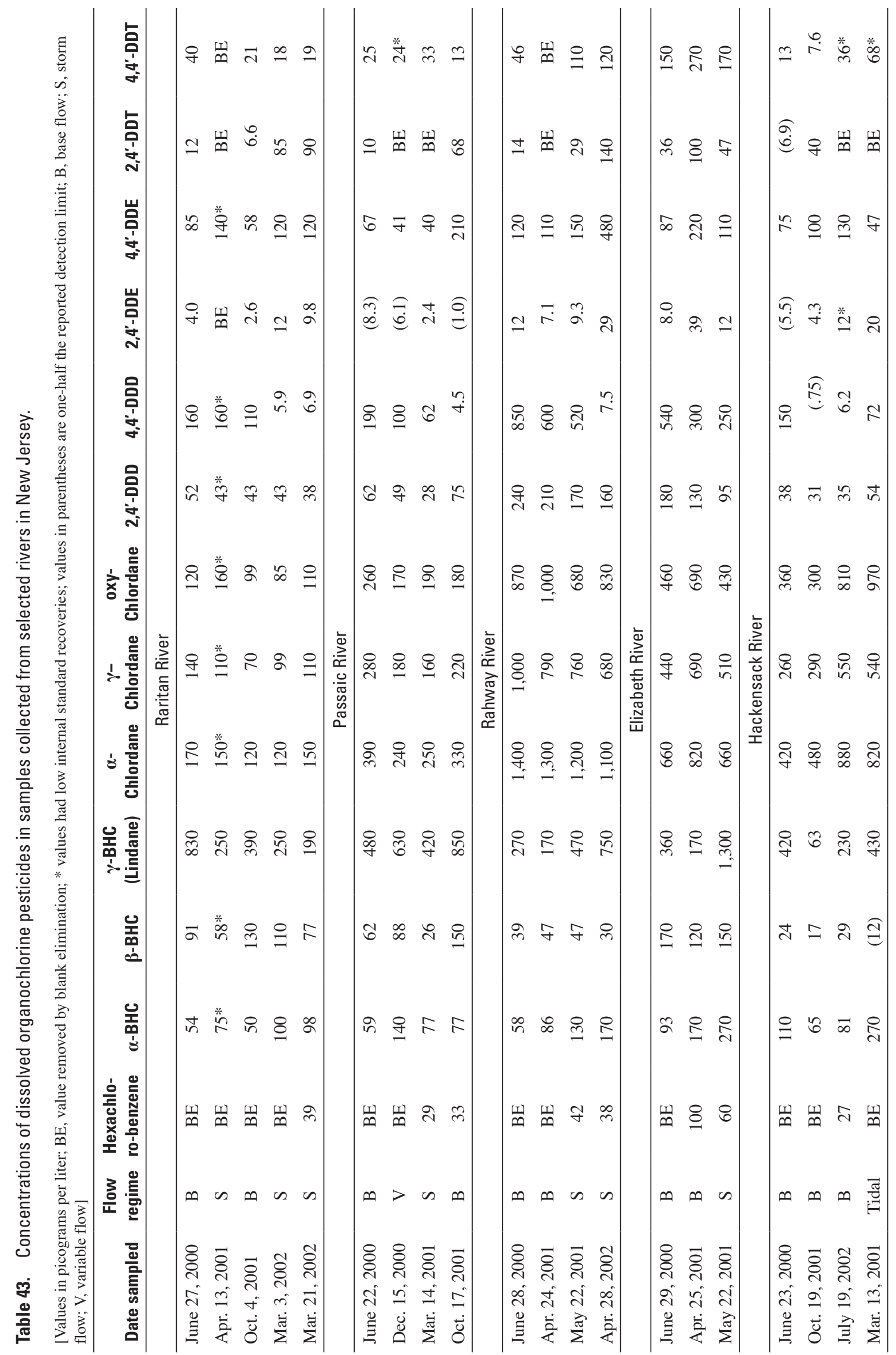




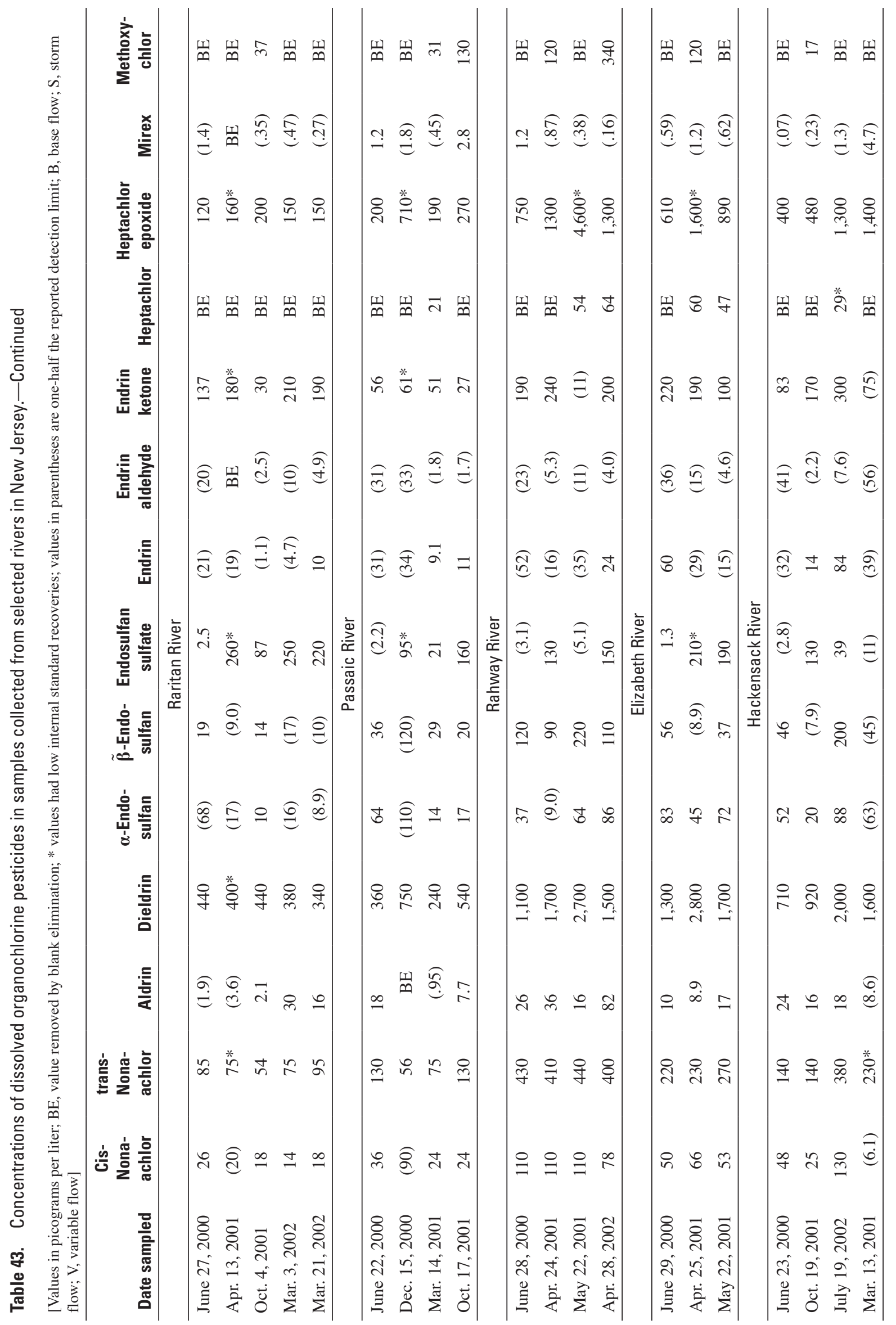




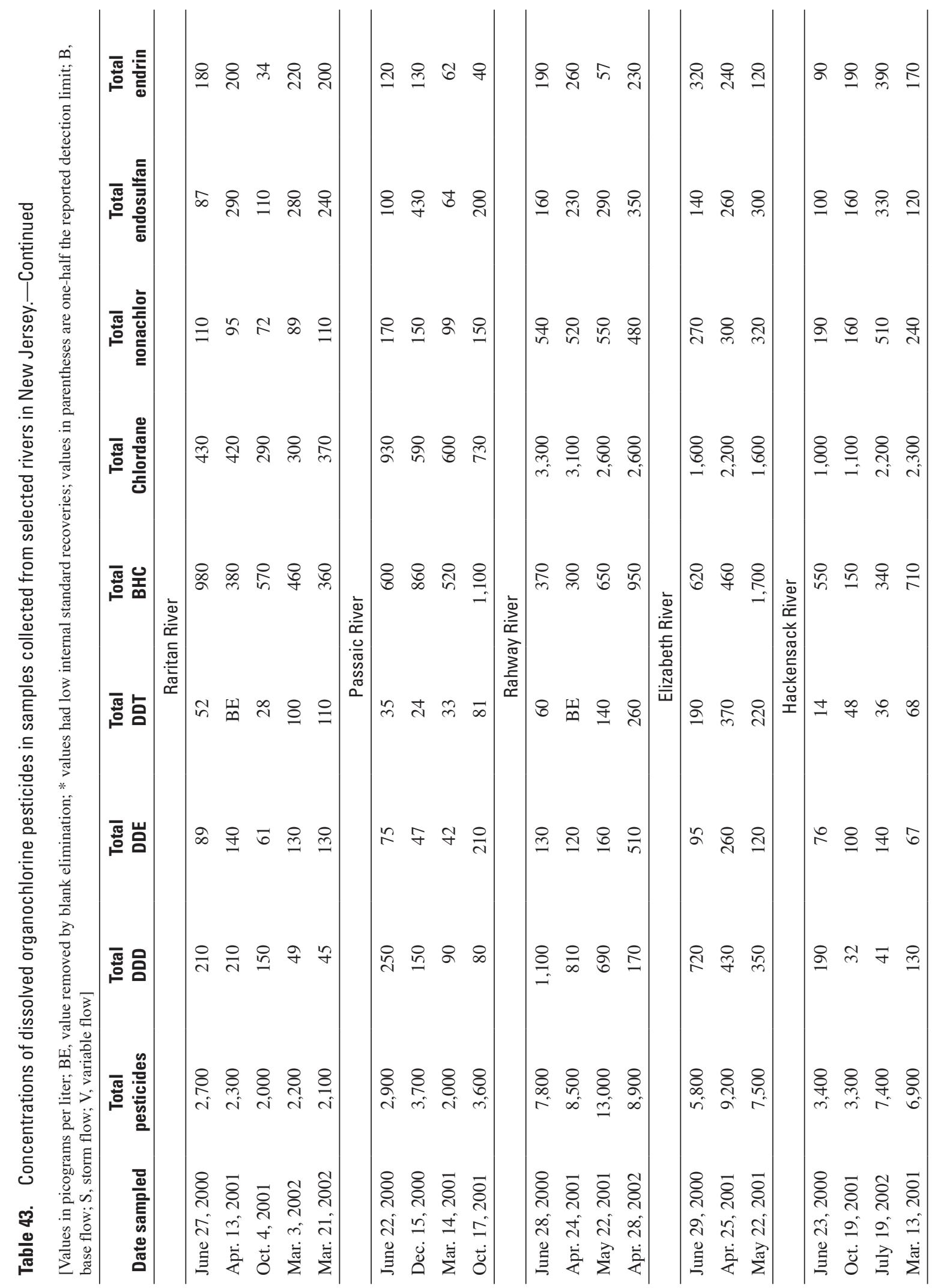




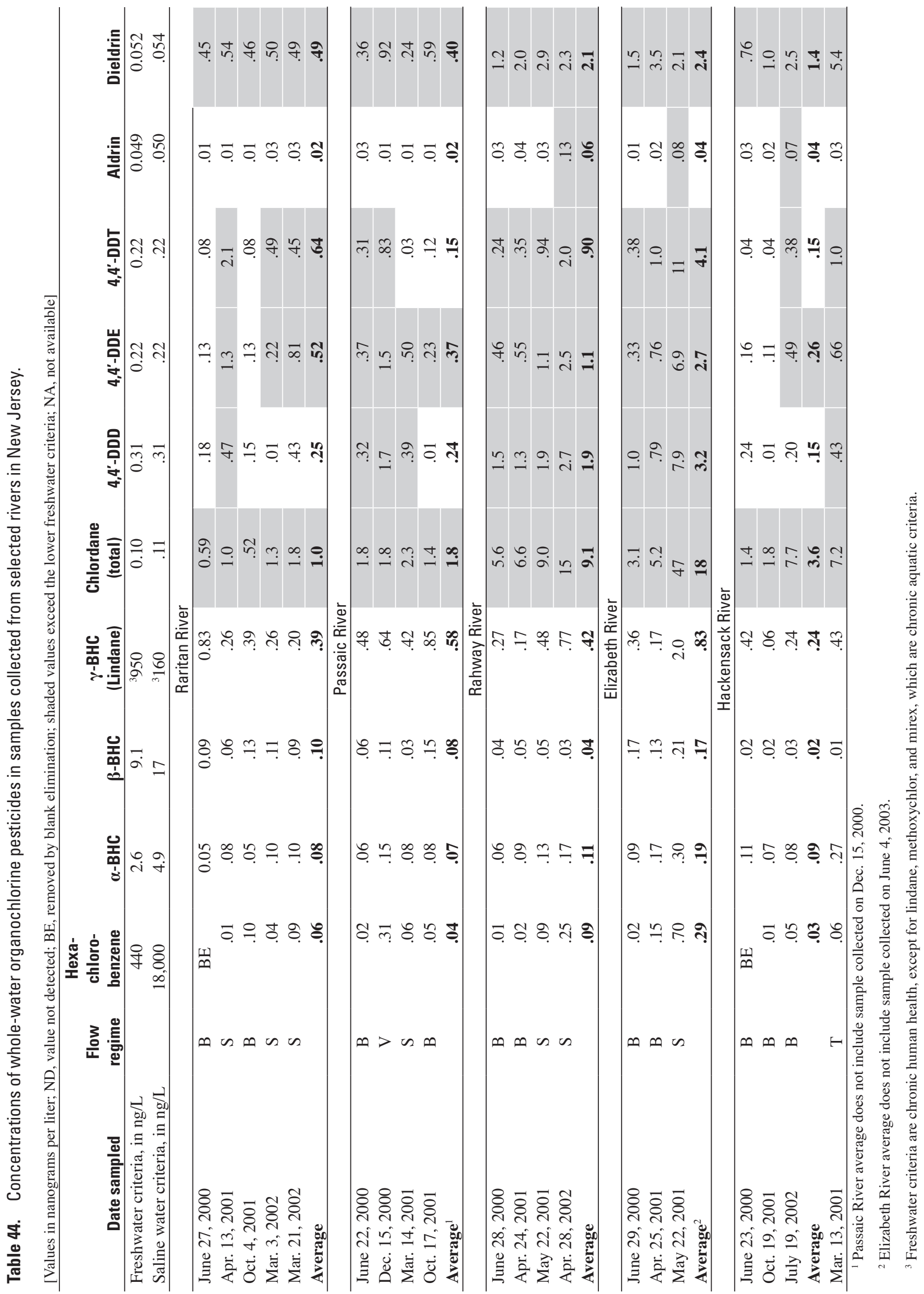




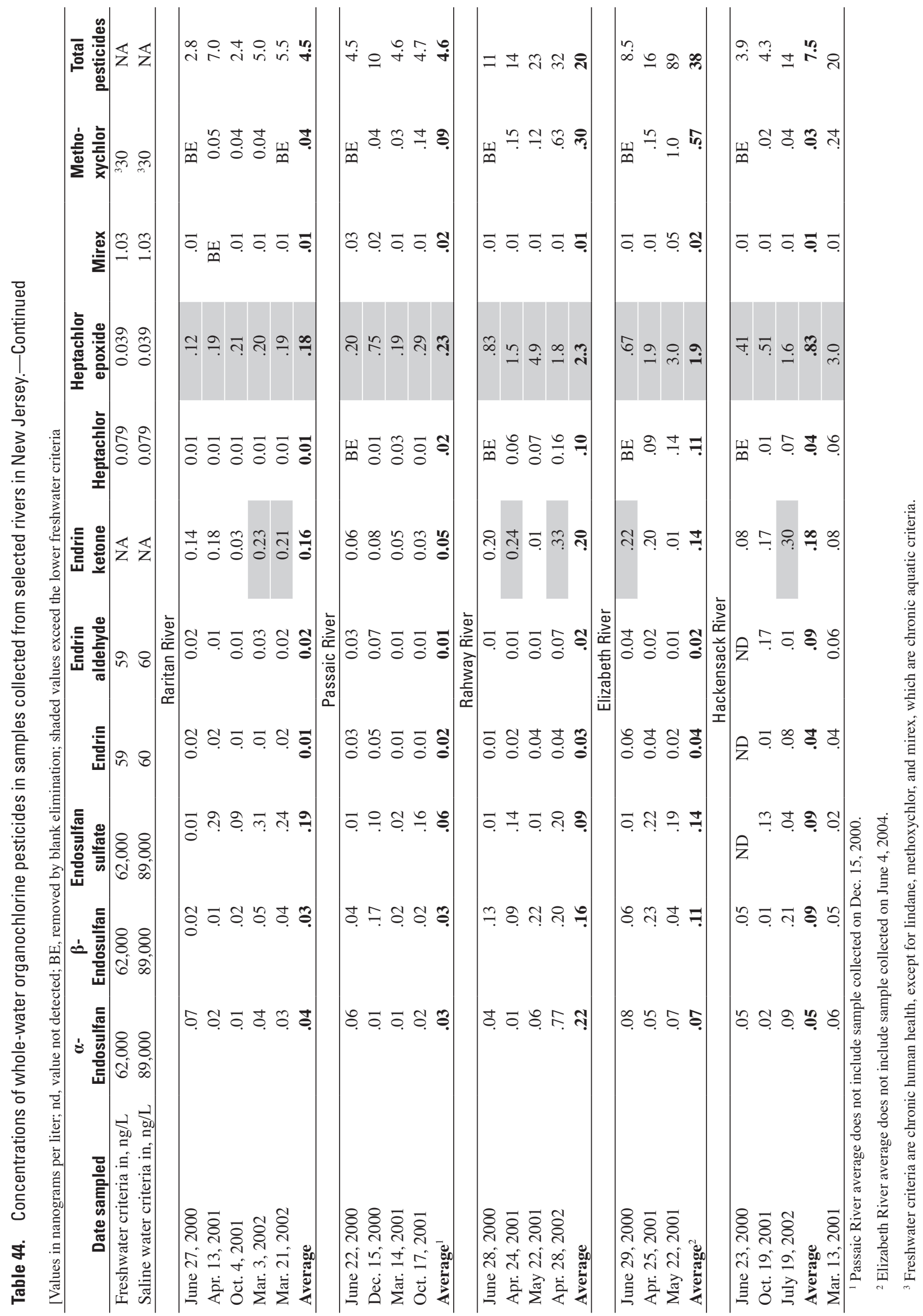


Table 45. Average concentrations of dissolved organochlorine pesticides in samples collected from selected rivers in New Jersey.

[Pesticide values are in picograms per liter; average values were calculated by replacing nondetected values with one-half the reported detection limit; *, value calculated from one or less measured value and/or estimated detection levels; --, no data available]

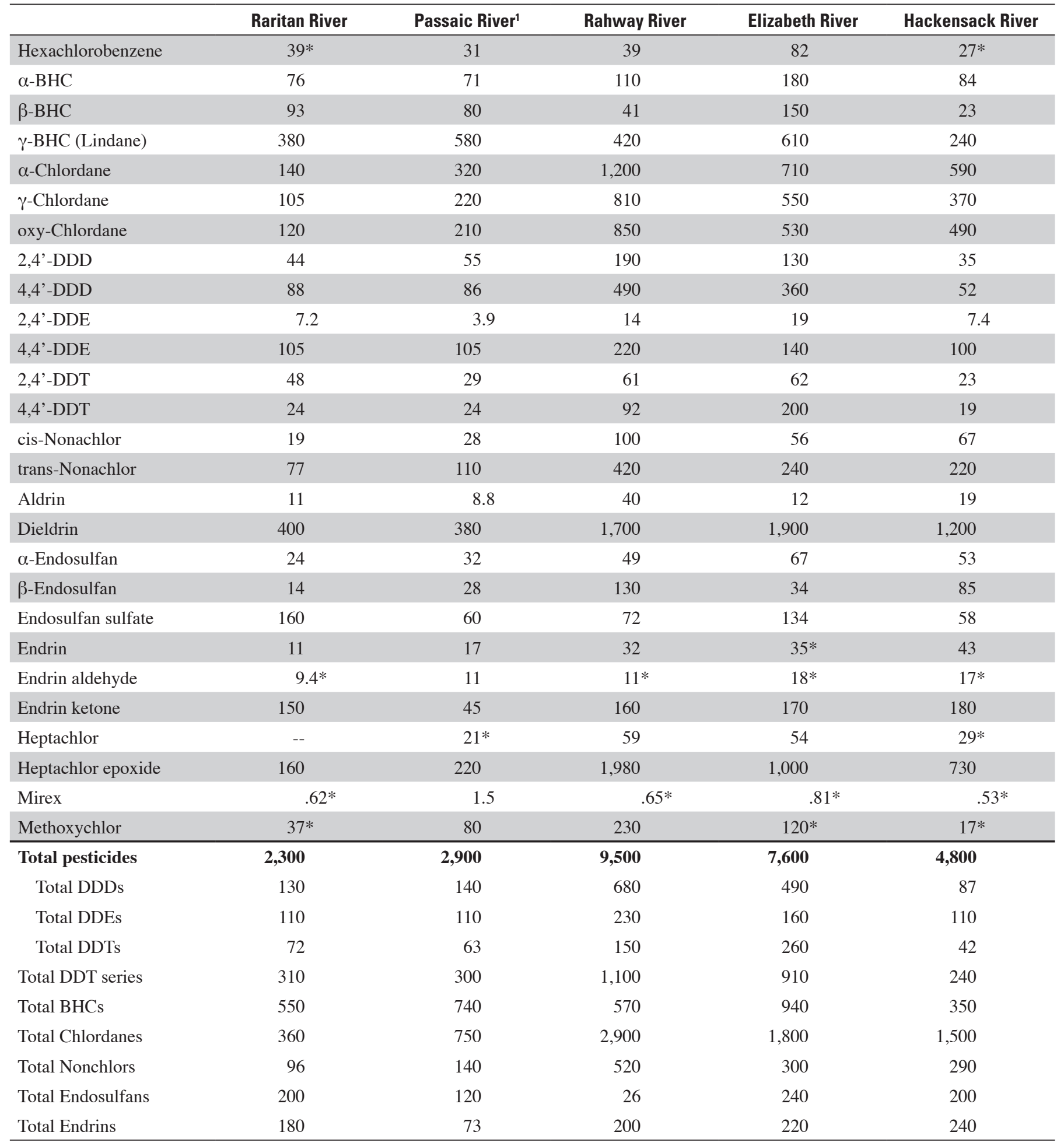

\footnotetext{
${ }^{1}$ Average does not include the sample results from December 15, 2000.
} 
Table 46. Average concentrations of organochlorine pesticides in suspended sediment in samples collected from selected rivers in New Jersey.

[Pesticide values are in nanograms per gram; average values were calculated by replacing nondetected values with one-half the reported detection limit; *, value calculated from one or less measured value and/or estimated detection levels; --, no data available

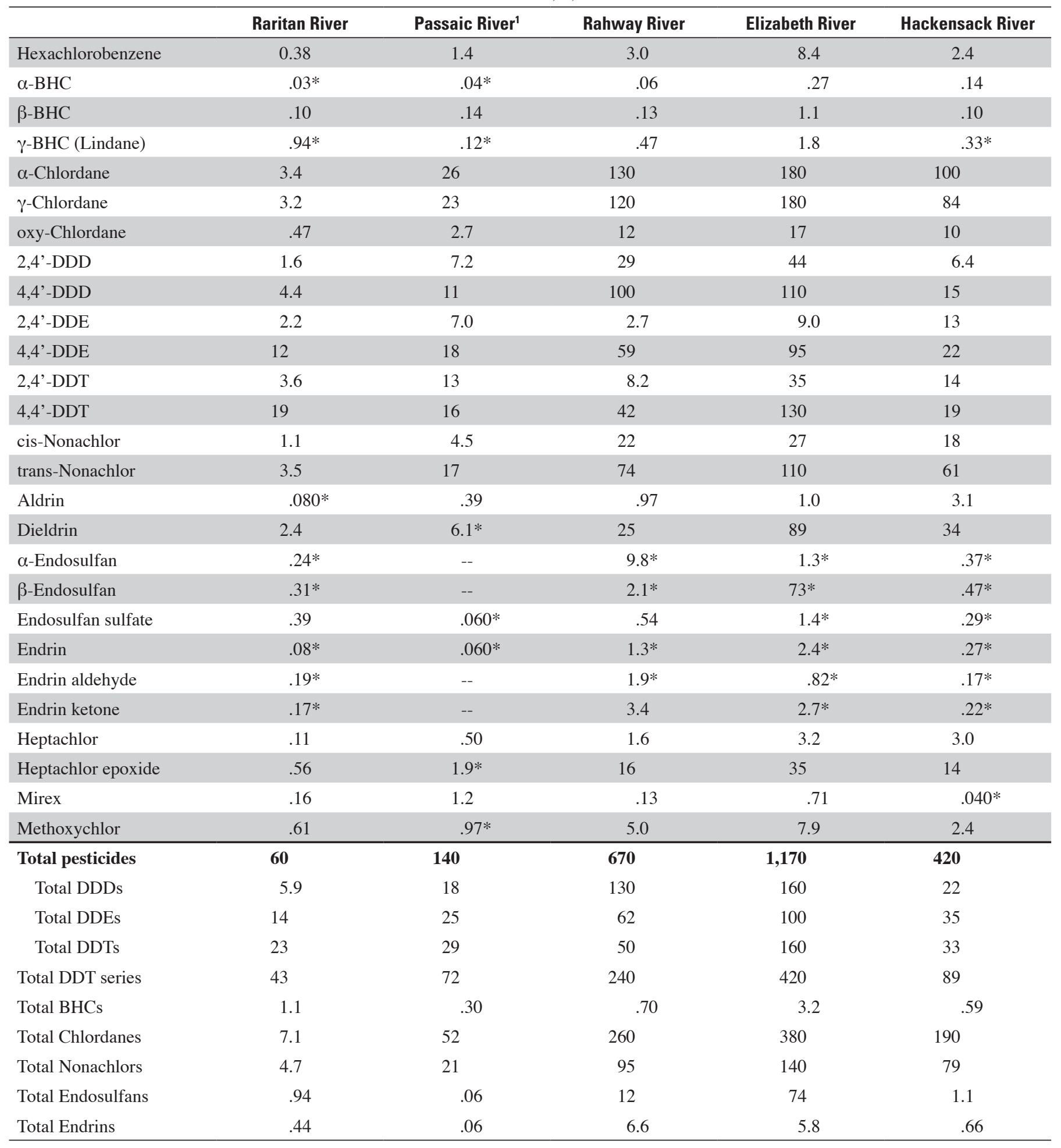

\footnotetext{
${ }^{1}$ Average does not include the sample results from December 15, 2000
} 
Table 47. Average concentrations, normalized to carbon, of organochlorine pesticides in suspended sediment from samples collected in selected rivers in New Jersey.

[Pesticide values are in nanograms per gram of carbon ; --, no data available; Average values were calculated by replacing nondetected values with one-half the reported detection limit; *, value calculated from one or less measured concentration and/or estimated detection levels.]

\begin{tabular}{|c|c|c|c|c|c|}
\hline & Raritan River & Passaic River $^{1}$ & Rahway River & Elizabeth River & Hackensack River \\
\hline Hexachlorobenzene & 10 & 22 & 33 & 57 & 6.7 \\
\hline$\alpha-\mathrm{BHC}$ & $.69^{*}$ & $.94^{*}$ & .82 & 1.9 & .49 \\
\hline$\gamma$-BHC (Lindane) & $13 *$ & $1.5^{*}$ & 4.7 & 13 & $1.0^{*}$ \\
\hline$\alpha$-Chlordane & 92 & 380 & 1,400 & 1,300 & 340 \\
\hline oxy-Chlordane & 12 & 37 & 120 & 110 & 34 \\
\hline 2,4'-DDD & 36 & 110 & 320 & 360 & 29 \\
\hline 4,4'-DDD & 120 & 170 & 1,100 & 1,050 & 97 \\
\hline 2,4'-DDE & 34 & 80 & 29 & 54 & 37 \\
\hline cis-Nonachlor & 26 & 78 & 230 & 200 & 64 \\
\hline trans-Nonachlor & 90 & 250 & 800 & 820 & 200 \\
\hline Aldrin & $2.3^{*}$ & 6.7 & 11 & 8.7 & 11 \\
\hline Dieldrin & 54 & $67 *$ & 250 & 540 & 126 \\
\hline$\alpha$-Endosulfan & $6.8^{*}$ & -- & $126^{*}$ & $4.6^{*}$ & $1.1^{*}$ \\
\hline$\beta$-Endosulfan & $8.3^{*}$ & -- & $27 *$ & $300 *$ & $1.4^{*}$ \\
\hline Endosulfan sulfate & 9.1 & $.60 *$ & 5.4 & $10 *$ & $1.2^{*}$ \\
\hline Endrin & $2.1^{*}$ & $.60^{*}$ & $17 *$ & $8.5^{*}$ & $.72 *$ \\
\hline Endrin aldehyde & $5.2^{*}$ & -- & $25^{*}$ & $2.9 *$ & $.52 *$ \\
\hline Total pesticides & 1,540 & 2,400 & 7,220 & 7,980 & 1,520 \\
\hline Total DDDs & 156 & 280 & 1,400 & 1,410 & 130 \\
\hline Total DDEs & 354 & 390 & 670 & 730 & 150 \\
\hline Total DDTs & 570 & 490 & 550 & 990 & 120 \\
\hline Total DDT series & 1,080 & 1,160 & 2,600 & 3,130 & 400 \\
\hline Total BHCs & 16 & 4.6 & 6.8 & 21 & 2.1 \\
\hline Total Chlordanes & 190 & 750 & 2,700 & 2,500 & 640 \\
\hline Total Nonachlors & 120 & 330 & 1,000 & 1,000 & 260 \\
\hline Total Endosulfans & 24 & .60 & 160 & 310 & 3.7 \\
\hline Total Endrins & 13 & .60 & 86 & 17 & 1.9 \\
\hline
\end{tabular}

${ }^{1}$. Average does not include the sample results from December 15, 2000 
in the Raritan, 1,520 ng/gC in the Hackensack, 2,400 ng/gC in the Passaic, 7,280 ng/g in the Rahway, and 7,950 ng/gC in the Elizabeth River. Normalizing to carbon had the effect, therefore, of making average concentration in the Raritan, Passaic, and Hackensack Rivers - and the Rahway and Elizabeth Rivers - about equal. Except in the Raritan River, $\alpha$-chlordane and $\gamma$-chlordane had the highest carbon-normalized concentrations, followed by 4,4'-DDE, 4-4'-DDT, 4-4'DDD, trans-nonachlor, and dieldrin. In the Raritan River, the 4-4'DDT compounds (DDD, DDE, and DDT) had the highest concentrations followed by trans-nonachlor, $\alpha$-chlordane, and $\gamma$-chlordane, and 4,4'-DDD.

The contribution of the different compounds or pesticide series to the total OCP content of the sediment differed among the rivers (fig. 39). Seven pesticide series are shown for the suspended sediment: the DDT, BHC, chlordane, nonachlor, endosulfan, endrin series and dieldrin. In the Raritan River, the DDT series was the largest contributor to total pesticide concentration (up to 70 percent of the total OCP mass). In the Passaic, Rahway, and Elizabeth Rivers, the DDT and chlordane series were the largest contributors; each group contributed 32 to 45 percent of the total. In the Hackensack River, the chlordane series was dominant, contributing nearly 45 percent of the total OCP; the various DDT metabolites and nonachlor compounds were also important.

The contributions of these selected pesticide series to the total dissolved pesticide concentrations (fig. 40) differed from their contribution to the sediment composition. In the Raritan River, the BHC series was dominant and made up roughly 25 percent of the total pesticide content. In the Passaic River, the $\mathrm{BHC}$ and chlordane series were dominant; each contributed roughly 25 percent of the total dissolved pesticide concentration. In the Rahway, Elizabeth, and Hackensack Rivers, the chlordane series was the principal OCP, accounting for 20 to 30 percent of the total, followed by dieldrin. The relative contribution to the dissolved total pesticide content reflected the source (sediment composition, runoff, waste discharge) and the solubilities of the pesticides. The sediment composition was dominated by the DDT, followed by chlordane, the nonachlor series, and the dieldrin series. The higher percentage of chlordane, oxychlordane in the dissolved phase, relative to DDT, probably reflected their greater presence in the sediment and solubility.

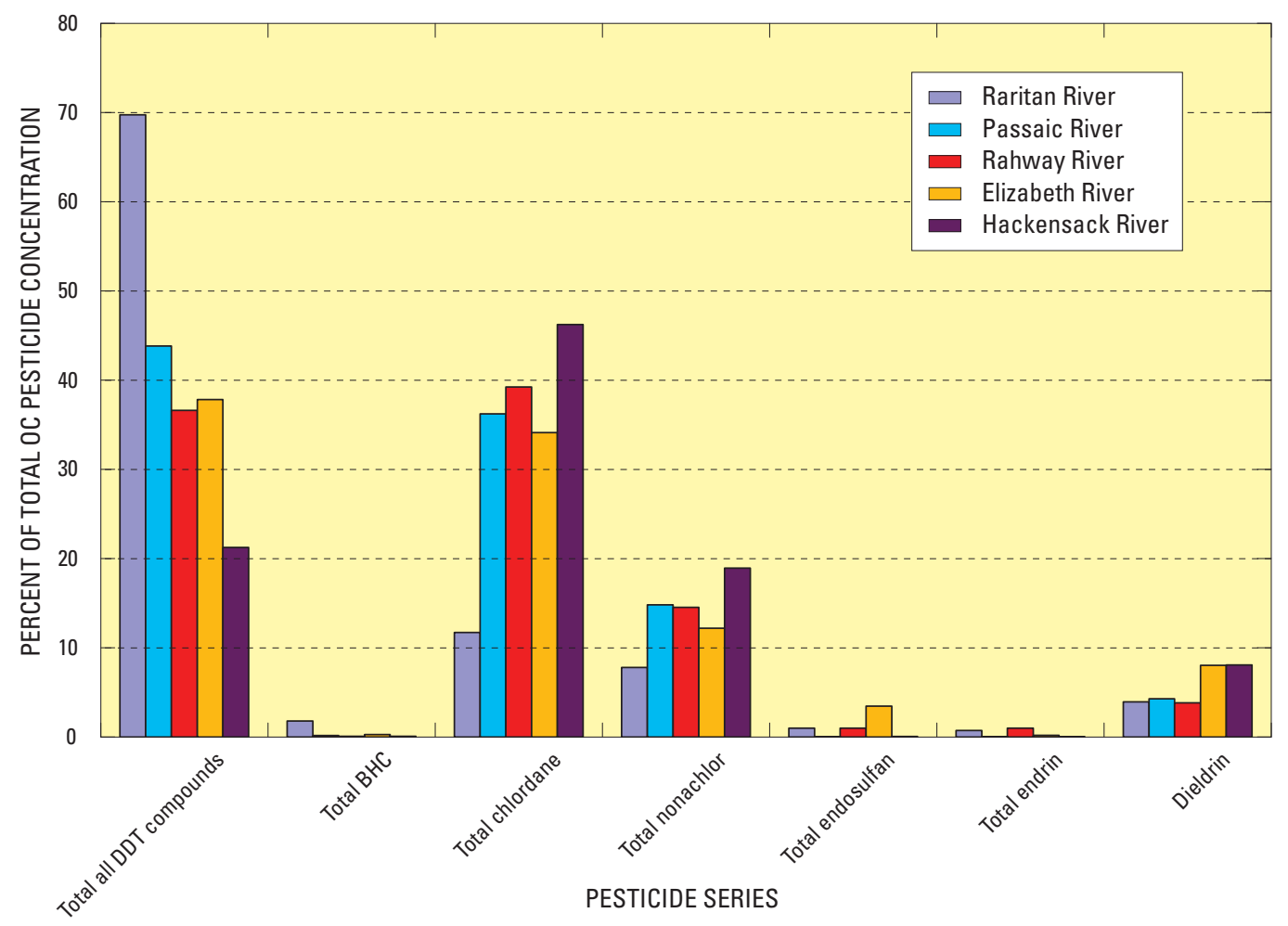

Figure 39. Percent contribution of selected organochlorine pesticide $(\mathrm{OC})$ groups to the total average concentrations of organochlorine pesticides in suspended-sediment samples collected from selected rivers in New Jersey. [Data from table 46.] 


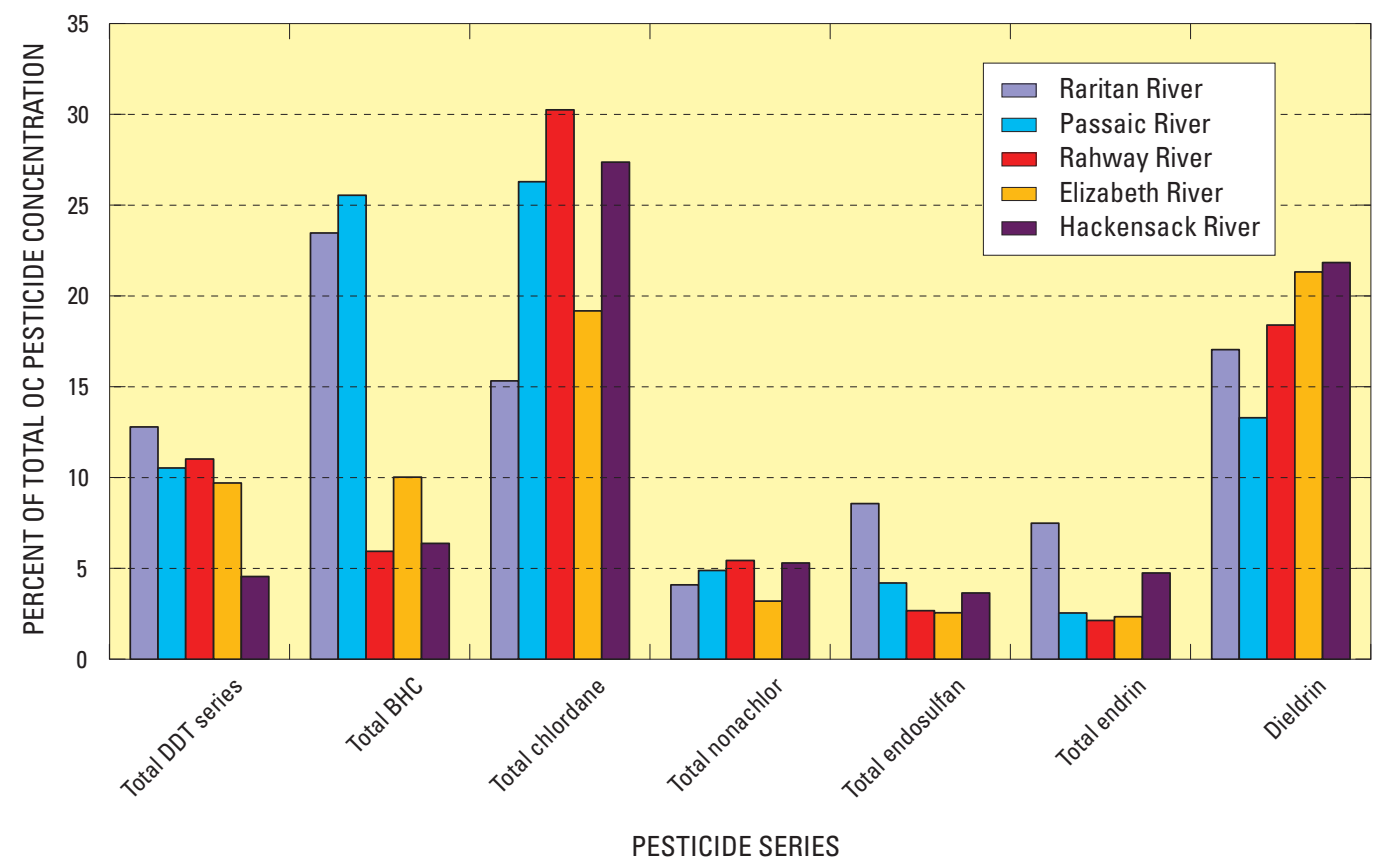

Figure 40. Percent contribution of selected organochlorine pesticide groups to the total dissolved organochlorine pesticide concentrations in water samples collected from selected rivers in New Jersey. [Data from table 45.]

\section{Relation of Whole-Water Concentrations to Surface- Water-Quality Criteria}

Regulatory water-quality criteria for chemicals in surface water are based on "whole-water" concentrations in units of mass per volume. Whole-water concentrations are the sum of the dissolved and sediment-bound concentrations. New Jersey regulatory water-quality levels have been set for selected individual chlorinated compounds but not for total pesticides as was the case for PCBs. Human-health criteria have been set for freshwater streams (class FW2) and for saline estuarine and coastal waters (table 44), however, criteria have not been set for all OCPs in all exposure categories.

Whole-water concentrations for the OCPs and their associated water-quality criteria (expressed in units of nanograms per liter) are listed in table 44 . All of the samples exceeded the water-quality criteria for total chlordane (each of the components alpha-, gamma-, and oxy-chlordane exceeded the criteria), dieldrin, and heptachlor. A number of samples from the Rahway, Elizabeth, and Hackensack Rivers exceeded the criteria for 4,4'-DDD, 4,4'-DDE, and 4,4'-DDT. Note that the criteria chosen here are the carcinogenic effect-based humanhealth criteria, which are typically the lowest of the promulgated criteria for freshwater.

\section{Concentrations During Stormflow and Low Flow}

The changes in concentration and relative make-up of selected OCPs (DDT + metabolites, chlordane+metabolites, dieldrin, hexachlorobenzene, mirex, and methoxychlor, along with the BHC and nonachlor series) were evaluated in sediment and water between storm and low-discharge flow conditions (table 48). To make this evaluation, the ratio of concentrations in selected storm and low-flow samples were calculated using absolute concentrations (tables 42 and 43). The ratio of total OCP concentrations (sum of all OCPs in each sample), SS, POC, and DOC were also calculated so comparisons could be made between concentration and these constituents. As discussed in the PCB section of this report, decreases in chemical concentrations in the dissolved phase can be the result of dilution by clean(er) precipitation and runoff. Decreases in suspended sediment-normalized concentrations can result from the addition of cleaner sediment carried by runoff. Increases in concentrations associated with the sediment phase may indicate the mobilization of buried sediment, and increases in dissolved concentrations can be related to releases of waste or dissolved compounds carried in overland flow. In contrast to the PCBs, however, it is the absolute concentration of the OCPs that are of interest rather than 


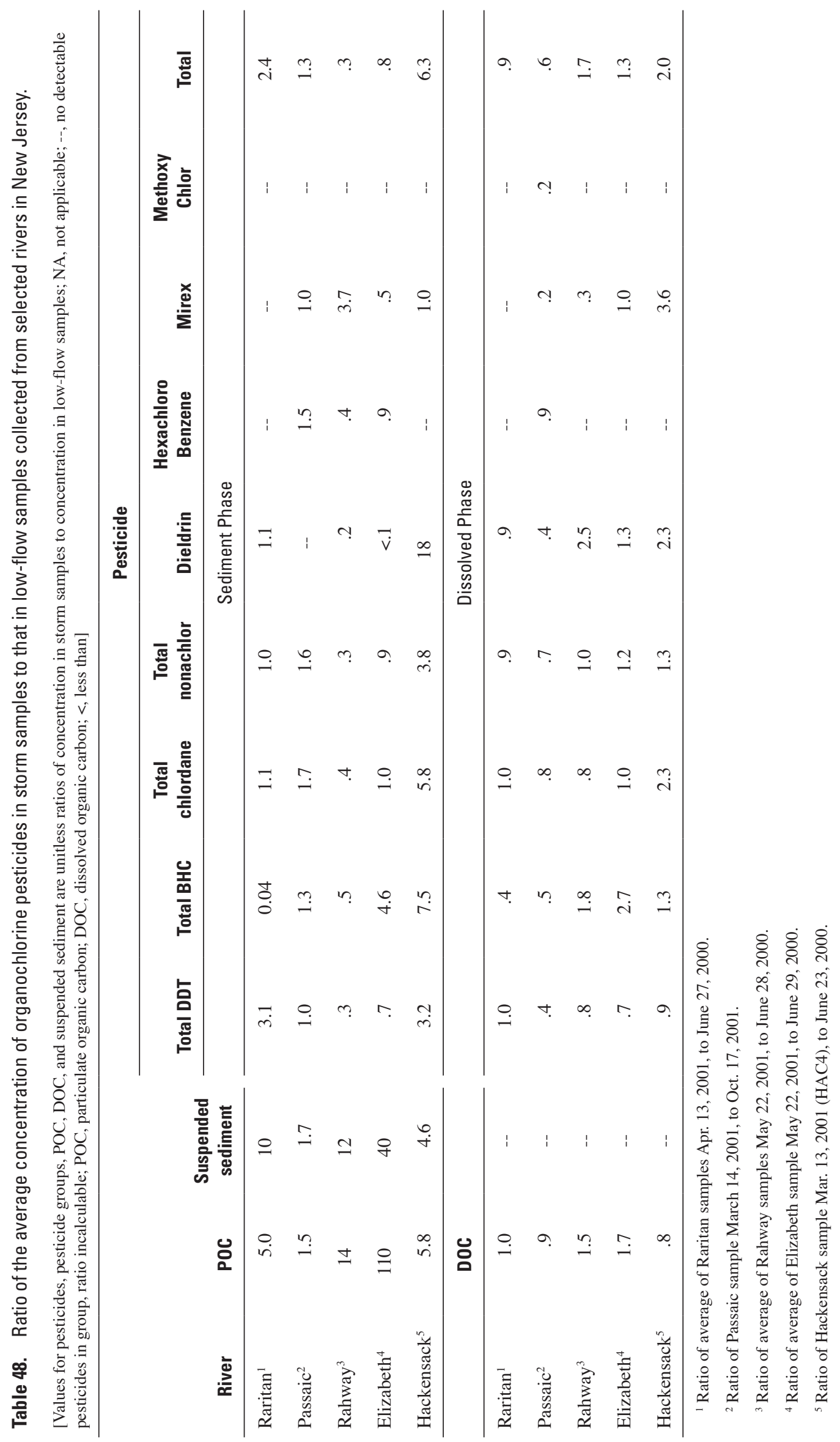


the relative concentration. This is because the concentrations of the different OCPs are independent of one another, unlike the suite of PCB congeners.

Inspection of the storm/low-flow concentration ratios (table 48) showed the following:

- Raritan River (storm sample Apr. 13, 2001, and lowflow sample June 27, 2000): SS increased 10 fold, POC increased 5 fold, and total OCP concentration increased 2.4 times. In the sediment phase, the ratios show that DDT increased, and total BHC decreased; the other compounds did not change appreciably. In the dissolved phase, DOC and total OCP did not change from low-flow concentrations, and only the concentration of total $\mathrm{BHC}$ declined in the storm water.

- Passaic River (storm sample March 14, 2001, to low-flow sample Oct. 17, 2001): The ratio for SS was 1.7 , indicating the sediment content increased by roughly 70 percent. Likewise, the ratio for POC (1.5) and the ratio for total OPC (1.3) showed similar increases in concentration. Total chlordane, total nonachlor, total BHC, and hexachlorobenzene all increased in concentration in the suspended-sediment phase. While DOC remained approximately steady, the dissolved total OCP concentration in the storm water declined by 40 percent from the low-flow concentration. All compounds decreased in the dissolved phase of the storm flow.

- Rahway River (storm sample May 22, 2001, and low-flow sample June 28, 2000): Suspended sediment concentration increased by 12 fold, POC concentration increased by a similar amount ( 14 fold), but the total OCP concentration ratio was 0.3 , indicating a much lower concentration of total pesticides existed in the storm sediment. All of the compounds decreased in concentration in the storm sediment. The ratio for DOC (1.5) shows this component increased by 50 percent, while the dissolved total OCP concentration increased by nearly 70 percent. In the dissolved phase, total BHC and dieldrin increased in concentration in the storm water

- Elizabeth River (storm sample from May 22, 2001, and low-flow sample from June 29, 2000): Suspended sediment increased by 40 fold, POC showed a very large increase (110 fold), but total OCP was only 80 percent of the low-flow concentration. Only the concentration of total BHC increased; total chlordane, hexachlorobenzene, and nonachlor did not change; all other compounds decreased in concentration during the storm. DOC increased by 75 percent, and total dissolved OCP concentration increased 30 percent during the storm. Only total DDT decreased in the dissolved phase.
- Hackensack River (the sample collected from the tidally influenced area HAC4 collected March 13, 2001, was compared to the low-flow sample collected from above the lower dam on June 23, 2000): Suspended-sediment concentration increased 4.6 fold below the lower Oradell dam, similar to the increase in POC (5.8 times) and total OCP (6 fold). Concentrations of total DDT, total BHC, chlordane, dieldrin, and nonachlor increased downstream from the dam. DOC decreased roughly 20 percent, while total dissolved OCP concentration doubled, due to a large increase in dieldrin and chlordane.

In summary, total OCP concentrations in the suspended sediment from the Raritan and Passaic Rivers increased during storms (as did the concentrations in sediment from below the Oradell Dam on the Hackensack River). In the Raritan River, the increase in total OCP was mainly the result of increased total DDT. In the Passaic River, increases were observed in total chlordane and nonachlor. These observations indicate that additional source(s) of these sediment-bound pesticides occur during storms on the Passaic and Raritan Rivers. In the Hackensack River, the data indicate that sediment from below the lower-dam has been impacted with high concentrations of all the studied compounds.

Total OCP concentrations in the Rahway and Elizabeth Rivers decreased during storms. In the Rahway River, the concentrations of all of the studied compounds decreased in the storm-transported suspended sediment. In spite of a decrease in total OCP in the Elizabeth River, a very large increase in total BHC was observed during the storm event. These observations indicate that while "cleaner" sediment (containing lower concentrations of all compounds) was mobilized in the Rahway River, a large amount of sediment containing elevated total BHCs was mobilized during the storm on the Elizabeth River.

In contrast to the suspended sediment concentrations, dissolved total OCP concentrations increased during storms in the Rahway and Elizabeth Rivers (and also increased below the Oradell Dam on the Hackensack River). These increases were mainly the result of dissolved total BHC and dieldrin, suggesting additional stormwater sources of these pesticides. Water from below the Oradell Dam on the Hackensack River has been clearly impacted with higher dissolved pesticide concentrations, particularly total chlordane and dieldrin. Dissolved total OCP concentrations decreased in the Passaic River, but stayed nearly constant in the Raritan River. These observations indicate that dilution by "cleaner" water affects the dissolved OCP concentrations in the Passaic and Raritan Rivers. 


\section{Pesticide Degradation, Relative Concentrations of Metabolites, and Indicator Ratios}

The relative percentages of the metabolites within the different series of OCPs help demonstrate the extent to which the source pesticides have degraded or weathered during their cycling through the environment. The relative concentrations of OCP metabolites and ratios of selected OCPs to other species may also help identify the sediment from each tributary and may possibly identify contaminant or sediment sources. As previously mentioned, even though OCPs are designed to remain stable in the environment, they will slowly degrade through oxidation, dechlorination reactions, photodegradation, and (in some cases) by biologically mediation reactions (Larson and others, 1999; Schwarzenbach and others, 1993). For example, DDT transforms to DDE through dechlorination, which can then oxidize to DDD (Schwarzenbach and others, 1993). DDE should be the most persistent of the DDT series compounds, so DDE should predominate in weathered stream sediments (Aguilar, 1984). Likewise, aldrin is slowly metabolized to dieldrin by soil microbes (Larson and others, 1999). Despite degradation, the OCPs are "persistent chemicals" because of their very long residence time in the environment, which is evident from the data collected in this study. For example, in spite of the fact that DDT was banned from use over 30 years ago, the parent compound DDT still remains in the river sediment and water studied here.

The contribution of individual compounds to the total concentration of three OCP series in the sediment - the DDT, aldrin and dieldrin, and the heptachlor series are shown in figure 41 . The percentages shown were calculated using the average suspended-sediment concentrations from table 46; the total DDD, DDE, and DDT concentrations are the sum of the isomer concentrations. Inspection of this plot shows that (1) in the Raritan River, DDT is the dominant (greater than 50 percent of the total series concentration) species in the DDT series; in the Rahway River, DDD dominates (over 55 percent of the total). DDE dominated (48 percent) in the Hackensack River, while in the other rivers, DDT, DDE, and DDD were present in roughly equal percentages ( 25 to 40 percent of the total). (2) The metabolite dieldrin clearly dominates aldrin in all rivers, accounting for over 90 percent of the total series, and (3) heptachlor epoxide dominates over heptachlor in all rivers, accounting for 80 to 90 percent of the total. These observations show these OCP have been in these river systems for a sufficient length of time to allow for substantial degradation.

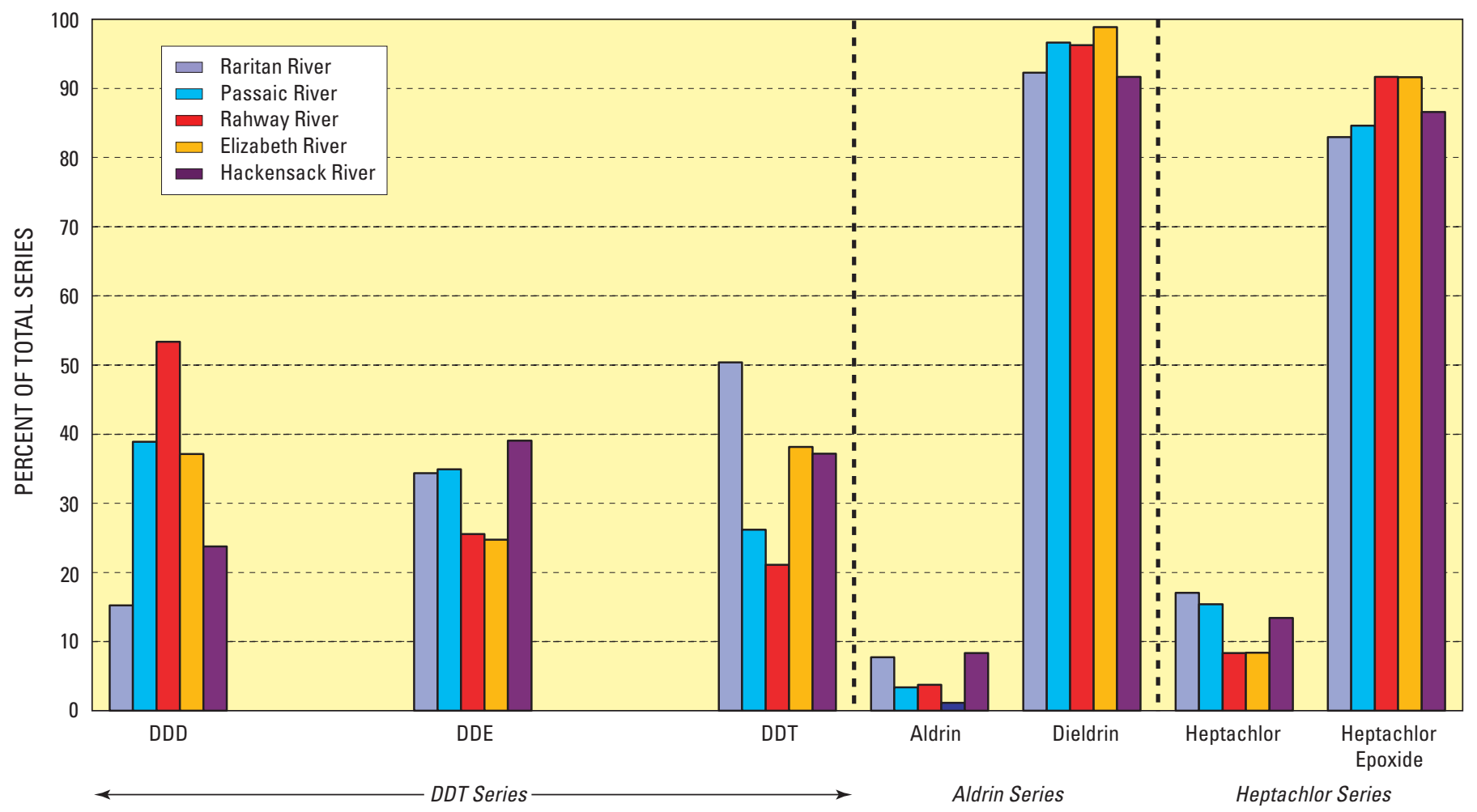

Figure 41. Percent contribution of selected organochlorine pesticides in average suspended-sediment composition of samples from selected rivers in New Jersey. [Data from table 46.] 
The same OCP series in the dissolved phase are plotted in figure 42 (using the data from table 45). In the dissolved phase, DDD represented 38 to 62 percent, DDE represented 18 to 48 percent, and DDT represented 14 to 29 percent of the total DDT series mass. DDD represented the majority of this series, in contrast to the sediment, where the distribution was roughly equal between the three metabolite compounds (in most rivers). Similar to the sediment, dieldrin represents 97 to 99 percent of the aldrin series, and heptachlor epoxide represented 91 to 100 percent of the heptachlor series.

The metabolites and isomers may also serve as indicators for identifying the sediment of the tributaries; for example, high ratios of DDD/DDT (or DDD/total DDT) potentially can be used to identify the sediment derived from the Rahway River Basin. Concentration ratios may also be useful for identifying other sources of OCP contamination. Bopp and others (1991) and Chaky (2003) suggested the concentrations of the isomers of DDT and ratios of selected OCPs to other compounds such as hexachlorobenzene and 2,3,7,8-TCDD can be useful indicators of contaminant and sediment sources in the tidal Passaic River. Fry and Toone (1981) and Johnson and others (1988) suggested that the ratio of o,p'-DDT to p,p'-DDT $\left(2,4^{\prime}\right.$-DDT/4,4'-DDT) is a useful indicator of commercial DDT sources, based on the fact that commercial DDT products contain 22 to 25 percent o,p'-DDT (Gunther and Gunther, 1971). Thus, o,p'-DDT/p,p-DDT concentration ratios in sediment contaminated by application of commercially available DDT products will have values of roughly 1:4 to 1:5. As discussed below, Bopp and others (1991) and Chaky (2003) suggest that DDD/TCDD ratios may be useful in discerning Passaic River sediment.

The DDT suite of isomers can only be used as concentration ratio markers if it can be demonstrated that DDT and its isomers degrade slowly enough to maintain their presence in the environment, especially compared with the highly recalcitrant compounds such as 2,3,7,8-TCDD. Clearly, DDT and its isomers are still present in these river basins some 30 years after its ban. Other studies show similar results; for example, Fry and Toone (1981) found the less persistent metabolites of DDT (o,p'-DDD, o,p'-DDT, and o,p'-DDE) in eggs of seabirds and fish, thereby showing that isomers of the source DDT and the degradation products (DDD, DDE) will remain in the environment long enough to be bioaccumulated by higher trophic levels. This further supports the hypothesis that concentration ratios of the DDT isomers remain sufficiently constant to be used for trackdown. Johnson and others (1988) measured the isomers of the DDT series in sediment from the Yakima River and its associated tributaries that were affected by DDT application. Their study showed that (1) the percentages of 4,4'-DDT were equal to or greater than the percent-

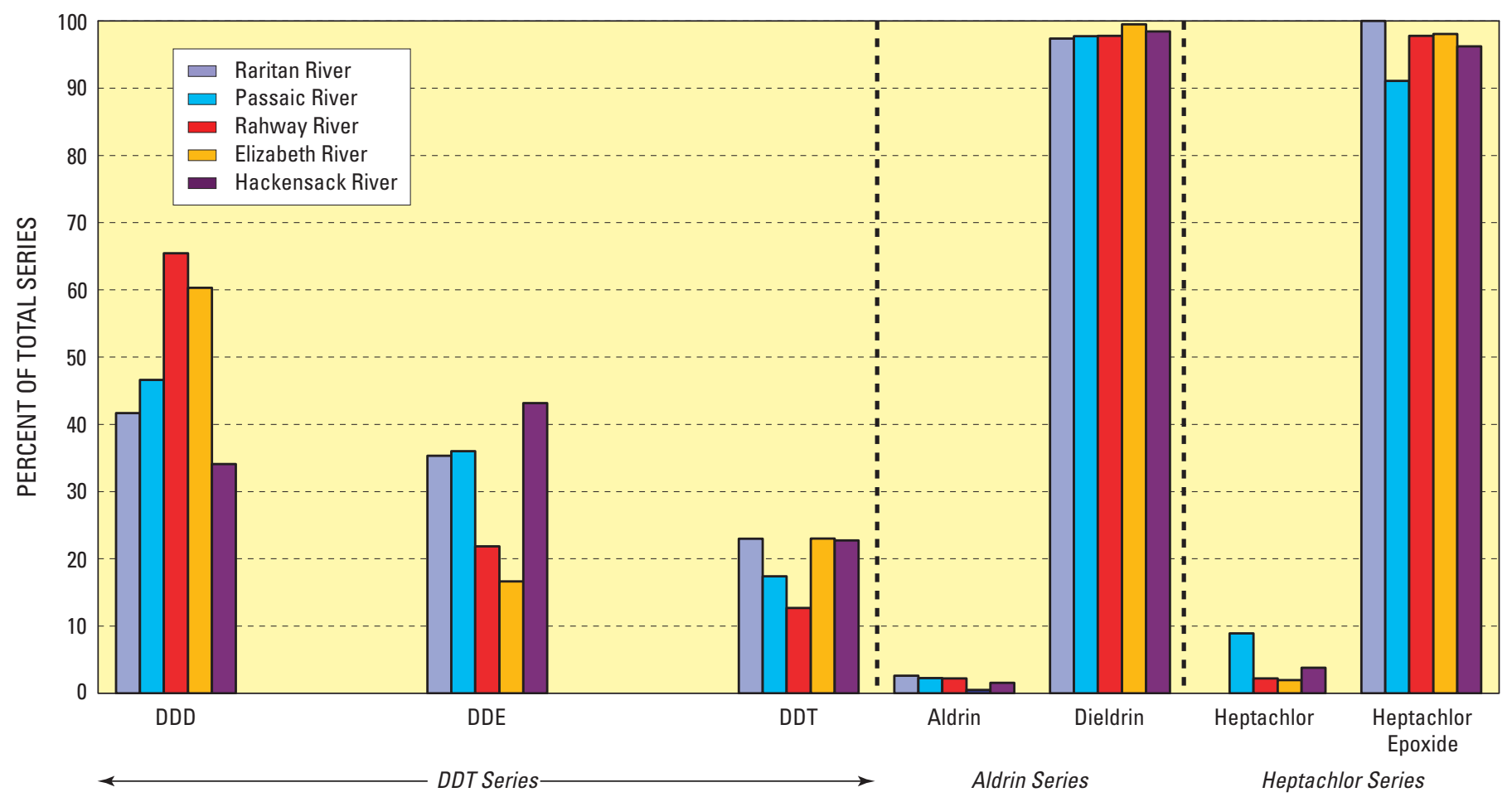

Figure 42. Percent contribution of selected organochlorine pesticides in average dissolved composition of samples from selected rivers in New Jersey. [Data from table 45.] 
age of 4,4'-DDE, thereby supporting the slow degradation of DDT, and (2) the 2,4'-DDT/4,4'-DDT ratios remaining in the sediment were nearly identical to the $1: 4$ to $1: 5$ ratio of commercial DDT. These observations indicate a large amount of undegraded DDT remains in the Yakima River Basin even after its ban 15 years previous, and that isomer ratios are useful indicators of sources. A similar conclusion can be made regarding the New Jersey River Basins.

Commercial DDT was used throughout the river basins of this present study, so ratios of 2,4'-DDT/4,4'-DDT concentrations are expected to be rather consistent among the basins. The average ratios of 2,4'-DDT/4,4'-DDT in sediment samples (table 49) were found to be 0.19 for the Raritan River, 0.81 for the Passaic River, 0.20 for the Rahway River, 0.27 for the Elizabeth River, and 0.79 for the Hackensack River. The sediment being delivered by the Raritan, Rahway, and Elizabeth Rivers had 2,4'-DDT/4,4'-DDT ratios near the 1:4 to 1:5 ratio of commercial DDT products. However, the ratio for the Passaic and Hackensack Rivers had much higher 2,4'DDT/4,4'-DDT ratios, near 0.8 (1:1.25). The high ratio for the Passaic and Hackensack River sediment is curious and cannot be explained at present.

As was shown previously (fig. 41), the contributions of total-DDT, DDE, and DDD (sum of 2,4' and 4,4' isomers) were about equal (25-40 percent), on average, in the sediment from the Passaic, Elizabeth, and Hackensack Rivers. In the Raritan and Rahway Rivers, DDT or DDD, respectively, contributed a higher percentage, roughly 50 percent of the total concentration. Assuming that DDT was the principal compound used (and not DDD), this suggests DDT was weathered to roughly the same extent in the Passaic, Elizabeth, and Hackensack Rivers. In contrast, DDT appears to have weathered to a lesser degree in the Raritan River, and to a greater degree in the Rahway River.

The 4,4'-DDE/4,4'-DDT ratios (not shown) showed a slightly different trend-average ratios were 0.63 in the Raritan, 0.74 in the Elizabeth, 1.4 in the Rahway, 1.1 in the Passaic, and 1.1 in the Hackensack. If the 4,4'-DDE isomer is considered to be the most persistent and stable of the DDT isomers (Johnson and others, 1988; Aguillar, 1984), these ratios suggest the DDT in the Rahway, Passaic, and Hackensack Rivers was the most degraded. If the 4,4'-DDD compound is considered to be the most persistent, the average sediment 4,4'-DDD/4,4'-DDT ratios (0.2 in the Raritan, 0.8 in the Hackensack and Elizabeth, 0.7 in the Passaic, and 2.3 in the Rahway) indicate the DDT in the Rahway River was the most degraded.

Variation in these ratios within the tidal portions of the rivers may be especially useful for discerning sediment contributions and sources. DDT was produced in Newark, N.J., at a plant located alongside the Passaic and Hackensack Rivers. Residual wastes generated during the production of DDT, or as a by-product of the production of the defoliant 2,4,5-T (containing 2,3,7,8-TCDD) or hexachlorobenzene, may have had a $2,4^{\prime}$-DDT/4,4'-DDT ratio that differed from the ratio in commercial DDT product; for example, residual wastes may be enriched in 2,4'-DDT over commercial DDT. As Bopp and others (1991) and Chaky (2003) discuss, ratios of selected isomers or metabolite isomers of DDT to hexachlorobenzene or 2,3,7,8-TCDD may also be a useful indicator of the industrial sources of DDT and 2,4,5-T in the Passic-Hudson River estuaries.

Bopp and others (1991) suggested that the ratio of 4,4'DDD/2,3,7,8-TCDD may be a useful indicator for contaminant sources to the Passaic River and Hackensack River estuaries from an industrial source (80 Lister Avenue) along the Passaic River in Newark, N.J. Prior to 1948, this plant produced only DDT and likely released manufacturing wastes to the river. The data collected from this present study showed that DDT is present in slightly greater proportion than DDD (fig. 41). The 4,4'-DDD in the river sediments was likely produced by dechlorination of 4,4'-DDT and was the isomer assumed by Bopp and others (1991) to be the most environmentally persistent. Thus, Bopp and others (1991) used the DDD/DDT ratio as an indicator of DDT manufacturing at the Lister Avenue site. Beginning in 1948, the herbicides 2,4,5-T and 2,4-D were produced at this plant, at which time DDT production was phased out. In producing these herbicides, large amounts of 2,3,7,8-TCDD were produced as a by-product trace impurity in the herbicides. As discussed by Umbreit and others (1986), very high concentrations of 2,3,7,8-TCDD (up to $2,280 \mu \mathrm{g} / \mathrm{kg}$ ) have been found in the residual soils of the 80 Lister Avenue plant. Wastes generated during the production of DDT and 2,4,5-T were apparently released to the Passaic River and possibly to the Hackensack River (Bopp and others, 1991). These wastes may have been released during production, when the plant was decommissioned in 1970, when the manufacturing stills were removed in the 1980s and transported to a salvage yard a few blocks from Lister Avenue, and when the site was flooded in 1984 when the Passaic River flooded its banks (Umbriet and others, 1986, Bopp and others, 1991).

These scenarios were documented by Bopp and others (1991) using age-dated sediment cores collected from Newark Bay (cores F1 and F2). The 4,4-DDD/2,3,7,8-TCDD ratio in these cores were as high as $12[\mathrm{ng} / \mathrm{pg}]$ in sediment deposited prior to 1948 , and decreased to less than $0.5 \mathrm{ng} / \mathrm{pg}$ in sediment deposited after 1954 (and up to the time of collection in 1986), including the period (1950 to 1970) when 2,4,5-T was being manufactured.

The usefulness of the 4,4'-DDD/2,3,7,8-TCDD ratio as a marker for the effects of 2,4-T manufacturing in the Passaic River Basin is supported by the ratios found in this present work (albeit few measureable 2,3,7,8-TCDD values were found in this present work), which are much higher than 0.5 ng/pg found by Bopp and others (1991) for sediment deposited between ca. 1950 and 1970. In present-day sediment being delivered from the basin to the tidal portions of the estuary, the average ratio ranges from $1.8 \mathrm{ng} / \mathrm{pg}$ in the Raritan up to 40 ng/pg in the Rahway River (table 49), which are similar to the high ratios measured by Bopp and others (1991) in sediment deposited before the onset of 2,4-T manufacturing in 1950. The low ratios in buried sediment deposited during the years 


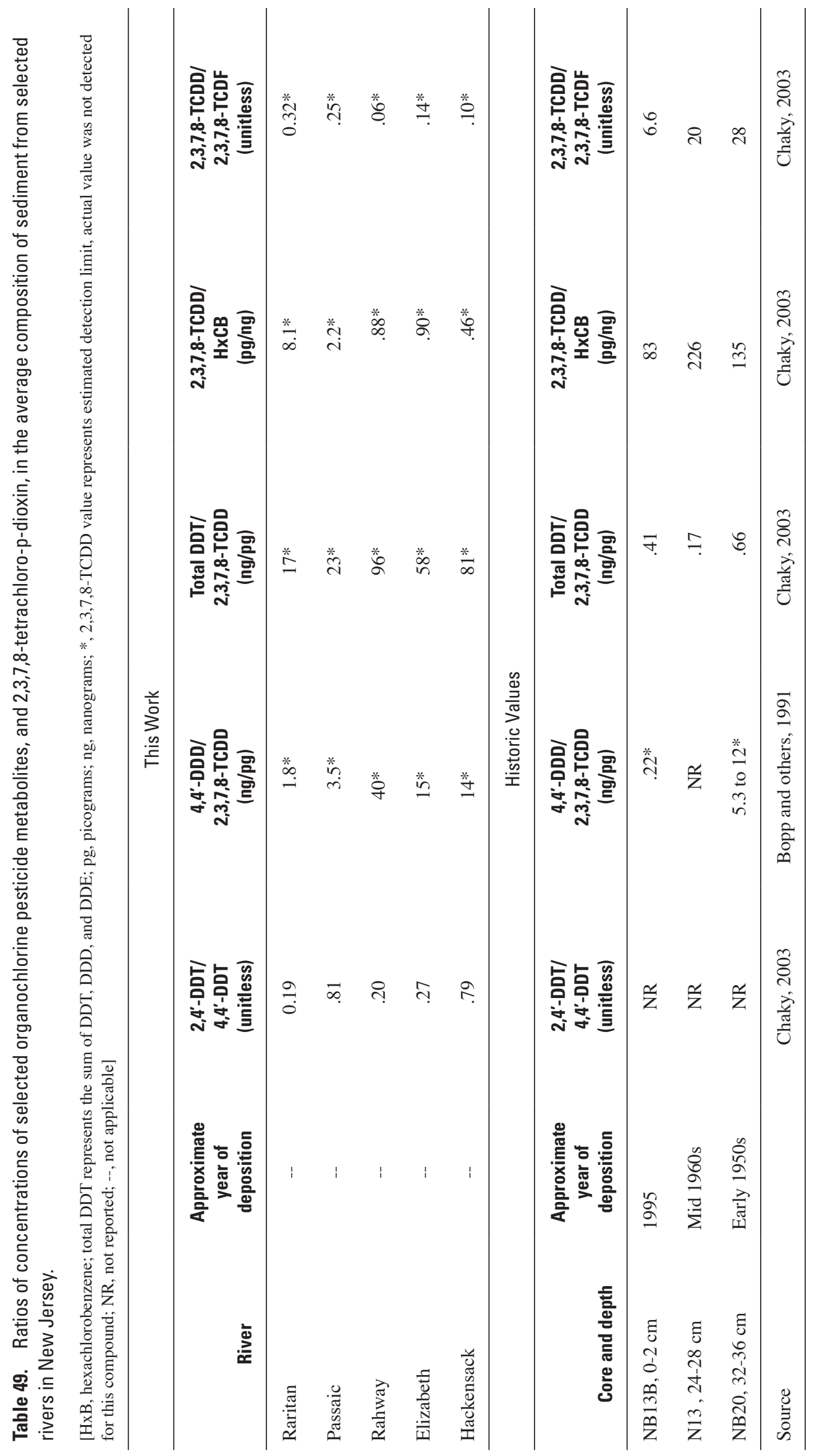


when 2,4,5-T was being manufactured were occurring, are clearly different from present-day (and historic) suspended sediment being transported into the estuary.

Chaky (2003) suggested that the concentration ratios of total DDT/2,3,7,8-TCDD, 2,3,7,8-TCDD/HxCB and 2,3,7,8TCDD/2,3,7,8-TCDF can also be indicators for the impacts of the Passaic River contamination source. Chaky (2003) measured these ratios in sections of three cores collected from Newark Bay (NB13, collected Feb. 23, 1985; NB20, collected July 27, 1985; and NB13B, collected May 27, 1995) having depositional ages dated from 1995 (from NB13B), the mid-1960s (from NB13) when the 2,4,5-T manufacturing was active, and the pre-1950s (NB20) when only DDT manufacturing was active. These ratios are presented and compared to the corresponding average ratio in the present sediment collected at the HOT in table 49. The total-DDT/2,3,7,8-TCDD concentration ratios in present-day sediment (eroded from the river basin above the HOT) were much greater than 1 and spanned a large range from 17 in the Raritan and Passaic Rivers to over 96 in the Rahway River. In the age-dated cores, regardless of deposition date, the ratio in the sediment was consistently less than 1. Similarly, the 2,3,7,8-TCDD/HxCB concentration ratio in all the present-day river sediments were less than 8.1 in the dated cores, the sediment ratio was greater than 80 . Finally, the 2,3,7,8-TCDD/2,3,7,8-TCDF concentration ratios in the present-day river sediments were less than 0.5 ; in the dated cores, this ratios was greater than 6 , regardless of the date of deposition. Thus, all three of these ratios were distinctly different in the present-day sediment from ratios in sediment deposited historically in the lower Passaic River estuary, regardless of deposition date. This further indicated the suspended sediment currently originating from the river basin (above HOT) has little impact on the hexachlorobenzene and 2,3,7,8-TCDD/ DF composition of the buried sediment in the tidal portion of the estuary. These ratios should be useful in helping to distinguish present-day sediment delivered from the river basins from sediment buried in the lower, tidal portion of the Passaic River during the years when 2,4,5-T was manufactured.

\section{Sediment-Water Partitioning}

The sediment to water concentration ratios were calculated for the pesticides using concentrations in low-flow samples from each river (table 50). Sediment concentration ratios ( $\mathrm{Kd}$, in units of liters per kilogram) were calculated using low-flow sediment normalized concentrations (mass per kilogram of sediment), and the sediment-carbon ratios $\left(\mathrm{K}_{\mathrm{oc}}\right.$, in units of liter per kilogram of carbon) were calculated using carbon-normalized sediment concentrations (mass per kilogram of carbon). The low-discharge samples selected for these calculations were selected on the basis of having few (or no) nondetected concentrations. In spite of the reduced number of data sets chosen, partitioning constants could not be calculated for some compounds. The most complete suite of $\mathrm{K}_{\mathrm{oc}}$ values, from the Elizabeth River samples, were compared with published octanol-water partitioning coefficients (MacKay and others, 2000) in figure 43.

The $\mathrm{K}_{\mathrm{oc}}$ ratios calculated using the Elizabeth River data are 0.5 to $1.5 \log$ unit greater than the corresponding reported $\mathrm{K}_{\mathrm{oc}}$ values and are generally closer to the experimental $\mathrm{K}_{\mathrm{ow}}$ values. The measured ratios for oxy-chlordane and beta-endosulfan showed the greatest divergence from expected values; measured values were over $2.5 \log$ units ( 2.5 orders of magnitude) higher than their corresponding $\mathrm{K}_{\mathrm{oc}}$ and $\mathrm{K}_{\mathrm{ow}}$ values. Aldrin and oxychlordane showed the greatest divergence from the published $\mathrm{K}_{\mathrm{oc}}$ and $\mathrm{K}_{\mathrm{ow}}$ values. It is difficult to interpret the cause of the differences. Partitioning values $\left(\mathrm{K}_{\mathrm{oc}}\right)$ are typically derived from agricultural soil studies and are apparently rarely reported for stream sediments. The differences may stem from differences in the nature of the organic matter in the streams and soils. Alternatively, the methods used to sequester the OCPs from the dissolved phase (XAD resin) may be overestimating the dissolved concentrations. In any case, using published $\mathrm{K}_{\mathrm{oc}}$ or $\mathrm{K}_{\mathrm{ow}}$ values would underestimate the dissolved concentrations or overestimate the sediment concentrations compared with measured values.

\section{Mercury, Cadmium, and Lead}

The concentrations of the trace elements $\mathrm{Hg}, \mathrm{Me}-\mathrm{Hg}$, $\mathrm{Cd}$, and $\mathrm{Pb}$ were measured in water and suspended sediment collected from the Raritan, Passaic, Rahway, Elizabeth, and Hackensack Rivers, the major tributaries to the Newark and Raritan Bays. Flow-weighted composite and discrete grab samples were collected during low-flow and storm-discharge conditions. These data were used to make interpretations and to calculate riverine loads of these trace elements to Newark and Raritan Bays from the watersheds above the HOT.

Mercury exists in two methylated forms, mono-methylated $\left(\mathrm{CH}_{3}-\mathrm{Hg}^{+}\right)$and di-methylated mercury $\left(\left(\mathrm{CH}_{3}\right)_{2}-\mathrm{Hg}^{\circ}\right)$, their relative proportions being dependant on numerous factors that include the availability of $\mathrm{Hg}^{+}$ions and $\mathrm{CH}_{3}$. The $\mathrm{Me}-\mathrm{Hg}$ concentrations reported in this work are the sum of the dissolved mono- and di-methylated species and, like $\mathrm{Pb}$ and $\mathrm{Cd}$, are reported as total $(\mathrm{tMeHg})$, dissolved $(\mathrm{dMeHg})$, or particulate $(\mathrm{pMeHg})$ phase species. In the initial rounds of sampling, only the dMe-Hg species were measured. Subsequent rounds included the analysis of $\mathrm{tMe}-\mathrm{Hg}$ (measured in unfiltered samples), thereby allowing the particulate $\mathrm{pMeHg}$ to be calculated by difference.

The geochemical cycles of $\mathrm{Hg}$ and $\mathrm{Me}-\mathrm{Hg}$ (fig. 44) have been the focus of study for some time now, due in part to numerous reported incidents of human and biologic poisoning (Forstner and Whittmann, 1983). The cycling of $\mathrm{Hg}$ is complicated by the fact it involves the sediment, aquatic, and atmospheric reservoirs along with biota ranging from bacteria to higher trophic-level organisms. $\mathrm{Me}-\mathrm{Hg}$ is especially troublesome due to its toxic effects in organisms. Me-Hg is produced through abiotic and biotic pathways. In the abiotic pathway, methylation occurs when dissolved ionic mercury (as well as $\mathrm{Pb}, \mathrm{As}$, and other metals) interacts with dissolved 


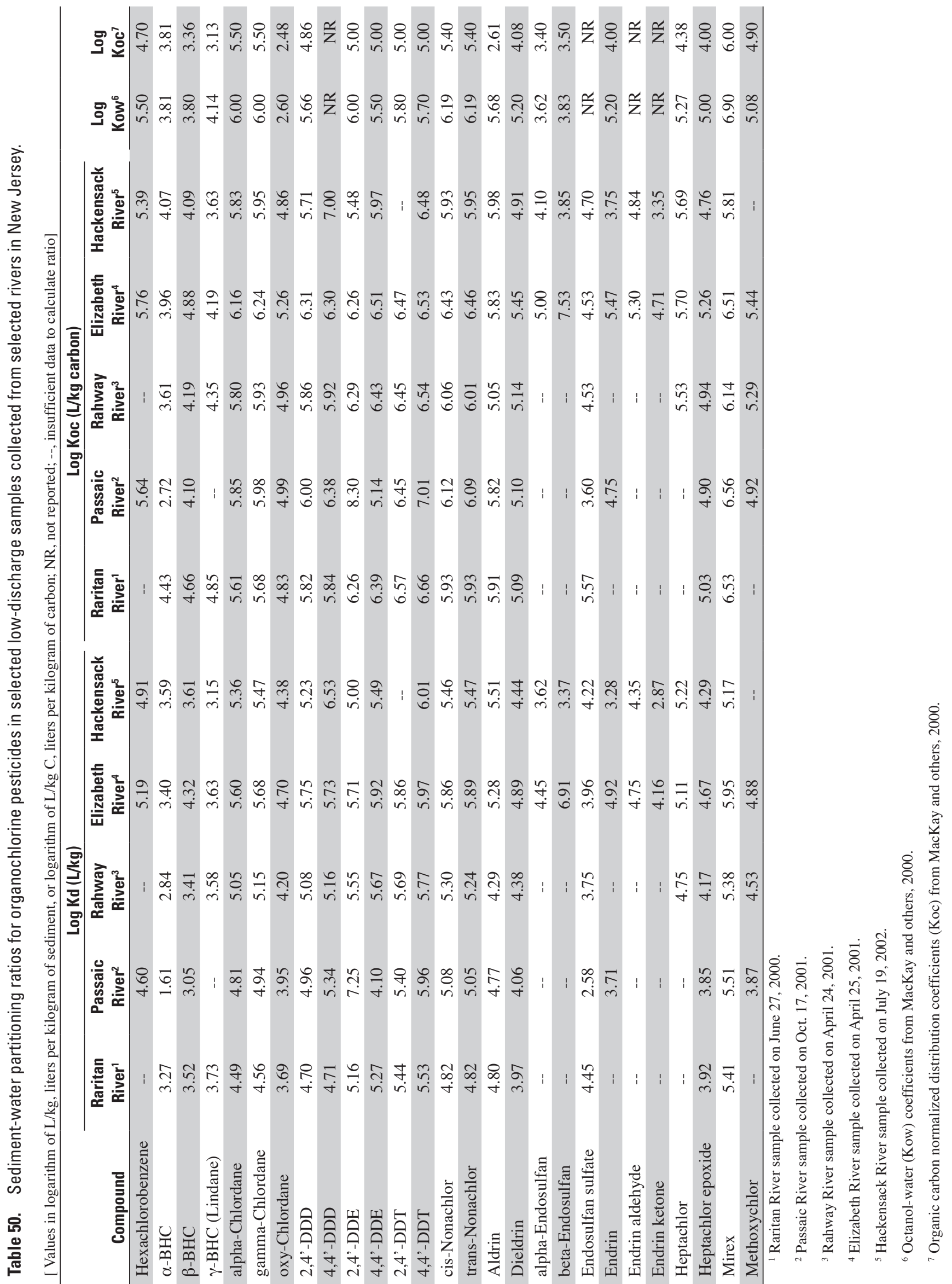




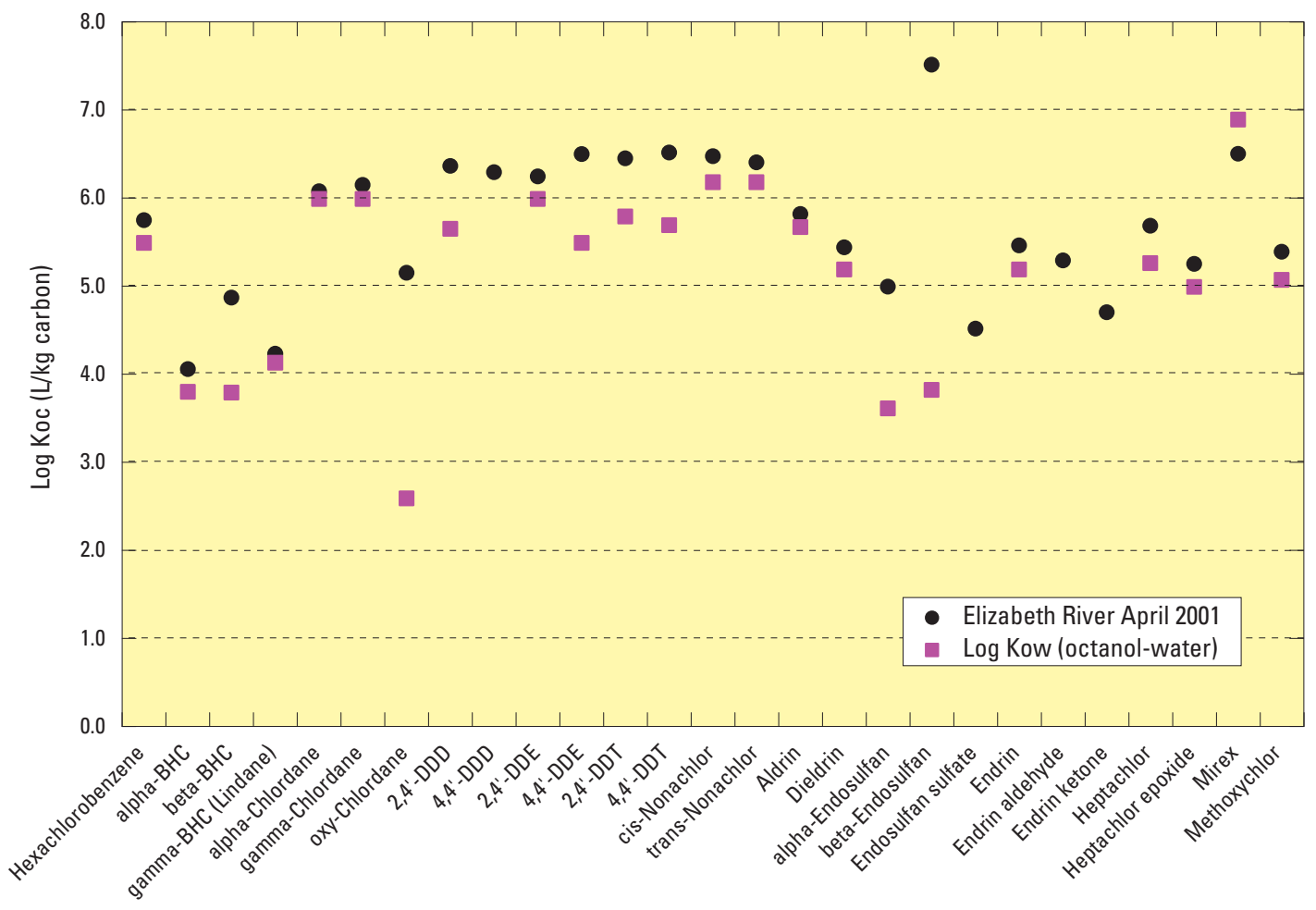

Figure 43. Sediment-carbon water ratios for pesticide compounds in a low-flow sample collected from the Elizabeth River, Hillside, NJ, April 25, 2001.

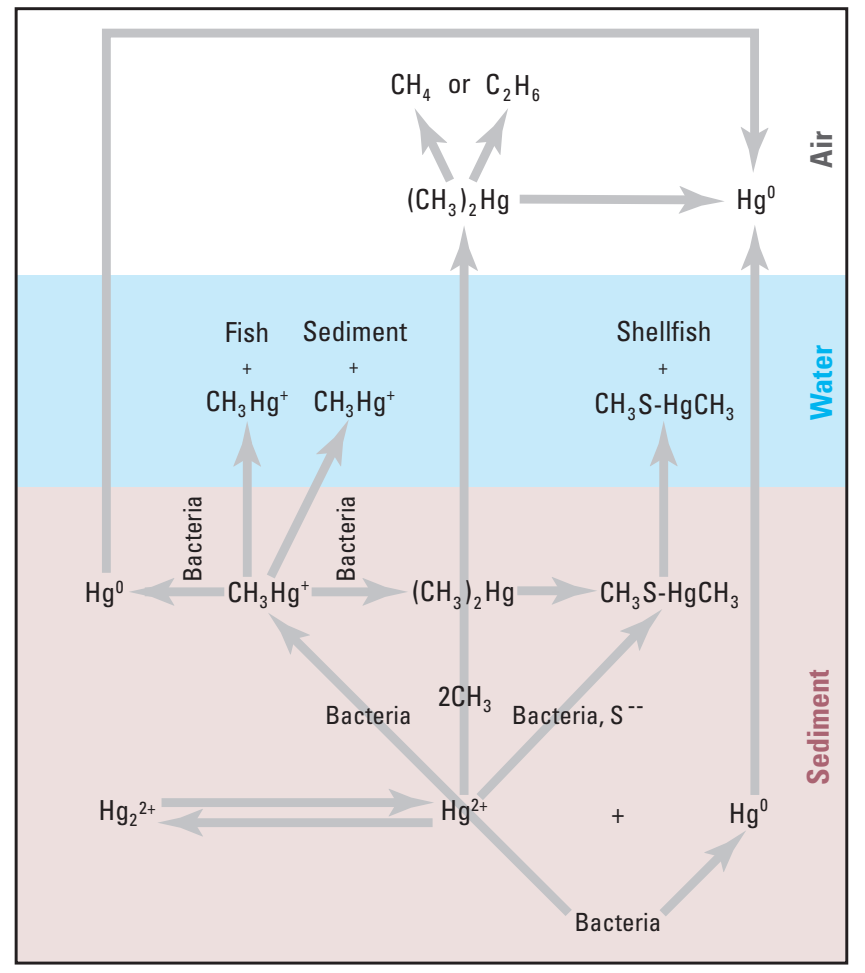

Figure 44. The biologic cycle of mercury and methyl mercury in the environment (from Wood, 1975). The arrows show the pathways of inorganic and biologic transformations that occur in sediment, water, aquatic organisms, and the atmosphere. $\left[\mathrm{Hg}\right.$, mercury; $\mathrm{CH}_{3^{\prime}}$ methyl; S, sulfur] 
methyl ions. This typically occurs in pore waters of bottom sediments that contain $\mathrm{Hg}^{++}$ions, particulate carbon, sulfur (or sulfate), and the proper suite of bacteria. As bacteria decompose the organic matter in the sediment, methane and dissolved methyl-ions are produced that can interact with dissolved ionic $\mathrm{Hg}$ to form $\mathrm{Me}-\mathrm{Hg}$. The amount of each form of Me-Hg will be a function of the rate at which methyl ions are produced, the rate at which the $\mathrm{Hg}^{++}$diffuses and interacts with the methyl species, and the rates at which the methylated species diffuse to the overlying water, sorb to the sediment, or the rate at which $\mathrm{Hg}^{++}$ions react with dissolved sulfur $\left(\mathrm{S}^{=}\right)$. Sorption of mono-methylated $\mathrm{Hg}$ is highly favored because of the ionic nature of this compound. Dissolved Me- $\mathrm{Hg}$ is lost in various ways including reactions with dissolved ionic sulfur and through a number of de-methylation reactions, typically involving oxidation reactions. $\mathrm{Me}-\mathrm{Hg}$ in the bottom sediment and pore water is also transferred to the overlying river water through diffusion in pore water, or when bottom sediments and associated pore water transfer into the overlying water column. A second methylation pathway involves bacteria and any other organisms capable of synthesizing vitamin B12 (Hay, 1984). Hg, as well as Me-Hg, is ingested by bottom-dwelling organisms that consume bacteria and associated organic matter for their energy source, as well as when they ingest water and sediment. The metals are then passed through higher trophic level organisms and ultimately accumulate in the fatty tissue of fish and other organisms. Many Hg-based health-warnings associated with fish can be ultimately traced to the presence of methylation in metal-bearing bottom sediments (Forstner and Wittmann, 1983).

Because of the relation between methylation, bacteria, and sediment-carbon, Me-Hg is typically associated with low-oxygen content bottom sediment where anerobic organic carbon degradation and methane production occur. Dissolved concentrations of $\mathrm{Me}-\mathrm{Hg}$ in aerobic river water are commonly low because of low rates of $\mathrm{CH}_{3}^{+}$production in an aerobic environment typical of rivers. Concentrations of particulate species in rivers are expected to be erratic because they are related to periods when bottom sediments or marshy bank sediments are eroded, rather than constant rates of production such as is typical in lake environments.

\section{Methods}

Both grab and composite samples were collected during each sampled event to provide information on different aspects of the river chemistry. During storm events, grab samples of unfiltered and filtered water were collected near the peak discharge. For low-flow conditions, the grab samples were collected near the mid-point of the sample-collection period. Unfiltered samples contain dissolved and particulate-bound elements and provide concentrations of "total" or whole-water concentrations. The filtered samples provided concentrations of dissolved (operationally defined) constituents only. Filtered samples were collected by attaching a pre-cleaned length of silicon pump tubing directly to the inlet line running to the stream. The pump tubing was passed through a peristaltic pump and then either directly into a precleaned Teflon bottle or to a Gellman 0.45-micron pore size capsule filter whose outlet was placed directly in the sample bottle. The filtered and unfiltered samples were collected within a few minutes and were considered to be simultaneous samples of river water. The difference between the total and dissolved concentrations represents the concentration of particulate-bound constituents. The grab-sample concentrations provide insight into the distribution of trace elements between the solid and dissolved phases in the rivers.

The composite samples were collected to provide "totalmetal" or "whole-water" concentrations (dissolved plus particulate) averaged over a storm event. These "flow" weighted samples were produced by collecting and compositing equal-volume aliquots of water collected at a pre-set discharge interval during the sampling event. It was necessary to hold the composite samples within the sampler for a period of time (hours to days), during which time a substantial redistribution of the trace elements between the phases could be expected. As a result, only total concentrations were measured in this work. Information from the grab samples allowed the phase concentrations in the composite samples to be estimated.

The sampling and analytical methods are discussed in detail by Bonin and Wilson (2006) and are only summarized here. Care was taken throughout the sampling to minimize sample contamination. Tubing, filters, polytetrafluoroethylene (PTFE) bottles, and caps were provided pre-cleaned by the analytical laboratory following USEPA guidelines.

Composite samples were collected using an automatic sampler attached directly to the sampling line. The samples were collected in pre-cleaned 4-L glass bottles that were obtained pre-cleaned to class-A level (Eagle-Pitcher, Miami, Fla). Once collected, the composite sample was sealed and transported on ice to the USGS-New Jersey District laboratory where the composite sample was poured directly into teflon bottles that were shipped on ice overnight to the laboratory for analysis.

\section{Quality Assurance}

Quality-control and assurance data generated using field and equipment blanks were used to address the contamination caused by the field environment and sampling equipment. Laboratory contamination was addressed in the analysis by subtracting lab blank concentrations and required no further corrections.

\section{Contamination of Blanks and Data Censoring}

Because the setting (highly urbanized) in which this study was conducted and because of the sampling scheme used, the potential existed for the samples to become contaminated from sources such as the atmosphere, dust, and sample handling. Equipment and field blanks were used as a surrogate of 
contamination caused by the equipment and the environment. Effort was made to reduce the possibility of contamination by, for example, keeping the tubing connections to a minimum, sampling from a line through which water was continuously pumped, and shielding the sample bottles from wind and dust. In order to maintain consistency in quality, tubing, bottles, and filters were only cleaned by the contract laboratory.

Method blanks were prepared by the laboratory using lab distilled water. The reported concentrations were adjusted by subtraction of method-blank concentrations and no other evaluation was required by the investigators.

Field and equipment blanks were collected during each sampling event. Field blanks for the grab samples were prepared using de-ionized water provided by the contract laboratory that was placed in a PTFE bottle left open to the atmosphere at the field site. The equipment blank for each grab sample was prepared by pumping de-ioinized laboratory water through the tubing and filter to be used for obtaining the filtered grab sample. The equipment blank was collected immediately before the grab sample was collected. Field blanks for the composite sample were prepared by leaving a bottle of laboratory water open in the bottom of the automatic sampler chamber. Once the composite sample was collected, the field blank was sealed and shipped for analysis with the samples.

Using the field and equipment blank data, a blank-elimination procedure was instituted to censor data that may have been affected by environmental contamination (New Jersey Department of Environmental Protection, 2001). Concentrations in samples at or below a level five times the highest blank value (the higher of the concentrations in the field or equipment blank) were censored (censored values are shaded in the summary tables, tables 51 and 52). Because particulate concentrations are derived from the total concentrations, blank elimination of a total value resulted in the censoring of the associated particulate concentration. Fortunately, only a few total $\mathrm{Cd}$ and dissolved $\mathrm{Hg}$ concentrations in the grab samples were eliminated by this procedure. None of the composite samples were affected by the blank elimination.

Inspection of the concentrations (table 51 and 52) also shows that, for any of the rivers, concentrations that would be "blank" eliminated are very similar to the other concentrations measured in the rivers on other sampling dates. This suggests the samples were not appreciably affected by contamination during collection, and the censored data may provide useful information. The blank-eliminated data were flagged and left in the summary table for the readers use but were not used to calculate average concentrations.

\section{Concentrations}

The trace-element concentrations are presented in tables 51 and 52, respectively; the average concentrations for both types of samples are listed in table 53, and the average concentrations normalized to organic carbon are listed in table 54. Total(tM) and dissolved (dM) concentrations in the grab samples are presented in units of nanograms per liter. Total metal concentrations in the composite samples are reported in units of nanograms per liter. Suspended-sediment concentrations (SS) and POC used in these calculations were measured in discrete grab samples collected concurrently with the grab samples for trace elements (Bonin and Wilson, 2006). The concentrations of SS and POC needed for the composite samples were calculated as the geometric mean of the concentrations measured in discrete SS samples collected continually over the period of storm discharge.

The concentrations of trace elements in the grab samples are summarized as follows:

1. Dissolved Cd ranged from 4.5 to $202 \mathrm{ng} / \mathrm{L}$, and particulate Cd ranged from 0.130 to $25.1 \mu \mathrm{g} / \mathrm{g}$. The highest average concentrations of Cd (all forms) were in the Elizabeth River, and the lowest were in the Hackensack River. Total $\mathrm{Cd}$ and particulate-Cd were elevated in some of the Rahway River samples. The average total Cd concentrations fall in the order:

\section{Hackensack $<$ Raritan $<$ Passaic $<$ Rahway $<$ Elizabeth}

2. Dissolved $\mathrm{Pb}$ ranged from 14.2 to $4,200 \mathrm{ng} / \mathrm{L}$, and particulate $\mathrm{Pb}$ ranged from 14.4 to $1,360 \mu \mathrm{g} / \mathrm{g}$. The highest average concentrations of dissolved and particulate $\mathrm{Pb}$ were in the Elizabeth River, but the highest average total $\mathrm{Pb}$ concentration was in the Rahway River. The lowest average concentrations were in the Hackensaclk River. The highest concentration of total $\mathrm{Pb}(22,900 \mathrm{ng} / \mathrm{L})$ in a single sample was was measured in the Rahway River. Average total $\mathrm{Pb}$ concentration ranked in the order:

\section{Hackensack $<$ Passaic $<$ Raritan $<$ Elizabeth $<$ Rahway}

3. Dissolved $\mathrm{Hg}$ ranged from 0.49 to $10.8 \mathrm{ng} / \mathrm{L}$, and particulate $\mathrm{Hg}$ ranged 0.030 to $6.92 \mu \mathrm{g} / \mathrm{g}$. Average concentrations of dissolved and particulate $\mathrm{Hg}$ were highest in the Elizabeth River, but the highest total $\mathrm{Hg}$ concentration was in the Rahway River. Average concentrations of dissolved and total Hg were lowest in the Hackensack River, and the average concentrations of particulate $\mathrm{Hg}$ were lowest in the Raritan River. The highest concentration of total $\mathrm{Hg}$ in a single sample was measured in the Rahway River $(72.3 \mathrm{ng} / \mathrm{L})$. Average concentrations of total $\mathrm{Hg}$ were ranked in the order:

\section{Hackensack $<$ Raritan $<$ Passaic $<$ Elizabeth $<$ Rahway}

4. Concentrations of dissolved $\mathrm{Me}-\mathrm{Hg}$ ranged from 0.006 $\mathrm{ng} / \mathrm{L}$ to $0.222 \mathrm{ng} / \mathrm{L}$. Concentrations of particulate $\mathrm{Me}-\mathrm{Hg}$ concentrations ranged from 1.0 to $20 \mathrm{ng} / \mathrm{g}$. The highest concentration of particulate $\mathrm{Me}-\mathrm{Hg}$ was measured in the Hackensack River, and the lowest was in the Raritan River. Average concentrations of total $\mathrm{Me}-\mathrm{Hg}$ were ranked in the order:

Hackensack $<$ Passaic $<$ Elizabeth $<$ Raritan $<$ Rahway 
$\mid$

نे

苞

青

s.

웅 홀

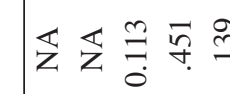

艺艺艺㧝

艺艺艺。

㞼

范

焉

모ㄹㅗㅗㅇ $\varangle$

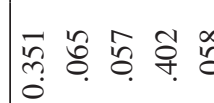

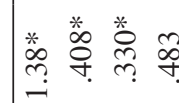

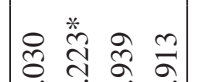

œ

草

产

Tis

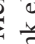

焉

की

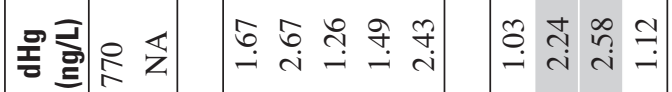

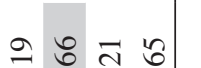

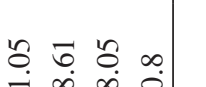

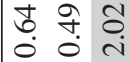

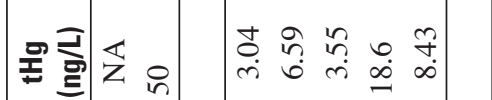

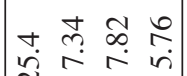

กิ กิ

$\infty$ m.

\&

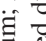

焉

$\forall \stackrel{0}{0}$

b 0 a +2

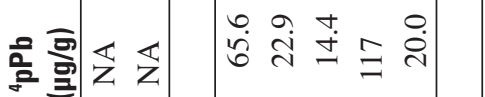

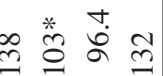

in $2 \infty$

울 융

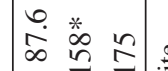

窂言

惫

so

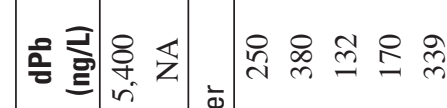

$\lim _{\infty}^{\infty}$

i.t.

ㅇ. ก

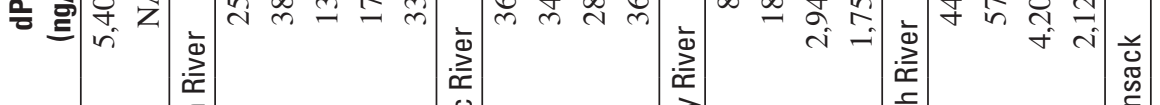

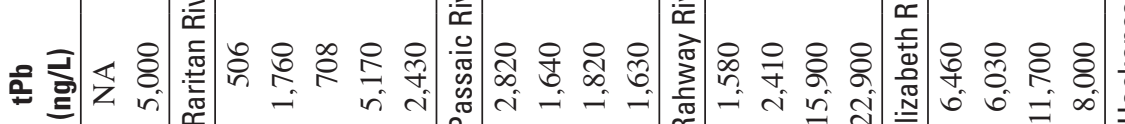

흠

政

$<$

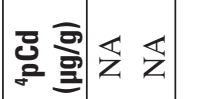

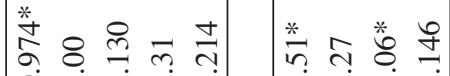

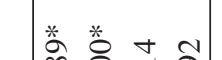

芩

要

क.

고

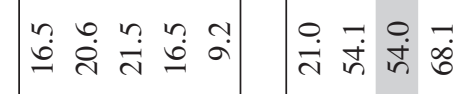

을

흐 z Z

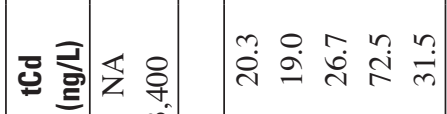

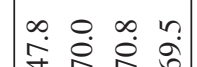

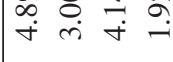

\&. ฉ m -

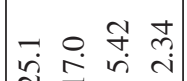

ஸे

i

节

$\stackrel{5}{\because}$

萇

잉 굴 $\mathbb{z}$

तิ $\infty$ in

考合

वे चै

일

然骂

2 혹

表范

喆

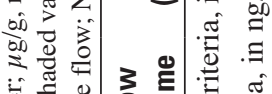

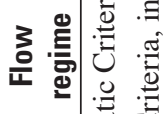

咅 >

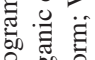

ठ

言节

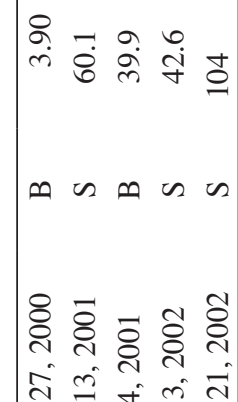

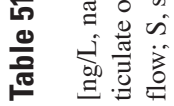

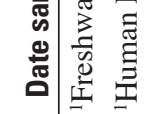

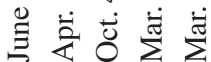

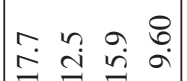

ก்ุ

은

유ำ

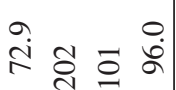

융 
Table 52. Concentrations of total mercury, cadmium, and lead in composite samples collected from selected rivers in New Jersey.

[Cd, cadmium; Hg, mercury; Pb, lead; mg/L, milligrams per liter; ng/L, nanograms per liter; NA, not applicable]

\begin{tabular}{|c|c|c|c|c|c|c|c|}
\hline River & Date & $\begin{array}{l}\text { Flow } \\
\text { regime }\end{array}$ & $\begin{array}{c}\text { Suspended } \\
\text { sediment } \\
\text { (mg/L) }\end{array}$ & $\begin{array}{c}\text { Particulate } \\
\text { organic carbon } \\
\text { (mg/L) }\end{array}$ & $\begin{array}{l}\text { Total Cd } \\
\text { (ng/L) }\end{array}$ & $\begin{array}{c}\text { Total Pb } \\
\text { (ng/L) }\end{array}$ & $\begin{array}{c}\text { Total Hg } \\
\text { (ng/L) }\end{array}$ \\
\hline \multicolumn{3}{|c|}{ Freshwater Human Health Criteria, in ng/L } & NA & NA & 3,400 & 5,000 & 50 \\
\hline \multicolumn{3}{|c|}{ Freshwater Aquatic Chronic Criteria, ng/L } & NA & NA & NA & NA & NA \\
\hline \multirow[t]{2}{*}{ Raritan } & April 13, 2001 & B & 32.4 & 1.26 & 26.0 & 1,590 & 5.40 \\
\hline & Oct. 4, 2001 & B & 66.7 & 2.18 & 32.4 & 1,250 & 5.65 \\
\hline \multirow[t]{2}{*}{ Passaic } & Mar. 14, 2001 & S & 16.4 & 1.28 & 107 & 2,500 & 10.3 \\
\hline & Oct. 17,2001 & B & 9.40 & .86 & 78.0 & 1,840 & 6.50 \\
\hline \multirow[t]{2}{*}{ Rahway } & Apr. 24, 2001 & B & 9.40 & 1.63 & 46.0 & 2,960 & 5.34 \\
\hline & May 22, 2001 & S & 39.3 & 3.57 & 67.7 & 5,520 & 12.9 \\
\hline Hackensack & Oct. 19,2001 & B & 2.80 & 1.05 & 5.00 & 385 & 1.33 \\
\hline Hackensack & Mar. 13, 2001 & Tidal & 20.2 & 2.51 & 116 & 1,020 & 26.8 \\
\hline
\end{tabular}

The average $\mathrm{Cd}$ and $\mathrm{Pb}$ carbon-normalized concentrations are highest in the Elizabeth River, while the average Hg concentration is highest in the Passaic River. The lowest average cabon-normalized concentrations for all three metals are in the Hackensack River.

\section{Relation of Whole-Water Concentrations to Surface- Water-Quality Criteria}

Surface-water standards have been set by the New Jersey Department of Environmental Protection for the metals $\mathrm{Hg}$, $\mathrm{Cd}$, and $\mathrm{Pb}$ for freshwater Aquatic Chronic and Human Health criteria. The Aquatic Chronic criteria for dissolved $\mathrm{Hg}$ and $\mathrm{Pb}$ were not exceeded in any of the samples. The Human Health criteria are based on whole-water concentrations, which are the sum of the concentrations in the dissolved and suspended sediment phases, corrected for the mass of sediment per liter of water. The total Human Health water-quality criteria $(50 \mathrm{ng} / \mathrm{L})$ was exceeded in three samples - the Rahway River, April 28, 2002 grab and composite samples and in the composite sample from the Elizabeth River collected on June 4, 2003. The total $\mathrm{Pb}$ water-quality criteria $(5,000 \mathrm{ng} / \mathrm{L})$ was exceeded in all of the grab samples and two composite samples collected from the Elizabeth River, all of the grab samples collected during storms from the Rahway River, the grab sample from the Raritan River collected on March 3, 2002, and the composite sample collected from the Raritan River on March 21, 2001.

Although the grab and composite samples were collected for different purposes, it is instructive to compare the concentrations produced by the two sampling methods. To make this comparison, the ratio of the average concentration (total) in the composite sample to the total concentrations in the grab samples was calculated (from table 53), along with the corresponding ratios for suspended sediment and POC. These ratios could not be calculated for the Hackensack River because of the limited amount of data available. The average ratios for the rivers are presented in table 55 .

The ratios for suspended sediment, organic carbon, and trace elements within each river are relatively consistent for the Passaic, Rahway, and Raritan Rivers, and are highly variable for the Elizabeth River. The ratios in the Elizabeth River are much higher than the ratios for the other rivers and also showed the most variation among the metals. The composite samples collected from the Elizabeth River had concentrations four to nine times higher than concentrations in the associated grab samples. This indicates that various sources of metals (for example, nonpoint sources) may affect the Elizabeth River water during storm-discharge events. For the other rivers, the ratios indicate that source(s) having a more a consistent chemistry (for example, nonpoint sources) effect the rivers during storms.

Also, the ratios for the trace elements (except for $\mathrm{Pb}$ in the Elizabeth River) differed only slightly from the ratios for suspended sediment and carbon, suggesting that the differences in the total metal composition of the composite and grab samples were the result of the amount of sediment and/or carbon captured. 


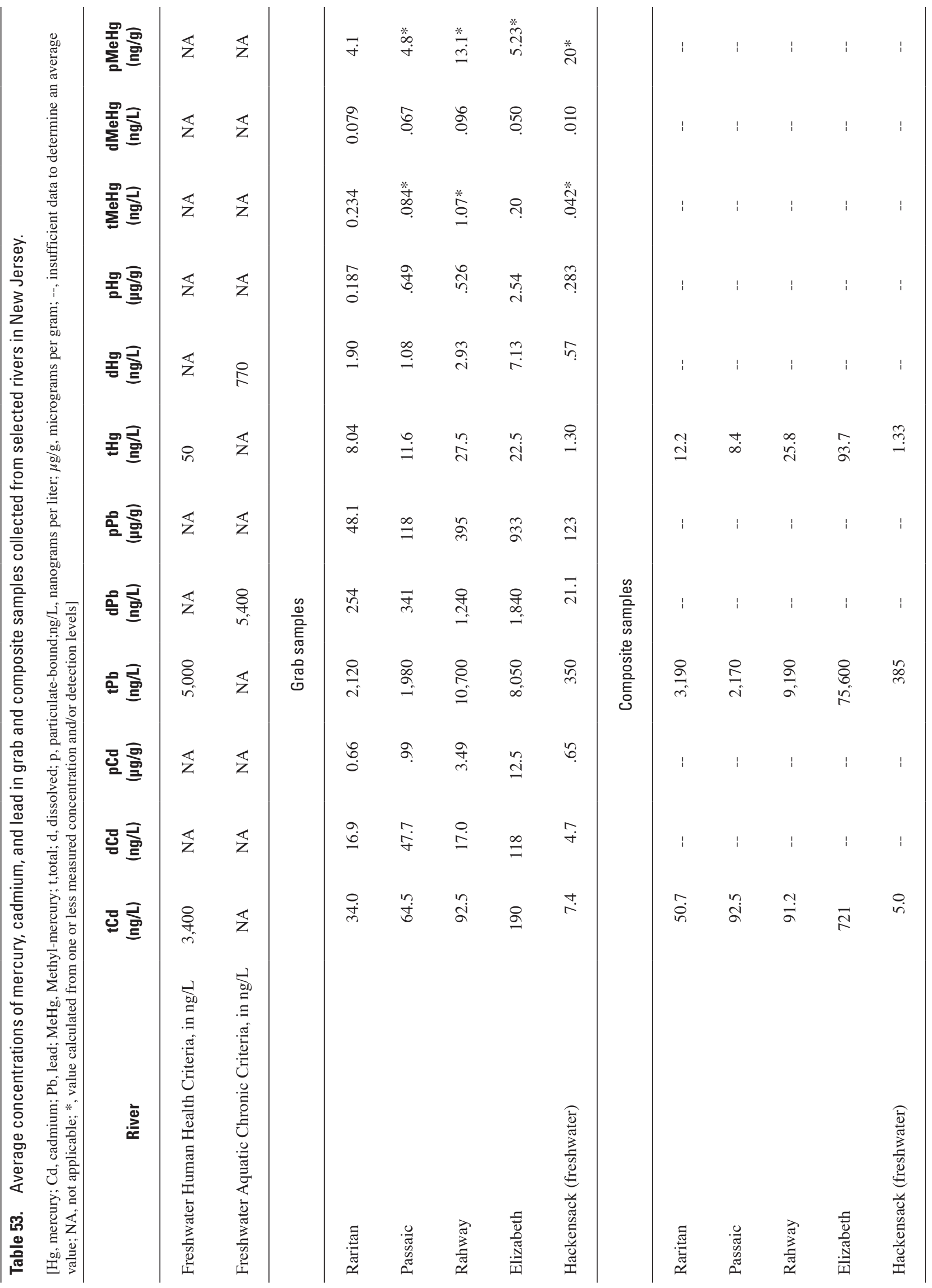


Table 54. Concentrations of particulate-bound mercury, cadmium, and lead in grab samples normalized to particulate carbon in samples collected from selected rivers in New Jersey.

[Hg, mercury; $\mathrm{Cd}$, cadmium; $\mathrm{Pb}$, lead; fom, fraction of organic matter in sample; $\mu \mathrm{g} / \mathrm{gC}$, microgram per gram of particulate carbon; --, not detected; *, indicates concentration would be removed due to blank elimination of associated dissolved or total value; B, ;low flow; S, storm; V, variable]

\begin{tabular}{|c|c|c|c|c|c|}
\hline Date & $\begin{array}{c}\text { Flow } \\
\text { regime }\end{array}$ & $f_{\text {om }}$ & $\begin{array}{c}p C d \\
(\mu g / g C)\end{array}$ & $\begin{array}{c}p P b \\
(\mu g / g C)\end{array}$ & $\begin{array}{c}\mathrm{pHg} \\
(\mu \mathrm{g} / \mathrm{gC})\end{array}$ \\
\hline \multicolumn{6}{|c|}{ Raritan River } \\
\hline June 27, 2000 & B & 0.056 & $17.3 *$ & 1,170 & 6.26 \\
\hline Apr. 13, 2001 & $\mathrm{~S}$ & .030 & -- & 757 & 2.15 \\
\hline Oct. 4, 2001 & B & .064 & 2.02 & 224 & .89 \\
\hline Mar. 3, 2002 & S & .040 & 33.0 & 2,950 & 10.1 \\
\hline Mar. 21, 2002 & S & .010 & 21.3 & 1,990 & 5.73 \\
\hline Average & & .040 & 18.4 & 1,418 & 5.03 \\
\hline \multicolumn{6}{|c|}{ Passaic River } \\
\hline June 22, 2000 & B & .025 & $60.4^{*}$ & 5,520 & $54.9 *$ \\
\hline Dec. 15,2000 & V & .076 & 16.7 & $1,360 *$ & $5.35^{*}$ \\
\hline March 14, 2001 & S & .073 & $14.5^{*}$ & 1,320 & $4.53 *$ \\
\hline Oct. 17,2001 & B & .079 & 1.85 & 1,680 & 6.13 \\
\hline Average & & .063 & 23.3 & 2,470 & 17.7 \\
\hline \multicolumn{6}{|c|}{ Rahway River } \\
\hline June 28,2000 & B & .089 & $55.0 *$ & 6,240 & .33 \\
\hline Apr. 25, 2001 & B & .186 & $16.1^{*}$ & 1,640 & $1.20 *$ \\
\hline May 22, 2001 & S & .112 & 37.1 & 3,920 & 8.41 \\
\hline Apr. 28, 2002 & S & .078 & 24.7 & 3,620 & 11.7 \\
\hline Average & & .116 & 33.2 & 3,860 & 5.4 \\
\hline \multicolumn{6}{|c|}{ Elizabeth River } \\
\hline June 29, 2000 & B & .080 & 314 & 16,700 & $11.2^{*}$ \\
\hline Apr. 24, 2001 & B & .203 & 68.9 & 5,530 & 28.1 \\
\hline May 22, 2001 & S & .176 & 30.8 & 4,440 & 10.6 \\
\hline June 4, 2003 & S & 0.111 & 11.5 & 1,230 & 2.51 \\
\hline Average & & .177 & 106 & 6,980 & 13.1 \\
\hline \multicolumn{6}{|c|}{ Hackensack River } \\
\hline June 23, 2000 & B & .099 & $13.2 *$ & 882 & $1.89 *$ \\
\hline Oct. 19, 2001 & B & .584 & -- & $270 *$ & $.65^{*}$ \\
\hline Average & & .341 & $13.2 *$ & 580 & 1.3 \\
\hline Mar. 13, 2001 & Tidal & .099 & $9.24 *$ & 1,770 & $4.84 *$ \\
\hline
\end{tabular}

Table 55. Ratio of average concentrations of trace elements in composite samples to concentrations in grab samples collected from selected rivers in New Jersey.

\begin{tabular}{lccccc}
\hline River & $\begin{array}{c}\text { Suspended } \\
\text { sediment }\end{array}$ & $\begin{array}{c}\text { Particulate } \\
\text { organic } \\
\text { carbon }\end{array}$ & $\begin{array}{c}\text { Total } \\
\text { cadmium }\end{array}$ & $\begin{array}{c}\text { Total } \\
\text { lead }\end{array}$ & $\begin{array}{c}\text { Total } \\
\text { mercury }\end{array}$ \\
\hline Raritan & 1.9 & 1.6 & 1.5 & 1.5 & 1.5 \\
Passaic & 1.0 & 1.1 & 1.4 & 1.1 & 0.7 \\
Rahway & 0.8 & 0.9 & 1.0 & 0.9 & 0.9 \\
Elizabeth & 5.9 & 4.6 & 3.8 & 9.4 & 4.2 \\
\hline
\end{tabular}

\section{Sediment-Water Partitioning}

The partitioning of metals between the dissolved and particulate phases is an important process controlling the geochemical behavior of trace elements in aqueous environments. The in situ partitioning of the trace elements can be evaluated using the concentrations measured in the grab samples. The slope of best-fit lines calculated for the relation between dissolved and particulate concentrations defines the linear distribution coefficient $\mathrm{Kd}$. In essence, the Kd is the average sediment-water concentration ratio. The Kd value can be calculated on a sediment-mass basis, on a carbon-normalized mass basis, or in unitless form:

$$
\begin{aligned}
& K d=p M / d M \\
& K_{o c}=p M^{\prime} / d M
\end{aligned}
$$

where

$p M \quad=$ concentration in the sediment per unit mass of sediment, nanograms per kilogram of particulate sediment;

$d M \quad=$ dissolved concentration, in nanograms per liter of water;

$p M^{\prime}=$ carbon-normalized particulate-bound concentration, in nanograms of metal per kilogram of particulate carbon;

$K d=$ distribution coefficient, in units of liters per kilogram;

and

$$
K_{o c} \quad=\text { carbon-normalized distribution coefficient, }
$$
in units of liters per kilogram of carbon.

$\mathrm{Kd}$ and $\mathrm{K}_{\mathrm{oc}}$ are related through the fraction of organic matter in the sediment:

$$
K_{o c}=K d / f_{o c}
$$

where

$$
f_{o c} \quad=\text { the fraction of organic matter. }
$$

In many natural systems, the relation between dissolved and particulate concentrations is logarithmic, so values are typically reported as $\log -\mathrm{Kd}$. Care must be taken when using $\mathrm{Kds}$ that the concentration data are transformed to the correct unit system corresponding to the $\mathrm{Kd}$ values being used. Two unit systems are typically used when reporting Kd, either volume per mass (liters per kilogram) or as a unitless value. Unitless values can be applied to any data set in which the particulate and dissolved values are presented using the same units, such as nanograms per liter or moles per liter.

The Kds generated from field data are termed apparent distribution coefficients, in contrast to coefficients derived from laboratory experiments or calculated using thermodynamic data. In developing the distribution coefficient concept, 
it is assumed that equilibrium exists between the trace elements in the sediment and water phases. However, it is often found that sediment-water concentration ratios (apparent Kds) are not consistent even when derived from samples collected from a single environmental system and under relatively constant conditions. This suggests that non-equilibrium conditions exist, for example, resulting from rapid changes in river composition during storms. Non-equilibrium conditions are especially of concern when studying rivers where sediment can be quickly eroded and a "new" water chemistry can be encountered, for example, where overland flow, CSO outfalls, seawater, or other sources of water enter the river, and the sediment-bound concentrations slowly readjust to the new composition of the river water. Sediment that has deposited in a new environment will also slowly readjust to new conditions and pore-water compositions. Different distribution coefficients can be found during different seasons, for example, when increased primary production of carbon increases the amount of POC in the water column, or increased rain fall increases the SS content (Allan, 1983). While it is not surprising that sediment-water ratios are often not constant in river environments, the apparent partitioning coefficients for metals are useful for providing a baseline for evaluating and modeling the behavior of trace metals in the environment.

Apparent distribution coefficients were determined as the average of the ratios of particulate to dissolved concentrations in the combined data set (figs. 45 to 47). The relation between the dissolved and particulate-bound concentrations is weak, regardless of whether data from an individual stream or the combined river data set are studied. Using the carbon-normalized sediment-bound concentrations strengthens the relation, especially for $\mathrm{Pb}$. The weak correlation between sediment and dissolved concentrations indicates that the partitioning is more complex than predicted by simple equilibrium models.
The average sediment-water concentration ratios, $\mathrm{Kd}$ and Koc, calculated using the concentrations in the grab samples, are listed in units of $\mathrm{L} / \mathrm{g}, \mathrm{L} / \mathrm{gC}$, and as unitless $\mathrm{Kd}$ values in table 56 . The average $\mathrm{Kd}$ values $(\mathrm{L} / \mathrm{kg})$ for each metal vary among the rivers up to $0.7 \log$ unit, and by $0.8 \log$ Koc unit (exclusive of the Hackensack River, for which the data were too limited to evaluate). Within each river, variability among the metals in log Koc tended to be slightly greater than that for $\log \mathrm{Kd}$. As expected, the apparent $\log \mathrm{Kd}$ values differ between the metals within each river, as well as between rivers for the same metal.

It is instructive to compare the $\mathrm{Kd}$ values calculated in this work to values reported by researchers in other freshwater environments, especially for $\mathrm{Hg}$. Log Kd values for $\mathrm{Hg}$ in freshwater have been reported to fall within a rather large range. Values for log $\mathrm{Kd}$ for $\mathrm{Hg}$ reported by Babiarz and others (2001) for samples collected from non-impacted forested areas in Michigan, Minnesota, and Wisconsin ranged from 3.1 to 5.5, which are similar to the Kd values reported here. Values for $\log \mathrm{Kd}$ for $\mathrm{Hg}$ in the Wabigoon River system in Ontario, Canada, during non-high flow conditions were found to be 2.43 (Allan, 1983), lower than found in this study. $\mathrm{Log} \mathrm{Kd}$ values for $\mathrm{Hg}$ in organic rich water (POC and DOC concentrations up to 34 and $26 \mathrm{mg} / \mathrm{L}$, respectively) of the Everglades, and from the organic-rich Suwanee River (POC $47 \mathrm{mg} / \mathrm{L}$, DOC $24 \mathrm{mg} / \mathrm{L}$ ), were generally higher than for the forested streams, ranging from 4.2 to 6.4 (Cai and others, 1999). Although a large range exists in the Kd values from the various studies, the similarity in values between the Kds determined from this urbanized area with values from non-urbanized areas is encouraging and may be interpreted as showing that some degree of sediment-water equilibrium occurs in these New Jersey river systems.

Table 56. Average apparent sediment-water distribution coefficients

[L, liter; kg, kilograms; kg C, kilograms of particulate carbon; Kd; sediment normalized partition coefficient; Koc, carbon normalized partition coefficient; NA, no data available for this compound]

\begin{tabular}{|c|c|c|c|c|c|c|c|c|c|}
\hline \multirow[b]{2}{*}{ River } & \multicolumn{3}{|c|}{ Cadmium } & \multicolumn{3}{|c|}{ Lead } & \multicolumn{3}{|c|}{ Mercury } \\
\hline & $\begin{array}{l}\log K_{d} \\
(L / k g)\end{array}$ & $\begin{array}{c}\mathbf{K}_{\mathrm{d}} \\
\text { (unitless) }\end{array}$ & $\begin{array}{l}\log K_{o c} \\
(L / k g ~ C)\end{array}$ & $\begin{array}{l}\log K_{d} \\
(L / k g)\end{array}$ & $\underset{\text { (unitless) }}{\mathbf{K}_{\mathrm{d}}}$ & $\begin{array}{l}\log K_{o c} \\
(\mathrm{~L} / \mathrm{kg} \mathrm{C})\end{array}$ & $\begin{array}{l}\log K_{d} \\
(L / k g)\end{array}$ & $\begin{array}{c}\mathbf{K}_{\mathrm{d}} \\
\text { (unitless) }\end{array}$ & $\begin{array}{l}\log K_{o c} \\
(\mathrm{~L} / \mathrm{kg} \mathrm{C})\end{array}$ \\
\hline Raritan & 4.5 & 1.6 & 5.9 & 5.2 & 8.9 & 6.6 & 4.8 & 3.6 & 6.3 \\
\hline Passaic & 4.2 & .48 & 5.4 & 5.5 & 4.8 & 6.8 & 5.5 & 8.0 & 6.8 \\
\hline Rahway & 5.3 & 3.6 & 6.3 & 5.9 & 12 & 6.8 & 5.0 & 6.6 & 5.9 \\
\hline Elizabeth & 4.9 & .74 & 5.7 & 5.8 & 6.9 & 6.6 & 5.3 & 2.2 & 6.0 \\
\hline Hackensack ${ }^{1}$ & NA & 1.1 & NA & 6.8 & 17 & 7.4 & 5.7 & 1.3 & 6.3 \\
\hline
\end{tabular}

${ }^{1}$ Only one sample from the Hackensack River was suitable for calculating $\mathrm{K}_{\mathrm{d}}$ values. 

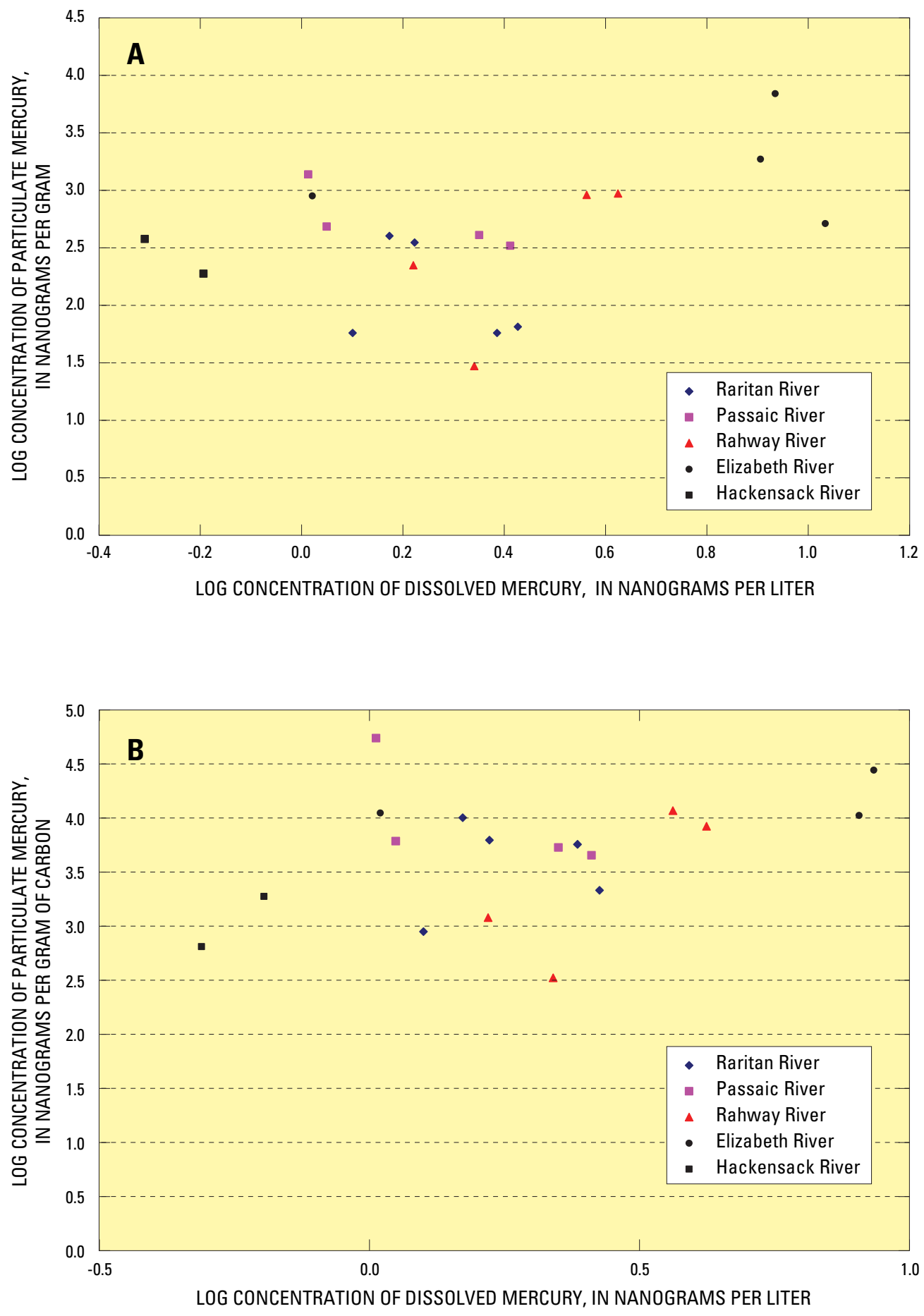

Figure 45. Relation between concentration of dissolved mercury and (A) concentration of particulate-bound mercury and (B) concentration of particulate-carbon-bound mercury in samples collected from selected rivers in New Jersey. 

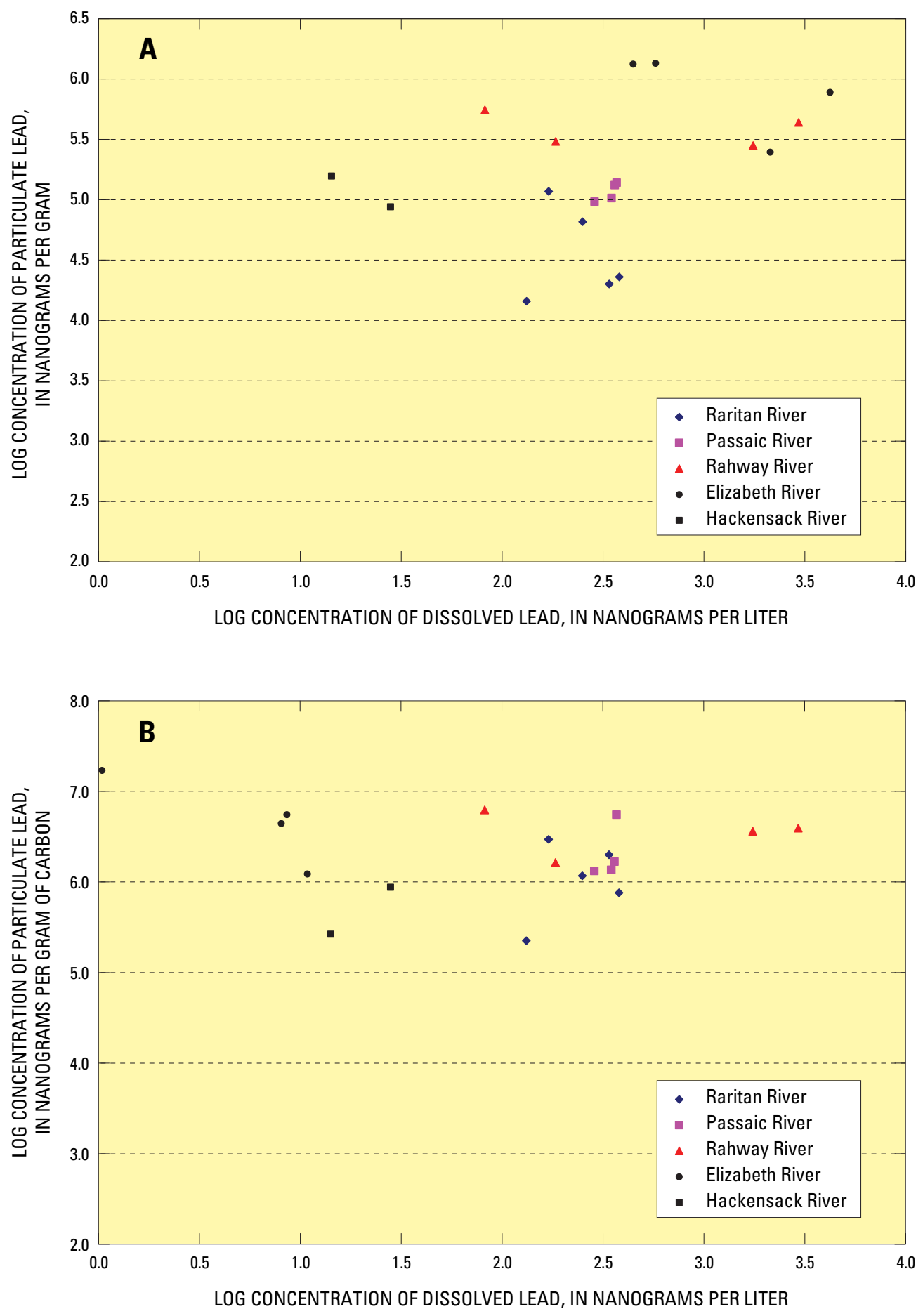

Figure 46. Relation between concentration of dissolved lead and (A) concentration of particulate-bound lead and (B) concentration of particulate-carbon-bound lead in grab samples collected from selected rivers in New Jersey. 

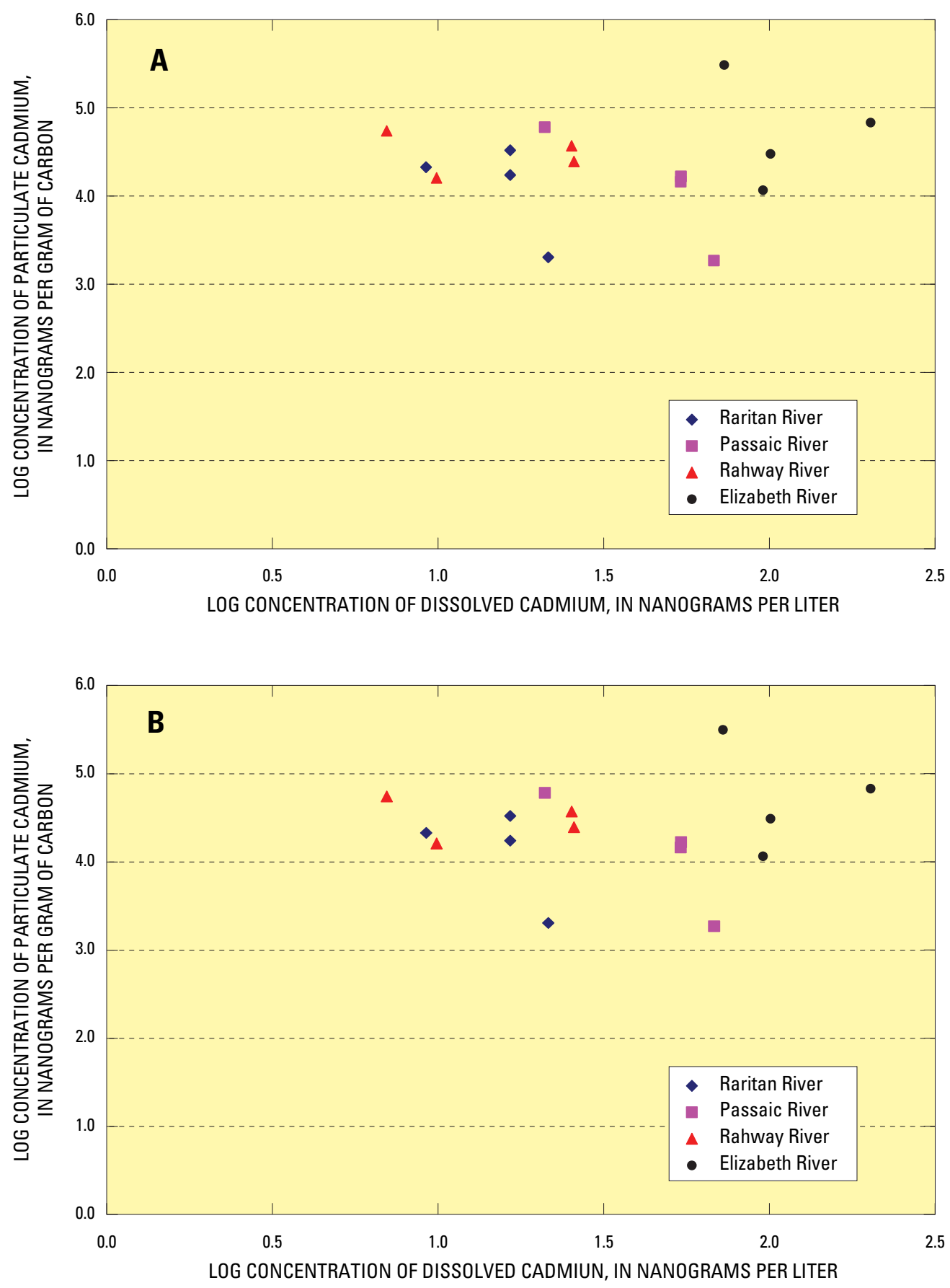

Figure 47. Relation between concentration of dissolved cadmium and (A) concentration of particulate-bound cadmium and (B) concentration of particulate-carbon bound-cadmium in grab samples collected from selected rivers in New Jersey. 


\section{Predicted Concentrations in the Sediment and Water Phases}

Flow-averaged total (whole-water) concentrations, derived from the composite samples, were used to provide total metal loads in the rivers. It is of interest to divide these loads into estimates of the dissolved and suspended sediment loads. To calculate the concentrations of the dissolved-phase and sediment-bound metals requires using the average unitless $\mathrm{Kd}$ values derived earlier from the grab samples. Using the definitions for $\mathrm{Kd}$ and the total metal concentration, the concentrations in the phases can be calculated using:

$$
\begin{gathered}
t M=d M+p M \\
t M=(p M / K d)+p M \\
p M^{\prime}=t M /(1+1 / K d) \\
d M^{\prime}=t M-p M^{\prime}
\end{gathered}
$$

where

$$
\begin{aligned}
K d= & \text { unitless distribution coefficient; } \\
t M= & \text { total metal concentration; } \\
p M^{\prime}= & \text { estimated sediment-bound metal } \\
& \text { concentration; }
\end{aligned}
$$

and

$$
d M^{\prime} \quad=\text { estimated dissolved metal concentration. }
$$

The average concentrations of the trace elements predicted to be in the sediment and dissolved phases are presented in table 57, and were calculated using the average total metal concentrations of the composite samples (table 53) and the average unitless $\mathrm{Kd}$ values (table 56).

Concentrations of total, dissolved, and particulate $\mathrm{Me}-\mathrm{Hg}$ species measured in the river water are listed in table 58 for the grab samples. The small number of data presently available makes it difficult to draw firm conclusions, but the data can be summarized as follows. Concentrations of tMe-Hg are low, ranging from 0.113 to $1.07 \mathrm{ng} / \mathrm{L}, \mathrm{dMe}-\mathrm{Hg}$ concentrations ranged from 0.006 to $0.222 \mathrm{ng} / \mathrm{L}$, and $\mathrm{pMe}-\mathrm{Hg}$ concentrations ranged from 1.0 to $20 \mathrm{ng} / \mathrm{g}$. The Hackensack River had the highest pMe-Hg concentration of all samples collected in this study. It is hypothesized this was the result of production in

\begin{tabular}{|c|c|c|c|c|c|}
\hline River & $\begin{array}{l}\text { Distribution } \\
\text { coefficient } \\
\text { (Kd) }\end{array}$ & $\begin{array}{l}\text { Average total metal } \\
\text { concentration in } \\
\text { composite samples } \\
\text { (measured, in ng/L) }\end{array}$ & $\begin{array}{c}\text { Dissolved metal } \\
\text { concentration } \\
\text { (predicted, in ng/L) }\end{array}$ & $\begin{array}{c}\text { Sediment-bound metal } \\
\text { concentration } \\
\text { (predicted, in ng/L) }\end{array}$ & $\begin{array}{l}\text { Percentage of total metal } \\
\text { in sediment phase } \\
\text { (predicted, in percent) }\end{array}$ \\
\hline \multicolumn{6}{|c|}{ Mercury } \\
\hline Raritan & 3.6 & 12 & 2.6 & 9.4 & 78 \\
\hline Passaic & 8.0 & 8.4 & 0.9 & 7.5 & 89 \\
\hline Hackensack & 1.3 & 1.3 & 0.6 & .7 & 53 \\
\hline \multicolumn{6}{|c|}{ Lead } \\
\hline Raritan & 8.9 & 3,200 & 300 & 2,900 & 91 \\
\hline Passaic & 4.8 & 2,200 & 400 & 1,800 & 82 \\
\hline Raritan & 1.6 & 51 & 20 & 31 & 61 \\
\hline Passaic & .48 & 93 & 63 & 30 & 32 \\
\hline Rahway & 3.6 & 91 & 20 & 71 & 78 \\
\hline Elizabeth & .74 & 720 & 410 & 310 & 44 \\
\hline Hackensack & 1.1 & 5.0 & 2.4 & 2.6 & 52 \\
\hline
\end{tabular}
the Oradell Reservoir and in the small impoundment immediately upstream from the sampling site. Small impoundments also exist upstream of the sampling sites on the Elizabeth and Rahway Rivers, which may explain the higher concentrations of $\mathrm{Me}-\mathrm{Hg}$ in these rivers.

Table 57. Average concentrations of mercury, lead, and cadmium predicted for water and sediment in selected rivers in New Jersey.

$\underline{\text { [ng/L, nanograms per liter; Kd, unitless distribution coefficient from table 56; data from table 53] }}$ 
Table 58. Concentrations of methyl-mercury in samples collected from selected rivers in New Jersey and apparent partitioning coefficients.

[ng/L, nanograms per liter; ng/g, nanograms per gram; ng/gC, nanograms per gram of carbon; L/kg, liters per kilogram; L/kgC, liter per kilogram of carbon; $\mathrm{Kd}$, apparent distribution coefficient; Koc, apparent distribution coefficient normalized to carbon; --, not measured or not applicable. Shaded values would be removed because of blank elimination; $\mathrm{B}$, low-flow; $\mathrm{S}$, storm; V, variable flow]

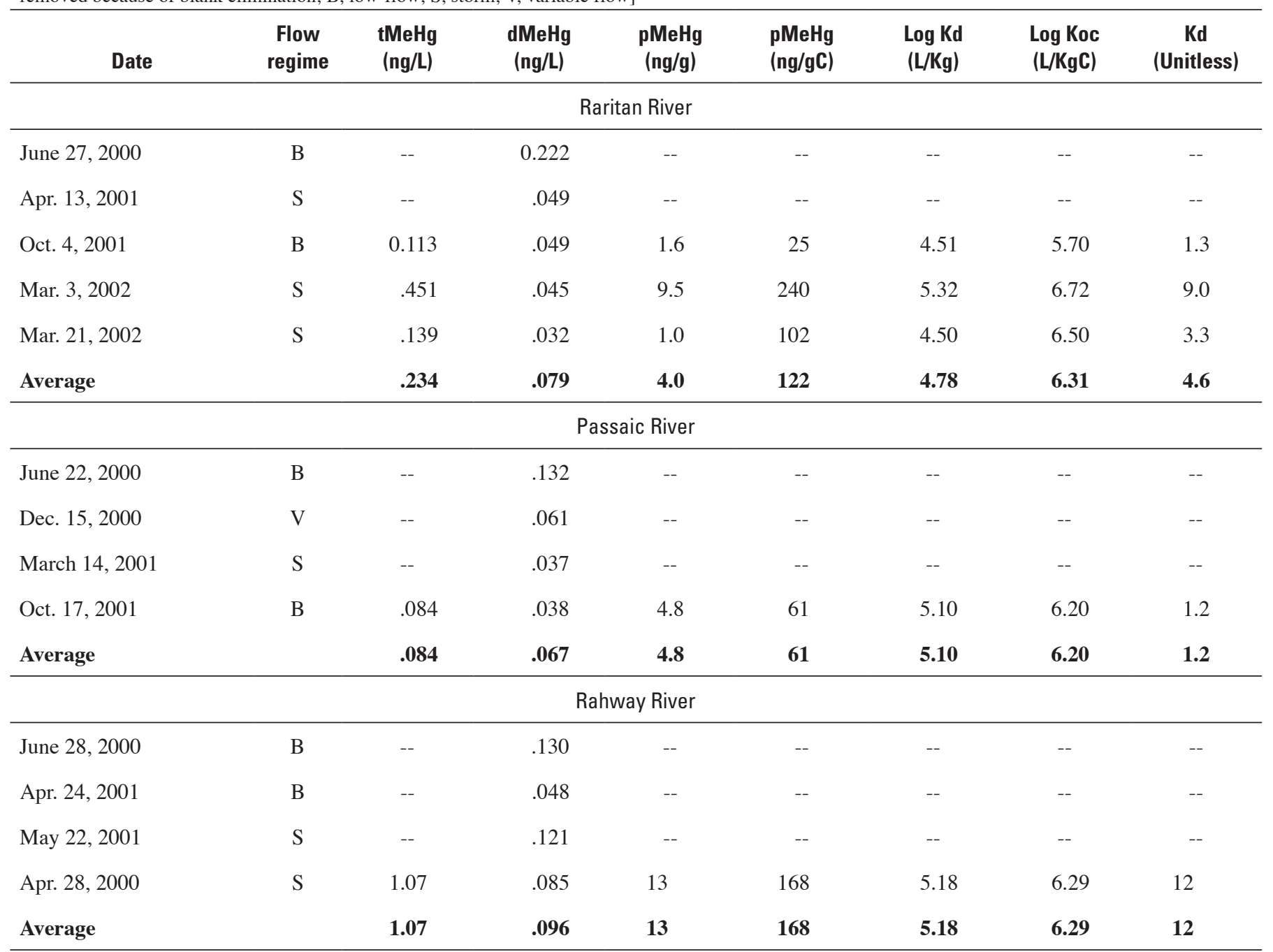

Elizabeth River

\begin{tabular}{|c|c|c|c|c|c|c|c|c|}
\hline June 29, 2000 & $\mathrm{~B}$ & -- & .012 & -- & -- & -- & -- & -- \\
\hline June 4, 2003 & $\mathrm{~S}$ & .198 & .075 & 5.23 & 25.8 & 4.84 & 5.54 & 1.64 \\
\hline Average & & -- & .053 & 5.2 & 26 & 4.8 & 5.5 & 1.6 \\
\hline June 23, 2000 & $\mathrm{~B}$ & -- & .014 & -- & -- & -- & -- & -- \\
\hline Oct. 19, 2001 & $\mathrm{~B}$ & .042 & .006 & 20 & 34.3 & 6.52 & 6.75 & 6.0 \\
\hline Average & & .042 & .010 & 20 & 34.3 & 6.52 & 6.75 & 6.0 \\
\hline
\end{tabular}




\section{Tributary Loads of Sediment, Carbon, and Chemicals}

A fundamental objective of this work is to estimate the loads of sediment and the associated chemicals entering the New Jersey estuary and harbor systems from the river tributaries. Loads or flux are interchangeable terms used to describe the mass of material moved by a river over a defined period of time. "Load" is commonly used to describe the mass of material moved over long periods of times, such as day, week, month, or year; "flux" is typically used to describe loads over shorter times or in relation to a unit cross-sectional area (Thibodeaux, 1979).

Chemical and sediment loads are closely linked in aquatic environments (Forstner and Wittman, 1983). Chemicals are transported in rivers in two phases, either as molecules dissolved in the water or associated with solid or semi-solid particulate matter. Dissolved chemicals may exist as freely dissolved molecules (surrounded by a hydration sphere) or as molecules bonded with other forms of DOC. While most organic chemicals are soluble to some degree, they are typically hydrophobic and are thermodynamically favored to associate with, or dissolve into, solid or semi-solid organic matter. This organic matter exists as distinct particles or as coatings on inorganic particles.

Particulates may be either completely suspended in the water column ("suspended sediment") or may move along the river bottom as "bed load." Loads can be calculated for bed load; however, the special sampling techniques required to measure this load were not employed in this work. "Suspended sediment" represents a mixture of inorganic and organic matter, typically rock particles (sand, silt, or clay sized) with organic coatings, intermixed with particles of solid or semisolid organic matter. In temperate climate rivers, suspended sediment can be up to 10 percent by weight organic carbon or higher, for example, when leaf litter (during the fall) or algae (during the summer) are present in a river.

In this work, suspended sediment, inorganic and organic, for chemical analysis was captured on 0.5-micron pore-size filters. Chemicals measured in the captured material are considered to be associated with the particulate phase. Chemicals are considered to be dissolved if they were captured from the filtered water onto exchange resin (XAD), or for metals, measured in filtered ( 0.45 micron pore-size) water.

Loads associated with suspended sediment are calculated using the volumetric discharge of water and estimates of suspended sediment and carbon concentrations, and are defined by the load integral as:

$$
L=\underset{\overline{0}}{\stackrel{T}{\equiv}} C_{S S, C} Q d t
$$

where

$$
\begin{aligned}
L & =\text { load of suspended sediment, in mass; } \\
Q & =\text { volumetric discharge during time } \mathrm{dt} \\
C_{S S, C} & =\text { concentration of } \mathrm{SS}, \text { carbon, or chemicals, }
\end{aligned}
$$

and

$$
=\text { initial time; }
$$$$
T \quad=\text { final time. }
$$

If SS concentrations and discharge were measured continuously, this integral could be solved for the time period of interest. However, continuous monitoring of SS is impractical, so an approximation method is used whereby SS and discharge are measured at discrete time intervals, separated by as short a time as possible. The load integral is then approximated by:

$$
L=\bullet{ }_{t=1}^{T} C_{i} Q_{i} \quad t
$$

where

and

$$
\begin{aligned}
L= & \text { time "integrated" load for the time period } \\
& \text { of interest, } \mathrm{T}, \text { in mass; } \\
C_{i}= & \text { average } \mathrm{SS} \text { or } \mathrm{C} \text { concentration during the } \\
& \text { time interval } \mathrm{i}, \text { in mass per volume; }
\end{aligned}
$$

$$
Q_{i}=\begin{aligned}
& \text { discharge during interval } \mathrm{i}, \text { in volume per } \\
& \text { time. }
\end{aligned}
$$

This approximation was used to estimate the load of sediment and carbon for the storm events sampled in this work. As discussed below, further approximations of the load integral were necessary to estimate yearly sediment and chemical loads.

\section{Loads of Suspended Sediment and Carbon}

The loads of suspended sediment and carbon were estimated for the low-flow and storm events that were sampled.

\section{Methods Used to Calculate Sediment and Carbon Loads}

River discharge data (15-minute interval) were obtained for the USGS streamflow-gaging station nearest to the sampling location for each event (Bonin and Wilson, 2006). USGS discharge data typically has an accuracy estimated to be $+/-10$ percent, which is acceptable for the load calculations. With this information, the key to estimating accurate sediment loads becomes assigning accurate concentrations of suspended sediment (SS) or POC in rivers during each 15-minute interval. To help reduce the uncertainty in concentrations, from 40 to more than 100 discrete grab samples of river water were collected during each storm event. These samples were collected throughout the rise and fall of the storm discharge hydrograph each time an aliquot was collected for chemical analysis. These grab samples were analyzed for SS, POC, and DOC (Bonin and Wilson, 2006).

The load of sediment and carbon (particulate and dissolved) was calculated for each storm and low-flow event sampled by combining the measured sample concentrations 
with the stream discharge measured at the adjacent USGS gaging station over the time of sample collection. Concentrations of SS and carbon were interpolated between the measured values at $5 \mathrm{mg} / \mathrm{L}$ intervals for $\mathrm{SS}$ and at $0.5 \mathrm{mgC} / \mathrm{L}$ intervals for POC and DOC. Examples of the resulting concentrationdischarge relation are presented in figures 48 to 51 for the Raritan and Elizabeth Rivers. Loads were calculated using equation 29 by multiplying the discharge values by the measured or estimated concentrations and summing the 15-minute loads to produce a total load for each storm. Initial points for each storm event were chosen so that at least one pre-storm discharge and one measured concentration were included. The ending time was chosen at a point where the discharge was asymptotically approaching the pre-storm discharge, with the caveat that the last measured concentration represented a point in time when at least 90 percent of the total volume of discharge during the event had passed. This minimized the contribution to the total load from values extrapolated past the last measured concentration in the receding tail of the hydrograph.

Loads during low-flow discharge were calculated by multiplying the mean daily discharge (MDD) for the sampling date and the geometric mean of the SS, POC, and DOC concentrations measured during the sampling period. Typically, four to six grab samples were collected through the low-flow events. Loads for lowflow were normalized to a 24 -hour period of discharge.

\section{Concentrations and Loads of Particulates During Sampled Events}

Average concentrations of SS, POC, and DOC for each event sampled for chemical analysis (low-discharge and storm events) are presented in table 59. In addition to the events sampled for chemical analysis, a number of storm events were sampled for the purpose of measuring SS only (Bonin and Wilson, 2006). Mean concentrations and loads for these events were calculated indentically to the events sampled for chemical analysis. The mean concentrations measured during the events are presented in table 59 as "composite sample" values, and are compared with the mean for the interpolated concentrations used to calculate loads for the events, and to the concentrations in the discrete grab samples collected for metal analysis, which were presented in the previous section of this report. Inspection of these values shows the average concentrations for the interpolated data set (used for calculating event loads) were, for most samples, very near the composite sample concentrations for the storm events. In some cases, the grab-sample concentrations were near the interpolated and composite concentrations, but in some cases the grab samples deviated greatly. Thus, using grab-sample concentrations to calculate river loads could produce spurious values. These data also indicate the effort needed to interpolate the concentrations over the duration of a storm may not be necessary, but it is imperative that (at least) composite samples are produced and used for calculating river loads.

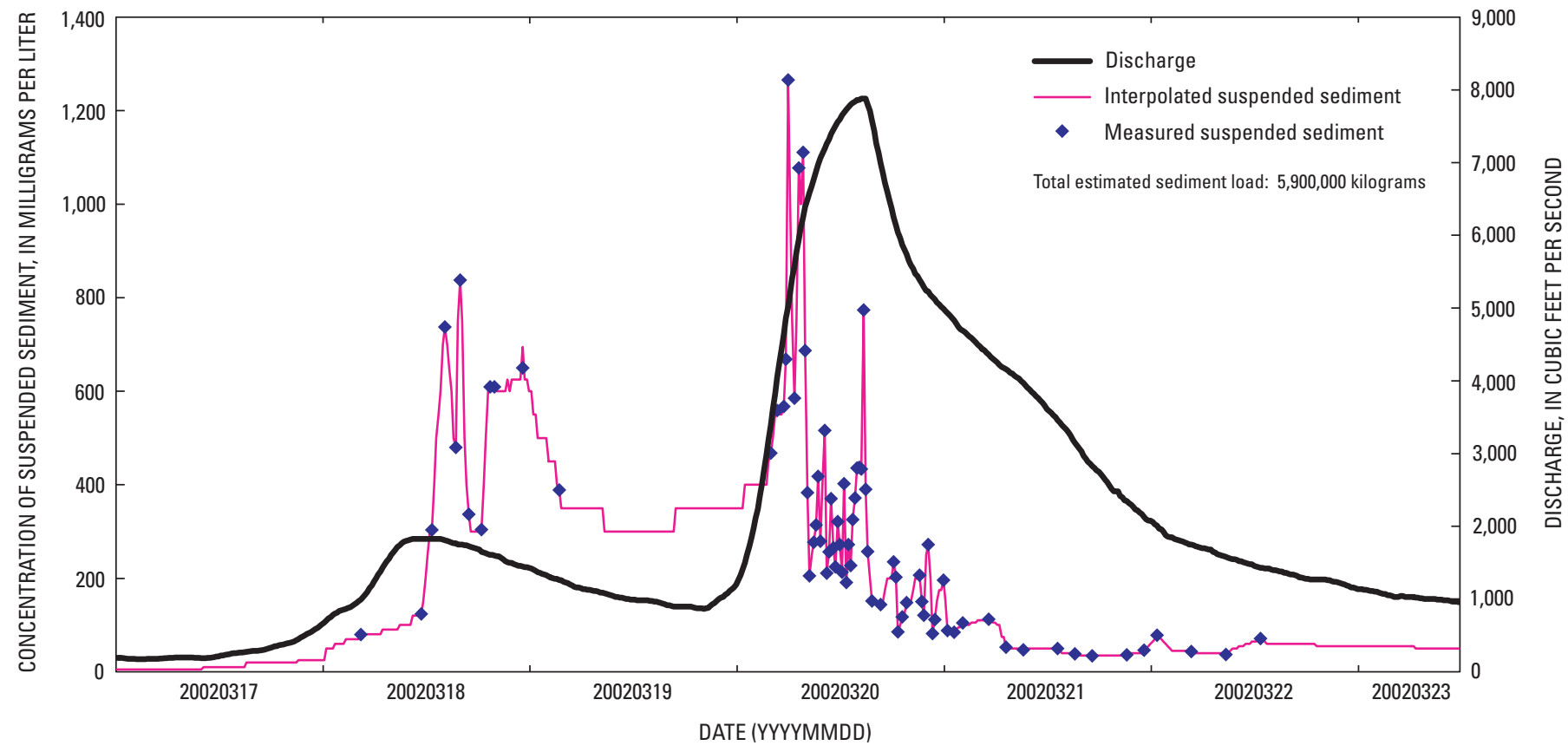

Figure 48. Discharge and the concentration of suspended sediment in samples collected from the Raritan River at Bound Brook, NJ, March 17 to 23, 2002. 


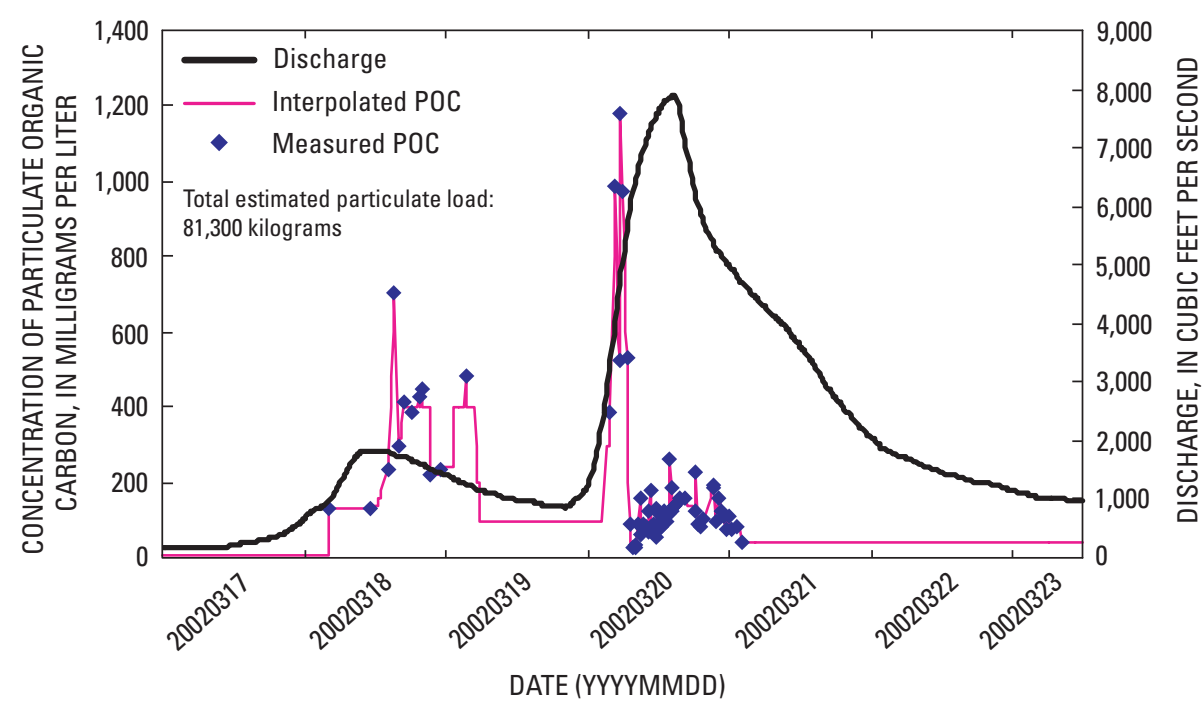

Figure 49. Discharge and the concentration of particulate organic carbon (POC) in samples collected from the Raritan River at Bound Brook, NJ, March 17 to 23, 2002.

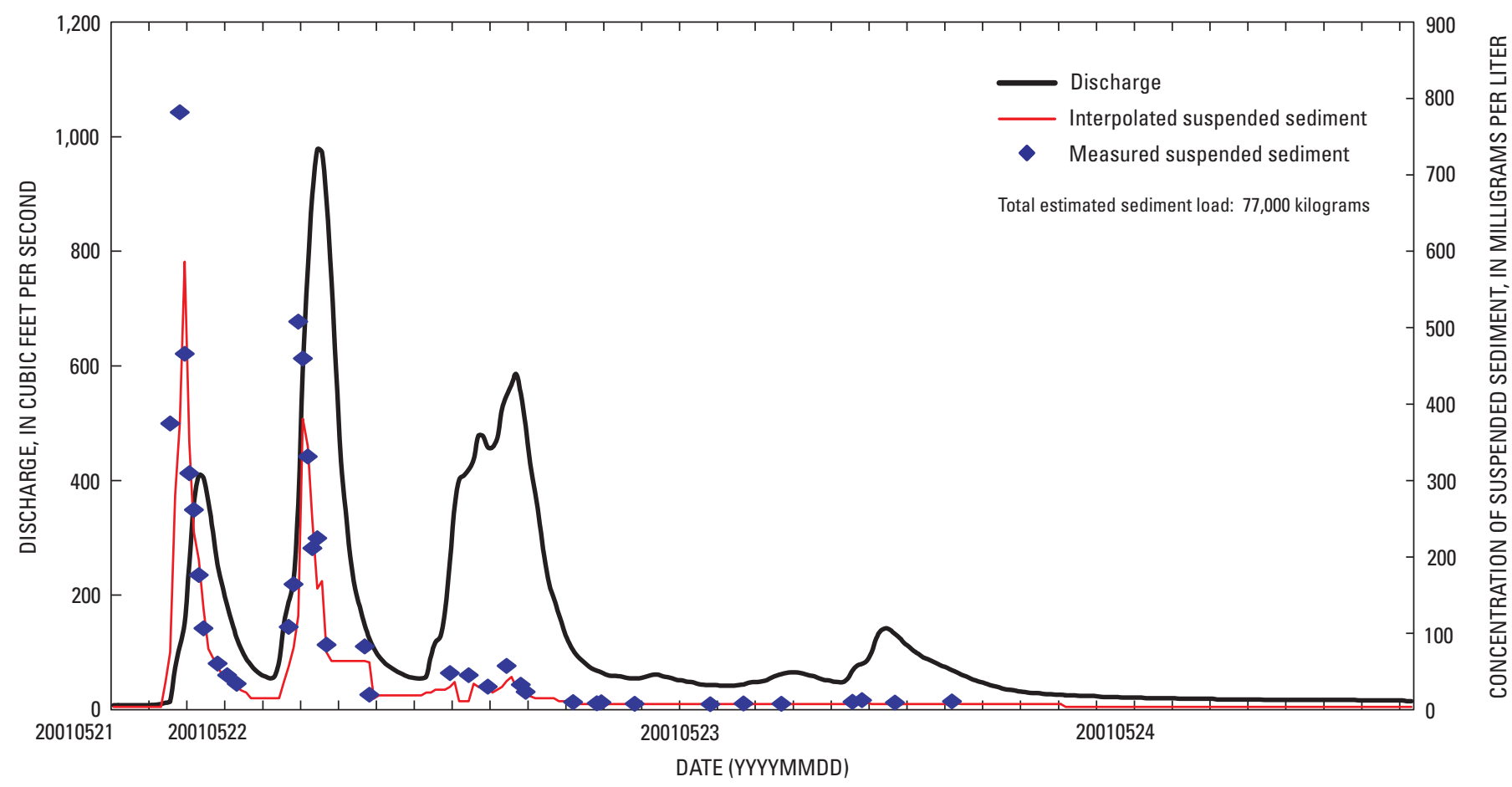

Figure 50. Discharge and the concentration of suspended sediment in samples collected from the Elizabeth River at Hillside, NJ, May 21 to $24,2001$. 


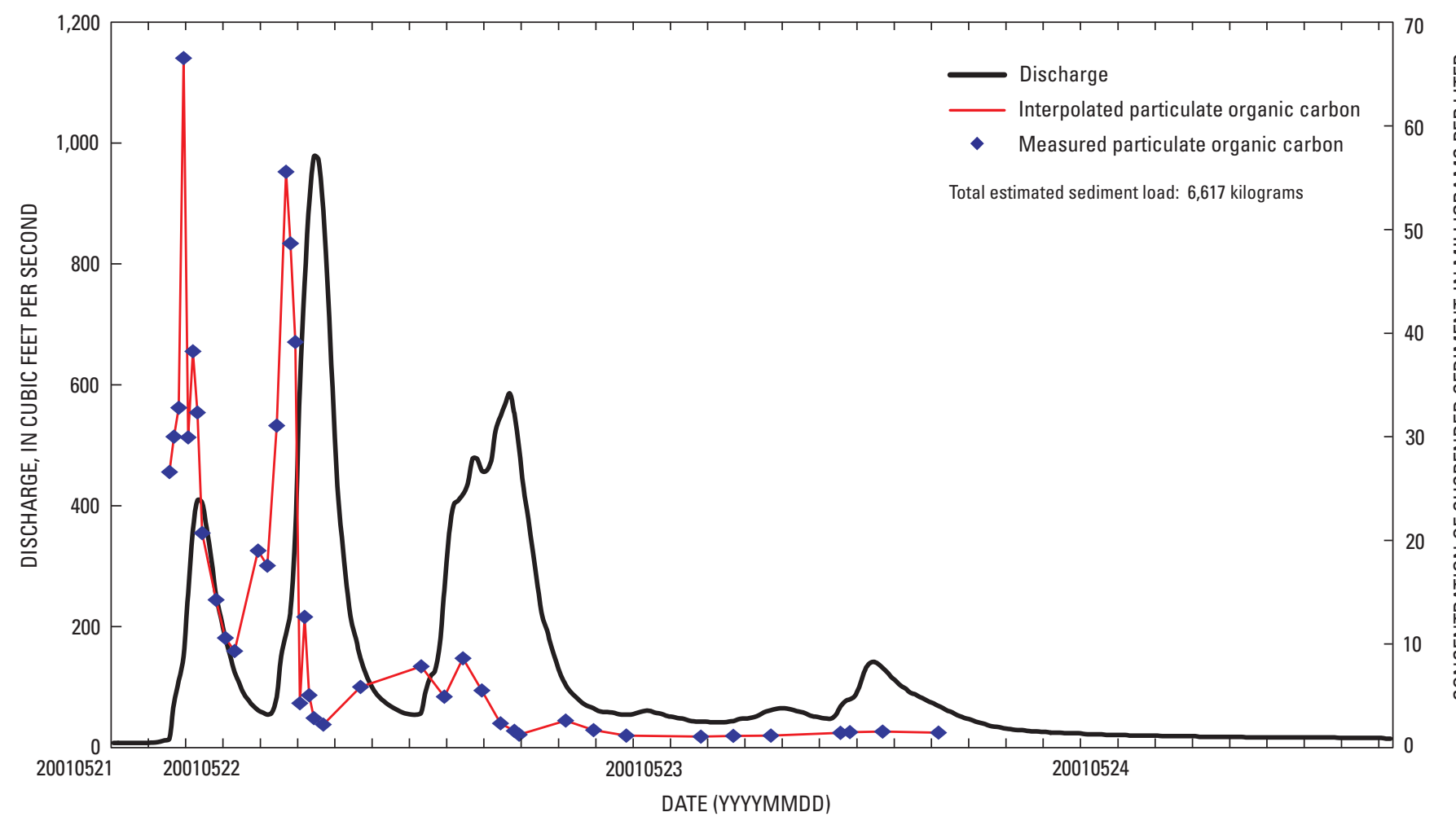

Figure 51. Discharge and the concentration of particulate organic carbon (POC) in samples collected from the Elizabeth River at Hillside, NJ, May 21 to 24, 2001.

To help in describing the events, a magnitude was assigned to each storm event on the basis of the maximum discharge (in cubic feet per second) reached during the event (table 60). Ranges in the discharge for each "magnitude" were determined from the 90-, 75-, 50- and 25-percent exceedance value for the discharge, as determined from frequency plots of the 15-minute discharge data for the period 1975 through 2000. The discharge for each storm magnitude and the number of storm events during an average year (based on the 1975 to 2000 water year record) are listed in table 60.The storm and low-flow events (table 61 and 62) measured in this work ultimately represented only a few of the different-sized magnitude storms, especially those sampled for chemical analysis (trace organics and metals). For example, the three storms ultimately sampled on the Raritan River were all from the group 6 magnitude. The largest sediment load measured in a storm was from the Raritan River (5.9 million $\mathrm{kg}$ ), and the smallest $(2,980 \mathrm{~kg})$ was from the Rahway River. As can be expected, the largest sediment and particulate organic carbon loads were associated with the largest river sampled (the Raritan), and the smallest were associated with the Elizabeth and Rahway Rivers. Unfortunately, no storm events were obtained on the Hackensack River, because of the controlled discharge from the Oradell Reservoir during the years of this study.
The estimated loads for the low-flow discharge conditions (table 62) ranged from $82 \mathrm{~kg} / \mathrm{d}$ in the Elizabeth River up to $32,200 \mathrm{~kg} / \mathrm{d}$ for the Passaic River (excluding the Hackensack River which is controlled flow). Again, this large sediment load in the Passaic River was because of the high daily discharge recorded for that day. More typical low-flow sediment loads for the Raritan and Passaic Rivers are 2,000 to $4,000 \mathrm{~kg} / \mathrm{d}$. POC loads ranged from $5.92 \mathrm{~kg} / \mathrm{d}$ in the Hackensack River up to $1,430 \mathrm{~kg} / \mathrm{d}$ in the Passaic River, and DOC loads ranged from $18.2 \mathrm{~kg} / \mathrm{d}$ in the Hackensack up to 9,090 $\mathrm{kg} / \mathrm{d}$ in the Passaic River.

Average composite concentrations during low-flow discharge events (discharge below the 90- percent exceedance level) on the Raritan, Rahway, Elizabeth, and Hackensack Rivers are typically 3 to about $10 \mathrm{mg} / \mathrm{L}$ for SS and 0.25 to over $2 \mathrm{mgC} / \mathrm{L}$ for POC (table 59). In the Passaic River, concentrations of SS (up to $16 \mathrm{mg} / \mathrm{L}$ ) and POC during low flow are typically nearer upper values of these ranges. During storm discharge, concentrations of SS and POC increased and maximum concentrations (in individual samples) were often in excess of 1,000 mg/L and $65 \mathrm{mgC} / \mathrm{L}$, respectively. Composite concentrations during storm events typically ranged between $25 \mathrm{mg} / \mathrm{L}$ and $50 \mathrm{mg} / \mathrm{L}$ for SS, and 1.25 to $5 \mathrm{mg} \mathrm{C} / \mathrm{L}$ for POC. In the Elizabeth River, SS and POC concentrations are typi- 


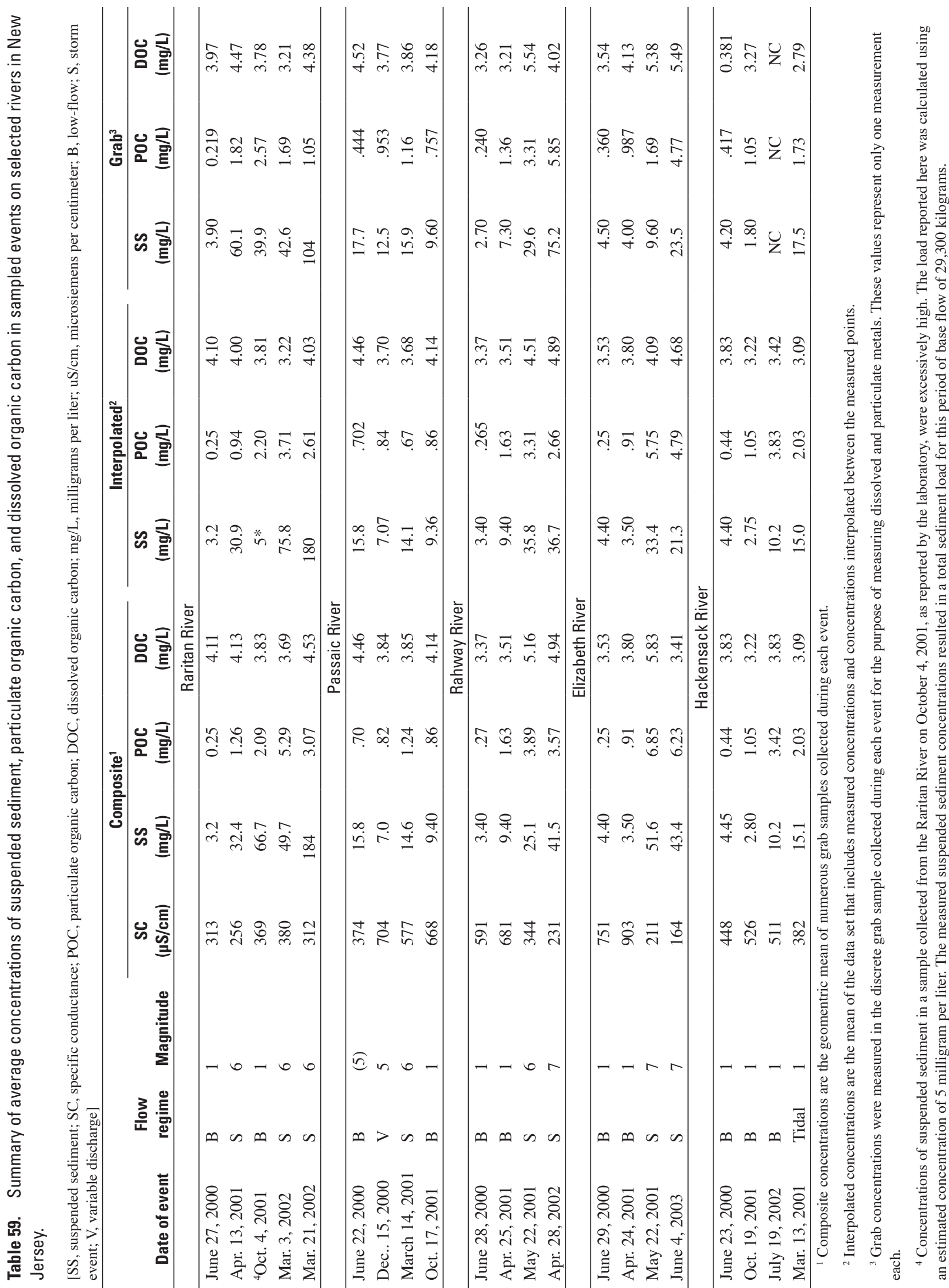


Table 60. Ranges in discharge for storm events during an average year for selected rivers in New Jersey.

[Based on data from 1975 through 2000; discharge in cubic feet per second; <, less than]

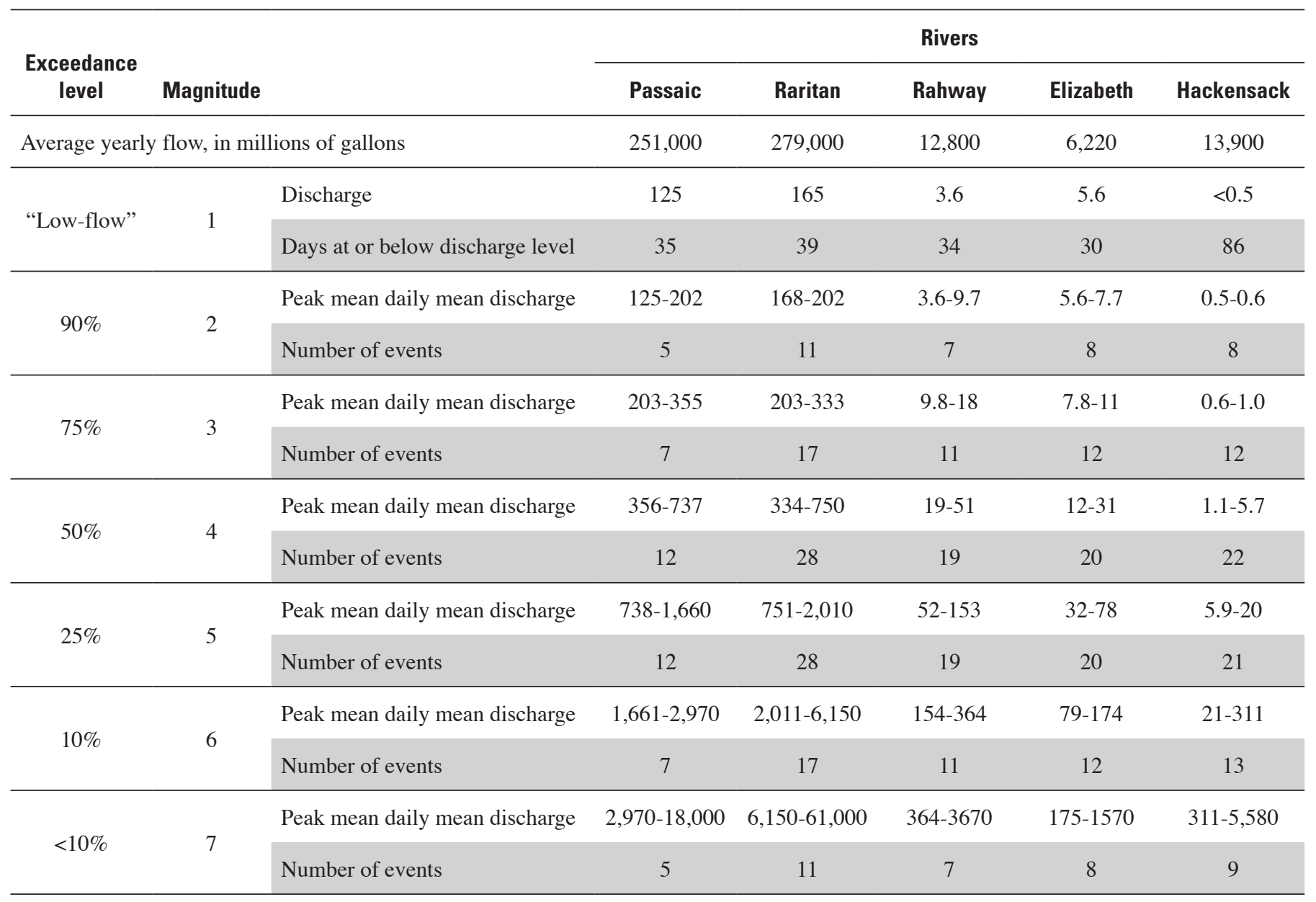

cally even higher than these ranges during storm events. DOC concentrations during both low-flow and storm events were relatively constant in all the rivers at 3 to $5 \mathrm{mg} \mathrm{C} / \mathrm{L}$. DOC commonly showed a decrease during storm events; this likely representes the effect of dilution by (low-DOC content) precipitation.

The ratio of the mean concentration of POC to SS (POC/SS) in the rivers ranged from 0.017 to 0.38 , with very little variability related to discharge conditions. An exception to this was the Elizabeth River, where this ratio was consistently greater during storm events. Ratios were more typically lower in the Raritan and Passaic Rivers $(<0.01)$, slighty higher in the Elizabeth River and Rahway River (0.057-0.173), and the highest in the Hackensack Rivers $(>0.1)$. Thus, between 2 and 11 percent of the mass of the particles transported by the Raritan and Passaic Rivers during storms was organic carbon, while more than 10 percent was organic carbon in the other rivers.

Storm-event hydrographs with the interpolated SS and carbon concentrations were prepared for each event sampled for trace organics. Storm hydrographs for the larger rivers commonly exhibited two or more successive peaks in discharge that resulted from the passing of multiple storm fronts and pulses of precipitation, or as discharge from upstream tributaries passed the sampling station. Large spikes in concentrations of SS and POC were usually observed near each discharge peak. Smaller spikes in SS and POC that did not relate to discharge also were observed. These smaller peaks may represent pulses of material derived from tributaries or other point sources nearby in the basins that did not substantially increase the discharge. In the larger Passaic and Raritan Rivers, the discharge, SS, and carbon typically remained elevated for several days to a week (fig. 48 and 49). In contrast, the smaller Elizabeth and Rahway Rivers were "flashy," exhibiting multiple spikes of SS and POC in conjunction with peaks in discharge that typically lasted hours to a day (figs. 50 and 51). In all rivers, POC concentrations often remained elevated over their low pre-storm concentrations well after the water discharge had decreased and well after SS had declined (fig. 49 and 51). This demonstrates that fine-grained organic matter continued to be transported after the larger inorganic particles had settled. 
Table 61. Estimated loads of suspended sediment and dissolved and particulate carbon in samples collected during storms from selected rivers in New Jersey.

[ft $3 / \mathrm{s}$ : cubic feet per second; Mgal, million gallons; kg, kilogram; -- not collected]

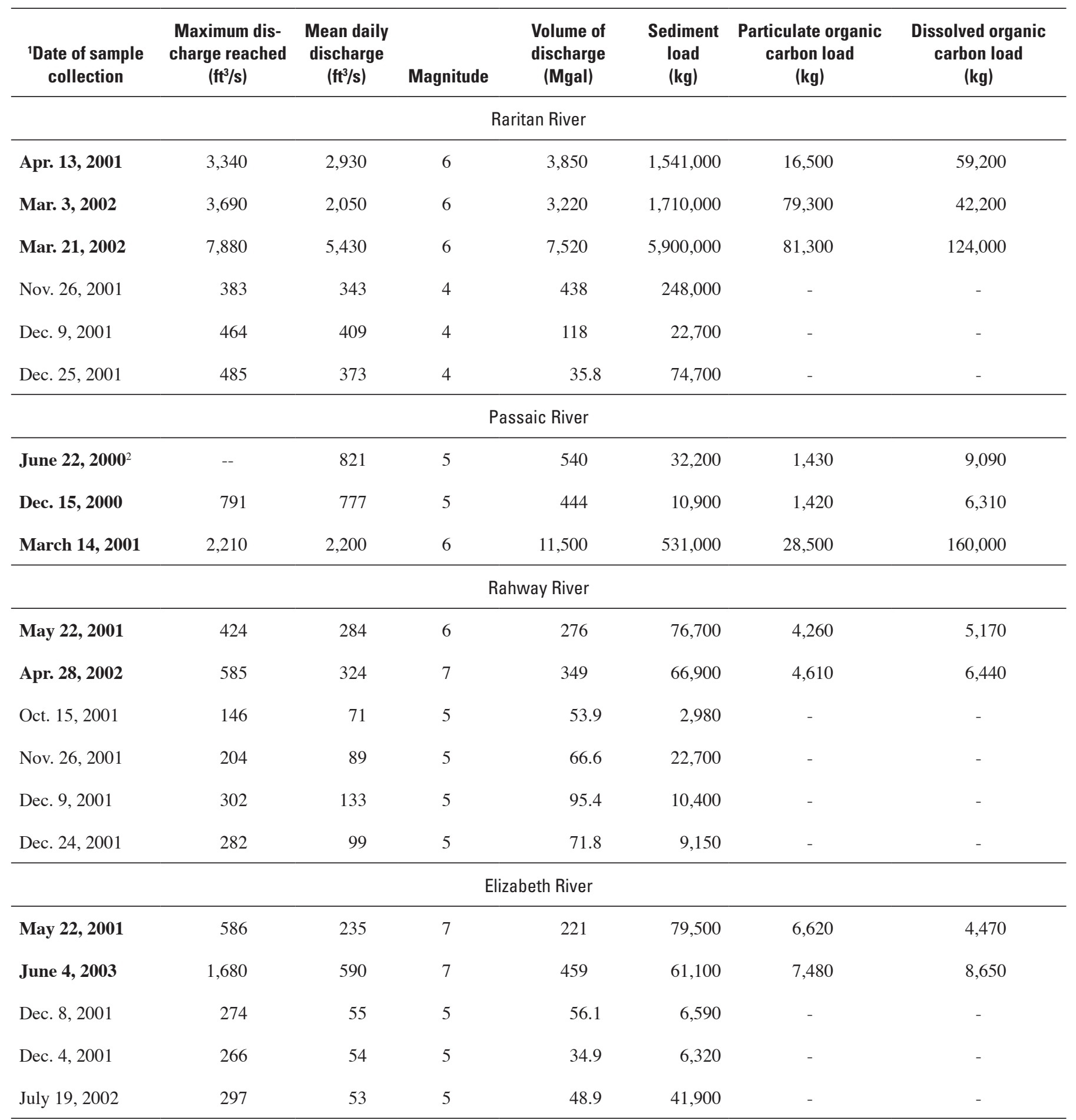

\footnotetext{
${ }^{1}$ Dates in bold indicate samples collected during storm events and analyzed for suspended sediment, carbon, and organic chemicals; non-bolded data indicate samples analyzed only for suspended sediment.

${ }^{2}$ The sample obtained on June 22, 2000, was collected at a time when the river was not at or below the historic 90 -percent exceedance level, thus was not at true base flow $\left(122 \mathrm{ft}^{3} / \mathrm{s}\right)$. This sample was collected at a steady flow, and is neither a base-flow nor a storm sample.
} 
Table 62. Estimated daily loads of suspended sediment, dissolved, and particulate carbon during low flow in selected rivers in New Jersey.

[MDD, mean daily discharge; $\mathrm{ft}^{3} / \mathrm{s}$, cubic feet per second; Mgal/d, million gallons per day; $\mathrm{kg} / \mathrm{d}$, kilogram per day]

\begin{tabular}{llccccc}
\hline \multicolumn{1}{c}{ River } & Date sampled & $\begin{array}{c}\text { MDD } \\
\text { (ft3/s) }\end{array}$ & $\begin{array}{c}\text { Volume of } \\
\text { discharge, } \\
\text { (Mgal/d) }\end{array}$ & $\begin{array}{c}\text { Sediment load } \\
\text { (kg/d) }\end{array}$ & $\begin{array}{c}\text { Particulate organic } \\
\text { carbon load } \\
\text { (kg/d) }\end{array}$ & $\begin{array}{c}\text { Dissolved organic } \\
\text { carbon load } \\
\text { (kg/d) }\end{array}$ \\
\hline Raritan & June 27, 2000 & 286 & 188 & 2,270 & 180 & 2,925 \\
Raritan & 'Oct. 4, 2001 & 180 & 118 & 2,240 & 983 & 1,700 \\
Passaic & 2June 22, 2000 & 821 & 539 & 32,200 & 1,430 & 9,100 \\
Passaic & Oct. 17, 2001 & 171 & 112 & 3,970 & 365 & 1,760 \\
Rahway & June 28, 2000 & 25 & 16.4 & 211 & 16.4 & 209 \\
Rahway & Apr. 24, 2001 & 27 & 17.7 & 630 & 109 & 235 \\
Elizabeth & June 29, 2000 & 11 & 7.22 & 120 & 6.83 & 96.4 \\
Elizabeth & Apr. 25, 2001 & 10 & 6.56 & 87 & 22.6 & 94 \\
Hackensack & June 23, 2000 & 14 & 9.05 & 151 & 14.9 & 131 \\
Hackensack & Oct. 19, 2001 & 2.3 & 1.49 & 15.5 & 5.92 & 18.2 \\
Hackensack & July 19, 2002 & 4.5 & 2.91 & 113 & 42.2 & 37.7 \\
Hackensack ${ }^{3}$ & Mar. 13, 2001 & 11 & 7.11 & 404 & 54.6 & 83.1 \\
\hline
\end{tabular}

${ }^{1}$ Concentrations of suspended sediment in a sample collected from the Raritan River on October 4, 2001, as reported by the laboratory, were excessively high. The load reported here was calculated using an estimated concentration of 5 milligram per liter. The measured suspended sediment concentrations resulted in a total sediment load for this period of base flow of 29,300 kilograms.

${ }^{2}$ The sample obtained on June 22, 2000, was collected at a time when the river was not at or below the historic 90 percent exceedance level, and thus was not at true base flow $\left(122 \mathrm{ft}^{3} / \mathrm{s}\right)$. This sample was collected at a steady flow, and is neither base flow nor a storm sample.

${ }^{3}$ Loads calculated for this sample may not be realistic. This sample was collected from a tidally influenced region.

Loads for the sampled storm events (table 61) were estimated to range from $2,980 \mathrm{~kg}$ to $5.9 \times 10^{6} \mathrm{~kg}$ for sediment, 1,420 to $81,300 \mathrm{~kg}$ for POC, and 4,470 to $160,000 \mathrm{~kg}$ for DOC. Loads for low-flow conditions, normalized to a $24-$ hour period (table 62), ranged from $15.5 \mathrm{~kg} / \mathrm{d}$ to $32,200 \mathrm{~kg} / \mathrm{d}$ for sediment, $5.92 \mathrm{~kg} / \mathrm{d}$ to $1,430 \mathrm{~kg} / \mathrm{d}$ for POC, and $18.2 \mathrm{~kg} / \mathrm{d}$ to $9,100 \mathrm{~kg} / \mathrm{d}$ for DOC. The large daily load for the Passaic River sampled on June 22, 2000, was because of the fact that the mean-daily flow reported for this date $\left(821 \mathrm{ft}^{3} / \mathrm{s}\right)$ was well above the upper limit of the "low-flow" discharge $\left(125 \mathrm{ft}^{3} / \mathrm{s}\right)$ determined from the historic discharge data set. This event was, however, classified by the program as a "low-flow" event.

Inspection of the estimated loads and the hydrographic data shows that, as expected, the size of the peak discharge reached during an event correlated with the total load of sediment and carbon transported. However, this relation is only rough, because the peak discharge reached during an event may not directly relate to other factors such as the length of time a river remained at high-flow conditions. Other meteorological factors, such as rainfall intensity and conditions within the basin such as the degree to which the soil was frozen or the length of time since last rainfall, play a role in how each river responded to precipitation. These factors all contribute to the total sediment/carbon load carried by the rivers during the storms.

\section{Annual Loads of Sediment Estimated From Historical Data}

If the load of sediment was known for each "magnitude" of event, then by knowing the number of storms during a year, the yearly load of sediment/carbon could be calculated. Unfortunately, few storms were ultimately sampled in this work, so this approach could not be used. Instead, the ratingcurve approach was used to estimate yearly loads. A "rating curve" relates the mean daily sediment load to the mean daily discharge and is produced using the concentrations in samples collected repeatedly over time. Each SS concentration is multiplied by the mean daily discharge for the date of collection to obtain a daily sediment load. With a sufficient number of samples, a relation (usually logarithmic) can be produced that can be used to predict loads for a selected time period. This method assumes the concentration (SS, carbon, 
etc.) measured in a grab or composite sample collected on a specific day represents the average concentration for the entire day of flow, which in turn is represented by the mean daily discharge. While this approach is useful for rivers that have been routinely sampled, the assumption that the concentration measured in a sample represents the conditions for the flow during the entire collection day is a substantial weakness. Generally, concentrations of SS are higher during times of high discharge, although the relation is not simple and a substantial hysteresis occurs as the discharge rises and falls.

Consider, for example, the concentrations of SS in the Raritan River (March 18-25, 2002) that are plotted against the discharge at the time of the collection in figure 52. The arrows in this plot show the sequence in which the samples were collected. The SS and the discharge do not correlate, and the highest SS concentrations did not occur at the time of peak discharge. Rather, the maximum SS was measured when the discharge first began to rise, the time when the water was accelerating and had the greatest ability to erode bottom sediment. The SS fell off rapidly after discharge had peaked, even though the discharge remained elevated. As a result, very different concentrations of SS were measured for the same discharge, depending on whether the discharge was rising or falling. Unless a SS sample happened to be collected at the instant the mean discharge had been reached, its concentration would not accurately characterize the daily stream load. A second problem arises because the stream constituents (discharge, sediment concentrations, etc.) are usually log-normally dis- tributed. Unless numerical steps are taken to transform values between "log-space" to "real space" (Landwehr, 1978; Cohn and others, 1989), the calculated loads will be biased low. The larger the scatter in concentrations around the best-fit "rating curve," the larger the bias will be in the predicted load. A correction factor must be applied to adjust the predicted sediment loads for bias due to transformation.

SS and carbon data have been collected for many years on New Jersey rivers at the USGS/NJDEP Cooperative National Ambient Surface Water Quality Network stations (NASQAN) (table 63). Standardized collection techniques used at these stations included collecting either individual grab or cross-channel samples that were composited into one sample. Concentrations of SS and carbon from the 1968 to 2001 NASQAN data set, along with the mean daily discharge from the associated USGS gaging sites, were used to produce rating curves for the Passaic, Rahway, Elizabeth, Hackensack, and Raritan Rivers (table 64). The data used were all collected at sites very near the sampling sites used in this study. The sediment data collected in this present study were not combined with the historic data but were compared with the rating curves to demonstrate correspondence in the load estimates.

The distribution of the SS and C data was first tested using graphical and statistical means and was found to be log-normally distributed. The Raritan River data set is shown as an example because of the large number of data available $(n=215)$ (fig. 53). The chi-square procedure showed the SS, POC, and discharge data were log-normally distributed at a

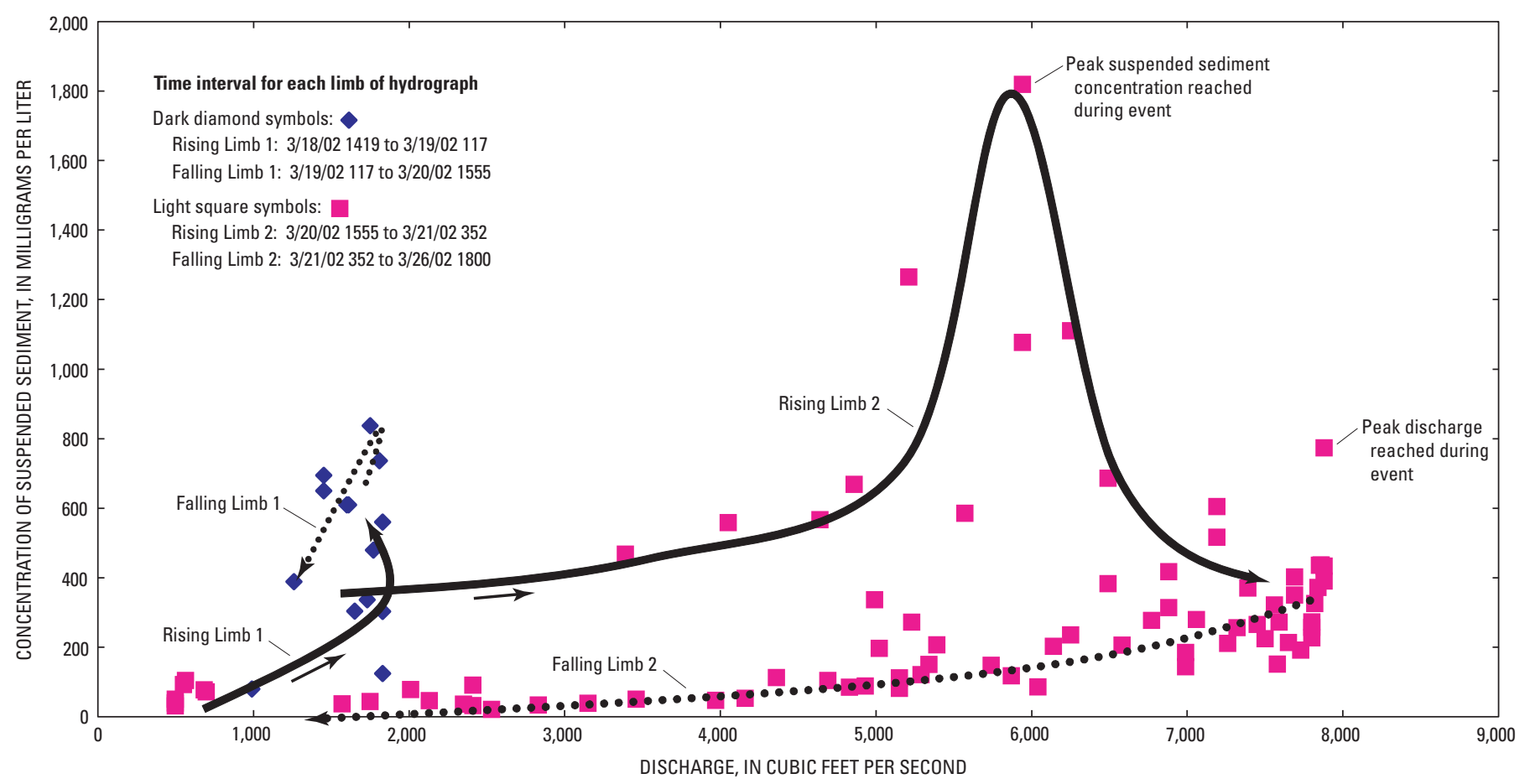

Figure 52. Concentrations of suspended sediment and instantaneous discharge in the Raritan River, March 18 to 25, 2002. 
Table 63. Summary of water-quality data available for selected rivers in New Jersey.

[SS, suspended sediment; POC, particulate organic carbon; DOC, dissolved organic carbon; MDD, mean daily discharge; $\mathrm{ft}^{3} / \mathrm{s}$, cubic feet per second; -- insufficient data]

\begin{tabular}{|c|c|c|c|c|c|}
\hline Constituent & $\begin{array}{c}\text { First } \\
\text { sample } \\
\text { date } \\
\text { used }\end{array}$ & $\begin{array}{l}\text { Last } \\
\text { sample } \\
\text { date } \\
\text { used }\end{array}$ & $\begin{array}{c}\text { Number } \\
\text { of data } \\
\text { values }\end{array}$ & $\begin{array}{c}\text { Minimum } \\
\text { MDD } \\
\left(\mathrm{ft}^{3} / \mathrm{s}\right)\end{array}$ & $\begin{array}{l}\text { Maximum } \\
\operatorname{MDD}\left(\mathrm{ft}^{3} / \mathrm{s}\right)\end{array}$ \\
\hline \multicolumn{6}{|c|}{ Raritan River } \\
\hline SS & $3 / 14 / 68$ & $8 / 28 / 01$ & 215 & 109 & 23,600 \\
\hline POC, DOC & $11 / 1 / 98$ & $9 / 27 / 01$ & 80 & 109 & 12,600 \\
\hline \multicolumn{6}{|c|}{ Passaic River } \\
\hline SS & $8 / 15 / 78$ & $9 / 16 / 94$ & 138 & 55 & 6,630 \\
\hline POC, DOC & $5 / 30 / 79$ & $9 / 5 / 01$ & 162 & 49,42 & 4,930 \\
\hline \multicolumn{6}{|c|}{ Rahway River } \\
\hline SS & $2 / 13 / 79$ & $6 / 6 / 94$ & 30 & 5.8 & 343 \\
\hline POC, DOC & $8 / 7 / 91$ & $8 / 21 / 02$ & 48 & 2.4 & 269 \\
\hline \multicolumn{6}{|c|}{ Elizabeth River } \\
\hline SS & $2 / 27 / 78$ & $8 / 1 / 94$ & 27 & 5.4 & 83 \\
\hline POC, DOC & $8 / 6 / 91$ & 7/29/97 & 30 & 5.4 & 57 \\
\hline \multicolumn{6}{|c|}{ Hackensack River } \\
\hline SS & $11 / 29 / 79$ & $3 / 30 / 94$ & 15 & 1 & 946 \\
\hline POC,DOC & -- & -- & -- & -- & -- \\
\hline
\end{tabular}

Table 64. Calculated regression lines used for predicting load of suspended sediment from discharge in selected rivers in New Jersey.

(SS, suspended sediment load, in kilograms per day; Q, mean daily discharge, in million gallons per day; ln, natural logarithm; equations are calculated with low-flow data removed)

\begin{tabular}{llc}
\hline \multicolumn{1}{c}{ Location } & \multicolumn{1}{c}{ Regression equation } & $\mathbf{r}^{2}$ \\
\hline $\begin{array}{c}\text { Raritan River at } \\
\text { Bound Brook, N.J. }\end{array}$ & $\ln (\mathrm{SS})=1.9741 * \ln (\mathrm{Q})-2.0156$ & 0.809 \\
$\begin{array}{l}\text { Passaic River at Little } \\
\text { Falls, N.J. }\end{array}$ & $\ln (\mathrm{SS})=1.209 * \ln (\mathrm{Q})+3.037$ & .752 \\
$\begin{array}{l}\text { Rahway River at } \\
\text { Rahway, N.J. }\end{array}$ & $\ln (\mathrm{SS})=1.367 * \ln (\mathrm{Q})+2.384$ & .865 \\
$\begin{array}{l}\text { Elizabeth River at } \\
\text { Hillside, N.J. }\end{array}$ & $\ln (\mathrm{SS})=1.557 * \ln (\mathrm{Q})+1.848$ & .704 \\
$\begin{array}{l}\text { Hackensack River at } \\
\text { Oradell, N.J. }\end{array}$ & $\ln (\mathrm{SS})=0.811 * \ln (\mathrm{Q})+4.274$ & .916 \\
\hline
\end{tabular}

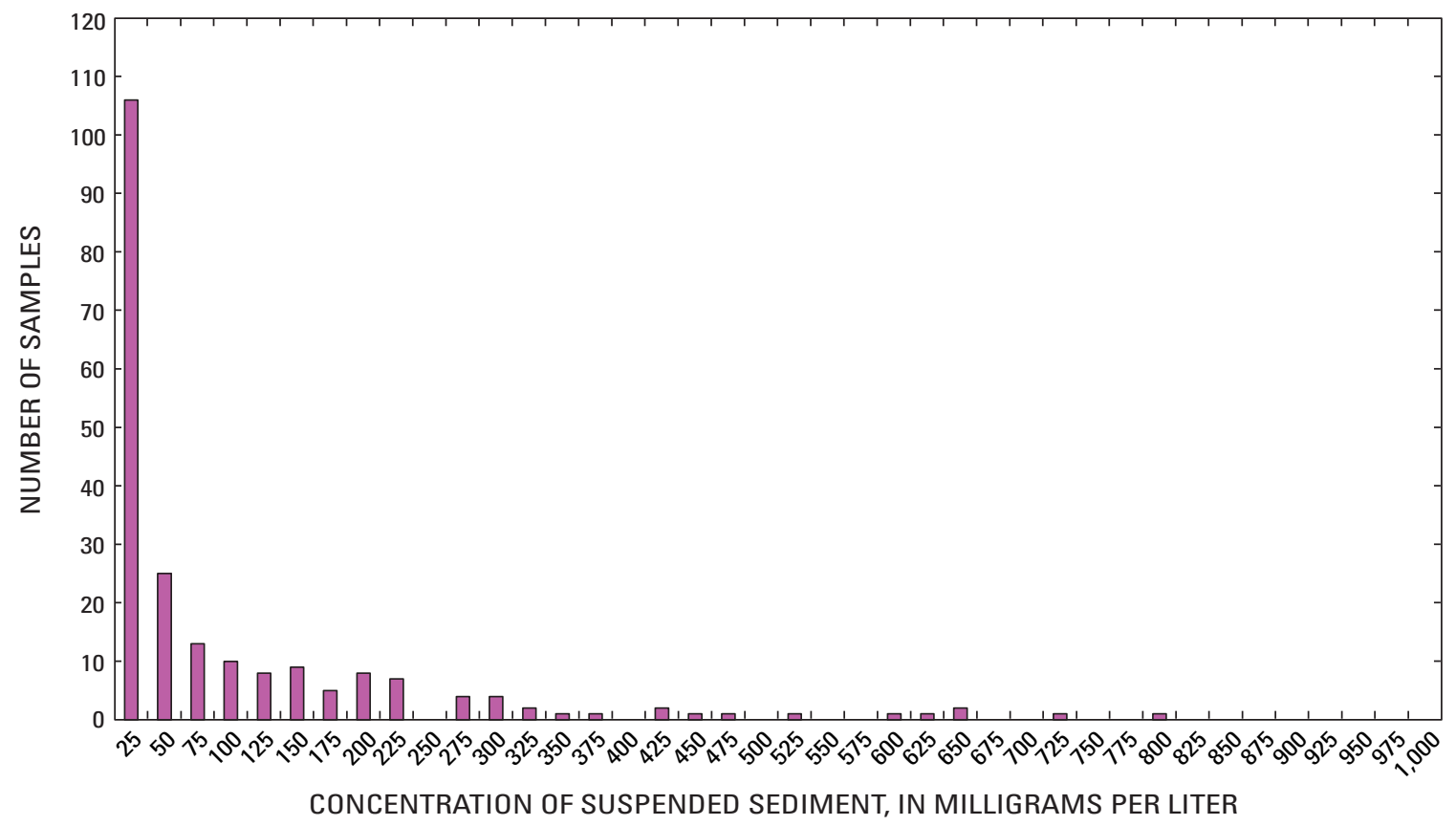

Figure 53. Distribution of concentrations of suspended sediment in samples from the Raritan River at Queens Bridge, Bound Brook, NJ. 
99-percent confidence level. Therefore, the SS, carbon, and discharge data were log-transformed (natural log) before the best-fit regression lines were calculated (fig. 54, table 64). The data were also grouped on the basis of whether the SS sample was collected on a day the discharge was steady, rising, or falling or on a day when it peaked compared with the adjacent days. In all cases, the best-fit regression lines (on the basis of $\mathrm{r}^{2}$ values) were found when data for the "steady" flow days were removed. Generally, "steady-day" samples were collected on days of low discharge and were removed from the data set before regression analysis was performed. However, loads on low-flow days contributed very little to yearly loads of sediment or carbon and thus did not appreciably affect the total load calculations. With the exception of the low-flow data, there was no other indication that the SS-discharge data were stratified; no breaks in the slope of the discharge-load relation were indicated.

The rating-curve equation predicts a logarithmic sediment load for each mean-daily discharge value, which must then be transformed back into a "real" value before being used. As discussed by Ferguson (1986, 1987), Landwehr (1978), and Koch and Smillie (1986), unless a correction is applied, the predicted load will be underestimated by the transformations. Numerical methods developed to account for the bias introduced by transformations include the Quasi-Maximum Likelihood Estimator (QMLE) and the Bradu-Mundlak Maximum Variance Uncertainty Estimator (MVUE) (Bradu and Mundlak, 1970; Cohn and others, 1989).
The QMLE estimator described by Ferguson (1986) uses the variance of the best-fit prediction line to estimate the bias. The QMLE estimation of the real concentration $\left(\mathrm{E}\left(\mathrm{C}_{\mathrm{i}}\right)\right)$ is obtained from the log-concentration $\left(\mathrm{C}_{\mathrm{i}}^{\prime}\right)$ predicted by the rating curve, using:

$$
E\left(C_{i}\right)=\exp \left(C^{\prime}{ }_{i}\right) \exp \left(s^{2} / 2\right)
$$

where

$s^{2} \quad$ is an unbiased estimator of the variance in the best-fit rating curve line

$$
s^{2}=\bullet{ }_{1}^{n}\left(\ln C_{i}-\ln C_{i}^{\prime}\right)^{2} /(n-2)
$$

where

$$
\begin{aligned}
C_{i}= & \text { the measured concentration; } \\
C^{\prime}{ }_{i}= & \text { the concentration predicted by the best-fit } \\
& \text { rating line; }
\end{aligned}
$$

and

$$
\begin{aligned}
n= & \text { the number of points used in the prediction } \\
& \text { line. }
\end{aligned}
$$

The QMLE adjustment to predicted concentrations has been shown to be useful and easy to apply for many data sets; however, it can result in a large bias in estimated loads especially for the large discharges that are typical during storms (when the majority of sediment is transported in rivers) (Cohn

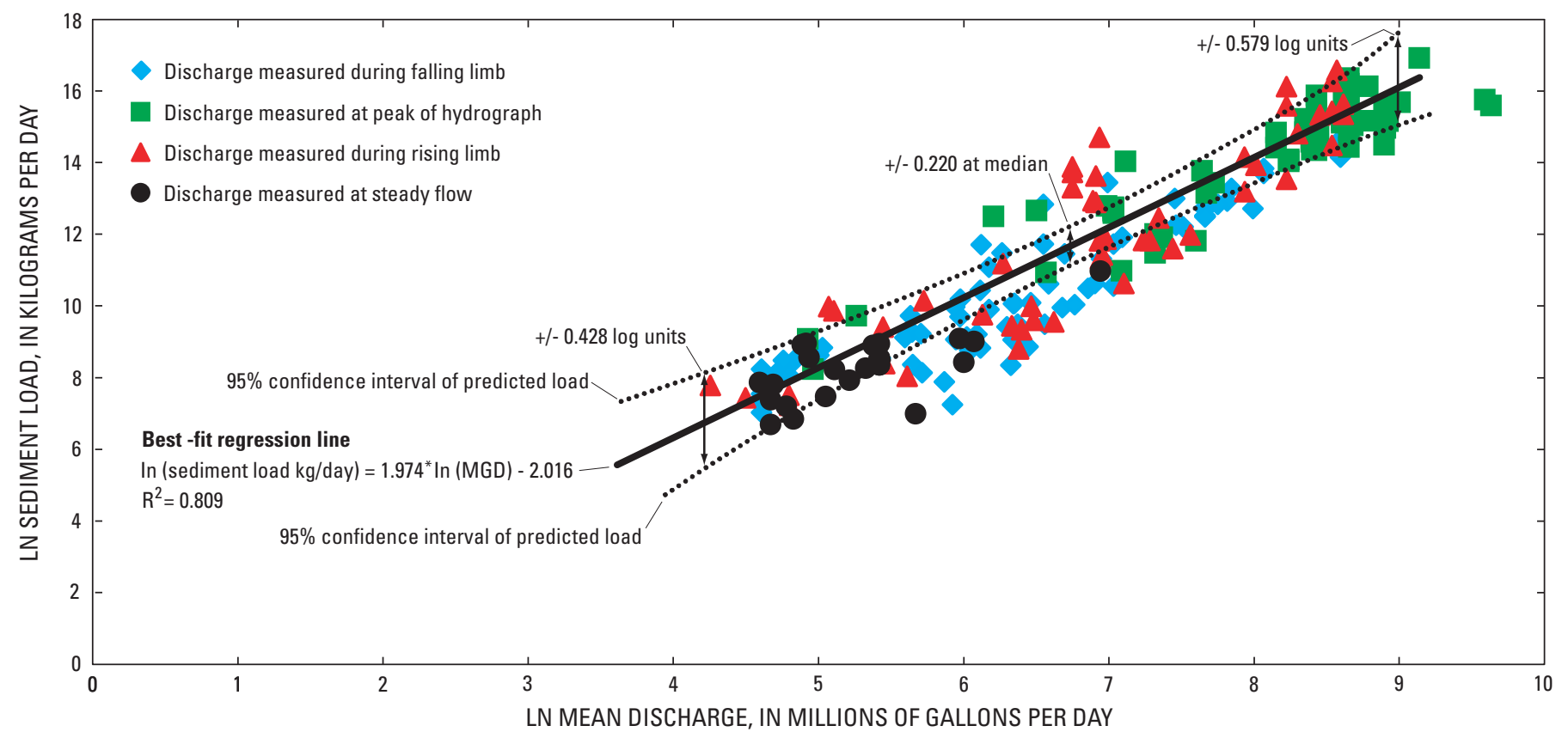

Figure 54. Relation between mean daily discharge (0) and daily sediment load for the Raritan River at Bound Brook, NJ. [In, natural logarithm] 
and others, 1989). Another corrector is the MVUE, which is unbiased in all cases, and is defined as:

$$
C_{\text {MVUE }}=\exp \left(\mu^{\prime}\right) g_{m}\left(m+1 / 2 m\left\{(1-V) s^{2}\right\}\right)
$$

where

$$
\begin{aligned}
g_{m}(z)=\bullet_{p=0-p} & \frac{m^{p}(m+2 p)}{m(m+2) \ldots(m+2 p)} \quad \frac{m}{m+1} \quad \frac{z^{p}}{p !} \\
C_{M V U E}= & \text { estimated load predicted for discharge } Q^{*} ; \\
\mu^{\prime} & \log \text { of load predicted from rating curve for } \\
& \text { discharge } Q^{*} ; \\
g_{m}(z)= & \text { Finney's }(1941) \text { transformation function; } \\
m=N-2= & \text { the number of degrees of freedom in the } \\
& \text { error distribution; } \\
= & \left\{1 / N+\ln ^{2}\left(Q^{*}\right) / \Sigma_{i=1}\left(\ln \left(Q_{i}\right)-\ln (Q)^{2}\right\} ;\right. \\
Q^{*} & \text { the flow for which a concentration estimate } \\
& \text { is desired; }
\end{aligned}
$$

and

$$
\begin{aligned}
N= & \text { the number of data points used in the } \\
& \text { estimation set. }
\end{aligned}
$$

This is a more difficult adjustment to apply, but the transformation is non-biased in all cases of discharge and concentration. Finney's (1941) transformation function $\left(\mathrm{g}_{\mathrm{m}}(\mathrm{z})\right)$ was calculated using the equation described in Cohn and others (1989).

The total annual discharge values measured at USGS gaging stations for water years 1988, 1994, 1998, 1999, 2000, 2001, and 2002, were calculated (table 65). These discharges are nearly equal to those calculated from the mean daily discharge values tabulated in the yearly reports prepared by the USGS. The rating curves were then used to predict uncor- rected daily sediment loads, which were then transformed using the MVUE estimator. Daily loads were also calculated for the entire discharge record of 1975 to 2000 . The loads were then summed for the 1975-2000 period, divided by the total number of days, and multiplied by 365 to obtain the average yearly loads.

The average annual loads of sediment ranged from 0.395 million kilograms of sediment per year in the Hackensack River up to 93.1 million kilograms per year in the Raritan River (table 66). The Raritan River Basin was estimated to provide approximately four times more sediment than did the Passaic, which can be related to the size and characteristics of the two basins (Bonin and Wilson, 2006). Of the smaller rivers, the Rahway is estimated to contribute about twice the sediment of the Elizabeth River, which was somewhat surprising considering the similarities in these urbanized basins.

The sediment loads calculated from the 2000 water year on the Raritan River were used to demonstrate the effect of the QMLE and MVUE corrections on calculated yearly loads. The uncorrected load predicted using the rating curve was $2.77 \times 10^{7}$ $\mathrm{kg} / \mathrm{yr}$, the QMLE adjusted load was $4.52 \times 10^{7} \mathrm{~kg} / \mathrm{yr}$, and the MVUE adjusted load was $4.33 \times 10^{7} \mathrm{~kg} / \mathrm{yr}$. The closeness of the QMLE and MVUE loads is a result of the low scatter in the discharge and, more significantly, scatter in the SS values. The corrected loads for this example are nearly 35 percent greater than the non-corrected sediment load estimate.

The loads predicted using the rating-curve methods were also compared with the loads calculated for the individual storms sampled in this study (table 67). The mean daily discharges for each day of the storm event were used as input to the rating curve. The non-corrected loads and the loads corrected using the MVUE estimator were calculated and compared with the measured total loads for each storm. The results of the comparision are mixed, sometimes the MVUE corrected

Table 65. Total annual discharge for water years 1988, 1994, and 1998-2002 and the average annual discharge for water years 1975 to 2000 in selected rivers in New Jersey.

[Values in million gallons per year]

\begin{tabular}{cccccc}
\hline Water Year & Raritan River & Passaic River & Rahway River & Elizabeth River & Hackensack River \\
\hline 1988 & 238,000 & 202,000 & 10,000 & 5,440 & 4,070 \\
\hline 1994 & 328,000 & 255,000 & 15,000 & 6,630 & 12,700 \\
\hline 1998 & 279,000 & 279,000 & 16,800 & 7,320 & 15,000 \\
\hline 1999 & 223,000 & 160,000 & 12,900 & 6,130 & 7,830 \\
\hline 2000 & 202,000 & 225,000 & 11,200 & 5,890 & 7,390 \\
\hline 2001 & 238,000 & 193,000 & 12,200 & 6,500 & 13,000 \\
\hline 2002 & 102,000 & 47,000 & 5,700 & 3,500 & 210 \\
\hline 25-year average & $\mathbf{2 7 9 , 0 0 0}$ & $\mathbf{2 5 1 , 0 0 0}$ & $\mathbf{1 2 , 9 0 0}$ & $\mathbf{6 , 2 2 0}$ & $\mathbf{1 3 , 9 0 0}$ \\
\hline
\end{tabular}


Table 66. Estimated annual sediment loads predicted for selected water years for selected rivers in New Jersey.

[WY, water year; MVUE, maximum value likelihood estimator correction applied; >, greater than]

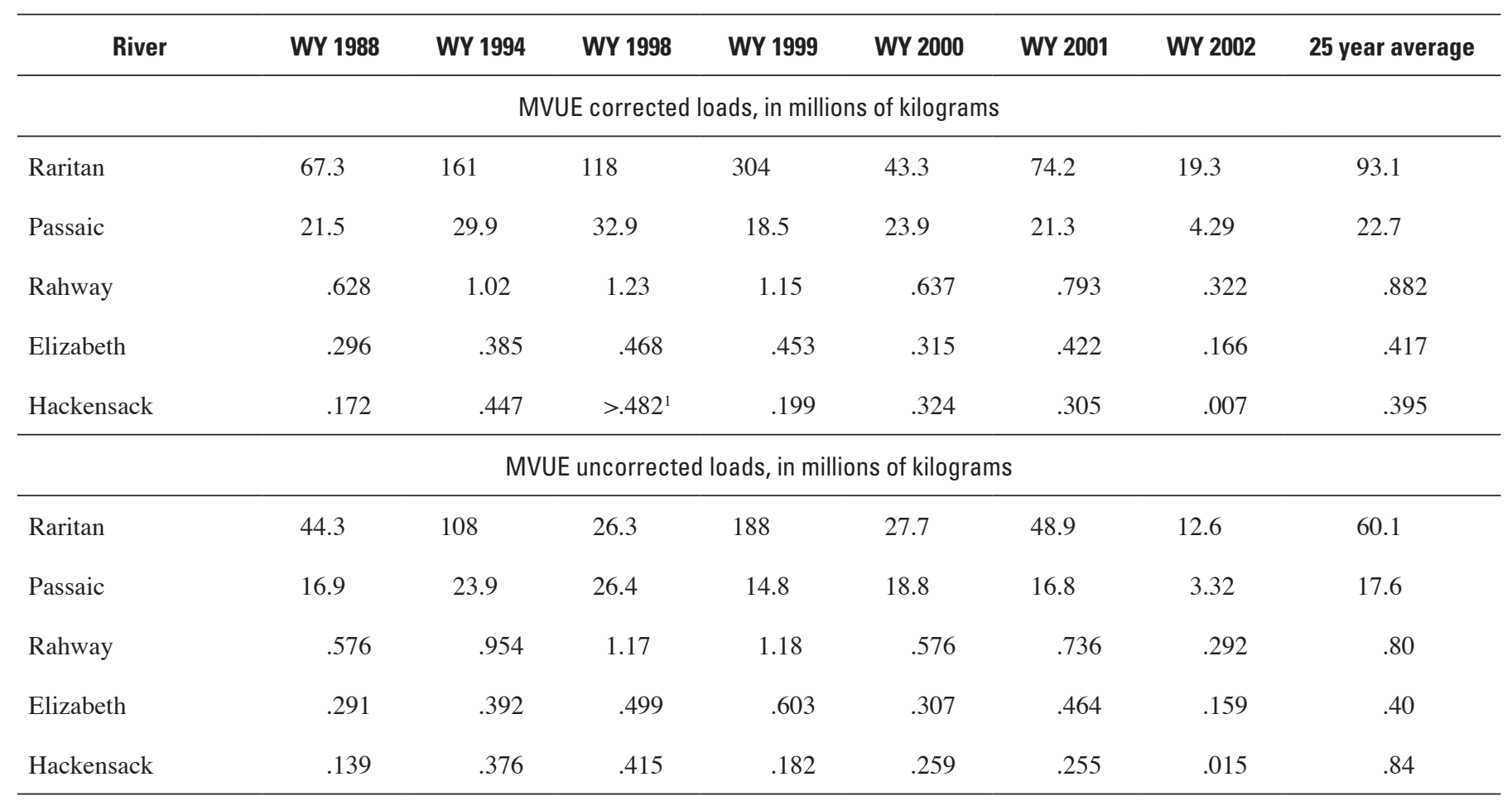

${ }^{1}$ Only partial discharge records were available for the Hackensack River WY 1998. The value presented is a minimum estimated value.

predicted loads were near the measured load, and sometimes they were less than the measured load. For the Passaic River (all events), loads derived from the rating curves (MVUE corrected) were greater than the measured loads; in the other rivers, the corrected rating curve loads were near or less than measured loads. Loads (event specific) calculated for low-flow events on the Rahway, Elizabeth, and Hackensack Rivers were less than the corresponding loads calculated using the rating curve. Considering the assumptions and the data available, loads derived from rating curves are likely to underestimate actual loads.

\section{Annual Loads of Dissolved and Particulate Carbon Estimated From Historical Data}

The concentrations of POC and DOC in the composite samples ranged between 0.25 and $3.42 \mathrm{mg} / \mathrm{L}$ and 3.22 and $4.46 \mathrm{mg} / \mathrm{L}$ respectively, during low flow in all rivers (table 59). During storms, the concentration of POC in individual grab samples would rise considerably, in some cases to over $1,000 \mathrm{mg} / \mathrm{L}$; DOC would increase to roughly 4 to $6 \mathrm{mg} / \mathrm{L}$. The concentration of POC in the rivers appeared to track the concentration of SS and peaked before the peak in discharge (see for example, figs. 48 to 51). In contrast, concentrations of DOC typically peaked at or slightly after the peak discharge (fig. 55). POC is controlled by physical processes involving particle resuspension and settling and by rates of primary production. In contrast, DOC in river water is affected mostly by rates of dissolution and the mixing of water masses - such as from inputs of water from point sources such as waste discharges and from precipitation. Evidence for mixing of water masses is observed in the specific conductance values, a measured value that is related to the dissolved ion content of the water. In the Raritan River example (fig. 55), the specific conductance decreased as DOC increased just after the large peak in discharge, indicating river water had mixed with water having high DOC but a low dissolved ion content, such as surface runoff.

The POC and DOC loads were calculated in the same manner as SS, for the sampled storms and low flow by interpolating concentrations between measured values and combining the concentrations with the 15-minute discharge data. The DOC load during storms ranged from $4,470 \mathrm{~kg}$ to $160,000 \mathrm{~kg}$ of carbon (table 61). Loads during low flow ranged from 5.92 $\mathrm{kg} / \mathrm{d}$ to $1,430 \mathrm{~kg} / \mathrm{d}$ for POC, and $18.2 \mathrm{~kg} / \mathrm{d}$ to $9,100 \mathrm{~kg} / \mathrm{d}$ for DOC, respectively. The highest loads for low-flow discharge (table 62) were for the Passaic River on June 22, 2000, and again, were the result of the high daily discharge reported by the USGS gaging station for that date. 
Table 67. Sediment loads measured during sampled events and loads predicted using rating-curve method for selected rivers in New Jersey.

[ft $\mathrm{ft}^{3} / \mathrm{s}$, cubic feet per second; MDD, mean daily discharge; $\mathrm{kg}$, kilogram; $\mathrm{B}$, low- flow event; $\mathrm{S}$, storm flow; $\mathrm{V}$, variable flow; MVUE, minimum variance unbiased estimator; MDD, mean daily discharge; POC, particulate organic carbon; DOC, dissolved organic carbon]

\begin{tabular}{|c|c|c|c|c|c|c|}
\hline $\begin{array}{c}\text { Date of } \\
\text { sample } \\
\text { collection }\end{array}$ & $\begin{array}{c}\text { Flow } \\
\text { regime }\end{array}$ & $\begin{array}{c}\text { Storm } \\
\text { magnitude }\end{array}$ & $\begin{array}{c}\text { Maximum MDD for } \\
\text { storm event } \\
\left(\mathrm{ft}^{3} / \mathrm{s}\right)\end{array}$ & $\begin{array}{l}\text { Measured load of } \\
\text { sediment } \\
(\mathrm{kg})\end{array}$ & $\begin{array}{l}\text { Load of sediment from } \\
\text { rating curve, } \\
\text { uncorrected } \\
(\mathrm{kg}) \\
\end{array}$ & $\begin{array}{l}\text { Load of sediment from } \\
\text { rating curve, } \\
\text { corrected using MVUE } \\
(\mathrm{kg})\end{array}$ \\
\hline \multicolumn{7}{|c|}{ Raritan River } \\
\hline Apr. 13, 2001 & $\mathrm{~S}$ & 6 & 2,930 & $1,540,000$ & $1,034,000$ & $1,317,000$ \\
\hline Mar. 3, 2002 & $\mathrm{~S}$ & 6 & 2,050 & $1,710,000$ & 370,000 & 554,000 \\
\hline Mar. 21, 2002 & S & 6 & 5,430 & $5,900,000$ & $2,230,000$ & $3,290,000$ \\
\hline Nov. 26, 2001 & $\mathrm{~S}$ & 4 & 343 & 248,000 & 12,400 & 18,990 \\
\hline Dec. 9, 2001 & $\mathrm{~S}$ & 4 & 409 & 22,700 & 9,500 & 14,500 \\
\hline Dec. 25, 2001 & $\mathrm{~S}$ & 4 & 373 & 74,700 & 7,900 & 12,100 \\
\hline June 27, 2000 & B & 1 & 286 & 2,270 & 4,730 & 6,900 \\
\hline Oct. $4,2001^{1}$ & $\mathrm{~B}$ & 1 & 180 & 2,230 & 1,940 & 2,190 \\
\hline \multicolumn{7}{|c|}{ Passaic River } \\
\hline Dec. 15,2000 & $\mathrm{~V}$ & 5 & 777 & 10,900 & 63,600 & 80,300 \\
\hline Mar. 14, 2001 & S & 6 & 2,200 & 531,000 & $1,190,000$ & $1,470,000$ \\
\hline June 22, 2000 & B & 5 & 821 & 32,200 & 56,700 & 52,700 \\
\hline Oct. 17, 2001 & $\mathrm{~B}$ & 1 & 171 & 3,970 & 8,500 & 8,140 \\
\hline \multicolumn{7}{|c|}{ Rahway River } \\
\hline May 22, 2001 & $\mathrm{~S}$ & 6 & 284 & 76,700 & 17,600 & 18,900 \\
\hline Apr. 28,2002 & $\mathrm{~S}$ & 7 & 324 & 66,900 & 24,700 & 25,000 \\
\hline Oct. 15, 2001 & $\mathrm{~S}$ & 5 & 71 & 2,980 & 2,250 & 2,330 \\
\hline Nov. 26, 2001 & $\mathrm{~S}$ & 5 & 89 & 22,700 & 3,370 & 1,960 \\
\hline Dec. 9, 2001 & $\mathrm{~S}$ & 5 & 133 & 10,400 & 5,270 & 5,550 \\
\hline Dec. 24, 2001 & S & 5 & 99 & 9,150 & 3,260 & 3,610 \\
\hline June 28, 2000 & B & 1 & 25 & 211 & 497 & 579 \\
\hline Apr. 24, 2001 & $\mathrm{~B}$ & 1 & 27 & 630 & 553 & 642 \\
\hline \multicolumn{7}{|c|}{ Elizabeth River } \\
\hline May 22, 2001 & $\mathrm{~S}$ & 7 & 235 & 79,500 & 19,300 & 17,300 \\
\hline Dec. 8, 2001 & S & 5 & 55 & 6,590 & 2,570 & 2980 \\
\hline Dec. 24, 2001 & S & 5 & 54 & 6,320 & 1,650 & 1400 \\
\hline July 19, 2002 & $\mathrm{~S}$ & 5 & 53 & 41,900 & 2,130 & 2410 \\
\hline June 29, 2000 & B & 1 & 11 & 120 & 138 & 182 \\
\hline Apr. 25, 2001 & B & 1 & 10 & 87 & 118 & 158 \\
\hline \multicolumn{7}{|c|}{ Hackensack River } \\
\hline June 23, 2000 & B & 1 & 14 & 151 & 364 & 570 \\
\hline Oct. 19, 2001 & B & 1 & 2.3 & 15.5 & 61.2 & 505 \\
\hline
\end{tabular}

${ }^{1}$ Concentration of suspended sediment was estimated at $5 \mathrm{mg} / \mathrm{L}$ for this sample. 
Table 67. Sediment loads measured during sampled events and loads predicted using rating-curve method for selected rivers in New Jersey.-Continued

[ft $\mathrm{ft}^{3} / \mathrm{s}$, cubic feet per second; MDD, mean daily discharge; $\mathrm{kg}$, kilogram; $\mathrm{B}$, low- flow event; $\mathrm{S}$, storm flow; $\mathrm{V}$, variable flow; MVUE, minimum variance unbiased estimator; MDD, mean daily discharge; POC, particulate organic carbon; DOC, dissolved organic carbon]

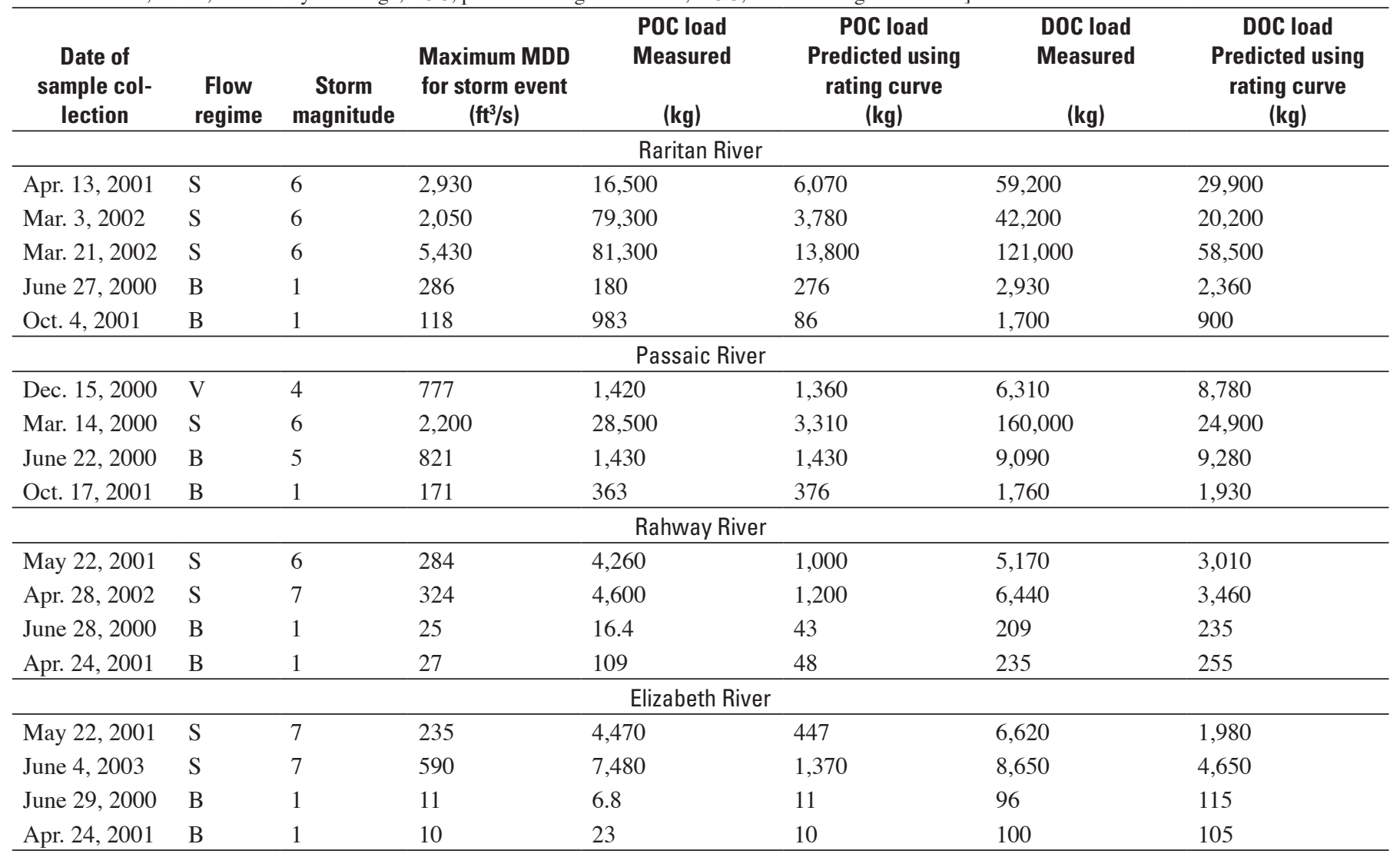

${ }^{1}$ Concentration of suspended sediment was estimated at $5 \mathrm{mg} / \mathrm{L}$ for this sample.

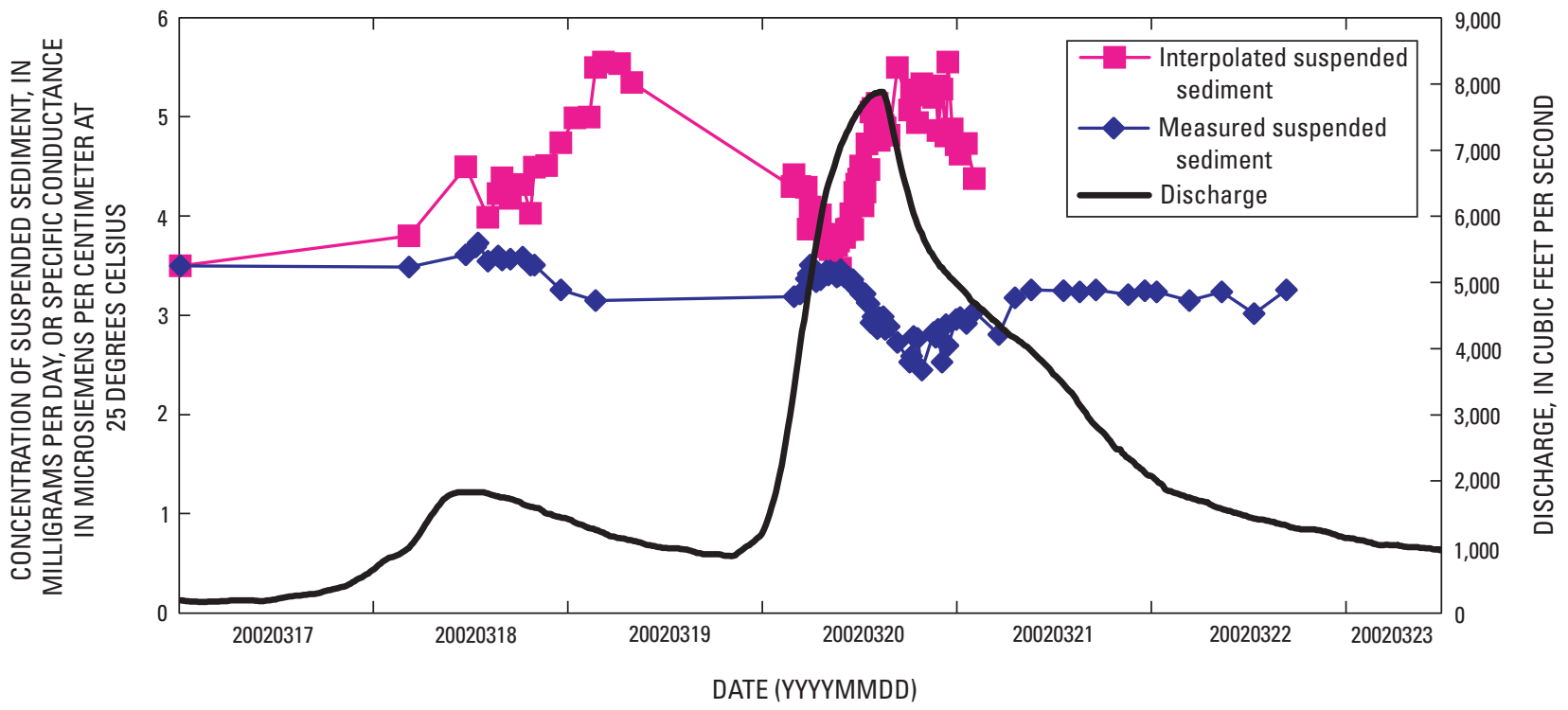

Figure 55. Discharge, specific conductance, and concentrations of dissolved organic carbon in the Raritan River at Bound Brook, NJ, March 18 to 23, 2001. 
Rating curves (table 68) were prepared for POC and DOC using data from the USGS NWIS database (fig. 56). Because of a lack of data, a meaningful rating curve could not be constructed for the Hackensack River, so for this river, a total carbon load was generated by multiplying the mean of the measured DOC and POC concentrations by the yearly discharge for the various time periods of interest. The DOC concentrations were found to be less scattered than the historical suspended-sediment data presented earlier (for example, compare fig. 54 and fig. 56).

Several characteristics regarding stream characteristics are noted in the calculated regression curves. The best-fit regression lines for the DOC rating curves (table 68) have slopes very close to 1 for all rivers. Thus, a 1:1 logarithmic relation is evident between the DOC load and the mean daily discharge. Slopes for POC regression lines are greater than 1 for all rivers except the Passaic but are slightly less than the slopes calculated for SS (table 64). Thus, POC increased with discharge but at a slightly slower rate than SS. The significance of the low slope for POC in the Passaic River is curious and can not be explained at present. Also, the y-intercepts for the POC regression lines are smaller than the intercepts for the SS regression lines, reflecting the fact that the POC values at lowflow were consistently lower than the SS in these rivers. As was the case for SS, loads of POC and DOC for the sampled events that were estimated using the annual-load regression curves typically differ from the measured loads (table 66). Predicted loads are generally lower than the measured loads, especially for the larger magnitude discharge events.

DOC and POC loads were calculated for water years 1988, 1994, 1998, 1999, 2000, 2001, and 2002 and for the average year using the mean daily discharge measurements from the respective USGS gaging stations. The predicted daily loads were corrected using the MVUE method described earlier before being summed to obtain yearly loads, and these corrected loads are presented along with the uncorrected loads for comparison (table 69 and 70). Average annual loads ranged from 14,400 to $866,000 \mathrm{~kg} / \mathrm{yr}$ for POC, and 89,000 to 4.3 million $\mathrm{kg} / \mathrm{yr}$ for DOC. On the basis of the 25 -year average values, the loads of POC were ranked in the following order:

- Elizabeth $<<$ Rahway $<$ Hackensack $<<$ Passaic $<$ Raritan.

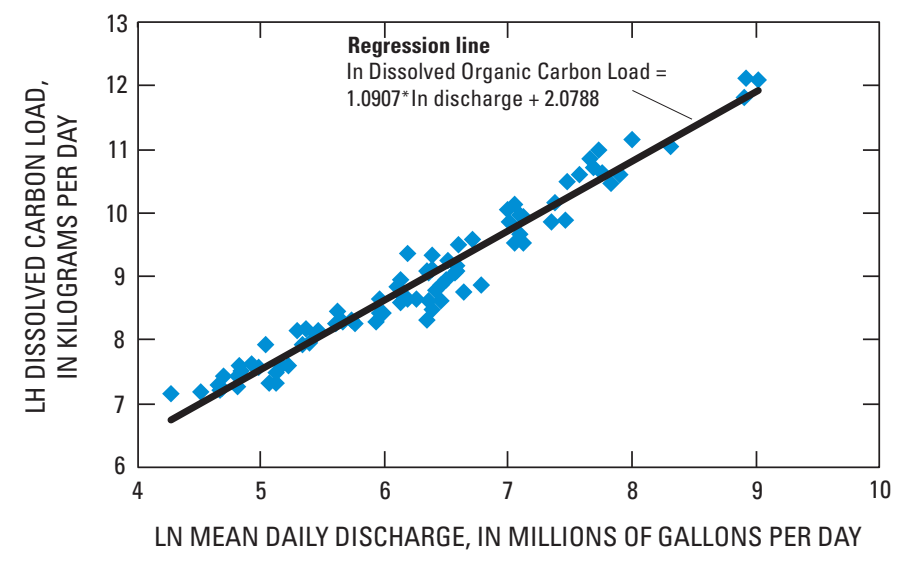

Figure 56. Relation between mean daily discharge and daily load of dissolved organic carbon in the Raritan River at Bound Brook, NJ. [In, natural logarithm]

Average loads for DOC were ranked in the following order:

- Elizabeth $<$ Rahway $<$ Hackensack $<$ Raritan $<$ Passaic.

Summing the POC and DOC results in total organic carbon loads (table 71) that ranged from $103,400 \mathrm{~kg}$ in the Elizabeth River up to $5,056,000 \mathrm{~kg}$ in the Raritan. Of these totals, POC represented between 12 and 34 percent of the total organic carbon transported in the rivers.

Because the regression coefficients are similar for the different rating curves, the yearly loads for SS, POC, and DOC in these rivers generally tracked with the magnitude of the water discharge in each of these rivers. However, characteristics unique to each river are found in the ratios of the loads of suspended sediment, POC, and DOC. The ratio of the average POC/SS load (table 72), calculated for the 25-year average discharge conditions, indicates that each gram of SS (a mix of inorganic and organic matter) in the Rahway River contained $73 \mathrm{mg}$ of carbon, but each gram of sediment carried by the Raritan River contained only 9.3 mg of carbon. Thus, particu-

Table 68. Calculated regression lines for predicting load of particulate organic carbon and dissolved organic carbon from discharge in selected rivers in New Jersey.

[POC, particulate organic carbon load, in kilograms per year; DOC, dissolved organic carbon load, in kilograms per year; Q, daily mean discharge, in million gallons per day; ln, natural logarithm; --, insufficient data were available to calculate regression lines; equations were calculated with low-flow data removed; regression lines were calculated to include the Maximum Variance Uncertainty Estimator transformation adjustment]

\begin{tabular}{lcc}
\hline \multicolumn{1}{c}{ Sampling Site } & POC & DOC \\
\hline Raritan River at Bound Brook, N.J. & $\ln \mathrm{POC}=1.327 * \ln \mathrm{Q}-1.303, \mathrm{r}^{2}=0.88$ & $\ln \mathrm{DOC}=1.090 * \ln \mathrm{Q}+2.079, \mathrm{r}^{2}=0.955$ \\
Passaic River at Little Falls, N.J. & $\ln \mathrm{POC}=0.851 * \ln \mathrm{Q}+1.926, \mathrm{r}^{2}=0.67$ & $\ln \mathrm{DOC}=1.000 * \ln \mathrm{Q}+2.861, \mathrm{r}^{2}=0.936$ \\
Rahway River at Rahway, N.J. & $\ln \mathrm{POC}=1.291 * \ln \mathrm{Q}+0.179, \mathrm{r}^{2}=0.88$ & $\ln \mathrm{DOC}=1.048 * \ln \mathrm{Q}+2.547, \mathrm{r}^{2}=0.929$ \\
Elizabeth River at Elizabeth, N.J. & $\ln \mathrm{POC}=1.218 * \ln \mathrm{Q}-0.015, \mathrm{r}^{2}=0.56$ & $\ln \mathrm{POC}=0.929 * \ln \mathrm{Q}+2.923, \mathrm{r}^{2}=0.668$ \\
Hackensack River at Oradell, N.J. & -- & -- \\
\hline
\end{tabular}


Table 69. Estimated loads of particulate organic carbon in selected rivers in New Jersey.

[MVUE, maximum value unbiased estimator; WY, water year; --, insufficient data available to estimate loads]

\begin{tabular}{|c|c|c|c|c|c|c|c|c|}
\hline River & WY 1988 & WY 1994 & WY 1998 & WY 1999 & WY 2000 & WY 2001 & WY 2002 & $\begin{array}{c}\text { Average year } \\
(1975-2000)\end{array}$ \\
\hline \multicolumn{9}{|c|}{ MVUE corrected loads, in kilograms } \\
\hline Passaic & 629,000 & 740,000 & 798,000 & 476,200 & 701,000 & 594,000 & 173,000 & 589,000 \\
\hline Rahway & 47,900 & 76,600 & 92,000 & 83,600 & 49,300 & 60,000 & 24,900 & 64,800 \\
\hline Elizabeth & 10,100 & 12,500 & 13,900 & 11,300 & 11,000 & 12,000 & 6,350 & 14,400 \\
\hline \multicolumn{9}{|c|}{ MVUE uncorrected loads, in kilograms } \\
\hline Raritan & 681,000 & $1,130,000$ & 928,000 & 903,000 & 525,000 & 707,000 & 240,000 & 767,000 \\
\hline Passaic & 526,000 & 623,000 & 673,000 & 400,000 & 586,000 & 496,000 & 142,000 & 483,500 \\
\hline Rahway & 45,200 & 72,800 & 87,600 & 82,000 & 46,200 & 56,800 & 23,400 & 60,900 \\
\hline Elizabeth & 11,900 & 15,100 & 17,600 & 15,900 & 12,800 & 15,700 & 7,140 & 16,200 \\
\hline
\end{tabular}

${ }^{1}$ Load for particulate organic carbon in the Hackensack River was estimated using a concentration of 2 milligrams per liter.

Table 70. Estimated loads of dissolved organic carbon in selected rivers in New Jersey.

[MVUE, maximum value unbiased estimator; --, Insufficient data available to estimate loads; WY, water year]

\begin{tabular}{|c|c|c|c|c|c|c|c|c|}
\hline River & WY 1988 & WY 1994 & WY 1998 & WY 1999 & WY 2000 & WY 2001 & WY 2002 & $\begin{array}{c}\text { Average year } \\
(1975-2000)\end{array}$ \\
\hline \multicolumn{9}{|c|}{ MVUE corrected loads, in kilograms } \\
\hline Raritan & $3,713,000$ & $5,360,000$ & $4,584,000$ & $3,719,000$ & $3,081,000$ & $3,750,000$ & $1,500,000$ & $4,190,000$ \\
\hline Passaic & $3,730,000$ & $4,723,000$ & $5,150,000$ & $2,960,000$ & $4,161,000$ & $3,586,000$ & 871,000 & $4,260,000$ \\
\hline Rahway & 166,000 & 244,000 & 280,000 & 219,000 & 181,000 & 199,000 & 91,600 & 205,000 \\
\hline Elizabeth & 94,200 & 101,000 & 101,000 & 82,900 & 85,800 & 89,800 & 53,800 & 89,000 \\
\hline Hackensack & -- & -- & -- & - & - & -- & -- & $215,000^{1}$ \\
\hline \multicolumn{9}{|c|}{ MVUE uncorrected loads, in kilograms } \\
\hline Raritan & $3,590,000$ & $5,200,00$ & $4,900,000$ & $3,620,000$ & $2,980,000$ & $3,630,000$ & $1,450,000$ & 837,000 \\
\hline Passaic & $3,540,000$ & $4,490,000$ & $4,900,000$ & $2,820,000$ & $3,940,000$ & $3,400,000$ & 825,000 & $4,040,000$ \\
\hline Rahway & 159,000 & 234,900 & 270,000 & 211,000 & 174,000 & 192,000 & 87,900 & 845,000 \\
\hline Elizabeth & 79,800 & 95,900 & 104,000 & 86,600 & 86,400 & 92,700 & 53,300 & 88,200 \\
\hline Hackensack & -- & -- & -- & -- & -- & -- & -- & -- \\
\hline
\end{tabular}

${ }^{1}$ Load for dissolved organic carbon in the Hackensack River was calculated using a concentration of 3.8 milligrams per liter.

Table 71. Estimated average annual loads of total organic carbon in selected rivers in New Jersey.

$[\mathrm{kg}$, kilograms $]$

\begin{tabular}{|c|c|c|c|c|}
\hline River & $\begin{array}{c}\text { Particulate organic } \\
\text { carbon load' } \\
(\mathrm{kg})\end{array}$ & $\begin{array}{c}\text { Dissolved organic } \\
\text { carbon load } \\
(\mathrm{kg})\end{array}$ & $\begin{array}{c}\text { Total organic } \\
\text { carbon load } \\
(\mathrm{kg})\end{array}$ & $\begin{array}{c}\text { Percent of total carbon } \\
\text { load due to particulate } \\
\text { organic carbon } \\
(\mathrm{kg})\end{array}$ \\
\hline Passaic & 589,000 & $4,260,000$ & $4,849,000$ & 12 \\
\hline Rahway & 64,800 & 205,000 & 269,800 & 24 \\
\hline
\end{tabular}

\footnotetext{
${ }^{1}$ Values are for the average year based on discharge record for the water years 1975-2000.

${ }^{2}$ For the Hackensack River, load of particulate organic carbon based on an estimated average concentration of 2 milligrams per liter POC; load of dissolved organic carbon based on an estimated average concentration of 3.8 milligrams per liter.
} 
Table 72. Average ratio of concentrations of particulate and dissolved organic carbon to suspended sediment in loads calculated for selected rivers in New Jersey water years 19882001.

[SS, suspended sediment; POC, particulate organic carbon; DOC, dissolved organic carbon; g, gram; mg, milligrams]

\begin{tabular}{lcc}
\hline \multicolumn{1}{c}{ River } & $\begin{array}{c}\text { POC/SS } \\
\text { (g POC/g SS) }\end{array}$ & $\begin{array}{c}\text { POC/DOC } \\
\text { (g POC/g DOC) }\end{array}$ \\
\hline Raritan & $9.3 \times 10^{-3}$ & 0.21 \\
Passaic & $25 \times 10^{-3}$ & .14 \\
Rahway & $73 \times 10^{-3}$ & .32 \\
Elizabeth & $34 \times 10^{-3}$ & .16 \\
\hline
\end{tabular}

lates transported in the Rahway River contained the most (by weight) particulate organic matter; particulates carried by the Raritan River contain the lowest mass of organic carbon. Likewise, the low ratio of POC to DOC load in the Elizabeth and Passaic Rivers may indicate a source of high dissolved carbon existed in these river basins, for example, sewage outfalls or other sources of dissolved carbon.

Another useful descriptor of the rivers is the relative load of suspended sediment and organic carbon per unit volume of discharge delivered from the basin. These values are derived by dividing the estimated average annual loads of SS, POC, and DOC by the average annual discharges, in essence, the long-term (yearly) average concentrations of these components. Values calculated using the average discharge and average yearly loads (table 73) show that each million gallon of discharge in the Raritan River transported $334 \mathrm{~kg}$ of sediment, $3.1 \mathrm{~kg}$ of POC, and $15 \mathrm{~kg}$ of DOC. The large average yearly concentrations of SS and carbon calculated for the Raritan River during WY 1999 were the result of a high annual discharge caused by hurricane "Floyd" that affected the area in September of 1999. Comparing the average yearly values shows the Raritan River transported roughly 3.7 times the amount of sediment as the Passaic River and roughly 5 times the mass in the Elizabeth and Rahway Rivers, and 12 times that in the Hackensack Rivers. An example of sediment-trapping behind dams is the low value for SS in the Hackensack River, which flows through the Oradell Reservoir immediately upstream of the sampling site. The lower sediment yield on the Passaic River may be a response to the water withdrawl system on this river or the presence of the Passaic River Great Swamp area (just upstream of the sampling site). Diverting water from the Passaic River would remove suspended sediment and POC and would reduce the ability of the river to transport materials. The values for sediment in the Rahway and Elizabeth Rivers are nearly equal, which was likely the result of the similar characteristics of these highly urbanized basins. However, the largest values for POC were found in the Rahway River, and the smallest were for the Elizabeth River. The long-term DOC concentrations were generally constant throughout the water years and were similar among the rivers.

Table 73. Suspended sediment, particulate organic carbon, and dissolved organic carbon loads normalized to discharge for selected rivers in New Jersey.

[WY, water year]

\begin{tabular}{|c|c|c|c|c|c|c|c|c|}
\hline River & WY 1988 & WY 1994 & WY 1998 & WY 1999 & WY 2000 & WY 2001 & WY 2002 & Average year \\
\hline Raritan & 279 & 491 & 423 & 1,360 & 214 & 312 & 189 & 334 \\
\hline Passaic & 105 & 115 & 116 & 114 & 105 & 108 & 91 & 90 \\
\hline Rahway & 61 & 68 & 72 & 88 & 56 & 64 & 56 & 68 \\
\hline Elizabeth & 54 & 57 & 63 & 73 & 53 & 64 & 47 & 67 \\
\hline \multicolumn{9}{|c|}{ Particulate organic carbon, in kilograms per million gallons of discharge } \\
\hline Raritan & 3.1 & 3.8 & 3.5 & 4.2 & 2.9 & 3.2 & 2.7 & 3.1 \\
\hline Passaic & 3.1 & 2.9 & 2.8 & 2.9 & 3.1 & 3.0 & 3.7 & 2.3 \\
\hline Rahway & 4.6 & 5.1 & 5.4 & 6.4 & 4.3 & 4.8 & 4.4 & 5.0 \\
\hline Passaic & 18 & 18 & 18 & 18 & 18 & 18 & 18 & 17 \\
\hline Rahway & 16 & 16 & 16 & 17 & 16 & 16 & 16 & 16 \\
\hline Elizabeth & 17 & 15 & 14 & 13 & 14 & 14 & 14 & 14 \\
\hline
\end{tabular}




\section{Tributary Loads of Chemicals}

The estimated annual loads of sediment and carbon can be combined with the average chemical concentrations to estimate annual loads of each chemical or chemical class originating from the tributary basins.

\section{Methods Used to Estimate Chemical Loads}

A primary goal of this work was to accurately estimate the chemical loads in the rivers. Originally the plan was to measure loads in storms of various magnitudes and assign these loads to the numbers of storms (of each magnitude) during a time period of interest. Unfortunately, only a small number of storms were ultimately sampled because of the drought experienced in the area. Therefore, a second method was used wherein historic SS, POC, and discharge data were combined with the average concentrations of the chemicals of interest described earlier.

Chemical loads are estimated using the present-day concentrations of chemicals, the measured volumetric water discharge, and the estimated loads of sediment or POC that were described earlier in this report. It should be realized that each variable has a degree of uncertainty associated with it, and that while chemical loads can be calculated for any time period of interest, it must be remembered that present-day chemical concentrations are only rough approximations of concentrations that existed in the past. Depending on the approximations made and the availability of data, the load estimates present here contain varying degrees of uncertainty.

The load for a chemical associated with particulate matter in a river over a defined period of time is given by a load equation similar to that described for sediment:

$$
L_{\text {chemical }}=\stackrel{T}{\equiv} C_{s s} C_{\text {chemical }} Q d t
$$

$$
\begin{aligned}
\text { where } & \begin{aligned}
L_{\text {chemical }}= & \text { load of chemical for time period } 0 \text { to } \mathrm{T}, \text { in } \\
& \text { mass; } \\
Q \quad & \text { volumetric discharge during time dt, in } \\
& \text { volume per time; } \\
C_{s s}= & \text { concentration of SS or particulate carbon } \\
& \text { during period of interest, in mass per } \\
& \text { volume; } \\
C_{\text {chemical }}= & \text { average concentration of chemical during } \\
& \text { period of interest, in mass per mass of } \\
& \text { sorbent; }
\end{aligned} \\
= & \text { initial time; }
\end{aligned}
$$

and

$$
T \quad=\text { final time. }
$$

Dissolved loads are defined by removing the value of $\mathrm{C}_{\mathrm{ss}}$ from this (and subsequent) equations, and by replacing $\mathrm{C}_{\text {chemical }}$ with the dissolved concentration in units of mass per volume of water. In reality, $\mathrm{C}_{\mathrm{ss}}, \mathrm{C}_{\text {chemicall }}$, and $\mathrm{Q}$ are functions of time as well.

The characteristics of the discharge and the sediment transport in rivers, and the types and amounts of data that can be collected, force the use an approximation to the load integral. Concentrations of chemicals, sediment, and POC may vary considerably as river discharge varies and may vary independently of one another. If a sufficient number of Css and Cchemical measurements are made, separated by short time intervals, then a sufficiently accurate load estimate can be made using the following approximation to the load integral:

$$
L=\bullet{ }_{t=1}^{n} C_{s s, i} C_{\text {chemical }, i} I Q_{i} t
$$

where

$$
\begin{aligned}
L= & \begin{array}{l}
\text { time "integrated" load of chemical for the } \\
\text { time period of interest, } \mathrm{T}, \text { in mass; }
\end{array} \\
C_{s s, i}= & \begin{array}{c}
\text { concentration of suspended sediment (or } \\
\text { particulate carbon) during the time interval }
\end{array} \\
& \mathrm{I}, \text { in mass per volume; } \\
C_{\text {chemical }, i}= & \begin{array}{l}
\text { concentration of chemical associated with } \\
\text { the particulate phase during time period i, }
\end{array} \\
& \text { in mass per mass of sorbent; } \\
Q_{i}= & \begin{array}{l}
\text { discharge during interval } \mathrm{I}, \text { in volume per } \\
\text { time; }
\end{array} \\
\Delta t= & \text { discrete time interval; and } \\
n & \text { number of discrete intervals sampled } \\
& \text { during time period of interest. }
\end{aligned}
$$

This approximation typically is used to estimate loads of chemicals that are inexpensive and/or easy to measure, thereby allowing sufficient data to be collected to provide acceptable resolution and accuracy in the estimated loads. However, in most studies, only a few data points will be available to define Cchemical, even though numerous measurements of Css are available. For chemicals that are difficult or expensive to measure, such as those studied in this work, typically only a few chemical data points will be available. A composite sample is then relied on that provides an "average" concentration that characterizes the river at any discharge. A further approximation is then needed to estimate the total load-making concentrations of chemicals independent of time:

$$
L_{e s t}=C_{\text {chemical }, i} \bullet{ }_{t=1}^{n} C_{s s, i} C_{\text {chemical }, i} I Q_{i} \quad t=C_{\text {contaminant }, s s} L_{s s, i}
$$

where

$$
\begin{aligned}
L_{e s t}= & \text { estimated load, in mass; } \\
C_{\text {contamint ss }}= & \text { "average" concentration of chemical in } \\
& \text { suspended particulate matter, in mass per } \\
& \text { mass of sediment or carbon; }
\end{aligned}
$$

and

$$
\begin{aligned}
L_{s s, i}= & \text { load of suspended sediment or particulate } \\
& \text { carbon for time period of interest. }
\end{aligned}
$$

For dissolved phase chemicals, the approximation is:

$$
L_{\text {est }}=C_{\text {chemical, }} Q_{t}
$$


where

$$
\begin{aligned}
Q_{t}= & \text { the volumetric discharge for the time } \\
& \text { period of interest; and } \\
C_{\text {chemical }, d}= & \begin{array}{l}
\text { an estimation of the concentration of } \\
\text { dissolved chemical of interest, in mass per } \\
\text { volume. }
\end{array}
\end{aligned}
$$

The different approximations of the load integral will provide different degrees of uncertainties in estimated loads. Concentrations of chemicals (dissolved and sediment bound) are expected to vary by perhaps an order of magnitude or less. Discharge is usually known to a relatively high degree of accuracy due to the nature of USGS gaging systems. Ultimately, the uncertainty in load estimates is controlled by the uncertainty in sediment-load estimation, which is typically a fairly large number. As discussed previously, the rating-curve method used to estimate daily sediment load is a second-order approximation method, with an accuracy that improves with the number of SS analyses available to produce the regression curve. Even with sufficient data points, the accuracy of a rating curve is likely to be biased low by some unknown amount because of the fact that typically one concentration is used to calculate each daily load.

Uncertainty is also inherited from the calculated best-fit rating-curve equation. For example, as a measure of the precision of the rating-curve estimation, the 95-percent confidence band was calculated for the Rartian River data (fig. 54) using the equations in Steel and Torrie (1980). The smallest error, $+/-0.22 \log$ units, or $+/-46,000 \mathrm{~kg} / \mathrm{d}$, was associated with the median discharge value of $361 \mathrm{Mgal} / \mathrm{d}$ and represented an uncertainty of approximately 22 percent in the predicted load at this discharge. At the largest discharge for which measured SS data exists $(3,689 \mathrm{Mgal} / \mathrm{d})$, the error in the predicted load was $+/-343,900 \mathrm{~kg} / \mathrm{d}$, which was equivalent to 57 percent of the predicted load. An estimated error in the loads predicted for this river would fall between these values, becoming greatest near the ends of the discharge spectrum and smallest near the mean discharge. Because of the fewer SS data available to construct the rating-curve equations, the uncertainties in the uppermost predicted loads for the Rahway, Elizabeth, and Hackensack Rivers were as high as 50 percent. In general, an uncertainty of roughly 30 percent is assumed reasonable for the sediment loads predicted in this work.

The uncertainty in chemical loads is also a function of the uncertainty in analytical concentration values. Although each chemical measurement may have a suitable accuracy and precision (+/- 10 to 15 percent, Bonin and Wilson, 2006), the fact that only a few analyses were ultimately available to be averaged into a single concentration introduced an unknown amount of uncertainty in loads. The concentrations reported here may not be representative of concentrations throughout the year and were certainly not representative of past (or future) conditions. However, concentration values were very small compared with the water and sediment discharges and are likely to be fairly representative of the average annual concentrations. Another factor affecting the estimated total chemical load is the use of the EDLs (or one-half the EDL) for nondetected concentrations. The analytical methods and large volume samples used in this work resulted in very low detection levels. Replacing nondetected values with EDLs is likely to have increased the total chemical load over the load that would result if nondetected values were dropped from the data. In spite of the sensitive analytic methods employed in this work, replacing nondetected values by one-half the EDL may have caused substantial increases for dissolved PCBs and PAHs. For example, the sample collected from the Hackensack River (June 23, 2000) had a total PCB concentration of $647 \mathrm{pg} / \mathrm{L}$ (table 74) (using one-half EDL and no blank correction), of which 74 percent $(481 \mathrm{pg} / \mathrm{L})$ were concentrations of

\begin{tabular}{|c|c|c|c|c|c|}
\hline Homolog group & $\begin{array}{l}\text { All data, ND = 1/2 EDL, } \\
\text { Not blank eliminated }\end{array}$ & $\begin{array}{l}\text { Blank eliminated data } \\
\text { set, } N D=1 / 2 \text { EDL }\end{array}$ & $\begin{array}{l}\text { Detected concentra- } \\
\text { tions only, blank } \\
\text { eliminated data set }\end{array}$ & $\begin{array}{l}\text { Blank eliminated con- } \\
\text { centrations only }\end{array}$ & $\begin{array}{c}\text { Total of the } 1 / 2 \text { EDL } \\
\text { values only }\end{array}$ \\
\hline Mono + Di & 83 & 29 & 15 & 54 & 14 \\
\hline Tetra & 205 & 187 & 177 & 19 & 8 \\
\hline Penta & 94 & 94 & 88 & 0 & 5 \\
\hline Hexa & 50 & 50 & 31 & 0 & 19 \\
\hline Octa & 17 & 17 & 0 & 0 & 17 \\
\hline Nona & 4 & 4 & 0 & 0 & 4 \\
\hline Deca & 2 & 2 & 0 & 0 & 2 \\
\hline Total PCB & 647 & 576 & 481 & 73 & 95 \\
\hline $\begin{array}{l}\text { Percent of total PCB } \\
\text { in "all data" set }\end{array}$ & 100 & 89 & 84 & 11 & 15 \\
\hline
\end{tabular}
detected congeners ("hits"). The blank-elimination procedure

Table 74. Contribution to total concentration from estimated detection levels for dissolved polychlorinated biphenyls in a sample collected from the Hackensack River, New Jersey, on June 23, 2000.

[EDL, estimated detection limit; values in picograms per liter] 
described earlier removed about 11 percent $(73 \mathrm{pg} / \mathrm{L})$ of this total, whereas the replacement of the nondetected values by one-half the EDL added 15 percent $(95 \mathrm{pg} / \mathrm{L})$ to the total $\mathrm{PCB}$ in this sample (table 74). As can be seen in the breakdown of these values by homolog group, blank elimination generally affected the lighter homologs, and nondetected values were mainly from the heavier homolog groups. These were typical percentages of blank elimination and nondetected values in the dissolved samples; sediment samples were not greatly affected by blank elimination and nondetected values. As a result of the replacement of nondetects by their (one-half) EDL, approximately 10 to 20 percent of the load of dissolved total PCBs in any river may be the result of the EDL values used. Considering all these factors, the level of uncertainty to the chemical loads was obtained from the uncertainty in sediment loads and was assumed to be 30 percent of the reported value.

Estimates of the dissolved and particulate-bound chemical loads for the discrete storm or low-flow events sampled were calculated using equation 34 . Estimates of annual sediment-bound and dissolved chemical loads for water years between 1988 and 2002, the water years of interest to the NJ DEP (New Jersey Department of Environmmental Protection, 2001) were calculated using equation 35 and 36, respectively. Because the river discharge in New Jersey varied widely during the selected years, it was difficult to compare among the various tributaries. A more representative base mark of the loads was the "average year," which was calculated using the mean daily discharge and average loads of sediment and POC for the water years 1975 to 2000, as discussed previously. These "average year" sediment loads, the average annual water discharge, and the present-day average chemical concentrations were used to obtain the chemical loads for each river for an "average" year. It should emphasized that the true chemcial load over this period cannot be defined because the present-day concentrations do not represent past concentrations in these rivers. Nontheless, the "average" values presented a useful measure to compare among rivers.

\section{Polychlorinated Biphenyls}

The loads of sediment and dissolved total PCBs were calculated for each storm and base-flow event sampled (table 75). The total PCB concentrations used were the sum of the individual congener concentrations in the blank-eliminated data set with nondetected values replaced by one-half the reported EDL. The PCB loads (table 75) are tabulated in order of increasing total volume discharge for storm events, or the average daily discharge for the low-flow events. The storm event on the Elizabeth River, June 4, 2003, transported the largest total load of PCBs (234 g), of which $230 \mathrm{~g}$ of PCB were associated with the sediment and $4 \mathrm{~g}$ were dissolved PCBs. By far, the largest sediment, and total PCB load (12 $\mathrm{g}$ /day) during low flow conditions were in the Passaic River (June, 2000). As expected, a strong positive relation exists between the magnitude of discharge and the dissolved PCB loads in each river. The relation between sediment-bound load and discharge is more complicated because of the fact that sediment loads are not linearly related to discharge. This independence between discharge and sediment load during a storm results in large changes in the relative contributions of the sediment and dissolved phase to the total chemical loads during each storm. In contrast, the use of a "rating" curve to estimate daily or annual sediment loads forces a logarithmic relation to exist between daily discharge and daily sediment load, and thus, sediment-bound chemical load.

As a measure of the importance of the storm discharges in transporting chemicals in these rivers, the number of equivalent base-flow days was calculated for each event. Equivalent base-flow days were calculated by dividing the total load for the event by the smallest load measured on each river during low-flow conditions. The equivalent base-flow days represented the number of days of low-flow discharge needed to deliver the same mass of chemicals transported during a storm. For example, the largest sampled storm event on the Raritan River (March 21, 2002) moved as much PCBs as were transported in 580 days of low flow (table 75). By definition, low-flow conditions are when discharge is at a level that is exceeded 90 percent of each year, so low-flow conditions occur 36.5 days each year. Therefore, this single storm delivered as much PCB from the basin as would be transported in nearly 16 years of low flow. In the smaller Elizabeth River where the concentrations of PCB are much higher, the largest storm event that was sampled (June 4, 2003) also transported a load of PCB equivalent to 573 days, or 15.6 years of low flow, nearly identical to the value in the much larger Raritan River.

The relative contribution of the dissolved and sedimentbound loads to the total load is demonstrated by calculating the ratio of the loads during the events (table 75). This ratio is found to vary as a function of storm magnitude (measured by peak discharge reached), demonstrating how the two phases vary in importance in the chemical transport. For example, in the Raritan River, the ratio of particulate load to dissolved load was much less than 1 for the low-discharge events, showing that the water was most important in transporting PCBs to the estuary under these conditions. As the "magnitude" of the storm increased (measured by the peak discharge reached), the particle load / dissolved load ratio increased, until a maximum was reached. In the Raritan River, a maximum ratio of 19 was reached, indicating that roughly 20 times more PCBs (by mass) were transported with the particulate phase than with the dissolved phase. As the size of the event increased further, the ratio declined and the dissolved phase gained in importance. A variation in relative importance of each phase in transporting PCBs also was indicated in the loads for the other rivers, but more samples would be needed to determine if this relation holds, especially for the Passaic River.

The annual dissolved and sediment-bound PCB loads for selected water years were calculated (table 76) using the average concentrations of total PCB in the sediment and water (table 12), the annual average discharge (table 65), and average annual sediment loads (table 67). The total yearly discharge was determined from daily mean discharge recorded 


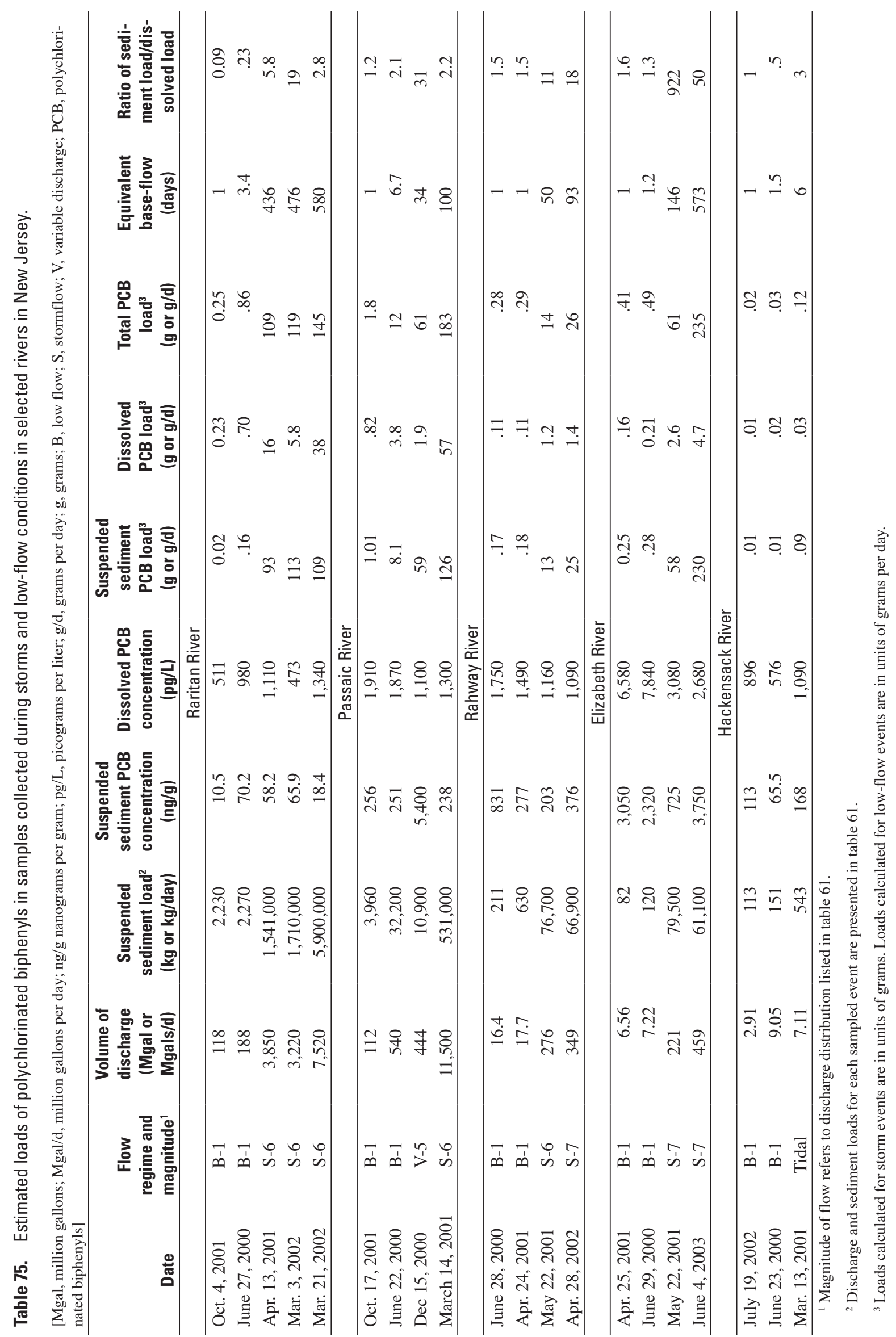


Table 76. Estimated loads of sediment-bound and dissolved phase polychlorinated biphenyls (PCBs) for water years 1988 through 2002, and for the average annual discharge in selected rivers in New Jersey.

$\underline{\text { [WY, water year; --, not applicable; load values in grams] }}$

\begin{tabular}{|c|c|c|c|c|c|c|c|c|c|}
\hline \multirow[b]{2}{*}{ River } & \multicolumn{8}{|c|}{ Load, in grams } & \multirow{2}{*}{$\begin{array}{c}\text { Contribution to } \\
\text { average annual } \\
\text { load } \\
\text { (percent) }\end{array}$} \\
\hline & WY1988 & WY1994 & WY1998 & WY1999 & WY2000 & WY2001 & WY2002 & $\begin{array}{c}\text { Average } \\
\text { annual }\end{array}$ & \\
\hline Raritan & 3,000 & 7,100 & 5,200 & 13,500 & 1,900 & 3,300 & 860 & 4,100 & 82 \\
\hline Passaic & 5,300 & 7,400 & 8,200 & 4,600 & 5,900 & 5,300 & 1,100 & 5,600 & 78 \\
\hline Hackensack & 15 & 40 & 43 & 18 & 29 & 27 & .62 & 35 & 47 \\
\hline Total for WY & 9,300 & 16,000 & 15,000 & 20,000 & 8,900 & 10,000 & 2,500 & 11,000 & -- \\
\hline \multicolumn{10}{|c|}{ Dissolved PCBs } \\
\hline Raritan & 790 & 1,100 & 900 & 740 & 670 & 790 & 340 & 920 & 18 \\
\hline Total for WY & 2,300 & 3,000 & 3,000 & 2,000 & 2,300 & 2,300 & 740 & 2,700 & -- \\
\hline \multicolumn{10}{|c|}{ Total PCBs } \\
\hline Raritan & 3,800 & 8,300 & 6,200 & 14,000 & 2,600 & 4,100 & 1,200 & 5,000 & -- \\
\hline Passaic & 6,600 & 9,000 & 9,900 & 5,600 & 7,300 & 6,500 & 1,400 & 7,200 & -- \\
\hline Rahway & 320 & 510 & 610 & 550 & 330 & 400 & 170 & 440 & -- \\
\hline Elizabeth & 830 & 1,100 & 1,300 & 1,200 & 890 & 1,200 & 480 & 1,150 & -- \\
\hline Hackensack & 27 & 75 & 85 & 40 & 50 & 64 & 1.2 & 74 & -- \\
\hline Total for WY & 11,000 & 19,000 & 18,000 & 22,000 & 11,000 & 12,000 & 3,200 & 14,000 & -- \\
\hline $\begin{array}{l}\text { Percent contribu- } \\
\text { tion to total load } \\
\text { from sediment } \\
\text { (percent) }\end{array}$ & 85 & 84 & 83 & 91 & 81 & 83 & 78 & 79 & -- \\
\hline
\end{tabular}

at USGS gaging stations. The average yearly loads (for water years 1975 to 2000) also were calculated.

The largest loads of sediment-bound and dissolved total PCBs (table 76) were on the Passaic River for all years except during WY 1999 (sediment) and WY2002 (dissolved), when the largest loads were on the Raritan River. This was the result of a single, very large discharge event associated with a hurricane in September 1999, which apparently affected the Raritan River Basin more than the Passaic River Basin. The low total loads on all rivers during the 2000 water year were the result of a drought during this time.

Average annual sediment-bound PCB loads were highest in the Passaic River $(5,600 \mathrm{~g} / \mathrm{yr})$ and lowest in the Hackensack River (35 g/yr). Dissolved loads ranged from 1,600 g in the Passaic River down to $39 \mathrm{~g}$ in the Hackensack River. Average annual loads for total PCB ranged from $74 \mathrm{~g}$ in the Hackensack up to 7,200 $\mathrm{g}$ in the Passaic River. In an average year, a total of $14 \mathrm{~kg}$ of PCBs was estimated to be delivered to Newark and Raritan Bays by these tributaries.

The relative contribution of the particulate-bound PCBs to the total PCB load and the contributions of the individual
PCB homologs to the load also were calculated (table 77). The average homolog distribution (table 13) and the average sediment PCB concentration (table 12) were used in these calculations. Particulate-bound PCBs contributed from 47 percent of the total PCBs in the Hackensack River up to 90 percent in the Elizabeth River. The low percentage in the Hackensack River was the result of the lack of storm-event data and the sediment trapping in the Oradell Reservoir. During low-flow discharge, the distribution of PCB load between the two phases was nearly equal in all the rivers, which was the result of the low $\mathrm{SS} /$ water ratio that existed in rivers during low flow. This occurs in spite of the much higher concentrations (per equal mass) of PCBs in the sediment phase. The PCBs in the sediment phase were dominated (greater than 32 percent) by the penta-chloro congeners in all rivers except the Elizabeth, where roughly 31 percent of the sediment PCB load consisted of the hexachloro- and 24 percent by the hepta-chloro congeners. As discussed previously, the PCB congener makeup of the Elizabeth River sediment differed from the makeup of the other studied rivers in that the hexa- and hepta-chlorinated congeners dominate. 
Table 77. Contribution of sediment-bound polychlorinated biphenyl (PCB) homologs to the total polychlorinated biphenyl load for the average annual discharge in selected rivers in New Jersey.

[Values in percent of total mass unless noted; PCB, polychlorinated biphenyl]

\begin{tabular}{|c|c|c|c|c|c|}
\hline & $\begin{array}{l}\text { Raritan } \\
\text { River }\end{array}$ & $\begin{array}{l}\text { Passaic } \\
\text { River }\end{array}$ & $\begin{array}{l}\text { Rahway } \\
\text { River }\end{array}$ & $\begin{array}{l}\text { Elizabeth } \\
\text { River }\end{array}$ & $\begin{array}{l}\text { Hackensack } \\
\text { River }\end{array}$ \\
\hline Homolog group & \multicolumn{5}{|c|}{ Percent of total suspended sediment load } \\
\hline mono $+\mathrm{di}$ & 0.73 & 1.7 & 0.47 & 1.4 & 1.6 \\
\hline tri & 3.3 & 10 & 5.9 & 6.9 & 4.1 \\
\hline tetra & 16 & 26 & 20 & 12 & 21 \\
\hline penta & 36 & 32 & 36 & 17 & 40 \\
\hline hexa & 25 & 18 & 24 & 31 & 23 \\
\hline hepta & 13 & 7.4 & 10 & 24 & 8.2 \\
\hline octa & 4.2 & 2.5 & 3.1 & 6.2 & 2.3 \\
\hline nona & 1.1 & .81 & .56 & 1.0 & .60 \\
\hline deca & .70 & .51 & .27 & .44 & .31 \\
\hline Total PCB sediment load, in grams & 4,130 & 5,630 & 366 & $\mathbf{1 , 0 3 0}$ & 35 \\
\hline Total PCB load, in grams & 5,060 & 7,200 & 438 & 1,150 & 74 \\
\hline $\begin{array}{l}\text { Contribution of sediment-bound } \\
\text { PCBs to total PCB load, in percent }\end{array}$ & 82 & 78 & 84 & 90 & 47 \\
\hline
\end{tabular}

\section{Dioxins, Furans, and Dioxin-Like Polychlorinated Biphenyls}

The estimated loads of sediment-bound dioxins and furans for the sampled storms and for low flow events were calculated in units of total mass and toxic equivalencies (TEQs) (table 78), using the data from table 19. Annual loads were calculated as the product of the average total concentrations (table 20) or the average total TEQ values for dioxins, furans, and co-planar PCBs (table 22 and 23) and the estimated annual sediment loads (MVUE corrected, table 67) for the respective river and years. The total concentrations were calculated by summing all 2,3,7,8 substituted CDD and CDFs concentrations in the blank-eliminated data set with the nondetected values replaced by one-half the reported EDL. The average TEQs are the sums of the TEQs for the individual dioxins (CDDs), furans (CDFs), and the co-planar PCBs in the average sediment composition. TEQ loads represent the mass of 2,3,7,8-TCDD needed to generate an equivalent toxicity to that of the mixture of CDDs, CDFs, and PCBs in the suspended sediment. The contribution to the sediment toxicity by the PCBs is important because the PCB content in these rivers greatly exceeded the dioxin and furan content.

The total mass of sediment-bound CDD+CDFs delivered by the storms ranged from a high of $44 \mathrm{~g}$ in the Raritan River storm (Apr. 13, 2001) down to $0.46 \mathrm{~g}$ in the Rahway River storm on May 22, 2001 (table 78). During low-flow periods, the total CDD+CDF loads ranged from $0.33 \mathrm{~g} / \mathrm{d}$ in the Passaic River down to less than $0.001 \mathrm{~g} / \mathrm{d}(1 \mathrm{mg} / \mathrm{d})$ in the Hackensack River. The largest storm load in the Raritan River carried a total CDD+CDF load equivalent to 11,000 days of low-flow discharge. When calculated as TEQs, the rivers transported very low total toxicity loads. The largest storm on the Raritan River transported $69 \mathrm{mg}$ (as 2,3,7,8-TCDD) of TEQ; in all rivers, the low-flow discharges carried TEQ loads of approximately $2 \mathrm{mg}$ or less (table 78).

The mass loads of the CDD plus CDFs calculated for the average yearly sediment load ranged from slightly over 2.2 $\mathrm{g} / \mathrm{y}$ for the Hackensack River up to $1,070 \mathrm{~g} / \mathrm{yr}$ in the Raritan River (tables 79 and 80). Mass loads for the dioxin like co-planar PCBs range from $4.7 \mathrm{~g} / \mathrm{yr}$ in the Hackensack River up to $570 \mathrm{~g} / \mathrm{yr}$ in the Passaic River (table 80). The co-planar PCBs contribute between 31 percent (Raritan River) and 92 percent (Elizabeth River) of the total PCDD+PCDF+co-planar PCB mass (table 80). The dioxin-like PCBs are from the tetrathrough hepta-chlorinated congener groups, and as discussed previously, the majority of the mass of the 2,3,7,8-substituted dioxins and furans in these rivers was from octa-dioxin (OCDD) (82 to 95 percent of total CDD+CDF mass, figure 17) and octa-difuran (OCDF), and followed to a lesser extent by the hepta-chlorinated dioxin congeners.

Average annual loads calculated as total TEQs (from CDD plus CDF) ranged from $9 \mathrm{mg} / \mathrm{yr}$ in the Hackensack River up to $1,340 \mathrm{mg} / \mathrm{yr}$ in the Raritan River (table 79 and 80). The co-planar PCBs add additional toxicity, ranging from $2 \mathrm{mg} / \mathrm{yr}$ in the Hackensack River up to $510 \mathrm{mg} / \mathrm{yr}$ in the Raritan River. Total TEQ values, which is the sum of the CDD, CDF, and co-plananr toxicity values for the average annual discharge conditions range from $11 \mathrm{mg} / \mathrm{yr}$ in the Hackensack River up to $1,900 \mathrm{mg} / \mathrm{yr}$ in the Raritan, and fall in the order Hackensack River $<$ Rahway River $<$ Elizabeth River $<$ Passaic River $<$ Raritan River. 
Table 78. Estimated loads of polychlorinated dioxins and difurans in samples collected during storms and low-flow conditions in selected rivers in New Jersey.

[Mgal, million gallons; Mgal/d, million gallons per day; pg/g picograms per gram; kg/d, kilograms per day; g/d, grams per day; B, low flow; S, storm flow; V, variable discharge; TEQ, toxic equivalency quotient]

\begin{tabular}{|c|c|c|c|c|c|c|c|}
\hline Date & $\begin{array}{l}\text { Flow } \\
\text { regime and } \\
\text { magnitude }^{1}\end{array}$ & $\begin{array}{c}\text { Volume of } \\
\text { discharge } \\
\text { (Mgal or Mgal/d) }\end{array}$ & $\begin{array}{l}\text { Suspended } \\
\text { sediment } \\
\text { load }^{2} \\
(\mathbf{k g ~ o r ~ k g / d )}\end{array}$ & $\begin{array}{c}\text { Suspended } \\
\text { sediment } \\
\text { CDD +CDF } \\
(\mathrm{pg} / \mathrm{g})\end{array}$ & $\begin{array}{c}\text { Suspended } \\
\text { sediment TEQ } \\
(\mathrm{pg} / \mathrm{g})\end{array}$ & $\begin{array}{l}\text { PCDD+PCDF } \\
\text { suspended } \\
\text { sediment } \\
\text { load }^{3} \\
\text { (grams or g/d) }\end{array}$ & $\begin{array}{c}\text { PCDD+PCDF } \\
\text { suspended } \\
\text { sediment TEQ } \\
\text { load }^{3} \\
\text { (grams or } \mathrm{g} / \mathrm{d} \text { ) }\end{array}$ \\
\hline \multicolumn{8}{|c|}{ Raritan River } \\
\hline June 27, 2000 & B-1 & 188 & 2,270 & 13,700 & 22.2 & 0.03 & $5.0 \times 10^{-5}$ \\
\hline Apr. 13, 2001 & S-6 & 3,850 & $1,541,000$ & 28,700 & 28.8 & 44.4 & $4.4 \times 10^{-2}$ \\
\hline Mar. 3, 2002 & S-6 & 3,220 & $1,710,000$ & 10,800 & 12.7 & 18.5 & $2.2 \times 10^{-2}$ \\
\hline Mar. 21, 2002 & S-6 & 7,520 & $5,900,000$ & 2,630 & 2.92 & 15.5 & $1.7 \times 10^{-2}$ \\
\hline${ }^{4}$ Dec. 15,2000 & $\mathrm{~V}-5$ & 444 & 10,900 & 12,500 & 277 & .14 & $3.0 \times 10^{-3}$ \\
\hline March 14, 2001 & S-6 & 11,500 & 531,000 & 11,100 & 28.1 & 5.9 & $1.5 \times 10^{-2}$ \\
\hline \multicolumn{8}{|c|}{ Rahway River } \\
\hline June 28, 2000 & B-1 & 16.4 & 211 & 23,100 & 88.7 & .005 & $1.9 \times 10^{-5}$ \\
\hline Apr. 24, 2001 & B-1 & 17.7 & 630 & 7,620 & 32.9 & .005 & $2.1 \times 10^{-5}$ \\
\hline May 22, 2001 & S-6 & 276 & 76,700 & 5,980 & 23.6 & .46 & $1.8 \times 10^{-3}$ \\
\hline Apr. 28, 2002 & S-7 & 349 & 66,900 & 9,930 & 32.3 & .66 & $2.2 \times 10^{-3}$ \\
\hline \multicolumn{8}{|c|}{ Hackensack River } \\
\hline June 23, 2000 & B-1 & 9.05 & 151 & 3,420 & 11.5 & 0.0005 & $1.7 \times 10^{-6}$ \\
\hline July 19, 2002 & B-1 & 2.91 & 113 & 7,870 & 32.4 & .001 & $3.7 \times 10^{-6}$ \\
\hline Mar. 13, 2001 & Tidal & 7.11 & 543 & 9,500 & 47.4 & .005 & $2.6 \times 10^{-5}$ \\
\hline
\end{tabular}

${ }^{1}$ Magnitude of flow refers to discharge distribution listed in table 6.

${ }^{2}$ Discharge and sediment loads for each sampled event are presented in table 61.

${ }^{3}$ Loads calculated for storm events are in units of grams. Loads calculated for low-flow events are in units of grams per day.

${ }^{4}$ Values for Dec. 15, 2000 samples were not included in calculating average concentration values. 
Table 79. Estimated loads of sediment-bound dioxin, difurans, and co-planar polychlorinated biphenyls for water years 1988 through 2002, and for the average annual discharge in selected rivers in New Jersey

[WY, water year; --, not applicable; <, less than]

\begin{tabular}{|c|c|c|c|c|c|c|c|c|}
\hline River & WY1988 & WY1994 & WY1998 & WY1999 & WY2000 & WY2001 & WY2002 & $\begin{array}{c}\text { Average } \\
\text { annual }\end{array}$ \\
\hline \multicolumn{9}{|c|}{ Suspended sediment CDD+CDF load, in grams } \\
\hline Raritan & 770 & 1,900 & 1,400 & 3,500 & 500 & 850 & 220 & 1,070 \\
\hline Passaic & 250 & 340 & 380 & 210 & 280 & 250 & 49 & 260 \\
\hline Elizabeth & 8.5 & 11 & 14 & 13 & 9.1 & 12 & 4.8 & 12 \\
\hline Hackensack & 1.0 & 2.5 & 2.7 & 1.1 & 1.8 & 1.7 & $<0.01$ & 2.2 \\
\hline Total for WY & 1,040 & 2,270 & 1,810 & 3,740 & 800 & 1,120 & 278 & 1,350 \\
\hline Passaic & .59 & .82 & .90 & .51 & .66 & .58 & .12 & .62 \\
\hline Rahway & .028 & .045 & .054 & .051 & .028 & .035 & .014 & .039 \\
\hline Elizabeth & .040 & .052 & .063 & .061 & .043 & .057 & .022 & .056 \\
\hline Hackensack & .004 & .010 & .011 & .004 & .007 & .007 & $<.001$ & .009 \\
\hline Total for WY & 1.62 & 3.2 & 2.7 & 4.9 & 1.4 & 1.7 & .43 & 2.1 \\
\hline \multicolumn{9}{|c|}{ Total TEQ load, co-planar PCBs, in grams as 2,3,7,8-TCDD } \\
\hline Raritan & .38 & .90 & .66 & 1.70 & .24 & .42 & .11 & .52 \\
\hline \multicolumn{9}{|c|}{ Total TEQ load, CDD+CDF plus co-planar PCBs, in grams as 2,3,7,8-TCDD } \\
\hline Raritan & 1.3 & 3.2 & 2.4 & 6.1 & .87 & 1.5 & .38 & 1.8 \\
\hline Passaic & .83 & 1.2 & 1.3 & .71 & .92 & .82 & .17 & .87 \\
\hline Rahway & .040 & .064 & .078 & .073 & .040 & .050 & .020 & .056 \\
\hline Elizabeth & .060 & .077 & .082 & .091 & .065 & .075 & .033 & .084 \\
\hline Hackensack & .005 & .012 & .013 & .005 & .009 & .008 & $<.001$ & .011 \\
\hline Total for WY & 2.2 & 4.6 & 3.9 & 6.8 & 1.9 & 2.4 & .60 & 2.8 \\
\hline
\end{tabular}


Table 80. Loads of dioxin, furans, and dioxin-like polychlorinated biphenyls estimated for the average annual discharge in selected rivers in New Jersey.

[TEQ, toxic equivalencies, as 2,3,7,8-TCDD; CDD, polychlorinated dioxins; CDF, polychlorinated difurans; PCB, polychlorinated biphenyls]

\begin{tabular}{|c|c|c|c|c|c|}
\hline River & $\begin{array}{l}\text { Total CDD Load } \\
\text { (grams) }\end{array}$ & $\begin{array}{c}\text { Total CDF load } \\
\text { (grams) }\end{array}$ & $\begin{array}{l}\text { Total dioxin-like } \\
\text { PCB load } \\
\text { (grams) }\end{array}$ & $\begin{array}{c}\text { Total load } \\
\text { (grams) }\end{array}$ & $\begin{array}{c}\text { Contributed to total load } \\
\text { by dioxin-like PCBs } \\
\text { (percent) }\end{array}$ \\
\hline Raritan & 1,050 & 15 & 500 & 1,600 & 31 \\
\hline Passaic & 250 & 13 & 570 & 830 & 69 \\
\hline Rahway & 9.5 & .71 & 37 & 47 & 79 \\
\hline Elizabeth & 11 & 1.0 & 110 & 120 & 92 \\
\hline River & $\begin{array}{c}\text { TE0 from CDD } \\
\text { (grams) }\end{array}$ & $\begin{array}{c}\text { TEQ from CDF } \\
\text { (grams) }\end{array}$ & $\begin{array}{c}\text { TEO from } \\
\text { dioxin-like PCB } \\
\text { (grams) } \\
\end{array}$ & $\begin{array}{c}\text { Total TEQ load } \\
\text { (grams) }\end{array}$ & $\begin{array}{c}\text { Contribution to total TEQ } \\
\text { load by dioxin-like PCBs } \\
\text { (percent) }\end{array}$ \\
\hline Raritan & 0.88 & 0.46 & 0.51 & 1.9 & 27 \\
\hline Passaic & .38 & .25 & .25 & .88 & 28 \\
\hline Total & 1.3 & .75 & .81 & 2.9 & 28 \\
\hline
\end{tabular}

The percentage of the toxicity in these loads resulting from co-planar PCBs was from 18 percent in the Hackensack River up to 33 percent in the Elizabeth River. In the Rahway and Elizabeth Rivers, where the highest concentrations of the co-planar PCBs were measured (table 80) the percent contributions from co-planar PCBs in the average annual load was nearly equal at 30 and 33 percent, respectively. These estimates show the importance of considering the co-planar PCBs, dissolved and sediment bound, when evaluating dioxin toxicity in these rivers, because the PCBs can account for roughly one-third of the estimated total TEQ values.

Because the dissolved dioxin and furan concentrations were not measured, it was not possible to calculate the relative contribution of dioxin loads by the two phases. Generally, the vast majority of CDD and CDF compounds were expected to partition into the sediment phase, and in early trials measurable dissolved concentrations could not be found.

However, an estimate can be made of the dissolved dioxin/difuran loads in the rivers. One sample of dissolved XAD (1USG00020SA) was collected from the Passaic River on March 14, 2001. The results of this analysis are presented in table 81 .

Most of the CDD/CDF compounds in this 121 liter sample were not detected. OCDD and OCDF were measured in the highest mass in the XAD sample (260 pg and $38 \mathrm{pg}$, respectively). In this sample (table 81 ), the measured total concentrations $(3.0 \mathrm{pg} / \mathrm{L})$ results in a total CDD+CDF disolved load for the Passaic River of roughly 3 grams per year of CDD+CDF mass, which is slightly greater than 1 percent of the sediment-bound CDD+CDF load in this river. This supports that dissolved dioxin-difurans contribute negliable amounts to the total load in these rivers.
Table 81. Concentrations of dissolved dioxin and difuran compounds in a sample collected from the Passaic River, N.J.

[pg/L, picograms per liter; -- not detected; U, compound not detected at or above the estimated detection level; B, compound found in method blank; J, value less than lowest standard used]

\begin{tabular}{lccc}
\hline \multicolumn{1}{c}{ Compound } & $\begin{array}{c}\text { Concentration } \\
\text { (pg/L) }\end{array}$ & Flag & $\begin{array}{c}\text { Estimated } \\
\text { detection level } \\
\text { (pg/L) }\end{array}$ \\
\hline $2,3,7,8-\mathrm{TCDD}$ & -- & $\mathrm{U}$ & 0.12 \\
$1,2,3,7,8-\mathrm{PeCDD}$ & -- & $\mathrm{U}$ & .06 \\
$1,2,3,7,8,9-\mathrm{HxCDD}$ & -- & $\mathrm{U}$ & .06 \\
$1,2,3,4,7,8-\mathrm{HxCDD}$ & -- & $\mathrm{U}$ & .07 \\
$1,2,3,6,7,8-\mathrm{HxCDD}$ & -- & $\mathrm{U}$ & .06 \\
$1,2,3,4,6,7,8-\mathrm{HpCDD}$ & 0.48 & $\mathrm{~B} \mathrm{~J}$ & .10 \\
OCDD & 2.1 & $\mathrm{~B} \mathrm{~J}$ & .13 \\
$2,3,7,8-\mathrm{TCDF}$ & -- & $\mathrm{U}$ & .11 \\
$2,3,7,8-\mathrm{TCDF}$ & -- & $\mathrm{U}$ & .04 \\
$2,3,4,7,8-\mathrm{PeCDF}$ & -- & $\mathrm{U}$ & .04 \\
$1,2,3,4,7,8-\mathrm{HxCDF}$ & -- & $\mathrm{U}$ & .03 \\
$2,3,4,6,7,8-\mathrm{HxCDF}$ & .033 & $\mathrm{~B} \mathrm{~J}$ & .03 \\
$1,2,3,6,7,8-\mathrm{HxCDF}$ & .049 & $\mathrm{~B} \mathrm{~J}$ & .04 \\
$1,2,3,7,8,9-\mathrm{HxCDF}$ & -- & $\mathrm{U}$ & .05 \\
$1,2,3,4,6,7,8-\mathrm{HpCDF}$ & .065 & $\mathrm{~B} \mathrm{~J}$ & .04 \\
$1,2,3,4,7,8,9-\mathrm{HpCDF}$ & -- & $\mathrm{U}$ & .07 \\
OCDF & .29 & $\mathrm{~B} \mathrm{~J}$ & .10 \\
\hline Total & $\mathbf{3 . 0}$ & -- & -- \\
\hline
\end{tabular}




\section{Polycyclic Aromatic Hydrocarbons}

Loads calculated for the PAHs in the individual storms and low-flow events sampled in this study are presented in table 82. Estimates of annual loads in the rivers (table 83) were made using the average chemical compositions (table 30 and 31), the average yearly annual discharge (table 65), and the average yearly estimated sediment loads (table 67). The average concentrations were calculated using the blankeliminated data set with the non-detected values replaced by one-half the reported EDL.

The total sediment-bound PAH load for the storm events sampled (table 82) ranged from $25.5 \mathrm{~kg}$ in the Passaic River storm (Mar. 14, 2001) down to $.31 \mathrm{~kg}$ in the Rahway River storm (May 22, 2001) (excluding the high load in the Raritan River, where the average concentrations was influenced by a questionable concentration). The percentage of these total loads due to sediment-bound PAHs was variable within and among the rivers. For example, during the April 132001 storm on the Raritan River, 91 pecent of the total load was calculated to be due to sediment-bound PAHs, while in the Mar. 21, 2002 storm, 63 percent was attributed to the transport of sediment. During low-flow discharge, total sediment-bound PAH loads were estimated to be from $42 \mathrm{~g} / \mathrm{d}$ in the Passaic River down to roughly $0.085 \mathrm{~g} / \mathrm{d}$ in the Hackensack River. Again, the contribution to the total load by sediment-bound PAHs was highly variable within and among the rivers.

The total PAH load (sediment-bound plus dissolved) of the rivers during an average year (table 83) ranged from $15 \mathrm{~kg} /$ $\mathrm{yr}$ in the Hackensack Rivers, up to $1,400 \mathrm{~kg} / \mathrm{yr}$ in the Raritan River, andincreased in the following order:

- Hackensack (15 kg/y) <Rahway (69) <Elizabeth $(280)<$ Passaic $(1,000)<$ Raritan $(1,400)$

The dissolved PAHs loads for the average year ranged from $9.5 \mathrm{~kg}$ in the Hackensack River up to $630 \mathrm{~kg}$ in the Passaic River (table 83). The dissolved PAH loads in the Raritan and Passaic Rivers differed by about a factor of 2, and the loads on these rivers were 5 to 10 times greater than the loads in each of the other rivers. The dissolved load in the Elizabeth River (220 kg) is five times the load in the Rahway River (44 $\mathrm{kg}$ ), reflecting the large differences in PAH concentrations measured in these rivers (table 26). As previously discussed, a number of difficulties were encountered in the dissolved PAH collection and analysis scheme used, and a large number of dissolved PAH concentrations were removed because of blank contamination or were not detected because of the low analytical response from the small sample volumes used. Therefore, these loads should be considered rough estimates and are likely underestimate of the true loads.

The average annual sediment-bound PAH loads ranged (table 83) from about $6 \mathrm{~kg} / \mathrm{yr}$ for the Hackensack River up to $1,000 \mathrm{~kg} / \mathrm{yr}$ in the Raritan River. Of particular note is that the total sediment-bound load in the Passaic River was roughly one-half of the total sediment load in the Raritan River, but the dissolved load in the Passaic River was roughly 1.5 times greater than the dissolved load in the Raritan River.

Only in the Raritan River is the sediment-bound phase the principal route of transport for most of the PAH compounds. In all other rivers, the dissolved phase was responsible for the majority of the total PAH transport. For example, in the Elizabeth River, an estimated 80 percent of the total load was in the dissolved phase (table 83). Inspection of the average annual loads calculated for the individual compounds shows that for some compounds, however, the sediment phase is the princiapal transport route (table 84). This is the result of the extremely high concentrations in the sediment for some compounds, especially the high molecular weight hydrophobic compounds such as pyrene, chrysene, and others. The differences in the loads among the sediment and dissolved phases relates to the differences in solubility of the compounds, the differences in affinity for particulates exhibited by the compounds, and the differences in concentrations in the stream sediment and the other sources of PAHs in the river basins. To some extent, this variation may also reflect different inputs of liquid-phase PAHs or particulate-bound PAHs. For example, the contribution of the total biphenyl load from the suspended sediment load ranged from 12 to 100 percent, indicating tremendous variation in contribution by each phase. For many of the PAH components, less than 50 percent of the load was estimated to be transported by the sediment. Generally, these are the more soluble PAHs. It is important to recall, however, that some of these compounds (such as 2,3,5-trimethylnaphthalene) have few detected measurements or were greatly affected by blank contamination. Those PAHs having 100 percent (or near 100 percent) of their loads derived from sediment are likely to be the compounds that did not have dissolved concentrations reported.

\section{Organochlorine Pesticides}

Loads calculated for the OCPs in the individual storms and low-flow events sampled in this study are presented in table 85. Estimates of the annual loads in the rivers (table 86) were made using the average chemical compositions (tables 45 and 46), the average yearly annual discharge (table 65), and the estimated average annual sediment loads for each river (table 67). The average OCP concentrations were calculated using the blank-eliminated data set with the nondetected values replaced by one-half the reported EDL. As discussed previously, several of the samples had poor IS recoveries for compound series such as the DDTs, BHCs, endosulfans, and endrins. This may introduce larger uncertainty in the load calculations because the suspect concentrations were not removed from the data sets before calculating the average concentrations. Also, the Passaic River sample collected on December 15, 2000 was removed before the average for this river was calculated. Loads are also presented for selected compound groups including the DDT, BHC, chlordane, aldrin, endosulfan, endrin, and heptachlor series, calculated for the average year discharge (table 87). 


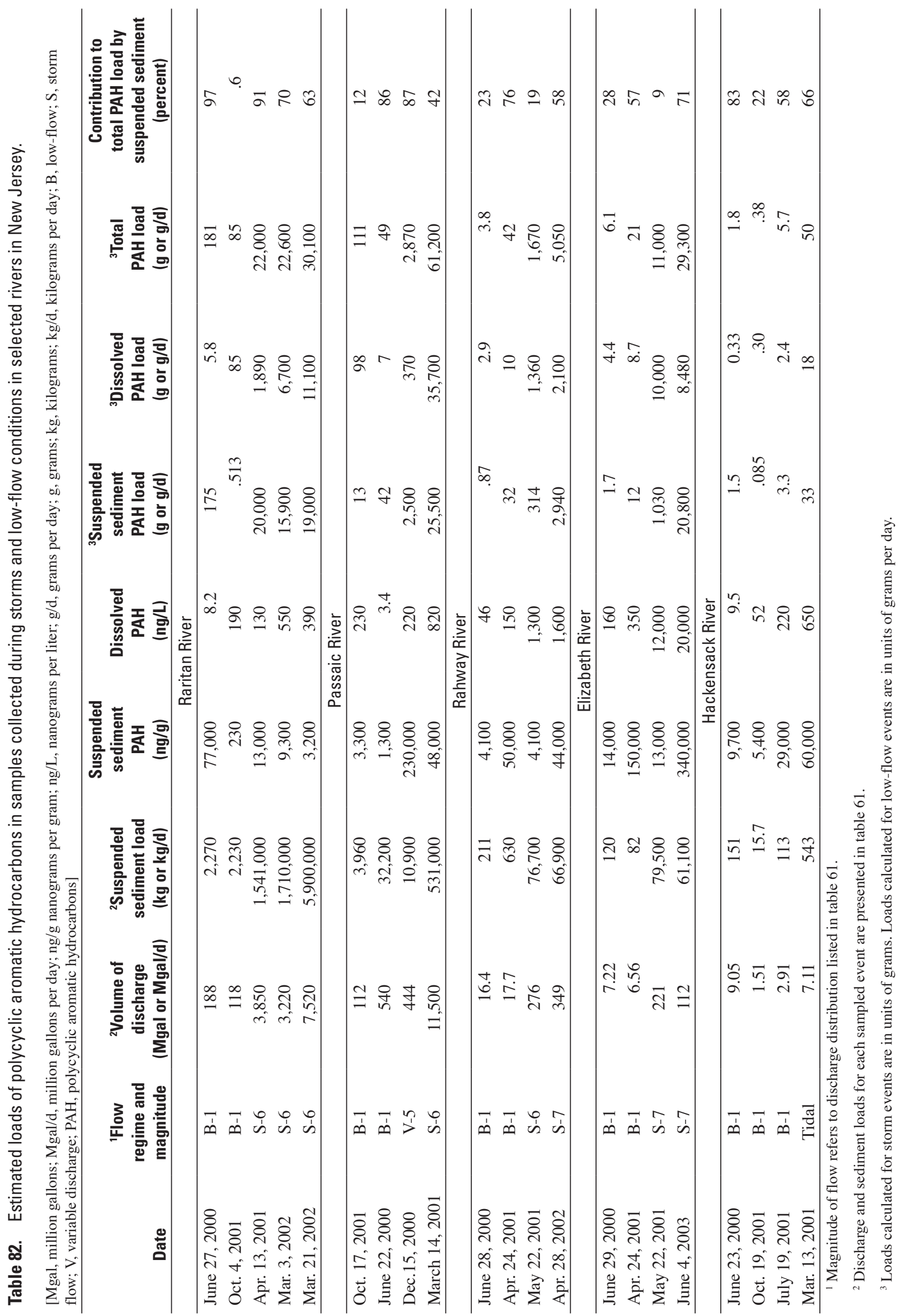


Table 83. Estimated loads of sediment-bound and dissolved total polycyclic aromatic hydrocarbons (PAH) for water years 1988 through 2002, and for the average annual discharge in selected rivers in New Jersey.

[WY, water year; --, not applicable]

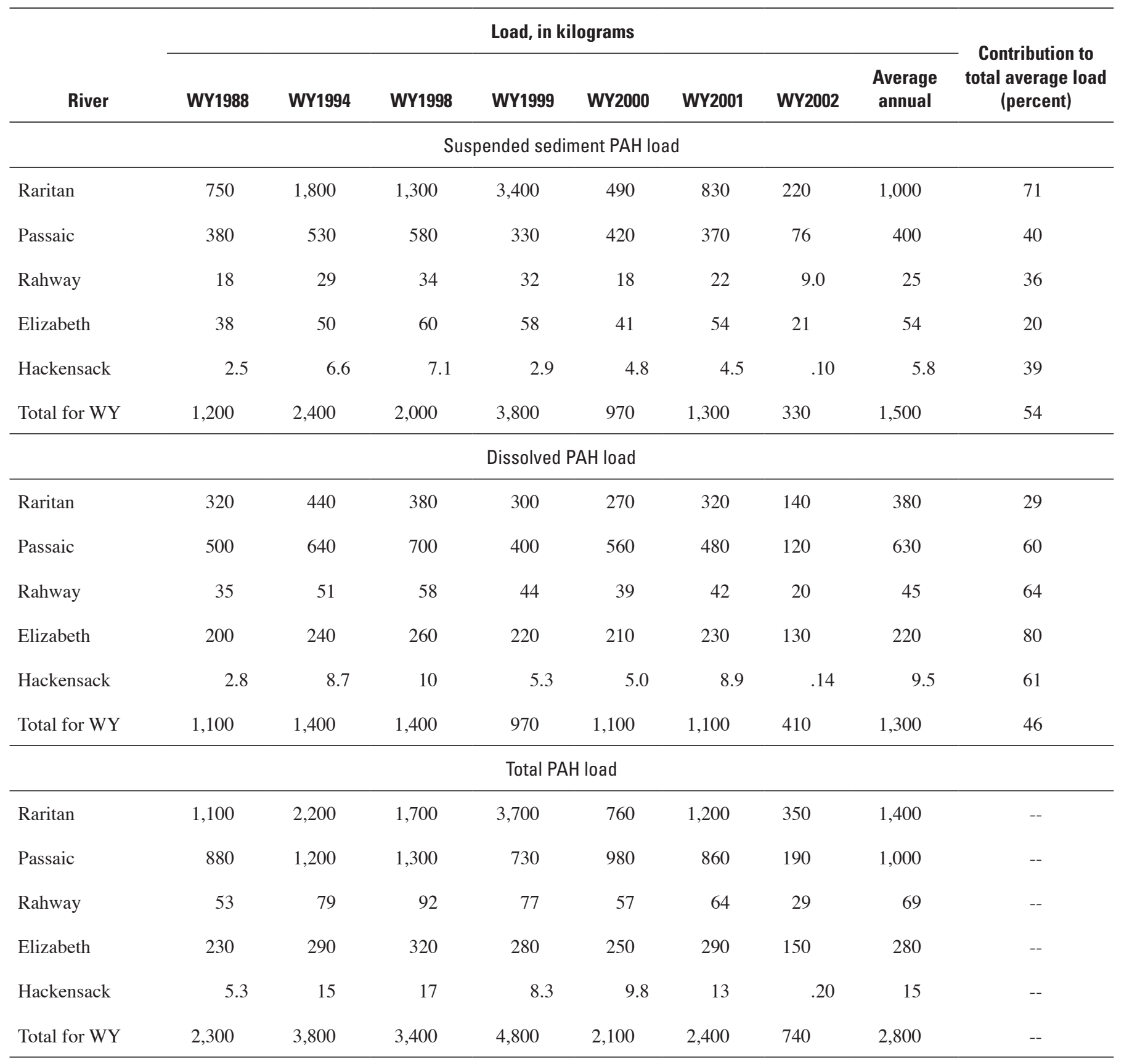




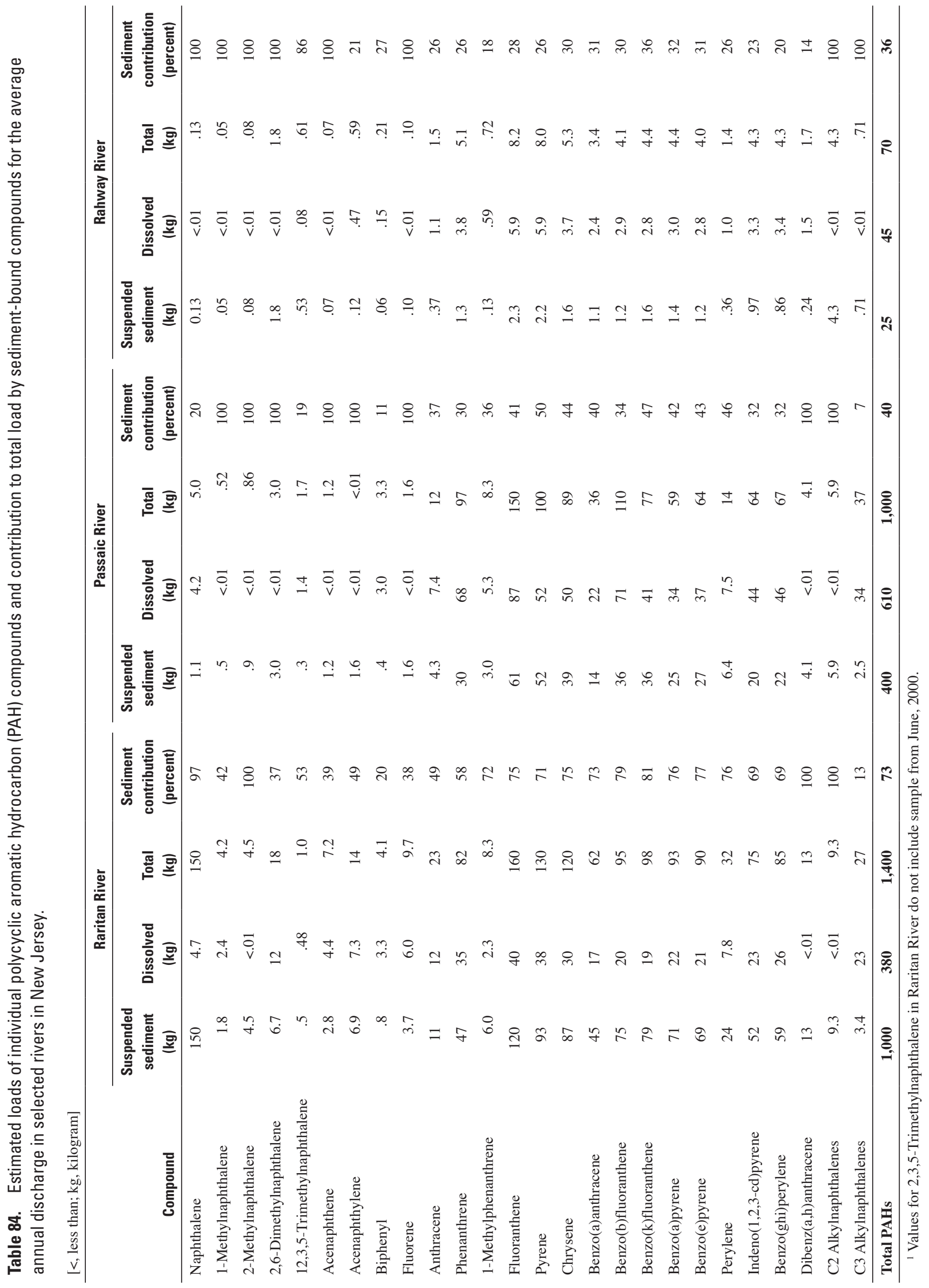




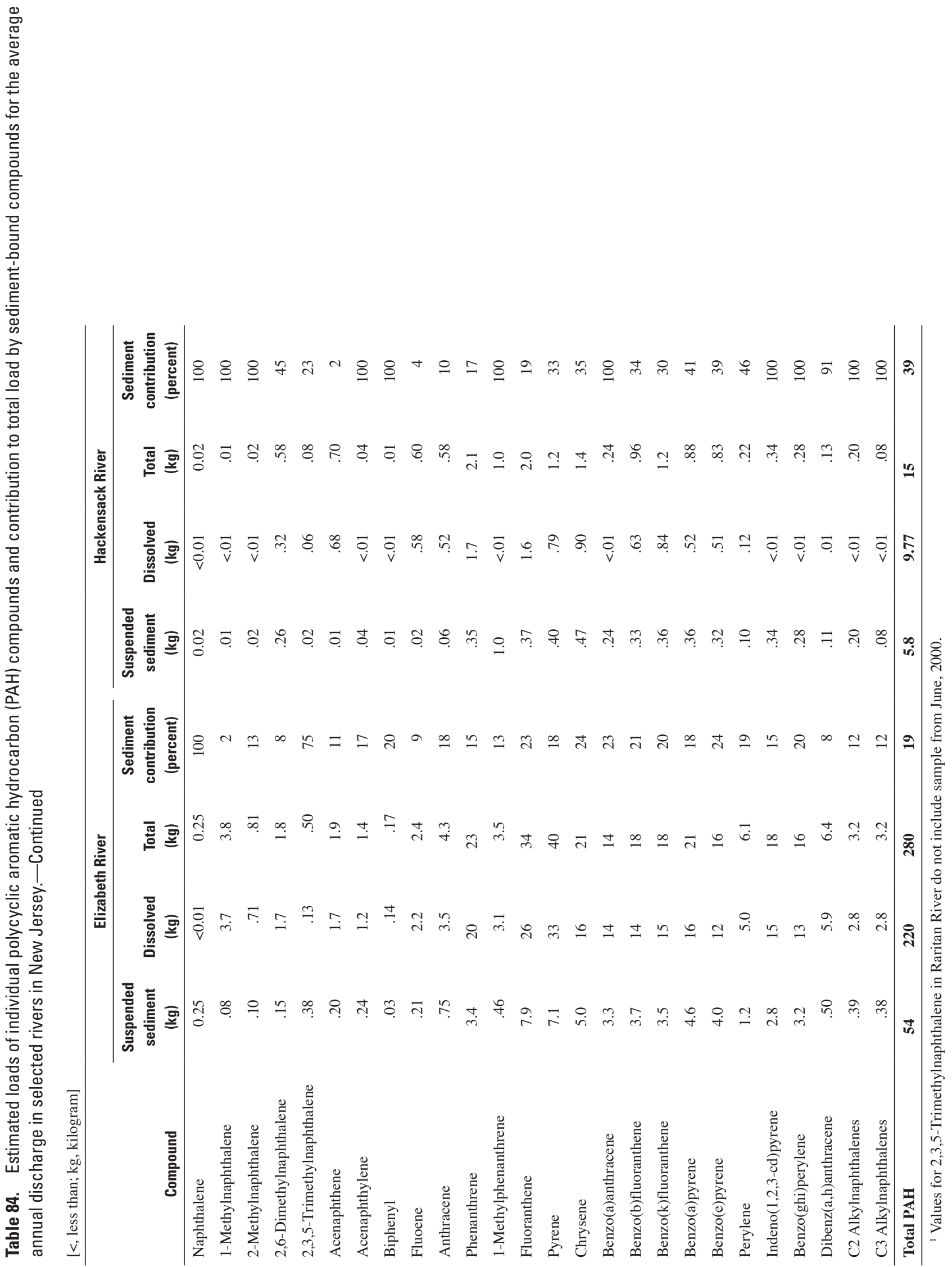




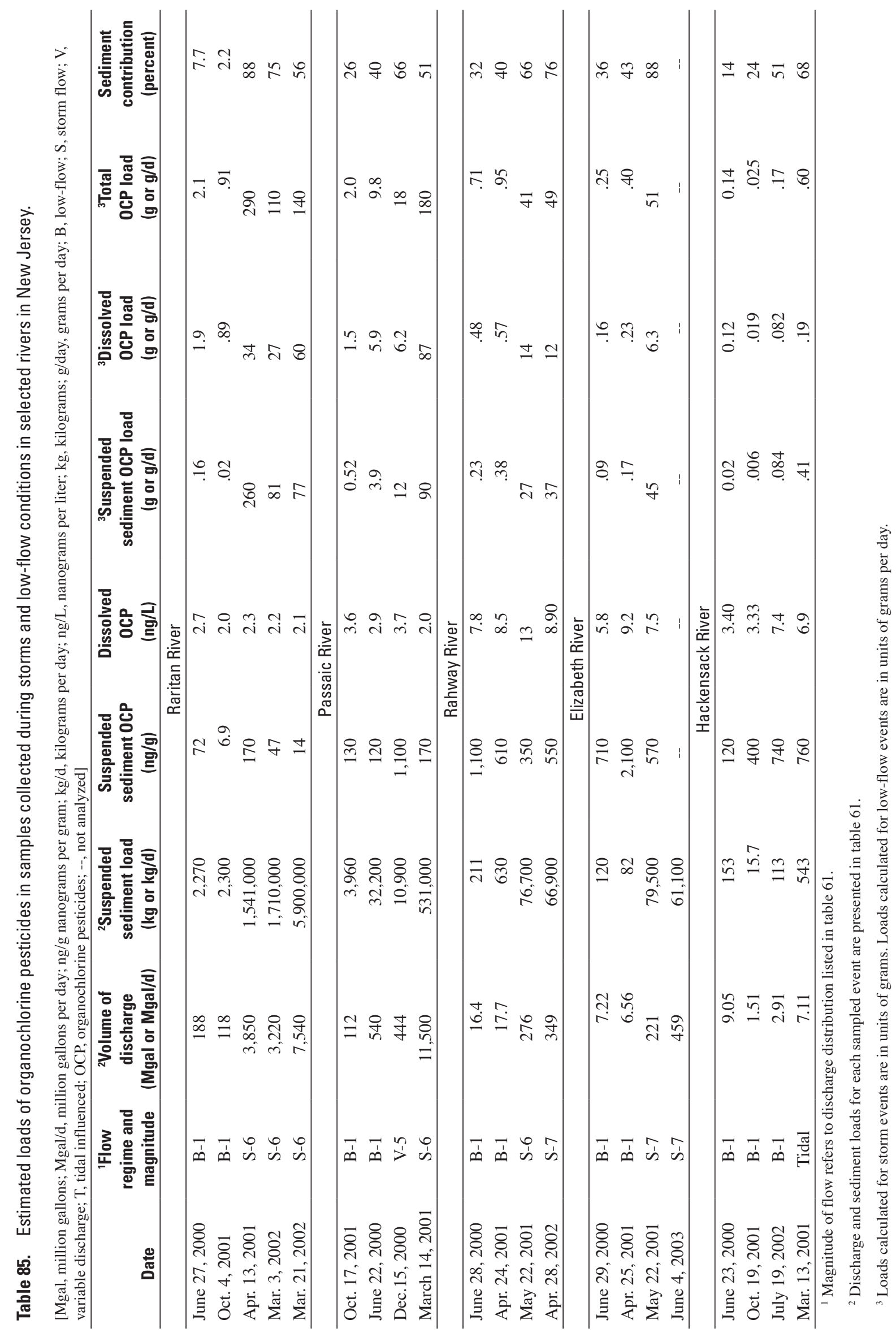


Table 86. Estimated loads of sediment-bound and dissolved total organochlorine pesticides (OCP) for water years 1988 through 2002, and for the average annual discharge in selected rivers in New Jersey.

[WY, water year; --, not applicable]

\begin{tabular}{|c|c|c|c|c|c|c|c|c|c|}
\hline \multirow[b]{2}{*}{ River } & \multicolumn{8}{|c|}{ Load, in grams } & \multirow{2}{*}{$\begin{array}{l}\text { Contribution to } \\
\text { average total load } \\
\text { (percent) }\end{array}$} \\
\hline & WY1988 & WY1994 & WY1998 & WY1999 & WY2000 & WY2001 & WY2002 & $\begin{array}{c}\text { Average } \\
\text { annual }\end{array}$ & \\
\hline \multicolumn{10}{|c|}{ Suspended sediment OCP load } \\
\hline Raritan & 4,000 & 9,700 & 7,100 & 18,000 & 2,600 & 4,500 & 1,200 & 5,600 & 70 \\
\hline Passaic & 3,100 & 4,200 & 4,700 & 2,600 & 3,400 & 3,000 & 610 & 3,200 & 53 \\
\hline Rahway & 420 & 680 & 820 & 770 & 430 & 530 & 220 & 590 & 54 \\
\hline Hackensack & 72 & 190 & 200 & 84 & 140 & 130 & 3.0 & 170 & 40 \\
\hline Total & 8,000 & 15,000 & 13,000 & 22,000 & 7,000 & 8,700 & 2,200 & 10,100 & 62 \\
\hline \multicolumn{10}{|c|}{ Dissolved OCP load } \\
\hline Raritan & 2,200 & 3,000 & 2,500 & 2,000 & 1,800 & 2,200 & 930 & 2,400 & 30 \\
\hline Passaic & 2,200 & 2,800 & 3,100 & 1,800 & 2,500 & 2,100 & 520 & 2,800 & 47 \\
\hline Total & 5,000 & 6,700 & 6,700 & 4,600 & 5,000 & 5,100 & 1,800 & 6,200 & 38 \\
\hline \multicolumn{10}{|c|}{ Total OCP load } \\
\hline Raritan & 6,200 & 13,000 & 9,600 & 20,000 & 4,400 & 6,700 & 2,100 & 8,000 & -- \\
\hline Passaic & 5,300 & 7,000 & 7,800 & 4,400 & 5,900 & 5,100 & 1,100 & 6,000 & -- \\
\hline Rahway & 790 & 1,200 & 1,400 & 1,200 & 830 & 970 & 420 & 1,100 & -- \\
\hline Elizabeth & 520 & 650 & 770 & 720 & 550 & 700 & 300 & 670 & -- \\
\hline Hackensack & 150 & 420 & 470 & 220 & 270 & 370 & 7.0 & 420 & -- \\
\hline Total & 13,000 & 22,000 & 20,000 & 27,000 & 12,000 & 14,000 & 3,900 & 16,700 & -- \\
\hline
\end{tabular}

Loads of total OCPs (sum of all OCP loads) calculated for the sampled storm events ranged from $290 \mathrm{~g}$ in the Raritan River (Apr. 13, 2001) down to $41 \mathrm{~g}$ in the Rahway River May 22, 2001 sample (table 85). Dissolved loads for the storm events ranged from $87 \mathrm{~g}$ in the Passaic River March 14, 2001 sample down to $6.3 \mathrm{~g}$ in the Elizabeth River May 22, 2001 sample. Loads of sediment bound OCPs in the storms ranged from $260 \mathrm{~g}$ in the Raritan Apr. 13, 2001 sample down to $27 \mathrm{~g}$ in the Rahway May 22, 2001 sample. For low-flow conditions, total OCP loads ranged from about $10 \mathrm{~g} / \mathrm{d}$ on the Passaic River down to $0.025 \mathrm{~g} / \mathrm{d}$ in the Hackensack River. Generally, OCPs were associated with the sediment phase particularly during storm events; typical contributions to the total OCP load were between 51 to 88 percent of the total storm load. The contribution by sediment in the low-flow conditions was estimated to be lower, less than 44 percent, particularly in the Raritan River ( 2 to 8 percent). These results show that, in general, loads during the storm events are much greater than the loads estimated for low-flow conditions, and that a larger percentage of the OCPs are delivered by sediment during storm flow than during low-flow.

The loads of total pesticides (dissolved plus sedimentbound) in the annual average discharge (table 86) ranged from $420 \mathrm{~g}$ in the Hackensack River up to $8.0 \mathrm{~kg}$ in the Raritan River, and increased in the following order:
- Hackensack (420 g/yr) <Elizabeth (670) <Rahway $(1,100)<$ Passaic $(6,000)<$ Raritan $(8,000)$

Like the storm samples described above, the majority of the total OCP load in an average year was associated with the particulate phase (40 to 74 percent). The low percent contribution (40 percent) in the Hackensack River was likely the result of sediment being trapped in the Oradell Reservoir.

However, inspecting the annual average loads of the compound groups (table 87) showed that a large range of contribution by the sediment/water phases is predicted, depending on the compound; the sediment contribution ranged from $<1$ percent up to 96 percent of the total annual load. Principal compounds in the sediment phase included the DDT series, the chlordane series, the nonachlor series, and to a lesser extent, dieldrin.

Total OCP loads for the dissolved phase ranged from $180 \mathrm{~g} / \mathrm{yr}$ in the Elizabeth River up to 2,800 g/yr in the Passaic River (table 86). The average annual loads for various dissolved OCP pesticide groups of interest ranged from $0.02 \mathrm{~g} / \mathrm{yr}$ for Mirex in the Elizabeth River up to $710 \mathrm{~g} / \mathrm{yr}$ for total chlordane in the Passaic River (table 87). These estimates clearly show that a substantial dissolved load of some OCPs existed, specifically BHC, aldrin+dieldrin, endosulfan, endrin, and the heptachlor series. This reflects the higher dissolved concentrations for these compounds (table 46). 
Table 87. Estimated loads of dissolved and sediment-bound organochlorine pesticides and contribution to total load by sedimentbound compounds for the average annual discharge in selected rivers in New Jersey.

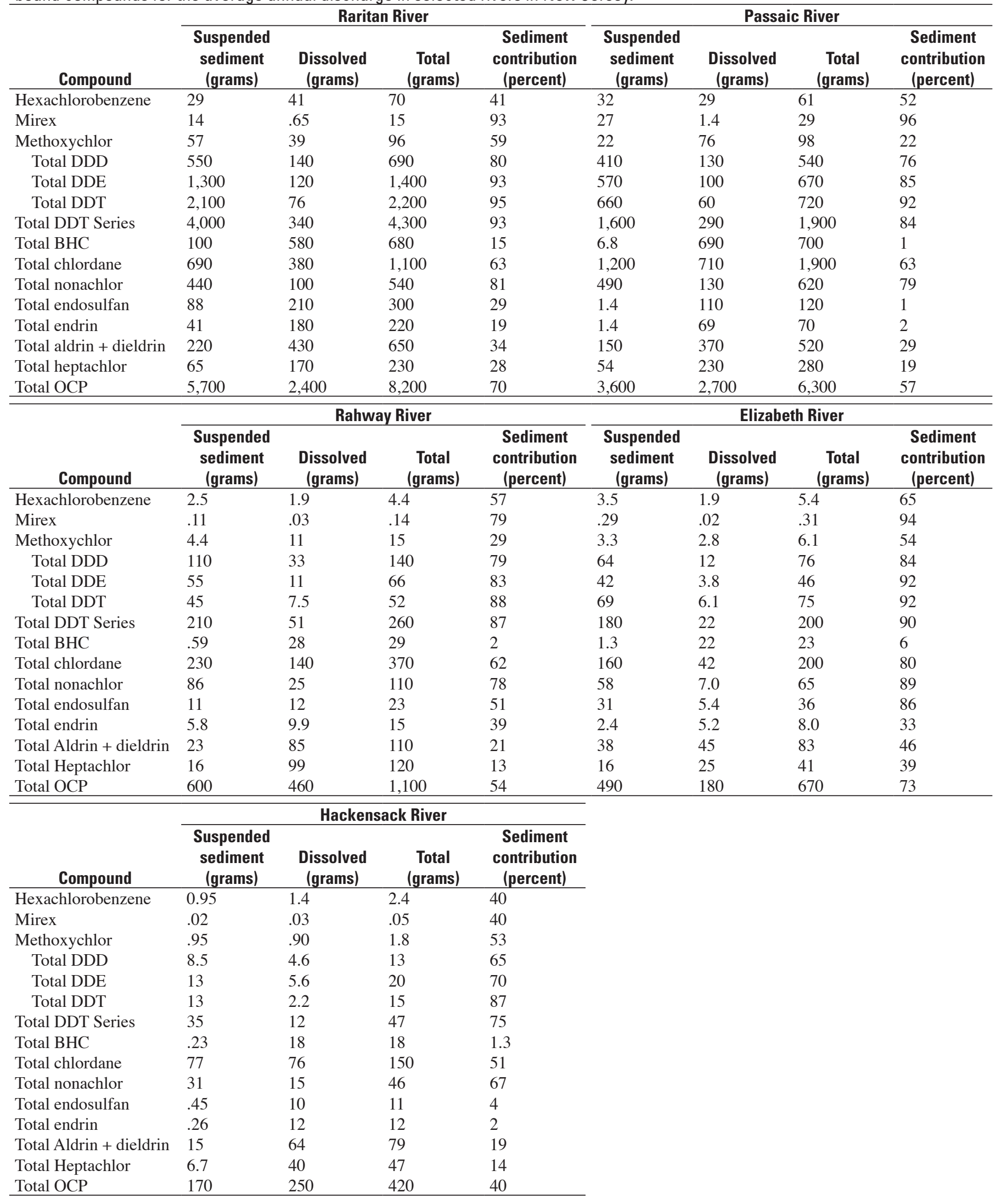




\section{Mercury, Cadmium, and Lead}

Loads calculated for the trace elements in the individual storms and low-flow events sampled in this study are presented in table 88 . These loads and the estimates of the annual and the average annual loads in the rivers (table 89) were calculated using the average whole-water (grab sample total concentration) chemical concentrations (table 53) and the average discharge (table 65). The average concentrations were calculated using the blank-eliminated data set for the grab samples; nondetected values were replaced by one-half the reported EDL.

For the storm events sampled (table 88), the composite sample concentrations result in loads of total $\mathrm{Hg}$ ranging from $10 \mathrm{~g}$ in the Elizabeth River up to $340 \mathrm{~g}$ in the Mar. 14, 2002 event on the Passaic River. Loads during low-flow discharge were much lower, ranging from $0.01 \mathrm{~g} / \mathrm{d}$ in the Hackensack River up to $52 \mathrm{~g} / \mathrm{d}$ in the Passsaic River. Generally, low-flow discharge loads are less than $2.5 \mathrm{~g} /$ day. The load of total $\mathrm{Pb}$ in the storm events ranged from 3,400 $\mathrm{g}$ in the Elizabeth River up to 79,200 $\mathrm{g}$ in the Passaic Riverr. Loads during low-flow discharge were lower then the storm load, ranging from 1.7 $\mathrm{g} / \mathrm{d}$ in the Hackensack River up to 5,800 g/d in the Passaic River. Loads of total $\mathrm{Cd}$ in the storms ranged from $64 \mathrm{~g}$ in the Elizabeth River up to 3,100 g in the Passaic River (Mar. 14, 2001). Loads for low-flow events ranged from $0.03 \mathrm{~g} / \mathrm{d}$ in the Hackensack River up to $98 \mathrm{~g} / \mathrm{d}$ in the Pasaic River. Generally, low-flow loads were less than $30 \mathrm{~g} /$ day.

The storm event loads correlate with the the volume of discharge that occurred during the event, which is a result of using whole-water concentrations and total volume of discharge to calculate the loads. As discussed earlier in this report, whole-water concentrations of trace compounds in rivers were related to the amount of suspended sediment that was captured in a sample. Because a "grab sample" of river water collected during a storm event can have a very wide range of suspended matter in it, estimates of loads can vary greatly from these values. The concentrations used in calculating these loads were from composite samples that likely were a more accurate representation of the average concentration in the stream.

The average annual discharge (table 89 ) predicts loads of total $\mathrm{Hg}$ estimated to range from $70 \mathrm{~g} / \mathrm{yr}$ in the Hackensack River up to $13,000 \mathrm{~g} / \mathrm{yr}$ in the Raritan River. Annual loads for total lead are much greater than for the other two elements (table 89), and range from 20 kilograms per year in the Hackensack River up to 3,400 kg/yr per in the Raritan River. Average annual loads for total Cd ranged from $260 \mathrm{~g} / \mathrm{yr}$ in the Hackensack River up to $88,000 \mathrm{~g} / \mathrm{yr}$ in the Passaic River. Although differences may occur depending upon variation in the yearly discharges in the each river basin, in general, the rivers can be ranked on the magnitude of the loads for total $\mathrm{Hg}$ and $\mathrm{Pb}$ :

- Hackensack $<$ Rahway $<$ Elizabeth $<$ Passaic $<$ Raritan
Alternatively, the annual loads can be calculated using the average concentrations of trace elements in the grab samples (table 53) or the concentrations predicted using the composite samples and unitless distribution coefficients (table 57), along with the annual discharge (table 65). This allows estimations to be made of the dissolved and particulate trace metal loads presented in table 90 . The total or whole-water loads are calculated as the sum of the dissolved and sediment-bound loads for comparision with the loads calculated using composite sample concentrations (table 89). Although differences existed for specific years, the average annual loads (table 90) calculated using the average concentrations (either measured in grab samples or predicted using Kd's) only roughly correspond to the the loads calculated using composite samples - typically differing by 50 to 100 percent. The sediment-bound trace element concentrations measured using the composite samples should be considered the most reliable in characterizing the loads transported in the rivers. Using these estimated average annual loads, the percent of each trace metal load associated with the sediment phase was calculated (table 91). Between 76 and 94 percent of the $\mathrm{Hg}$ load, 85 and 98 percent of the $\mathrm{Pb}$ load, and 34 to 79 percent of the $\mathrm{Cd}$ load was estimated to be transported by sediment in an average year.

\section{Summary and Conclusions}

A study was undertaken to measure the concentrations and loads of polychlorinated biphenyls (PCBs), dioxins, furans, polycyclic aromatic hydrocarbons (PAHs), organchlorine pesticides (OCPs), $\mathrm{Hg}, \mathrm{Cd}$, and $\mathrm{Pb}$ in the major tributaries to Newark and Raritan Bays, in northeastern New Jersey. Flow-weighted, large-volume (greater than $50 \mathrm{~L}$ ) composite samples of co-existing water and sediment in low-flow and storm discharge events were collected from above the head-oftide of the Raritan, Passaic, Rahway, Elizabeth, and Hackensack Rivers. Composite samples of suspended particulate matter were collected using filtration, and the dissolved phase was sampled using exchange resin. Samples for analysis of inorganic trace elements were collected using grab-sample and composite methods. Using these measured concentrations, and measured and historical data on the river discharge and concentrations of SS and dissolved and particulate organic carbon, the loads of these chemicals were estimated for the average annual river discharge and for selected water years. The findings of the study are summarized as follows.

\section{Polychlorinated Biphenyls}

1. PCBs were measured using U.S. Environmental Protection Agency (USEPA) method 1668-A (modified), which used high-resolution, gas chromatography/mass-spectrometry methods to analyze for 114 polychlorinated biphenyls (PCB) congeners. 


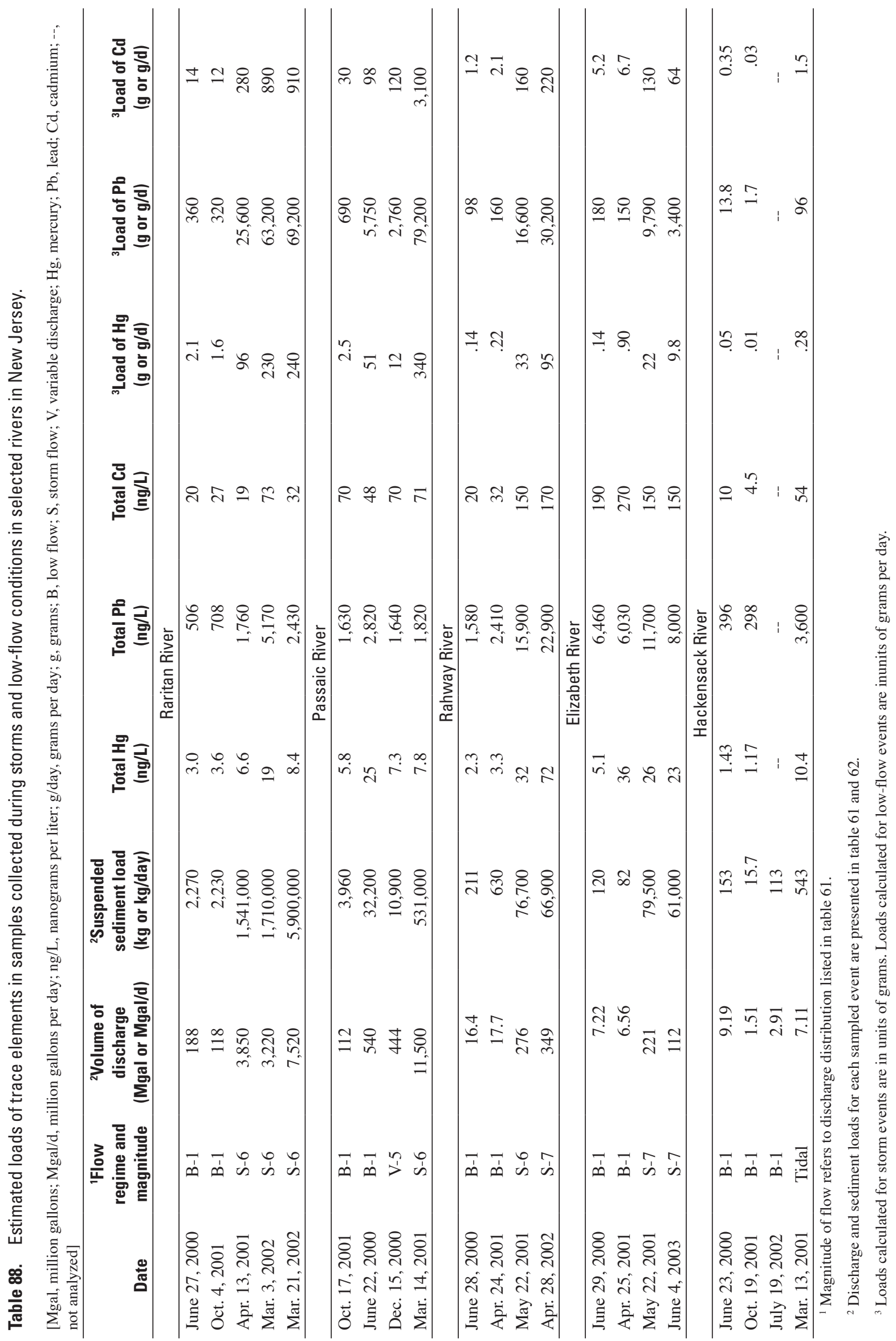


Table 89. Estimated loads of sediment-bound and dissolved total mercury, lead, and cadmium for water years 1988 through 2002, and for the average annual discharge in selected rivers in New Jersey.

\begin{tabular}{|c|c|c|c|c|c|c|c|c|}
\hline \multirow[b]{2}{*}{ River } & \multicolumn{8}{|c|}{ Load } \\
\hline & WY1988 & WY1994 & WY1998 & WY1999 & WY2000 & WY2001 & WY2002 & Average annual \\
\hline \multicolumn{9}{|c|}{ 'Total mercury, in grams } \\
\hline Raritan & 11,000 & 15,100 & 12,900 & 10,300 & 9,400 & 11,000 & 4,700 & 13,000 \\
\hline Passaic & 6,400 & 8,100 & 8,900 & 5,100 & 7,200 & 6,100 & 1,500 & 8,000 \\
\hline Rahway & 1,000 & 1,400 & 1,600 & 1,300 & 1,100 & 1,200 & 560 & 1,300 \\
\hline Elizabeth & 1,900 & 2,400 & 2,600 & 2,200 & 2,100 & 2,300 & 1,300 & 2,200 \\
\hline Hackensack & 21 & 64 & 76 & 39 & 37 & 65 & 1.0 & 70 \\
\hline Total & 20,000 & 27,000 & 26,000 & 19,000 & 20,000 & 21,000 & 8,000 & 25,000 \\
\hline \multicolumn{9}{|c|}{${ }^{1}$ Total lead, in kilograms } \\
\hline Raritan & 2,900 & 4,000 & 3,400 & 2,700 & 2,400 & 2,900 & 1,300 & 3,400 \\
\hline Passaic & 1,700 & 2,100 & 2,300 & 1,300 & 1,800 & 1,600 & 390 & 2,100 \\
\hline Rahway & 350 & 510 & 590 & 450 & 390 & 420 & 200 & 450 \\
\hline Elizabeth & 1,600 & 1,900 & 2,100 & 1,800 & 1,700 & 1,900 & 1,000 & 1,800 \\
\hline Hackensack & 5.9 & 19 & 22 & 11 & 11 & 19 & .31 & 20 \\
\hline Total & 6,600 & 8,500 & 8,400 & 6,300 & 6,300 & 6,800 & 2,800 & $\mathbf{7 , 8 0 0}$ \\
\hline \multicolumn{9}{|c|}{${ }^{1}$ Total cadmium, in grams } \\
\hline Raritan & 45,600 & 63,000 & 53,000 & 43,000 & 39,000 & 46,000 & 20,000 & 54,000 \\
\hline Passaic & 70,600 & 89,000 & 98,000 & 56,000 & 79,000 & 68,000 & 16,000 & 88,000 \\
\hline Rahway & 3,500 & 5,100 & 5,800 & 4,400 & 3,900 & 4,200 & 2,000 & 4,500 \\
\hline Elizabeth & 15,000 & 18,000 & 20,000 & 17,000 & 16,000 & 18,000 & 9,600 & 17,000 \\
\hline Hackensack & 77 & 240 & 280 & 150 & 140 & 250 & 4.0 & 260 \\
\hline Total & 135,000 & 175,000 & 177,000 & 121,000 & 138,000 & 136,000 & 47,600 & 164,000 \\
\hline
\end{tabular}

\footnotetext{
${ }^{1}$ Calculated using average concentrations in composite samples listed in table 53 and average annual discharge values from table 65.
}

Table 90. Estimated loads of sediment-bound mercury $(\mathrm{Hg})$, cadmium $(\mathrm{Cd})$, and lead $(\mathrm{Pb})$ for the average annual discharge in selected rivers in New Jersey, calculated using grab sample and predicted concentrations.

[g/yr, grams per year; $\mathrm{kg} / \mathrm{yr}$, kilograms per year]

\begin{tabular}{|c|c|c|c|c|c|c|c|c|c|}
\hline River & $\begin{array}{l}{ }^{1} \mathrm{dHg} \\
(\mathrm{g} / \mathrm{yr})\end{array}$ & $\begin{array}{l}{ }^{2} \mathrm{pHg} \\
(\mathrm{g} / \mathrm{yr})\end{array}$ & $\begin{array}{l}{ }^{3} \mathrm{tHg} \\
(\mathrm{g} / \mathrm{yr})\end{array}$ & $\begin{array}{c}{ }^{1} \mathrm{dPb} \\
(\mathrm{kg} / \mathrm{yr})\end{array}$ & $\begin{array}{c}{ }^{2} \mathrm{pPb} \\
(\mathrm{kg} / \mathrm{yr})\end{array}$ & $\begin{array}{c}{ }^{3} \mathrm{tPb} \\
(\mathrm{kg} / \mathrm{yr})\end{array}$ & $\begin{array}{l}{ }^{1} d C d \\
\text { (g/yr) }\end{array}$ & $\begin{array}{l}{ }^{2} \mathrm{pCd} \\
(\mathrm{g} / \mathrm{yr})\end{array}$ & $\begin{array}{c}{ }^{3} \mathrm{tCd} \\
(\mathrm{g} / \mathrm{yr})\end{array}$ \\
\hline \multicolumn{10}{|c|}{ Loads estimated using average grab-sample concentrations } \\
\hline Raritan & 2,000 & 17,000 & 19,000 & 270 & 4,500 & 4,800 & 17,800 & 61,000 & 79,000 \\
\hline Passaic & 1,030 & 15,000 & 16,000 & 320 & 2,700 & 3,000 & 45,000 & 23,000 & 68,000 \\
\hline Rahway & 140 & 460 & 600 & 61 & 350 & 410 & 830 & 3,100 & 3,900 \\
\hline Elizabeth & 170 & 1,100 & 1,300 & 43 & 390 & 430 & 2,800 & 5,200 & 8,000 \\
\hline \multicolumn{10}{|c|}{ Loads estimated using composite sample concentrations and unitless $\mathrm{Kd}$ values ${ }^{4}$} \\
\hline Raritan & 2,800 & 10,100 & 13,000 & 340 & 3,000 & 3,400 & 21,000 & 32,000 & 53,000 \\
\hline Passaic & 900 & 7,100 & 8,000 & 360 & 1,700 & 2,100 & 59,000 & 29,000 & 88,000 \\
\hline Rahway & 170 & 1,100 & 1,300 & 35 & 420 & 450 & 970 & 3,500 & 4,50 \\
\hline
\end{tabular}

${ }^{1}$ Dissolved loads calculated using average concentrations of grab samples from table 53 and average discharge from table 65.

${ }^{2}$ Particulate loads calculated using average particulate concentrations of grab samples from table 53, and sediment loads from table 67.

${ }^{3}$ Total loads are sum of dissolved and particulate loads estimated using grab sample concentrations from table 53

${ }^{4}$ Loads calculated using total concentrations from composite samples and unitless partition values, listed in table 57 
Table 91. Contribution of sediment-bound trace elements to the total load of trace metals for the average annual discharge in selected rivers in New Jersey.

[Values in percent of total mass; percent contributed by sediment calculated using loads in table 90 that were calculated using average concentration in grab samples listed in table 53]

\begin{tabular}{lccccc}
\hline $\begin{array}{c}\text { Trace } \\
\text { element }\end{array}$ & $\begin{array}{c}\text { Raritan } \\
\text { River }\end{array}$ & $\begin{array}{c}\text { Passaic } \\
\text { River }\end{array}$ & $\begin{array}{c}\text { Rahway } \\
\text { River }\end{array}$ & $\begin{array}{c}\text { Elizabeth } \\
\text { River }\end{array}$ & $\begin{array}{c}\text { Hackensack } \\
\text { River }\end{array}$ \\
\hline Mercury & 89 & 94 & 77 & 85 & 79 \\
Lead & 94 & 90 & 85 & 91 & 98 \\
Cadmium & 77 & 34 & 79 & 65 & 53 \\
\hline
\end{tabular}

2. Average concentrations of total dissolved PCBs ranked in the following order of increasing concentration (values in picograms per liter):

- Hackensack River (740 pg/L) < Raritan River (880) < Rahway River $(1,400)<$ Passaic River $(1,700)<$ Elizabeth River $(5,050)$

3. Average concentrations of sediment-bound total PCBs were ranked in the following order of increasing concentration (values in nanograms per gram):

- Raritan River (45 ng/g) < Hackensack River (89) < Passaic River (248)< Rahway River (420) < Elizabeth River $(2,460)$.

4. Whole-water concentrations (sediment plus dissolved fractions) for total PCBs exceeded the New Jersey surface freshwater criteria for carcinogenic human-health criteria in all rivers studied. Individual samples from the Passaic, Rahway, and Elizabeth Rivers exceeded the freshwater total PCB standard for aquatic life.

5. Differences were measured in the absolute and relative concentrations of dissolved and sediment-bound PCBs for base-flow and storm-discharge samples in all rivers. In the smaller Rahway and Elizabeth Rivers, the absolute concentrations of total PCBs in the suspended sediment decreased during storms; little change was observed in the suspended sediment PCB concentrations in the larger Passic River, while the concentrations increased in the Raritan River during storm events. In all four of the rivers, the relative proportion of each homolog group did not vary greatly between low-flow and high discharge samples. The suspended sediment in the tidally affected area just below the Oradell Dam was clearly different from the sediment released from the Oradell Reservoir. Changes in dissolved PCB concentrations were more difficult to characterize. Generally, concentrations of dissolved total PCBs declined during storms, except in the Raritan River where concentrations increased during storm events. In the Rahway and Elizabeth Rivers, the relative percentages of penta- and higher dissolved congeners increased during storms. The percentage of these homologs decreased in the Raritan and Passaic Rivers during storm events.

6. In general, the observed sediment-water partitioning agreed well with the partitioning predicted by octanolwater coefficients for the mono- through penta-homologs. However, measured ratios for the octa- through deca-chlorinated homologs were less than the respective octanolwater partitioning coefficients $\left(\mathrm{K}_{\mathrm{ow}}\right)$.

\section{Dioxin and Furans}

1. Seventeen 2,3,7,8-substituted chlorodibenzene-p-dioxin (CDD) and chlorodibenzene-p-furans (CDF) were measured in suspended sediment using USEPA Method 1613.

2. Average concentrations of total dioxins and furans ranged from 5,600 pg/g in the Hackensack River to 28,900 pg/g in the Elizabeth River and were ranked in the following order of increasing average concentration (values in picograms per gram):

- Hackensack River $(5,600$ pg/g) $<$ Passaic River $(11,500)$ $=$ Raritan River $(11,500)=$ Rahway River $(11,700)<$ Elizabeth River $(28,900)$.

3. The 2,3,7,8-TCDD whole-water concentration, calculated from the measured concentration and the average suspended-sediment concentration, exceeded the New Jersey fresh surface-water-quality criteria only for the samples from the Raritan River (Mar. 21, 2002), the Passaic River (June 22, 2000 and Dec. 15, 2000) and the Elizabeth River (June 4, 2003). In all other samples, this congener was not detected (below EDL concentration). However, with the exception of two samples from the Hackensack River, the EDL for 2,3,7,8-TCDD in all samples was above the water-quality criteria. Therefore, exceedances cannot be unequivocally ruled out using the data generated in this work.

4. The dioxin compounds were the largest contributors to the total $\mathrm{CDD} / \mathrm{CDF}$ content in all rivers, with mean values ranging from 91 to 98 percent of the total CDD+CDF concentrations. The highest concentrations were generally measured for the congeners OCDD, 1,2,3,4,6,7,8 HpCDD, OCDF, and occasionally 1,2,3,4,6,7,8-HpCDF.

5. The compound 2,3,7,8-TCDD (TEF=1) was measured in one sample from the Elizabeth River (12 pg/g) and in trace amounts in one sample from the Raritan River $(0.15$ $\mathrm{pg} / \mathrm{g}$ ) and one from the Passaic River (2.1 pg/g). Another sample from the Passaic River (collected Dec. 15, 2000) had a very high concentration of 2,3,7,8-TCDD (150 pg/ $\mathrm{g}$ ), the cause for which was unknown but may be related 
to the extremely high PCB concentrations that were also measured in this sample. 2,3,7,8-TCDD was not detected in any sample collected from the Rahway or Hackensack Rivers.

6. Other toxic congeners detected in the suspended sediment included 1,2,3,7,8-PeCDD ( $\mathrm{TEF}=1)$, at average concentrations of 1.8 to $31 \mathrm{pg} / \mathrm{g} ; 2,3,7,8-\mathrm{TCDF}(\mathrm{TEF}=0.1)$, at average concentrations of 7.7 up to $51 \mathrm{pg} / \mathrm{g}$; and 2,3,4,7,8$\mathrm{PeCDF}(\mathrm{TEF}=0.1)$ at average concentrations of 3.8 to $34 \mathrm{pg} / \mathrm{g}$. Averages for several of these congeners were skewed by the high percentage of nondetected values that were replaced by one-half the EDL values for the calculations. Generally, the highest concentrations of these toxic dioxins and furans were measured in the Elizabeth River.

7. Sediment toxicity, determined from toxicity equivalent quotients (TEQs), was present in the sediment from all rivers studied. Average total TEQ values for CDD plus CDF compounds ranged in the following order of increasing average TEQ value (values in picogram per gram as 2,3,7,8-TCDD):

- Raritan River (14) <Hackensack River (22) < Passaic River (28)< Rahway River (44) < Elizabeth River (135).

The major contributors to the sediment toxicity (as percentage of the total TEQ), in all rivers, are 1,2,3,7,8PentaCDD; 1,2,3,4,6,7,8-HeptaCDD; and 2,3,4,7,8PentaCDF. The contribution of several of the congeners (2,3,7,8-TCDD; 1,2,3,7,8-PeCDD; and 1,2,3,7,8,9$\mathrm{HxCDF}$ ) was skewed because of the replacement of a large number of nondetected values with one-half the reported EDLs before calculating the sediment toxicity.

8. Dioxin-like, co-planar PCBs also contributed toxicity to the sediment and average values were ranked in the following order (values in picogram per gram as 2,3,7,8TCDD):

- Hackensack River (5.3) < Raritan River (5.5) < Passaic River (11) <Rahway River (19) <Elizabeth River (66)

The PCB toxicity for average compositions ranged from 20 percent up to 33 percent of the total $\mathrm{CDD}+\mathrm{CDF}+\mathrm{PCB}$ toxicity values.

\section{Polycyclic Aromatic Hydrocarbons}

1. Polycyclic aromatic hydrocarbon (PAH ) compounds in water and sediment were measured using low-resolution GC/MS, isotope-dilution methods.

2. Dissolved PAH concentrations, measured in flowweighted composite samples (1 to $2 \mathrm{~L}$ total volume), were typically low in all rivers except the Elizabeth. However, dissolved concentrations were greatly affected by method and field blank contamination, and as a result, a large number of data points were culled from the useable data set. Average total dissolved PAH concentrations ranged from $180 \mathrm{ng} / \mathrm{L}$ in the Hackensack River to 9,500 ng/L in the Elizabeth River, and were ranked in the following order (values in nanograms per liter):

- Hackensack River (180) < Raritan River (360 ng/L) < Passaic River (660 ng/L) < Rahway River $(910$ ng/L) $<$ Elizabeth River $(9,500 \mathrm{ng} / \mathrm{L})$

3. Average sediment-bound total PAH concentrations ranged from 11,200 ng/g in the Raritan up to $129,000 \mathrm{ng} / \mathrm{g}$ in the Elizabeth River, and were ranked in the following order (values in nanograms per gram):

- Raritan River $(11,200)<$ Hackensack River $(14,700)<$ Passaic River $(17,600)<$ Rahway River $(28,000)<$ Elizabeth River $(129,000)$

4. Whole-water concentrations of several PAH compounds were found to exceed the New Jersey fresh surfacewater-quality human-health criteria in all rivers studied. Compounds found to exceed the criteria in more than 50 percent of the samples included benzo(a)anthracene, benzo(b)fluoranthene, benzo(k)fluoranthene, benzo(a)pyrene, indeno(1,2,3-cd)pyrene, pyrene, and $\operatorname{dibenz}(\mathrm{a}, \mathrm{h})$ anthracene.

5. Heavy molecular weight compounds (MW greater than 202) are the dominant PAH compounds (by weight) in the suspended-sediment fraction. On a molecular scale, the Passaic, Rahway, Hackensack, and Raritan Rivers (without the sample collected on June 22, 2000) were dominated by fluoranthene, pyrene, and chrysene, followed by the other heavy molecular weight compounds.

6. Ratios of indicator PAH compounds suggested a mix of pyrogenic, petrogenic, and diagenetic sources affected the river sediment. The dominant processes were pyrogenic, and the ratios of indicator PAHs indicated grass/wood/ coal combustion, and in some cases, fossil-fuel (petroleum) combustion. However, the presence and dominance of alkylated-napthalenes and alkyl-phenanthrene homologs support the conclusion that petrogenic sources of PAHs also were present in the basins. The detection of perylene in the sediment was interpreted as showing diagenetic sources (anaerobic degradation of organic matter) also were present in the river basins.

7. Sediment-water partitioning was investigated to the extent that the limited number of dissolved concentrations would allow. A large range of concentration ratios were observed for each compound, indicating the PAHs were not at concentrations predicted by empirical equations describing equilibrium partitioning. 


\section{Organochlorine Pesticides}

1. Dissolved and suspended sediment bound organochlorine pesticides (OCPs) were measured with an isotope dilution method using high resolution GC/MS for analysis, based on methods adapted from the PCB analysis. Difficulties were found with the recoveries for several IS compounds in the sediment fraction, including the labeled IS for endosulfan and $\alpha$-BHC. These difficulties in turn caused difficulties in quantifying the corresponding native compounds along with native endrin, dieldrin, and heptachlor epoxide in the sediment samples.

2. Average dissolved total organochlorine pesticide concentrations were ranked in the following order (values in nanograms per liter):

Raritan River (2.3)<Passaic River (2.9)<Hackensack River (4.8)<Elizabeth River (7.6)<Rahway River (9.5).

3. Average suspended sediment-bound total pesticide concentrations were ranked in the following order (values in nanograms per gram):

- Raritan River (60)<Passaic River (140)<Hackensack River $(420)<$ Rahway River $(670)<$ Elizabeth River $(1,170)$.

4. Whole-water concentrations of OCPs exceeded the New Jersey fresh surface-water-quality standards for $4,4^{\prime}$ DDD, 4,4'-DDE, and 4,4'-DDT in all of the Elizabeth and Rahway River samples, most of the Passaic River samples, and some of the samples from the other rivers.

5. In the dissolved phase, the chlordane series was usually dominant, representing up to 30 percent of the total pesticide concentration in the Rahway and Hackensack Rivers. In the Raritan and Passaic Rivers, the BHC series of pesticides was dominant, representing roughly 25 percent of the total concentration. The second most abundant OCP in the rivers was dieldrin, which constituted 13 to 25 percent of the total OCP concentration. In all rivers the DDT series (DDD, DDE, and DDT) represented 5 to 14 percent of the total pesticide content.

6. In the sediment phase in most of the rivers (and particulary the sediment from the Raritan River), the DDT series was the dominant species representing 20 to 70 percent of the total pesticide concentration, followed by the chlordane series, which accounted for 10 to 45 percent of the total pesticide concentration. The chlordane series dominates in the Hackensack River, followed by the total DDT series. Dieldrin represented 4 to 8 percent of the total in all rivers.

7. Concentrations of total pesticides in suspended-sediment in the Raritan, Passaic, Rahway, and Elizabeth Rivers were generally lower during storm events than in low- flow. Cocentrations of total dissolved pesticides generally remained the same in storm and low-flow.

8. The distribution coefficients for samples having dissolved and sediment-bound concentrations were calculated. Distribution coefficients normalized to sediment carbon content $\left(\mathrm{K}_{\mathrm{oc}}\right)$ were generally larger than published octanol-water partitioning coefficients $\left(\mathrm{K}_{\mathrm{ow}}\right)$ or published $\mathrm{K}_{\mathrm{oc}}$ values for most compounds.

\section{Mercury, Cadmium, and Lead}

1. Grab and composite samples were measured using ICPmass spectrometry (USEPA Method 1638) for cadmium $(\mathrm{Cd})$ and lead $(\mathrm{Pb})$, and cold-vapor atomic fluorescence spectrometry (USEPA Method 1631B and 1630) for mercury $(\mathrm{Hg})$ and methyl-Hg. Composite samples were analyzed only for total (whole water) concentrations.

2. Although some differences existed for specific metals, concentrations of total $\mathrm{Hg}, \mathrm{Pb}$, and $\mathrm{Cd}$ in the rivers generally were generally ranked in the order (values in nanograms per liter):

- tHg: Hackensack River (1.30)<Raritan River (8.04)<Passaic River (11.6)<Elizabeth River (22.5)<Rahway River (27.5)

- tPb: Hackensack River (350)<Passaic River $(1,980)<$ Raritan River $(2,120)<$ Elizabeth River $(8,050)<$ Rahway River $(10,700)$

- tCd: Hackensack River (7.4)<Raritan River (34.0)<Passaic River (64.5)<Rahway River (92.5)<Elizabeth River (190)

The Human Health Freshwater Criteria for total Hg was rarely exceeded in all of the rivers. The total $\mathrm{Pb}$ criteria was frequently exceeded in the Elizabeth River and was exceeded during storm events in the Rahway River.

3. Average concentrations of dissolved $\mathrm{Cd}$ in grab samples ranged from $4.7 \mathrm{ng} / \mathrm{L}$ in the Hackensack River to $118 \mathrm{ng} / \mathrm{L}$ in the Elizabeth. Average concentrations were ranked in the following order (values in nanograms per liter):

- Hackensack River (4.7)<Raritan River (16.9)=Rahway River (17.0)<Passasic River (47.7)<Elizabeth River (118)

4. Average concentrations of particulate $\mathrm{Cd}$ in grab samples ranged from $0.65 \mathrm{ng} / \mathrm{g}$ in the Hackensack River, up to $12.5 \mathrm{ng} / \mathrm{g}$ in the Elizabeth River and were ranked in the following order (values in nanograms per gram):

- Hackensack River (0.65)=Raritan River $(0.66)<$ Passaic River (0.99)<Rahway River (3.49)<Elizabeth River (12.5) 
5. Average concentrations of dissolved $\mathrm{Pb}$ in grab samples ranged from $21.1 \mathrm{ng} / \mathrm{L}$ in the Hackensack River up to $1,840 \mathrm{ng} / \mathrm{L}$ in the Elizabeth River and were ranked in the following order (values in nanograms per liter):

- Hackensack River (21.1)<Raritan River (254)<Passaic River $(341)<$ Rahway River $(1,240)<$ Elizabeth River $(1,840)$

The Aquatic Chronic Water Quality criteria for dissolved $\mathrm{Pb}$ was not exceeded in any of the samples.

6. Average concentrations of particulate-bound $\mathrm{Pb}$ in grab samples ranged from $48.1 \mathrm{ug} / \mathrm{g}$ in the Raritan River up to $933 \mathrm{ug} / \mathrm{g}$ in the Elizabeth River and were ranked in the following order (values in micrograms per gram):

- Raritan River (48.1)<Passaic River (118)< Hackensack River (123)<Rahway River (395)<Elizabeth River (933)

7. Average concentrations of dissolved $\mathrm{Hg}$ in grab samples ranged from $0.57 \mathrm{ng} / \mathrm{L}$ in the Hackensack River up to 7.1 $\mathrm{ng} / \mathrm{L}$ in the Elizabeth River and were ranked in the following order (values in nanograms per liter):

- Hackensack River (0.57)<Passaic River (1.08)<Raritan River (1.90)<Rahway River (2.93)<Elizabeth River (7.13)

The Aquatic Chronic Water Quality criteria for dissolved $\mathrm{Hg}$ was not exceeded in any of the samples.

8. Average concentrations of particulate-bound $\mathrm{Hg}$ in grab samples ranged from $0.187 \mathrm{ng} / \mathrm{g}$ in the Raritan River up to $2.54 \mathrm{ng} / \mathrm{g}$ in the Elizabeth River and were ranked in the following order (values in nanograms per gram):

- Raritan River $(0.187)<$ Hackensack River $(0.283)<$ Rahway River $(0.526)<$ Passaic River $(0.649)<$ Elizabeth River (2.54)

9. Average concentrations of dissolved $\mathrm{Me}-\mathrm{Hg}$ in grab samples ranged from $0.01 \mathrm{ng} / \mathrm{L}$ in the Hackensack River up to $0.96 \mathrm{ng} / \mathrm{L}$ in the Rahway River and were ranked in the following order (values in nanograms per liter):

- Hackensack River $(0.01)<$ Elizabeth River $(0.050)<$ Passaic River (0.067)<Raritan River (0.079)<Rahway River (0.096)

Only a few grab samples were available to determine particulate $\mathrm{Me}-\mathrm{Hg}$. Concentrations of $\mathrm{Me}-\mathrm{Hg}$ ranged from $4.1 \mathrm{ng} / \mathrm{g}$ in the Raritan River up to $20 \mathrm{ng} / \mathrm{g}$ in the Hackensack River and were ranked in the following order (values in nanograms per gram):

- Raritan River (4.1)<Passaic River (4.8)<Elizabeth River (5.2)<Rahway River (13.1)<Hackensack River (20)
10. Sediment water partitioning coefficients were calculated for grab samples having dissolved and sediment-bound metals. Values were not constant within or between rivers, but for $\mathrm{Hg}$, were within the range of partitioning values reported in other published studies.

\section{Sediment and Carbon Loads}

1. Multiple samples of sediment (SS), dissolved organic carbon (DOC), and particulate organic carbon (POC) were collected from the Raritan, Passaic, Rahway, Elizabeth, and Hackensack Rivers during low-flow and storm discharge conditions to provide concentrations required to calculate loads of these constituents during the sampled events.

2. Two types of hydrologic response were observed in the discharge and sediment concentrations in the rivers during storms. In the larger basins of the Raritan and Passaic Rivers, the storm hydrographs were observed to rise and fall slowly, typically over days. Sediment concentrations would typically peak before peak discharges on these rivers; POC concentrations commonly would lag behind the peak in discharge. In the smaller Rahway and Elizabeth River Basins, the storm hydrograph had multiple rises in discharge that typically would last for several hours or less. Sediment and POC concentrations in these rivers would typically peak before discharge but in later discharge peaks, would commonly not increase. The discharge in the Hackensack River was controlled in large part by releases from the Oradell Reservoir, which commonly were initiated before the onset of precipitation.

3. Because of the limited number of events that were ultimately sampled, the rating-curve method was used to calculate yearly loads of SS, POC, and DOC. Rating curves were produced using historic USGS water-quality and mean daily discharge data for each river and were used to estimate loads of sediment, particulate organic carbon, and dissolved organic carbon during selected water years and for the average yearly load over the period 1975 to 2000. Comparison of loads calculated using the rating curve to loads measured during the sampled storm events indicated rating curves are likely to underestimate the actual annual loads.

4. Sediment loads during an "average" year ranged from 0.395 million kilograms per year for the Hackensack River up to 93.1 million kilograms per year for the Raritan and were ranked in the following order (values in million kilograms per year):

- Hackensack River (0.395)<Elizabeth River (0.417)<Rahway River (0.882)<Passaic River (22.7) $<$ Raritan River (93.1). 
5. Loads of particulate organic carbon during an "average" year ranged from $14,400 \mathrm{~kg} / \mathrm{yr}$ in the Elizabeth up to $866,000 \mathrm{~kg} / \mathrm{yr}$ in the Raritan River, and were ranked in the following order (values in kilograms per year):

- Elizabeth River $(14,400)<$ Rahway River $(64,800)$ $<$ Passaic River $(589,000)<$ Raritan River $(866,000)$

A rating curve could not be produced for $\mathrm{POC}$ in the Hackensack River. Assuming an average concentration of $2 \mathrm{mg} / \mathrm{L}$ for POC resulted in an estimated average yearly POC load of $113,000 \mathrm{~kg} / \mathrm{yr}$.

6. Loads of dissolved organic carbon during an average year were calculated and ranged from $89,000 \mathrm{~kg} / \mathrm{yr}$ in the Elizabeth River, up to 4,260,000 kg/yr in the Passaic River, and were ranked in the following order (values kilograms per liter):

- Elizabeth River $(89,000)<$ Rahway River $(205,000)$ $<$ Raritan River $(4,190,000)<$ Passaic River $(4,260,000)$

A rating curve for DOC could not be produced for the Hackensack River. Assuming an average concentration of $3.8 \mathrm{mg} / \mathrm{L}$ for DOC resulted in an estimated average yearly load of $215,000 \mathrm{~kg} / \mathrm{yr}$.

\section{Chemical Loads}

1. Estimations were made of the loads of selected organic chemicals and metals at the head-of-tide of the major tributaries to Newark and Raritan Bays. Loads were calculated for the storm and base-flow events sampled in this work, using flow-weighted average concentrations for the chemicals of concern, sediment, and carbon.

2. Estimates of long-term loads of chemicals were made using historic river discharge measurements collected for the period 1975 to 2000 , along with the sediment and carbon loads estimated using rating curves prepared using water-quality data collected by the USGS. The average annual discharge and sediment loads (for the period 1975 to 2000) were combined with the average present-day concentrations of chemicals generated in this work, to estimate chemical loads for the rivers studied. The sediment and discharge estimates also allowed loads to be calculated for specific water years of interest.

3. Estimates of loads for PCBs, dioxins-furans, PAHs, OCPs, and $\mathrm{Hg}, \mathrm{Cd}$, and $\mathrm{Pb}$ are presented for selected water years, and for the average annual discharge in the rivers (on the basis of the 1975-2000 yearly discharge records). The general ranking by increasing magnitude of total chemical load (dissolved load plus sediment-bound load) for the average annual discharge (over the period 1975-2000) for the chemical groups studied here are (values in kilograms per year of total PCB):

Hackensack River (74) $<$ Rahway River (440) $<$ Elizabeth River $(1,100)<$ Raritan River $(5,000)<$ Passaic River $(7,200)$

Of these loads, sediment-bound PCBs represented between 47 and 90 percent of the total load. In the Hackensck River, the sediment-bound contribution was lowest (47 percent), likely because of sediment trapping in the Oradell Reservoir. However, the mass contributed by sediment varied greatly by congener and homolog group.

For sediment-bound dioxin and difurans (values in grams per year):

- Hackensack River (2.2) <Rahway (10)<Elizabeth River $(12)<$ Passaic River $(260)<$ Raritan River $(1,070)$

The largest proportion of the dioxin-difuran mass was due to the octa-chlorinated dioxin/difuran congeners.

The dioxin-like co-planar PCBs (values in grams per year):

- Hackensack River (3.6)< Rahway River (37)<Elizabeth River (110) < Raritan River (490) < Passaic River (570)

For total TEQ due to dioxins and furans (values in milligrams per year as 2,3,7,8-TCDD):

- Hackensack River (9) <Rahway River (39)< Elizabeth River (56) <Passaic River (640) < Raritan River $(1,300)$

For TEQ due to dioxin-like co-planar PCBs (values in milligrams per year):

- Hackensack River (2) <Rahway River (17)<Elizabeth River (28)< Passaic River (250) < Raritan River (510)

Total TEQ due to dioxins, furans, and co-planar PCBs (values in milligrams per year):

- Hackensack River (11) < Rahway River (56) < Elizabeth River (84) < Passaic River (890) < Raritan River $(1,800)$

Approximately 18 to 33 percent of the total TEQ load resulted from the co-planar, dioxin-like PCBs.

For total PAHs in the average annual discharge (values in kilograms per year):

- Hackensack River (15) < Rahway River (69) <Elizabeth River $(270)<$ Passaic River $(1,000)<$ Raritan River $(1,400)$

Between 20 and 71 percent of these estimated loads were calculated to be associated with suspended sediment. However, the mass contributed by sediment varied greatly by chemical - generally the HMW compounds were associated with the sediment phase, and the LMW compounds with the aqueous phase. A large percentage of the low-weight dissolved PAH compounds had non-detectable concentrations; loads for these compounds were set by the use of estimated detection levels. 
For total OCPs in the average annual discharge (values in grams per year):

- Hackensack River (420) < Elizabeth River (680) < Rahway River $(1,100)<$ Passaic River $(6,400)<$ Raritan River $(6,600)$

Between 40 and 74 percent of these total estimated loads were calculated to be associated with suspended sediment. However, the mass contributed by sediment varied greatly by chemical.

For total $\mathrm{Hg}$ (values in kilograms per year), the average annual loads were estimated to be:

- Hackensack River (0.073) < Rahway River (1.3) < Elizabeth River (2.2) < Passaic River (8.0) < Raritan River (13)

Using data from grab samples, it was estimated that between 76 and 94 percent of the total $\mathrm{Hg}$ load was associated with sediment.

For total $\mathrm{Pb}$ (values in kilograms per year), the average annual loads were estimated to be:

- Hackensack River (20) <Rahway River (450) < Elizabeth River $(1,800)<$ Passaic River $(2,100)<$ Raritan River $(3,400)$

Between 85 and 98 percent of the total $\mathrm{Pb}$ load was estimated to associated with sediment

For total Cd (values in kilograms per year), the average annual loads were estimated to be:

- Hackensack River (0.26) < Rahway River (4.5) <Elizabeth River (17) < Raritan River (54) < Passaic River (88)

Between 33 and 79 percent of the total cadmium load was estimated to be associated with sediment.

\section{Acknowledgments}

The authors thank Nicholas Smith of the USGS for assistance with sampling; Joel Pecchioli, Floyd Genicola, and Gary Buchanan of the New Jersey Department of Environmental Protection for program coordination and review; David Thal of STL Laboratories, Knoxville Tennessee for guidance in chemical analysis protocols; and Scott Douglas of the New Jersey Department of Transportation for guidance in program development.

\section{References Cited}

Aguillar, A., 1984, Relationship between DDE/DDT in marine mammals to the chronology of DDT input to the ecosystem: Canadian Journal of Fisheries and Aquatic Sciences, v. 41, p. 840-844.
Albarede, Frances, 1995, Introduction to geochemical modeling: New York, Cambridge University Press, 543 p.

Albrecht, I.D., Barkovskii, A.L., and Adriaens, Peter, 1999, Production and dechlorination of 2,3,7,8-tetrachlorodibenzo-p-dioxin in historically-contaminated estuarine sediments: Environmental Science and Technology, v. 33, no. 5, p. 737-744.

Allan, R.J., 1983, The role of particulate matter in the fate of chemicals in aquatic ecosystem: Part I, Transport and burial: Second Water Management Symposium, Chisholm Institute of Technology, Melbourne, Australia, 53 p.

Babiarz, C.L., Hurley, J.P., Hoffmann, S.R., Andren, A.W., Shafer, M.M., and Armstrong, D.E., 2001, Partitioning of total mercury and methylmercury to the colloidal phase in freshwater: Environmental Science and Technology, v. 35, no. 24 , p. 4773-4782.

Barkovskii, A.L., and Adriaens, Peter, 1996, Microbial dechlorination of historically present and freshly spiked chlorinated dioxins and diversity of dioxin-dechlorinating populations: Applied and Environmental Microbiology, v. 62 , no. 12 , p. $4556-4562$.

Boehm, P.D., Page, D.S., Gilfillan, E.S., Bence, A.E., Burns, W.A., and Mankiewicz, P.J., 1998, Study of the fates and effects of the Exxon Valdez oil spill on benthic sediments in two bays in Prince William Sound, Alaska-1. Study design, chemistry, and source fingerprinting: Environmental Science and Technology, v. 32, no. 5, p. 567-576

Bonin, J.L., and Wilson, T.P. (2006). Organic compounds, trace elements, suspended sediment, and field characteristics at the heads-of-tide of the Raritan, Passaic, Hackensack, Rahway, and Elizabeth Rivers, New Jersey, 2000-03: U.S. Geological Survey Data File Series D-123, 32 p. plus CD.

Bopp, R.F., Gross, M.L., Tong, H., Simpson, H.J., Monson, S.J., Deck, B.L., and Moser, F.C., 1991, A major incident of dioxin contamination-Sediments of New Jersey estuaries: Environmental Science and Technology, v. 25, no. 5, p. 951-956.

Bradu, D., and Mundlak, Y., 1970, Estimation in lognormal linear models: Journal of the American Statistical Association, v. 65, no. 329, p. 198-211.

Brooks, G.T., 1979, Chlorinated insecticides, vol. I: Boca Raton, Fla., CRC Press, 450 p.

Brown, J.F., Bedard, D.L., Brennan, M.J., Carnahan, J.C., Feng, H., and Wagner, R.E., 1987, Polychlorinated biphenyl dechlorination in aquatic sediments: Science, v. 236, p. 709-712. 
Bumard, P., Budzinski, H., and Garrigues, P., 1998, Polycyclic aromatic hydrocarbons in sediments and mussels of the Western Mediterranean Sea: Environmental Toxicology and Chemistry, v. 17, p. 765-776.

Burkhardt, M.R., Kammer, J.A., Jha, V.K., O. Mara-Lopez, P.G., and Woodworth, M.T., 1997, Methods of analysis by the U.S. Geological Survey National Water Quality Laboratory-Determination of nonpurgeable suspended organic carbon by wet-chemical oxidation and infrared spectrometry: U.S. Geological Survey Open-File Report 97-380, 12 p.

Butcher, J.B., Garvey, E.A., and Bierman Jr., V.J., 1998, Equilibrium partitioning of PCB congeners in the water column-Field measurements from the Hudson River: Chemosphere, v. 36 , no. 15 , p. 3149-3166.

Cai, Y., Jaffe, R., and Jones, R.D., 1999, Interactions between dissolved organic carbon and mercury species in surface waters of the Florida Everglades: Applied Geochemistry, v. 14 , p. 395-407.

California Environmental Protection Agency-Air Resource Board, 1997, California Environmental Protection Agency Air Resources Board Method 429, Determination of polycyclic aromatic hydrocarbons (PAH) emissions from stationary sources: Sacramento, Calif.

Chaky, D.A., 2003, Polychlorinated biphenyls, polychlorinated dibenzo-p-dioxins and furans in the New York metropolitan area-Interpreting atmospheric deposition and sediment chronologies: unpublished Ph.D. dissertation, Troy, N.Y., Rensselaer Polytechnic Institute, 431 p.

Cleverly, D., Schaum, J., Schweer, G., Becker, J., and Winters, D., 1997, The congener profiles of anthropogenic sources of chlorinated dibenzo-p-dioxins and chlorinated dibenzofurans in the United States: Organohalogen Compounds, v. 32 , p. 430-435.

Cohn, T.A., DeLong, L.L., Gilroy, E.J., Hirsch, R.M., and Wells, D.K., 1989, Estimating constituent loads: Water Resources Research, v. 25, no. 5, p. 937-942.

Ehrlich, R., Wenning, R.J., Johnson, G.W., Su, S.H., and Paustenbach, D.J., 1994, A mixing model for polychlorinated dibenzo-p-dioxins and dibenzofurans in surface sediments from Newark Bay, New Jersey, using polytropic vector analysis: Archives of Enviromental Contamination Toxicology, v. 27, p. 486-500.

Erickson, M.D., 1997, Analytical chemistry of PCB's (2d ed.): Boca Ratan, Fla., CRC Press, 667 p.

Ferguson, R.I., 1986, River loads underestimated by rating curves: Water Resources, v. 22, no. 1, p. 74-76.

Ferguson, R.I., 1987, Accuracy and precision of methods for estimating river loads: Earth's Surficial Processes and Landforms, v. 12, p. 95-104.
Fernandez, M.P., Ikonomou, M.G., Courtenay, S.C., and Wirgin, I.I., 2004, Spatial variation in hepatic levels and patterns of PCBs and PCDD/Fs among the young-of-year and adult Atlantic Tomcod (Microgadus tomcod) in the Hudson River: Environmental Science and Technology, v. 38, no. 4, p. 976-983.

Fiedler, H., Lau, C., Cooper, K., Andersson, R., Kulp, S.E., Rappe, C., Howell, F., and Bonner, M., 1995, PCDD/PCDF levels in sediments from a river system in southern Mississippi: Organohalogen Compounds, v. 24, p. 349-352.

Finney, D.J., 1941, On the distribution of a variate whose logarithm is normally distributed; Journal Research of the Statistical Society Supplement, v. 7, p. 155-161.

Forstner, U., and Wittmann, G.T.W., 1983, Metal pollution in the aquatic environment, (2d ed.): New York, N.Y, SpringerVerlag, $486 \mathrm{p}$.

Fry, D.M., and Toone, C.K., 1981, DDT-induced feminization of gull embryos: Science, v. 213, p. 922-924.

Gillis, C.A., Bonnevie, N.L., Su, S.H., Ducey, J.G., Huntley, S.L., and Wenning, R.J., 1995, DDT, DDD, and DDE contamination of sediment in the Newark Bay Estuary, New Jersey: Archives of Environmental Contaminant Toxicology, v. 28, p. 85-92.

Gunther, F.A., and Gunther, J.D., 1971, Residues of pesticides and other foreign chemicals in foods and feeds: Residue Reviews, v. 36, p. 69-77.

Hagenmaier, H., Lindig, C., and She, J., 1994, Correlation of environmental occurrence of polychlorinated dibenzop-dioxins and dibenzo-p-furans with possible sources: Chemosphere, v. 29, no. 9 to 11, p. 2163-2174.

Hansen, L.G., 1999, The ortho-side of PCBs, occurrence and disposition: Boston, Mass., Kluwer Academic Publishers, 269 p.

Hay, R.W., 1984, Bio-inorganic chemistry: Chichinster, U.K., Ellis Horwood Limited, 210 p.

Hites, R.A., Laflamme, R.E., and Windsor, J.G., 1980, Polycyclic aromatic hydrocarbons in marine aquatic sediments - Their ubiquity, in Petrakis, L., and Weiss, F.T., eds., Petroleum in the marine environment: American Chemical Society Advances in Chemistry Series 185, p. 289-311.

Hydroqual, 2000, A model for the evaluation and management of contaminants of concern in water, sediment, and biota in the NY/NJ Harbor estuary: Unpublished proposal to the NY-NJ Harbor Estuary Plan, September 8, 2000. 
Johnson, A., Norton, D., and Yake, B., 1988, Persistence of DDT in the Yakima River drainage, Washington: Archives of Environmental Contamination and Toxicology, v. 17, p. 289-297.

Karickhoff, S.W., 1981, Semi-empirical estimation of sorption of hydrophobic pollutants on natural sediments and soils: Chemosphere, v. 10, no. 8, p. 833-846.

Khalili, N.R., Scheff, P.A., and Holsen, T.M., 1995, PAH source fingerprinting for coke ovens, diesel and gasoline engines, highway tunnels, and wood combustion emissions: Atmospheric Environment, v. 29, p. 533-542.

Koch, R.W., and Smillie, G.M., 1986, Bias in hydrologic prediction using log-transformed regression models: Water Resources Bulletin, v. 22, no. 5, p.717-723.

Laflamme, R.E., and Hites, R.J., 1978, The global distribution of polycyclic aromatic hydrocarbons in recent sediments: Geochimica et Cosmochimica Acta, v. 42, p. 289-303.

Landwehr, J.M., 1978, Some properties of the geometric mean and its use in water quality standards: Water Resources Research, v. 14, no. 3, 467-473.

Larson, S.J., Capel, P.D., and Majewski, M.S., 1999, Pesticides in surface waters, Distribution, trends, and governing factors: Chelsea, Mich.,Ann Arbor Press, 373 p.

Litten, S., 2003, Contaminant Assesment and Reduction Project, CARP, New York State Department of Environmental Conservation, Bureau of Water Assessment and Management, Division of Water, $158 \mathrm{p}$.

Litten, S., Fowler, B.I., and Luszniak, D., 2002, Identification of a novel PCB source through analysis of 209 PCB congeners by USEPA modified method 1668: Chemosphere, v. 46, p. $1457-1459$.

Mackay and others, 2000, Physical-Chemical Properties and Environmental Fate Handbook CRCnetBASE2000: Boca Ratan, Fla., CRC Press, 4451 p.

Means, J.C., Wood., S.G., Hassett, J.J., and Banwart, W.L., 1980, Sorption of polynuclear aromatic hydrocarbons by sediment and soils: Environmental Science and Technology, v. 14 , no. 12 , p 1524-1528.

Morrison, R.T., and Boyd, R.N., 1987, Organic chemistry (5th ed.): Boston, Mass., Allyn and Bacon, Inc., 1434 p.

Naf, C., Broman, D., Petterson, H., Rolff, C., and Zebuhr, Y., 1992, Dioxin degradation: Environmental Science and Technology, v. 26, p. 1444-1457.
New Jersey Department of Environmental Protection, 2001, New Jersey Toxics Reduction Workplan (NJTRWP) and Standard Operating Procedures (SOP) NJTRWP-01, Rev. 1.0, March 2, 2001: New Jersey Department of Environmental Protection, $112 \mathrm{p}$.

New York/ New Jersey Harbor Estuary Program Final Comprehensive Conservation and Management Plan, March 1996.

Rappe, C., Bergqvist, P.A., Kjeller, L.O., and Swanson, S., 1991, Levels and patterns of PCDD and PCDF contamination in fish, crabs, and lobsters from Newark Bay and the New York Bight: Chemosphere, v. 22, no. 3-4, p. 239-266.

Safe, S., 1990, Polychlorinated biphenyls (PCBs), polychlorinated dibenzo dioxins (PCDD), polychlorinated dibenzo furans (PCDF), and related compounds-Environmental and mechanistic considerations which support the development of toxic equivalency factors: Critical Reviews in Toxicology, v. 21, no. 1, p. 51-88.

Schwarzenbach, R., Gschwend, P.M., and Imboden, D.M., 1993, Environmental organic chemistry: New York, N.Y. John Wiley and Sons, Inc., 681 p.

Sholar, C.J., and Shreve, E.A., 1998, Quality-assurance plan for the analysis of fluvial sediment by the Northeastern Region: U.S. Geological Survey Open-File Report 98-384, $20 \mathrm{p}$.

Simpson, C.D., Mosi, A.A., Cullen, W.R., and Reimer, K.J., 1996, Composition and distribution of polycyclic aromatic hydrocarbon contamination in surficial marine sediments from Kitimat Harbor, Canada: The Science of the Total Environment, v. 181, p. 265-278.

Smicik, M.F., Eisenreich, S.J., Golden, K.A., Liu, S.P., Lipiatou, E., Swackhammer, D.L., and Long, D.T., 1996, Atmospheric loading of polycyclic aromatic hydrocarbons to Lake Michigan as recorded in the sediments: Environmental Science and Technology, v. 30, no. 10, p. 3039-3046.

Sporsto., S., Gjos, N., Lichtenthaler, R.G., Gustavsen, K.O., Urdal, K., and Oreld, F., 1983, Source identification of aromatic hydrocarbons in sediments using GC/MS: Environmental Science and Technology, v. 17, no. 5, p. 282-286.

Steel, R.G.D., and Torrie, J.H., 1980, Principles and procedures of statistics, a biometrical approach (2nd ed.): New York, N.Y., McGraw-Hill Book Company, 633 p.

Steinhauer, M.S., and Boehm, P.D., 1992, The composition and distribution of saturated and aromatic hydrocarbons in near-shore sediments, river sediments, and coastal peat of the Alaskan Beaufort Sea: Implications for detecting anthropogenic hydrocarbon inputs: Marine Environmental Research, v. 33, p. 223-253. 
Thibodeaux, L.J., 1979, Chemodynamics - Environmental movement of chemicals in air, water, and soil: New York, John Wiley and Sons, $501 \mathrm{p}$.

Thomas, V.M., and Spiro, T.G., 1996, The U.S. dioxin inventory-Are there missing sources?: Environmental Science and Technology, v. 30, 82A-85A.

Umbreit, T.H., Hesse, E.J., and Gallo, M.A., 1986, Bioavailability of dioxin in soil from a 2,4,5-T manufacturing site: Science, v. 232, p. 497-499.

U.S. Environmental Protection Agency, 1994, USEPA Method 1613 - Tetra- through octa- chlorinated dioxins and furans by isotope dilution HRGC/HRMS: U.S. Environmental Protection Agency Office of Water, EPA Report Number EPA/821/B-94/005, 86 p.

U.S. Environmental Protection Agency, 1996a, USEPA Method 1669-Sampling ambient water for trace metals at EPA water quality criteria levels: U.S. Environmental Protection Agency Office of Water, EPA Report Number EPA-821-R-96-011, 36 p.

U.S. Environmental Protection Agency, 1996b, USEPA Method 1638-Determination of trace elements in ambient waters by inductively coupled plasma-mass spectrometry: U.S. Environmental Protection Agency Office of Water, EPA Report Number EPA/821/R-96-005, 46 p.

U.S. Environmental Protection Agency, 1998a, USEPA Method 8081-Organochlorine pesticides by GC: U.S. Environmental Protection Agency Office of Water, EPA Report Number EPA/SW-846/Ch 4.3.1, 16 p.

U.S. Environmental Protection Agency, 1998b, USEPA Method 1630-Methyl mercury in water by distillation, aqueous ethylation, purge and trap, cold vapor atomic fluorescence spectrometer: U.S. Environmental Protection Agency Office of Water, EPA Report Number EPA/R/01020, 49 p.

U.S. Environmental Protection Agency, 1999a, USEPA Method 1631, Revision B-Mercury in water by oxidation, purge and trap, and cold vapor atomic fluorescence spectrometry: U.S. Environmental Protection Agency Office of Water, EPA Report Number EPA/821/R-99/005, 40 p.

U.S. Environmental Protection Agency, 1999b, USEPA Method 1668, Revision A - Chlorinated biphenyl congeners in water, soil, sediment, and tissues by HRGC/HRMS: U.S. Environmental Protection Agency Office of Water, EPA Report Number EPA-821-R-00-002, 112 p.

U.S. Environmental Protection Agency, 2001, Database of sources of environmental releases of dioxin-like compounds in the United States: Reference years 1987 and 1995: Washington, D.C., U.S. Environmental Protection Agency Office of Research and Development, EPA/600/R01/012, 53 p.
VanLeeuwen, F.X.R., 1997, Derivation of toxic equivalency factors (TEFs) for dioxin-like compounds in humans and wildlife: Organohalogen Compounds, v. 34, p. 237-255.

Wenning, R.J., Harris, M.A., Ungs, M.J., Paustenbach, D.J., and Bedbury, H., 1992, Chemometric comparison of polychlorinated dibenzo-p-dioxin and dibenzofuran residues in surficial sediments from Newark Bay, New Jersey and other industrial waterways: Archives of Environmental Contamination and Toxicology, v. 22, p. 397-413.

Wenning, R.J., Harris, M.A., Finley, B., Paustenbach, D.J., and Bedbury,H., 1993, Application of pattern recognition techniques to evaluate polychlorinated dibenzo-p-dioxin and dibenzofuran distributions in surficial sediments from the lower Passaic River and Newark Bay: Ecotoxicology and Environmental Safety v. 25, p. 103-125.

Wood, J.M., 1975, Biological cycles for trace elements in the environment: Natuwissenschaften, v. 62, p. 357-364.

Yunker, M.B., Macdonald, R.W., Cretney, W.J., Fowler, B.R., and McLaughlin, F.A., 1993, Alkane, terpene, and polycyclic aromatic hydrocarbon geochemistry of the Mackenzie River and Mackenzie shelf - Riverine contributions to Beaufort Sea coastal sediment: Geochimica et Cosmochimca Acta, v. 57, p. 3041-3061.

Yunker, M.B., Snowdon, L.R., MacDonald, R.W., Smith, J.N., Fowler, M.G., Skibo, D.N., McLaughlin, F.A., Danyushevskaya, A.I., Petrova, V.I., and Ivanov, G.I., 1996, Polycyclic aromatic hydrocarbon composition and potential sources for sediment samples from the Beaufort and Barents seas: Environmental Science and Technology, v. 30, no. 4, p. 1310-1320.

Yunker, M.B., Macdonald, R.W., Vingarzan, R., Mitchell, R.H., Goyette, D., and Sylvester, S., 2002, PAHs in the Fraser River basin - a critical appraisal of PAH ratios as indicators of PAH source and composition: Organic Geochemistry, v. 32, p. 489-515.

Zimmermann, C.F., Keefe, C.W., and Bashe, J., 1997, Method 440.0 , Determination of carbon and nitrogen in sediment and particulates of estuarine/coastal waters using elemental analysis: Cincinnati, Ohio, U.S. Environmental Protection Agency National Exposure Research Laboratory, Office of Research and Development, $10 \mathrm{p}$. 
For additional information, write to:

Director

U.S. Geological Survey

New Jersey Water Science Center

810 Bear Tavern Road, Suite 206

West Trenton, NJ 08628

or visit our Web site at:

http://nj.usgs.gov/ 
